\title{
REVISTA
}

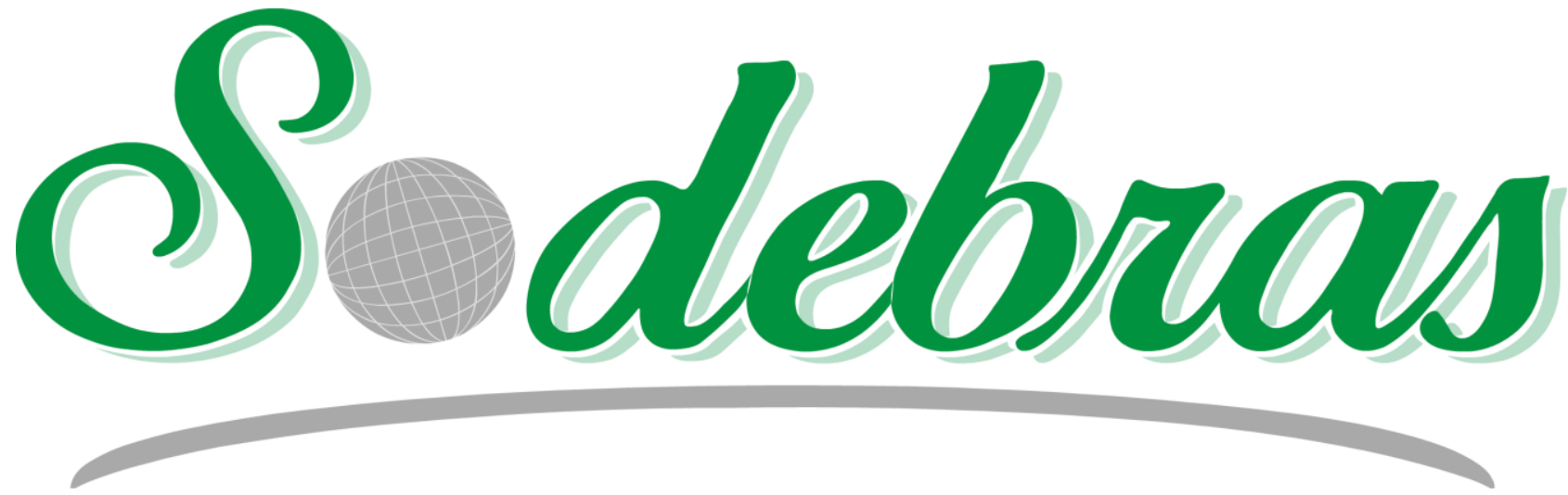

SOLUÇÕES PARA O DESENVOLVIMENTO DO PAÍS 
Volume 14 - No 159 - Março/2019.

XL International Sodebras Congress

10 a 12 de dezembro de 2018 - Vitória - ES.

\title{
ARTIGOS PUBLICADOS
}

\author{
PUBLICAÇÃO MENSAL \\ Nesta edição
}

\begin{abstract}
GERENCIALISMO: UMA NOVA ABORDAGEM DAS FERRAMENTAS GERENCIAIS
\end{abstract}
MANAGEMENT: A NEW APPROACH TO MANAGEMENT TOOLS - Danilo Alves Do Nascimento; Alexandre

Rabelo Neto; Carlos Antônio Mendes De Carvalho Buenos Ayres

\begin{abstract}
A EVOLUÇAO DE INCUBADORAS NO ESTADO DO PARANÁ - UMA VERTENTE AO
EMPREENDEDORISMO INOVADOR
\end{abstract}

THE EVOLUTION OF INCUBATORS IN THE STATE OF PARANÁ - A BRAND OF INNOVATIVE

ENTREPRENEURSHIP - Maria Paulina Manjama; Elaine Silva Ramos; Claudia Crisostimo; Paulo Rogerio

Pinto Rodrigues

\section{A INOVAÇÃO NO SISTEMA CARCERÁRIO BRASILEIRO COM O USO DO MONITORAMENTO ELETRÔNICO}

THE INNOVATION IN THE BRAZILIAN CARCERARY SYSTEM WITH THE USE OF ELECTRONIC MONITORING - Cliver Lucas Silveira Campos; Elaine Silva Ramos; Paulo Rogério Pinto Rodrigues; Maico Taras Da Cunha

BALANÇO ENERGÉTICO E DE EMISSÕES DE AEROGERADORES CONSIDERANDO DIFERENTES REGIÕES DE A PRODUÇÃO E OPERAÇÃO

ENERGY AND EMISSIONS BALANCE OF WIND TURBINES CONSIDERING DIFFERENT REGIONS OF PRODUCTION AND OPERATION - Bettina Pereira De Azevedo Carvalho; Ivan Felipe Silva Dos Santos; Maria Claudia Costa De Oliveira Botan; Nathalia Duarte Braz Vieira; Marina Souza Santos

REQUISITOS MÍNIMOS PARA A CRIAÇÃO DE CENTROS DE INOVAÇÃO, DEFININDO OBJETIVOS E ÁREA DE ABRANGÊNCIA

MINIMUM REQUIREMENTS FOR THE ESTABLISHMENT OF INNOVATION CENTERS, DEFINING OBJECTIVES AND AREA OF SCOPE - Victor Sebastian Korocoski; Luana Esteche Nunes Korocoski; Cláudia Crisostimo; Paulo Rogério Pinto Rodrigues

RISCOS NA TRANSFERÊNCIA DE TECNOLOGIA NAS PARCERIAS DE DESENVOLVIMENTO PRODUTIVO (PDP) NA ÁREA DE SAÚDE

THREATS IN THE TECHNOLOGY TRANSFER IN THE PRODUCTION DEVELOPMENT PARTNERSHIPS (PDP) IN THE HEALTH AREA - Marcus Julius Zanon; Paulo Rogerio Pinto Rodrigues; Vanessa Ishikawa Rasoto

A CONTRIBUIÇÃO DAS ACELERADORAS DE NEGÓCIOS PARA AS STARTUPS: O CASO DO ESPAÇO NAVE - NÚCLEODE ACELERAÇÃO E VALORIZAÇÃO DA ESTÁCIO

THE CONTRIBUTION OF THE BUSINESS ACCELERATOR FOR STARTUPS: THE CASE OF THE SPACE SHIP - CORE OF ACCELERATION AND EXPLOITATION OF ESTÁCIO - Pedro Paulo Lacerda Sales; Durval Correa Meirelles 
ANÁLISE DA CONTRIBUIÇÃO DO CURSO DE ADMINISTRAÇÃO NOTURNO DA UFES PARA A FORMAÇÃO DE EMPREENDEDORES POR MEIO DOS PROGRAMAS DAS DISCIPLINAS ANALYSIS OF

THE CONTRIBUTION OF THE NORTH ADMINISTRATION COURSE OF UFES FOR THE TRAINING OF ENTREPRENEURS BY MEANS OF DISCIPLINARY PROGRAMS - Lorrara Silvya Imagawa De Oliveira; Rubens De Araújo Amaro

ANÁLISE DO DESEMPENHO LOGISTICO NO ALMOXARIFADO DE MEDICAMENTOS DO MUNICIPIO DE PORTO VELHO-RO

ANALYSIS OF LOGISTIC PERFORMANCE IN THE MEDICINES OF THE MUNICIPALITY OF PORTO VELHO-RO - Sandra Sena Reis; Samuel Dos Santos Junio; Jana Aparecida Pereira Lopes

ANÁLISE ESTRATÉGICA DOS RESULTADOS DA IMPLANTAÇÃO DO PROGRAMA NACIONAL DE GESTÃO PÚBLICA E DESBUROCRATIZAÇÃO - GESPÚBLICA EM RONDÔNIA

STRATEGIC ANALYSIS OF RESULTS OF THE IMPLEMENTATION OF THE NATIONAL PROGRAM OF PUBLIC MANAGEMENT AND BUDGETING - GESPÚBLICA IN RONDÔNIA - Gabriele Aires Da Silva; Samuel Dos Santos Junio

É POSSÍVEL APRENDER: REVISÃO NARRATIVA SOBRE O ENSINO DO EMPREENDEDORISMO

IT CAN BE LEARNED: NARRATIVE REVIEW ON ENTREPRENEURSHIP TEACHING - Lorrara Silvya Imagawa De Oliveira; Rubens De Araújo Amaro

EFEITOS DA ESTRUTURA DE MERCADO E DA POSIÇÃO COMPETITIVA NO DESEMPENHO DA FIRMA, EM TEMPOS DE CRISE

EFFECTS OF MARKET STRUCTURE AND COMPETITIVE POSITION ON FIRM'S PERFORMANCE IN TIMES OF CRISIS - Alexandre Teixeira Dias; Sebastião Nunes Rocha De Souza; Marcelo Barbosa Costa; Alexandre Gabriel Fontenelle

GESTÃO E AVALIAÇÃO DO DESEMPENHO DE EMPREGADOS: SOLUÇÕES PARA UMA SOCIEDADE DE ECONOMIA MISTA DE GRANDE PORTE

MANAGEMENT AND ASSESSMENT' PERFORMANCE OF EMPLOYEES: SOLUTIONS FOR A LARGE JOINT CAPITAL COMPANY - Uerlei Valdomiro Araujo; Roquemar De Lima Baldam; Thalmo De Paiva Coelho Junior; Leonardo Carneiro Da Costa

O PLANEJAMENTO ESTRATÉGICO NA EDUCAÇAO A DISTÂNCIA NO INSTITUTO FEDERAL DE RONDÔNIA

THE STRATEGIC PLANNING IN DISTANCE EDUCATION AT THE FEDERAL INSTITUTE OF RONDÔNIA Sebastião Gonçalves Neves; Samuel Dos Santos Junio; Aloir Pedruzzi Junior; Jonimar Silva Souza

SAUBARA: TERRITÓRIO E IDENTIDADE

SAUBARA: TERRITORY AND IDENTITY - Valdir Silva Da Conceição; Angela Machado Rocha; Silvio Liberato De Moura Filho

CARACTERIZAÇÃO EPIDEMIOLÓGICA DOS CASOS DE DENGUE NOTIFICADOS NO HOSPITAL DE DOENÇAS TROPICAIS DA UNIVERSIDADE FEDERAL DO TOCANTINS (UFT- HDT), BRASIL, NO PERÍODO DE 2013 A 2017

EPIDEMIOLOGICAL CHARACTERIZATION OF THE DENGUE CASES NOTIFIED IN THE TROPICAL DISEASE HOSPITAL OF THE FEDERAL DO TOCANTINS UNIVERSITY (UFT-HDT), BRAZIL, IN THE PERIOD FROM 2013 TO 2017 - Silva, Júlia Santana Da; Amorim, Jhonatham Dias; Costa, Angla Alves Da; Santos-Júnior, Antônio Oliveira; Mariano, Wagner Dos Santos 
HANSENÍASE: CARACTERIZAÇÃO CLÍNICA-EPIDEMIOLÓGICA DOS CASOS NOTIFICADOS NO HOSPITAL DE DOENÇAS TROPICAIS DA UNIVERSIDADE FEDERAL DO TOCANTINS (UFT- HDT), BRASIL, NO PERÍODO DE 2013 A 2017

HANSENIASIS: CLINICAL AND EPIDEMIOLOGICAL CHARACTERIZATION OF THE NOTIFIED CASES IN THE TROPICAL DISEASE HOSPITAL OF THE FEDERAL DO TOCANTINS UNIVERSITY (UFT-HDT), BRAZIL, IN THE PERIOD FROM 2013 TO 2017 - Sampaio, Ana Cristina Mendanha; Mariano, Wagner Dos Santos; Silva, Júlia Santana Da Silva; Cavalcante, Patrícia Alves De Mendonça; Rocha, Marceli Diana Helfenstein Albeirice Da Rocha

PARACOCCIDIOIDOMICOSE: CARACTERIZAÇÃO CLÍNICO-EPIDEMIOLÓGICA DOS CASOS NOTIFICADOS NO HOSPITAL DE DOENÇAS TROPICAIS DA UNIVERSIDADE FEDERAL DO TOCANTINS (UFT- HDT), BRASIL, NO PERÍODO DE 2016 A 2018

PARACOCCIDIOIDOMYCOSIS: CLINICAL AND EPIDEMIOLOGICAL CHARACTERIZATION OF THE NOTIFIED CASES IN THE TROPICAL DISEASES HOSPITAL OF THE FEDERAL UNIVERSITY OF TOCANTINS (UFT-HDT), BRAZIL, IN THE PERIOD 2016 TO 2018 - Santos-Júnior, Antônio Oliveira; Rocha, Marceli Diana Helfenstein Albeirice Da; Cavalcante, Patrícia Alves De Mendonça; Ribeiro, Rebeca Saiter; Mariano, Wagner Dos Santos

MODELAGEM DE DADOS PLUVIOMÉTRICOS EM BRASÍLIA-DF: UMA APLICAÇÃO DE CADEIAS DE ORDEM VARIÁVEL

MODELING OF PLUVIOMETRIC DATA IN BRASÍLIA-DF: AN APPLICATION OF VARIABLE ORDER CHAINS - Lucas Moreira; Matheus Ferreira Marques Cavacante

ESQUEMA ARGUMENTATIVO EM TEXTOS: ENCONTRAR DEFINIÇÃO CONCEITUAL NO TEXTO ACADÊMICO E GERAR QUESTÕES QUE A JUSTIFICA

ARGUMENTATIVE SCHEME IN TEXTS: FIND CONCEPTUAL DEFINITION IN THE ACADEMIC TEXT AND GENERATE QUESTIONS THAT JUSTIFY IT - Koichi Sanoki; Ítalo Santiago Veja

SISTEMA DE REALIDADE VIRTUAL PARA TREINAMENTO DE OPERADORES DE LOCOMOTIVAS

VIRTUAL REALITY SYSTEM FOR TRAINING LOCOMOTIVE OPERATORS - Pablo Pereira E Silva; Rodrigo Varejão Andreão; Mário Mestria

EM BUSCA DA SUSTENTABILIDADE: CÉLULA SOLAR PRODUZIDA COM CORANTE EXTRAÍDO DA MORUS NIGRA

IN PURSUIT OF SUSTAINABILITY: SOLAR CELL PRODUCED WITH DYE EXTRACTED FROM MORUS NIGRA - Julianno Pizzano Ayoub; Gideã Taques Tractz; Everson P. Banczek; Paulo R. P. Rodrigues

AVALIAÇÃO DO CONSERVADORISMO DO MÉTODO DE ANÁLISE TÉRMICA DO PRCI QUANTO AO RISCO DE PERFURAÇAO NO REPARO COM SOLDAGEM EM OPERAÇAO DE OLEODUTO COM BAIXA ESPESSURA

EVALUATION THE CONSERVATIVENESS OF PRCI'S THERMAL ANALYSIS METHOD REGARDING THE BURN-THROUGH RISK DURING IN-SERVICE WELDING REPAIRS OF LOW THICKNESS OIL PIPELINE Higor José Bravim; André Gustavo De Sousa Galdino; Temistocles De Sousa Luz

MODOS DE RUPTURA DE LIGAÇÃO MADEIRA LAMINADA COLADA CRUZADA E CONCRETO

CROSSED AND CONCRETE WOUNDED LAMINATED WOOD CONNECTION RUPTURE - Ramos, F. M.

G.; Carrasco, E. V. M.; Rodrigues, F. C.

INTEGRAÇÃO DE FERRAMENTAS DE MODELAGEM E SIMULAÇÃO DE SISTEMAS UTILIZANDO O PROTOCOLO OPC-UA

INTEGRATION OF MODELING AND SIMULATION TOOLS USING OPC-UA PROTOCOL - Alex Brandão Rossow 
EFICIÊNCIA LUMÍNICA EM INSTITUIÇÕES DE ENSINO SUPERIOR - UM ESTUDO DE CASOS NA UNIVERSIDADE FEDERAL DA BAHIA (UFBA)

LIGHTING EFFICIENCY IN HIGHER EDUCATION INSTITUTIONS - A CASE STUDY IN THE FEDERAL UNIVERSITY OF BAHIA (UFBA) - Maria Fabiana Baldoino Da Paixão; Antonio Santos Sánchez; Miguel Angel Iglesias Duro

LOCALIZAÇÃO EFICIENTE DE ESTAÇÕES DE CARREGAMENTO DE VEÍCULOS ELÉTRICOS NUMA REGIÃO METROPOLITANA UTILIZANDO METAHEURÍSTICA CRO E TRAJETOS VEICULARES REAIS

EFFICIENT PLACEMENT OF ELECTRIC VEHICLE CHARGING STATIONS IN A METROPOLITAN AREA UTILIZING CRO AND REALISTIC VEHICLE ROUTING INFORMATION - Danilo Cesar Azeredo Silva; Mário Mestria

PLANEJAMENTO ESTRATÉGICO NO SETOR ELÉTRICO: UMA MODELAGEM UTILIZANDO A MATRIZ DE ATRATIVIDADE DE MERCADO X FORÇA COMPETITIVA STRATEGIC

PLANNING ON ENERGY SECTOR: AN MODELING USING ATTRACTIVENESS VERSUS COMPETITIVENESS MATRIX - Flávio Dayrell Miserani Nunes; Petr lacovlevitch Ekel; Rose Mary De Souza Batalha

SELEÇÃO DE CARACTERÍSTICAS DE SINAIS CEREBRAIS PARA USO EM APLICAÇÕES DE INTERFACE CÉREBRO-COMPUTADOR

FEATURE SELECTION OF BRAIN SIGNALS FOR USE IN BRAIN-COMPUTER INTERFACE APPLICATIONS - Alex Brandão Rossow; Anibal Cotrina

ANÁLISE DA ACIDEZ DA SOLUÇÃO EXTRATORA PARA PRODUÇÃO DE CORANTES EMPREGADOS EM CÉLULAS SOLARES DE TERCEIRA GERAÇÃO

ANALYZE OF DYE ACIDIFIED SOLUTION USED IN THIRD GENERATION OF SOLAR CELLS

PRODUCTION - Julianno Pizzano Ayoub; Gideã Taques Tractz; Douglas Kais Silva; Paulo R. P. Rodrigues ...

MODELAGEM CINEMÁTICA DO ROBÔ COLABORATIVO UR5

KINEMATIC MODELING OF THE COLLABORATIVE ROBOT UR5 - Alexandre G. Soares; Felipe A. A. Macedo; Leonardo César De O. Marques; Luiz Paulo G. Ribeiro

RESOLUÇÃO DA CINEMÁTICA INVERSA DE ROBÔS INDUSTRIAIS POR ALGORITMOS DE OTIMIZAÇÃO INVERSE KINEMATICS RESOLUTION OF INDUSTRIAL ROBOTS THROUGH OPTIMIZATION ALGORITHMS - Michel Alba; Alexandre G Soares; Luiz Ribeiro; Jose Herskovits

AVALIAÇÃO DE RISCO ECOTOXICOLÓGICO COM BASE EM RESULTADOS DO MODELO USETOX® PARA O TRICLOSAN PARA AS REGIÕES HIDROGRÁFICAS BRASILEIRAS

EVALUATION OF ECOTOXICOLOGICAL RISK BASED ON RESULTS OF THE USETOX® MODEL FOR TRICLOSAN FOR THE BRAZILIAN HYDROGRAPHIC REGIONS - Pedro Henrique Bolanho Simões; Biagio Fernando Giannetti; Lucas Alegretti; Maurea Nicoletti Flynn

CONFLITOS DE USO DO SOLO DE ÁREAS DE PRESERVAÇÃO PERMANENTE DA BACIA

HIDROGRÁFICA DA SERRA DA MANTIQUEIRA - UGRHI 1

SOIL USE CONFLICTS OF PERMANENT PRESERVATION AREAS OF THE SERRA DA MANTIQUEIRA WATERSHED - UGRHI 1 - SILVA, M.H.; TRANNIN, I. C. B.; CATELANI, C. S.

DIAGNÓSTICO E PROPOSIÇÃO DE MEDIDAS PARA O CONTROLE DAS PERDAS DE ÁGUA NO SISTEMA DE ABASTECIMENTO DE GUARATINGUETÁ (SP)

DIAGNOSIS AND PROPOSAL OF MEASURES FOR CONTROLLING WATER LOSSES IN THE SUPPLY SYSTEM GUARATINGUETÁ (SP) - YOSHIMOTO, M. K.; TRANNIN, I. C. B . 
PROPOSTA PARA APROVEITAMENTO DE RESÍDUOS DA CONSTRUÇÃO CIVIL GERADOS EM CANTEIROS DE OBRAS

PROPOSAL FOR USE OF WASTE FROM CIVIL CONSTRUCTION SITES - PERINA, J.M.; TRANNIN, I. C.

B.

O USO DO BIG DATA NO ESTUDO DO MERCADO CONSUMIDOR, POTENCIALIDADES PARA APLICAÇÃO NO BRASIL

THE USE OF BIG DATA IN THE CONSUMER MARKET STUDY, POTENTIAL FOR THE APPLICATION IN BRAZIL - Alex Brandão Rossow

USO GERENCIAL DAS FERRAMENTAS DA QUALIDADE PARA TOMADA DE DECISÃO: UM ESTUDO DE CASO SOBRE O ELEVADO ÍNDICE DE DEVOLUÇÃO NA DISTRIBUIÇÃO LOGÍSTICA E A CRIAÇÃO DA ÁREA DE CUSTOMER SERVICE

MANAGEMENT USE OF QUALITY TOOLS FOR DECISION MAKING: A CASE STUDY ON HIGH RETURN INDEX OF LOGISTICAL DISTRIBUTION AND CREATING THE CUSTOMER SERVICE AREA - Lucas De Souza Campos; José Elmo De Menezes 
Volume 14 - No 159 - Março/2019.

XL International Sodebras Congress

10 a 12 de dezembro de 2018 - Vitória - ES.

\section{Área: Interdisciplinar}

\begin{tabular}{|c|c|}
\hline $9-0$ & $\begin{array}{l}\text { ERENCIALISMO: UMA NOVA ABORDAGEM DAS FERRAMENTAS } \\
\text { ERENCIAIS } \\
\text { ANAGEMENT: A NEW APPROACH TO MANAGEMENT TOOLS } \\
\text { anilo Alves Do Nascimento; Alexandre Rabelo Neto; Carlos Antônio Mendes De } \\
\text { arvalho Buenos Ayres }\end{array}$ \\
\hline $9-1$ & $\begin{array}{l}\text { EVOLUÇAO DE INCUBADORAS NO ESTADO DO PARANÁ - UMA VERTENTE } \\
\text { O EMPREENDEDORISMO INOVADOR } \\
\text { HE EVOLUTION OF INCUBATORS IN THE STATE OF PARANÁ - A BRAND OF } \\
\text { VNOVATIVE ENTREPRENEURSHIP } \\
\text { laria Paulina Manjama; Elaine Silva Ramos; Claudia Crisostimo; Paulo Rogerio } \\
\text { into Rodrigues }\end{array}$ \\
\hline $9-1$ & $\begin{array}{l}\text { A INOVAÇÃO NO SISTEMA CARCERÁRIO BRASILEIRO COM O USO DO } \\
\text { MONITORAMENTO ELETRÔNICO } \\
\text { THE INNOVATION IN THE BRAZILIAN CARCERARY SYSTEM WITH THE USE OF } \\
\text { ELECTRONIC MONITORING } \\
\text { Cliver Lucas Silveira Campos; Elaine Silva Ramos; Paulo Rogério Pinto Rodrigues; } \\
\text { Maico Taras Da Cunha }\end{array}$ \\
\hline $9-1$ & $\begin{array}{l}\text { BALANÇO ENERGÉTICO E DE EMISSÕES DE AEROGERADORES } \\
\text { CONSIDERANDO DIFERENTES REGIÕES DE A PRODUÇÃO E OPERAÇÃO } \\
\text { ENERGY AND EMISSIONS BALANCE OF WIND TURBINES CONSIDERING } \\
\text { DIFFERENT REGIONS OF PRODUCTION AND OPERATION } \\
\text { Bettina Pereira De Azevedo Carvalho; Ivan Felipe Silva Dos Santos; Maria Claudia } \\
\text { Costa De Oliveira Botan; Nathalia Duarte Braz Vieira; Marina Souza Santos }\end{array}$ \\
\hline $9-1$ & $\begin{array}{l}\text { REQUISITOS MÍNIMOS PARA A CRIAÇÃO DE CENTROS DE INOVAÇÃO, } \\
\text { DEFININDO OBJETIVOS E ÁREA DE ABRANGÊNCIA } \\
\text { MINIMUM REQUIREMENTS FOR THE ESTABLISHMENT OF INNOVATION } \\
\text { CENTERS, DEFINING OBJECTIVES AND AREA OF SCOPE } \\
\text { Victor Sebastian Korocoski; Luana Esteche Nunes Korocoski; Cláudia Crisostimo; } \\
\text { Paulo Rogério Pinto Rodrigues }\end{array}$ \\
\hline $9-1$ & $\begin{array}{l}\text { RISCOS NA TRANSFERÊNCIA DE TECNOLOGIA NAS PARCERIAS DE } \\
\text { DESENVOLVIMENTO PRODUTIVO (PDP) NA ÁREA DE SAÚDE } \\
\text { THREATS IN THE TECHNOLOGY TRANSFER IN THE PRODUCTION }\end{array}$ \\
\hline
\end{tabular}




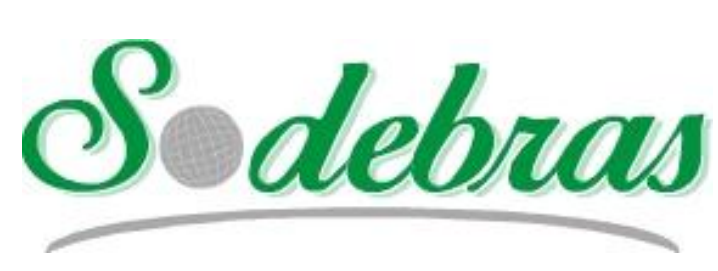

Volume $14-\mathrm{N}^{\mathrm{o}} 159$ - Março/2019.

XL International Sodebras Congress

10 a 12 de dezembro de 2018 - Vitória - ES.

\title{
GERENCIALISMO: UMA NOVA ABORDAGEM DAS FERRAMENTAS GERENCIAIS
}

\author{
MANAGEMENT: A NEW APPROACH TO MANAGEMENT TOOLS
}

\author{
DANILO ALVES DO NASCIMENTO ${ }^{1 \cdot 2^{3},}$; ALEXANDRE RABELO NETO ${ }^{2 \cdot 3}$; CARLOS ANTÔNIO \\ MENDES DE CARVALHO BUENOS AYRES'; ;
}

\section{1 - INSTITUTO FEDERAL DO PIAUÍ; 2 - UNIVERSIDADE FEDERAL DO PIAUÍ; 3 - PROGRAMA DE PÓS-GRADUAÇÃO EM GESTÃO PÚBLICA}

\author{
daniloalves@ifpi.edu.br; alexandrenaka@hotmail.com;menayres@ig.com.br
}

\begin{abstract}
Resumo - O presente artigo tem como objetivo descrever a influência das tecnologias gerenciais sobre o modelo gerencial de administração pública, razão pela qual determinados procedimentos técnicos foram delineados pela pesquisa bibliográfica a partir de uma revisão dos principais conceitos sobre o assunto. Como consequência, pode-se perceber claramente que tais tecnologias influenciam a forma de agir dos servidores públicos, bem como os resultados obtidos pelo Estado, pois se espera que com a utilização das ferramentas gerenciais, já testadas no mercado, que o Estado venha a ter uma maior eficácia, eficiência e efetividade nas suas ações. Por fim, o trabalho aponta a indispensabilidade de um aprofundamento teórico que possibilite futuras discussões sobre esse tema tão à ordem do dia em nossa contemporaneidade.
\end{abstract}

Palavras-chave: Gerencialismo. Tecnologias Gerenciais. Ferramentas Gerenciais.

\begin{abstract}
This article aims to describe the influence of management technologies on the managerial model of public administration, which is why certain technical procedures were delineated by the bibliographical research from a review of the main concepts on the subject. As a consequence, it can be clearly seen that these technologies influence the way public servants act, as well as the results obtained by the State, since it is expected that with the use of management tools, already tested in the market, that the State will have greater effectiveness, efficiency and effectiveness in their actions. Finally, the paper points out the indispensability of a theoretical deepening that allows future discussions on this subject so much to the order of the day in our contemporaneity.
\end{abstract}

Keywords: Managerialism. Management Technologies. Management Tools.

\section{INTRODUÇÃO}

Os efeitos da globalização, das novas tecnologias, da rapidez das informações e da competitividade no mercado fizeram surgir cidadãos/usuários mais conscientes e exigentes quanto aos serviços e/ou produtos oferecidos pelo Estado, a saber: bens e serviços, atos administrativos e legais. Logo, considerando que a competitividade é um dos processos sociais dissociativos empregados para ganhar e manter posições favoráveis mundialmente, apesar das grandes e imprevisíveis transformações tecnológicas do mundo globalizado, este é o desafio enfrentado pela maioria das empresas privadas como também pelas entidades públicas (PALUDO, 2016).

O ato de administrar para Maximiano (1985, p. 23) é "um processo de planejar, organizar, dirigir e controlar a aplicação de recursos humanos, materiais, financeiros e informacionais, visando à realização de objetivos". No mesmo sentido, Buenos Ayres (2013, p. 12), afirma que "administrar é tomar decisões no sentido da definição de objetivos realistas aliado ao uso racional de recursos indispensáveis para o seu alcance".

Vários autores defendem que esteja surgindo um novo paradigma administrativo global (OSBORNE \& GAEBLER, 1994 e KETTL, 1996), e a introdução de mecanismos da lógica empresarial são cada vez mais comuns na administração pública. Para Misoczky (2014, p. 12), “(...) nas últimas décadas, a lógica da administração empresarial e o valor do empreendedorismo invadiram praticamente sem resistências os espaços da administração pública". E nesse diapasão, o gestor público passa a ser cobrado por mais eficiência (value for money) dentro de um cenário - Estado - onde os recursos são escassos. Caiden (1991) aponta para uma saída: “O governo não pode ser uma empresa, mas pode se tornar mais empresarial”, ocasião em que se consolidam os princípios fundamentais do neoliberalismo.

A título de esclarecimento, convém assinalar que os conceitos do Estado e do Governo não se confundem, razão pela qual faz-se necessário distingui-los. Assim, podemos dizer que o Estado (invenção jurídica) exerce seu poder através do Governo (organização institucional do Estado), mas não se confunde com ele, uma vez que o Estado é um ente plenipotenciário permanente, dotado de autoridade moral e intangível por sua própria natureza jurídica, enquanto o Governo, por sua vez, é um ente políticoadministrativos transitório, real e tangível (PALUDO, 2016).

Para dar conta do objetivo do trabalho, além desta primeira seção introdutória, o artigo é composto por mais quatro seções. Na segunda seção apresentamos uma breve revisão da literatura acerca do patrimonialismo ao modelo 
gerencial e uma breve revisão sobre ferramentas gerenciais. $\mathrm{Na}$ terceira seção deste trabalho expõe-se a metodologia utilizada, seguida das considerações finais e propostas de trabalhos futuros.

\section{REFERENCIAL TEÓRICO}

É objetivo central desta seção do artigo descrever de forma simples e breve os tipos puros da administração pública: patrimonialista, burocrática e gerencial. Como forma de contextualizar e introduzir o ponto principal da discussão que são as ferramentas gerenciais.

$\mathrm{O}$ modelo patrimonialista foi a primeira forma de administração do Estado. Mesmo que de modo desorganizado, o Estado era tido como propriedade do soberano, em que os bens públicos e particulares eram confundidos, os cargos eram todos de sua livre nomeação, podendo, assim, utilizar livremente dos bens e propriedades em geral sem qualquer prestação de contas à sociedade, uma vez que não existiam carreiras organizadas no serviço público. Em face da não distinção entre o público e o privado, a corrupção e o nepotismo foram traços marcantes desse tipo de administração (PALUDO, 2016).

Para Maria Sylvia Di Pietro (2015, p. 35), "Era a época das monarquias absolutas, em que todo o poder pertencia ao soberano; a sua vontade era a lei... o rei não podia ser submetido aos tribunais, pois seus atos se colocavam acima de qualquer ordenamento jurídico". Buenos Ayres (2013, p. 65) afirma que o modelo patrimonialista concretiza-se pela tradição:

O modelo de gestão patrimonialista é típico da ordem feudal estamentária. A administração patrimonial, ou patrimonialista, é vinculada à emergência de um quadro administrativo e militar exclusivamente pessoal do senhor. Norteia-se pela tradição e se realiza em função de pleno direito pessoal, ou seja, o direito do senhor convertido em seu direito próprio [...].

Paludo (2016) define algumas características do modelo patrimonialista, são elas: caráter discricionário e arbitrário das decisões; ausência de carreiras administrativas; desorganização do Estado e da administração; cargos denominados prebendas ou sinecuras; descaso pelo cidadão e pelas demandas sociais; poder oriundo da tradição/hereditariedade; não só o soberano, mas os seus auxiliares e servidores agiam de forma arbitraria. $\mathrm{Na}$ medida em que o século XIX se aproxima, algumas dessas características começam a desaparecer.

A ascensão da burguesia comercial e industrial, o surgimento e fortalecimento das organizações de grande porte, a pressão pelo atendimento de demandas sociais, a corrupção e o nepotismo existentes na área pública, indicavam que o Estado deveria ser mais organizado. A administração pública burocrática no mundo surgiu na segunda metade do século XIX, na época do Estado liberal, enquanto que no Brasil ela surge e se desenvolve em plena ditadura, no governo militar (PALUDO, 2016).

Uma organização ou burocracia é um sistema social racional, ou sistema social em que a divisão do trabalho é racionalmente realizada tendo em vista os fins visados (MOTTA; BRESSER-PEREIRA, 1980). Para Max Weber (1966), organização é qualquer grupo social empenhado na consecução de objetivos explícitos e declarados, através de esforços manifestamente coordenados. A burocracia, por sua vez, era uma forma de poder ou dominação, que os governantes exerciam sobre seus governados.

Müller (1990, p. 10), define a burocracia como “[...] uma forma social que se apoia na organização racional dos meios em função dos fins". Na mesma corrente, Buenos Ayres $(2013$, p. 65) afirma que a burocracia é a forma mais racional de dominação, pois através dela pode-se alcançar a eficiência:

[...] A administração puramente burocrática, portanto, a administração burocrático-monocrática mediante documentação, considerada do ponto de vista formal, é, segundo toda a experiência, a forma mais racional de exercício de dominação, porque nela se alcança tecnicamente o máximo de rendimento em virtude de precisão, continuidade, disciplina, rigor e confiabilidade [...].

A nomenclatura burocrática weberiana não é consenso na literatura especializada, "whitehall" foi o modelo executado na Grã-Bretanha e "progressive public administration" nos EUA, também conhecida como 'era progressista' (HOOD, 1996).

A administração pública burocrática surge com o objetivo de combater as práticas patrimonialistas. Visando evitar a corrupção e o nepotismo os controles administrativos eram sempre "a priori". Partiu-se de uma desconfiança nos administradores públicos e nos cidadãos (agentes), havia uma necessidade de controles mais rígidos nos processos de admissão de pessoal, compras e no atendimento a demandas (PALUDO, 2016).

São dimensões consensuais da administração burocrática: hierarquia de autoridade; divisão do trabalho (baseado na especialização funcional); competência técnica (meritocracia); previsibilidade de funcionamento; normas de procedimento para atuação no cargo (rotinas e procedimentos padronizados); normas que controlam o comportamento dos empregados; autoridade limitada ao cargo; gratificação diferencial por cargo; impessoalidade dos contatos pessoais; separação entre propriedade e administração; ênfase nas comunicações escritas; e disciplina racional. Somente através da burocracia, uma organização consegue atingir o máximo de eficiência (WEBER; HALL, 1966).

É comum ver o termo burocracia ser utilizado em contexto negativo, de lentidão e ineficiência. Paludo (2016, p. 98), explica a diferença entre burocracia e as disfunções da burocracia:

Não confunda a burocracia com as disfunções da burocracia. Burocracia é o modelo constituído por Weber para garantir a eficiência nas organizações. Disfunções da burocracia correspondem ao excesso de regras e regulamentos, ao amontoado de papelório, à rigidez dos procedimentos, ao descaso pelo cliente-cidadão, resistência a mudanças, falta de flexibilidade etc.

Estas disfunções levam à ineficiência e às imperfeições, pois as disfunções da burocracia são anomalias de funcionamento responsáveis pelo sentido negativo do termo burocracia na atualidade contemporânea.

As brechas encontradas na legislação brasileira foram um dos empecilhos para a não consolidação da burocracia no Brasil, segundo os termos técnico-administrativos de Max Weber, que por sua vez idealizou uma burocracia de caráter racional-legal. Bresser-Pereira (2002, p. 75), referindo-se à burocracia brasileira, afirma que "o Brasil 
nunca foi capaz de ter um serviço público similar ao francês ou mesmo ao americano". Em outras palavras: o Brasil nunca implantou o modelo burocrático weberiano puro.

Voltado cada vez mais para si mesmo, o modelo burocrático tradicional foi caminhando no sentido contrário aos anseios dos cidadãos, perdendo a noção de sua missão, que é servir à sociedade. Rayner (1984, p. 56) afirmou que "A burocracia tem muitos amigos", fazendo uma alusão à época em que a burocracia passou ser classificada como um "grupo de interesse" e não um corpo técnico neutro a serviço dos cidadãos (PALUDO, 2016).

O senso comum contra a burocracia, também definido como "senso antiburocrático", cresceu exponencialmente no final dos anos 70 "tomando forma de uma epidemia generalizada" (KAUFMAN, 1981); e todo esse sentimento foi fundamental para o surgimento de um novo pacto, um novo olhar, uma nova forma de administrar.

Pollit e Bouckaert (2011, p. 2) definem reforma da gestão pública como "conjunto de mudanças deliberadas nas estruturas e processos das organizações do setor público com o objetivo de fazer com que elas funcionem (em algum sentido) melhor". A reforma da administração pública foi uma condição para a ampliação da governabilidade, pois fazia-se necessário a confiança da sociedade nas instituições públicas democráticas, como bem nos assegura BresserPereira (2010, p. 116):

Do ponto de vista administrativo, a transição do Estado Burocrático para o Estado Gerencial, revelou-se um instrumento fundamental das sociedades modernas para neutralizar a ideologia neoliberal que buscava diminuir o tamanho do Estado, na medida em que, ao tornar mais eficiente (embora jamais tão eficiente como gostaríamos) a provisão dos serviços sociais públicos ou coletivos, legitima o próprio Estado Social, e garante seu aprofundamento futuro

"O antagonismo ao Welfare state é um dos traços neoliberais mais característicos. O Welfare state é visto como a fonte de todos os males, de maneira parecida àquela como o capitalismo era visto outrora pela esquerda revolucionária" (GIDDENS, 1999, p.23). Por outro lado, Bresser-Pereira (2010, p. 115) contesta as críticas segundo à qual a reforma do Estado teria cunho neoliberal: "ficou claro que sua consequência primeira foi fortalecer o próprio Estado, e não enfraquecê-lo como almejavam os neoliberais".

Para Cabral Neto (2009, p. 172), a reforma gerencial apresenta no seu conjunto de objetivos "a desburocratização, a descentralização, a transparência, a ética, o profissionalismo, a competitividade e o enfoque no cidadão". De acordo com Ball (2005, p. 544) tais receituários "são frutos de uma reforma política e de reengenharia cultural do setor público" chamada de gerencialismo.

Buenos Ayres (2013, p. 66) define o modelo gerencial a partir da contextualização do momento histórico, em que os governos sofriam crises de legitimidade e o mercado é cada vez mais aquecido pelo aumento da competitividade entre as grandes empresas:

[...] o modelo de gestão gerencial é aquele assinalado pela crise de legitimidade que se abateu sobre o setor público dos países ocidentais, na década de 1950-60, paralelamente à alta competitividade das empresas capitalistas no mercado internacional.
Alecian e Foucher (2001, p. 22) ratificam o gerenciamento como "[...] a atividade que consiste em conduzir, a partir de um contexto dado, um grupo de homens e mulheres que busquem o atingimento comum de um ou diversos objetivos, de acordo com as finalidades da organização". O managerialism tinha como ponto central o conceito de produtividade, um dos livros fundamentais daquela época tinha como título Doing more with less, que significa fazendo mais com menos (UKELES, 1982).

O gerenciamento público, ou administração pública gerencial, consiste em um conjunto de "métodos racionais a serviço dos decisores públicos" (HUSSENOT, 1983, p. 24). Segundo Peters, "mesmo quando a noção de 'privatização' tem conotações negativas, como na Escandinávia, a expressão 'modernização' aparece como positiva para a maioria dos cidadãos" (1992, p. 307).

A "não-politização" da administração pública, aliada ao foco no conceito de eficiência governamental, fez com que Pollitt (1990), crítico do managerialism, classificasse o modelo gerencial inglês como um "neotaylorismo" (novotaylorismo), um modelo centrado na busca incessante da produtividade e na implantação do modelo de gestão privada dentro do setor público. O discurso do gerencialismo para o setor público assume uma característica tripartite, a saber: "excelência, efetividade e qualidade" (BALL, 2006, p.12). Hypólito (2008, p. 69), por sua vez, aponta que "esses discursos penetram o gerencialismo em diferentes áreas e setores, transformando várias formas de senso comum e criando novas concepções para estado, mercado, economia, escola pública e administração pública".

Uma visão recorrente é que o argumento em prol do aumento da eficácia, eficiência, efetividade e competitividade se materializa no modelo gerencial, sob forte influência da ideologia neoliberal e de um conjunto de teorias econômicas e valores normativos. A administração pública gerencial, também denominada de "a nova administração pública", é um amplo movimento reformista no aparelho do Estado, pois se trata de um modelo prescritivo pós-burocrático para a estruturação e o gerenciamento da máquina pública baseado nos princípios e diretrizes oriundos de organizações privadas. Outras características que são úteis para se compreender este movimento é o empowerment do cidadão no processo de escolha de serviços via competição entre os órgãos; accountability e o processo de compartilhamento de responsabilidades para o setor privado e o terceiro setor (privatizações, desregulações, contratação de serviços externos (contracting-out) e parcerias público-privadas PPPs) (CAVALCANTE, 2017).

Para facilitar a compreensão de cada momento da evolução do gerencialismo, torna-se necessário classificá-lo em três momentos diferentes, conforme quadro abaixo:

Figura 1 - Três teorias do modelo gerencial.

\begin{tabular}{|c|c|c|c|}
\hline & $\begin{array}{c}\text { GERENCIALISMO } \\
\text { PURO }\end{array}$ & CONSUMERISM & $\begin{array}{c}\text { PUBLIC SERVICE } \\
\text { ORIENTATION }\end{array}$ \\
\hline $\begin{array}{c}\text { PRINCIPAL } \\
\text { OBJETIVO }\end{array}$ & $\begin{array}{c}\text { Economia/eficiência } \\
\text { (produtividade) }\end{array}$ & Efetividade/qualidade & Accountability/equidade \\
\hline PÚBLICO-ALVO & $\begin{array}{c}\text { Tax Paypers } \\
\text { (contribuintes) }\end{array}$ & Clientes/consumidores & Cidadãos \\
\hline
\end{tabular}

Fonte: Reproduzido de Abrucio (1999). 
Tornar a administração pública mais eficiente e eficaz na resolução das demandas da sociedade é uma tarefa do modelo gerencial, para isso o gestor público utiliza-se de várias ferramentas gerenciais que já foram testadas no mercado, buscando maximizar a efetividade das políticas públicas.

Cabe definir que eficiência é o uso racional e econômico dos insumos na produção de bens e serviços; é uma relação entre: insumos, produtos, qualidade e custo. Eficácia diz respeito ao grau de alcance das metas (ou objetivos de curto prazo), já que se constitui em uma medida de resultados utilizada para avaliar o desempenho da administração. Efetividade, por sua vez, é o impacto final das ações, o grau de satisfação das necessidades e dos desejos da sociedade pelos serviços prestados pela instituição, indo além das entregas imediatas (metas/ objetivos), permitindo analisar as transformações causadas pela execução das ações administrativas (PALUDO, 2016).

\section{METODOLOGIA}

A pesquisa adotou a perspectiva qualitativa e os dados foram obtidos através de pesquisa bibliográfica em livros, artigos, dissertações e teses. O levantamento de dados foi realizado entre 05 de março a 25 de setembro de 2018.

Quanto à pesquisa qualitativa, a revisão bibliográfica não se limita apenas à etapa inicial, mas desempenha um papel de extrema importância durante toda a pesquisa.

A revisão bibliográfica é um levantamento de algumas obras que chamam a atenção sobre esta temática, de caráter exploratório pelo fato de levantar dados junto à literatura especializada para elaboração do arcabouço teórico do trabalho. Desta maneira, permitiu atualizar conhecimentos visando apreciar os diversos posicionamentos que os estudiosos têm sobre o tema.

Este trabalho é resultado da disciplina Estado e Gestão Pública, do programa de Pós-Graduação em Gestão Pública realizado em convênio pelas instituições IFPI/UFPI.

\section{RESULTADOS}

Nesta seção, como resultados e discussão da pesquisa, o trabalho vai apresentar algumas das ferramentas e/ou técnicas gerenciais hoje utilizadas pela gestão pública, mas que foram criadas para suprir necessidades da gestão de empresas:

\section{Benchmarking}

Mittelstaedt (1992, p. 301) define benchmarking como "o processo de medir as atuais operações da empresa e compará-las com as empresas que apresentam as melhores práticas nestas operações”. Enquanto para David T. Kearns (1986, p. 21), “benchmarking é o processo contínuo de medição de produtos, serviços e práticas em relação aos mais fortes concorrentes, ou em relação às empresas reconhecidas como líderes em suas indústrias".

A operacionalização da ferramenta benchkmarking pode ser externo ou interno, e seu emprego está orientado para identificar/copiar/implementar as melhores práticas de outros setores ou departamentos da organização. Procura-se selecionar o "best of the best" (melhor do melhor), ou seja, os fatores-chave que influenciam a produtividade, a qualidade e os resultados dessas empresas. Nas organizações privadas o benchkmarking é utilizado para aumentar a competitividade, porém nas instituições públicas seu emprego volta-se para a identificação das organizações públicas de excelência (melhores resultados) com vistas a promover avanços na prestação de serviços públicos (PALUDO, 2016).

\section{Balanced Scorecard}

Kaplan e Norton (1996) propõem que o Balanced Scorecard (BSC) traduza a visão e a estratégia da organização em objetivos e métricas, por meio das dimensões descritas no modelo. Para Lopes (2013) o Balanced Scorecard foca no equilíbrio organizacional e busca transformar a visão e a estratégia empresarial em objetivos estratégicos mensuráveis e iniciativas.

Tavares (2010) afirma que o BSC é uma contribuição inovadora em relação às metas empresariais, cujo objetivo é estimar os acontecimentos no futuro e proporcionar informações referentes ao valor de longo prazo, visando a sustentabilidade das empresas.

Figura 2 -Balanced Scorecard.

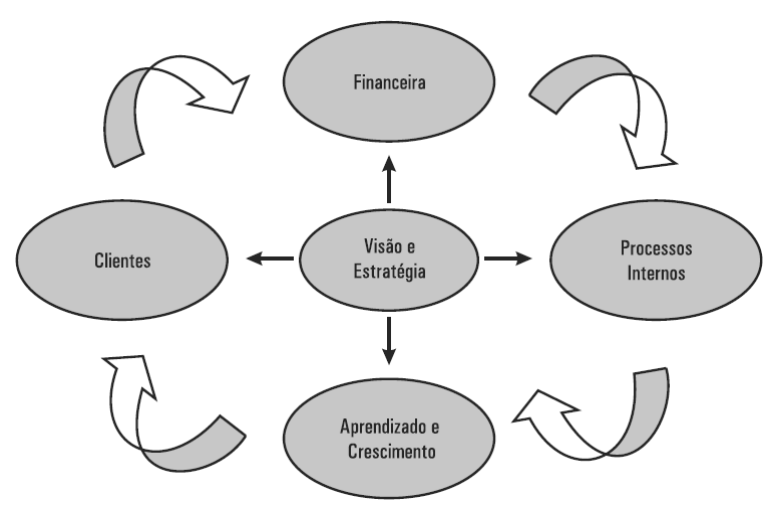

Fonte: Reproduzido de Kaplan e Norton (1996).

A ferramenta em análise, quando utilizada no mercado, é uma metodologia de medição (controle), gestão de desempenho e implementação de estratégia, desenvolvida a partir de 4 (quatro) perspectivas estratégicas, são elas: perspectiva financeira; perspectiva clientes, perspectiva processos internos e perspectiva de aprendizado.

Segundo Kaplan e Norton (1996, p. 46), o BSC "pode proporcionar foco, motivação e responsabilidade em empresas públicas e instituições sem fins lucrativos". A utilização do BSC pela administração pública insere-se no contexto da administração gerencial, ocasião em que as perspectivas do BSC devem funcionar como modelo, podendo ser adaptadas de acordo com a realidade de cada organização, eliminando assim o caráter rígido e fechado.

Não existe um consenso do modelo BSC aplicado na administração pública. O que existe são várias adaptações feitas para cada órgão ou departamento público, levando em consideração suas características, necessidades e peculiaridades. Este trabalho apresenta o modelo proposto por Felix, Felix e Timóteo (2011), que adaptou o BSC para Administração Pública Federal.

Figura 3 - BSC voltado para Administração Pública Federal. 


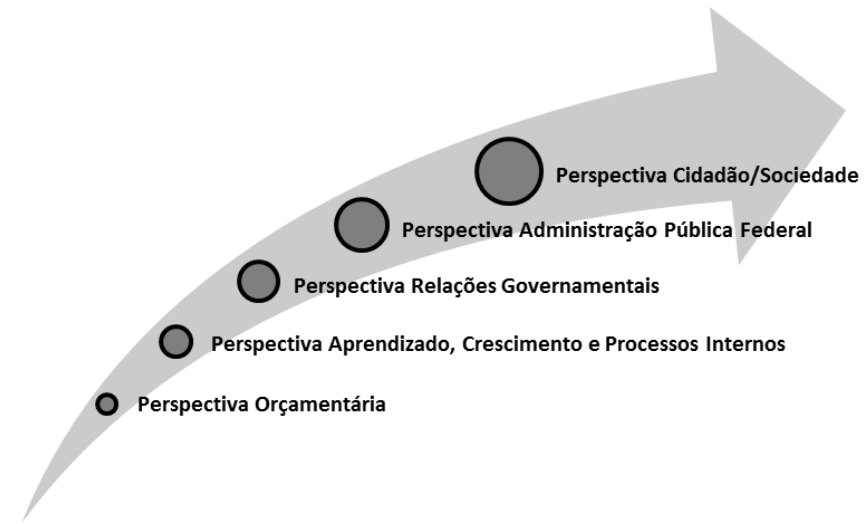

Fonte: Adaptado de Felix, Felix e Timóteo (2011)

Na figura 3 pode-se verificar que a gestão estratégica nas organizações públicas é possível, utilizando-se de um modelo concebido na iniciativa privada, como forma de contribuir com o gerenciamento das ações públicas.

\section{Ciclo PDCA}

O Ciclo PDCA (Plan, Do, Check, Action), segundo Marshall Junior et al. (2008), é um método gerencial para a promoção da melhoria contínua e reflete a base da filosofia do melhoramento contínuo, através de quatro etapas integradas: planejamento, execução, verificação e ação corretiva.

É uma metodologia para solução de problemas baseada na melhoria contínua, possibilitando que os objetivos traçados pelo planejamento estratégico sejam viabilizados na empresa, sendo de extrema importância o alinhamento de toda organização (colaboradores) com o método (FALCONI, 2014).

Para o glossário do GesPública (2014), ciclo PDCA, também chamado de ciclo da melhoria contínua, é uma ferramenta que busca a lógica para fazer certo desde a primeira vez. O PDCA padroniza as informações de controle, reduz e evita erros lógicos, facilita o entendimento das informações, melhora a realização das atividades e proporciona resultados mais confiáveis. Ele parte da insatisfação para com o "estado atual das coisas" e analisa os processos com vistas a realizá-los de maneira otimizada (PALUDO, 2016).

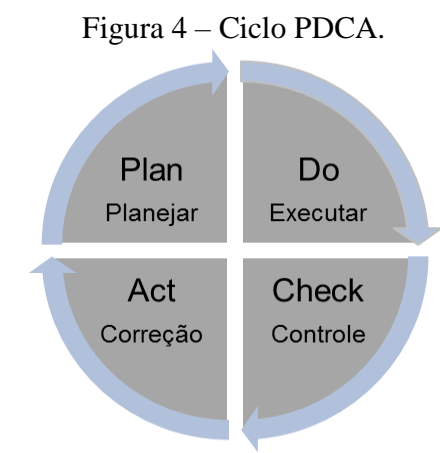

Fonte: Reproduzido de Paludo (2016).

O PDCA pode ser bastante útil para a administração pública no momento de formular, implementar e avaliar suas políticas públicas, sejam quais forem os agentes públicos nelas envolvidas. Além do mais, o caráter cíclico do PDCA vai ao encontro das necessidades da administração, pois os problemas enfrentados a cada dia são diferentes e mais complexos.

Diante do exposto, considerando as questões específicas deste, observa-se que através das ferramentas gerenciais, que já foram testadas no mercado, o Estado consegue ser mais efetivo no ataque aos problemas e dilemas enfrentados pela administração pública.

Dentro do recorte desta pesquisa evidenciaram-se influências neoliberais no modelo gerencial, porém o Estado nunca teve um modelo puro de gestão, ainda detectam-se práticas patrimonialistas e burocráticas bem acentuadas na gestão pública.

Apesar das limitações, essa revisão concluiu que o gerencialismo, como modelo de gestão, tornou-se de fundamental importância dentro do contexto globalizado e que o mesmo ainda precisa ser aperfeiçoado, devido à complexidade do orçamento público e das diversas demandas da sociedade.

\section{CONSIDERAÇÕES FINAIS}

Convém ressaltar, por fim, que o debate aqui levantado ainda requer, certamente, de um acúmulo de conhecimentos sobre outros estudos que possam, por sua vez, engrandecer a análise, principalmente no que diz respeito às novas ferramentas gerenciais.

Portanto, o presente trabalho se apresenta como uma singela colaboração para uma reflexão e discussão sobre aspectos considerados imprescindíveis para uma sensata compreensão do tema.

O presente trabalho propõe como futuras investigações, estudos posteriores que ressaltem a influência do gerencialismo ou das ferramentas gerenciais na formulação, implementação e avaliação de políticas públicas.

\section{REFERÊNCIAS BIBLIOGRÁFICAS}

ABRUCIO, Fernando Luiz, "Os avanços e os dilemas do Modelo pós-burocrático: a reforma da administração pública à luz da experiência recente". Rio de Janeiro, Editora FGV. 1999.

ALECIAN, Serge; FOUCHER, Dominique. Guia de Gerenciamento no Setor Público. Rio de Janeiro: Revan; Brasília, DF, 2001.

BALL, Stephen J. Profissionalismo, gerencialismo e performatividade. Cadernos de pesquisa, v. 35, n. 126, p. 539-564, 2005

BALL, Stephen J. Sociologia das políticas educacionais e pesquisa crítico-social: uma revisão pessoal das políticas educacionais e da pesquisa em política educacional. Currículo sem Fronteiras, v. 6, n. 2, p. 10-32, 2006.

BRESSER PEREIRA, Reforma da nova gestão pública: agora na agenda da América Latina. Revista do Serviço Público, Brasília: Enap,jan.-mar. 2002.

BRESSER-PEREIRA, L. C. Democracia, Estado social e reforma gerencial. Revista de Administração de Empresas, 50 (1), 112-116. 2010.

BUENOS AYRES, Carlos Antônio Mendes de Carvalho. Administração no setor público. Teresina: EDUFPI/UAPI; Teresina, 2013. 
CABRAL NETO, Antônio. Gerencialismo e gestão educacional: cenários, princípios e estratégias. In: FRANÇA, Magna; BEZERRA, Maura Costa (org.). Política educacional: gestão e qualidade do ensino. Brasília: Liber livro, 2009.

CAIDEN, G.E. Administrative reform comes of age. Berlin/New York: Walter de Gruyter. 1991.

CAVAlCANTE, Pedro. Gestão Pública Contemporânea: do movimento gerencialista ao pós-npm. Rio de Janeiro: Ipea , 2017.

DI PIETRO, Maria Sylvia Z. Direito administrativo. 28. ed. São Paulo: Atlas, 2015.

FALCONI, V. TQC: controle da qualidade total. 8. ed. Nova Lima, MG: INDG Tecnologia e Serviços Ltda. 256 p, 2014.

FELIX, R.; FELIX, P. P.; TIMOTEO, R. Balanced Scorecard: adequação para a gestão estratégica nas organizações públicas. Revista do Serviço Público, Brasília, ed. 62, p. 51-74, 2011.

GIDDENS, Anthony. A Terceira Via. Tradução de Maria Luiz X. de A. Borges. $1^{\text {a }}$ Ed. $2^{a}$ Triagem. Brasília: Instituto Teotônio Vilela, 1999.

GESPÚBLICA. Modelo de Excelência em Gestão Pública, 2014. Disponível em: 〈www.gespublica.gov. br〉.

HYPÓLITO, Álvaro Moreira. Estado gerencial, reestruturação educativa e gestão da educação. Revista RBPAE - v. 24, n. 1, p. 63-78, jan./abr. 2008.

HOOD, C. “Beyond 'progressivism': a new 'global paradigm' in Public Management?”. International Journal of Public Administration, vol 19, n.2. 1996.

HUSSENOT, Philippe. La Gestion Publique par Objectifs: des ambitions à la pratique. Paris: Les Éditions d'Organisation, 1983.

KAPLAN, R. S; NORTON, D. P. Balanced scorecard: translating strategy into action. Boston: Harvard Business School Press. 1996.

KAUFMAN, H. "Fear of bureaucracy: a ranging pandemic", Public Administration Review, vol 41, n.1. 1981.

KEARNS, David T. Quality improvement begins at the top. Ed. World 20, 1986.

KETTL, D. “The global revolution: reforming government sector management", A Reforma do Estado na América Latina e no Caribe, Seminário internacional, Brasília, 16 e 17 de maio 1996.

LOPES, António Carlos Vaz. Adoção de inovação organizacional: o caso do balanced scorecard (BSC) em empresas no Brasil. 2013. 284f. Tese (Doutorado) Universidade Nove de Julho - UNINOVE, São Paulo, 2013.

MARSHALL JUNIOR et al. Gestão da qualidade. 9. ed. Rio de Janeiro: Editora FGV, 2008.

MAXIMIANO, Antonio Cesar Amaru. Introdução à Administração. São Paulo:Atlas, 1985.

MISOCZKY, M. C. Administração Pública Contemporânea. Porto Alegre: Ministério da
Cultura/UFRGS/EA, Módulo 4. Apostila do Curso de Extensão em Administração Pública da Cultura. 2014.

MITTELSTAEDT, R. E. Benchmarking: how to learn from best-in-class practices. National Productivity Review. vol. 11, n. 3, p. 301-315, 1992.

MOTTA, Fernando P.; BRESSER-PEREIRA, L.C. Introdução à organização burocrática. São Paulo: Thomson, 1980.

MÜLLER, Pierre. Les Politiques Publiques [As Políticas Públicas]. Paris: Presses Universitaires de France, 1990.

OSBORNE, D. \& GAEBLERR, T. "Reinventando o governo - como o espírito empreendedor está transformando o governo. Brasília: MH Comunicação.1994.

OSÓRIO, V. L. T. A utilização do balanced scorecard no aperfeiçoamento da administração pública gerencial: estudo de caso de uma autarquia municipal. 2003. 227 p. Dissertação (Mestrado Profissionalizante em Engenharia) Universidade Federal do Rio Grande do Sul, Porto Alegre, 2003. Disponível em <http://www.producao.ufrgs.br/arquivos/publicacoes/vera_o sorio.pdf>. Acesso em: 22 mar. 2018.

PALUDO, Augustinho Vicente. Administração pública. 5. ed. rev., atual. e ampl. - Rio de Janeiro: Forense; São Paulo. 2016.

PETERS, B.G. (1992), "Reorganizando o governo em uma era de contenção e compromisso", Dados, vol.35, n.3, Rio de Janeiro. 1992.

POLLITT, C. Managerialism and the public services the angloamerican experience. Oxford/Massachusetts: Basil Blackwell. 1990.

POLlitT, C.; BOUCKAERT, G. Public Management Reform: a comparative analysis-new public management, governance, and the Neo-Weberian state. UK: Oxford University Press, 2011.

RAYNER, L. The unifinished agenda. London: Athlone Press. 1984.

TAVARES, Mauro C. Gestão estratégica. 3. ed. São Paulo: Atlas, 2010.

UKELES, J. Doing more with less: turning public management around. New York: AMACOM. 1982.

WEBER, Max. Sociologia da burocracia. Tradução de Edmundo Campus. Rio de Janeiro: Zahar Editores, 1966.

\section{AGRADECIMENTOS}

Ao Instituto Federal do Piauí - IFPI pelo apoio à pesquisa e desenvolvimento do servidor e ao programa de mestrado em Gestão Pública da Universidade Federal do Piauí - UFPI.

\section{COPYRIGHT}

Direitos autorais: Os autores são os únicos responsáveis pelo material incluído no artigo. 


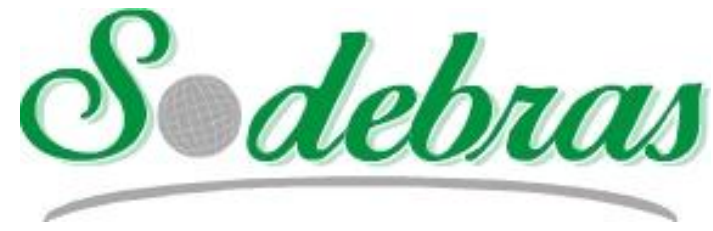

Volume $14-\mathrm{N}^{\mathrm{o}} 159$ - Março/2019.

XL International Sodebras Congress

10 a 12 de dezembro de 2018 - Vitória - ES.

\title{
A EVOLUÇAO DE INCUBADORAS NO ESTADO DO PARANÁ - UMA VERTENTE AO EMPREENDEDORISMO INOVADOR
}

\section{THE EVOLUTION OF INCUBATORS IN THE STATE OF PARANÁ - A BRAND OF INNOVATIVE ENTREPRENEURSHIP}

\author{
MARIA PAULINA MANJAMA ${ }^{1}$; ELAINE SILVA RAMOS ${ }^{1}$; CLAUDIA CRISOSTIMO ${ }^{1}$; PAULO $^{2}$ \\ ROGERIO PINTO RODRIGUES ${ }^{1 .}$
}

\section{1-UNIVERSIDADE ESTADUAL DO CENTRO-OESTE-UNICENTRO.}

mariamanjama@gmail.com; elaineramos9@hotmail.com; claudia@unicentro.br;prprodrigues@gmail.com

\begin{abstract}
Resumo - Incubadoras de empresas são ambientes de incentivo a atividades inovadoras $e$ ao empreendedorismo, por meio de criação de novas empresas com potencial diferenciado. Foi realizada uma análise das incubadoras de empresas no estado do Paraná, como instituições de estímulo ao empreendedorismo e inovação e apoio ao desenvolvimento, quanto ao número de empresas de base tecnológicas incubadas nos últimos dez anos.

Palavras-chave: Incubadoras. Incubadas, Empreendedorismo inovador.

Abstract - Incubators are incentive environments for innovative activities and entrepreneurship, through the creation of new companies with differentiated potential. An analysis was made of incubators of companies in the state of Paraná, as institutions to stimulate entrepreneurship and innovation and development support, regarding the number of technological base companies incubated in the last ten years.
\end{abstract}

Keywords: Incubators. Incubated, Innovative Entrepreneurship

\section{INTRODUÇÃO}

A incubação de Empresas no Brasil, teve seu início na década de 1970. A ideia de incubadoras no Brasil surgiu através de um projeto da Universidade do Estado de São Paulo (UNESP), o qual visava implantar incubadoras no país, dado o contexto de alta mortalidade de micro e pequenas empresas. As incubadoras seriam um recurso para diminuir este índice de mortalidade e incentivar o empreendedorismo no país (NASSIF MANTOVANI et al., 2006).

Empreendedores interessados em desenvolver ou lançar novos produtos viram nas incubadoras uma maneira viável de criar e sustentar suas empresas, com a disponibilidade de usufruírem de infraestrutura adequada e o desenvolvimento de recursos e capacidades de extrema relevância para o sucesso do negócio (STOROPOLI et al., 2013)

A oferta de ambientes propícios à criação e ao crescimento de negócios e soluções inovadoras tem se mostrado, ao longo dos anos, uma ferramenta importante de impulso ao desenvolvimento econômico, tecnológico e social (ANPROTEC, 2016)
$\mathrm{O}$ apoio do setor privado ao empreendedorismo inovador no Brasil se disseminou, mas, apesar das novas iniciativas e dos avanços crescentes em relação ao tema, o Brasil ainda precisa avançar nesse processo. Fatores como instabilidade de recursos, descontinuidade de programas e ausência de uma cultura de avaliação de resultados inibem a consolidação de uma política de Estado para inovação que tenha eficiência (FREIRE; MARUYAMA; POLLI, 2017).

Sendo o apoio local por vezes insuficiente para a manutenção das incubadoras e suas empresas, o Governo Federal, junto com outras instituições públicas e privadas tem se disponibilizado a fornecer apoio técnico e financeiro.

Os programas de apoio ao empreendedorismo e pequenas empresas que no Brasil são: Conexão StartupIndústria (2017), Criatec I (2007), Criatec II (2013), Criatec III (2016), BNDES MPME Inovadora (2014), Inova Talentos (2013), Procompi (1998), RHAE (1987), Pipe I e II (1997), Inovar(2013), Pappe Subvenção/Integração (2006), Tecnova (2012), Inovacred (2014), Pipe/Pappe(PIPE III) (2005), Finep Startup (2017), Seed-MG (2013), Sinapse da Inovação(2005), Pitch-GovSP (2015), Startup Brasil (2015), PNI (Incubadoras) (2012), Inovativa (2013), Techsampa (Vaitec) (2014), ALI (Agentes Locais de Inovação) (2008), Sebraelab (2016), Sesi-Senai de Inovação (2004), Startup Sebrae.

Segundo dados da Anprotec, em 2016, o Brasil contava com 369 incubadoras de empresas que abrigavam 2310 incubadas e 2815 graduadas com mais de 16000 postos de trabalho. 
Figura 1- Percentual das Incubadoras do Paraná.

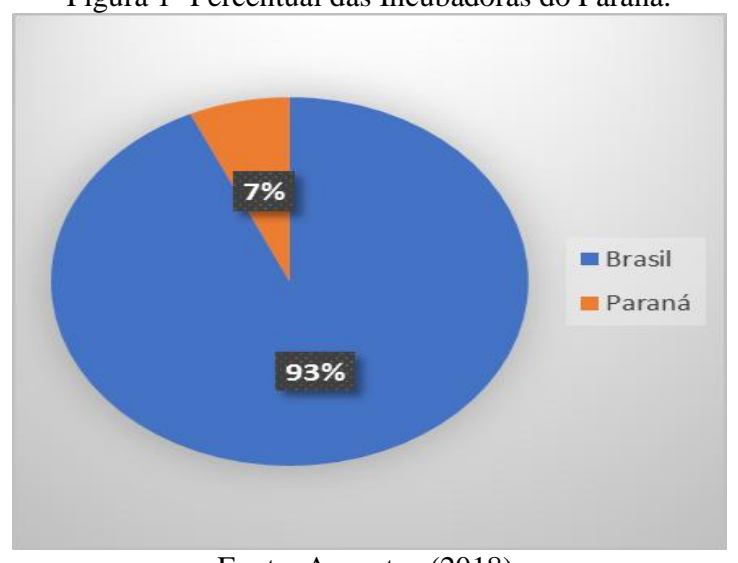

Fonte: Anprotec (2018).

Observa-se pela Fig. 1 que as incubadoras existentes no estado do Paraná correspondem a aproximadamente somente $7 \%$ em relação ao resto do Brasil.

No Paraná, em 2000, foi criada a REPARTE (Rede Paranaense de Tecnologia e Inovação), com o objetivo de integração de programas de incubação no estado, através do incentivo ao empreendedorismo e desenvolvimento de novas tecnologias. Mais tarde, após a extinção da surgiu em 2016 a REINOVA-PR (Rede Paranaense de Incubadoras e Aceleradoras de Empreendimentos Inovadores), que tem como um de seus objetivos promover a cultura de empreendedorismo e inovação no estado do Paraná da qual fazem parte o maior número das incubadoras do estado.

\begin{tabular}{l} 
Quadro 1- Incubadoras existentes no Paraná 2018. \\
\begin{tabular}{|l|}
\hline INCUBADORAS NO ESTADO DO PARANÁ \\
\hline HT-CM. Campo Mourao \\
\hline EDUCERE, Campo Mourao \\
\hline IESD/PTI, Foz do Iguaçu \\
\hline FUNDETEC, Cascavel \\
\hline ITEC-PB, Pato Branco \\
\hline IUT/UTFPR-PB, Pato Branco \\
\hline IUT/UTFPR-MD, Medianeira \\
\hline SUDOTEC, Dois Vizinhos \\
\hline INTEG, Guarapuava \\
\hline IEP, Curitiba \\
\hline INTEC, Curitiba \\
\hline NEMPS/UFPR, Curitiba \\
\hline ISAE/FGV, Curitiba \\
\hline ITCP/UFPR, Cuririba \\
\hline Incubadora da Universidade Positivo/Curitiba \\
\hline HPI-CIC/SENAI, Curitiba \\
\hline IUT/UTFPR-CT, Curitiba \\
\hline IUT/UTFPR-PG, Ponta Grossa \\
\hline INTECPONTA, Ponta Grossa \\
\hline ITM, Maringa \\
\hline INTUEL, Londrina \\
\hline IUT/UTFPR-CP,Coronel Procopio \\
\hline FINDEX \\
\hline Incubadora Bernardino Aelindo Barbieri-Palotina \\
\hline FINDEX/ Francisco Beltrão \\
\hline INTEC/Entre Rios \\
\hline Incubadora Sistema FIEP \\
\hline
\end{tabular} \\
\hline
\end{tabular}

Fonte: Adaptado de Anprotec; Sebrae.

Verifica-se noo Quadro 1 que a maior parte das incubadoras está localizada na capital do Estado. Este fato pode ser devido ao elevado nível de desenvolvimento, universidades e centros de pesquisa que lá existem, o que traz consigo um elevado índice de investimento em inovação tecnológica em relação as outras cidades.

Com as grandes mudanças socioeconômicas que tem vindo a acontecer nos últimos tempos, surge a necessidade de se adaptar a estrutura e os serviços oferecidos ao mercado local. Para isso, a ANPROTEC em parceria com o SEBRAE resolveu criar um modelo de gestão de incubadoras denominado CERNE (Centro de Referência para Apoio a Novos Empreendimentos), que visa apoiar e ampliar a capacidade de atuação das incubadoras de modo a obterem melhores resultados e maiores taxas de sucesso nos empreendimentos com base na inovação. A gestão por meio do CERNE funciona de acordo com o uso de boas práticas usadas em processos-chave que são divididos em quatro eixos que são o empreendimento, incubadora, rede de parceiros e inovação.

\section{METODOLOGIA}

O estudo foi baseado no método de revisão bibliográfica, com o estudo da arte, elaborando uma busca em bancos de dados de periódicos como: Periódicos Capes, Scielo, Google Scholar, e também informações retiradas de bancos de dados da Rede Estadual de incubadoras e da Associação Nacional de Entidades Promotoras de Empreendimentos Inovadores (ANPROTEC).

\section{RESULTADOS}

Em relação ao apoio ao empreendedorismo inovador no Brasil, foram criados diferentes programas que direta ou indiretamente têm contribuído para o desenvolvimento de empresas iniciantes e pequenas que desejam inovar. Essas ações vêm melhorando o ambiente inovador no Brasil.

A incubadora é o melhor processo para gerar inovação e deve ser utilizada para a criação desses ambientes, que podem estar nas empresas, universidades e cidades e devem ter e manter capital intelectual e capital social(SENAI, 2008).

Até então, verifica-se 26 programas de apoio a pequenas empesas, startups e inovação. Estes programas foram oferecidos por dezesseis instituições, sendo três de instituições público-privadas e na sua maioria entrarão em vigência a partir de 2008.

As incubadoras tendem a focar em dicas sobre o funcionamento do mercado, tecnologias e seus aspectos, e a viabilidade de apoio financeiro, criando um ambiente adepto ao surgimento e fortalecimento de novos empreendimentos, objetivando tornar seus incubados em empresas graduadas bem-sucedidas.(SAUKA, 2015)

A evolução das incubadoras, os resultados obtidos demonstraram que, em 2008 haviam ao todo 19 incubadoras, 123 empresas incubadas e 130 empresas graduadas no Paraná. O número de incubadoras no Estado do Paraná cresceu de 19 para 27, mas o número de incubadoras que participam da REINOVA-PR continua o mesmo.

Entretanto, o número de incubadoras não aumentou significativamente, mas apresenta um maior nível de desenvolvimento, incentivo e aumento do número de empresas incubadas. Este fenômeno tem como consequência a maior geração de empregos na comunidade e distribuição de renda. 
Para o trabalho foi elaborou-se um levantamento do número total de incubadoras existentes no período pós-crise econômica no Brasil. Dos três tipos de incubadoras existentes de acordo com a classificação da ANPROTEC, as de base tecnológica, são as de maior numero, seguidas das incubadoras mistas e as de setores tradicionais.

Em geral, no Estado do Paraná, não houve um aumento significativo quanto ao número de incubadoras criadas no período em estudo, sendo que o país se encontrava numa fase de recuperação econômica, conforme Figura 2.

Figura 2- Evolução do número de incubadoras e incubadas no Estado do Paraná-2008 a 2018.

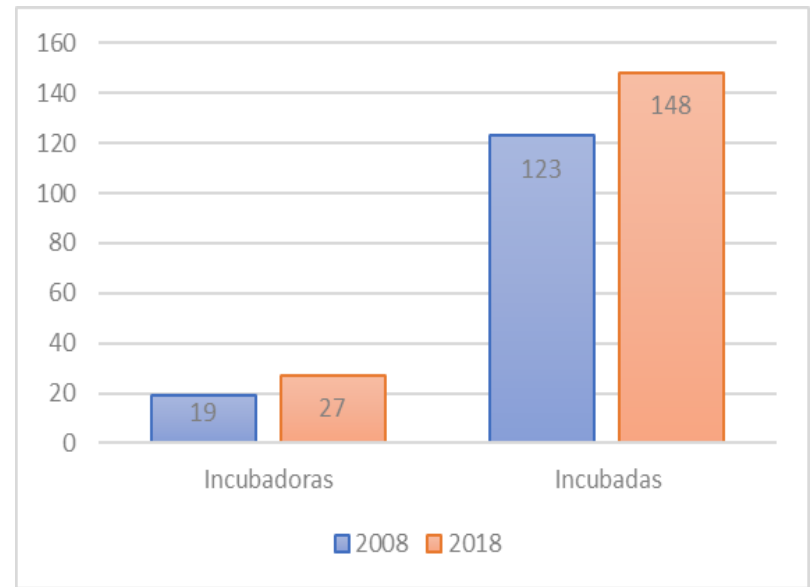

Fonte: SEBRAE PR.

\section{CONCLUSÃO}

As Incubadoras de empresas são ambientes de incentivo a atividades inovadoras e ao empreendedorismo, por meio de criação de novas empresas com potencial diferenciado. É notória a sua relevância e sua contribuição na geração de empregos e renda, pois podemos consideralas mecanismos de apoio e promoção ao desenvolvimento econômico e social sustentável regional devido aos mais variados tipos de auxílio oferecidos aos empreendedores locais, ajudando desenvolver o empreendedorismo. Concluise que o número de incubadoras no estado do Paraná teve um aumento de ordem de 5,13\%. E acompanhando este aumento o número de incubadas também cresceu podendo ter como um dos motivos o aumento dos incentivos a inovação e a grande procura de auto sustentabilidade por editais governamentais de fomento ao empreendedorismo neste período.

\section{REFERÊNCIAS BIBLIOGRÁFICAS}

ANPROTEC. Estudo de impacto econômico: segmento de incubadoras de empresas do BrasilAnprotec: Sebrae. Basilia. Disponível em: <www.anprotec.org.br>. Acesso em: 25 ago. 2018.

FREIRE, C. T.; MARUYAMA, F. M.; POLLI, Marco. Innovation and entrepreneurship: Public policies and private actions | Inovação e empreendedorismo: Políticas públicas e ações privadas. Novos Estudos CEBRAP, [s. 1.], v. 36, n. 3, p. 51-76, 2017. Disponível em: <http://www.scielo.br/pdf/nec/v36n3/1980-5403-nec-36-0351.pdf>. Acesso em: 10 out. 2018.

NASSIF Mantovani, Brasil et al. O PAPEL DAS
INCUBADORAS DE EMPRESAS NO DESENVOLVIMENTO LOCAL: UM ESTUDO DE CASO Daie. RAI-Revista de Administração e Inovação, [s. 1.], v. 3, n. 1, p. 90-101, 2006. Disponível em: <http://www.redalyc.org/articulo.oa?id=97317268007>. Acesso em: 14 out. 2018.

RAUPP, F. M., \& BEUREN, I. M. Compartilhamento do conhecimento em incubadoras brasileiras associadas à Anprotec. Revista de Administração, Mackenzie, 8(2), 2007 , p. $38-58$

SAUKA, Jean Elizeu. Um panorama das incubadoras de empresa no estado do paraná, brasil. [s. 1.], 2015. Disponível em: <https://www.rio2015.esocite.org/resources/anais/5/144077 9058_ARQUIVO_Incubadoras_Parana_Jean_Elizeu_Sauka _2015.pdf>. Acesso em: 4 out. 2018.

SENAI, PROGRAMA INOVA. Faces do empreendedorismo inovador. [s.l: s.n.]. Disponível em: $<$ http://www.unisul.br/wps/wcm/connect/7b05c644-7adf432d-b881-e3b1e8276318/livro_faces-empreend-inovadorvol-III_agetec.pdf?MOD=AJPERES>. Acesso em: 22 out. 2018.

SINGH, A.S.; et al. Incubadoras do Paraná e a Obtenção de Recursos: um estudo de multicasos sob a perspectiva das capacidades relacionais. Anais do VI SINGEP, São Paulo/SP, nov 2017.

STOROPOLI, José Eduardo et al. O desenvolvimento de capacidades e recursos em incubadoras de empresas. [s.l: s.n.]. Disponível em: <http://www.anpad.org.br/admin/pdf/2013_EnANPAD_ES O1948.pdf $>$. Acesso em: 4 out. 2018.

\section{AGRADECIMENTOS}

O presente trabalho foi realizado com apoio da Coordenação de Aperfeiçoamento de Pessoal de Nível Superior-Brasil (CAPES). Agradecimentos ao CNPq, FINEP, Fundação Araucária e Fundação de Apoio ao Desenvolvimento da Unicentro, FAU/UNICENTRO.

O presente foi realizado com apoio da Coordenação de Aperfeiçoamento de Pessoal de Nível Superior - Brasil (CAPES) - Código de financiamento 001. 


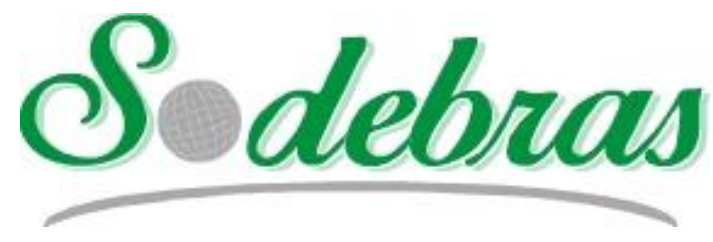

Volume 14 - No 159 - Março/2019.

XL International Sodebras Congress

10 a 12 de dezembro de 2018 - Vitória - ES.

\title{
A INOVAÇÃO NO SISTEMA CARCERÁRIO BRASILEIRO COM O USO DO MONITORAMENTO ELETRÔNICO
}

\section{THE INNOVATION IN THE BRAZILIAN CARCERARY SYSTEM WITH THE USE OF ELECTRONIC MONITORING}

\author{
CLIVER LUCAS SILVEIRA CAMPOS; ELAINE SILVA RAMOS; PAULO ROGÉRIO PINTO \\ RODRIGUES; MAICO TARAS DA CUNHA;
}

\section{1 - Universidade Estadual do Centro-Oeste do Paraná UNICENTRO}

clivercampos7@gmail.com; elaineramos9@hotmail.com; prprodrigues@gmail.com; maico_tc@yahoo.com.br.

\begin{abstract}
Resumo - O presente artigo visa discorrer sobre a possibilidade de instalação de monitoramento eletrônico nos custodiados que cumprem pena no regime semiaberto na comarca de Guarapuava/PR, substituindo o atual modelo que conta com uma Unidade Penal exclusiva para essa finalidade.
\end{abstract}

Palavras-chave: Inovação. Sistema prisional. Monitoramento eletrônico. Escritório Social. Tornozeleira eletrônica. Regime semiaberto.

\begin{abstract}
This article aims to discuss the possibility of installing electronic monitoring in custodians who serve their sentence in the semi-open regime in the Guarapuava / PR region, replacing the current model that has an exclusive Criminal Unit for this purpose.
\end{abstract}

Keywords: Innovation. Prison system. Electronic monitoring. Social Office. Electronic ankle brace. Semi-open regime.

\section{INTRODUÇÃO}

\section{1 - Monitoramento eletrônico}

Em face de um dos maiores desafios da sociedade brasileira, que é a questão do encarceramento, a busca por métodos inovadores e aplicação de novas tecnologias são essenciais ferramentas para que haja uma maior eficiência do sistema penal brasileiro, em especial na sua fase de execução da pena.

Assim surge como opção o monitoramento eletrônico, sendo já usado há vários anos em outros países, em especial na Bélgica, como relata Vanhaelemeesch (2013) que desde o ano 2000 é aplicado ao cumprimento de pena a condenados até 3 anos de punição, como também na vizinha Argentina, como explicita Di Tella (2013), que no ano de 1997 a província de Buenos Aires foi pioneira no uso de monitoramento eletrônico na América Latina.

O uso de monitoramento eletrônico não é algo novo também no sistema penal pátrio, Machado (2009) discorre que a utilização de meios alternativos de vigilância sobre detentos tem-se revelado como uma notável alternativa para a fiscalização da execução de penas e cumprimentos de normas penais. No Brasil, o uso de tecnologias dentro dos presídios e o monitoramento eletrônico de detentos à distância por ordem judicial, devem ser utilizados de maneira que não violem direitos fundamentais do acusado ou do detento provisório, e que, ao mesmo tempo, possam ser uma eficiente ferramenta de controle e fiscalização penal.

Duarte Junior e Menezes (2015) salientam que, através do monitoramento eletrônico, o Estado pode oferecer um tratamento mais humano e digno ao encarcerado, aplicando-lhe uma medida cautelar, como o monitoramento, isso facilitaria o regresso do acusado, posteriormente, à sociedade, mesmo condenado. Neste caso, a função da medida ou da pena possui um caráter mais fidedigno, ou seja, reintegrar o indivíduo à sociedade.

Fabris (2010), em seu trabalho, analisa a fiscalização do detento fora da cadeia pública, dando maior enfoque na humanidade desses indivíduos que estariam a cumprir penas de total privação de liberdade e, com a modernidade, os meios tecnológicos, por exemplo, a tornozeleira eletrônica, que pode dar a localização do detento com razoável precisão em tempo real, contribuindo para a diminuição do problema de superlotação do sistema penitenciário brasileiro.

Corrêa Junior (2012) delineia que a vigilância eletrônica nasce como uma solução para os sistemas carcerários, sendo que o monitoramento do detento é influenciado pela cultura do controle do delito, a busca por alternativas ao modelo do cárcere já é bem antiga e com essas novas alternativas, por si só não irão resolver a redução dos detentos e a reincidência do crime, porém oferecem vantagens econômicas. Essa vigilância eletrônica, ainda, tem como grande função a execução de penas restritivas que substitui o cárcere para delitos menores.

Corrêa Junior (2012) também nos traz os primeiros usos do monitoramento eletrônico, quando a ideia surgiu em Harvard na década de 1960 com os irmãos professores Ralph Schwitzgebel e Robert Schwitzgebel no uso para pessoas com transtornos mentais; e depois nos anos 80 pelo Juiz Jack Love, inspirado em uma história em quadrinhos do homem aranha, no condado de Albuquerque, na aplicação de penas por crimes de embriaguez ao volante e de origem financeira. 
Figura 1 - Tira da história do Homem-Aranha que inspirou o juiz Jack Love.

the AMAZING SPIDER-MAN.
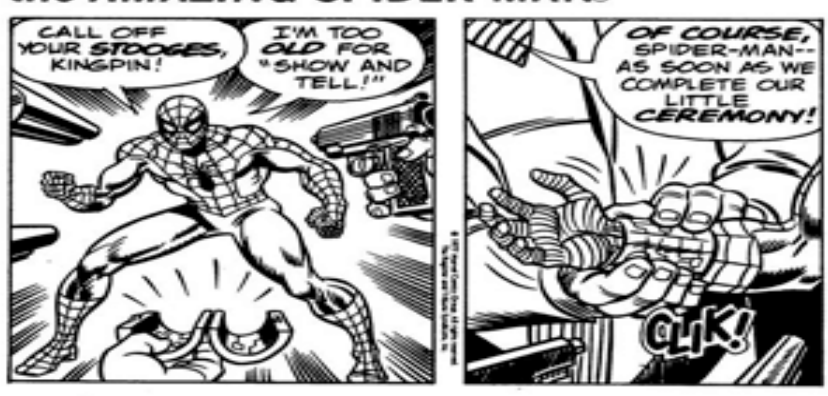

\section{2 - Regimes de pena no Brasil}

Quanto ao tipo de regime de cumprimento de pena aqui sugerido para a aplicação da tornozeleira eletrônica, seria o semiaberto, um dos três tipos de cumprimento de pena que existe no Brasil, conforme explica a diferença entre eles o Conselho Nacional de Justiça:

Nos últimos anos tem sido cada vez mais frequente, no noticiário e em outras fontes de informação, a citação de palavras que se referem aos três regimes de cumprimento de penas de prisão - o fechado, o semiaberto e o aberto. Segundo o Código Penal brasileiro, quanto mais grave é o crime cometido, mais rigoroso é o tratamento dispensado ao réu.

No caso do condenado a mais de oito anos de prisão, por exemplo, o início do cumprimento da pena deve ser no regime fechado. Nessa condição, o detento fica proibido de deixar a unidade prisional, como presídio e penitenciária ou mesmo a Associação de Proteção e Assistência ao Condenado (APAC) em que estiver cumprindo a pena.

Já o condenado a pena superior a quatro anos e não superior a oito anos de prisão, se não for reincidente, deve iniciar o cumprimento de pena no regime semiaberto, em colônia agrícola ou estabelecimento similar, como as APACs. Nessa condição, ele é autorizado a deixar a unidade penitenciária durante o dia para trabalhar, devendo retornar à noite. No caso do réu reincidente, ele inicia o cumprimento da pena no regime fechado.

A legislação penal brasileira permite que o condenado em regime fechado ingresse no semiaberto após o cumprimento de $1 / 6$ da pena, desde que tenha bom comportamento carcerário. Nos crimes contra a Administração Pública, como, por exemplo, a corrupção, o condenado só muda de regime, após $1 / 6$ da pena, se tiver bom comportamento e também reparar o prejuízo aos cofres públicos, exceto quando ele comprovar a impossibilidade de fazê-lo. Para os crimes hediondos, como estupro, a progressão de regime se dá após o cumprimento de $2 / 5$ da pena, se o condenado for primário, e de $3 / 5$ da pena, se reincidente.

O regime aberto, por sua vez, é imposto a todo réu condenado a até quatro anos de prisão, desde que não reincidente. Nesse regime, a pena é cumprida em casa de albergado ou, na falta deste, em estabelecimento adequado, como, por exemplo, a residência do réu. $\mathrm{O}$ condenado é autorizado a deixar o local durante o dia, devendo retornar à noite. Para o regime aberto podem progredir os que se encontram no semiaberto, após o cumprimento dos requisitos previstos na legislação penal
By Stan Lee and John Romita
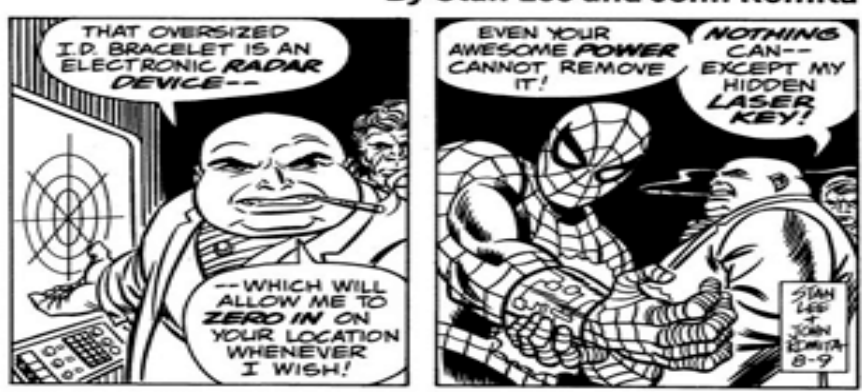

brasileira, como tempo de cumprimento de pena e bom comportamento.

\section{3 - Unidades penais em Guarapuava/PR}

A Unidade que hoje abriga os custodiados que cumprem pena no regime semiaberto em Guarapuava/PR é o Centro de Regime Semiaberto de Guarapuava, e essa é sua descrição no sitio do DEPEN/PR: 'Estabelecimento Penal de segurança média, destinado a presos do sexo masculino cumprindo pena em regime semiaberto. Rua Flávio Correia dos Santos, 400 - Guarapuava / PR CEP: 85053-390 - Email: craguarapuava@depen.pr.gov.br' e ainda pelo sitio do DEPEN é possível fazer uma consulta ao SIGEP, Sistema Integrado de Gestão da Execução Penal, sendo atualizada essa informação diariamente e na qual consta: quantidade total de presos, quantidade de presos por tempo custodiado nas Unidades, gênero, nacionalidade, faixa etária, e cor de pele.

Já numa análise rápida dos dados dos presos de região de Guarapuava/PR, chama a atenção as peculiaridades dos dados, quando comparados com o encarceramento nacional, $61 \%$ dos presos tem a cor da pele branca, e $4 \%$ tem a cor da pele negra; a idade dos presos também em sua maioria tem mais de 30 anos. Já nos dados nacionais, fornecidos pelo Conselho Nacional de Justiça, $64 \%$ dos presos tem a cor da pele negra e $35 \%$ tem a cor da pele branca, e $55 \%$ dos presos tem menos de 30 anos de idade.

Mas o dado que mais chama atenção e é um dos focos deste trabalho, é o número de vagas e taxa de ocupação entre duas das três Unidades da Região de Guarapuava, o Centro de regime semiaberto (CRAG) e a Penitenciária Industrial de Guarapuava (PIG), a qual é destinada para presos condenados cumprindo pena no regime fechado. Em quanto a ocupação no CRAG é de 185 presos para 215 vagas instaladas, na PIG a ocupação gira em torno de 300 presos para 240 vagas instaladas.

Quanto a terceira Unidade a situação de superlotação é ainda mais gritante, se trata da carceragem da $14^{\mathrm{a}}$ Subdivisão Policial de Guarapuava. Não existem informações oficiais sobre as ocupações disponíveis nos meios de comunicação do Governo do Paraná, mas esporadicamente o DEPEN repassa essas informações aos meios de comunicação quando estes informam sobre algum incidente ocorrido, tal como fugas e rebeliões. Tem assim que a capacidade da carceragem é para 166 presos, mas existe uma ocupação média de 330 a 380 presos, sendo o perfil destes presos o mais variado, sendo homens e 
mulheres, condenados e provisórios, ações de natureza criminal e civil (divida alimentícia).

São nessas condições precárias de encarceramento que se encontram na superlotação as seguintes condições segundo Oliveira (2007) os estabelecimentos prisionais se tornando na sua maioria um verdadeiro inferno em vida, onde o recluso se amontoa a outros em celas totalmente sujas, úmidas, anti-higiênicas e principalmente, superlotadas, de tal maneira que, em não raros exemplos, o preso deve dormir sentado, enquanto os outros revezam em pé.

\section{4 - Escritório Social}

Como explicitado acima, o réu no regime semiaberto pode sair da Unidade Penal sem supervisão para trabalhar e assim começar seu processo de reinserção na sociedade, não fazendo sentindo a manutenção de uma vaga e uma cela em um presídio para somente ser usada no repouso noturno, sendo tal vigilância substituível pelo monitoramento eletrônico.

Mas não basta apenas melhorar e humanizar o sistema de encarceramento, para NEVES (2017) é dever da administração pública garantir a efetivação dos direitos sociais prestacionais, tais como, a saúde, a alimentação, a moradia, o transporte e etc.

Para tanto surge a proposta inovadora de criação do Escritório Social, a qual sua área de atuação e origem está descrita no sítio do DEPEN como:

Inaugurado no Paraná em junho de 2017, o segundo Escritório Social do país presta assistência às pessoas em monitoração eletrônica e egressas do sistema prisional do Estado. A iniciativa faz parte do projeto Cidadania dos Presídios, do Conselho Nacional de Justiça.

\begin{abstract}
A proposta do Escritório Social é reunir em um mesmo local, atendimentos e serviços para dar suporte àqueles, que estão em monitoramento e aos egressos, em diversas áreas, como: saúde, qualificação, encaminhamento profissional, atendimento psicossocial, assistência jurídica e regularização de documentação civil. Dessa forma, aqueles que já deixaram o sistema prisional podem resgatar sua cidadania e vencer as barreiras no retorno à sociedade.
\end{abstract}

Para realizar este trabalho, a equipe do Escritório Social avalia e monitora as pessoas ali atendidas e também realiza interlocução com outras instituições públicas sempre que necessário

\section{METODOLOGIA}

A metodologia utilizada neste estudo foi a revisão bibliográfica, com a utilização de dados disponíveis em sites oficiais dos governos Estaduais e Federais.

Também foi realizado buscas no Google Acadêmico e no Bireme com a utilização dos termos: monitoramento eletrônico, sistema prisional, tornozeleira eletrônica, electronic ankle support, electronic monitoring, e electronic Tagging.

Por fim foram feitas buscas em base de dados de patentes do INPI e WIPO utilizando os termos de busca: electronic ankle support, electronic monitoring, e electronic Tagging.

\section{RESULTADOS}

De acordo com o contrato feito pelo Estado do Paraná, hoje o custo do aluguel de uma tornozeleira é de $\mathrm{R} \$ 260,00$ mensais, que é quase um décimo do valor se comparado a média do custo de um preso em uma Unidade Penitenciária, que gira em torno de R\$2.400,00 (ANDRÉ, 2006).

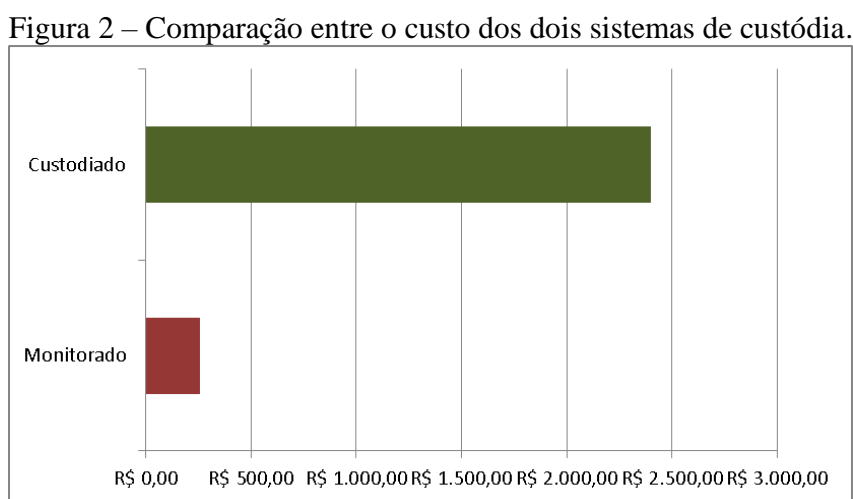

Fonte: Governo do Paraná, 2018, Conselho Nacional de Justiça, 2012.

A diferença do custo se justifica por vários fatores, o preso custodiado em uma Unidade Penal, o Estado arca com vários custos, tais como equipe de segurança de agentes penitenciários (entre 15 a 30 por dia a depender do tamanho da Unidade), os quais no Paraná recebem em torno de $\mathrm{R} \$$ 5.747,00 LOVEMONDAYS (2018), custo de manutenção da Unidade, água, luz, e alimentação.

Já no monitorado o custo é praticamente do aluguel do equipamento, já que as determinações judiciais do cumprimento da tornozeleira são pré-programadas no sistema integrado ao equipamento, tais condições são o local da residência, local de trabalho ou estudo e permissões para transitar pela comarca, sendo que todas essas condições são vinculadas a horários específicos do dia, como por exemplo a condição do período noturno e do fim de semana o monitorado deva permanecer em sua residência. Assim somente quando o monitorado descumpre uma de suas condições é que o DEPEN e o Poder Judiciário são avisados, de forma automática e simultânea pelo sistema.

Portanto o primeiro resultado esperado com essa aplicação inovadora é a diminuição drástica do custo do encarceramento para o Governo do Estado.

O segundo resultado esperado é uma redução na reincidência criminal, que é definida por OLIVEIRA e MIRANDA (2018) é um instituto que está acertado à Constituição Federal, fundando a prática de um novo crime considerando um crime anterior cuja sentença já está transitada em julgado, ou seja, o indivíduo cometeu o primeiro crime, houve o trânsito em julgado e, depois ele pratica um novo crime.

\section{CONCLUSÃO}

A inovação, em todas as suas facetas, deve ser usada como uma importante ferramenta para resolver os problemas da sociedade contemporânea, sendo que a questão do encarceramento ainda é carente de investimentos e pesquisas de novas patentes ou uso inovador de tecnologias já patenteadas.

Assim, nesse panorama ainda esquecido pelo sistema de inovação nacional, é que se busca por possibilidades de 
substituição do encarceramento em Unidades penais de semiaberto, sendo a opção pelo monitoramento eletrônico através do uso de tornozeleira, a ultima iniciativa do Departamento Penitenciário do Estado do Paraná.

Uma das inegáveis vantagens é explicada por Correia Junior (2012) O monitoramento eletrônico é justificado por sua natureza mais pragmática. Com efeito, o monitoramento eletrônico cresceu e se generalizou em muitos países como medida alternativa a prisão, destinada a combater a superpopulação carcerária, bem como para reduzir os custos elevados do encarceramento.

O sistema usado no Paraná é o que combina GPS (global positioning system) que permite a localização instantânea em qualquer local do planeta, combinado com a base cartográfica do Google Earth ${ }^{\circledR}$, de acordo com a empresa Spacecom, atual administradora do sistema de monitoramento paranaense, inclusive contando com um modelo já patenteado pela empresa sob o registro BR 2013102506820130930.

O uso de monitoração eletrônica não é só mais barato para poder público, cera de $90 \%$ de menor custo que o sistema tradicional, como também impulsiona a inovação nacional, já que tanto a tornozeleira em si, como também o software que a fiscaliza foram desenvolvidos em Curitiba/PR.

Portanto, a substituição dos presídios de regime semiaberto por tornozeleiras eletrônicas, devidamente monitoradas e fiscalizadas, combinada com uma politica pública proativa na garantia dos direitos sociais nos trazem a última palavra em inovação no tratamento penal brasileiro.

\section{REFERÊNCIAS BIBLIOGRÁFICAS}

ANDRÉ, Isabel, Finisterra, XLI, 81, 2006, pp. 121-141.

BIBNETTI, LUIZ PAULO. As inovações sociais: uma incursão por ideias, tendências e focos de pesquisa. Ciências Sociais Unisinos, São Leopoldo, Vol. 47, N. 1, p. 3-14, jan/abr 2011

CONSTITUIÇÃO DA REPÚBLICA FEDERATIVA DO BRASIL DE 1988. Recuperado em 26 de agosto, 2018, de http://www.planalto.gov.br/ccivil_03/Constituicao/Constitui cao.html

CONSELHO NACIONAL DE JUSTIÇA. RECUPERADO EM 26 DE AGOSTO DE 2018, de http://www.cnj.jus.br/noticias/cnj/62364-entenda-osdiferentes-regimes-de-cumprimento-de-pena

CORRÊA JUNIOR, A. (2012). Monitoramento eletrônico de penas e alternativas penais (Tese de doutorado). Faculdade de Direito, Universidade de São Paulo, São Paulo, SP, Brasil. Recuperado em 5 de junho, 2016, deHttp://www.teses.usp.br/teses/disponiveis/2/2136/tde20062013-132709/pt-br.php

DEPARTAMENTO PENITENCIÁRIO DO ESTADO DO PARANÁ, Recuperado em 26 de agosto de 2018, de http://www.depen.pr.gov.br/modules/conteudo/conteudo.ph p? conteudo $=221$

DI TELLA, RAFAEL, AND ERNESTO SCHARGRODSKY. "Criminal Recidivism after Prison and Electronic Monitoring." Journal of Political Economy 121, no. 1 (February 2013): 28-73.
DUARTE JUNIOR, A. P., \& MENEZES, M.(2015). Monitoramento eletrônico: uma alternativa para crise vivida pelo Sistema Penitenciário Brasileiro. Revista FSA, 12(04), 68-86. Recuperado em 5 de junho, 2016, de http://dx.doi.org/10.12819/2015.12.4.5

FABRIS, L. R. (2010). Monitoramento eletrônico de presos. Revista Jus Navigandi, 15(2594). Recuperado em 5 de junho, 2016 , de https://jus.com.br/artigos/17136/monitoramento-eletronicode-presos/3

LEI DE EXECUÇÃO PENAL. Recuperado em 26 de agosto de 2018 , http://www.planalto.gov.br/ccivil_03/LEIS/L7210.html

LOVEMONDAYS, acessado em 26 de novembro de 2018, https://www.lovemondays.com.br/trabalhar-na-governo-doestado-do-parana/salarios/cargo/agente-penitenciario

MACHADO, Nara Borgo Cypriano. Crise no sistema penitenciário brasileiro: o monitoramento eletrônico como medida de execução penal. Campo dos Goytacazes, 2009. Disponível em: http://www.publicadireito.com.br/conpedi/manaus/arquivos/ Anais/sao_paulo/2913.pdf>. Acesso em: 05 outubro 2017.

OLIVEIRA, Hiderline Camara de. A FALÊNCIA DA POLÍTICA CARCERÁRIA BRASILEIRA, III JORNADA INTERNACIONAL DE POLÍTICAS PÚBLICAS São Luís - MA, 28 a 30 de agosto 2007

NEVES, ALDIVANE BRASIL. Institutos de participação popular na administração pública de caráter vinculante e efetivação de direitos sociais prestacionais. UEA Univerdade do Estado do Amazonas. Manaus-AM, 2017.

OLIVEIRA, MALKON SANTANA CUNHA DE. MIRANDA, YARA RODRIGUES SILVA. O IMPACTO DA AUDIÊNCIA DE CUSTÓDIA NA REINCIDÊNCIA CRIMINAL EM GOIÂNIA. Polícia Militar de Goiás, Goiania-GO, 2018.

VANHAELEMEESCH, Delphine, Experiencing electronic monitoring. Centre for Crime and Justice Studies 10.1080/09627251.2014.902198 .cjm no. 95 March 2014. London-UK.

\section{AGRADECIMENTOS}

Agradecimentos a CAPES, CNPq, UNICENTRO, Fundação de Apoio ao Desenvolvimento da UNICENTRO FAU, e Fundação Araucária.

O presente foi realizado com apoio da Coordenação de Aperfeiçoamento de Pessoal de Nível Superior - Brasil (CAPES) - Código de financiamento 001. 


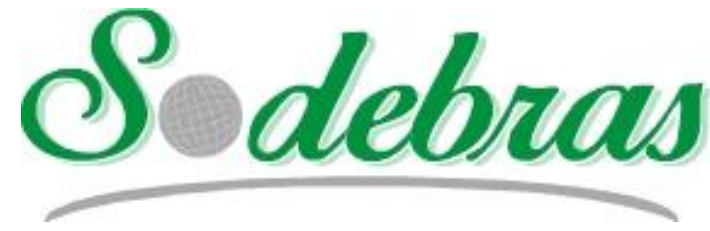

Volume 14 - No 159 - Março/2019.

XL International Sodebras Congress

10 a 12 de dezembro de 2018 - Vitória - ES.

\title{
BALANÇO ENERGÉTICO E DE EMISSÕES DE AEROGERADORES CONSIDERANDO DIFERENTES REGIÕES DE A PRODUÇÃO E OPERAÇÃO
}

\author{
ENERGY AND EMISSIONS BALANCE OF WIND TURBINES CONSIDERING \\ DIFFERENT REGIONS OF PRODUCTION AND OPERATION
}

\author{
BETTINA PEREIRA DE AZEVEDO CARVALHO ${ }^{1}$, IVAN FELIPE SILVA DOS SANTOS ${ }^{1}$, \\ MARIA CLAUDIA COSTA DE OLIVEIRA BOTAN ${ }^{1}$, NATHALIA DUARTE BRAZ VIEIRA ${ }^{2}$, MARINA \\ SOUZA SANTOS ${ }^{1}$.
}

\section{1 - UNIVERSIDADE FEDERAL DE ITAJUBÁ - UNIFEI; 2 - UNIVERSIDADE ESTADUAL DE CAMPINAS - UNICAMP}

\begin{abstract}
bettinacarvalho1@gmail.com;ivanfelipedeice@hotmail.com; maclau_oliveira@hotmail.com; nathaliadbv.ufop@gmail.com; souzasmarina@gmail.com
\end{abstract}

\begin{abstract}
Resumo - A utilização de energia elétrica é um fator indispensável ao crescimento econômico de um país. No cenário atual, os recursos tradicionais para geração de energia elétrica ou se tornaram escassos ou os efeitos de sua utilização passaram a ser questionados pelo seu efeito negativo na natureza. Frente a esta situação, coloca-se o desafio de se suprir as necessidades energéticas inerentes ao processo de crescimento econômico com a maximização da utilização de fontes renováveis, que possuem menores impactos ambientais. Dentre estas fontes está a energia eólica, fonte de forte crescimento no Brasil nos últimos anos. Com objetivo de estudar as vantagens da utilização da energia eólica, o presente trabalho compreende uma análise do tempo de vida útil efetivamente limpa de aerogeradores sob diferentes cenários em função dos locais de produção e operação dos mesmos. $O$ estudo foi realizado pata turbinas eólicas de $2 \mathrm{MW}$. Os resultados obtidos demonstram que o tempo que o aerogerador opera de forma limpa é elevado, operando no mínimo por 20 dos seus 25 anos de vida de forma limpa, mostrando-se eficiente na compensação de energia por fontes poluidoras e emissões de $\mathrm{CO}_{2}$.
\end{abstract}

Palavras-chave: Energia eólica, balanço energético, emissões de CO2, tempo de vida útil efetivamente limpa.

Abstract - The use of electricity is an indispensable factor for the economic growth of a country. In the current scenario, traditional resources for electric power generation have either become scarce or the effects of their use have come to be questioned for their negative effect on nature. Facing this situation, the challenge is to meet the energy needs inherent to the process of economic growth with the maximization of the use of renewable sources, which have lower environmental impacts. Among these sources is wind energy, a source of strong growth in Brazil in recent years. In order to study the advantages of using wind energy, the present work comprises an analysis of the effective life time of wind turbines under different scenarios according to their production and operation sites. The study was carried out on $2 \mathrm{MW}$ wind turbines. The results show that the time the wind turbine operates in a clean way is high, operating at least 20 of its 25 years of life in a clean way, proving efficient in the compensation of energy by polluting sources and $\mathrm{CO}_{2}$ emissions.
Keywords: Wind energy, energy balance, $\mathrm{CO}_{2}$ emissions, effectively clean working life.

\section{INTRODUÇÃO}

O aumento da população mundial e das indústrias traz uma demanda cada vez maior de energia, enquanto que diminui a disponibilidade de combustíveis fosseis. Dessa forma são necessárias alternativas que possibilitem o avanço do crescimento na produção energia de forma que a mesma não se esgote ou falte para as gerações futuras. É neste contexto que as fontes renováveis de energia ganham importância.

Dentre as diversas fontes renováveis se destaca a fonte eólica, que tem crescido em todo mundo. Mais de 54 GW de energia eólica renovável limpa foram instalados em todo o mercado global em 2016, que agora compreende mais de 90 países, incluindo 9 com mais de $10.000 \mathrm{MW}$ instalados e 29 que passaram a marca de 1.000 MW. A capacidade acumulada global cresceu $12,6 \%$, atingindo um total de 486,8 GW em 2016 (GWEC, 2016).

No Brasil a energia eólica também tem apresentado crescimento acelerado. A produção nacional de eletricidade a partir da fonte eólica alcançou 12.210 GWh em 2014, equivalente a um aumento de $85,6 \%$ em relação ao ano anterior, quando se atingiu $6.578 \mathrm{GWh}$ (EPE, 2015a). Em 2016 este valor cresceu ainda mais e superou $30.000 \mathrm{GWh}$, como se pode observar na figura 1 (EPE, 2017). A estimativa do governo, presente no Plano Decenal de Expansão de Energia (PDE 2024), é de que a capacidade instalada eólica do Brasil em 2024 atinja aproximadamente 24.000 MW. Desse total, 21.000 MW deverão ser gerados na região Nordeste, o que deverá representar $45 \%$ do total de energia produzido na região (EPE, 2015b). 
Figura 1 - Evolução eólica no Brasil, em GW. Fonte: EPE (2017).

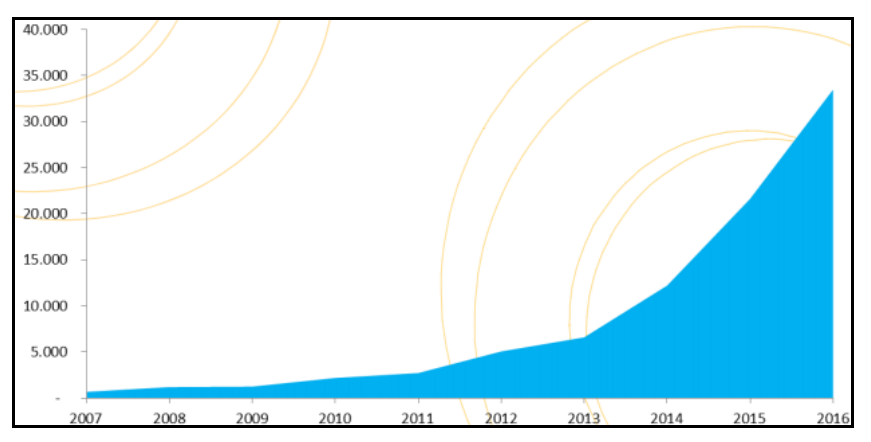

A energia eólica tem um impacto significativamente menor sobre o meio ambiente do que as tradicionais tecnologias fósseis de geração de eletricidade. No entanto, ainda que a energia eólica não possua emissões diretas durante a operação, ele ainda tem impactos ambientais negativos sobre as fases de operação, fabricação e desmontagem. Uma abordagem de avaliação de impacto é, portanto, importante, a fim de identificar as cargas associadas com o ciclo de vida de uma turbina eólica, a partir de obtenção de matérias-primas das diferentes partes da turbina, até que a instalação seja desativada. Durante as diferentes etapas, gases de efeito estufa (GEE), que são responsáveis pelo aquecimento global, especialmente $\mathrm{CO}_{2}$, são liberados no meio ambiente. Identificar fontes de emissão de $\mathrm{CO}_{2}$ em toda a vida dos aerogeradores poderia ajudar a encontrar formas para tornar a energia eólica uma fonte ainda mais limpa de energia. (Guezuraga et al., 2012).

Neste contexto, o objetivo geral do presente trabalho é verificar o tempo de vida útil efetivamente ambiental (Do inglês environmental useful lifetime - EULT) de aerogeradores através do calculo do tempo de amortização da energia consumida e das emissões ocasionadas pela sua produção, considerando diversas regiões de produção e operação. Serão consideras as variações do fator de emissão em função da região de produção e operação da turbina bem como os passivos ambientais e energéticos relacionados ao transporte do aerogerador, o que permite uma avaliação mais completa dos reais impactos dos aerogeradores.

\section{METODOLOGIA}

Foram consideradas nas análises as emissões de $\mathrm{CO} 2$ e o consumo de energia as seguintes etapas do ciclo de vida do aerogerador analisado: i) Extração de materiais; ii) Manufatura do aerogerador e iii) Transporte do aerogerador entre a região de produção e operação.

Os cálculos foram feitos considerando-se diferentes países de produção e operação do aerogerador, dado que em cada país se tem um fator de capacidade médio e um fator de emissão de eletricidade. Esta metodologia é a mesma aplicada por Tiago Filho et al. (2016) com painéis fotovoltaicos. Os países analisados foram: Brasil; Argentina, Colômbia, China e EUA e Alemanha. A escolha da Argentina e Colômbia teve por objetivo a inserção de países da América Latina. A Alemanha foi incluída reconhecidamente estar buscando limpar totalmente a sua matriz energética. China e EUA foram incluídos devido ao alto fator de emissão da matriz energética destes países e devido a sua posição de destaque no cenário econômico mundial. Os passos dos cálculos realizados em cada etapa deste trabalho são apresentados nas seções a seguir.

\section{1 - Energia consumida na produção}

Para o aerogerador em questão foram considerados os materiais e a energia gasta para a obtenção dos mesmos descritos na tabela 1. Segundo Ghenai (2012), a energia consumida na manufatura corresponde a aproximadamente $7,7 \%$ da energia consumida na extração dos materiais. Este índice foi utilizado para cálculo da energia total utilizada na produção do aerogerador $\left(\mathrm{E}_{\mathrm{C}}\right)$ dada pela soma da manufatura com a extração dos materiais.

Tabela 1 - Energia incorporada em diferentes estágios do ciclo de vida da turbina eólica.

\begin{tabular}{|c|c|c|c|}
\hline Materiais & $\begin{array}{c}\text { Massa } \\
\text { necessária } \\
\text { para } \\
\text { produção } \\
\text { de um } \\
\text { aerogerador } \\
\text { de } 2 \mathrm{MW} \\
(\mathrm{Kg})^{\mathrm{a}}\end{array}$ & $\begin{array}{l}\text { Consumo total } \\
\text { de energia } \\
\text { primária }(\mathbf{M J}) \\
\text { para produção } \\
\text { de materiais } \\
\text { específicos por } \\
\text { kg }\end{array}$ & $\begin{array}{l}\text { Total de } \\
\text { energia } \\
\text { em MJ }\end{array}$ \\
\hline Aço & 296.400 & 25,65 & 7.602 .660 \\
\hline Plástico + Epóxi & 12.400 & 45,7 & 566.680 \\
\hline Ferro & 39.350 & 36,3 & 1.428 .405 \\
\hline Vidro & 24.300 & 9,3 & 225.990 \\
\hline Cobre & 2.400 & 78,2 & 187.680 \\
\hline Concreto & 1.164 .000 & 3,68 & 4.283 .520 \\
\hline Total & 1.538 .850 & 198,83 & 14.294 .935 \\
\hline \multicolumn{4}{|c|}{${ }^{\mathrm{a}}$ Guezuraga et al. (2012) } \\
\hline
\end{tabular}

\section{2 - Emissões e energia associada ao transporte}

Para o cálculo das emissões de consumo energético associado ao transporte do aerogerador entre as regiões de produção e operação, foi necessária a obtenção de distâncias médias entre todos os países. Estas estão apresentadas na tabela 2. O valor da distância para a produção e operação dentro de um mesmo país foi adotado como sendo igual a $100 \mathrm{~km}$

Tabela 2 - Distância entre os países selecionados. Fonte: Portal Distance to $(\mathrm{S} / \mathrm{d})$

\begin{tabular}{|cc|}
\hline Países & Distâncias [km] \\
\hline Brasil x Argentina & 2920 \\
\hline Brasil x China & 16610 \\
Brasil x EUA & 7307 \\
\hline Brasil x Colômbia & 3230 \\
\hline Brasil x Alemanha & 9419 \\
\hline Argentina x China & 18873 \\
\hline Argentina x EUA & 9006 \\
\hline Argentina x Colômbia & 4898 \\
\hline Argentina x Alemanha & 12263 \\
\hline China x EUA & 11632 \\
\hline China x Colômbia & 15496 \\
\hline China x Alemanha & 7214 \\
\hline EUA x Colômbia & 4217 \\
\hline EUA x Alemanha & 7851 \\
\hline Colômbia x Alemanha & 9233 \\
\hline
\end{tabular}


De acordo com o LIPASTO (2017), no transporte por navio são gastos $0,272 \mathrm{gCO}_{2} / \mathrm{t} . \mathrm{km} \mathrm{e} 0,000103 \mathrm{MWh} / \mathrm{t} . \mathrm{km}$ de energia elétrica. Dessa forma escrevemos as equações 1 e 2 .

$$
\begin{aligned}
& e_{T}=\left(\frac{0,272}{M \times D}\right) \\
& E_{T}=\left(\frac{0,000103}{M \times D}\right)
\end{aligned}
$$

Onde: $\mathrm{e}_{\mathrm{T}}=$ Emissões de $\mathrm{CO}_{2}$ associadas ao transporte $\left[\mathrm{tCO}_{2}\right], \mathrm{ET}=$ Energia gasta no transporte $[\mathrm{MWh}], \mathrm{M}=$ Massa transportada $[\mathrm{t}]$ e $\mathrm{D}=$ Distancia percorrida $[\mathrm{km}]$.

\section{3 - Emissões associadas à produção}

A partir da seleção dos países, foram obtidos os fatores de emissão da rede de eletricidade de cada país, apresentados na Tabela 3. De posse destes, foram calculadas as emissões totais (e) associadas à produção e transporte dos aerogeradores a partir da Equação 3.

Tabela 3 - Fatores de emissão para cada país. Fonte: Brander et al. (2011).

\begin{tabular}{cc}
\hline País & Fator de emissão em tCO $\mathbf{~} / \mathbf{M W h}$ \\
\hline Brasil & 0,074 \\
Argentina & 0,392 \\
China & 0,973 \\
EUA & 0,547 \\
Colômbia & 0,111 \\
Alemanha & 0,672 \\
\hline
\end{tabular}

$e=\left(F_{E} x E_{C}\right)+e_{T}$

Onde: $\mathrm{F}_{\mathrm{E}}=$ Fator de emissão da produção de eletricidade; $\mathrm{E}_{\mathrm{C}}=$ Energia utilizada na manufatura $\mathrm{e}$ obtenção de materiais [MWh]; $\mathrm{e}_{\mathrm{T}}=$ emissões associadas ao transporte $[\mathrm{MWh}$ ] e $e=$ emissões totais associadas ao aerogerador.

\section{4 - Energia produzida pelo aerogerador}

A energia produzida pelo aerogerador é dada considerando uma potencia de 2 MW e um período ininterrupto de operação de 8760 horas por ano, apresentada na equação 4 (Liu et al., 2017).

$E_{G}=2 \cdot 8760 \times F_{C}$

Onde: $\mathrm{F}_{\mathrm{C}}=$ Fator de capacidade do país de operação. Os valores de fator de capacidade médios utilizados estão apresentados na Tabela 4.
Tabela 4 - Fatores de Capacidade para cada país.

Fonte: EIA (2015), MME (2015) e Liu et al. (2017).

\begin{tabular}{cc}
\hline País & Fator de capacidade médio \\
\hline Brasil & 0,24 \\
Argentina & 0,26 \\
China & 0,18 \\
EUA & 0,27 \\
Colômbia & 0,26 \\
Alemanha & 0,17 \\
\hline
\end{tabular}

De posse da energia gerada $\mathrm{E}_{\mathrm{G}}$, pode-se calcular as emissões evitadas devido ao uso do aerogerador.

$e_{e v}=F_{E} \times E_{G}$

Onde: $\mathrm{F}_{\mathrm{E}}=$ Fator de emissão da região de produção de eletricidade; $\mathrm{E}_{\mathrm{G}}=$ Energia gerada pelos aerogeradores $[\mathrm{MWh}]$ e $\mathrm{e}_{\mathrm{ev}}$ $=$ emissões evitadas associadas ao uso do aerogerador.

\section{5 - Payback time de energia}

Este parâmetro é definido como o total de requisitos cumulativos de energia divididos pela energia anual total gerada pela turbina (Guezuraga et al., 2012). Para esse calculo utilizamos o EPBT- tempo para amortização de energia (ou Payback Time energético), que é a relação entre a energia consumida no processo $\left(\mathrm{E}_{\mathrm{c}}\right)$ e a energia produzida pelo aerogerador $\left(\mathrm{E}_{\mathrm{G}}\right)$ (Equação 6).

$E P B T=\frac{E_{C}}{E_{G}}$

\section{6 - Payback time de emissões}

O Payback Time do carbono calcula quanto tempo o sistema tem que funcionar para compensar o $\mathrm{CO}_{2}$ por ele emitido. Em outras palavras, é uma medida para determinar qual o tempo necessário que um empreendimento de mitigação de $\mathrm{CO}_{2}$ tem que funcionar para compensar o $\mathrm{CO}_{2}$ por ele lançado na atmosfera durante todo o seu ciclo de vida (Marimuthu e Kirubakaran, 2013). Designaremos o Payback Time de $\mathrm{CO}_{2}$ por ePBT - tempo para a amortização da emissão de produção, que é a relação entre a as emissões do processo (e) e as emissões abatidas $\left(\mathrm{e}_{\mathrm{ev}}\right)$, dadas pela Equação 7.

$e P B T=\frac{e}{e_{e v}}$

2.7 - EULT - Enviromental usefull life time (tempo de vida útil efetivamente limpo).

Para este cálculo leva-se em conta o tempo de vida de um aerogerador. De acordo com Machuca (2015), parques eólicos tem vida util de 20 a 30 anos. Assim sendo, neste trabalho será usada uma média, com valor fixado de 25 anos de vida util. Dessa forma, para chegar ao EULT (environmental usefull life time - Tempo de vida útil efetivamente limpa) utiliza-se a Equação (8). 


$$
\text { EULT }=25-\lambda
$$

Onde $\lambda$ é o valor máximo entre os valores encontrados para o tempo para a amortização da emissão de produção e o tempo para amortização de energia, como mostra a Equação 9.

$$
\lambda=\max (E P B T, e P B T)
$$

\section{RESULTADOS}

\section{1 - Resultados em função dos países}

A energia referente à obtenção de materiais somada a energia de manufatura, foi transformada para $\mathrm{MWh}$, obtendo-se um valor de 1368,831 MWh. Esse valor foi posteriormente somado à energia consumida no transporte do aerogerador, que resulta de um valor constante para cada tonelada de material transportado por quilometro e cresce na medida em que a distância entre país de origem e de destino do aerogerador é maior. De acordo com as distancias entre os países e os fatores de emissão e capacidade, foi plotada uma Tabela (5) com os valores de EULT para cenários diferentes de produção e operação do aerogerador.

Quanto maior for a emissão de $\mathrm{CO}_{2}$ pelo país de produção, menor é o valor de do EULT, como pode ser observado na Tabela 5. Isso nos mostra que o uso de aerogeradores diminui os impactos ambientais, visto que operam em média mais de 23 anos de forma limpa.

O melhor cenário, é observado quando a produção é feita em países com matriz energética mais limpa, na Tabela 5 apresentado como os países da América do Sul, e que operam em países com matriz mais suja. Nestes casos o EULT é de 24,7 anos.

\begin{tabular}{|c|c|c|c|c|c|c|c|}
\hline & \multicolumn{7}{|c|}{ EULT } \\
\hline & & & & & $\hat{\mathrm{A} O}$ & & \\
\hline \multirow{6}{*}{ 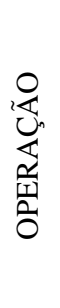 } & País & Brasil & Argentina & China & EUA & Colômbia & Alemanha \\
\hline & Brasil & 24,674 & 23,276 & 20,722 & 22,593 & 24,510 & 22,043 \\
\hline & Argentina & 24,674 & 24,700 & 24,254 & 24,581 & 24,700 & 24,485 \\
\hline & China & 24,674 & 24,700 & 24,566 & 24,711 & 24,700 & 24,540 \\
\hline & EUA & 24,674 & 24,700 & 24,486 & 24,711 & 24,700 & 24,540 \\
\hline & Colômbia & 24,674 & 23,943 & 22,377 & 23,525 & 24,700 & 23,187 \\
\hline
\end{tabular}

Tabela 5 - EULT sob diferentes cenários de regiões de produção e operação.

O pior cenário é observado quando o aerogerador é produzido em países com matriz energética mais suja e opera em países em que a matriz energética é mais limpa, visto na produção da China e operação no Brasil, com EULT de 20,7 anos, já que as emissões acumuladas na produção são altas e a substituição das emissões no país de operação não é tão eficaz, visto que substitui uma matriz que já emite menos GEE.

Através da Tabela 5 observa-se também que o mercado de exportação de aerogeradores do Brasil para países da região da América Latina pode ser promissor do ponto de vista ambiental, visto que o EULT criado por essa possibilidade, de 24,67, está acima da média entre os países analisados.

Se compararmos os resultados de EULT aqui obtidos com outra fonte renovável como a fotovoltaica, de acordo com Thiago Filho et. al. (2016), se tratando de painéis fotovoltaicos, os custos ambientais a serem amortizados podem chegar a mais de 25 anos. Essa discrepância no tempo de amortização para as duas fontes de energia pode ser explicada pelo fato da purificação e dopagem do silício nos painéis fotovoltaicos demandarem altas quantidades de energia.

\section{2 - Resultados em função do fator de emissão}

Para comparação do EULT levando-se em conta os fatores de emissão de operação e produção, foi plotado um gráfico relacionando a razão entre esses valores e o EULT para três diferentes fatores de capacidade (figura 2).
A partir da Figura 2, observa-se que quanto maior a relação dos fatores de emissão de origem e destino, menor o EULT, ou seja, a energia renovável é mais limpa quando a tecnologia é produzida em países limpos e usada em países sujos. A fim de verificar a alteração do EULT a partir das diferentes distancias entre país de origem e destino, a variação do EULT em função das distancias em função utilizando diferentes séries de valor de relação ente o fator de emissão de origem pelo de destino (Figura 3).

Esse fato, atrelado à busca de tecnologias que operem de forma limpa por mais tempo, poderia gerar uma política internacional de incentivo a produção de tecnologia em países limpos como o Brasil, visto que o tempo demandado para amortizar as emissões geradas pela produção no Brasil é baixo. É importante levar em consideração o local de produção desses aerogeradores, já que o fator de emissão do país de origem influencia diretamente o tempo de operação limpa. Países com matriz energética suja emitem uma quantidade muito maior de $\mathrm{CO}_{2}$ do que um país de matriz energética limpa para a produção de um mesmo aerogerador, fazendo com que os investimentos na produção desse tipo de tecnologia sejam menos atrativos, pela questão ambiental, nesses países. 
Figura 2 - Relação dos fatores de emissão de origem e destino com o EULT, para três valores de fator de capacidade.

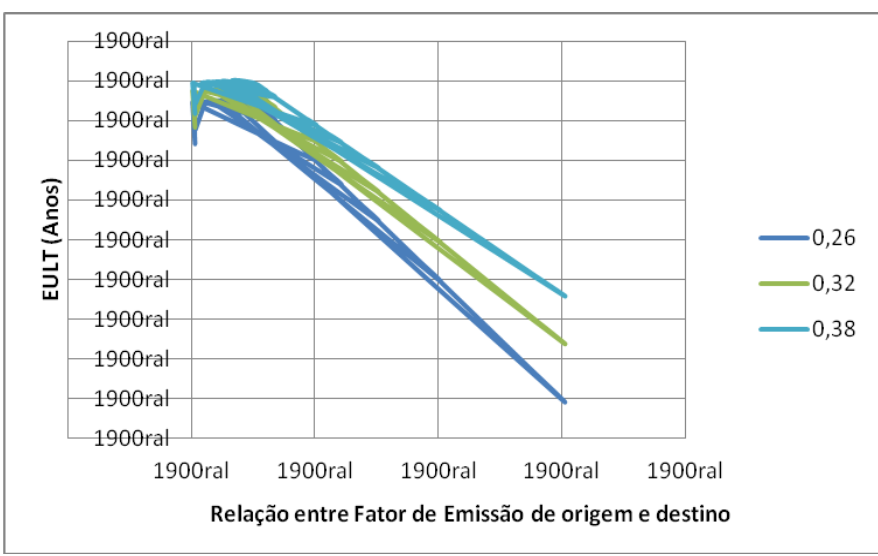

Figura 3 - Relação das distâncias percorridas pelo transporte com o EULT.

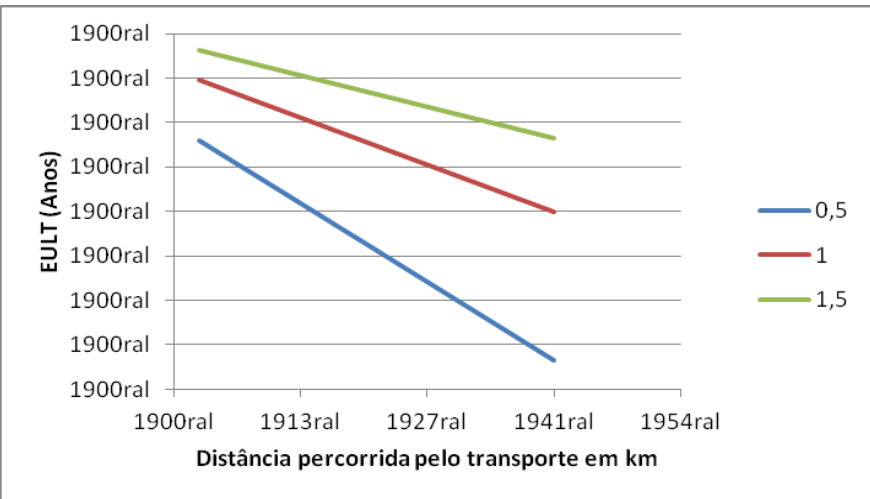

\section{CONCLUSÕES}

A energia eólica tem se mostrado muito promissora no Brasil e se tornou uma componente relevante na matriz energética brasileira, que busca ser formada por fontes cada vez mais limpas. O presente estudo se propôs a estudar o tempo de vida útil efetivamente limpo de um aerogerador em função dos países de produção e operação.

Dentre os cenários criados para a obtenção do EULT, é possível observar que quanto maiores as emissões do país de produção, maior será o tempo demandado para a amortização destas emissões no país de origem. Os valores de EULT variaram de 0,29 anos para o melhor cenário, que foi a produção e operação em países da América do sul que possuem alto fator de capacidade e baixos fatores de emissão, a até 4,28 anos para o pior cenário, mostrado com a produção na China e operação no Brasil, visto que as distâncias de transporte e as emissões de produção são bastante altas e que o aerogerador viria operar em uma matriz limpa.

Com relação à possibilidade de exportação de aerogeradores do Brasil para os países da região, como Argentina e Colômbia, pode-se observar que seria interessante do ponto de vista ambiental, pois resultaria em valores de EULT bastante elevados, iguais a 24,67 anos, além de trazer benefícios econômicos para o Brasil e benefícios energéticos para estes países, que possuiriam um maior índice de renováveis em sua matriz elétrica.

Para a produção desse tipo de tecnologia, é importante levar em consideração os locais de produção. O objetivo da energia eólica é operar de forma sustentável, com uma menor geração de impactos. No entanto a produção, manutenção e descarte do aerogerador geram emissões, que são intensificadas quando ocorrem em países de matriz energética suja, fazendo com que o tempo de amortização dos impactos causados durante a vida do aerogerador seja maior. Dessa forma, seria interessante a criação de políticas internacionais que levassem a incentivos na produção de tecnologias limpas em países de matriz energética limpa, como o Brasil, a fim de diminuir os impactos da sua produção e consequentemente o tempo de amortização dos mesmos.

\section{REFERÊNCIAS}

BRANDER, M. SOOD, A. WYLIE, C. HAUGHTON, A. LOVELL, J. Electricity-specific emission factors for grid electricity. Ecometrica, Emission Factors. Disponível em < https://ecometrica.com/assets/Electricity-specificemission-factors-for-grid-electricity.pdf $>$.

Acesso: 05/06/2018.

EIA. Energy Information Administration. Electric generator capacity factors vary widely across the world. 2015. Disponível

em

<https://www.eia.gov/todayinenergy/detail.php?id=22832>. Acesso: 05/06/2018.

EPE. Empresa de Pesquisa Energética. Ministério de Minas e Energia. Balanço Energético Nacional 2015: Ano base 2014. Disponível em:

https://ben.epe.gov.br/BENRelatorioSintese.aspx?anoColeta =2015\&anoFimColeta=2014 > Acesso em: 20 jul 2017 .

EPE. Empresa de Pesquisa Energética. Plano decenal de expansão de energia 2024. 2015. Disponível em <http://www.epe.gov.br/pt/publicacoes-dadosabertos/publicacoes/Plano-Decenal-de-Expansao-deEnergia-2024>. Acesso 31/05/2018.

EPE. Empresa de Pesquisa Energética. Ministério de Minas e Energia. Balanço Energético Nacional 2017: Ano base 2016. Disponível em:

https://ben.epe.gov.br/downloads/Relatorio_Final_BEN_20 17.pdf> Acesso em: 31 mai 2018.

GHENAI, C. Life Cycle Analysis of Wind Turbine. Sustainable Development Energy, Engineering and Technologies - Manufacturing and Environment. IntechOpen, 2012. Disponível em: <https://www.intechopen.com/books/sustainabledevelopment-energy-engineering-and-technologiesmanufacturing-and-environment/life-cycle-analysis-ofwind-turbine>. Acesso: 05/06/2018.

GUEZURAGA, B. et al. Life cycle assessment of two different 2 MW class wind turbines. Renewable Energy 37. 2012. p $37-44$.

GWEC. Conselho Global de Energia Eólica. Global Wind Report, 2016. Disponível em: <http://www.gwec.net/publications/global-wind-report2/global-wind-report-2016/>. Acesso em: 25 jul. 2017.

LIPASTO. Unit Emissions. Technical Research Centre of Finland. 2017. Disponível em $<$ http://lipasto.vtt.fi/yksikkopaastot/indexe.htm>. Acesso: 05/06/2017. 
LIU, C. WANG, Y. ZHU, R. Assessment of the economic potential of China's onshore wind electricity. Resources, Conservation and Recycling. V. 121, p. 33-39, 2017.

MACHUCA, M. Análise Ambiental, Técnica E Econômica Da Pós-Operação De Parques Eólicos. Trabalho de Conclusão de Curso, UFSC. 2015. 118p.

MARIMUTHU, C. E K. Carbon pay-back period for solar and wind energy project installed in India: A critical review . V. 2013. Gandhigram : s.n., Julho de 2013, Renewable and Sustainable Energy Reviews, Vol. 23, pp. 80-90.

MME. Ministério de Minas e Energia. Energia Eólica no Brasil e no mundo. 2015. Disponível em < http://www.mme.gov.br/documents/10584/3894319/Energia +E\%C3\%B3lica+-+ano+ref++2015+(3).pdf/f5ca897d-bc63400c-9389-582cd4f00ea2>. Acesso: 05/06/2018.

Portal Distance to. Calculador de distâncias. Disponível em < https://pt.distance.to/>. Acesso: 05/06/2018.

TIAGO FILHO, G.L. et. al. Study of the energy balance and environmental liabilities associated with the manufacture of crystalline $\mathrm{Si}$ photovoltaic modules and deployment in different regions. Solar Energy Materials \& Solar Cells. 2016. p 383-394.

\section{AGRADECIMENTOS}

Os autores agradecem a CAPES pela concessão de bolsas de doutorados aos autores Ivan Felipe Silva dos Santos e Nathalia Duarte Braz Vieira.

\section{COPYRIGHT}

Direitos autorais: $\mathrm{O}(\mathrm{s})$ autor(es) é(são) o(s) único(s) responsável(is) pelo material incluído no artigo. 


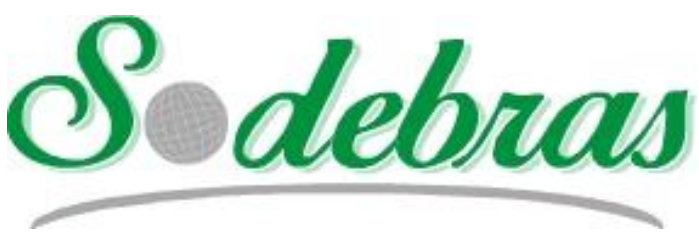

Volume 14 - No 159 - Março/2019.

XL International Sodebras Congress

10 a 12 de dezembro de 2018 - Vitória - ES.

\title{
REQUISITOS MÍNIMOS PARA A CRIAÇÃO DE CENTROS DE INOVAÇÃO, DEFININDO OBJETIVOS E ÁREA DE ABRANGÊNCIA
}

\section{MINIMUM REQUIREMENTS FOR THE ESTABLISHMENT OF INNOVATION CENTERS, DEFINING OBJECTIVES AND AREA OF SCOPE}

\author{
VICTOR SEBASTIAN KOROCOSKI ${ }^{1}$; LUANA ESTECHE NUNES KOROCOSKI ${ }^{1}$; CLÁUDIA \\ CRISOSTIMO $^{1}$; PAULO ROGÉRIO PINTO RODRIGUES ${ }^{1}$
}

\section{1 - UNIVERSIDADE ESTADUAL DO CENTRO OESTE.}

victorsebbastian@hotmail.com; luanaesteche@yahoo.com.br; claudia@unicentro.br; prprodrigues@unicentro.br

\begin{abstract}
Resumo - Visando o desenvolvimento e fomento da inovação tecnológica nacional fez-se necessário o incentivo ao intercâmbio de informações e troca de experiências entre diversos atores $e$ instituições que venham a compor o processo de inovação tecnológica. Com esse intuito, a criação de habitats propícios para a integração entre o poder públicos, universidades $e$ iniciativa privada, passaram a ser indispensáveis. Os centros de inovação tecnológica restam como peça essencial, na medida que vem para desenvolver cultura inovadora e empreendedora, permeando desde a pré-incubação da empresa inovadora, até a transferência da tecnologia por ela desenvolvida.
\end{abstract}

Palavras-chave: 1. desenvolvimento 2. habitats de inovação 3. parque tecnológico

\begin{abstract}
Aiming at developing and fostering national technological innovation, it was necessary to encourage the exchange of information and the exchange of experiences among various actors and institutions that may be part of the technological innovation process. With this in mind, the creation of habitats conducive to integration between public authorities, universities and private initiative, became indispensable. The centers of technological innovation remained as essential piece, as it comes to develop innovative and entrepreneurial culture, permeating from the pre-incubation of the innovative company to the transfer of technology developed by it.
\end{abstract}

Keywords: 1. development 2. innovation habitats 3. technology park.

\section{INTRODUÇÃO}

As alterações na Lei de Inovação ${ }^{\circ}$ 10.973/2004, trazidas pela Lei $\mathrm{n}^{\circ} 13.243 / 2016$, definitivamente veio impactar o ambiente de inovação nacional. Esse dispositivo jurídico foi considerado como um marco legal da Ciência, Tecnologia e Inovação nacional, na medida que fomenta e simplifica a relação entre as empresas e as instituições de pesquisa.

Com vistas ao desenvolvimento e fomento da inovação tecnológica nacional fez-se necessário o incentivo ao intercâmbio de informações e troca de experiências entre diversos atores e instituições que possam participar do processo de inovação.

Para tanto criou-se o Sistema Nacional de Inovação Tecnológica, que para Ferreira Netto (2001) "compreende todos os elementos que contribuem para o desenvolvimento, introdução, difusão e utilização das inovações, incluindo além das universidades, centros de pesquisa e laboratórios de P\&D e outros agentes dos setores público e privado".

Nazareno (2016) ao comentar as mudanças trazidas pela legislação, considera que as mesmas poderiam ser responsáveis por uma das maiores reestruturações do setor desde 2004, quando foi promulgada a Lei de Inovação (10.973/04).

Como consequência disso, verificou-se o surgimento de Parques Tecnológicos, bem como de Centros de Inovações Tecnológica de iniciativa pública ou privada.

Empresas como Ambev, Intel, Merck Deutsche Post DHL Group, Hospital Albert Einstein, Du Pont, sistema Sesi, dentre outras passaram a instalar Centros de Inovação em sua estrutura, visando o desenvolvimento de estudo, ideias e tecnologias relacionadas a sua atividade fim.

Entretanto, o presente estudo se restringirá aos Centros de Inovação cuja iniciativa pressuponha a participação do Poder Público e universidades, visando diferenciá-lo dos demais ambientes inovadores, bem como seus requisitos mínimos.

\section{METODOLOGIA}

O presente estudo se iniciou mediante uma análise conceitual e doutrinária entre Incubadora, Parque Tecnológico e Centros de Inovação, para que se possa formar uma distinção clara entre os institutos, e posteriormente delimitar a abrangência de atuação e objetivos específicos dos Centros de Inovação. 


\section{RESULTADO E DISCUSSÃO}

Uma das primeiras perguntas que será analisada no presente trabalho é a diferença conceitual entre Incubadoras, Parques Tecnológicos e Centros de Inovação, bem como onde se encontram definidos seus conceitos.

Dessa forma passou-se a analisar a Lei de Inovação Federal $\mathrm{n}^{\mathrm{o}} 10.973 / 2004$ e suas alterações, Decreto Regulamentador $\mathrm{n}^{\circ}$ 9.283/2018, bem como Leis Estaduais e Municipais que conceituem os Institutos.

$\mathrm{Na}$ análise preliminar da legislação de incentivo à ciência, tecnologia e inovação, Lei Federal no 10.973/2004, têm-se que apesar de a mesma instituir medidas de incentivo à inovação tecnológica, esta não priorizava a participação da iniciativa privada como agente produtor da inovação tecnológica. Esta lei nos trouxe o primeiro conceito de ICT (Instituição de Ciência e Tecnologia), como sendo "órgão ou entidade da administração pública que tenha por missão institucional, dentre outras, executar atividades de pesquisa básica ou aplicada de caráter científico ou tecnológico". (BRASIL, 2004, art.2 ${ }^{\circ}, \mathrm{V}$ )

O conceito de Núcleo de Inovação Tecnológica, NITs, foi inaugurado pela Lei Federal $\mathrm{n}^{\circ} 10.973 / 2004$, sendo constituído "por uma ou mais ICT com a finalidade de gerir sua política de inovação".

Diante da necessidade de uma maior interação entre todos os agentes que produzem a inovação tecnológica, uma aproximação entre a iniciativa privada com a pública e com as Universidades era medida primordial, a chamada hélice tripla do sistema de inovação.

A Lei $n^{\circ} 13.246 / 2016$ veio para regular uma necessidade premente de aproximação entre os agentes produtores de inovação. Em seu bojo trouxe essa previsão de forma expressa, com vista na promoção da cooperação e interação entre os participantes do processo de inovação, sejam eles oriundos de setores públicos, privados ou iniciativa empresarial. Desde então, a figura das incubadoras tecnológicas passou a existir legalmente, tendo seu conceito definido pela legislação como ${ }^{1}$ :
Art. $2^{\circ}(\ldots)$
III- organização ou estrutura que objetiva estimular ou prestar apoio logístico, gerencial e tecnológico ao empreendedorismo inovador e intensivo em conhecimento, com o objetivo de facilitar a criação e o desenvolvimento de empresas que tenham como diferencial a realização de atividades voltadas à inovação. (BRASIL, 2004)

As incubadoras tecnológicas, segundo Ribeiro, Andrade e Zambalde (2005), possuem como objetivo:

(...) dar suporte a pequenas e microempresas de base tecnológica - que busquem a diversificação e a revitalização econômica, agregando valor aos seus produtos -, viabilizando a interação com centros de ensino e pesquisa, para que a região beneficiada tenha maior produtividade e seja mais competitiva no mercado. Da mesma forma, propiciam o desenvolvimento de novos empreendimentos que sejam financeiramente viáveis e capazes de se adaptar ao mercado após o período de permanência na incubadora.

\footnotetext{
${ }^{1}$ Lei Federal no ${ }^{\circ} 10.973 / 2004$, art. $2^{\circ}$, III.
}

De iniciativa pública ou privada, as incubadoras, estão normalmente vinculadas a Universidades, diante da proximidade com os centros de pesquisas universitários e laboratórios.

Dessa forma, as incubadoras tecnológicas pressupõem como requisito mínimo para sua constituição, segundo Raupp (2012)

existência de empreendedores interessados; viabilidade técnica e comercial das propostas; parceiros comprometidos com o empreendimento; e apoio político à incubadora e disponibilidade de laboratórios e de recursos humanos.

O marco legal de 2016 inaugurou ainda o conceito de Parques Tecnológicos que, por sua vez, constitui um complexo planejado de desenvolvimento empresarial e tecnológico, cujo objetivo é ser promotor da cultura de inovação, da competitividade industrial, da capacitação empresarial e da promoção de sinergias em atividades de pesquisa científica, de desenvolvimento tecnológico e de inovação, entre empresas e uma ou mais ICTs, com ou sem vínculo entre si.

Os Parques Tecnológicos, segundo LIMA et al (2015), apud Camargo (2010), Stainsack (2003) e Lunardi (1997), se caracterizam mediante iniciativa localizada em um espaço urbano adequado, havendo uma relação harmônica e comprometida entre os agentes inovadores. Para o autor, os parques tecnológicos, possuem três características principais, quais sejam:

1. a obtenção de ligações formais com a universidade ou outras instituições de ensino e pesquisa;

2. a permissão da formação e crescimento de empresas de base tecnológica e outras organizações que também se situam no local;

3. na coordenação que desempenha as funções de gerente do parque, a qual estimula a transferência de tecnologia e promove ações voltadas ao aumento da capacitação das empresas e dos demais empreendimentos que residem no local.

Os Centros e Inovação Tecnológica não tiveram seu conceito definido em lei, entretanto, segundo Andala, et al, (2016), eles se caracterizam como:

\begin{abstract}
um espaço criado para estimular o crescimento e competitividade das micro e pequenas empresas por meio do avanço tecnológico. Adaptado às condições e necessidades locais, o empreendimento concentra e oferece um conjunto de mecanismos e serviços de suporte ao processo de inovação das empresas, promovendo ainda a interação entre empreendedores e pesquisadores para o desenvolvimento de setores econômicos.
\end{abstract}

Os Centros de Inovação podem ser de iniciativa pública ou privada, entretanto, ambos devem possuir como contexto primordial a interação entre Universidades, Estados e empresas.

Diferentemente dos Parques Tecnológicos, os Centros de Inovação, são locais que visam o estímulo da inovação nas empresas, passando desde o período de pré-incubação, até a proteção da propriedade intelectual e transferência de tecnologia. Sendo composto por um conjunto de serviços de apoio e estimulo a inovação tecnológica, considerado como um dos pré-requisitos para a instalação do parque tecnológico. 
De acordo com Anuar, Osmar e Ismail (2012), os Centros de Inovação, possuem como função precípua:

a) Promover e comunicar atividades de inovação;

b) Aconselhar e avaliar as inovações;

c) Aconselhar sobre propriedade intelectual;

d) Auxiliar na gestão de projetos e produtos; Assessoria em marketing e comercialização;

e) Financiamento parcial ou total do produto patenteado; f) E no modelo proposto, os setores de um centro contam com vários componentes, como: desenvolvimento de competências: g) técnicas, conceitual, gerencial, liderança, organizacional, marketing; h) Redes e articulação: bancos, investidores, empresas de negócios; i) Transferência de tecnologia: adoção, comercialização, licenciamento; j)Serviços e facilidades: espaço físico, serviços administrativos, logística, equipamentos, design; 1) Consultorias: planejamento, contabilidade, finanças; $m$ ) Serviços para comunidade: aconselhamento, família, organizações não governamentais (ONGs), berçário, entre outros.

Analisando por uma perspectiva Nacional, Abdala, et all (2018) relacionam como função dos Centros de Inovação: promover o desenvolvimento regional; desenvolver inovações por meio de negócios; oferecer instalações, serviços e outros recursos compartilhados; e promover a cultura e a conexão entre inovação e empreendedorismo.

O Estado de São Paulo ao instituir o Sistema Paulista de Inovação Tecnológica, através do Decreto Estadual $\mathrm{n}^{\circ}$ $60.286 / 2014$, trouxe como requisito mínimo para a instalação de um Centro de Inovação:

Artigo 21 - A Secretaria de Desenvolvimento Econômico, Ciência, Tecnologia e Inovação poderá autorizar o credenciamento na Rede Paulista de Centros de Inovação Tecnológica - RPCITec do empreendimento que cumpra os seguintes requisitos:

I - A existência de pessoa jurídica sem fins lucrativos encarregada da gestão do Centro de Inovação Tecnológica, cujo ato constitutivo demonstre:

a) tratar-se de entidade privada ou de entidade do setor público da Administração Indireta e Fundacional;

b) ter objetivos compatíveis com os arrolados no artigo 19 deste decreto;

c) ter modelo de gestão adequado à realização de seus objetivos;

II - A apresentação de:

a) requerimento pela entidade gestora, contendo justificativa do pleito e caracterização detalhada do empreendimento;

b) documento comprobatório de que a área destinada à instalação do Centro de Inovação Tecnológica esteja situada em local cujo uso seja permitido pelo zoneamento urbano e compatível com as finalidades do empreendimento;

III - O oferecimento do espaço físico, que poderá conter infraestrutura e instalações de uso compartilhado, como biblioteca, serviços administrativos e de escritório, salas de reunião, auditório, utilidades, facilitando, ainda, o acesso a incubadoras, laboratórios e grupos de pesquisas de universidades, institutos, centros de pesquisa e instituições de formação profisssional. (SÃO PAULO, 2014).

Assim como o Estado de São Paulo, Santa Catarina também investe nos Centros de Inovação para fomentar sua política de ciência e tecnologia, cujo projeto prevê a implementação de doze Centros de Inovação em áreas estratégicas do Estado.

Segundo a Secretaria de Estado e Desenvolvimento de Santa Catarina, o papel dos Centros "vai além dos limites do seu prédio. Eles deverão não apenas realizar atividades de promoção da cultura inovadora, como também influenciar, apoiar e articular a criação de ações, programas e políticas que favoreçam esta nova cultura em ascensão". (SANTA CATARINA, 2017).

\section{CONCLUSÃO}

O presente estudo buscou inicialmente diferenciar os conceitos de incubadoras, parques tecnológicos e centros de inovação, os quais são atores que integram o habitat nacional de inovação.

Os resultados indicaram que as incubadoras tecnológicas possuem papel bem delimitado na legislação, na medida que visam abrigar empresas, fornecendo ambiente propício para seu desenvolvimento, visando prestar assessoria em inovação.

Os Parques Tecnológicos, por sua vez, correspondem a "condomínios", caracterizados como um espaço mínimo, no qual universidades, incubadoras, instituições de pesquisa e empresas passam a compartilhar do mesmo espaço, caracterizando-se como ambiente propício para compartilhamento de pesquisas e desenvolvimento em escala industrial.

Os Centros de Inovações Tecnológica possuem conceito incerto no âmbito nacional, entretanto o Decreto do Estado de São Paulo, veio definir sua conceituação de forma expressa.

Assim, para o dispositivo legal do Estado de São Paulo, Decreto Estadual n ${ }^{\circ} 60.286 / 2014$, os centros de inovação tecnológica são efetivamente ambientes realizados de acordo com a necessidade da região, oferecendo serviços e mecanismos de suporte às empresas ali instaladas, no que se refere a inovação tecnológica, podendo compreender desde o processo de pré-incubação, até a transferência da tecnologia desenvolvida.

Identificou-se através do presente estudo, que existem requisitos mínimos para a implementação de um centro de inovação, os quais contemplam estrutura física adequada que contemple escritórios, salas de reuniões, laboratórios, etc, bem como gestão mediante órgão oriunda da administração pública direta e indireta.

Os Entes Federativos, União, estados e Municípios, têm apostado na implementação de centros de inovação tecnológica para alavancar o desenvolvimento de novas tecnologias e, por consequência, o crescimento regional, como instituição que pode anteceder a instalação de um parque tecnológico, demonstrando sua efetiva importância no habitat da inovação nacional. 


\section{REFERÊNCIAS BIBLIOGRÁFICAS}

ANUAR, R.; OSMAN, M.; ISMAIL, K. Innovation centers in Malaysia: A proposed model. In: 2012 International Conference on Innovation Management and Technology Research (ICIMTR), IEEE, 2012. p. 337- 341.

BRASIL. Lei no 10.973, de 2 de dezembro de 2004.Dispõe sobre incentivos à inovação e à pesquisa científica e tecnológica no ambiente produtivo e dá outras providências. Disponível

http://www.planalto.gov.br/ccivil_03/_ato2004-

2006/2004/lei/110.973.htm, acessado em 30/08/2018.

BRASIL. Lei $\mathrm{N}^{\circ} 13.243$, de 11 de janeiro de 2016. Dispõe sobre estímulos ao desenvolvimento científico, à pesquisa, à capacitação científica e tecnológica e à inovação. Disponível em:

http://www.planalto.gov.br/ccivil_03/_ato2015-

2018/2016/lei/113243.htm, acessado em 30/08/2018.

FERREIRA NETTO, Maria J. S.; ANTUNES, Adelaide M. S.; VAINSTOK, Otilia. A importância de um sistema nacional de inovação para o setor de termoplásticos no Mercosul. Polímeros, São Carlos , v. 11, n. 1, p. 16-26, Mar. 2001. Available from $<$ http://www.scielo.br/scielo.php?script=sci_arttext\&pid=S0 104-14282001000100007\&lng=en\&nrm=iso $>$.accesson 04 Nov. $2018 . \quad$ http://dx.doi.org/10.1590/S010414282001000100007.

LIMA, Marcilene Barros; AQUINO Roseane de Souza; LIMA, Maria José Barros; JUNIOR, Oscar Galdino de Oliveira- Parque Ciêntífico e Tecnológico: Uma análise do processo de implantação e operacionalização a partir do estudo de caso no centro de apoio ao desenvolvimento tecnológico (cdt/UNB) como gestor do parque da universidade de Brasília (unb).- XV Colóquio Internacional de Gestão Universitária - CIGU, 2015, disponível em https://repositorio.ufsc.br/bitstream/handle/123456789/1361 61/102_00094.pdf?sequence=1, acessado 04/11/218.

NAZARENO, C. As mudanças promovidas pela Lei $n^{\circ}$ 13.243 , de 11 de janeiro de 2016 (novo marco legal de ciência, tecnologia e inovação) e seus impactos no setor. Estudo Técnico da Câmara dos Deputados. Brasília: Câmara dos Deputados, 2016.

NOVELINO ABDALA, Lucas et al. Centro de Inovação: alinhamento conceitual. 1. 2016. Disponível em: <http://via.ufsc.br>. Acesso em: 04 nov. 2018.

RAUPP, Fabiano Maury. Perfil das Incubadoras de Empresas Brasileiras, XXXII Encontro Nacional de Engenharia de Producão Desenvolvimento Sustentável e Responsabilidade Social: As Contribuições da Engenharia de Produção, disponível em http://www.abepro.org.br/biblioteca/enegep2012_TN_STP_ 164_955_19427.pdf, acessado em 04/11/2018.

RIBEIRO, Simone Abreu; ANDRADE, Raphael Medina Gomes de; ZAMBALDE, André Luiz. Incubadoras de empresas, inovação tecnológica e ação governamental: o caso de Santa Rita do Sapucaí (MG). Cad. EBAPE.BR, Rio de Janeiro , v. 3, n. spe, p. 01-14, 2005 . Available from $<\mathrm{http}: / /$ www.scielo.br/scielo.php?script=sci_arttext\&pid=S1 679-39512005000500010\&lng=en\&nrm=iso $>$. access on 04 Nov. 2018. http://dx.doi.org/10.1590/S167939512005000500010 .
SANTA CATARINA, Secretaria de Estado do Desenvolvimento Econômico Sustentável Guia de Implantação dos Centros de Inovação: Livro I- conceito e fundamentos / Secretaria de Estado de Desenvolvimento Econômico Sustentável. -Florianópolis: SDS, 2017, disponível em http://via.ufsc.br/wpcontent/uploads/2018/01/Centro-Inovacao-SDS-GuiaImplantacao-Livro2.pdf, acesso 04/11/2018

SANT'ANA DE OLIVEIRA, Jessica SANT'ANA. Habitats de inovação. 2015. 26 p. Trabalho de Conclusão de Curso (Jornalismo)- Centro de Comunicação e Expressão, da Universidade Federal de Santa Catarina, Florianópolis, $2015 . \quad$ Disponível em: <https://repositorio.ufsc.br/bitstream/handle/123456789/133 661/TCC_JESSICA\%20SANT\%27ANA\%20DE\%20OLIV EIRA_RELATORIO.pdf? sequence $=2 \&$ is Allowed $=\mathrm{y}>$. Acesso em: 31 ago. 2018.

\section{AGRADECIMENTOS}

Agradecimentos a CAPES, CNPq, UNICENTRO, Fundação de Apoio ao Desenvolvimento da UNICENTRO, e Fundação Araucária.

O presente foi realizado com apoio da Coordenação de Aperfeiçoamento de Pessoal de Nível Superior - Brasil (CAPES) - Código de financiamento 001.

\section{COPYRIGHT}

Direitos autorais: Os autores são os únicos responsáveis pelo material incluído no artigo. 
Volume $14-\mathrm{N}^{\mathrm{o}} 159$ - Março/2019.

XL International Sodebras Congress

10 a 12 de dezembro de 2018 - Vitória - ES.

\title{
RISCOS NA TRANSFERÊNCIA DE TECNOLOGIA NAS PARCERIAS DE DESENVOLVIMENTO PRODUTIVO (PDP) NA ÁREA DE SAÚDE
}

\author{
THREATS IN THE TECHNOLOGY TRANSFER IN THE PRODUCTION \\ DEVELOPMENT PARTNERSHIPS (PDP) IN THE HEALTH AREA
}

\author{
MARCUS JULIUS ZANON ${ }^{1}$, PAULO ROGERIO PINTO RODRIGUES ${ }^{3}$; VANESSA ISHIKAWA \\ RASOTO $^{2}$
}

\section{1 - INSTITUTO DE TECNOLOGIA DO PARANÁ - (TECPAR); 2 - UNIVERSIDADE TECNOLÓGICA FEDERAL DO PARANÁ - (UTFPR); 3 - UNIVERSIDADE ESTADUAL DO CENTRO OESTE -}

\author{
(UNICENTRO)
}

mjzanon@tecpar.br,ishikawa@utfpr.edu.br,prprodrigues@unicentro.br

\begin{abstract}
Resumo - Para reduzir o forte peso dos biofármacos no orçamento anual do Ministério da Saúde, da ordem de 60\%, o governo implantou um programa de parcerias entre laboratórios nacionais e estrangeiros para absorção de conhecimento $e$ transferência de tecnologia para a produção local. O objetivo é que o Brasil ingresse no grupo de países que investem em pesquisa, desenvolvimento e inovação (PD\&I) da chamada rota biotecnológica, voltada para o desenvolvimento de medicamentos destinados principalmente ao tratamento de doenças graves. Conhecidos por Parcerias de Desenvolvimento Produtivo (PDPs), os projetos têm como requisitos a participação de laboratórios públicos e o fornecimento ao Sistema Único de Saúde (SUS) de remédios com preço inferior ao do mercado após a extinção do lapso temporal de exclusiva da patente de produtos antigos bemsucedidos, portanto torna-se imprescindível analisar os riscos envolvidos neste processo.
\end{abstract}

Palavras-chave: Transferência de Tecnologia, Parcerias de Desenvolvimento Produtivo (PDP). Medicamentos para câncer.

Abstract - In order to reduce the heavy weight of biopharmaceuticals in the annual budget of the Ministry of Health, by $60 \%$, the government implemented a partnership program between domestic and foreign laboratories for absorption of knowledge and technology transfer to local production. The goal is that Brazil join the select group of countries that invest in research, development and innovation (RD\&I) of the biotechnological route, focused on the development of drugs designated mainly for the treatment of severe diseases. Known as Productive Development Partnerships (PDPs), the projects have requirements as the participation of public laboratories and supply drugs to the Unified Health System (SUS), the national health system, with lower price than the regular market after the patent's expiration of successful oldproducts. Therefore, it is essential to evaluate the risks involved in this process.

Key-words: Technology Transfer. Development Partnerships Productive (PDP). Cancer Drugs.

\section{INTRODUÇÃO}

De acordo com um relatório da Globaldata: The State of the Biopharmaceutical Industry, Technology trends, challenges and opportunities in focus, 2018, o ano de 2017 foi marcado por inovações significativas em todas as áreas de terapia, tendo como pano de fundo avanços notáveis em tecnologia e a crescente presença de biossimilares. Em oncologia e imunologia, os biossimilares estão se tornando uma escolha terapêutica crescentemente competitiva.

Figura 1 - Oncologia em 2017 - As 10 maiores empresas em
oncologia. Fonte: Globaldata, Pharmaceutical Intelligence oncologia. Fonte: Globaldata, Pharm
Center, 2018.

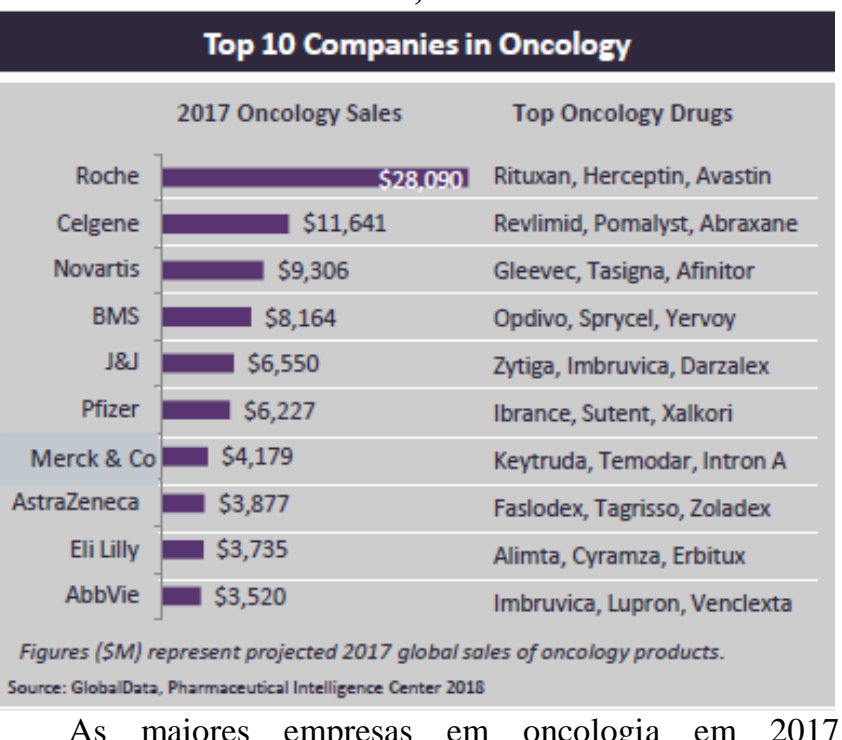
continuaram as mesmas de 2016, mas mudaram de posições.

- AbbVie ficou entre as 10 maiores em 2017 com crescimento de $33 \%$ em cima de, enquanto a Amgen caiu para a décima primeira posição.

- Roche liderou em 2017, com vendas quase que três vezes maiores do que a Celgene.

- Pfizer, em sexto lugar, teve um crescimento significante de $40 \%$.

O surgimento dos medicamentos biológicos revolucionou o tratamento de diversas doenças. O custo de seu processo de produção é caro e complexo, pois baseia-se em organismos vivos que produzem grandes e complexas 
estruturas moleculares, e pequenas alterações na concepção e execução do processo podem afetar diretamente seu perfil de eficácia e segurança. $O$ processo é tão crítico para o produto final que a maioria das empresas obtêm patente do processo de produção e não necessariamente do próprio medicamento biológico.

O término do período de proteção de patentes de vários medicamentos biológicos permite que diversas empresas desenvolvam e comercializem tais produtos. Devido às particularidades do processo de produção, que não é totalmente compartilhado e divulgado pela empresa originadora, a concepção de uma cópia idêntica é praticamente impossível, tornando, assim, a experiência adquirida com os medicamentos genéricos (que são obtidos por síntese química) não é aplicável aos medicamentos biológicos, originando preocupações relevantes relacionadas com a eficácia, a segurança e a imunogenicidade destes produtos.

Atualmente, há 16 parcerias para transferência de tecnologia entre empresas privadas estrangeiras e/ou nacionais e laboratórios públicos oficiais para produção de biossimilares no país usados no tratamento de diferentes doenças, desde cânceres, como o de mama; doenças inflamatórias, como a artrite reumatoide; doenças autoimunes, esclerose múltipla e diabetes. No Brasil, neste momento, há sete biossimilares aprovados pela ANVISA e pelo menos outros 13 em processo de aprovação. O presente documento estará organizado da seguinte forma: mercado farmacêutico no Brasil e no mundo e riscos na transferência de tecnologia nas Parcerias de Desenvolvimento Produtivo (PDP). Este trabalho visa analisar o mercado de fármacos no Brasil e no mundo e demonstrar que o mercado público de medicamentos biológicos no Brasil sofrerá um importante incremento em termos de valor agregado, autonomia e soberania pois as PDPs visam ampliar o acesso a medicamentos e produtos para saúde considerados estratégicos para o Sistema Único de Saúde (SUS), por meio do fortalecimento do complexo industrial do país, além de financiar o desenvolvimento nacional para reduzir os custos de aquisição dos medicamentos e produtos que atualmente são importados ou que representam um alto custo para o sistema.

\section{METODOLOGIA}

A pesquisa foi essencialmente exploratória e descritiva para compreensão das PDPs adotadas no setor da saúde no país. Não se trata de uma avaliação de impacto da política, visto que o escopo está relacionado a um levantamento preliminar para entendimento de suas características e limitações como uma política de inovação pelo lado da demanda.

Para cumprir seu objetivo, a metodologia da pesquisa consistiu em um exame do referencial bibliográfico existente sobre a indústria farmacêutica e sobre as políticas de inovação pelo lado da demanda. Adicionalmente houve um levantamento sobre a legislação que trata diretamente sobre as PDPs e políticas governamentais vigentes no setor da saúde, bem como exame dos dados disponíveis sobre as parcerias em andamento que são permanentemente atualizados no site do Ministério da Saúde (MS).

E para discutirmos os temas mais relevantes sobre as particularidades referentes à introdução de biossimilares no mercado brasileiro, foi realizada uma pesquisa qualitativa nas principais bases de dados de artigos científicos publicados (Globaldata, PubMed e LILACS) e de organizações da saúde e autoridades sanitárias nacionais e internacionais (Agência Nacional de Vigilância Sanitária ANVISA -, Ministério da Saúde, Organização Mundial da Saúde - OMS -, Food and Drug Administration - FDA - e European Medicines Agency - EMA).

\section{POLÍTICA DE PARCERIAS PARA O DESENVOLVIMENTO PRODUTIVO DO SETOR DE SAÚDE (PDP)}

As Parcerias para o Desenvolvimento Produtivo (PDP) - instrumento de política de inovação pelo lado da demanda - são conceituadas como um arranjo jurídico para a efetivação do uso do poder de compra pelo Estado, no âmbito da saúde pública no Brasil. Caracterizam-se pelo estabelecimento de cooperação entre agentes públicos e privados para "o acesso a tecnologias estratégicas e a posterior produção de produtos para o fornecimento ao Sistema Único de Saúde e a apropriação da tecnologia por entidades públicas nacionais" (SANTOS et al., 2017).

Também consideradas um instrumento de política industrial, as PDP possuem um arcabouço jurídicoinstitucional sofisticado, haja vista que demandam uma série de contrapartidas para que sejam realizadas as compras públicas de fármacos, medicamentos, equipamentos e dispositivos para o Sistema Único de Saúde (SUS). Dentre as contrapartidas: o desenvolvimento tecnológico e a transferência de tecnologia para um produtor nacional durante o contrato de parceria em que são concretizadas as compras governamentais do SUS (VARRICHIO, 2017).

\section{QUADRO JURÍDICO-INSTITUCIONAL}

Atualmente, a Portaria $\mathrm{n}^{\circ} 2.531$, de 12 de novembro de 2014, do Ministério da Saúde (MS), é o principal instrumento que define as PDP. Essa é a norma que também consolida as diretrizes e critérios para a definição da lista de produtos estratégicos para aquisição pelo SUS. Cumpre lembrar que essa portaria revogou o marco normativo anterior, a Portaria no 837, de 18 de abril de 2012, que definia as diretrizes e os critérios para o estabelecimento das PDP.

Além da Portaria, no 2.531, de 2014, existe um marco regulatório, de competência da Agencia Nacional de Vigilância Sanitária - ANVISA, atinente às PDP, sendo a Resolução de Diretoria Colegiada $n^{\circ} 50$, de 13 de setembro de 2012, a mais importante, haja vista que dispõe sobre os procedimentos adotados pela ANVISA para registro de produtos em processo de desenvolvimento ou de transferência de tecnologias objetos de Parcerias de Desenvolvimento Produtivo público-público ou públicoprivado de interesse do Sistema Único de Saúde.

Cumpre ressaltar, ademais, que a compra de medicamentos pelo SUS dos produtores oficiais (laboratórios públicos parceiros, caso do Tecpar), no âmbito das PDP, conta com a possibilidade legal de dispensa de licitação. Isso porque a Lei $\mathrm{n}^{\circ} 12.715$, de 17 de setembro de 2012, a qual altera o Artigo 24 da Lei $n^{\circ} 8.666$, de 1993, encerra essa possibilidade, prevendo, em seu Artigo 73, que:

Art. 24. É dispensável a licitação:

(...) 
"Inciso XXXII: na contratação em que houver transferência de tecnologia de produtos estratégicos para o Sistema Único de Saúde - SUS, no âmbito da Lei no 8.080, de 19 de setembro de 1990, conforme elencados em ato da direção nacional do SUS, inclusive por ocasião da aquisição destes produtos durante as etapas de absorção tecnológica". (BRASIL, 2012)

Nesse sentido, constata-se que Lei ${ }^{\circ} 12.715$, de 2012, em complemento à Lei de Inovação (Lei no 10.973 de 2004), estabeleceu a possibilidade de o governo estimular e apoiar a formação de "alianças estratégicas" e o desenvolvimento de projetos de cooperação entre empresas nacionais, ICT e organizações de direito privado, e tem conferido respaldo legal a contratação direta dessas parcerias estratégicas que originam as PDP.

\section{DA IMPORTAÇÃO DOS MEDICAMENTOS}

Atualmente, o Ministério da Saúde importa essas drogas para pacientes atendidos pelo sistema Único de saúde (SUS). Fonte: Entendendo os Medicamentos Biológicos, 2012. Estas drogas estão com a patente por expirar. Só a partir desse ponto é que os biossimilares (assim como acontece com os genéricos) podem ser produzidos no país.

A grande vantagem do biofármaco é sua capacidade de se encaixar perfeitamente nos receptores das células afetadas pela doença, sem atingir as células sadias. Os medicamentos biológicos são produzidos a partir de células vivas modificadas geneticamente, para gerar mecanismos de defesa equivalentes aos do organismo. Trata-se de um processo complexo, mas hoje, é possível criar produtos altamente específicos, dirigidos para qualquer alvo molecular, como marcadores de células cancerígenas, substâncias endógenas, enzimas e receptores.

O mercado dos produtos biológicos é composto ainda por vacinas, medicamentos, anticorpos monoclonais e derivados do sangue. Existem atualmente no mercado mundial mais de 250 drogas biológicas, para algo em torno de 400 indicações. Cerca de outros 300 novos produtos estão em fase de avaliação, sendo que metade é de fármacos para o tratamento de vários tipos de câncer e doenças autoimunes. As patentes dos primeiros medicamentos biológicos começaram a perder a validade nos últimos anos e, até 2020, outras dezenas de patentes vão expirar. O biossimilar não é como o medicamento genérico, que é uma cópia exata da droga de referência, o biossimilar nasce de um processo de engenharia reversa, em que, por meio da análise da molécula pronta, tenta-se descobrir como ela foi produzida, uma vez que o fim da patente não obriga o fabricante a revelar qual é a fórmula criada no seu laboratório. (BARATA, 2017). https://bit.ly/2yudU4W

\section{O QUE SÃO OS MEDICAMENTOS BIOLÓGICOS?}

Medicamentos biológicos são medicamentos produzidos por biossíntese em células vivas, ao contrário dos sintéticos que são produzidos por síntese química. Fonte: Entendendo os Medicamentos Biológicos, 2012. Assim, a química orgânica dá lugar à biologia molecular e aos processos biotecnológicos. Sob o ponto de vista industrial, a maioria dos produtos farmacêuticos biológicos é produzida em cultura de células geneticamente modificadas. Os biológicos representam atualmente a maior fonte de inovação da indústria farmacêutica e soluções para inúmeras doenças, até então não tratadas eficazmente com as terapias tradicionais.

Os biológicos são uma classe diversa e heterogênea de produtos. Existem hormônios, fatores de crescimento e de diferenciação celular, enzimas capazes de dissolver coágulos, anticoagulantes para prevenir a sua formação e os modernos anticorpos monoclonais que vêm revolucionando o tratamento do câncer e doenças autoimunes.

\section{O QUE SÃO ANTICORPOS MONOCLONAIS?}

O sistema imune exerce sua função protetora e destrutiva de invasores por meio da atividade de uma classe de glóbulos brancos chamados linfócitos. Um tipo especial de linfócito, o Linfócito $\mathrm{B}$, produz glicoproteínas conhecidas como anticorpos. Os anticorpos ligam-se de forma muito específica às substâncias consideradas estranhas contra as quais foram projetados e produzidos. As substâncias que induzem a formação de anticorpos são chamadas de antígenos. Os anticorpos produzidos naturalmente são em geral policlonais, isto porque são produzidos por vários clones de Linfócitos B. São específicos, mas possuem algum grau de heterogeneidade. Fonte: Entendendo os Medicamentos Biológicos, 2012

Atualmente, é possível produzir anticorpos monoclonais, derivados de um único clone de linfócitos, e podem ser dirigidos a qualquer alvo molecular, como marcadores de células tumorais, substâncias endógenas, enzimas e receptores. Fonte: Entendendo os Medicamentos Biológicos, 2012. Funcionam como mísseis teleguiados que localizam a substância contra a qual foram produzidos de forma muito precisa e específica. Assim, podem marcar ou destruir células tumorais, inativar enzimas, estimular ou silenciar receptores, ligar ou desligar funções fisiológicas e interromper processos patológicos. Os anticorpos monoclonais têm grande aplicação na oncologia, no tratamento de doenças autoimunes, para prevenir a rejeição de transplantes, como marcadores para testes diagnósticos e instrumentos de investigação científica. Os anticorpos monoclonais recebem nomes complicados que terminam com o sufixo - mabe (derivado do inglês - mab: monoclonal antibody). Exemplos: infliximabe, rituximabe e adalimumabe.

\section{O QUE SÃO BIOSSIMILARES?}

Biossimilares são cópias autorizadas dos produtos biológicos e com os quais foram comparados em termos de qualidade, segurança e eficácia. Fonte: Entendendo os Medicamentos Biológicos, 2012. Os medicamentos sintéticos são produzidos por meio de reações químicas bem definidas e a partir de reagentes bem conhecidos. São facilmente replicáveis e permitem cópias idênticas. Os medicamentos biológicos, ao contrário, são produzidos em sistemas vivos, a partir de insumos variáveis e a identidade do produto final depende de muitos fatores e da consistência do processo de produção. Desta forma não podem ser replicados de forma idêntica.

Após o vencimento das patentes destes produtos, cópias podem ser legalmente produzidas e, se recebem aprovação regulatória, podem ser comercializadas. Cópias legais dos produtos sintéticos são os medicamentos genéricos, em princípio idênticos ao original e por consequiência, equivalentes. As cópias autorizadas dos 
medicamentos biológicos, em princípio diferentes, são usualmente chamadas de biossimilares. No entanto, a biossimilaridade deve ser comprovada por um conjunto de estudos comparativos.

\section{O QUE É BIOSSIMILARIDADE?}

A biossimilaridade é uma propriedade de um produto em relação a outro produto, considerado como referência e atestada pelo chamado exercício de comparabilidade. Fonte: Entendendo os Medicamentos Biológicos, 2012. Uma convincente demonstração de biossimilaridade transfere ao novo produto, parte da experiência e do conhecimento adquirido com o produto de referência, permitindo algum grau de redução dos requerimentos para aprovação.

A Organização Mundial da Saúde (OMS) define exercício de comparabilidade como sendo a comparação direta de um produto biológico (candidato a biossimilar) com o produto biológico inovador (referência), já aprovado, com o propósito de estabelecer similaridade em qualidade, segurança e eficácia. Os produtos devem ser comparados no mesmo estudo e usando os mesmos procedimentos. Produtos que não se submetem a estes estudos ou falham em demonstrar similaridade, podem candidatar-se, ainda assim, para a aprovação por meio de um dossiê completo e não devem ser classificados como biossimilares. Para estes produtos (cópias não biossimilares) fica comprometida a aplicabilidade da transferência dos dados e conhecimentos gerados pelo produto inovador.

\section{OS BIOSSIMILARES PODEM SER CONSIDERADOS UMA FORMA DE GENÉRICOS?}

Não. Para os produtos biológicos, o conceito de genérico não se aplica. Um genérico deve conter a mesma substância ativa do produto de referência e a formulação deve ser bioequivalente. A prova de bioequivalência não requer estudos de eficácia e segurança, pois isto já foi demonstrado pelo produto de referência. A comprovação de absorção e disposição da substância ativa (biodisponibilidade) é em geral suficiente. No caso dos biossimilares, a substância ativa não é inteiramente idêntica ao produto de referência e é necessário demonstrar que os efeitos clínicos não são muito diferentes e que as consequências clínicas foram avaliadas de forma apropriada. Os genéricos e os biossimilares estão sujeitos a regimes regulatórios totalmente diferentes.

\section{COMO FUNCIONAM AS PDP}

Nas Parcerias de Desenvolvimento Produtivo (PDP), o Ministério da Saúde firma acordos com laboratórios privados para que os mesmos se comprometam a transferir, aos laboratórios públicos brasileiros, a tecnologia para a produção de determinado medicamento dentro do prazo de cinco anos. Durante esse período, os laboratórios do setor privado são responsáveis pela produção do princípio ativo e transferência da tecnologia ao laboratório público.

Para que ambos sejam beneficiados durante o acordo, o governo garante aos laboratórios privados a exclusividade na compra desses produtos durante o mesmo período. Após o prazo para a transferência de tecnologia, o laboratório público nacional inicia, de forma autônoma, a produção completa do medicamento visando atender à demanda nacional. Com a produção sendo realizada no país, os laboratórios públicos ajudam a reduzir a dependência de importação e produzem medicamentos de qualidade, ampliando sua competitividade e capacitação tecnológica.

\section{DA ECONOMIA PARA OS COFRES PÚBLICOS COM AS PDP}

Figura 2 - Economia em aquisições no âmbito das PDP.

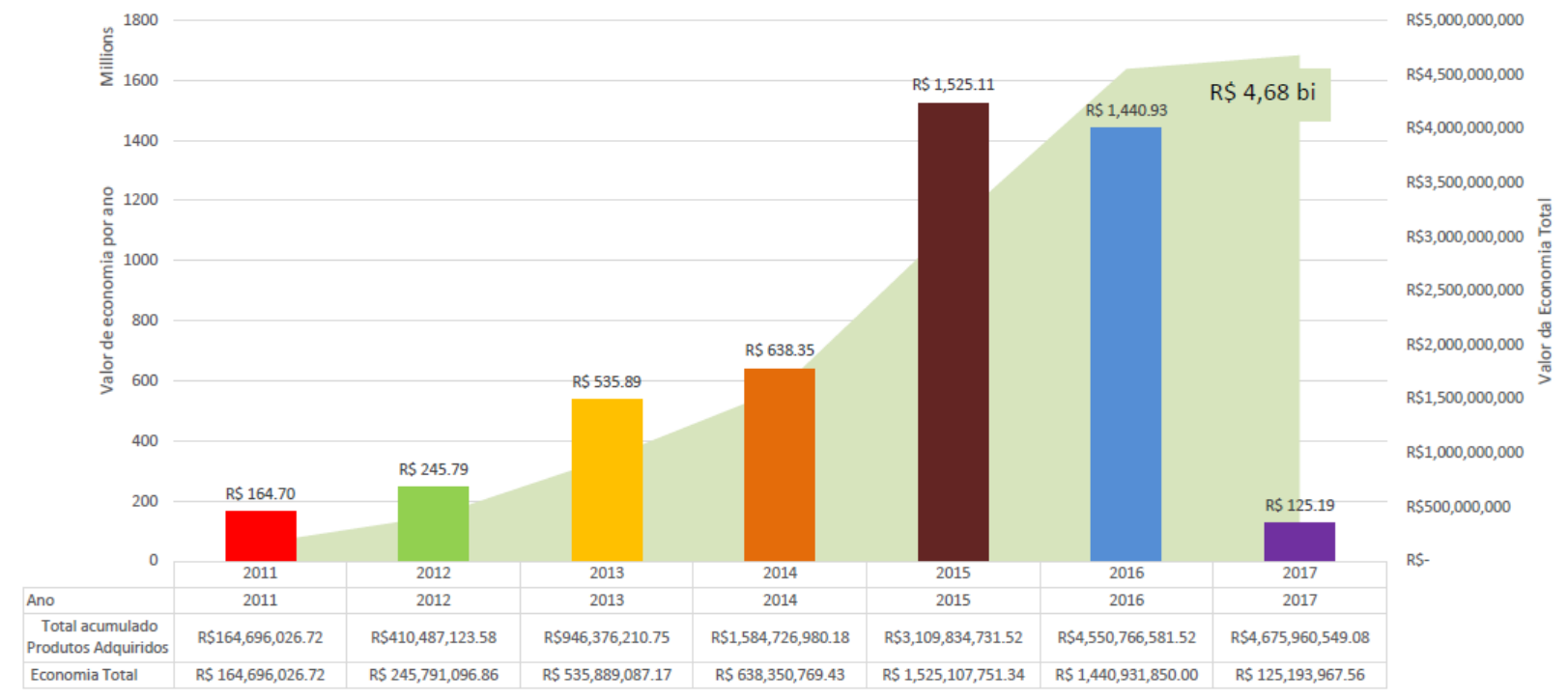

O cálculo da economia gerada através de aquisições no âmbito das Parcerias para o Desenvolvimento Produtivo (PDP) entre os anos de 2011 a 2017, conforme a Figura 2 acima, foi realizado considerando o somatório dos valores da economia anual de cada produto objeto da PDP. A economia anual para cada produto objeto de PDP refere-se à diferença entre o valor anual gasto pelo Ministério da Saúde na aquisição anterior ao estabelecimento da PDP 
(considerando o valor unitário gasto para o produto na aquisição anterior ao estabelecimento da PDP e a quantidade do produto adquirido em ano em cálculo) e o valor anual gasto pelo Ministério da Saúde com as aquisições do produto no âmbito da PDP para o ano em cálculo (considerando o valor unitário e a quantidade do produto adquirido no ano em cálculo). Como o ano de 2017 estava em curso, os valores referentes ao ano 2017 ainda estavam em aberto. Ao final dos projetos em fase III (PDP) prevê-se economia da ordem de $\mathrm{R} \$ 5$ bilhões. Disponível em https://bit.ly/2A2JI2M (Acessado em 10/10/2018).

\section{DOS RISCOS DA TRANSFERÊNCIA DE TECNOLOGIA NAS PDP}

\section{Do prazo de validade da patente:}

De acordo com a Lei da Propriedade Industrial (Lei ${ }^{\circ}$ 9.279/1996), a partir da data de depósito no INPI, a patente de invenção tem prazo de validade de 20 anos e a de modelo de utilidade, 15 anos. Essa última se refere a um objeto, ou parte dele, com nova forma que resulte em melhoria funcional ou de sua fabricação.

A mesma legislação assegura que, mesmo com a demora do exame e deferimento, o que não é raro, o prazo de vigência não seja inferior a dez anos para a patente de invenção e - a contar da data de concessão - a sete anos para a patente de modelo de utilidade.

O problema é que esta longa espera desestimula os investimentos, uma vez que, nestes casos, quando a patente é concedida, a inovação por ela coberta já se encontra obsoleta.

Nos casos em que o INPI demora mais de dez anos para examinar e deferir um pedido de patente, o artigo 40 da Lei prevê um prazo adicional de dez anos. Note-se que não se trata de uma extensão que possa ser "requerida" pelo depositante que, na verdade, não tem controle sobre o tempo que o órgão leva para examinar o caso. $O$ dispositivo previsto no artigo 40 consiste em uma garantia de que o depositante não seja penalizado com a concessão de uma patente com prazo de validade praticamente expirado, sendo que as tentativas para extingui-la devem ser fortemente repelidas.

As parcerias das PDP são realizadas entre duas ou mais instituições públicas ou entre instituições públicas e empresas privadas, buscando promover a internalização da produção. Em contrapartida, as empresas privadas se comprometem a transferir a tecnologia para laboratórios públicos durante o tempo de duração dos contratos, geralmente de cinco anos para medicamentos sintéticos e de dez anos para medicamentos biológicos, portanto torna-se imprescindível discutir e analisar os aspectos jurídicos, econômicos e de transferência de tecnologia destes produtos, principalmente com relação aos efeitos do backlog de patentes do Instituto Nacional da Propriedade Industrial (INPI) em relação ao artigo 40, parágrafo único, da Lei 9.279/1996, que regula direitos e obrigações relativos à propriedade industrial.

Este dispositivo possibilita a abertura de prazo indeterminado para a vigência de patentes de invenção afrontando o princípio da temporariedade da proteção patentária, previsto no inciso XXIX do artigo $5^{\circ}$ da Constituição Federal. Provocando forte lesão a direitos sociais e à ordem econômica, pois os demais interessados na exploração da criação industrial não podem prever e programar-se para iniciar suas atividades. $\mathrm{O}$ consumidor torna-se refém de preços e produtos definidos pelo detentor do monopólio, sem perspectiva de quando terá acesso a novas possibilidades. $\mathrm{O}$ dispositivo afronta a livre concorrência, a segurança jurídica, a defesa do consumidor, o princípio da eficiência e o da duração razoável do processo A expiração da patente de vários biológicos de câncer ocorrerá nos próximos anos, possibilitando a entrada de mais biossimilares no mercado.

\section{CONCLUSÃO}

Para reduzir o forte peso dos biofármacos no orçamento anual do Ministério da Saúde, da ordem de $60 \%$, o governo implantou um programa de parcerias entre laboratórios nacionais e estrangeiros para absorção de conhecimento e transferência de tecnologia para a produção local. O objetivo é que o Brasil ingresse no seleto grupo de países que investem em pesquisa e inovação da chamada rota biotecnológica, voltada para o desenvolvimento de medicamentos destinados principalmente ao tratamento de doenças graves. Conhecidos por Parcerias de Desenvolvimento Produtivo (PDPs), os projetos têm como requisitos a participação de laboratórios públicos e o fornecimento ao Sistema Único de Saúde (SUS) de remédios com preço inferior ao do mercado.

O mercado global de biossimilares é ainda pequeno, estimando-se para 2015 o valor de US\$ 3,7 bilhões em despesas de PD\&I. Entretanto, é aí que residem as maiores oportunidades em países em desenvolvimento, haja vista a previsão de que até 2020 doze produtos cujo mercado global atual é de US\$ 76 bilhões, terão suas patentes extintas (Fonte: Shaping the biosimilars opportunity - IMS Health). É nesse nicho que se assentam as maiores possibilidades da indústria brasileira no campo de biológicos.

O estímulo à inovação conta com linhas especiais de crédito do Banco Nacional de Desenvolvimento Econômico e Social (BNDES) - que tem financiado projetos para a instalação de fábricas mais modernas - e da Financiadora de Estudos e Projetos (Finep), cujas missões são incentivar a aquisição de novas rotas tecnológicas e promover o estudo de moléculas e organismos. Atualmente, $35 \%$ do esforço brasileiro de P\&D está concentrado no complexo da saúde.

O Brasil já está produzindo biossimilares - que, essencialmente, são cópias de medicamentos já produzidos em outros países - e partirá para a criação de seus próprios medicamentos, gerando patentes e divisas. "É um processo de aprendizado contínuo. A nacionalização da produção resultará em economia de $\mathrm{R} \$ 5,3$ bilhões por ano. Para manter o acesso a toda a população, temos de fomentar a indústria nacional".

A pouca experiência em fabricação e inovação de farmoquímicos impõe importantes dificuldades à indústria brasileira para incorporar a produção de produtos biológicos, uma vez que a própria natureza do processo produtivo, envolvendo células vivas, torna difícil dissociar a produção do biofármaco da formulação final do medicamento. Além disso, o escopo das PDPs prevê a incorporação de toda a produção em território nacional. Assim, o desafio que se impõe a muitas empresas é saltar da formulação de medicamentos genéricos, cuja composição físico-química e processos de produção são muito mais simples, para a produção de biofármacos, que requerem uma série de competências de maior complexidade tecnológica, em função da instabilidade dos microrganismos, dos altos 
riscos de contaminação e da distinta base de conhecimento para a operação das plantas produtivas e solução de problemas associados à produção.

A expiração das patentes e a cooperação de empresas multinacionais na transferência de tecnologia certamente facilitarão o trabalho dos laboratórios brasileiros. No entanto, um mínimo de capacidade de absorção e de intensidade de esforços de aprendizado será requerido dos laboratórios brasileiros, e isso se traduz em investimentos pesados na construção de plantas produtivas adequadas, contratação e treinamento de pessoal, aquisição de máquinas e equipamentos, escalonamento da produção (da bancada à indústria), realização de estudos clínicos e obtenção de registro junto à Anvisa.

A não reprodutibilidade fiel dos medicamentos biológicos decorrentes da instabilidade dos organismos vivos e da manipulação genética levou a Anvisa a requerer estudos clínicos que comprovem a segurança e a eficácia do medicamento "biossimilar", que são mais extensos e complexos do que os ensaios clínicos de biodisponibilidade e bioequivalência exigidos dos medicamentos genéricos. Esse requisito legal exigirá uma capacitação tecnológica adicional dos laboratórios brasileiros, não apenas na produção, mas também em pesquisas clínicas, principalmente daqueles que estão limitados à produção de medicamentos genéricos.

Assim, considerando o prazo de apenas 5 anos das PDPs, a complexidade da biotecnologia e a baixa capacidade prévia dos brasileiros nessa tecnologia, torna-se interessante a investigação sobre as estratégias dos laboratórios brasileiros, públicos e privados, para absorver a tecnologia externa, que é o objetivo deste trabalho.

Quando uma tecnologia objeto de patente passa a ser objeto de livre uso em virtude da extinção do lapso temporal de exclusiva, isto não importa afirmar que terceiros, pela mera leitura do relatório descritivo e das reivindicações do privilégio de invenção, serão capazes de reproduzir tal teor tecnológico.

Acreditamos que o ponto de equilíbrio será atingido quando estiver instalada no Brasil uma plataforma tecnológica que inclua infraestrutura fabril de ponta, domínio do conhecimento e recursos humanos qualificados. Essas conquistas virão a partir dos biossimilares, cujo desenvolvimento, fabricação e comercialização representarão o alicerce para que os produtos inovadores sejam desenvolvidos. $\mathrm{O}$ conhecimento adquirido durante o desenvolvimento de produtos biossimilares, ou mesmo na transferência de tecnologia de ponta para o Brasil, será fundamental para, em médio prazo, permitir que empresas nacionais tenham condição de desenvolver produtos realmente inovadores.

O artigo 40, parágrafo único, da LPI, prevê um prazo mínimo de proteção de 10 anos após a concessão, aplicado nos casos em que o exame ocorre mais de 10 anos após a solicitação. É preciso vetar o artigo 40 da LPI para abrir caminho para a produção de genéricos e reduzindo custos para o sistema público de saúde, pois a norma prorroga a vigência de patentes de invenção e de modelos de utilidade por prazo indeterminado, em afronta ao art. $5^{\circ}$, XXIX, da Constituição da República. A norma desestimula a resolução, em tempo razoável, de processos administrativos de exame de pedidos de patentes, com violação aos princípios da duração razoável do processo (art. $5^{\circ}$, LXXVIII) e da eficiência da administração pública (art. 37, caput). A incerteza do prazo de vigência da patente provoca insegurança jurídica e atenta contra o direito adquirido de terceiros de explorar-lhe o objeto.

\section{REFERÊNCIAS BIBLIOGRÁFICAS}

II Forum Latino-Americano e III Forum Brasileiro de Biossimilares, 2012, Perspectivas e preocupações com a entrada de biossimilares no mercado latino-americano

http://www.researchgate.net/publication/257700191. (Acesso em 28/08/2015)

BARBOSA, D. B. Biotecnologia e propriedade industrial. 2002. Disponível em: http://denisbarbosa.addr.com/81.doc.

INTERFARMA, Entendendo os Medicamentos Biológicos, 2012, https://bit.ly/2OjnwKc (Acesso em 10/10/2018).

JOACHIN, R. Estimating the cost of slow biosimilar uptake in the US: An infliximab case study. Globaldata Healthcare, 2018, Relatório.

SEVILLA, I. D. Rituximab Biosimilars - Is the hype warranted? Globaldata, 2018, Relatório.

ROBERTS, Dan., et al. Multiple myeloma - Global Drug Forecast and Market Analysis to 2023, Relatório disponível na base de dados Globaldata, 2015. Relatório.

ANNIS, A., et al. The biopharmaceutical industry in 2017: Highlights by Therapeutic Area, Relatório disponível na base de dados Globaldata, Fevereiro de 2018.

Acessado em 24 ago. 2018.

CountryFocus: Healthcare, Regulatory and Reimbursement Landscape - Brazil

Reference Code: GDHC0081CHR - Publication Date: July 2015 Globaldata

Brasil. Ministério da Saúde. Agência de Vigilância Sanitária. Resolução da Diretoria Colegiada - RDC n ${ }^{\circ} 55$, de 16 de dezembro de 2010. Dispõe sobre o registro de produtos biológicos novos e produtos biológicos e dá outras providências [Internet]. Brasília (DF): Diário Oficial da União; 2010; $\mathrm{n}^{\circ}$. 241, dezembro 17 [citado 2018 Jul 26]. Disponível em:

http://portal.anvisa.gov.br/documents/10181/2718376/RDC_55_20

10_COMPpdf/bb86b1c8-d410-4a51-a9df-a61e165b9618

Brasil. Ministério da Saúde. Parceria para o Desenvolvimento Produtivo - PDP [Internet]. Brasília (DF): Ministério da Saúde; 2014 [citado 2017 Mar 13]. Disponível em:

http://portalsaude.saude.gov.br/index.php/o-

ministerio/principal/leia-mais-o-ministerio/581-sctie-raiz/deciis/12deciis/12090-parceria-para-o-desenvolvimento-produtivo-pdp Brasil. Ministério da Saúde. Portaria n ${ }^{\circ} 2.531$, de 12 de Novembro de 2014 [Internet]. Brasília (DF): Ministério da Saúde; 2014 [citado 2017 Mar 13]. Disponível em:

http://bvsms.saude.gov.br/bvs/saudelegis/gm/2014/prt2531_12_11 _2014.html

Brasil. Ministério da Saúde. Balanço das Parcerias para o

Desenvolvimento Produtivo [Internet]. Brasília (DF): Ministério da Saúde; 2015 [citado 2017 Mar 13]. Disponível em:

http://portalarquivos.saude.gov.br/images/pdf/2015/julho/14/13-

07-2015-BALAN--O-PDP-FINAL-FINAL.pdf

The State of the Biopharmaceutical Industry, Technology trends, challenges and opportunities in focus, código do relatório: GD0257HC, 2018

\section{COPYRIGHT}

Direitos autorais: $\mathrm{O}(\mathrm{s})$ autor(es) é(são) o(s) único(s) responsável(is) pelo material incluído no artigo.

\section{AGRADECIMENTOS}

Agradecimentos a CAPES, CNPq, UNICENTRO, Fundação de Apoio ao Desenvolvimento da UNICENTRO - FAU, e Fundação Araucária.

O presente foi realizado com apoio da Coordenação de Aperfeiçoamento de Pessoal de Nível Superior - Brasil (CAPES) Código de financiamento 001. 


\section{Área: Ciências Humanas e Sociais}

\begin{tabular}{|c|c|}
\hline $6-2$ & $\begin{array}{l}\text { A CONTRIBUIÇÃO DAS ACELERADORAS DE NEGÓCIOS PARA AS STARTUPS: } \\
\text { O CASO DO ESPAÇO NAVE - NÚCLEODE ACELERAÇÃO E VALORIZAÇÃO DA } \\
\text { ESTÁCIO } \\
\text { THE CONTRIBUTION OF THE BUSINESS ACCELERATOR FOR STARTUPS: THE } \\
\text { CASE OF THE SPACE SHIP - CORE OF ACCELERATION AND EXPLOITATION } \\
\text { OF ESTÁCIO } \\
\text { Pedro Paulo Lacerda Sales; Durval Correa Meirelles }\end{array}$ \\
\hline $6-2$ & $\begin{array}{l}\text { ANÁLISE DA CONTRIBUIÇÃO DO CURSO DE ADMINISTRAÇÃO NOTURNO DA } \\
\text { UFES PARA A FORMAÇÃO DE EMPREENDEDORES POR MEIO DOS } \\
\text { PROGRAMAS DAS DISCIPLINAS } \\
\text { ANALYSIS OF THE CONTRIBUTION OF THE NORTH ADMINISTRATION } \\
\text { COURSE OF UFES FOR THE TRAINING OF ENTREPRENEURS BY MEANS OF } \\
\text { DISCIPLINARY PROGRAMS } \\
\text { Lorrara Silvya Imagawa De Oliveira; Rubens De Araújo Amaro }\end{array}$ \\
\hline $6-2$ & $\begin{array}{l}\text { ANÁLISE DO DESEMPENHO LOGISTICO NO } \\
\text { MEDICAMENTOS DO MUNICIPIO DE PORTO VELHO-RO } \\
\text { ANALYSIS OF LOGISTIC PERFORMANCE IN THE MEDICINES OF THE } \\
\text { MUNICIPALITY OF PORTO VELHO-RO } \\
\text { Sandra Sena Reis; Samuel Dos Santos Junio; Jana Aparecida Pereira Lopes }\end{array}$ \\
\hline $6-2$ & $\begin{array}{l}\text { ANÁLISE ESTRATÉGICA DOS RESULTADOS DA IMPLANTAÇÃO DO } \\
\text { PROGRAMA NACIONAL DE GESTÃO PÚBLICA E DESBUROCRATIZAÇÃO - } \\
\text { GESPÚBLICA EM RONDONIA } \\
\text { STRATEGIC ANALYSIS OF RESULTS OF THE IMPLEMENTATION OF THE } \\
\text { NATIONAL PROGRAM OF PUBLIC MANAGEMENT AND BUDGETING - } \\
\text { GESPÚBLICA IN RONDÔNIA } \\
\text { Gabriele Aires Da Silva; Samuel Dos Santos Junio }\end{array}$ \\
\hline $6-2$ & $\begin{array}{l}\text { É POSSIVEL APRENDER: REVISÃO NARRATIVA SOBRE O ENSINO DO } \\
\text { EMPREENDEDORISMO } \\
\text { IT CAN BE LEARNED: NARRATIVE REVIEW ON ENTREPRENEURSHIP } \\
\text { TEACHING } \\
\text { Lorrara Silvya Imagawa De Oliveira; Rubens De Araújo Amaro }\end{array}$ \\
\hline $6-2$ & $\begin{array}{l}\text { EFEITOS DA ESTRUTURA DE MERCADO E DA POSIÇÃO COMPETITIVA NO } \\
\text { DESEMPENHO DA FIRMA, EM TEMPOS DE CRISE } \\
\text { EFFECTS OF MARKET STRUCTURE AND COMPETITIVE POSITION ON FIRM'S } \\
\text { PERFORMANCE IN TIMES OF CRISIS } \\
\text { Alexandre Teixeira Dias; Sebastião Nunes Rocha De Souza; Marcelo Barbosa Costa; } \\
\text { Alexandre Gabriel Fontenelle }\end{array}$ \\
\hline
\end{tabular}




\begin{tabular}{|c|c|}
\hline $6-2$ & $\begin{array}{l}\text { GESTÃO E AVALIAÇÃO DO DESEMPENHO DE EMPREGADOS: SOLUÇÕES } \\
\text { PARA UMA SOCIEDADE DE ECONOMIA MISTA DE GRANDE PORTE } \\
\text { MANAGEMENT AND ASSESSMENT' PERFORMANCE OF EMPLOYEES: } \\
\text { SOLUTIONS FOR A LARGE JOINT CAPITAL COMPANY } \\
\text { Uerlei Valdomiro Araujo; Roquemar De Lima Baldam; Thalmo De Paiva Coelho } \\
\text { Junior; Leonardo Carneiro Da Costa }\end{array}$ \\
\hline $6-2$ & $\begin{array}{l}\text { O PLANEJAMENTO ESTRATÉGICO NA EDUCAÇAO A DISTÂNCIA NO } \\
\text { INSTITUTO FEDERAL DE RONDÔNIA } \\
\text { THE STRATEGIC PLANNING IN DISTANCE EDUCATION AT THE FEDERAL } \\
\text { INSTITUTE OF RONDÔNIA } \\
\text { Sebastião Gonçalves Neves; Samuel Dos Santos Junio; Aloir Pedruzzi Junior; } \\
\text { Jonimar Silva Souza }\end{array}$ \\
\hline $7-6$ & $\begin{array}{l}\text { SAUBARA: TERRITÓRIO E IDENTIDADE } \\
\text { SAUBARA: TERRITORY AND IDENTITY } \\
\text { Valdir Silva Da Conceição; Angela Machado Rocha; Silvio Liberato De Moura Filho }\end{array}$ \\
\hline
\end{tabular}


Volume $14-\mathrm{N}^{\mathrm{o}} 159$ - Março/2019.

XL International Sodebras Congress

10 a 12 de dezembro de 2018 - Vitória - ES.

\title{
A CONTRIBUIÇÃO DAS ACELERADORAS DE NEGÓCIOS PARA AS STARTUPS: O CASSO DO ESPAÇO NAVE - NÚCLEODE ACELERAÇÃO E VALORIZAÇÃO DA ESTÁCIO
}

\author{
THE CONTRIBUTION OF THE BUSINESS ACCELERATOR FOR STARTUPS: \\ THE CASE OF THE SPACE SHIP - CORE OF ACCELERATION AND \\ EXPLOITATION OF ESTÁCIO
}

\author{
PEDRO PAULO LACERDA SALES; DURVAL CORREA MEIRELLES
}
INSTITUTO FEDERAL DE EDUCAÇÃO CIÊNCIA E TECNOLOGIA SUDESTE DE MINAS GERAIS- MG; UNICESUMAR - CENTRO UNIVERSITÁRIO DE MARINGÁ-PR

pedro.sales@ifsudestemg.edu.br;durval.meirelles@unicesumar.edu.br

\begin{abstract}
Resumo. O mercado competitivo vem impondo mudanças na forma de gerir as organizações $e$ impulsionando inovações em produtos/serviços. Este ambiente tem atraído cada vez mais jovens empreendedores que a partir de ideias inovadoras buscam a criação de novos negócios e, neste contexto cresce a importância das startups e aceleradoras de negócios. $O$ objetivo deste trabalho foi identificar a real contribuição de uma aceleradora para o desempenho das startups pesquisadas. Os resultados sugerem que o apoio oferecido em termos de espaço físico, definição do negócio, treinamento, mentorias e network foram satisfatórios e que o apoio na definição de mercado (clientes) e na comercialização do produto/serviço, não foi satisfatório. $O$ estudo revelou também que as startups com melhor desempenho foram as que tinham equipes maiores $e$ fundadores/sócios com melhor formação acadêmica.
\end{abstract}

Palavras-Chave: Aceleradora de negócios; Startups; Avaliação de desempenho.

Abstract. The competitive market has been imposing changes in the way of managing organizations and boosting innovations in products/services. This environment has increasingly attracted young entrepreneurs that from innovative ideas seek to create new businesses and in this context, the importance of startups and business accelerators grows. This study's goal was to identify the real contribution of an accelerator to the surveyed startups' performance. Results suggest that offered support, in terms of physical space, business definition, training, mentoring and net working was indeed satisfactory, and that market definition support (customers) and marketing of the product/service itself were unsatisfactory. The study also revealed that the bestperforming startups were the ones with larger teams and better academic-trained founders/partners.

Keywords: Business accelerator; Startups; Performance evaluation.

\section{INTRODUÇÃO}

O ambiente empresarial tem apresentado grandes transformações nos últimos anos, influenciadas, de um lado, pelo grande avanço tecnológico e pela integração comercial provocada pela globalização, e por outro, pelas novas técnicas de gestão empresarial. Estes fatos proporcionam inovações tanto em produtos quanto em processos, como na forma de governança nas empresas.

De acordo com Dacorso (2000), as empresas que inovam seus produtos ou processos para se diferenciarem de seus concorrentes, se tornam mais lucrativas que outras empresas. Assim sendo, em especial as médias e micro e pequenas empresas, devido suas fragilidades, encontram na inovação uma solução para suas dificuldades pois isso as permitem obter um diferencial, não somente nas características do produto, mas também na produtividade e portanto, em sua lucratividade, o que lhes pode garantir um maior tempo de vida.

Neste contexto, a economia global apresenta oscilações adaptativas, ora com crescimento ora com declínio econômico. Esse contínuo processo de ajustes tem provocado um aumento do desemprego em todo o planeta. Isto ocorre pela utilização de forma massiva das novas tecnologias pelas empresas, como por exemplo, a substituição dos meios de produção por robôs ou softwares inteligentes, ou mesmo na transformação de um negócio real em virtual.

Por outro lado, a diminuição da oferta de emprego ocorre pelo crescimento nos processos de fusão e aquisição, pela crescente financeirização da economia ou pela flexibilização nas relações de trabalho.

Neste contexto, as grandes, médias ou microempresas precisam cada vez mais investir em conhecimento e inovação, até mesmo como meio de crescimento e sobrevivência, enquanto o homem se prepara constantemente investindo no aprendizado e no comportamento empreendedor.

Segundo Metcalfe (2005), sempre foi difícil definir o empreendedor através da teoria econômica em função das mais variadas formas de se empreender e criar coisas novas. Mas foi sem dúvida Schumpeter um dos grandes autores a tratar do empreendedorismo.

Nesse ambiente schumpeteriano, a busca por novos mercados atrai um grande número de jovens empreendedores, que a partir de ideias inovadoras buscam a 
criação de novos negócios mais adaptados a esse cenário econômico global.

Como exemplo podem ser destacados os negócios que surgem das parcerias entre os setores público e privado, em especial as parcerias entre universidades e indústrias, entre universidades e empresas, ou entre instituições de pesquisas e empresas, dentre outras. Assim surgiram as incubadoras de empresas, os arranjos produtivos locais, os pólos tecnológicos, as redes de tecnologia, as aceleradoras, dentre outras formas inovadoras de iniciativa empresarial.

De forma geral este artigo busca explorar o crescimento do mercado de startups e a importância das aceleradoras dentro desse novo contexto econômico e empresarial. Em particular, o texto tem o objetivo de avaliar a importância do suporte oferecido por uma aceleradora de negócios.

\section{METODOLOGIA}

Devido à importância das aceleradoras de negócios no ecossistema empreendedor e da importante participação das empresas nascentes no fomento à inovação e geração de riqueza e renda, tem-se a necessidade de maior investimento no conhecimento e entendimento dos resultados efetivos dos programas de aceleração de startups.

O estudo foi desenvolvido em 4 empresas, escolhidas por critério de acessibilidade, que estiveram ligadas ao Núcleo de Aceleração e Valorização da Estácio (Espaço NAVE) vinculado à Universidade Estácio de Sá no Rio de Janeiro. O processo de aceleração ocorreu no ano de 2015.

O Espaço NAVE é um programa de pré-aceleração em atividade desde 2014, sendo $100 \%$ gratuito, e que recebe Startups, após processo seletivo, para um ciclo de quatro meses em que oferece capacitação, validações reais, networking e mentorias com alguns dos principais empreendedores e especialistas do mercado.

\section{RESULTADOS}

Para melhor compreensão dos resultados, o texto será divido em três partes: (I) Caracterização das Startups, (II) Apresentação e Análise do Processo de Aceleração e (III) Apresentação e Análise de Variáveis de Desempenho das Startups.

A apresentação e análise dos resultados a seguir se originaram da contribuição de quatro Startups que passaram pelo processo de aceleração no Espaço NAVE no ano de 2015. Por envolver dados financeiros, projetos protegidos por contratos de confidencialidade entre outras restrições, as referidas empresas serão denominadas de: ALFA, BETA, GAMA e DELTA.

\section{1 - Caracterização das Startups}

Figura 1 - Caracterização das Startups

\begin{tabular}{|c|c|c|c|c|c|}
\hline EMPRESA & Cidade/Estado: & Cargo/função & $\begin{array}{c}\text { Formação dos } \\
\text { fundadores/sócios }\end{array}$ & $\begin{array}{c}\text { Data da } \\
\text { fundação }\end{array}$ & $\begin{array}{c}\text { Data do ingresso no } \\
\text { Espaço NAVE }\end{array}$ \\
\hline ALFA & Petrópolis - RJ & Sócio & Mestrado & Abr./12 & Mar./15 \\
\hline BETA & Rio de Janeiro - RJ & Fundador & Especialização/MBA & Nov./14 & Mar./15 \\
\hline GAMA & Rio de Janeiro - RJ & Fundador & Graduação & Jan./15 & Mar./15 \\
\hline DELTA & Rio de Janeiro - RJ & Fundador & Graduação & Out./14 & Aggo//15 \\
\hline
\end{tabular}

Fonte: Autores 2016

A empresa ALFA desenvolveu uma plataforma que permite que pessoas ou empresas criem cursos on-line a distância ou, no caso de cursos presenciais, insiram conteúdos no ambiente virtual para complementar o processo de aprendizado de alunos destes cursos. O produto/serviço foi desenvolvido potencialmente para o mercado nacional. A empresa foi fundada em 2012, ingressou no processo de aceleração em março de 2015 para, segundo o sócio respondente "aprender sobre diversas áreas do conhecimento",sendo que na época possuía dois sócios e mais de cinco pessoas atuando na empresa. Formação acadêmica do sócio/fundador respondente: Mestrado.

A empresa BETA focou em uma plataforma para conectar empresas a profissionais criativos de uma forma diferente, intermediando a oportunidade ou necessidade das empresas à capacidade de profissionais do mercado em diversas áreas, valorizando o melhor dos dois ambientes. $\mathrm{O}$ serviço foi desenvolvido potencialmente para o mercado nacional. Fundada em novembro de 2014, a empresa ingressou no processo de aceleração do ESPAÇO NAVE em março de 2015 com o objetivo, segundo o sócio fundador respondente, de "validar o modelo de negócio com mentorias e mercado". A empresa conta com três sócios fundadores e mais de cinco pessoas atuando no negócio. Formação acadêmica do sócio/fundador respondente: Especialização/MBA.

A empresa GAMA criou uma plataforma para prover informações sobre operações de câmbio das principais moedas, cotando, comparando e proporcionando ao usuário a possibilidade de buscar a melhor cotação em tempo real e finalizar a compra das referidas operações. $O$ serviço foi desenvolvido para os mercados nacional e internacional. A empresa foi fundada em janeiro de 2015 tendo três sócios fundadores à frente e atuando no negócio. Ingressou no processo de aceleração em março de 2015 para buscar suporte em "acompanhamento, mentorias e espaço colaborativo", afirmou o sócio fundador respondente. Formação acadêmica do sócio/fundador respondente: Graduação.

A empresa DELTA desenvolveu uma plataforma para oferecer planos de assinatura de forma acessível, para que profissionais de várias áreas possam utilizar estações de trabalho e salas de reunião em diversos co-workings e em vários pontos do país, permitindo uma flexibilização e ampliação das áreas de atuação destes profissionais sem a necessidade de aumento dos custos de estrutura física. O serviço foi desenvolvido para os mercados nacional $\mathrm{e}$ internacional. Com dois sócios fundadores atuando à frente dos negócios, a empresa foi fundada em outubro de 2014. A empresa ingressou no processo de aceleração em agosto de 2015, segundo o sócio fundador respondente "pela oportunidade de ter um acompanhamento de mentores e aprender um processo de inovação (muito do que aprendemos no Nave usamos até hoje) ". Formação acadêmica do sócio/fundador respondente: Graduação.

Em certa medida, os serviços ofertados pelas empresas podem ser categorizados, segundo definição da Pesquisa de Inovação Tecnológica PINTEC (IBGE, 2014), como uma inovação para a empresa, que é quando o produto ou serviço já existe no mercado, mas é novo para a empresa.

\section{2 - Apresentação e Análise do Processo de Aceleração}

Neste item são analisadas as informações fornecidas pelos respondentes, referentes à intensidade no uso dos 
serviços disponibilizados pelo ESPAÇO NAVE durante o processo de aceleração (nunca, pouco, médio ou muito).

Tais serviços são identificados na literatura como sendo essenciais para o processo de desenvolvimento do produto ou serviço de uma startup.

\section{Espaço Físico:}

Em relação ao nível de intensidade no uso do espaço físico disponibilizado pelo ESPAÇO NAVE, apenas a empresa ALFA informou ter usado pouco o referido espaço por já utilizar outra infraestrutura física disponível a eles. As demais empresas informaram que a infraestrutura física disponibilizada foi muito útil para a realização de reuniões, pitchs, gravação de vídeos etc. De forma geral, os respondentes veem no espaço físico um fator importante para o desenvolvimento das atividades, confirmando a afirmação de diversos autores sobre a importância da infraestrutura física para o bom andamento do processo de aceleração.

\section{Apoio à definição do negócio:}

Para as empresas ALFA, BETA e DELTA o apoio à definição do negócio foi muito importante, seja no melhoramento ou até mesmo no realinhamento do produto/serviço ao mercado. Conforme depoimentos, percebe-se que este tipo de suporte de uma aceleradora é de suma importância no momento inicial do processo de aceleração:

\begin{abstract}
"O Espaço NAVE nos ajudou com mentorias e reuniões sobre nosso negócio, mostrando falhas e
\end{abstract} apresentando possibilidades". (E. BETA)

\section{"Ajudou bastante a pensar fora da caixa, já que o negócio em si surgiu de outro que eu tive no passado". (E. DELTA)}

Já para a empresa GAMA o apoio à definição do negócio foi de média intensidade, uma vez que os sócios já tinham bem definido o serviço e o mercado que iriam atuar. Com exceção da empresa GAMA, verificou-se, para as demais empresas, a importância da aceleradora na contribuição, na definição ou no realinhamento do negócio.

\section{Treinamento:}

Assim como no item anterior, as empresas ALFA, BETA e DELTA classificaram como "muito" o nível de intensidade no uso do serviço de treinamento, que contempla cursos, palestras, workshops etc., ratificando a importância, qualificação e aprendizado contínuo dentro do processo de aceleração. A empresa ALFA classificou como excelente a maioria dos treinamentos recebidos, e a empresa BETA complementou que teve a oportunidade de contato com instrutores habilidosos e em diferentes áreas. Já a empresa DELTA informou que o treinamento:

\section{"Ajudou a gente a entender a importância de ter processos bem definidos, sem contar a oportunidade de aprender com gente mais experiente que a gente." (E. DELTA)}

Quanto a empresa GAMA, esta informou que no quesito treinamento o nível de intensidade na utilização deste serviço disponibilizado pela Aceleradora de Negócios foi médio, porém, não detalhou os motivos. Para três das quatro startups respondentes o treinamento foi classificado como muito importante no processo de aceleração, confirmando o que a literatura aponta.

\section{Mentorias:}

Foi informado como "muito" o nível de intensidade na utilização do serviço de mentorias pelos quatro respondentes. No detalhamento e comentários acerca da qualidade ou da frequência das mentorias, as empresas informaram, com exceção da empresa GAMA, que as mesmas foram fundamentais para o processo, sendo ricas e sempre focadas no momento em que a startup se encontrava e, por último, que todas as mentorias agregaram de alguma forma ao projeto do negócio.

Corroborando com a afirmação de diversos autores, fica evidenciado pelas informações dos respondentes que o serviço mentorias teve extrema importância no processo de aceleração e desenvolvimento das startups respondentes.

\section{Network:}

A empresa ALFA informou ter um nível médio de network durante $\mathrm{o}$ período de aceleração, porém complementou que, mesmo tendo este nível médio de contatos, os que foram mantidos classificou como excelentes. As empresas BETA, GAMA e DELTA informaram intensidade muito alta de contatos no período de aceleração, porém apenas a empresa GAMA não detalhou como foram ou que importância tiveram estes contatos. As empresas BETA e DELTA complementaram com as seguintes observações:

\begin{abstract}
"Toda semana tínhamos a presença de empreendedores, investidores e até mesmo delegações internacionais no espaço". (E. BETA)

"Nada tem mais valor que ter a confiança das pessoas. Através do Espaço Nave, consegui estabelecer alguns relacionamentos que até hoje se agregam, mutuamente". (E. DELTA)
\end{abstract}

Apesar da empresa GAMA ter realizado muitos contatos, mas não ter detalhado como foi a experiência de network durante o processo de aceleração,verificou-se que este serviço foi considerado fundamental para todas as startups respondentes, não apenas durante a passagem pelo ESPAÇO NAVE como também no pós-aceleração, confirmando assim o que a literatura apresenta.

Clientes (apoio para identificação de mercado potencial):

As startups respondentes demonstraram uma menor intensidade do uso deste serviço de apoio à identificação de mercado potencial. A empresa ALFA informou nunca ter demandado este serviço, detalhando que já haviam mapeado o mercado que iriam atuar. Já a empresa DELTA informou que, mesmo utilizando pouco este serviço, esta etapa do programa de aceleração "ajudou a explorar outros mercados, potenciais clientes, que não estavam no nosso radar".

Com relação às empresas BETA e GAMA, estas informaram que o nível de intensidade no uso deste serviço foi médio e apenas a empresa BETA detalhou sua experiência, complementando que uma etapa do programa era focada na identificação de clientes e parceiros para o negócio e que a aceleradora ajudou no processo de pesquisa de mercado e processo de comercialização.

Tendo por base as informações das empresas ALFA, BETA e DELTA,inferiu-se que esta etapa, apesar de alguns comentários positivos, não se mostrou impactante para as startups como as até aqui apresentadas. 
Em função das respostas há uma fragilidade ou uma contribuição efetiva na preparação dos empreendedores e suas startups em aspectos ligados especificamente ao processo de comercialização (clientes, mercados, técnicas de vendas/abordagens etc.).

\section{Financiamento (apoio e acesso a investidores):}

Em relação a apoio e acesso a investidores as startups respondentes informaram, de maneira geral, um nível baixo de intensidade na utilização deste serviço, ou seja, na busca ou aproximação a investidores: E. ALFA (nunca), E. BETA (médio), E. GAMA (nunca) e E. DELTA (não se aplica), cabendo assim descrever suas respectivas justificativas, ressaltando que a E. GAMA não deu nenhuma informação complementar.

\section{"Não tínhamos interesse". (E. ALFA) \\ "Tivemos mais de 2 cursos sobre captação de recurso através de investimento e outros programas". (E. BETA) \\ "Apesar de termos tido contato com investidores, não chegamos a buscar efetivamente investimento por conta da maturidade do projeto. Mas sei que outras startups conseguiram avançar neste sentido". A Aceleradora "...ajudou a entender como "modelar" a parte financeira para apresentar a investidores". (E. DELTA)}

Assim como no processo de comercialização, uma fragilidade em relação ao acesso a investidores e até mesmo no tratamento de temas relacionados à gestão financeira pôde ser percebido, podendo se inferir pelo depoimento do empreendedor da empresa DELTA que os projetos não se encontravam em estágio apropriado.

\section{Funcionário/colaboradores (apoio à estruturação de equipe)}

Em relação ao apoio da aceleradora na formação e estruturação de equipes nas startups respondentes, percebeuse que este serviço praticamente não foi demandado, tendo como principal justificativa por parte delas já terem equipe formada.

Pelo resultado das entrevistas verificou-se que os próprios sócios e fundadores atuam à frente dos negócios, não tendo assim a necessidade, pelo estágio inicial dos negócios, da contratação de equipe.

Importante observar que, como será descrito mais adiante quando da análise do desempenho das startups, o número de pessoas trabalhando efetivamente na equipe e no projeto influencia no resultado, cabendo então neste caso uma maior atenção das aceleradoras no dimensionamento dessas equipes em relação ao tamanho do projeto quando de um processo de seleção de novas startups.

\section{Sobre possíveis demandas não atendidas:}

Perguntados se houve alguma demanda por parte da startup ou equipe que não compunha o escopo do modelo de aceleração adotado pelo Espaço NAVE, as empresas ALFA, BETA e GAMA informaram não ter havido nenhuma demanda extra e, apenas a empresa DELTA informou ter sentido a necessidade de "maior apoio para participação em feiras ou eventos" e "networking mais intenso junto a empresários e mercado".

\section{3 - Apresentação e Análise de Variáveis de Desempenho}

Nesta seção serão apresentadas e analisadas variáveis de desempenho das startups entrevistadas, comparando as informações prestadas nas entrevistas com os indicadores encontrados na literatura, em especial das empresas do estudo da ABRAII (2015).
Figura 2 - Comparativo Indicadores e dados da pesquisa ABRAII com respondentes da pesquisa

\begin{tabular}{|c|c|c|c|c|c|c|}
\hline \multirow[b]{2}{*}{ INDICADOR } & \multicolumn{2}{|c|}{ Pesquisa ABRAII } & \multicolumn{4}{|c|}{ Pesquisa ESPAC̣O NAVE } \\
\hline & Sem aceleração & Com aceleraçào & ALFA & BETA & GAMA & DELTA \\
\hline Tempo validação do produto/serviço & 482 dias & 334 dias & 365 dias & 183 dias & 183 dias & 183 dias \\
\hline Número de fundadores por startup & $\mathrm{n} / \mathrm{d}$ & 2* & 2 & 3 & 3 & 2 \\
\hline Número de empregos gerados & $n / d$ & $2^{*}$ & 3 & 1 & 0 & 0 \\
\hline$\%$ crescimento faturamento & $4,20 \%$ & $21,4 \% *$ & $>30 \%$ & $>30 \%$ & $0 \%$ & $0 \%$ \\
\hline Break-eren point & $n / d$ & $23,00 \%$ & $n / d$ & $\mathrm{n} / \mathrm{d}$ & $\mathrm{n} / \mathrm{d}$ & $n / d$ \\
\hline $\begin{array}{c}\text { Investimentos direto e/ou lerantado } \\
\text { com apoio de aceleradoras ouß } \\
\text { proposta de aporte* }\end{array}$ & n/d & R\$320.000,00* & Não & Proposta & Proposta & Não \\
\hline
\end{tabular}

Fonte: Elaborado pelos autores (2016).

\section{Produto (tempo de desenvolvimento do produto e/ou serviço)}

Em relação a este quesito, a empresa ALFA foi a única que teve o tempo de validação do produto/serviço em tempo médio(365 dias),semelhante aos encontrados na literatura,as demais, BETA, GAMA e DELTA conseguiram validar seus produtos/serviços com praticamente metade do tempo (183 dias) da empresa ALFA e das empresas da pesquisa ABRAII.

Sobre estes resultados, duas considerações são importantes:

O produto/serviço da empresa BETA não existia quando do início do processo de aceleração, e ainda assim ela validou-o em tempo inferior ao da empresa ALFA. Pode-se fazer uma inferência de que o número de pessoas envolvidas no processo de desenvolvimento pode ter colaborado para este prazo, uma vez que, ao contrário das empresas GAMA (3 pessoas) e DELTA ( 2 pessoas)que tiveram apenas os fundadores atuando no projeto, a empresa BETA teve a participação dos três fundadores mais um colaborador, totalizando quatro pessoas na equipe;

A empresa ALFA é a que tinha à época o maior número de pessoas envolvidas com o desenvolvimento do produto/serviço (5 pessoas), porém como citado no item 4.3 (Caracterização das Startups) deste trabalho, o produto/serviço da empresa ALFA é mais complexo. Ainda assim, o tempo de validação se equivale ao das empresas da pesquisa da ABRAII (2016). Podemos inferir que em relação ao desenvolvimento e validação do produto a passagem das startups pela aceleradora foi exitosa quando comparada aos números da pesquisa com 266 startups feita pela ABRAII (2016).

\section{Geração de empregos}

Apenas duas das startups respondentes informaram ter contratado colaboradores para compor equipe junto com os fundadores, a empresa ALFA, três pessoas, e a empresa BETA, uma pessoa, mantendo assim uma similaridade com a média encontrada no estudo da ABRAII (2016) e, de certa forma, em concordância com a literatura.

\section{Volume de vendas - crescimento de faturamento}

Das quatro startups respondentes, três delas (BETA, GAMA e DELTA) informaram que não tinham nenhum tipo de faturamento no período pré-aceleração. A empresa ALFA não respondeu se havia faturamento, mas perguntada se caso tivesse faturamento se houve crescimento após a entrada no processo de aceleração, a resposta foi SIM, sugerindo, assim, ter havido.

O crescimento no faturamento informado pela empresa ALFA foi de mais de $30 \%$, número superior à média identificada no estudo da ABRAII (2016) que foi de $21,44 \%$. Neste contexto, a variável aumento do faturamento 
se confirma como indicador muito importante, tanto na literatura apresentada como no estudo acima citado, validando a contribuição da aceleradora para as startups neste quesito.

Informaram não ter havido crescimento durante ou no pósaceleração as empresas BETA, GAMA e DELTA. Em entrevista complementar, o empreendedor da empresa ALFA contribuiu com o seguinte comentário: "muitas empresas não conseguem iniciar a geração de receita pois geralmente o produto não está pronto para o mercado".

\section{Clientes ativos - base de clientes}

Em todas as quatro startups houve crescimento do número de clientes após o ingresso no programa de aceleração do Espaço NAVE. Apesar dos respondentes não terem quantificado este crescimento, isto confirma a contribuição da aceleradora neste quesito.

\section{Ponto de equilíbrio - atingimento do break-even point}

A empresa ALFA informou ter atingido o ponto de equilíbrio após 12 meses e a empresa GAMA em 6 meses. Importante ressaltar que estes prazos de 12 e 6 meses são, respectivamente, o mesmo prazo que estas empresas levaram para modelar e validar seus produtos na aceleradora, confirmando assim a efetiva contribuição, nestes casos, da aceleradora para estes resultados.

A empresa BETA informou não ter alcançado o ponto de equilíbrio durante o processo de aceleração, mesmo tendo neste período um crescimento de mais de $30 \%$ em seu faturamento. $\mathrm{O}$ motivo específico não foi informado pela startup, porém uma inferência pode ser feita: diferentemente da empresa ALFA, por exemplo, que ao captar um novo cliente tem receita recorrente (mensal) do mesmo cliente pela prestação do serviço, o modelo de negócio informado pela empresa BETA sugere não haver receita recorrente (mensal) por cliente, gerando assim, nesta fase inicial do negócio, provavelmente um fluxo de caixa negativo. A empresa DELTA não teve faturamento tanto nos períodos pré como duranteo processo de aceleração, desta forma não alcançou o ponto de equilíbrio.

\section{Investimento - aporte ou proposta de aporte recebida}

As empresas ALFA e DELTA informaram não ter recebido nenhuma proposta de aporte ou investimento no período de aceleração, mesmo tendo a empresa ALFA apresentado seu produto/serviço em mais de um evento demo-day ou pitch. As empresas BETA e GAMA informaram ter recebido proposta de aporte financeiro, mas não detalharam as condições ou cifras. Para uma destas startups (BETA) houve a apresentação do produto/serviço em mais de um evento demo-day ou pitch.

A empresa GAMA recebeu proposta de aporte sem ter apresentado seu produto em mais de um evento, inferindo-se que pode não haver uma relação direta entreapresentação em eventos (demo-day ou pitchs) e proposta de investimento.

\section{Sobrevivência - permanência no mercado}

No caso das startups que passaram pelo processo de aceleração do Espaço NAVE, apenas a empresa BETA (que ainda se mantém ativa no mercado com outro produto) informou que o produto/serviço que foi validado e desenvolvido no processo de aceleração não está mais no mercado.

As empresas ALFA, GAMA e DELTA informaram que seus produtos/serviços ainda se encontram no mercado, como já informado anteriormente, mesmo que em algumas não tenha sido atingido o ponto de equilíbrio ou recebido aporte financeiro.
Todas as quatro empresas informaram estarem ativas no mercado e as empresas BETA e GAMA complementaram estar com outro produto, mas preferiram não informar detalhes por envolver confidencialidade. O prosseguimento de três dos quatro produtos/serviços que passaram pela aceleradora permite inferir que o processo de aceleração contribuiu de alguma forma nesta manutenção.

\section{CONCLUSÃO}

De acordo com as respostas obtidas com a pesquisa junto às quatro empresas que passaram pelo processo de aceleração do Espaço NAVE, pode-se concluir que a contribuição oferecida pelo Núcleo de Aceleração e Valorização da Estácio (Espaço NAVE) para o desempenho de startups participantes de seus programas de aceleração de negócios foi,em especial, exitosa para a empresa ALFA, conforme se verifica abaixo:

4.1 Serviços Disponibilizados pelo Processo de Aceleração

Em relação ao primeiro objetivo intermediário, levantamento dos serviços disponibilizados no processo de aceleração do Espaço NAVE, conclui-se que os mesmos são bem similares àqueles encontrados na literatura $\mathrm{e}$ apresentados no referencial teórico, porém, a intensidade do uso destes serviços por parte dos empreendedores variou. As respostas confirmam que os serviços ofertados: "Espaço Físico", "Apoio à Definição do Negócio", "Treinamento", "Mentorias" e "Network" foram bastante utilizados pelas startups que passaram pelo processo de aceleração. Uma inferência que se pode fazer em relação ao bom nível de utilização destes serviços é a de que estes, para se efetivarem, dependem unicamente da participação dos empreendedores e da aceleradora, sem muita interação direta com o mercado.

A análise das respostas ligadas a serviços relacionados aos quesitos clientes (apoio para identificação de mercado potencial), financiamento (apoio a acesso a investidores) e funcionários/colaboradores (apoio à estruturação de equipe) permitiu concluir que o nível de intensidade na utilização dos mesmos por parte das startupsfoi menor. Estes três quesitos estão fortemente ligados à estruturação e preparação de equipe e aproximação com o mercado a ser explorado pela startup e, consequentemente, à geração de negócios e receita, o que permite inferir que estes quesitos não teriam contribuído de forma satisfatória para o desempenho das empresas aceleradas.

Figura 3 - intensidade do uso dos serviços

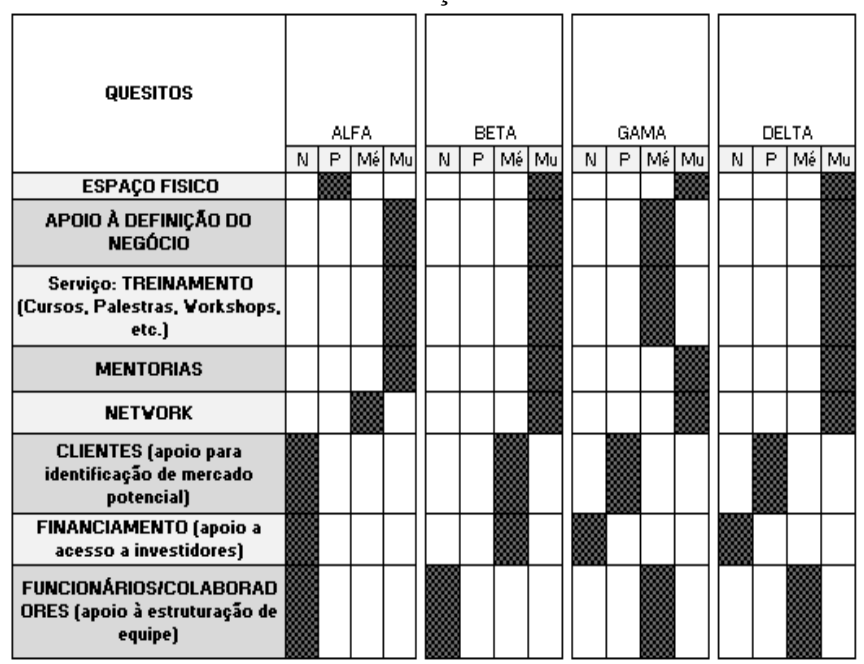


$\mathrm{N}=$ Nunca $\mathrm{P}=$ Pouco Mé=Médio Um=Muito

Fonte: Elaborado pelos Autores (2017)

\subsection{Desempenho Alcançado com a Participação no programa de Aceleração}

Em relação ao segundo objetivo intermediário, analisar o desempenho alcançado pelas startups com a participação no programa de aceleração, os resultados permitiram concluir que a aceleradora contribuiu mais fortemente para a startup ALFA. Isto ocorreu especialmente nos quesitos: "Tempo de Validação do Produto", "Geração de Emprego", "Início e Crescimento de Faturamento Durante o Processo de Aceleração", "Atingimento do Ponto de Equilíbrio", "Crescimento do Número de Clientes" e "Permanência da Empresa no Mercado".

Mister se torna reconhecer que na startup ALFA o número de pessoas envolvidas no desenvolvimento do produto/serviço foi de 5 pessoas, enquanto que nas empresas BETA, GAMA e DELTA foi de 3, 3 e 2 respectivamente, o que sugere que equipes maiores podem contribuir para um melhor desempenho.

Outro ponto que permitiu diferenciar o desempenho as empresas, é o fato da empresa ALFA ter "apresentado seus produtos/serviços em outros eventos" fora do ambiente do Espaço NAVE, o que sugere perfil empreendedor mais arrojado nesta startup.

Sobre a empresa BETA a análise das respostas permite inferir que o fato desta startup ter sido a única entre as entrevistadas que não tinha um produto modelado antes de ingressar no processo de aceleração pode ter contribuído para o não atingimento do "ponto de equilíbrio" e para a "manutenção do produto no mercado" após o processo.

Quanto ao desempenho das empresas GAMA e DELTA, os resultados sugerem que não houve s evolução satisfatória durante o processo de aceleração. Apesar de a empresa GAMA ter começado a faturar durante o processo de aceleração, o que lhe permitiu atingir o "ponto de equilíbrio" não houve "geração de emprego" nem "crescimento no faturamento", quesitos estes em que a empresa DELTA também apresentou baixo desempenho.

Figura 4 - Analise Do Desenvolvimento E Desempenho Do

\begin{tabular}{|c|}
\hline QUESITOS \\
\hline $\begin{array}{c}\text { Quantos meses transcorreram } \\
\text { entre o inicio do } \\
\text { projeto/modelagem do negócio até } \\
\text { a validadação do produto? }\end{array}$ \\
\hline
\end{tabular}
Negócio

\begin{tabular}{|c|c|c|c|}
\hline \multicolumn{2}{|c|}{ ALFA } & \multicolumn{2}{|c|}{ BETA } \\
\hline $6 \mathrm{~m}$ & $12 \mathrm{~m}$ & $6 \mathrm{~m}$ & $12 \mathrm{~m}$ \\
\hline & & & \\
\hline & & & \\
\hline & & \\
\hline
\end{tabular}

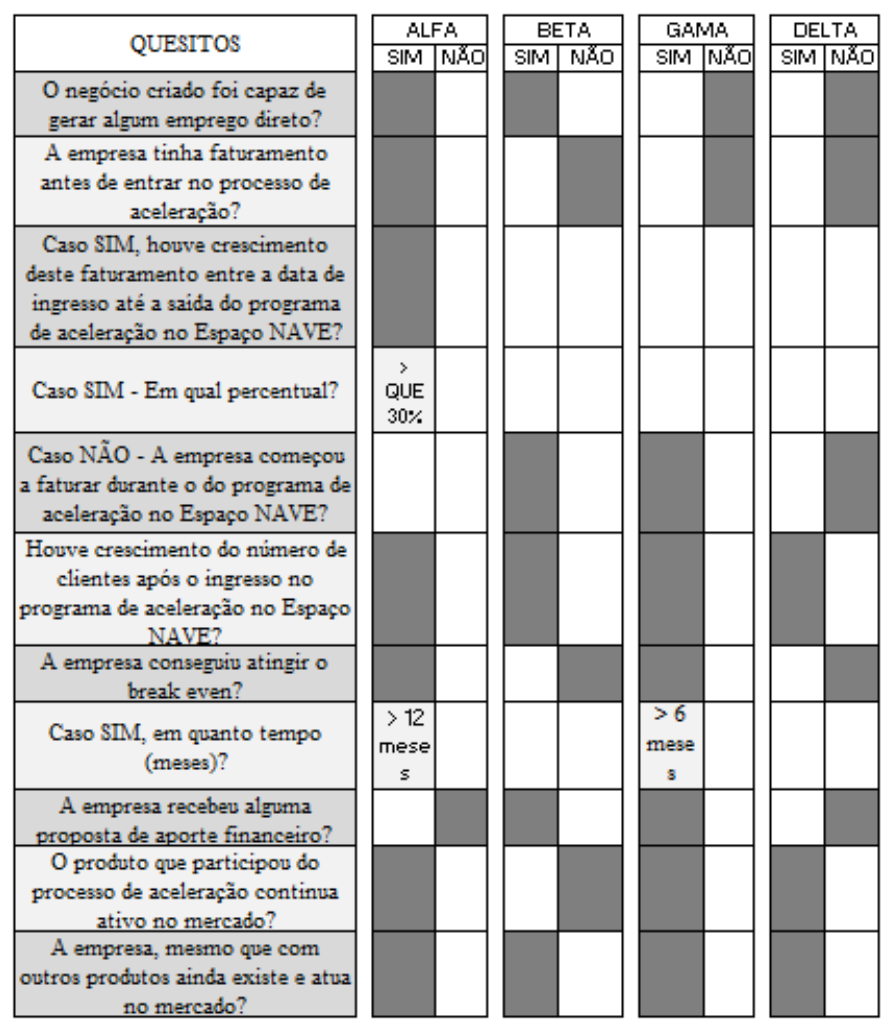

Fonte: Elaborado pelos Autores

Finalizando, dentre as quatro startups que participaram do estudo a empresa ALFA foi a que mais se destacou tanto quanto à utilização dos serviços disponibilizados quanto ao desempenho. Deve-se reconhecer, entretanto, que esta empresa se diferenciava em relação às demais startups participantes do estudo no que diz respeito ao: nível mais maduro do produto/serviço principal da empresa quando da entrada no processo de aceleração, possuir equipe mais numerosa e mercado potencial e também maduro para produto/serviço oferecido (plataforma para cursos a distância). Estes diferenciais podem ter influído no desempenho da startup e, consequentemente, no seu resultado positivo.

Outra empresa que apresentou um bom nível de utilização dos serviços disponibilizados pela aceleradora, bem como um bom desempenho na evolução da startup em termos de geração de emprego e crescimento da receita, mesmo não tendo o produto tão maduro quanto a empresa ALFA, foi a empresa BETA.

Como pontos comuns entre estas duas startups observa-se o número de pessoas envolvidas (equipes maiores) no desenvolvimento do produto/serviço (cinco) e o fato de os empreendedores possuírem pós-graduação, sendo mestrado para o empreendedor da empresa ALFA e MBA para o da empresa BETA.

Esta última constatação sugere que um maior nível de formação acadêmica pode contribuir no aproveitamento dos serviços disponibilizados por uma aceleradora e consequentemente no desempenho do negócio.

Em um estudo empírico realizado para avaliar se aceleradoras de fato contribuem para o desempenho de empresas que participam de programas de aceleração, Hallen, Bingham e Cohen(2014) concluíram que, embora para algumas startups o processo de aceleração possa contribuir para o desempenho do negócio, não há como generalizar, e argumentam ainda que o sucesso destes programas depende de uma combinação complexa de capital 
humano, redes e experiência, que deve ser construída ao longo do tempo.

\section{REFERÊNCIAS BIBLIOGRÁFICAS}

ABRAII - ASSOCIAÇÃO BRASILEIRA DE EMPRESAS ACELERADORAS DE INOVAÇÃO E INVESTIMENTO. Levantamento aceleradoras 2012 a 2014. Disponível em: $<$ http://startupi.com.br/wpcontent/uploads/2015/07/ABRAII_em_numeros.pdf> Acesso em: 25 jun. 2016.

ABREU, P. R. M.; CAMPOS N. M. O PANORAMA DAS ACELERADORAS DE STARTUPS NO BRASIL. CreateSpace Independent Publishing Plataform. USA, 2016. Disponível em: <http://www.imcgrupo.com/impress/gt/upload/O_Panaroma _das_Aceleradora_de_St artups_no_Brasil.pdf $>$ Acesso em: 22 jun. 2017.

DACORSO, A. L. R. Tomada de Decisão e Risco: A Administração da Inovação em Pequenas Indústrias Químicas. 2000. 236f. Tese (Mestrado em Administração) Departamento de Administração da Faculdade de Economia, Administração e Contabilidade, Universidade de São Paulo - FEA-USP, São Paulo-SP.

HALLEN, B. L.; BINGHAM, C. S.; COHEN, S. "Do Accelerators Accelerate"? A Study of Venture Accelerators as a Path to Success. Academy of Management Annual Meeting Proceedings; v1, p. 747, 2014

MEIRELLES, D. C. Inovação e Aprendizado Coletivo: interação e cooperação de empresas de base tecnológica em incubadoras de empresas. / São Paulo: Saraiva, 2012, capítulo 5, pp 79-89.

METCALFE, S. O empreendedor e o estilo da economia moderna. In Brasil em Desenvolvimento Vol 1 economia, tecnologia e competitividade, Orgs Ana Célia Castro \& Outros, Rio de Janeiro: Civilização Brasileira, 2005, Parte IV, pp, 385-417.

SCHUMPETER, J. A . A Teoria do Desenvolvimento Econômico. Trad. Maria Silvia Possas, São Paulo: Nova Cultural, 1985 (1911).๑

\section{COPYRIGHT}

Direitos autorais: $\mathrm{O}(\mathrm{s})$ autor(es) é(são) o(s) único(s) responsável(is) pelo material incluído no artigo. 
Volume 14 - No 159 - Março/2019.

XL International Sodebras Congress

10 a 12 de dezembro de 2018 - Vitória - ES.

\title{
ANÁLISE DA CONTRIBUIÇÃO DO CURSO DE ADMINISTRAÇÃO NOTURNO DA UFES PARA A FORMAÇÃO DE EMPREENDEDORES POR MEIO DOS PROGRAMAS DAS DISCIPLINAS
}

\author{
ANALYSIS OF THE CONTRIBUTION OF THE NORTH ADMINISTRATION \\ COURSE OF UFES FOR THE TRAINING OF ENTREPRENEURS BY MEANS \\ OF DISCIPLINARY PROGRAMS
}

\author{
LORRARA SILVYA IMAGAWA DE OLIVEIRA'; RUBENS DE ARAÚJO AMARO.
}

1 - UFES - UNIVERSIDADE FEDERAL DO ESPÍRITO SANTO.

lorrara.imagawa@gmail.com; rubens.amaro@ufes.br

\begin{abstract}
Resumo - Empreender está cada vez mais presente nos objetivos profissionais dos alunos que buscam a formação no curso de Administração. $O$ objetivo deste artigo é analisar como o curso de administração noturno da UFES - Universidade Federal do Espírito Santo - contribui para a formação de empreendedores. Foi realizada uma pesquisa qualitativa documental, tendo como corpus de análise o projeto pedagógico do curso e os programas das disciplinas. Os dados foram analisados por meio de categorização temática (GIBBS, 2009). Os resultados mostram que o curso promove um desenvolvimento da formação do empreendedor de modo geral. Conclui-se que o curso carece de disciplinas e metodologias específicas para fomentar esse processo. Surge a possibilidade de pesquisas futuras a partir da perspectiva dos alunos e dos professores, para identificar o que vem sendo trabalhado sobre empreendedorismo para além do projeto pedagógico e do programa das disciplinas.
\end{abstract}

Palavras-chave: Empreendedorismo. Educação empreendedora. Ensino do empreendedorismo. Graduação em administração.

\begin{abstract}
Entrepreneurship is increasingly present in the professional goals of students who seek training in the Administration course. The objective of this article is to analyze how the evening administration course of UFES - Federal University of Espirito Santo - contributes to the formation of entrepreneurs. A qualitative documentary research was carried out, having as corpus of analysis the pedagogical project of the course and the programs of the disciplines. The data were analyzed through thematic categorization (GIBBS, 2009). The results show that the course promotes a development of the formation of the entrepreneur in general. It is concluded that the course lacks specific disciplines and methodologies to foster this process. The possibility of future research from the perspective of the students and the teachers, to identify what has been worked on entrepreneurship beyond the pedagogical project and the program of the disciplines is emerging.
\end{abstract}

Keywords: Entrepreneurship. Entrepreneurial training. Teaching of entrepreneurship. Degree in administration.

\section{INTRODUÇÃO}

O empreendedorismo tem sido proposto como alternativa viável para tornar os países mais dinâmicos, desenvolver um rápido crescimento econômico e diminuir as taxas de desemprego (DORNELAS, 2015). Estimular o espírito empreendedor torna-se uma opção adequada e vantajosa, em vez de formar profissionais apenas para ocupar postos no mercado de trabalho.

Segundo Dolabela (2008) o termo empreendedorismo pode variar de acordo com seu contexto histórico, sendo nos dias de hoje os feitos inovadores e criativos de qualquer pessoa dedicada, crítica, persistente e comprometida que esteja em uma empresa ou tenha um negócio próprio. Drucker (2003) afirma que empreendedor é o indivíduo que inicia seu negócio criando um novo conceito ao produto ou serviço ofertado. O ensino do empreendedorismo deve englobar atividades ligadas a práticas que farão parte cotidiano do empreendedor, dentre outras: solução de problemas; realizar trabalhos e tomar decisões sob pressão; e identificar oportunidades (DOLABELA, 2008). Ismail, Sawang e Zolin (2018) afirmam a maneira como as atividades são ensinadas influenciam na aprendizagem do empreendedorismo e Bell e Bell (2018) demostram que o desenvolvimento para se tornar empreendedor a partir da graduação tem sido limitada. É necessário o uso de práticas inovadoras e criativas para promover o ensino da teoria e consolidar a aprendizagem prática dos alunos (CARDOW, SMITH, 2015; DZISI, ODOOM, 2017; KASSEAN, et al., 2015; OKEKE, YONG, 2016).

Segundo o relatório da pesquisa Global Entrepreneurship Monitor (GEM) atualmente 36\% dos brasileiros possuem um negócio ou realizaram alguma ação em 2015 para ser dono da sua própria empresa (SEBRAE, 2017). Empreender está cada vez mais presente nos objetivos profissionais dos alunos que buscam a formação no curso de Administração (LIMA, et al., 2015). O processo de empreender pode ser ensinado e envolve ações como identificar e avaliar a oportunidade, por meio da criação e percepção de oportunidades e valores. Consiste em desenvolver um plano de negócios com a equipe de gestão, fazendo uma análise de mercado, marketing, estrutura e plano financeiro. Determinar e captar os recursos necessários por meio de finanças pessoais, bancos, governo ou incubadoras. Gerenciar a empresa criada, considerado um fator crítico de sucesso, com a determinação do estilo de 
gestão profissional e sistemas de controle (DORNELAS, 2015; FILION, 1999; SEBRAE, 2017).

O Conselho Nacional de Educação - CNE, em sua resolução $\mathrm{n}^{\mathrm{o}} 4$ de 13 de julho de 2005, exige que a organização do curso de Administração deve ser oficializada por meio do projeto pedagógico do curso, apresentando diretrizes que informam o perfil desejável do aluno em relação às competências e habilidades. $\mathrm{O}$ projeto deve conter também os componentes curriculares, o estágio curricular supervisionado, as atividades complementares, o sistema de avaliação, o projeto de iniciação científica ou o projeto de atividade, bem como trabalho de conclusão de curso. A resolução exige que as instituições de nível superior, por meio dos cursos de Administração, formem alunos aptos a terem iniciativa, criatividade, determinação, capacidade de tomar decisões e ser adaptável a situações diversas (CNE, 2005). Essas características podem ser associadas ao processo do empreendedorismo (DOLABELA, 2008; DORNELAS, 2015).

Este trabalho investigou por meio da análise do projeto pedagógico e dos programas das disciplinas: como o curso de administração noturno da UFES - Universidade Federal do Espírito Santo contribui para a formação de empreendedores? Para responder o problema de pesquisa, esse estudo tem como princípios norteadores os seguintes objetivos específicos: analisar o projeto pedagógico do curso de administração noturno da UFES e suas relações com o empreendedorismo; e levantar relações das disciplinas do curso com o processo de empreendedorismo. Esse tema justifica-se devido à sua relevância social e acadêmica por meio da produção de novos conhecimentos norteadores para a formação de indivíduos que contribuam com o desenvolvimento econômico do país.

\section{METODOLOGIA}

Os procedimentos metodológicos adotados no estudo são apresentados, resumidamente, na figura 01 e detalhados a seguir.

Figura 01 - Procedimentos metodológicos

\begin{tabular}{|c|c|c|c|c|}
\hline Objetivo & Metodologia & Tipo de pesquisa & Coleta de dados & Investigação de dados \\
\hline $\begin{array}{l}\text { Contribuição do curso } \\
\text { da Administração } \\
\text { UFES para a formação } \\
\text { de empreendedores }\end{array}$ & $\begin{array}{l}\text { Qualitativa descritiva } \\
\text { exploratória }\end{array}$ & Documental & $\begin{array}{l}\text { Projeto pedagógico e } \\
\text { programas das } \\
\text { disciplinas }\end{array}$ & Análise de dados \\
\hline
\end{tabular}

Fonte: elaboração dos autores, 2018.

Este estudo é classificado como uma pesquisa qualitativa de caráter descritivo e documental. A pesquisa descritiva, segundo Gil (2008), tem a finalidade de propiciar a descrição das características de determinada população ou fenômeno. Segundo Vergara (2005), a pesquisa caracterizase como documental por ser realizada por meio de documentos institucionais. O corpus de análise desse estudo foi o projeto pedagógico e os programas das disciplinas do curso de Administração noturno da UFES. Os dados foram analisados por meio de categorização temática (GIBBS, 2009).

O curso superior em Administração noturno da UFES faz parte do Centro de Ciências Jurídicas e Econômicas CCJE - e foi criado por meio do Programa de Apoio aos Planos de Reestruturação e Expansão das Universidades Federais (REUNI), possibilitando o acesso de alunos que optam ou necessitam estudar no turno noturno. O curso é oferecido desde o segundo semestre do ano de 2009 e tem duração de 4,5 anos na modalidade presencial, conferindo titulação de Bacharel em Administração (UFES, 2018).

Dentre os objetivos, o curso busca formar profissionais aptos para organizar, planejar, comandar e controlar o andamento das organizações públicas, privadas e sociais, buscando o crescimento da rentabilidade e da produtividade e o controle dos resultados, em todas as áreas da Administração. O conteúdo do curso se divide em disciplinas de formação básica, profissional, quantitativa, tecnológica e complementar (UFES, 2007). Todas as disciplinas do curso foram analisadas em, pelo menos, um dos anos propostos. Em cada semestre é oferecido uma quantidade de disciplinas atreladas à organização das demandas das turmas, devido a isso, o ano de 2018 tem menos disciplinas ofertadas pelo programa e analisadas nesse estudo, conforme figura 02 e 03.

As Atividades Complementares têm por objetivo estimular o aprendizado e desenvolvimento de habilidades adquiridas proporcionando a diversificação e o enriquecimento do perfil do aluno. O estágio supervisionado deve possibilitar a oportunidade de vivenciar aspectos práticos relevantes à formação profissional e a aplicação dos conhecimentos adquiridos em sala, sendo exposto a situações técnicas, científicas, sociais e culturais (UFES, 2007).

Figura 02 - Disciplinas do projeto de curso de 2013

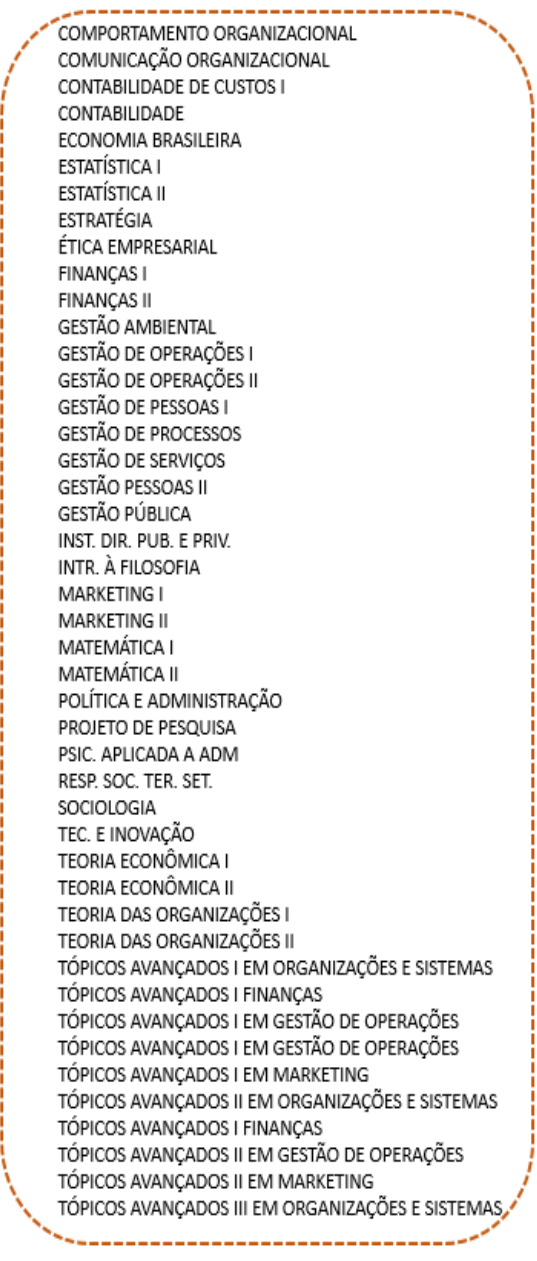

Fonte: elaboração dos autores, 2018. 
Figura 03 - Disciplinas do projeto de curso de 2018.

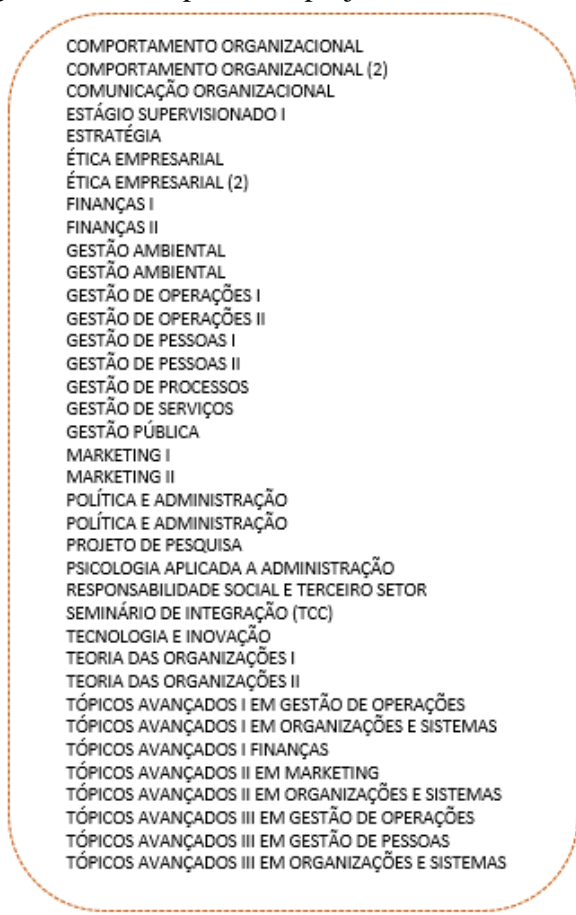

Fonte: elaboração dos autores, 2018.

Dentre as modalidades de trabalho de conclusão de curso, estão: monografia; relatório de pesquisa de iniciação científica; artigo apresentado em evento internacional de administração e/ou publicado em revista estrangeira especializada na área de administração; dois artigos apresentados em eventos de administração e/ou publicados em revistas nacionais especializadas na área de administração; plano de negócios; plano estratégico; relatório técnico; produção técnica (UFES, 2007).

$\mathrm{O}$ projeto pedagógico do curso foi analisado considerando em que medida objetivos do curso, atividades complementares, estágio supervisionado e o trabalho e conclusão de curso se correlacionam com o empreendedorismo, conforme figura esquemática 04.

Figura 04 - Análise projeto do curso

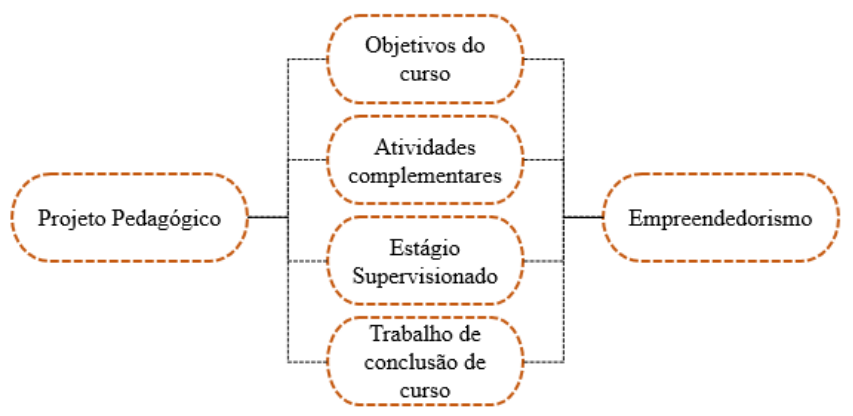

Fonte: elaboração dos autores, 2018.

Posteriormente, foram analisados os programas das disciplinas, observando de que maneira as nomenclaturas das disciplinas, ementas, objetivos, conteúdos programáticos, metodologias de ensino, metodologias de avaliações e bibliografia se correlacionam com aspectos do empreendedorismo, conforme figura 05. Foram coletados dados dos programas de todas as disciplinas do curso de Administração noturno da UFES do primeiro semestre dos anos de 2013 e 2018 para permitir um recorte temporal analisando se algo mudou em 5 anos. Cabe ressaltar que os professores têm autonomia para alterar os programas das disciplinas a partir da ementa, por isso existem mudanças nas mesmas disciplinas entre os anos analisados. Os documentos foram disponibilizados pela secretaria do curso e por meio do site da Instituição e foram investigados por meio da análise de dados (GIL, 2008).

Figura 05 - Análise dos programas das disciplinas

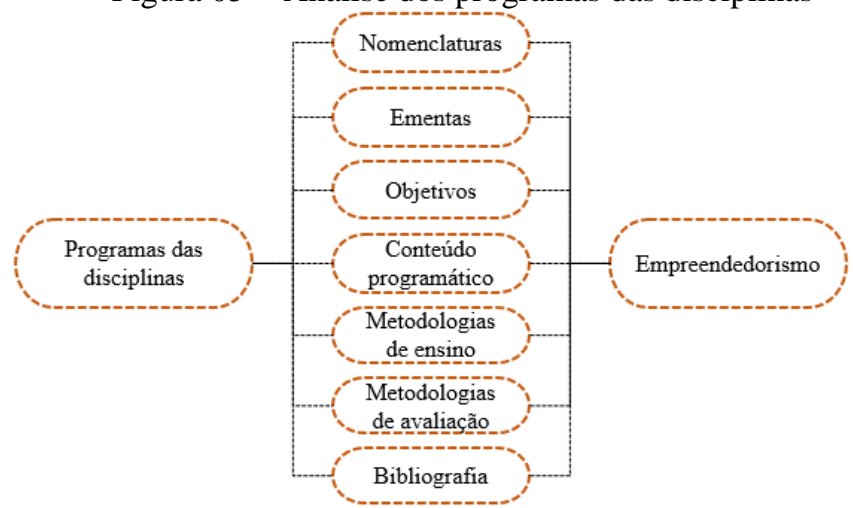

Fonte: elaboração dos autores, 2018.

\section{RESULTADOS}

Os documentos foram lidos em profundidade duas vezes para permitir a análise de dados (GIL, 2008). Para uma compreensão clara, optou-se por estruturá-los nas seguintes categorias: Projeto pedagógico e Programas de curso conforme Gibbs (2009). As principais contribuições foram condensadas nas tabelas 1 e 2 .

\section{1 - Projeto pedagógico}

O projeto pedagógico do curso de administração noturno tem como objetivo contribuir para que o aluno desenvolva habilidades, dentre outras, como: comunicação; criatividade; compreensão do ambiente organizacional de modo geral; desenvolvimento de estratégia; estabelecimento de prioridades; de adaptação a modelos inovadores de gestão (UFES, 2007). Tais habilidades costumam ser relacionadas ao empreendedor (DOLABELA, 2008; DORNERLAS, 2015; FILION, 1999). O curso busca contemplar na formação do aluno a internalização de valores de responsabilidade social, justiça e ética profissional; sólida formação humanística e visão global; sólida formação técnica e científica; competência para empreender, analisando criticamente as organizações, antecipando e promovendo suas transformações; capacidade para atuar de forma interdisciplinar; capacidade de compreensão da necessidade do contínuo aperfeiçoamento profissional e do desenvolvimento da autoconfiança. Tendo como um dos desafios conseguir ofertar uma formação de profissionais com perfis mais dinâmicos (UFES, 2007). Dentre esses tópicos citados acima, destacamos a "competência para empreender" que está diretamente ligada ao objetivo desse trabalho.

Cabe ressaltar que as atividades complementares devem ser compostas por trabalhos que permitam a aplicação dos conhecimentos teóricos, que proporcionem vivências práticas a partir desses conhecimentos, sendo desenvolvidas por meio de projetos de pesquisa, monitoria, iniciação científica, projetos de extensão, módulos temáticos, seminários, simpósios, congressos, conferências oficinas; 
palestras; visitas técnicas, disciplinas cursadas em outros departamentos (eletivas) ou outras instituições de ensino, entre outras (UFES, 2007). Proporcionar vivência prática empreendedora é de suma importância para o desenvolvimento do empreendedor (AHMAD; ABU BAKAR; AHMAD, 2018; DOLABELA, 2008; DORNERLAS, 2015; FILION, 1999).

O estágio supervisionado tem por objetivo comum também tentar unir a teoria à prática, aproximando o aluno à realidade, de modo que a partir dos conhecimentos adquiridos em sala, consiga colocá-los em prática fora do ambiente acadêmico, trabalhando e desenvolvendo esse estágio em um campo profissional, seja em organizações públicas, privadas ou sociais. A vivência prática segundo Ahmad, Abu Bakar e Ahmad (2018), Dolabela (2008) e Dornelas (2015) está diretamente ligada ao que o ensino do empreendedorismo deve proporcionar, englobando práticas citadas nos objetivos do estágio supervisionado, como a adaptação a mudanças e soluções ágeis de problemas.

O trabalho de conclusão pode ser desenvolvido dentre as modalidades: monografia; relatório de pesquisa de iniciação científica; artigos publicados de acordo com critérios específicos; plano de negócios; plano estratégico; relatório técnico; produção técnica (UFES, 2007). Dentre essas modalidades destacamos o plano de negócios e o plano estratégico, pois esses podem ser considerados maneiras de se colocar em prática os ensinos do empreendedorismo (DOLABELA, 2008; DORNERLAS, 2015). Segundo Ismail, Sawang e Zolin (2018) as práticas influenciam no processo de aprendizagem do aluno.

$\mathrm{Na}$ tabela 01 é apresentado um resumo com as principais contribuições observadas no projeto pedagógico do curso de administração da UFES na formação empreendedora.

Tabela 01 - Contribuições do projeto de curso Itens no projeto de curso Contribuição

Objetivos do curso

Competência para empreender

Atividades complementares $\quad$ Vivência prática

Estágio supervisionado

Vivência prática

Trabalho de conclusão de curso

Plano de negócio / plano estratégico

Fonte: Elaboração dos autores, 2018.

\subsection{Programas de curso}

Foram analisados os programas de curso do semestre de 2013/1 e 2018/1 formulados pelos professores que ministraram disciplinas nesses períodos. Deve ressaltar que, embora os programas devem estar alinhados às ementas que são estabelecidas no projeto pedagógico, os professores gozam de certa autonomia na sua elaboração. A análise das nomenclaturas das disciplinas revelou que não existe nenhuma disciplina com nome específico relacionado ao empreendedorismo, mas todas as disciplinas são importantes para a construção do profissional empreendedor em um contexto amplo e geral, pois de acordo com Filion (1999) um conjunto de atividades são necessárias ao desenvolvimento do empreendedor e devem ser ensinadas, como, dentre outras: descobrir oportunidades; conhecer o ramo, a concorrência e os clientes; avaliar recursos e custos; amenizar de riscos; aplicar técnicas de compras, vendas, marketing; administrar recursos humanos, comunicação e operações. Esses conhecimentos são adquiridos por meio das disciplinas ofertadas na graduação.

As ementas das disciplinas não abordam o conceito de empreendedorismo, mas abordam conceitos que contribuem de uma maneira ampla com a formação no empreendedor, como o trabalho de desenvolvimento de técnicas de estruturação, projeções e implementação de estratégias organizacionais. Os objetivos não abordam o conceito de empreendedorismo, mas contribuem com a formação do empreendedor a partir de alguns pontos, como elaborações, viabilizações e implementações de plano de ações, capacitação prática, acesso a prática e contato com a realidade. Isso se adequa ao proposto por Dolabela (2008) Dornelas (2015) e Filion (1999).

A partir da análise dos conteúdos programáticos, foi percebido que as únicas disciplinas que tratam especificamente de assuntos ligados ao empreendedorismo são a Tópicos Avançados em Organizações e Sistemas I (2013) e a disciplina Estratégia (2018). Em seus conteúdos programáticos, essas disciplinas abordam o tema empreendedorismo como um dos tópicos para as aulas. A metodologia de ensino dessas disciplinas contribui com a formação empreendedora por meio de métodos práticos, inovadores e criativos, utilizando situações simuladas, casos e aulas práticas, práticas gerenciais e resolução de problemas (CARDOW, SMITH, 2015; DZISI, ODOOM, 2017; KASSEAN, et al., 2015; OKEKE, YONG, 2016).

A metodologia de avaliação vista nas demais disciplinas é feita de uma maneira tradicional, por meio de provas, seminários, artigos, resenhas contribuindo com a formação do empreendedor de modo geral, quando os conteúdos são úteis ao empreendedor, e de modo específico, quando os conteúdos tratam pontualmente o empreendedorismo. O critério de auto avaliação na disciplina Política e Administração (2018) e resolução de problemas em Finanças I e II (2013) e ganham destaque por estarem diretamente ligadas ao contexto vivenciado pelos empreendedores (DOLABELA, 2008; DORNERLAS, 2015).

As bibliografias analisadas mostram apenas duas disciplinas com menção direta ao empreendedorismo. A disciplina Tópicos Avançados I em Organizações e Sistemas (2013), na biografia sugerida, indica o livro "Empreendedorismo: transformando ideias em negócios", de Dornelas, e Tópicos Avançados I em Organizações e Sistemas (2018) indica o artigo "O papel da criatividade na mediação do relacionamento entre a paixão empreendedora e a prontidão empreendedora", de Campos.

Tabela 2 - Principais destaques das disciplinas

\begin{tabular}{cc}
\hline Itens avaliados & Destaques \\
\hline Nomenclatura & Sem observação \\
Ementas & Implementação de estratégias \\
Objetivo & Planos de ações e vivência prática \\
Conteúdos programáticos & Empreendedorismo \\
Metodologias de ensino & Situações simuladas \\
Metodologias de avaliação & Resolução de problemas e auto \\
Bibliografia & avaliação \\
\hline Fonte: elaboração dos autores, 2018
\end{tabular}




\section{CONCLUSÃO}

A análise do projeto pedagógico do curso mostrou aspectos que permitem o desenvolvimento de características do processo de empreender. O Projeto pedagógico afirma que a formação do aluno deve contemplar a competência para empreender, a vivência prática dos conhecimentos teóricos adquiridos e permite como possibilidade que um plano estratégico ou um plano de negócios seja apresentado como trabalho acadêmico de conclusão de curso. A análise do projeto pedagógico mostrou correlações com conceitos e características ligadas ao empreendedorismo, entretanto, cabe ressaltar que o termo empreendedorismo é citado apenas uma vez, não sendo tratado especificamente em nenhuma atividade ou nos objetivos do curso e não é demostrando no projeto de curso como essa competência seria desenvolvida no aluno.

Foram analisados os programas de disciplinas do curso de administração investigando de que maneira os nomes das disciplinas, ementas, objetivos, conteúdos programáticos, metodologias, avaliações e bibliografia e apenas as disciplinas "Tópicos avançados em organização e sistemas 1" e "Estratégia" abordam o tema empreendedorismo de maneira específica em seu conteúdo. A análise dos programas das disciplinas do curso mostrou que todas contribuem com a formação do empreendedor de modo geral, ou seja, os conteúdos são úteis a formação empreendedor enquanto, por exemplo, gestor de pessoas, administrador de recursos, controlador de finanças (FILION, 1999). Entretanto, inexistem disciplinas específicas para trabalhar aspectos do processo de empreender. Frente ao exposto, conclui-se que o curso de Administração noturno da UFES contribui com a formação do empreendedor, entretanto, carece de disciplinas e metodologias específicas para se fomentar esse processo. Surge a necessidade de pesquisas futuras, a partir da perspectiva dos alunos e dos professores para identificar o que vem sendo trabalhado a respeito do empreendedorismo para além do projeto pedagógico e do programa das disciplinas.

\section{REFERÊNCIAS BIBLIOGRÁFICAS}

AHMAD, S. Z.; ABU BAKAR, A. R.; AHMAD, N. An evaluation of teaching methods of entrepreneurship in hospitality and tourism programs. International Journal Of Management Education, v. 16, n. 1, p. 14-25, 2018.

BELL, H.; BELL, R. Applying enterprise: active learning environments for business Higher National Diploma students. Journal Of Further And Higher Education, v. 42, n. 5, p. 649-661, 2018.

CARDOW, A.; SMITH, R. Using innovative pedagogies in the classroom Re-storying Gothic tales as entrepreneur stories. Industry And Higher Education, v. 29, n. 5, p. 361-374, 2015.

CONSELHO NACIONAL DE EDUCAÇÃO. Câmara de Educação Superior. Resolução no 4 de 13 de julho de 2005. Disponível em: <http://portal.mec.gov.br〉. Acesso em: 02 Outubro. 2018.

DZISI, S.; ODOOM, F. Entrepreneurship Education and Training in Higher Educational Institutions in Ghana. Journal Of International Entrepreneurship, v. 15, n. 4, p. 436-452, 2017.
DOLABELA, F. Oficina do empreendedor: a metodologia de ensino que ajuda a transformar conhecimento em riqueza. Rio de Janeiro: Sextante, 2008.

DORNELAS, J. C. A. Empreendedorismo: transformando ideias em negócios. $5^{\mathrm{a}}$. ed. Rio de Janeiro: Empreende, 2015.

DRUCKER, P. F. Inovação e Espírito Empreendedor: Prática e princípios. 1. ed. São Paulo: Pioneira, 2003.

FILION, L. J. Empreendedorismo: empreendedores e proprietários-gerentes de pequenos negócios. Revista de Administração da USP, São Paulo, v. 34, n. 2. 1999.

GIBBS, G. Análise de dados qualitativos. Porto Alegre: Artmed, 2009.

GIL, A. C. Como Elaborar um Projeto de Pesquisa. 4. ed. São Paulo: Atlas, 2008.

ISMAIL, A. B. T.; SAWANG, S.; ZOLIN, R. Entrepreneurship education pedagogy: teacher-studentcentred paradox. Education and Training, v. 60, n. 2, p. 168-184, 2018.

KASSEAN, H.; ET AL. Entrepreneurship education: a need for reflection, real-world experience and action. International Journal Of Entrepreneurial Behaviour \& Research, v. 21, n. 5, p. 690-708, 2015.

LIMA, E., Lopes, R. M. A., Nassif, V. M. J., \& Silva, D. Ser seu próprio patrão? Aperfeiçoando-se a educação superior em empreendedorismo. Revista de Administração Contemporânea, 19(4), 419-439. 2015.

OKEKE, C. O.; YONG, D. G. F. Assessment of entrepreneurship pedagogy on entrepreneurship knowledge and entrepreneurial human capital asset: A conceptual model. Knowledge Management \& E-Learning-An International Journal, v. 8, n.2, p. 243-258, 2016.

SERVIÇO BRASILEIRO DE APOIO ÀS MICRO E PEQUENAS EMPRESAS. Global Entrepreneurship Monitor - Empreendedorismo no Brasil 2016. Curitiba: IBQP, 2017.

UNIVERSIDADE FEDERAL DO ESPÍRITO SANTO. Curso de graduação em Administração. Disponível em: <http://http://www.administracao.ufes.br/>. Acesso em: 01 novembro. 2018.

UNIVERSIDADE FEDERAL DO ESPÍRITO SANTO. Departamento de Administração. Projeto Pedagógico do Curso de Graduação em Administração. Vitória, 2007.

VERGARA, S. C. Métodos de pesquisa em administração. São Paulo: Atlas, 2005.

\section{COPYRIGHT}

Direitos autorais: Os autores são os únicos responsáveis pelo material incluído no artigo. 


\title{
ANÁLISE DO DESEMPENHO LOGISTICO NO ALMOXARIFADO DE MEDICAMENTOS DO MUNICIPIO DE PORTO VELHO-RO
}

\author{
ANALYSIS OF LOGISTIC PERFORMANCE IN THE MEDICINES OF THE \\ MUNICIPALITY OF PORTO VELHO-RO
}

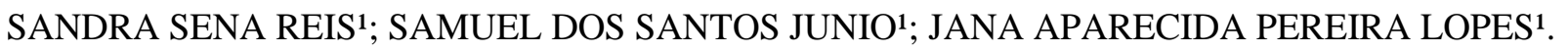

IFRO - INSTITUTO FEDERAL DE EDUCAÇÃO, CIÊNCIA E TECNOLOGIA DE RONDÔNIA. sandrasenareis14@gmail.com,samuel.santos@ifro.edu.br,jana.lopes@ifro.edu.br.

\begin{abstract}
Resumo - A pesquisa buscou responder o seguinte questionamento: Será que o processo de armazenamento dos medicamentos e a forma como são distribuídos nas unidades de saúde de Porto Velho estão adequados? No sistema de distribuição dos medicamentos é necessário saber como está sendo feito esse procedimento para as Unidades de saúde através da; Verificação dos mapas de distribuição (espécie de relatório das unidades). Analisa-se antes execução do cronograma de distribuição está sendo feito conforme padronização da farmácia. Observa-se como está sendo feito o transporte destes produtos até as unidades $e$ como são embalados quando estão sendo transportados. Na pesquisa foi abordada as práticas de armazenamento $e$ distribuição dos medicamentos no almoxarifado da farmácia da Secretaria Municipal de Saúde de Porto Velho, de acordo com os procedimentos adotados pela equipe de farmacêuticos.
\end{abstract}

Palavras-chave: Logística. Distribuição. Gestão.

Abstract - The research sought to answer the following question: Is the process of storing the medicines and how they are distributed in the health facilities of Porto Velho adequate? In the drug distribution system it is necessary to know how this procedure is being done for the Health Units through; Verification of distribution maps (sort of unit report). It is analyzed and before execution of the distribution schedule is being done according to the standardization of the pharmacy. It is observed how these products are being transported to the units and how they are packed when they are being transported. In the research the practices of storage and distribution of medicines in the pharmacy warehouse of the Municipal Health Department of Porto Velho were approached according to the procedures adopted by the pharmacists team.

Keywords: Logistics. Distribution. Management.

\section{INTRODUÇÃO}

Devido ao crescimento populacional global, as pessoas ficam expostas a inúmeras doenças as quais devem ser tratadas com uso de medicamentos, para que esses produtos sejam eficazes a saúde da população é necessário que o produto tenha qualidade, e para que isso ocorra é importante ter um bom armazenamento, boa distribuição e dispensação requisitos que garante a boa qualidade dos produtos, tornando-os seguros e eficazes no momento certo. Proporcionar saúde significa, além de evitar doenças e prolongar a vida, assegurar meios que aumentem a qualidade da vida, ampliando o bem-estar através dos valores socialmente definidos. (BUSS, 2000). Um dos maiores desafios no gerenciamento do fluxo de medicamentos na rede pública de saúde municipal é suprir as unidades básicas de saúde e levar a população medicamentos de qualidade com rapidez para efetivamente salvar vidas. Para isso acontecer de forma eficiente, é necessário ter um planejamento no gerenciamento dos medicamentos evitando assim o desperdício do produto, e que o mesmo tenha um armazenamento correto em local bem construído, arejado, organizado e seguro. $\mathrm{O}$ produto deve chegar ao consumidor final com a mesma particularidade que saiu de seu ponto de origem, através de procedimentos adequados para não causar risco a saúde do consumidor de acordo com as normas técnicas vigentes, e conforme Resolução no 328, de 22 de Julho de 1999. Nesse contexto algumas observações na logística de medicamentos devem ser avaliadas evitando a perda do produto.

A presente pesquisa teve por objeto verificar a dinâmica de armazenamento, dispensação e distribuição dos medicamentos no Almoxarifado de medicamentos da Secretaria Municipal de Saúde - SEMUSA de Porto Velho/RO, em conformidade com a Portaria de $\mathrm{n}^{\mathrm{o}} 3.916$, de 30 de Outubro de 1998, a qual vem tratar da política nacional de medicamentos constituindo elementos fundamentais para a efetiva implementação de ações capazes de promover a melhoria de condições da assistência à saúde da população. A Lei no $8.080 / 90$, em seu artigo $6^{\circ}$, estabelece como campo de atuação do Sistema Único de Saúde (SUS) a "formulação da política de medicamentos de interesse para a saúde garantindo necessária segurança, eficácia e qualidade dos medicamentos, pois estes são de suma importância a saúde pública, garantindo a população uma melhor qualidade de vida.

De acordo com a Constituição Federal "saúde é direito de todos e dever do Estado, garantindo mediante políticas sociais e econômicas que vise a redução dos riscos de doenças e de outros agravos e ao acesso universal e igualitário as ações e serviços para a sua promoção, proteção 
e recuperação". A lei do SUS assegura que todo cidadão tem direito de ter fornecimento gratuito dos medicamentos que necessita, para tanto as Unidades de Saúde devem obrigatoriamente fornecer os medicamentos receitados, pois os mesmos são destinados à prevenção da saúde e da vida.

Os medicamentos devem ser guardados de acordo com as práticas de armazenamento de medicamentos, em prateleiras ou em pallets, por ordem alfabética/programa/lote e validade mantendo sempre a integridade dos mesmos, controlando temperatura e ambiente limpo.

A RDC n ${ }^{\circ} 44$ de 17/08/2009 embasa bem as condições de armazenamento onde:

Todos os produtos devem ser armazenados de forma ordenada e sob condições que garantam a manutenção de sua identidade, integridade, qualidade, segurança, eficácia e rastreabilidade.

$\mathrm{O}$ ambiente deve ser mantido limpo, protegido da ação direta da luz solar, umidade e calor, de qualidade e segurança dos mesmos.

A Lei ${ }^{\circ}$ 5.991, de 17 de dezembro de 1973 em seu art. Paragrafo II conceitua medicamento como:

Produto farmacêutico, tecnicamente obtido ou elaborado, com finalidade profilática, curativa, paliativa ou para fins de diagnósticos. (PMPV 2018 Legislação)

A distribuição dos medicamentos consiste em suprir as necessidades conforme as demandas nas Unidades de Saúde, com qualidade, quantidade e tempo hábil para fazer dispensação à população. A logística de distribuição é feita através de cronogramas estabelecidos, com segurança garantindo que o produto chegue ao seu destino em quantidade correta e com qualidade através do transporte adequado e sistema de informação que garante a atualização dos dados e a movimentação do estoque, de acordo com o manual da Una-SUS Gestão da assistência farmacêutica. A distribuição consiste em entregar o material ao seu destino de forma correta e segura no tempo certo com eficiência e eficácia nos serviços prestados ao usuário.

Conforme (PADILHA; TOLEDO e ROSADA, 2014) os medicamentos são recursos terapêuticos essenciais a população os quais asseguram uma melhor relação custo/efetividade. Existe a necessidade de haver uma política municipal de medicamentos para assegurar a assistência prestada ao atendimento analisando os principais problemas de saúde comparando com o cenário sanitário do município.

Os autores (Padilha, Toledo e Rosada, 2014) afirmam ainda que a assistência Farmacêutica deve ter uma lista padronizada de medicamentos pois é esse mecanismo que auxilia na qualidade dos serviços a serem prestados garantindo uma visão construtiva de sustentabilidade do sistema de saúde ao nível municipal.

O município exerce papel fundamental de suprir a necessidade dos pacientes dispensando medicamentos. Para tanto se torna necessário o correto diagnóstico e a prestação de corretas orientações. Já que esses medicamentos podem causar efeitos adversos indesejados e diferentes interações medicamentosas. É importante ressaltar a presença do profissional farmacêutico nas farmácias públicas, obter protocolos objetivos para dispensação desses medicamentos e ter medidas de educação permanente aos demais profissionais de saúde. Podendo ser um importante passo para qualificação da equipe de saúde.

O almoxarifado de medicamentos da Secretaria Municipal de Saúde - SEMUSA atende todas as Unidades de Saúde; desde Unidades de saúde básica (Postos de saúde), UPAS, Unidades prisionais da capital até os Distritos de Porto Velho. Para tanto se faz necessário uma observação de como é feito o processo de Armazenamento, dispensação e a distribuição desses medicamentos até o consumidor final.

\section{METODOLOGIA}

A pesquisa foi realizada no Almoxarifado de medicamentos da Farmácia Municipal. Anexa a Secretaria Municipal de Saúde - SEMUSA que fica localizada na Avenida Governador Jorge Teixeira, e é ligada diretamente à Prefeitura de Porto Velho e tem por responsabilidade a gestão plena do Sistema Único de Saúde (SUS) no âmbito municipal. Além das ações e serviços de saúde oferecidos ao município, o órgão é responsável pela formulação e implantação de políticas, programas e projetos que visem à promoção de uma saúde de qualidade ao usuário do SUS.

Dentre os vários Departamentos (Departamento Administrativo, Departamento de Atenção Básica, Departamento de Vigilância em Saúde, Departamento de Média e Alta Complexidade, Departamento de Regulação Avaliação e Controle), instituídos pela SEMUSA, está o Departamento de Assistência Farmacêutica, com as Divisões de logística da Central de Abastecimento e Divisão Estratégica da Assistência Farmacêutica, que desenvolve suas atividades a partir das diretrizes do SUS referente a Política Nacional de Medicamentos, que tem como propósito precípuo de garantir a necessária segurança, eficácia e qualidade dos medicamentos, a promoção do uso racional e o acesso da população àqueles considerados essenciais (PMPV, 2018)

Com o objetivo de proporcionar melhor controle dos medicamentos, em 05 de setembro de 2016 por meio da Portaria No 217 /2016 GAB-SEMUSA, foi implementado a criação e operacionalização do sistema SISFARMA, que envolve o controle das entradas, saídas, dispensação e solicitação de medicamentos das Farmácias nas unidades de saúde da rede municipal aos pacientes, e está disponível no portal da transparência da Prefeitura Municipal do Município de Porto Velho.

Atualmente a Assistência Farmacêutica do Município de Porto Velho, conta com uma estrutura adequada para armazenamento dos medicamentos dentro da logística de atendimento as unidades de saúde e manter a qualidade conforme preconiza legislação.

\section{RESULTADOS}

De acordo com o dicionário logística é um substantivo feminino 1. Matemática Parte da álgebra que se ocupava das primeiras operações (soma, subtração). 2. Parte da arte militar que trata de todas as atividades não combatentes relativas ao abastecimento, transporte, alojamento e comunicações das forças armadas. A logística surgiu durante a guerra pelos militares sendo a metodologia usada por eles para armazenar, distribuir e manter vários tipos de materiais e isso vem desde a Roma antiga antes de Cristo. O termo logístico teve origem no se. XVIII no reinado de 
Luiz XIV, devido ao cargo de general de LOGIS, que era responsável por suprir e transportar os materiais nas batalhas, esse sistema logístico operacional permitia que as campanhas militares fossem realizadas com eficiência e eficácia pelos soldados contribuindo assim para a vitória da tropa. O primeiro General a usar esse termo foi o general Von Claussen de Frederico da Rússia e mais tarde a CIA usa na Segunda Guerra Mundial.

Em tempos antigos certas campanhas de guerra se valiam de algo parecido com a logística, devido ao longo período de duração das guerras, os militares incluíam táticas de logística para armamentos e suprimentos. Rotas de ataques eram pesquisadas e calculadas de acordo com os conceitos primitivos de logística. Já a logística moderna engloba vários fatores imprescindíveis para melhor desempenho e competitividade das empresas, seu crescimento começou a ser visto apenas na década de 60 quando o controle de qualidade e satisfação do cliente foram colocadas em primeiro plano. No Brasil a logística surge entre as décadas de 80 e 90 trazendo uma visão inovadora para as empresas, centralizando os depósitos obtendo agilidade na distribuição, diminuindo os estoques e melhorando o nível de serviços.

Com a globalização e o nascimento da internet, a logística se mostrou muito mais necessária. Com todas essas mudanças de estrutura através do sistema de informação, as empresas devem estar preparadas para competição logística a nível mundial realizando entregas em tempo hábil.

A logística passa a ter grande importância com a inclusão da visão sistêmica e contingencial na análise da administração fazendo com que as atividades logísticas passem a integrar suas ações para atingir objetivos comuns traçados pelas organizações. De acordo com Christopher (2001, p. 58-59), a natureza da logística assemelha-se a uma pedra lançada numa represa e os efeitos das políticas se espalham para além da sua área imediata de impacto. A boa atuação da logística provoca em uma maior eficiência da gestão e qualquer modificação na atividade logística afeta o resultado do gerenciamento.

Para Castiglioni e Junior (2014, p. 12), as atribuições da logística vão muito além do transporte e do armazenamento, pois há uma necessidade constante de monitoramento para saber se a carga chegará ao seu destino sem se perder pelos milhões de armazéns. Já Moura (2006, p. 18) diz que a logística tem importância crítica para a qualidade de vida e mesmo para a sobrevivência humana, disponibilizando nos quatros cantos do mundo, no tempo certo, os produtos e serviços que os consumidores e as organizações necessitam (máquinas, matérias primas medicamentos etc.).

A armazenagem é o conjunto de funções de recebimento, descarga, carregamento, arrumação e conservação de matérias-primas de produtos acabados e semiacabados. $\mathrm{O}$ processo de armazenagem envolve mercadorias produzindo resultados através de operações realizadas com o objetivo, de acrescentar valores por meio da melhoria da qualidade de recepção dos produtos. A armazenagem deve ir de acordo com as necessidades das empresas as quais necessitam de uma armazenagem racional, que traz inúmeros benefícios, que influenciam na redução de custos dos produtos na cadeia logística. É o espaço disposto para a administração do estoque com equipamentos apropriados e profissionais capacitados para o desempenho da função que vai desde o recebimento do produto a entrega ao consumidor final com objetivo de minimizar custos e agilizar a entrega de mercadorias, é a forma de estocar os materiais em ordem, com a máxima proteção dos itens armazenados proporcionando agilidade na busca dos produtos de acordo com suas especificações.

A distribuição tem uma função logística, a que se refere a circulação física do produto e do marketing, mais também estimula a compra e levantamento de informações sobre os consumidores, compreende as operações de transportes e entrega com a finalidade de suprir os pontos de vendas, consiste basicamente na movimentação dos produtos até os pontos de vendas. Tem como finalidade planear, implementar e controlar o fluxo eficiente, distribuindo as mercadorias a partir do ponto de origem até o ponto de consumo.

Chinelato, Cruz e Zivani (2012) afirmam que a utilização de intermediários é proporcional ao tipo de produto e as condições de armazenagem. Para tanto dividese em três tipos de sistema de distribuição exclusiva, onde o distribuidor trabalha com um fabricante exclusivo, intensiva a disponibilidade do produto é usada em diversos locais com vários pontos de vendas e a distribuição seletiva não é exclusiva porém mantém cautela com os canais de distribuição.

O fluxo da distribuição depende de diversos níveis envolvidos no processo, é necessário estabelecer uma comunicação permanente entre eles, definindo os critérios e o cronograma de distribuição. Definir, também, a data de prestação de contas e instrumentos a serem utilizados para que a distribuição seja efetuada de forma satisfatória (Assistência Farmacêutica na Atenção Básica Instruções e Técnicas para a sua Organização MS 2002).

A Assistência Farmacêutica, está relacionada as atividades de armazenamento, dispensação e distribuição dos medicamentos para atender a demanda das ações de saúde pública (Portela, Leal, Werner, Simões, Medeiros 2010). Pois quando se trata de armazenagem algumas características são relevantes, considerando que existem produtos que precisam de atenção especial, como os remédios controlados ou os que precisam estar em resfriamento. Os medicamentos, que recebem tratamento diferenciado devido a sua importância estratégica para as ações de saúde, são considerados materiais diferenciados pois, não garantem gerenciamento satisfatório comparados com os demais grupos de materiais. (Neto e Filho, 1998).

Visando a otimização dos serviços oferecidos pela assistência Farmacêutica municipal, através do armazenamento, dispensação e distribuição dos medicamentos foram traçadas algumas ações para o melhoramento dinâmico nos processos de trabalho, dentre as quais está o espaço físico que atualmente está nas dependências da Secretaria Municipal de Saúde SEMUSA, pois outrora era um galpão separado em outro prédio. Esse novo espaço favoreceu muito a interação entre os setores e os departamentos na otimização dos processos de distribuição.

A armazenagem dos produtos é a atividade relacionada ao abastecimento a qual exigi técnicas, métodos adequados e instalações apropriadas. A falta de profissionais capacitados é um problema enfrentado pela gestão causando transtornos no processo de trabalho.

Atualmente a Divisão de Apoio a Farmácia, atende mensalmente 61 Unidades, sendo; 29 Unidades de saúde na área urbana, 21 Unidades de saúde nas áreas rurais, 11 
Unidades de saúde no Baixo Madeira, Sistema penitenciário Estadual (SEJUS) e Federal (DEPEN), através de um cronograma mensal de distribuição dos medicamentos.

A Central de Abastecimento Farmacêutico - CAF é o local que se desenvolve atividades voltadas para a logística de medicamentos tais como o armazenamento adequado dos mesmos, respeitando-se as regras básicas de estocagem, manuseio, guarda e empilhamento máximo. Depende também da organização da CAF, a distribuição ou remanejamento dos fármacos que, por diminuição de consumo ou mudanças de protocolo, corram o risco de perder a validade; a conferência da entrega de remessas adquiridas por compra ou troca; o controle de lotes para organização adequada nas prateleiras e a confecção e organização de documentação para registro de entrada, saída, estorno e perdas de medicamentos, sempre de acordo com as características físico químicas das composições, em relação à temperatura e umidade, às orientações do fabricante e às determinações regulamentares. É também, a partir do trabalho desenvolvido na $\mathrm{CAF}$, que se apura o giro dos estoques, o consumo médio dos medicamentos padronizados e os estoques mínimos. A organização dos almoxarifados deve ser orientada de modo a cumprir três objetivos principais: garantir a correta recepção, conservação e distribuição, dentro de padrões e normas técnicas específicas; manter condições ambientais adequadas para assegurar o rendimento, a produtividade do trabalho, minimizar o risco de erros e possibilitar limpeza e manutenção e dispor de meios materiais e humanos para conseguir os dois objetivos anteriores. E para alcançar os objetivos, é necessário dotar o local de condições adequadas.

Atualmente a CAF da Secretaria Municipal de Saúde conta com espaço próprio e adequado para oferecer boas condições de armazenamento dentro da logística de atendimento de medicamentos às unidades de saúde, garantindo assim segurança e credibilidade nos serviços prestados (PMPV, 2018).

Atualmente, no organograma geral da Secretária Municipal de Saúde - SEMUSA, conforme figura 1 a seguir, as ações da AF estão inseridas dentro do Departamento de Atenção Básica - DAB denominada como "Divisão de Apoio à Farmácia - DAF”.

Figura 1- Organograma Geral da SEMUSA

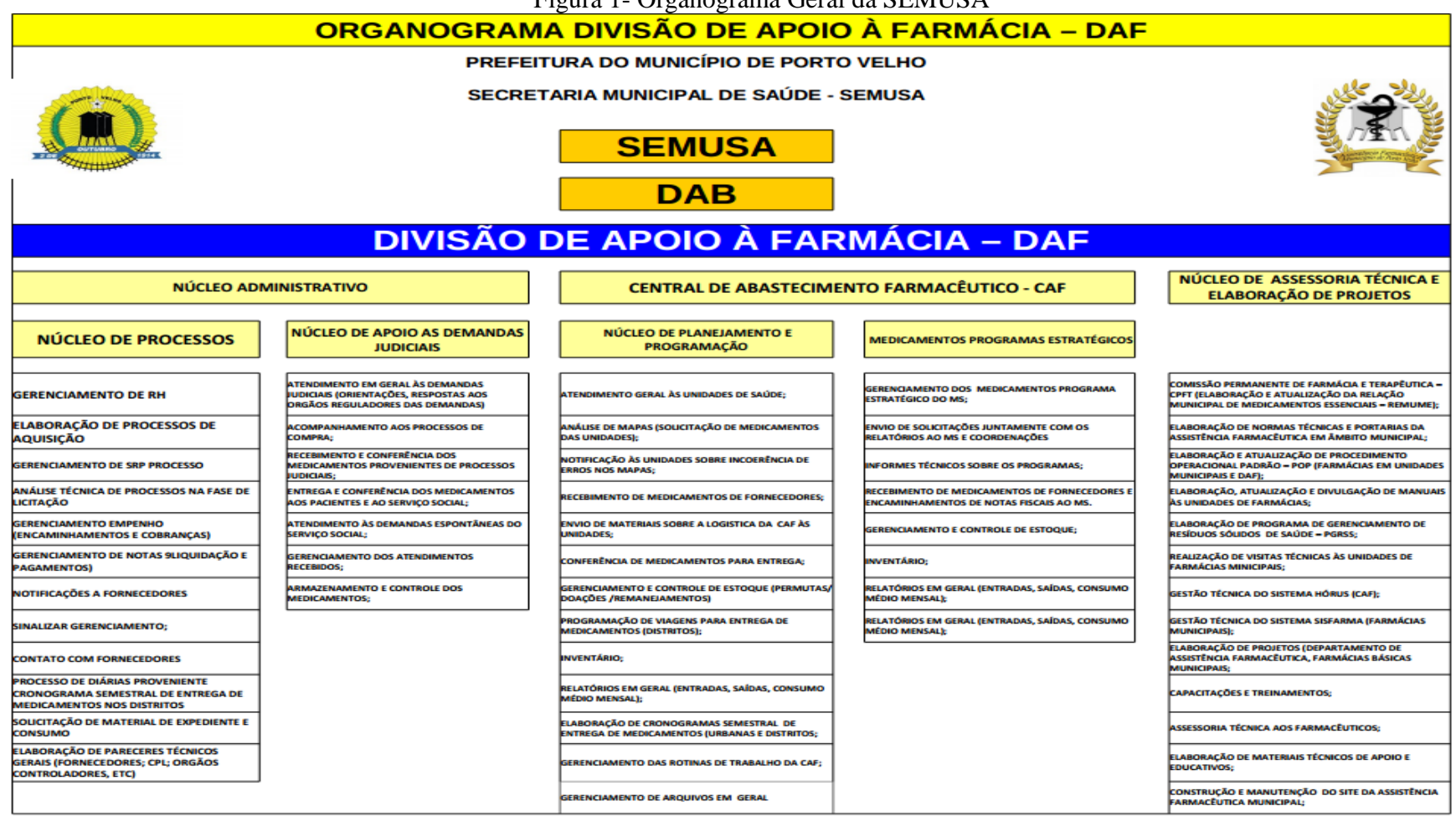

Fonte: PMPV Assistência Farmacêutica. Pesquisa em 25/10/2018

Para Dias (2012, p. 194), a dimensão e as características de materiais e produtos podem exigir desde a instalação de uma simples prateleira até complexos sistemas de armações, caixas e gavetas. As maneiras mais comuns de estocagem de materiais podem ser assim generalizadas: caixas, prateleiras, Racks e empilhamento. No almoxarifado da farmácia de medicamentos é comum usar as prateleiras metálicas, pallets de plástico resistente, refrigeradores e o ambiente precisa estar refrigerado para manter os medicamentos em temperatura ambiente.

A distribuição é a última fase da logística antes da utilização do produto pelo cliente, é a atividade em que o produto está pronto para ser entregue ao consumidor final, para tanto é necessário o uso de transporte os quais vem a ser rodoviário, marítimo, aéreo ou ferroviário.

Os mais usados pelo almoxarifado de medicamentos da Semusa são: rodoviários e marítimo, usado para atender a região do Baixo Madeira. Para Martins e Campos (2013, p. 406), o modal escolhido deve combinar com o sistema de movimentação de materiais e de armazenagem, além de ser flexível. Ainda segundo estes autores, no Brasil mais da metade do transporte de cargas se faz pelas rodovias por ser o menos produtivo dos modais em termos de carga por hora e de operador, e seu custo de mão de obra é elevado. Por isso é necessário uma análise no acompanhamento desse serviços para tanto nessa área deve-se observar os seguintes 
critérios: Armazenamento dos produtos por forma farmacêutica, pelo nome do princípio ativo em ordem alfabética rigorosa, da esquerda para a direita, por prazo de validade pois os que vão vencer primeiro devem ser armazenados à esquerda e na frente, Observar o empilhamento máximo permitido para o produto ( observando as recomendações do fabricante), Observar a temperatura ideal a que o produto deve ser armazenado e observar se as caixas que forem abertas foram riscadas, indicando a violação, a quantidade existente anotada e, em seguida, a caixa deve ser lacrada novamente.

As áreas de armazenamento devem ser identificadas de acordo com o grupo e os produtos, armazenados de maneira que permita a perfeita visualização do nome, número de lote e prazo de validade.

As áreas que abrigarão os materiais precisam ter ausência de umidade e de calor ou frio excessivos, proteção contra animais e parasitas, proteção contra incêndio, boa circulação de ar disposição adequada para movimentação de pessoas e materiais, área administrativa, área para produtos que necessitam de temperatura controlada e área para produtos inflamáveis. Alguns materiais necessitam de controles restritos de temperatura como os medicamentos termolábeis que precisam estar com a temperatura média de aproximadamente $25^{\circ} \mathrm{C}$, pois, se forem armazenados em locais quentes e sem ventilação podem ter suas características físico-quimicas alteradas. Para tanto são necessários aparelhos condicionadores de ar, que permitem total controle de temperatura interna favorável com máxima de $28^{\circ} \mathrm{C}$. É importante também que se proceda a m rigoroso estudo de cudo da capacidade de refrigeração dos aparelhos em relação à cubagem da sala, bem como observar a necessidade de esquadrias que permitem a ventilação natural caso haja cortes de energia elétrica.

\section{CONCLUSÃO}

A pesquisa buscou responder o seguinte questionamento: Será que o processo de armazenamento dos medicamentos e a forma como são distribuídos nas unidades de saúde de Porto Velho estão adequados? No sistema de distribuição dos medicamentos é necessário saber como está sendo feito esse procedimento para as Unidades de saúde através da; Verificação dos mapas de distribuição (espécie de relatório das unidades). Analisou-se a e antes execução do cronograma de distribuição está sendo feito conforme padronização da farmácia. Observou-se como está sendo feito o transporte destes produtos até as unidades e como são embalados quando estão sendo transportados. Na pesquisa foram abordadas as práticas de armazenamento e distribuição dos medicamentos no almoxarifado da farmácia da Secretaria Municipal de Saúde de Porto Velho, de acordo com os procedimentos adotados pela equipe de farmacêuticos. Segundo Caxito e colaboradores (2014, p. $145)$, os processos de armazenagem vinculam-se às especificações e particularidades de determinados produtos, como os produtos farmacêuticos que obedecem a critérios diferentes de armazenagem. Pois conforme Caxito, os insumos farmacêuticos que antecedem o produto acabado, ou seja, os medicamentos obedecem a regras rigorosas de critérios de armazenagem. Por isso se faz necessária esta observância na prática de armazenagem em um Órgão Público, verificando se os produtos estão sendo separados e especificados de acordo com lote/data de fabricação e espécie.

Um dos maiores desafios no gerenciamento do fluxo de medicamentos na rede pública de saúde municipal é suprir as unidades básicas de saúde e levar a população medicamentos de qualidade com rapidez para efetivamente salvar vidas. Para isso acontecer de forma eficiente, é necessário ter um planejamento no gerenciamento dos medicamentos evitando assim o desperdício do produto, e que o mesmo tenha um armazenamento correto em local bem construído, arejado, organizado e seguro. O produto deve chegar ao consumidor final com a mesma particularidade que saiu de seu ponto de origem, através de procedimentos adequados para não causar risco a saúde do consumidor de acordo com as normas técnicas vigentes, e conforme Resolução no 328, de 22 de Julho de 1999. Nesse contexto algumas observações na logística de medicamentos devem ser avaliadas evitando a perda do produto.

O município exerce papel fundamental de suprir a necessidade dos pacientes dispensando medicamentos. Para tanto se torna necessário o correto diagnóstico e a prestação de corretas orientações. Já que esses medicamentos podem causar efeitos adversos indesejados e diferentes interações medicamentosas. É importante ressaltar a presença do profissional farmacêutico nas farmácias públicas, obter protocolos objetivos para dispensação desses medicamentos e ter medidas de educação permanente aos demais profissionais de saúde. Podendo ser um importante passo para qualificação da equipe de saúde.

O almoxarifado de medicamentos da Secretaria Municipal de Saúde - SEMUSA atende todas as Unidades de Saúde; desde Unidades de saúde básica (Postos de saúde), UPAS, Unidades prisionais da capital até os Distritos de Porto Velho. Para tanto se fez necessário uma observação de como é feito o processo de Armazenamento, dispensação e a distribuição desses medicamentos até o consumidor final.

Observa-se que a logística de armazenagem e a importância desse processo pode contribuir para o interesse público. Realizar-se pesquisa com tema relacionado a distribuição de medicamentos no setor público se faz necessária, devido a falta de informação do usuário, informar e orientar a população da real situação e dos processos que os profissionais da área farmacêutica enfrentam é de suma importância para a comunidade, pois faz com que o usuário do órgão público saibam como devem ter acesso aos serviços oferecidos pela saúde municipal.

\section{REFERÊNCIAS BIBLIOGRÁFICAS}

BUSS PAULO MARCHIORI, Promoção da saúde e qualidade de vida Pág. 174

CAXITO FABIANO, Logística: enfoque prático - 2. Ed. São Paulo: Saraiva 2014.

CHINELATO, Flávia Braga, Cruz Diogo Batista de Freitas, Ziviani Fabricio. Canais de distribuição na exportação: o impacto da escolha para as empresas exportadoras. ReFAE - Revista da Faculdade de Administração e Economia, v.3, n. 2, p.137, 2012.

CHRISTOPHER, M. Logística e gerenciamento da cadeia de suprimentos: estratégias para a redução de custos e melhoria dos serviços. Traduzido por Francisco Roque 
Monteiro Leite. São Paulo: Pioneira Thomson Learning, 2001.

DIAS, Marco Arélio P., Administração de materiais: Princípios , conceito e gestão - $6^{\mathrm{a}}$ Ed. São Paulo: Editora Atlas S.A. - 2012.

Helfer AP, Camargo AL, Tavares NUL, Kanavos P, Bertoldi AD. Capacidade aquisitiva e disponibilidade de medicamentos para doenças crônicas no setor público. Rev Panam Saúde Pública 2012; 31(3):225-32.

MARQUES, Cícero Fernandes, ODA, Érico. Atividades Técnicas na Operação Logística. IESDE BRASIL SA; Pág. $18.2012 . \quad$ Disponível em http://www.sensorweb.com.br/blog/as-boas-praticas-noarmazenamento-de-medicamentos/ . Acesso 20 de janeiro de 2018.

MARTINS Petrônio Garcia, CAMPOS, Paulo Renato. Administração de materiais e recursos patrimoniais $-3^{\mathrm{a}}$ Ed, revista e atualizada: Editora Saraiva 2013.

MINETTO, Processos Logísticos $-1^{\mathrm{a}}$ Ed, Editora Érica 2014.

Ministério da Saúde, Secretaria de Políticas de saúde assistência farmacêutica na atenção básica instruções técnicas para a sua organização, p, 87, 2002.

MOURA, Benjamim Do Carmo, Logística, Conceitos e Tendências - $1^{\mathrm{a}} \mathrm{Ed}$, Centro Atlântico, Ltda., 2006.

GONZALO, Vencina, e REINHARDT, Wilson. Saúde e Cidadania, para Gestores Municipais de serviços de Saúde, Gestão de Recursos Materiais e de Medicamentos - São Paulo 1998.

PAOLESCHI, Bruno. Almoxarifado e Gestão de Estoques - Do recebimento, guarda e expedição à distribuição do estoque $-2^{a}$ Ed. São Paulo: Editora Érica, 2013. Disponível em

site

http://andromeda.ensp.fiocruz.br/visa/files/Volume12.pdf.

PINTO, Vanusa Barbosa. Uso Racional de Medicamentos: fundamentação em condutas terapêuticas e nos macroprocessos da Assistência Farmacêutica Armazenamento e Distribuição: o medicamento também merece cuidados. Políticas públicas de medicamentos: trajetória e desafios; Rev Ciênc Farm Básica Apl., p, 12. 2010;31(1):09-14 ISSN 1808-4532

\section{COPYRIGHT}

Direitos autorais: $\mathrm{O}(\mathrm{s})$ autor(es) é(são) o(s) único(s) responsável(is) pelo material incluído no artigo. 


\title{
ANÁLISE ESTRATÉGICA DOS RESULTADOS DA IMPLANTAÇÃO DO PROGRAMA NACIONAL DE GESTÃO PÚBLICA E DESBUROCRATIZAÇÃO - GESPÚBLICA EM RONDÔNIA
}

\section{STRATEGIC ANALYSIS OF RESULTS OF THE IMPLEMENTATION OF THE NATIONAL PROGRAM OF PUBLIC MANAGEMENT AND BUDGETING - GESPÚBLICA IN RONDÔNIA}

\author{
GABRIELE AIRES DA SILVA ${ }^{1}$; SAMUEL DOS SANTOS JUNIO ${ }^{1}$
}

1- INSTITUTO FEDERAL DE CIÊNCIA, TECNOLOGIA E EDUCAÇÃO DE RONDÔNIA - IFRO.

\author{
gabiaires.pena@gmail.com; samuel.santos@ifro.edu.br
}

\begin{abstract}
Resumo - Este trabalho tem por objetivo analisar estrategicamente os resultados que o Programa Nacional de Gestão Pública e Desburocratização - Gespública ocasionou para os órgãos públicos do Estado de Rondônia que aderiram, $e$ os benefícios que proporcionou para os cidadãos que utilizam dos serviços que esses órgãos oferecem. Foram selecionados para está pesquisa cinco órgãos que possuem grande relevância para o Estado, Companhia de Águas e Esgotos do Estado de Rondônia CAERD, Tribunal de Contas do Estado de Rondônia - TCE/RO, Departamento Estadual de Trânsito - DETRAN, Tribunal Regional do Trabalho da $14^{a}$ Região - TRT-14 e a Secretaria de Estado do Planejamento, Orçamento e Gestão - SEPOG. Este programa é o resultado das diversas iniciativas do Governo Federal para a promoção da gestão pública de excelência, visando contribuir para a qualidade dos serviços públicos prestados ao cidadão. $O$ interesse surgiu devido o foco do programa ser a modernização da gestão pública, com isso questionar o motivo que levou o interrompimento das ações do mesmo, não somente no Estado de Rondônia mas no âmbito nacional. $O$ presente estudo foi realizado através de pesquisa exploratória descritiva. Desse modo, foi constatado que o Programa Gespública com suas ferramentas foi muito importante para diversos órgãos públicos no Estado de Rondônia.
\end{abstract}

Palavras-chave: Gestão Pública; Desburocratização; Melhoria Contínua.

Abstract - The objective of this work is to analyze strategically the results that the National Public Management and Debureaucratization Program - Gespública has caused for the public bodies of the State of Rondonia that have joined, and the benefits it has provided for the citizens that use the services that these organs offer. Five bodies that have great relevance to the State, Rondônia State Water and Sewage Company - CAERD, Rondônia State Court of Accounts - TCE / RO, State Department of Transit - DETRAN, Regional Labor Court of the 14th Region - TRT-14 and the State Secretariat for Planning, Budget and Management - SEPOG. This program is the result of several initiatives of the Federal Government to promote public management of excellence, aiming to contribute to the quality of public services provided to citizens. The interest arose due to the program's focus being on the modernization of public management, with this questioning the reason that led to the interruption of its actions, not only in the State of Rondonia but at the national level. The present study was conducted through descriptive exploratory research. In this way, it was verified that the Gespública Program with its tools was very important for several public agencies in the State of Rondônia.

Keywords: Public administration; Reduction of bureaucracy; Continuous Improvement.

\section{INTRODUÇÃO}

A demanda por serviços públicos de qualidade provocou a ruptura da antiga forma de administração pública para uma administração que coloca em construção um Estado mais eficiente, que seja instrumento da ação coletiva da sociedade em transformação, com a consecução estratégica de desenvolvimento nacional (MORAES, 2010).

Com os avanços tecnológicos tornou-se necessário desenvolver novas formas de produzir os resultados esperados pela sociedade, através de processos menos burocráticos com ajuda de novas ferramentas, novas culturas organizacionais e com novas praticas de gestão. Utilizar ferramentas e métodos inovadores é uma forma estratégica para garantir qualidade, eficiência e posteriormente, excelência no serviço público.

Visto a constante busca por qualidade da prestação dos serviços públicos na administração pública, foi criado por meio do decreto $\mathrm{n}^{\mathrm{o}} 5.378$ de 23 de fevereiro de 2005, o Programa Nacional da Gestão Pública e Desburocratização - GESPÚBLICA. Segundo Andrade (2013), com o propósito de apoiar o desenvolvimento e a implantação de soluções que permitam um contínuo aperfeiçoamento dos sistemas de gestão das organizações públicas e de seus impactos junto aos cidadãos.

O Programa Nacional de Gestão Pública e Desburocratização - Gespública é o resultado das diversas iniciativas do Governo Federal para a promoção da gestão pública de excelência, visando contribuir para a qualidade dos serviços públicos prestados ao cidadão. (BELTRÃO, 1984). Visto como um programa que possuía suas ferramentas voltadas essencialmente para o público, orientando a qualidade da prestação dos serviços para o cidadão, o Gespública foi um desafio altamente complexo e 
de tal importância para a sociedade brasileira que não pôde se restringir à ação de poucos.

Com as organizações públicas em constates mudanças, que propiciam o desenvolvimento de uma nova cultura organizacional com novos princípios. A inovação na administração pública deve ser enfrentada como um desafio que gera subsídios para as pessoas e para toda estrutura organizacional. Portanto, esse estudo é importante para elucidar os resultados que a implantação do programa Gespública proporcionou ao Estado de Rondônia, realizando levantamento das ações mais importantes nos órgãos que aderiram ao programa.

$\mathrm{O}$ interesse surgiu devido à descontinuidade do programa, visto que o boom do Gespública foi tão grande e importante para a gestão pública no Estado. Sendo assim, por meio desse estudo será possível selecionar as melhores ações realizadas, analisar de forma estratégica os resultados que o programa Gespública ocasionou para os órgãos públicos que aderiram e os benefícios que propiciou para a sociedade.

\section{METODOLOGIA}

Este estudo será realizado através de pesquisa exploratória descritiva, realizando levantamento de informações sobre o Gespública no Estado de Rondônia. Depois de obtidas as informações, serão selecionadas as melhores ações realizadas por meio do Gespública nos órgãos do Estado de Rondônia que aderiram ao programa e posteriormente enunciar os principais resultados ocorridos nesses órgãos.

Analisar algo de forma estratégica é tornar evidentes os fatos mais importantes de um estudo, e este visa analisar os resultados da implantação do Programa Gespública em Rondônia para os serviços públicos, bem como destacar as principais ações efetivas que o programa proporcionou. A estratégia se revela por meio de um conjunto de objetivos, que por sua vez, se desdobram em projetos que se traduzem em ações concretas, tornando os desafios mais significativos e factíveis. (FERREIRA, 2012)

\section{RESULTADOS}

O Gespública chegou ao Estado de Rondônia em 2007, com cinco ferramentas:

- A Avaliação Continuada da Gestão Pública que é uma estratégia de melhoria e aprendizagem gerencial baseada na avaliação e melhoria do sistema de gestão, aplicada nos órgãos e entidades públicas. Ocorreram ciclos contínuos de auto avaliação e melhoria como objetivo de medir o avanço em termos de qualidade da gestão e de melhoria de resultados, além disso, para sensibilizar a organização para a implantação da gestão por resultados mediante a realização destes ciclos;

- A Carta de Serviço, um documento que visa informar aos cidadãos quais os serviços prestados por ela, como acessar e obter esses serviços e quais são os compromissos com o atendimento e os padrões de atendimento estabelecidos. A sua prática implica para a organização um processo de transformação sustentada em princípios fundamentais - participação e comprometimento, informação e transparência, aprendizagem e participação do cidadão. Esses princípios têm como premissas o foco no cidadão e a indução do controle social;
- A Pesquisa de Satisfação, que é uma metodologia de pesquisa de opinião padronizada que investiga o nível de satisfação dos usuários do serviço público e foi desenvolvida para se adequar a qualquer organização pública prestadora de serviços direto ao cidadão;

- O Guia "d" Simplificação Administrativa que foi elaborado para auxiliar qualquer organização pública interessada em simplificar seus processos e normas, eliminando exigências de rotinas que geram fluxos desconexos na tramitação de documentos que não agregam valor ao serviço prestado pela organização e, por consequência, pelo Estado. $O$ guia deve ser entendido como uma ferramenta de trabalho, eminentemente prática, para realizar a análise e melhoria de processos organizacionais.

- O Guia de Gestão de Processos é o instrumento que orienta a modelagem e a gestão de processos voltados ao alcance de resultados. A descrição envolve a reflexão acerca de características de validade dos produtos e serviços prestados, de referências (normas e conhecimentos) observadas, de recursos consumidos e dos insumos necessários à tomada de decisão com qualidade pelas pessoas e pelas instituições públicas.

Com o objetivo de alcançar a excelência em gestão e aperfeiçoar a prestação dos serviços públicos, representantes de vários órgãos do Estado de Rondônia participaram de eventos sobre a aplicação do Programa Gespública, o programa foi coordenado pela Secretaria de Estado do Planejamento, Orçamento e Gestão- SEPOG, que em parceria com os demais órgãos, articulou a vinda de consultores com o objetivo de fortalecer a execução do programa nas instituições. Eram formadas equipes de servidores públicos representantes de cada instituição que aderiram ao programa para participarem de diversas capacitações e para aplicar um diagnostico avaliando o órgão em oito critérios reconhecidos como norteadores de excelência, como por exemplo, governança, cidadãos, pessoas, processos, entre outros.

Até o ano de 2016, havia 23 organizações participantes que aderiram ao programa segundo o portal do Gespública, entretanto, o estudo analisará a implantação apenas na Companhia de Águas e Esgotos de Rondônia (CAERD), do Tribunal de Contas do Estado de Rondônia (TCE-RO), do Departamento Estadual de Trânsito (DETRAN), do Tribunal Regional do Trabalho da $14^{\mathrm{a}}$ Região (TRT-14) e da Secretaria de Estado do Planejamento, Orçamento e Gestão (SEPOG).

O Gespública foi aderido pela Companhia de Águas e Esgotos de Rondônia - CAERD, em 24 de novembro de 2011 através do Núcleo de Excelência Pública de Rondônia - NEP, onde a busca pela excelência se fortaleceu ainda mais com realização de palestras para sensibilização dos servidores, objetivando a implantação do programa e a realização da auto avaliação, que aconteceu em 2012, nos dias 20 de abril (capital) e 15 de maio (interior). No dia 15 de agosto de 2011 houve a validação da avaliação por um consultor externo, da qual resultou na certificação da CAERD - Certificado de Nível de Gestão, em outubro de 2012.

De dezembro/2012 a fevereiro/2013 a CAERD implantou a pesquisa de satisfação, que é uma das ferramentas do Gespública. Para tanto, foi utilizada a metodologia do software IPPS - Instrumento Padrão de 
Pesquisa de Satisfação. O universo da pesquisa abrangeu o total de usuários atendidos nas lojas de serviços, durante todo o mês de outubro/2012. Sendo a amostra retirada a partir dessa população, com margem de segurança de $95 \%$ e de erro 5\%. A pesquisa visou identificar o índice de satisfação da qualidade e da produtividade da água, entretanto, não tivemos acesso ao gráfico com o resultado desta pesquisa.

O Tribunal de Contas do Estado de Rondônia (TCERO) em 30 de junho de 2006 aderiu ao Programa Gespública, na oportunidade foi formado o comitê gestor interno da instituição, que ficou responsável por conduzir atividades do programa no órgão, a adesão aconteceu bem antes do Estado aderir por meio da SEPOG, o que ficou evidente a grande importância do Gespública para que o tribunal almejasse índices cada vez melhores de profissionalização na área da administração pública, tornando-se um forte instrumento com seus produtos para o atendimento ao cidadão.

O TCE-RO lançou o link do Gespública na página da intranet, com sua legislação, a participação do grupo de voluntários do Tribunal na realização de programas de melhoria na qualidade de vida dos servidores e dos serviços prestados à comunidade. De acordo com o grupo do Gespública do Tribunal de Contas o objetivo do link é promover uma troca de experiências e notícias com os outros órgãos públicos que já aderiram ao programa, além de, servir como um canal de comunicação para mostrar as atividades realizadas $\mathrm{e}$ as ações que possam ser desenvolvidas junto aos servidores. Outro serviço disponível pelo o link é o pensamento da semana, todas as sextas-feiras seriam publicadas mensagens com uma proposta positiva e que reflita na melhoria da qualidade. Além disso, criou a Carta de Serviço ao Usuário com o objetivo de dar ainda mais visibilidade e transparência a gestão do Tribunal de Contas do Estado de Rondônia.

Interessado em aperfeiçoar os serviços públicos prestados e contribuir com a modernização da gestão pública em Rondônia, o Departamento Estadual de Trânsito de Rondônia (DETRAN-RO) aderiu ao Gespública em 2009, com o objetivo de melhorar a qualidade da gestão utilizando as ferramentas apresentadas pelo Gespública nomeou um Comitê Gestor Interno, objetivando a modernização da gestão, para aprimorar por meio da cooperação de todos os servidores da autarquia o processo de simplificação de procedimentos e normas, no desenvolvimento de modelos e na melhoria do atendimento ao cidadão e na melhoria contínua dos setores.

O Comitê reuniu o time de excelência formado por servidores, para que a partir da auto avaliação fosse possível diagnosticar, quantificar e qualificar os principais fatores relacionados à organização, com ênfase em suas práticas de gestão e nos resultados institucionais. A equipe foi dividida em grupos dos seguintes critérios avaliativos: Governança; Estratégia e Planos; Público Alvo; Interesse Público e Cidadania; Informações e Conhecimentos; Pessoas; Processos e Resultados. Com o comitê interno do Gespública que traça estratégias de melhorias e aprendizagem gerencial do sistema de gestão, o DETRAN elaborou o Plano de Melhorias de Gestão que refletirá na qualidade dos serviços prestados aos cidadãos, este plano consiste em um conjunto de novas ações a serem adotadas pelo Detran, com o objetivo de mudar as práticas de gestão onde são definidos o quê, quem, quando e como será executada cada etapa dessas ações para atingir o objetivo estabelecido, alinhados às metas da instituição, com isso o DETRAN recebeu o certificado de excelência e qualidade de gestão no serviço público por meio da SEPOG.

A experiência do TRT da $14^{\mathrm{a}}$ Região com o Gespública foi um dos temas debatidos no "I Encontro de Qualidade" do Centro de Hemoterapia e Hematologia do Pará, uma oportunidade a mais para mostrar o desempenho alcançado desde 2005, quando o TRT fez sua adesão ao Programa Gespública. Em 2009, aconteceu à revisão do Plano Estratégico e, no ano seguinte, realizou os cursos "conhecendo o Gespública", que com a oportunidade o Tribunal divulgou a "Carta de Serviços ao Cidadão". No ano de 2012 foi concluído o Plano de Melhoria da Gestão (PMG). A adesão às ferramentas do Gespública tornou possível ao Tribunal realizar três auto avaliações da gestão, importantes passos para identificar os pontos fortes, as oportunidades de melhoria e os aspectos gerenciais menos desenvolvidos, que necessitam de aperfeiçoamento. Lançou também as edições impressas e em braile, disponibilizadas no portal eletrônico do Tribunal, PDF e áudio livro da Carta de Serviços ao Cidadão, contendo todas as informações sobre os canais de acesso e os serviços prestados.

Realizou ainda pesquisas de satisfação do usuário para medir o grau de satisfação do público externo. Na pesquisa mais recente, $83 \%$ dos entrevistados avaliaram o desempenho do TRT como "bom" e "ótimo". Por meio da utilização da guia "d" do Gespública foram simplificados procedimentos, normas e processos tanto no $2^{\circ}$ grau quanto no $1^{\mathrm{o}}$ grau, como, por exemplo, elaboração de pautas, acórdãos e minuta de votos; processo de retirada dos autos com carga, padronização de textos e documentos, termos de audiência, acordos e sentenças; além de aquisição de bens e serviços na área administrativa, e reclamação trabalhista desde a etapa da petição à sentença. Em 2012, a partir de atividades conduzidas pelo desembargador em função correicional, durante as correições realizadas na Vara do Trabalho de Cruzeiro do Sul (AC), uma nova metodologia passou a ser desenvolvida, como as chamadas correições compartilhadas que unificam a ação correcional às oficinas de desdobramento da estratégia. Nas oficinas de desdobramento da estratégia, realizadas durante três dias intercalados nos horários da correição, são reforçados os conceitos básicos do planejamento estratégico; missão, visão e valores da Vara do Trabalho; análise de ambiente interno e externo; e construção do mapa de contribuição da unidade judiciária.

O Gespública é o resultado da evolução histórica de uma série de iniciativas do Governo Federal para promover a gestão pública de excelência, e tem como principais características ser essencialmente público, ser contemporâneo, estar voltado para a disposição de resultados para a sociedade e ser federativo (ASCOM - TRT 14, 2012).

A Secretaria de Estado do Planejamento, Orçamento e Gestão - SEPOG, antiga Secretaria de Estado do Planejamento e Coordenação Geral - SEPLAN, visando contribuir com o fortalecimento do Gespública no Estado de Rondônia, tornou-se âncora do programa, desde 2006. O programa está instalado na coordenação do Programa Nacional de Modernização da Gestão Pública (PNAGE). Dada a junção de propósitos dos dois programas, as atividades do Gespública foram inseridas no Componente 4 do projeto do PNAGE, no Estado de Rondônia como 
estratégia de viabilizar financeiramente do Programa Nacional de Desburocratização. No decorrer dos anos, o Núcleo Estadual do Gespública desenvolveu várias ações junto às organizações adesas e parceiras, ampliando a rede no Estado. Atualmente, o Núcleo Estadual do Gespública conta com mais de 20 organizações adesas. O que demonstra o interesse das instituições públicas, em melhorar sua qualidade de gestão e consequentemente na melhoria do serviço prestado ao cidadão.

\section{CONCLUSÃO}

O Programa Nacional de Desburocratização, criado inicialmente por meio do Decreto $n^{\circ} 83.740$, de 18 de julho de 1979, por Helio Beltrão, que Instituía o Programa Nacional de Desburocratização e das outras providências (BELTRÃO, 1981), foi revogado pelo Decreto $\mathrm{n}^{\circ} 5.378$ de 23 de fevereiro de 2005 que Instituía o Programa Nacional de Gestão Pública e Desburocratização - GESPÚBLICA e o Comitê Gestor do Programa Nacional de Gestão Pública e Desburocratização, e das outras providências, posteriormente, foi revogado pelo atual Decreto $n^{\circ}$ 9.094, de 17 de julho de 2017 que dispõe sobre a simplificação do atendimento prestado aos usuários dos serviços públicos, ratifica a dispensa do reconhecimento de firma e da autenticação em documentos produzidos no País e institui a Carta de Serviços ao Usuário.

Conforme mencionado, o GESPÚBLICA foi revogado, mas a preocupação com o cidadão permaneceu com $\mathrm{O}$ decreto $\mathrm{n}^{\circ} 9.094$ que dispõe sobre simplificação do atendimento prestado aos usuários dos serviços públicos, com isso podemos observar que o foco em combater os excessos das exigências formais, muitas vezes, desnecessárias que atrasam ou impede os cidadãos de receberem serviços e terem seus direitos garantidos, continua em vigor por meio deste decreto.

O Programa Gespública com suas ferramentas foi muito importante para a gestão pública em vários órgãos do Estado de Rondônia, como os supracitados neste estudo. O seus produtos ou ferramentas como também são chamados, a Avaliação Continuada da Gestão Pública, a Carta de Serviço, a Pesquisa de Satisfação e a Simplificação de Processo "O Guia d", nos remete a recordar do ciclo PDCA, por serem utilizadas para a constante melhoria continua dos serviços públicos.

Dessa forma, acredita-se que um programa que necessite de orçamento público no momento de crise financeira que se instalou no país, é difícil manter-se por muito tempo, ainda mais quando não há prioridades corretas.

\section{REFERÊNCIAS BIBLIOGRÁFICAS}

ANDRADE Caio César Vioto de. A trajetória do Ministério Extraordinário para Desburocratização: Entre rupturas e permanências do Estado brasileiro. São Paulo: Universidade Federal de São Carlos, 2013.

Avanço do TRT 14 com adesão ao Gespública é apresentado em encontro da Hemopa no Pará. Ascom TRT 14, $2012 . \quad$ Disponível em:<https://trt14.jusbrasil.com.br/noticias/100117961/avanc os-do-trt-14-com-adesaoaogespublica-e-apresentado-emencontro-da-hemopa-nopara?ref=topic_feed $>$. Acesso em: 11 de ago de 2018.
BELTRÃO, Hélio. Desburocratização e Liberdade. Rio de Janeiro: Record, 1984.

BELTRÃO, Hélio. Programa nacional da desburocratização. Brasília: Palestra promovida pela Academia Brasileira de Ciência de Administração, 1981 - FGV.

Decreto $\mathrm{n}^{\circ} \mathbf{5 . 3 7 8}$, de 23 de fevereiro de 2005. Disponivel em:

<http://www.planalto.gov.br/ccivil_03/_Ato20042006/2005/

Decreto/D5378.htm\#art14>. Acesso em: 11 de ago de 2018.

Decreto no 83.740, de 18 de julho de 1979. Disponível em: <http://www.planalto.gov.br/ccivil_03/Decreto/D83740.htm >. Acesso em: 11 de ago de 2018.

Decreto $\mathrm{n}^{\circ}$ 9.094, de 17 de julho de 2017. Disponível em: <http://www.planalto.gov.br/ccivil_03/_Ato20152018/2017/ Decreto/D9094.htm\#art25>. Acesso em: 11 de ago de 2018.

FERREIRA, André Ribeiro. Modelo de Excelência em Gestão Pública. Revista eixo n. 1, v. 1, 2012.

Gespública - Comitê Gestor Interno reúne servidores representantes do time de excelência do DETRAN-RO. Disponível em: <https://www.detran.ro.gov.br/2015/10/gespublica-comitegestor-interno-reune-servidores-representantes-do-time-deexcelencia-do-detran-ro/>. Acesso em: 11 de ago de 2018.

Gespública debate ações com servidores do TCE. Disponível em: $<$ http://www.tce.ro.gov.br/index.php/gespublica-debateacoes-com-servidores-do-tce/>. Acesso em: 10 de ago de 2018.

Gespública em Rondônia. Disponível em: <http://www.sepog.ro.gov.br/Conteudo/Exibir/265>. Acesso em: 11 de ago de 2018 .

Gespública lança link na intranet. Disponível em: <http://www.tce.ro.gov.br/index.php/gespublica-lanca-linkna-intranet/>. Acesso em: 10 de ago de 2018.

Gespública. Disponível em: <http://www.gespublica.gov.br/>. Acesso em: 08 de ago de 2018.

Gespública/CAERD. Disponível em:<http://caerdro.com.br/gespublica.php>. Acesso em: 08 de agosto de 2018.

GESPÚBLICA: DETRAN recebe certificado de excelência em gestão. Disponível em:<https://www.detran.ro.gov.br/2012/03/gespublicadetran-recebe-certificado-e-excelencia-em-gestao/>. Acesso em: 11 de ago de 2018.

Mensagens Presidenciais (1889-1993). Disponível em: http://www.crl.edu/brazil/presidential. Acesso em: 11 de ago de 2018

MORAES, Marcelo Viana Estevão de. O novo Estado e o ano da gestão. Disponível em: <http://www.gespublica.gov.br/content/o-novo-estado-e-oano-da-gest $\%$ C3\%A3o?page $=34>$. Publicado em 25 Janeiro de 2010. Acesso em: 10 de ago de 2018.

Núcleo Gespública recebe Plano de Melhorias da Gestão do DETRAN. Disponível em: 
<http://www.sepog.ro.gov.br/Noticia/Exibir/404>. Acesso em: 11 de ago de 2018.

O que é o Gespública. Disponível em: <http://www.sepog.ro.gov.br/Conteudo/Exibir/252>. Acesso em: 10 de ago de 2018.

Práticas de gestão do DETRAN são avaliadas com ferramenta do Gespública. Disponível em: <https://www.detran.ro.gov.br/2015/11/praticas-de-gestaodo-detran-sao-avaliadas-com-ferramenta-do-gespublica/>. Acesso em: 11 de ago de 2018.

Produtos Gespública. Disponível em: <http://www.sepog.ro.gov.br/Conteudo/Exibir/33>. Acesso em: 10 de ago de 2018.

Programa Gespública. Modelo de Excelência em Gestão Pública. Brasília: MP, SEGEP, 2014.

TCE-RO adere ao programa Gespública. Disponível em: <http://www.tce.ro.gov.br/index.php/tce-ro-adere-aoprograma-gespublica/>. Acesso em: 10 de ago de 2018.

\section{COPYRIGHT}

Direitos autorais: $\mathrm{O}(\mathrm{s})$ autor(es) é(são) o(s) único(s) responsável(is) pelo material incluído no artigo. 


\title{
É POSSÍVEL APRENDER: REVISÃO NARRATIVA SOBRE O ENSINO DO EMPREENDEDORISMO
}

\author{
IT CAN BE LEARNED: NARRATIVE REVIEW ON ENTREPRENEURSHIP \\ TEACHING
}

\author{
LORRARA SILVYA IMAGAWA DE OLIVEIRA'; RUBENS DE ARAÚJO AMARO. \\ 1 - UFES - UNIVERSIDADE FEDERAL DO ESPÍRITO SANTO. \\ lorrara.imagawa@gmail.com; rubens.amaro@ufes.br
}

\begin{abstract}
Resumo - O presente artigo levantou o estado da arte das pesquisas científicas sobre o ensino do empreendedorismo por meio de uma revisão narrativa dos artigos publicados nos últimos cinco anos encontrados na base de dados Web Of Science por meio dos termos "Ensino do empreendedorismo" "Métodos de ensino do empreendedorismo", "Teaching Entrepreneurship” $e$ "Teaching methods of entrepreneurship" para compreender o foco de pesquisa. Os resultados apontam que as principais metodologias de ensino sugeridas são os cursos onlines, séries de televisão, entrevistas e palestras com empreendedores, plano de negócios, contato com a realidade, análise de casos $e$ incubadoras. Concluímos que o tema demostra ser atual $e$ relevante para a academia, merecendo atenção para pesquisas futuras a partir de novas abordagens de análise, lócus de pesquisa e recortes temporais.
\end{abstract}

Palavras-chave: Ensino do empreendedorismo. Produção científica. Revisão narrativa.

\begin{abstract}
This article has raised the state of the art of scientific research on the teaching of entrepreneurship through a narrative review of the articles published in the last five years found in the Web Of Science database through the terms "Teaching of entrepreneurship" "Teaching methods entrepreneurship, Teaching Entrepreneurship, "and" Teaching methods of entrepreneurship "to understand the focus of research. The results indicate that the main teaching methodologies suggested are online courses, television series, interviews and lectures with entrepreneurs, business plan, contact with reality, case analysis and incubators. We conclude that the theme proves to be current and relevant to the academy, deserving attention for future research from new analysis approaches, research locus and temporal cut - outs.
\end{abstract}

Keywords: Entrepreneurship teaching. Scientific production. Narrative review.

\section{INTRODUÇÃO}

O empreendedorismo se apresenta como meio de desenvolver a economia de regiões e países, bem como gerar emprego e renda (NDABENI, 2008). A produção acadêmica sobre o tema cresceu tanto nos últimos anos que levou Fletcher (2003) a cunhar o termo "movimento empreendedor" para identificar o fenômeno na academia. Embora os primeiros estudos tenham buscado características natas de empreendedores, os trabalhos recentes caminham na direção de que o empreendedorismo pode ser ensinado. A questão passou a ser sobre quais os melhores métodos para ensinar as pessoas a empreender (HAASE; LAUTTNSCHLÄGER, 2009). Al-Atabi e Deboer (2014) afirmam que o empreendedorismo está sendo ensinado cada vez mais como parte de vários programas de ensino. Redford (2015) identifica um processo de reforma educacional com intuito de fortalecer a aprendizagem do empreendedorismo em todos os níveis de ensino. Ismail, Sawang e Zolin (2018) afirmam que as práticas de ensino influenciam no aprendizado e na intenção de empreender. Beliaeva, Laskovaia e Shirokova (2017) afirmam que o ensino do empreendedorismo deve se adaptar a diferentes contextos e culturas, corroborando com as ideias de Dzisi e Odoom (2017). Krakauer, Serra e Almeida (2017) mencionam que o tema empreendedorismo está surgindo nas universidades brasileiras.

O desenvolvimento dos alunos de graduação para se tornarem empreendedores tem sido limitado (BELL, BELL, 2018). A abordagem tradicional de ensino, como exposição e leituras em sala de aula, não são mais suficientes para atender as necessidades da geração atual, tornando-se necessário o uso de práticas inovadoras e criativas para facilitar e consolidar a aprendizagem dos alunos (CARDOW, SMITH, 2015; DZISI, ODOOM, 2017; KASSEAN, et al., 2015; OKEKE, YONG, 2016). Conceitos e métodos inovadores no ensino suprem as necessidades educacionais dos alunos, entretanto, existe a necessidade de apoiar os professores por meio de programas de capacitação para se ensinar práticas empreendedoras de modo criativo (LOMBARDI, et al., 2017; REDFORD, 2015). Ahmad, Abu Bakar, Ahmad (2018) afirmam haver a necessidade de métodos de ensino que permitam uma vivência prática da teoria.

Considerando esse contexto, propomos o seguinte problema de pesquisa: qual o estado da arte das pesquisas científicas sobre o ensino do empreendedorismo nos últimos cinco anos, encontrados na base de dados Web of Science?

\section{METODOLOGIA}

A revisão teórica narrativa não sistemática permite mapear a produção de conhecimento com profundidade, compreendendo seu foco, suas contribuições e limitações 
(ROTHER, 2007). Alguns estudos foram publicados nesse sentido, entretanto, existe uma necessidade de atualizar os dados a partir de uma análise dos últimos 5 anos (SILVEIRA, et al, 2010; SILVA, PENA, 2017; NASSIF, et al, 2010; FERREIRA, PINTO, MIRANDA, 2015). Neste artigo, analisamos a produção científica sobre o ensino do empreendedorismo, a partir de uma revisão narrativa que possibilita encontrar lacunas para pesquisas futuras. A pesquisa caracteriza-se como qualitativa descritiva, com método de análise de dados conforme propõe Gibbs (2009). Os temas pesquisados foram "Ensino do empreendedorismo", "Métodos de ensino do empreendedorismo", "Teaching entrepreneurship" e "Teaching methods of entrepreneurship", para selecionar os artigos e compreender o foco de pesquisa e as definições dos conceitos. A base de dados Web Of Science foi escolhida por conferir confiabilidade e qualidade das produções nacionais e internacionais e permitir analisar as principais práticas de ensino do empreendedorismo. Foram analisados dezessete $(100 \%)$ artigos publicados presentes na base de dados selecionada ao longo dos últimos 5 anos a partir dos termos pesquisados. A Tabela 1 mostra a relação dos artigos selecionados, com indicação do nome dos autores e do ano de publicação.

Tabela 1 - Relação dos títulos dos artigos coletados, autores e ano de publicação

\begin{tabular}{|c|c|c|}
\hline N. & Título do artigo & $\begin{array}{l}\text { Autor(es) e ano } \\
\text { de publicação }\end{array}$ \\
\hline 1 & $\begin{array}{c}\text { Teaching entrepreneurship using } \\
\text { Massive Open Online Course (MOOC) }\end{array}$ & $\begin{array}{c}\text { AL-ATABI e } \\
\text { DEBOER (2014) }\end{array}$ \\
\hline 2 & $\begin{array}{l}\text { Using innovative pedagogies in the } \\
\text { classroom Re-storying Gothic tales as } \\
\text { entrepreneur stories. }\end{array}$ & $\begin{array}{l}\text { CARDOW e } \\
\text { SMITH (2015) }\end{array}$ \\
\hline 3 & $\begin{array}{l}\text { Entrepreneurship education: a need for } \\
\text { reflection, real-world experience and } \\
\text { action. }\end{array}$ & $\begin{array}{l}\text { KASSEAN, } \\
\text { VANEVENHOV } \\
\text { E, LIGUORI e et } \\
\text { al. (2015) }\end{array}$ \\
\hline 4 & $\begin{array}{c}\text { A start-up generation approach for } \\
\text { teaching entrepreneurship: an overview } \\
\text { of affective learning results }\end{array}$ & $\begin{array}{c}\text { LOI e DI } \\
\text { GUARDO (2015) }\end{array}$ \\
\hline 5 & $\begin{array}{l}\text { The use of modern pedagogical } \\
\text { techniques when introducing } \\
\text { information technology students to } \\
\text { entrepreneurship. }\end{array}$ & PARDEDE (2015) \\
\hline 6 & $\begin{array}{l}\text { Entrepreneurial teacher training in } \\
\text { Europe: an overview of European } \\
\text { policies and developments. }\end{array}$ & $\begin{array}{l}\text { REDFORD } \\
\text { (2015) }\end{array}$ \\
\hline 7 & $\begin{array}{l}\text { Entrepreneurs as creators of wealth and } \\
\text { regional development }\end{array}$ & $\begin{array}{l}\text { AGUILAR, } \\
\text { GUEVARA e } \\
\text { JAEN (2016) }\end{array}$ \\
\hline 8 & $\begin{array}{l}\text { Assessment of entrepreneurship } \\
\text { pedagogy on entrepreneurship } \\
\text { knowledge and entrepreneurial human } \\
\text { capital asset: A conceptual model }\end{array}$ & $\begin{array}{l}\text { OKEKE e YONG } \\
\text { (2016) }\end{array}$ \\
\hline 9 & $\begin{array}{l}\text { Entrepreneurial learning and } \\
\text { entrepreneurial intentions: a cross- } \\
\text { cultural study of university students }\end{array}$ & $\begin{array}{l}\text { BELIAEVA, } \\
\text { LASKOVAIA e } \\
\text { SHIROKOVA } \\
\text { (2017) }\end{array}$ \\
\hline 10 & $\begin{array}{c}\text { Entrepreneurship Education and } \\
\text { Training in Higher Educational } \\
\text { Institutions in Ghana }\end{array}$ & $\begin{array}{l}\text { DZISI e ODOOM } \\
(2017)\end{array}$ \\
\hline
\end{tabular}

11 Using experiential learning to teach entrepreneurship: a study with Brazilian undergraduate students

KRAKAUER, SERRA e

ALMEIDA (2017)

12 Emerging trends in entrepreneurial universities within Mediterranean regions An international comparison.

13 Teaching practice across disciplines: marketing and entrepreneurship for youths.

LOMBARDI e et al. (2017)

WORAPISHET (2017)

14 An evaluation of teaching methods of entrepreneurship in hospitality and tourism programs

AHMAD, ABU

BAKAR e AHMAD (2018)

Applying enterprise: active learning environments for business Higher National Diploma students

16 Entrepreneurship education pedagogy: teacher-student-centred paradox

BELL e BELL

ISMAIL, SAWANG e ZOLIN (2018)

17 Beyond "know-what' and "know-how' to "know-who': enhancing human capital with social capital in an Australian startup accelerator

SEET, JONES OPPELAAR e et al. (2018)

Fonte de elaboração: elaborado pelos autores, 2018.

\section{RESULTADOS}

Os artigos analisados elucidam que as práticas didáticas pedagógicas influenciam no desenvolvimento de habilidades empreendedoras e que as práticas para o ensino do empreendedorismo necessitam da aproximação entre teoria adquirida e vivência prática. A experiência real permite um aprendizado dinâmico e autêntico permitindo o desenvolvimento de habilidades empreendedoras. Conforme mostrado na Figura 1, percebe-se que a maioria dos artigos foi publicada em 2015 e 2017, com cinco artigos em cada ano e posteriormente em 2018 com quatro artigos, $2016 \mathrm{com}$ dois artigos e 2014 com um artigo. $\mathrm{O}$ assunto demostra ser relevante como pesquisa durante os últimos anos.

\section{Figura 1 - Anos de publicações dos artigos}

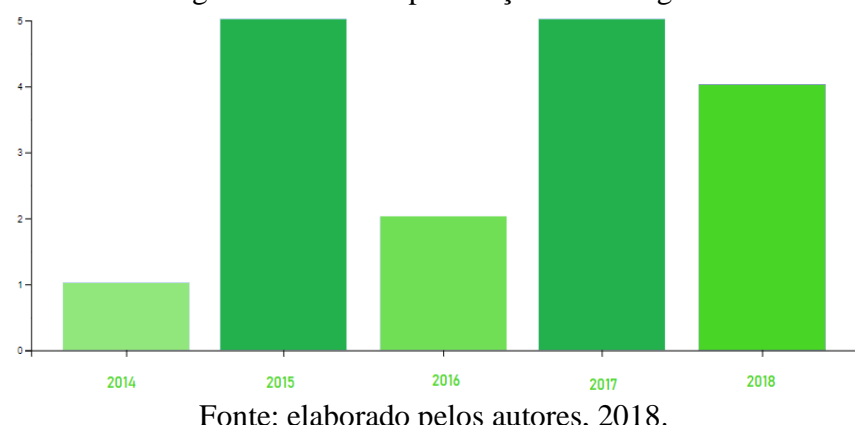

Os dezessete artigos selecionados foram escritos em alguns países, tendo destaque a Austrália, Malásia e EUA, com 3 artigos cada, seguidos pela Inglaterra e Itália com dois artigos e o Brasil e os demais países com um artigo cada, como mostra a Figura 2. 
Figura 2 - País de origem dos artigos.

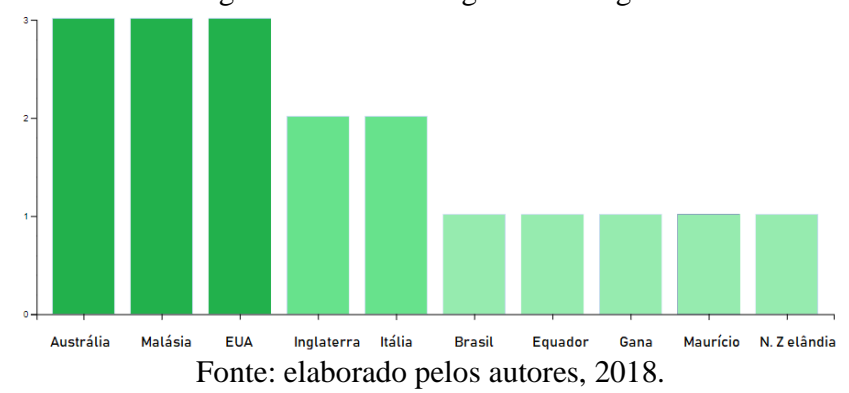

Al-atabi e Deboer (2014) analisam um programa de curso online que é utilizado para promover o ensino do empreendedorismo entre alunos de modo colaborativo e com de aspectos empresariais. O curso é oferecido online com palestras, tutoriais, teste e um projeto para se realizar em grupo e, assim, desenvolver habilidades empreendedoras. Os alunos devem recrutar outros participantes e concluir as tarefas por completo. O curso inclui aspectos para pensar, executar, criar projetos, criar valor, aprender, comunicar, vender, inspirar e agir como um empreendedor trabalhando conceitos como gerenciamento de recursos materiais e humanos, dentre outros pontos. A maioria dos alunos entrevistados começou o curso porque estava planejando iniciar seu próprio negócio ou para fins de progressão na carreira. Os alunos entrevistados indicam que o curso é satisfatório no que se pretende.

Cardow e Smith (2015) abordam uma prática de ensino do empreendedorismo por meio de séries de televisão, com o intuito de aproximar o aluno da realidade empreendedora. Os autores afirmam que os alunos interagem mais com personagens conhecidos do que com exemplos e casos gerenciais distantes de suas realidades. A partir de episódios de uma série de televisão surgem as analogias com o mundo empreendedor. Os exemplos passam de desconhecidos para acessíveis, aproximando os alunos e professores de uma compreensão compartilhada. $\mathrm{O}$ uso da ficção como ferramenta de ensino vem ganhando notoriedade no âmbito acadêmico. Os episódios permitem uma analogia entre o personagem principal e o empreendedor, de modo a fazer conexões entre os episódios e a aplicação da teoria empreendedora aprendida, como: necessidade de se adaptar; entender como alguns setores da sociedade se relacionam com empreendedores; exemplos de negócios que ilustram tomadas de decisão para iniciar um empreendimento, dentre outras conexões.

Bell e Bell (2018) analisam uma prática de ensino do empreendedorismo a partir da criação e implementação de um plano de negócios em equipes para uma loja com acompanhamento dos professores. Palestras foram utilizadas para complementar a atividade. Confiança, criatividade, controle e gerenciamento de conflitos foram algumas habilidades empreendedoras desenvolvidas que podem impactar também na empregabilidade desses alunos. O objetivo da prática de ensino foi conferir oportunidades empresariais reais como processo de educação do empreendedorismo.

Seet e et al. (2018) buscaram investigar a educação empreendedora em uma incubadora a partir de modelos de gerenciamentos estratégicos para negócios, como o Canvas. As técnicas são bem recebidas pelos participantes. Interações com especialistas são promovidas e permitem que os participantes da incubadora aprendam sobre a prática do empreendedorismo a partir da experiência dos especialistas, com exemplos reais de sucesso e fracasso. A partir dessas interações os aprendizes passam a ter uma melhor compreensão do que precisa ser feito ou evitado para desenvolver seu empreendimento.

Worapishet (2017) em seu artigo sugere como prática de ensino a utilização de casos de empreendedorismo, para exemplificar aspectos como conceitos e estratégias do empreendedorismo. Os casos são retirados de entrevistas em profundidade com proprietários e ajudam a esclarecer tópicos ensinados do empreendedorismo. Aguilar, Guevara e Jaen (2016) citam como ferramentas para o ensino de empreendedorismo o plano de negócios, o contato com a realidade e sua interpretação e a análise de casos.

Dzisi e Odoom (2017) seguem convergindo com outros autores e também sugerem palestras, trabalho de campo e plano de negócios. Incubadoras e a elaboração de planos de negócio são sugeridas como importantes no contexto do empreendedorismo, bem como palestras com especialistas para compartilhar seus sucessos e fracassos e possibilitar que os alunos tirem dúvidas (LOI, DI GUARDO, 2015; LOMBARDI, et al., 2017; PARDEDE, 2015).

Conforme Figura 3, cursos online, séries de televisão, entrevistas e palestras com empreendedores, plano de negócios, contato com a realidade, análise de casos e incubadoras, são algumas práticas que se destacam entre os artigos analisados para complementar a metodologia tradicional de ensino feita por meio de aulas expositivas.

Figura 3 - Principais práticas para ensino do empreendedorismo.

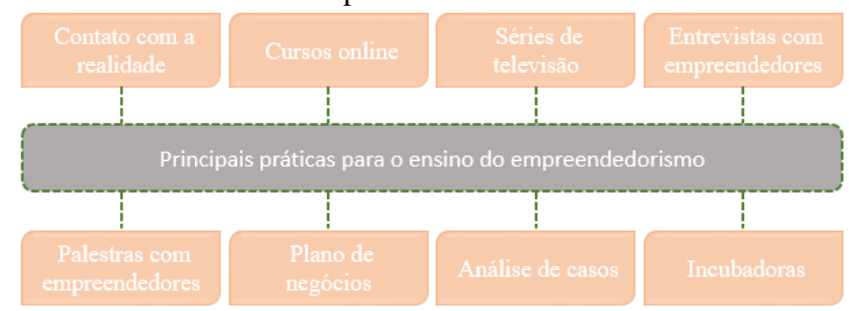

Fonte: elaborado pelos autores, 2018.

\section{CONCLUSÃO}

Por meio da análise dos artigos percebemos que a forma de se ensinar aspectos do empreendedorismo precisa ser dinâmica e possibilitar vivência prática dos conteúdos teóricos adquiridos. Os cursos online são adequados para ensinar empreendedorismo por promover reflexões e aprendizados a partir de situações colaborativas e empresariais. A prática de usar séries de televisão mostrouse como uma forma muito eficaz de envolver os alunos em histórias paralelas a partir de metáforas para aprender aspectos do empreendedorismo sem que tenham tido experiências reais na área. As abordagens experienciais podem preparar os alunos para aprender com os erros em vez de se sentirem sobrecarregados e fracassados.

Esse estudo complementa outros trabalhos de revisão de literaturas existentes sobre empreendedorismo a partir de um novo recorte de tempo e contexto (SILVEIRA, et al, 2010; SILVA, PENA, 2017; NASSIF, et al, 2010; FERREIRA, PINTO, MIRANDA, 2015). Objetivamos pautar a agenda atual sobre o ensino do empreendedorismo sem intenção de esgotar as fontes de informação sobre o tema. O tema demostra ser atual e relevante para a academia, merecendo atenção para pesquisas futuras a partir 
de novas abordagens de análise, lócus de pesquisa e recortes temporais.

\section{REFERÊNCIAS BIBLIOGRÁFICAS}

AGUILAR, L. M. R.; GUEVARA, L. R. V.; JAEN, M. P. F. Entrepreneurs as creators of wealth and regional development Revista Publicando, v. 3, n. 9, p. 566-580, 2016.

AHMAD, S. Z.; ABU BAKAR, A. R.; AHMAD, N. An evaluation of teaching methods of entrepreneurship in hospitality and tourism programs. International Journal Of Management Education, v. 16, n. 1, p. 14-25, 2018.

AL-ATABI, M.; DEBOER, J. Teaching entrepreneurship using Massive Open Online Course (MOOC). Technovation, v. 34, n. 4, p. 261-264, 2014

BELIAEVA, T.; LASKOVAIA, A.; SHIROKOVA, G. Entrepreneurial learning and entrepreneurial intentions: a crosscultural study of university students. European Journal Of International Management, v. 11, n. 5, p. 606-632, 2017.

BELL, H.; BELL, R. Applying enterprise: active learning environments for business Higher National Diploma students. Journal Of Further And Higher Education, v. 42, n. 5, p. 649 661,2018

CARDOW, A.; SMITH, R. Using innovative pedagogies in the classroom Re-storying Gothic tales as entrepreneur stories. Industry And Higher Education, v. 29, n. 5, p. 361-374, 2015.

DZISI, S.; ODOOM, F. Entrepreneurship Education and Training in Higher Educational Institutions in Ghana. Journal Of International Entrepreneurship, v. 15, n. 4, p. 436-452, 2017.

FERREIRA, M. P. V., PINTO, C. F., MIRANDA, R. M. Três décadas de pesquisa em empreendedorismo: uma revisão dos principais periódicos internacionais de empreendedorismo. Revista eletrônica de administração REAd, v. 81, n. 2, p. 406-436, 2015.

FLETCHER, D. Framing organizational emergence: discourse, identity and relationship. In: STEYAERT, C.; HJORTH, D. (Ed.). New movements in entrepreneurship. Massachusetts: Edward Elgar, 2003.

GIBBS, G. Análise de dados qualitativos. Porto Alegre: Artmed, 2009.

HAASE, H.; LAUTTNSCHLÄGER, A. Impact of a simulationbased pedagogy in entrepreneurship education: comparative insights from Germany, Spain, Thailand and China. International Review of Entrepreneurship, v. 7, n. 4, p. 327-352, Senate Hall Academic Publishing, 2009.

ISMAIL, A. B. T.; SAWANG, S.; ZOLIN, R. Entrepreneurship education pedagogy: teacher-student-centred paradox. Education and Training, v. 60, n. 2, p. 168-184, 2018.

KASSEAN, H.; et al. Entrepreneurship education: a need for reflection, real-world experience and action. International Journal Of Entrepreneurial Behaviour \& Research, v. 21, n. 5, p. 690-708, 2015.

KRAKAUER, P. V. C.; SERRA, F. A. R.; ALMEIDA, M. I. R. Using experiential learning to teach entrepreneurship: a study with Brazilian undergraduate students. International Journal Of Educational Management, v. 31, n. 7, p. 986-999, 2017.

LOI, M.; DI GUARDO, M. C. A start-up generation approach for teaching entrepreneurship: an overview of affective learning results. Journal Of Developmental Entrepreneurship, v. 20, n. 4, número do artigo: 1550027, 2015.

LOMBARDI, R.; et al. Emerging trends in entrepreneurial universities within Mediterranean regions An international comparison. Euromed Journal Of Business, v. 12, n. 2, p. 130145, 2017.

NASSIF, V. M. J., et al. Empreendedorismo: área em evolução? Uma revisão dos estudos e artigos publicados entre 2000 e 2008. Revista de Administração e Inovação, v. 7, n. 1, p. 175-192, 2010

NDABENI, L. L. The contribution of business incubators and technology stations to small enterprise development in South Africa, Development Southern Africa, v. 25, n. 3, p. 259-268, September, 2008.

OKEKE, C. O.; YONG, D. G. F. Assessment of entrepreneurship pedagogy on entrepreneurship knowledge and entrepreneurial human capital asset: A conceptual model. Knowledge Management \& E-Learning-An International Journal, v. 8, n.2, p. 243-258, 2016.

PARDEDE, E. The use of modern pedagogical techniques when introducing information technology students to entrepreneurship. Teaching In Higher Education, v. 20, n. 6, p. 636-651, 2015.

REDFORD, D. T. Entrepreneurial teacher training in Europe: an overview of European policies and developments. Journal For Educators Teachers And Trainers, v. 6, n. 2, p. 18-34, 2015.

ROTHER, E. T. Revisão sistemática $x$ revisão narrativa. Acta paulista de enfermagem, v. 20, n. 2, p. v-vi, 2007.

SEET, P.; et al. Beyond "know-what' and "know-how' to "knowwho': enhancing human capital with social capital in an Australian start-up accelerator. Asia Pacific Business Review, v. 24, n. 2, p. 233-260, 2018.

SILVA, J. F. D.; PENA, R. P. M. O "bê-á-bá" do ensino em empreendedorismo: uma revisão da literatura sobre os métodos e práticas da educação empreendedora. Revista de Empreendedorismo e Gestão de Pequenas Empresas, v.6, n.2, p. 372-401. 2017.

SILVEIRA, A.; et al. Empreendedorismo: produção científica na Base scielo 2004-2008. Revista de Administração FACES Journal, v. 9, n. 3, p. 13-32, 2010.

WORAPISHET, T. Teaching practice across disciplines: marketing and entrepreneurship for youths. Journal For International Business And Entrepreneurship Development, v. 10, n. 3, p. 258-272, 2017.

\section{COPYRIGHT}

Direitos autorais: Os autores são os únicos responsáveis pelo material incluído no artigo. 


\author{
Volume $14-\mathrm{N}^{\mathrm{o}} 159$ - Março/2019. \\ XL International Sodebras Congress \\ 10 a 12 de dezembro de 2018 - Vitória - ES.
}

\title{
EFEITOS DA ESTRUTURA DE MERCADO E DA POSIÇÃO COMPETITIVA NO DESEMPENHO DA FIRMA, EM TEMPOS DE CRISE
}

\author{
EFFECTS OF MARKET STRUCTURE AND COMPETITIVE POSITION ON \\ FIRM'S PERFORMANCE IN TIMES OF CRISIS
}

\author{
ALEXANDRE TEIXEIRA DIAS ${ }^{1}$; SEBASTIÃO NUNES ROCHA DE SOUZA ${ }^{1}$; MARCELO BARBOSA \\ COSTA $^{1}$; ALEXANDRE GABRIEL FONTENELLE ${ }^{1}$
}

\section{1 - PROGRAMA DE DOUTORADO E MESTRADO EM ADMINISTRAÇÃO - UNIVERSIDADE FUMEC}

\begin{abstract}
alexandre.tdias@fumec.br; snrsadm@hotmail.com; marcelo.barbosa2006@yahoo.com.br;
agfontenelle@gmail.com
\end{abstract}

\begin{abstract}
Resumo - O objetivo principal deste trabalho foi identificar quais as influências exercidas pela estrutura do mercado e pela posição competitiva da firma no seu desempenho, em tempos de crise. Para alcançar tal objetivo foram analisados, por meio de regressão múltipla, dados de empresas americanas de capital aberto, ativas nos anos de 2007, 2008 e 2009, inseridas em várias indústrias $e$ identificadas influências de intensidades diferentes das dimensões da estrutura de mercado em cada período, ao passo que a posição competitiva da firma apresenta efeitos semelhantes nos diferentes periodos. Os resultados apontam para uma maior influência da Rivalidade na indústria na variação do desempenho nos três períodos em análise, sendo que o Dinamismo somente se mostra relevante no ano de 2009 e a Concentração nos anos de 2008 e 2009.

Palavras-chave: Análise de regressão múltipla. Ambiente competitivo. Crise financeira. Desempenho. Posição competitiva.
\end{abstract}

Abstract - The main objective of this work was to identify the influences exerted by the market structure and the firm's competitive position in its performance in times of crisis. To achieve this objective, we analyzed data from publicly traded American companies, active in the years 2007, 2008 and 2009, inserted in various industries, by means linear multiple regression, and identified influences of different intensities from the dimensions of the market structure in each period, while the firm's competitive position has similar effects in the different periods. The results point to a greater influence of the rivalry in the industry in the variation of performance in the three periods under analysis, and the dynamism only shows relevance in the year 2009 and the concentration in the years 2008 and 2009.

Keywords: Multiple regression analysis. Competitive environment. Financial crisis. Performance. Competitive position.

\section{INTRODUÇÃO}

Quando consideradas as várias forças que atuam no ambiente competitivo, diferentes estratégias são requeridas por parte das empresas para responder à estrutura de mercado, sendo que tal estrutura pode ser compreendida por meio de vários componentes que determinam mark-up das empresas, envolvendo o tamanho e o número das firmas, os tipos de produtos desenvolvidos, a possibilidade de economias de escala, as barreiras de entrada, entre outros
(LIPCZYNSKI e WILSON, 2004). Compreender estas características de determinada indústria e consequentemente seu ambiente competitivo se torna essencial para o desenvolvimento de estratégias adequadas para o atingimento do desempenho esperado, uma vez que este depende da adoção de estratégias apropriadas, alinhadas às características da estrutura de mercado no qual as firmas estão inseridas (PEREIRA e BÁNKUTI, 2016).

Scherer e Ross (1990) propõem um modelo conceitual para análise da vantagem competitiva baseado na EstruturaConduta-Desempenho das firmas, sendo que o desempenho se apresenta como consequência das condutas ou dos comportamentos dos vendedores e dos compradores, das práticas e das políticas de determinação de preços, da cooperação tácita entre firmas, da linha de produtos e estratégias de divulgação, dos gastos com pesquisa e desenvolvimento, dos investimentos em técnicas de produção, das táticas legais e assim por diante. A conduta ou o comportamento, depende da estrutura predominante do mercado, caracterizada pelo número e pelo tamanho dos ofertantes e dos demandantes, pela presença ou ausência de barreiras de entrada de novas firmas, pelas formas das curvas de custo, pelo grau de integração vertical das firmas, entre outros fatores.

Neste contexto, a vantagem competitiva em relação às premissas de concorrência, pode ser compreendida a partir da observação e constatação das posições de mercado ocupadas pela organização em quatro posições: i) em desvantagem/inferioridade competitiva; ii) paridade competitiva; iii) vantagem temporária e iv) vantagem sustentável (HUNT e ARNETT, 2004; HUNT e DAVIS, 2012).

Também tem-se os trabalhos de Brito (2006), em que o autor realiza uma análise multinível relacionada aos efeitos do tamanho no desempenho da firma; e de Rumelt (1977), focado nas estratégias de diversificação e na sua relação com o desempenho financeiro e aqueles que os tomam por referência (BETTIS, 1981; HILL e HANSEN, 1991; KEATS, 1990; STIMPERT e DUHAIME, 1997) e das estratégias de diversificação com a lucratividade das firmas 
(RUMELT, 1982). Outro trabalho que merece destaque é o desenvolvido por Amit e Livnat (1988), que tecem considerações sobre o conceito de diversificação de conglomerados e suas relações com variações no contexto macroeconômico.

Assumindo-se que as informações econômicas e financeiras são as principais referências para a tomada de decisões no contexto empresarial e, considerando-se as demonstrações contábeis uma de suas principais fontes (PALEPU e HEALY, 2008), torna-se relevante o estudo da relação entre estrutura de mercado, posição competitiva e desempenho da firma com base no uso de métricas contidas na estrutura das demonstrações contábeis. É neste ponto que os postulados contábeis demostram guardar um alinhamento (aproximação) com as premissas do arcabouço conceitual da estratégia e da vantagem competitiva, no contexto da estrutura e das características de mercado (HENDRIKSEN e VAN BREDA, 1999).

Dentre os constructos representativos do desempenho mais frequentemente utilizados em pesquisas relacionadas à sua determinação, identificados por Combs, Crook e Shook (2005), será considerado nesta pesquisa o Retorno sobre o Patrimônio como variável resposta, assim como o ambiente competitivo e a posição competitiva da firma como constructos preditores. De acordo com Richard, Devinney, Yip e Johnson (2009, p. 719), “[o] desempenho é a variável dependente final para os pesquisadores interessados em praticamente qualquer área da administração.” Logo, por ser o avanço na compreensão de fatores determinantes do desempenho da firma o objetivo deste estudo, pode-se considerar então o desempenho como variável resposta.

Diante do apresentado, coloca-se como proposta principal deste trabalho a resposta à questão: Quais os efeitos da estrutura de mercado e da posição competitiva no desempenho de firmas americanas de capital aberto?

A definição do grupo de organizações com características e objetivos semelhantes é demasiado complexa, tornando quase impossível a colocação dos limites do segmento da indústria de atuação de modo exato e imutável (PORTER, 2004). A escolha destes limites define as características do ambiente oriundo da ação da concorrência, e a alteração destes limites consequentemente altera este ambiente, bem como o impacto dos efeitos deste sobre a firma.

$\mathrm{Na}$ busca de compreender o conjunto de características externas que afetam simultaneamente várias firmas concorrentes entre si, e pelo ambiente competitivo se tratar de uma particularidade externa comum a várias firmas, o impacto do contexto ambiental sobre a firma deve ser considerado na análise. A importância de incluir o constructo ambiente nos estudos de desempenho encontra justificativa na tese desenvolvida por Brito (2011, p. 56) a qual pontua que "em diferentes contextos, as empresas buscam resultados distintos (...) o desempenho organizacional é algo específico da escolha estratégica de cada empresa".

A competição por melhores resultados em seu ambiente da indústria tem levado os gestores a considerarem uma ampla gama de aspectos relacionados ao processo de tomada de decisão, objetivando a alocação ótima de recursos, a exploração efetiva das capacidades organizacionais, o estreitamento do relacionamento com os atores do ambiente competitivo, e desenvolvendo competência estratégica que propicie melhores níveis de desempenho (DIAS, 2009, p. 16).

Em se tratando da relação existente entre o dinamismo ambiental e sua importância sob a ótica longitudinal de análise, Simerly e Li (2000, p. 38) relatam que o aumento do dinamismo ambiental faz crescer nos gestores e demais personagens envolvidos com os negócios da firma a incerteza, e consequentemente, a incapacidade de prever com eficiência as condições ambientais, tanto do futuro quanto no presente.

Esta habilidade de previsão, quando ampliada, é capaz de aumentar potencialmente o impacto positivo na tomada de decisão acerca das atividades da firma, determinando as alternativas mais viáveis a serem seguidas pelos gestores. Em outras palavras, pode-se dizer que o aumento do dinamismo ambiental reduz o acesso ao conhecimento necessário para tomar decisões críticas em curto, médio e longo prazo. Desta maneira, como cada firma adota estratégias diferentes a fim de lidar com as mesmas exposições ambientais, infere-se que o sucesso, que pode ser parcialmente mensurado pelo desempenho, também será observado de maneira distinta; haja vista o posicionamento de cada uma frente às flutuações oriundas do ambiente, ou seja, frente ao dinamismo ambiental (SIMERLY e LI, 2000).

Neste mesmo sentido, a análise de várias pesquisas empíricas - Duncan (1972), Milliken (1987) ${ }^{1}$, Milliken $(1990)^{2}$ e Tung $(1979)^{3}$ apud Simerly e Li (2000) demonstra que uma maior incerteza sobre os aspectos ambientais está associada com o maior dinamismo ambiental, dinamismo este que é definido como o produto de várias forças operando em um mesmo tempo e que é mensurado, nos estudos de Dess e Beard (1984), como a taxa de instabilidade relacionada às mudanças ambientais.

Com base nas colocações anteriores, tem-se a proposição da hipótese:

$H_{1}$ - Quanto mais favorável a estrutura de mercado (mensurada em termos de dinamismo, concentração $e$ rivalidade), maior o desempenho da firma (mensurado em termos de Retorno sobre o Patrimônio).

Segundo Brito e Brito (2012) ao se abordar a busca por um desempenho superior, a questão mais importante é saber quais aspectos e variáveis de desempenho revelam o valor criado pela empresa e podem refletir com fidelidade a sua posição competitiva, isto é, como atribuir vantagem competitiva a uma empresa pelo estudo do seu desempenho. Para tal, faz-se necessário relacionar as medidas de desempenho com a abordagem teórica e o conceito de vantagem competitiva.

${ }^{1}$ Milliken, F. J. Three types of perceived uncertainty about the environment: State, effect, and response uncertainty. Academy of Management Review, v. 12, p. 133-143, 1987.

${ }^{2}$ Milliken, F. J. Perceiving and interpreting environmental change: An examination of college administrators' interpretation of changing demographics. Academy of Management Journal, v. 33, p. 42-63, 1990.

${ }^{3}$ Tung, R. L. Dimensions of organizational environments: An exploratory study of their impacts on organizational structure. Academy of Management Journal, v. 22, p. 672-693,1979. 
A década de 80 marca uma mudança de foco nos estudos na temática da estratégia, de modo que a vantagem competitiva passa a assumir uma posição central, ganhando maior relevância nas pesquisas sobre o assunto (REED e DEFILLIPPI, 1990). Estas pesquisas permitiram aos autores desenvolver aquilo que se entende por uma superioridade concorrencial, e a vantagem competitiva passa a ser diretamente associada ao desempenho superior e lucro econômico da empresa (AMIT e SCHOEMAKER, 1993; FOSS e KNUDSEN, 2003; MINTZBERG e QUINN, 1996; PETERAF, 1993; SOUTH, 1981; VASCONCELOS e BRITO, 2004). Com isto, a rentabilidade acima da média torna-se evidência da existência de uma vantagem competitiva; em uma relação causal direta e perfeita, os dois conceitos - vantagem competitiva e desempenho - passam a ser intercambiados nos estudos de estratégia (POWELL, 2001).

Observa-se o conceito de vantagem competitiva como a perspectiva de criação de maior valor econômico para a empresa, em relação ao concorrente (PETERAF e BARNEY, 2003; BRIDOUX, 2004). Além de Wernerfelt (1984), a concepção de vantagem competitiva aliada a Visão Baseada em Recursos teve mais contribuições nos trabalhos de Barney (1986) e Rumelt (1987) e em ambos, pode-se observar que a criação de vantagem competitiva na empresa tinha como produto final o desempenho superior.

O crescimento pode, eventualmente, levar a ganhos de escala que também se refletem na diminuição de custos e em maior lucratividade. No entanto, é importante considerar que o crescimento é uma forma de desempenho em si. O posicionamento de preço em relação à média do mercado determina tanto o potencial de crescimento como o nível de lucratividade, e os dois resultados de desempenho podem ser combinados ou individualmente favorecidos em diferentes momentos estratégicos. Entre outros, a estratégia de crescimento pode acelerar o acúmulo de conhecimento sobre a experiência de compra e uso do produto, e assim aumentar a utilidade percebida pelos clientes (PRIEM, 2007).

A possibilidade de diferentes estratégias suscita a ideia de que há um ponto ótimo de equilíbrio entre lucratividade e crescimento. Isso ressalta a importância do apreçamento como um complexo efeito moderador na relação entre vantagem competitiva e o desempenho financeiro. Como principal responsável pelas decisões estratégicas, o gestor tem o dilema de lidar com as escolhas de maximização do lucro ou do crescimento, conhecendo o melhor momento para cada decisão (CUBBIN e LEECH, 1986; PENROSE, 1959; SLATER, 1980). Portanto, à empresa com vantagem competitiva são possíveis diferentes combinações, apreçamento, e, assim, diferentes resultados de desempenho. O excedente do cliente é função direta da definição do preço, mas já o lucro dependerá da negociação do custo, o que acontece no processo de barganha com fornecedores, gestores e empregados. Brito e Brito (2012) complementam que a capacidade de manobra da firma dependerá do valor adicionado pela empresa. Em posição de vantagem competitiva, a empresa pode escolher estratégias que trazem um desempenho financeiro superior, seja lucratividade e/ou crescimento. Já empresas em paridade ou desvantagem não podem alcançar os mesmos resultados, sendo que para crescer, empresas com paridade competitiva têm que aumentar o excedente do cliente e sacrificar sua lucratividade; para conseguir lucratividade acima da média, podem perder mercado.

Assim, a posição competitiva da empresa será diretamente influenciada pelas configurações da competição na indústria em que ela atua, assim como influenciará o seu nível de desempenho, tanto em termos de expansão de mercado quanto em termos de lucratividade.

$\mathrm{H}_{2}$ - Quanto mais favorável a posição competitiva da firma (identificada em termos de vantagem, desvantagem $e$ paridade competitiva), maior o seu desempenho (mensurado em termos de Retorno sobre o Patrimônio).

\section{METODOLOGIA}

A pesquisa foi viabilizada por meio da análise de dados secundários. Para tanto, utilizou-se como unidades de análise firmas americanas de capital aberto, ativas no período 2007 a 2009, que apresentaram informações contábeis na base Economatica ${ }^{\circledR}$. Por limitações inerentes à disponibilidade de dados, compuseram a amostra firmas das indústrias: de alimentos, de computadores e produtos eletrônicos, de equipamentos de transporte, de máquinas, de papel, de produtos de metal, de produtos de petróleo e carvão, de produtos de plástico e borracha, química, siderurgia e indústria básica de outros metais e outras indústrias. Foram selecionadas 202 firmas em 2007, 200 firmas em 2008 e 200 firmas em 2009, após a exclusão de outliers.

O modelo de referência é apresentado na Equação 1 e considera a regressão a partir da origem, com o objetivo de viabilizar a comparação entre os parâmetros estimados para das variáveis independentes. A posição competitiva foi mensurada por meio de variáveis dummy, com a posição de vantagem competitiva como referência. Assim, os coeficientes negativos apurados para as variáveis PARidade e DESvantagem apontam para a redução do nível de desempenho, quando a firma está na posição competitiva de Paridade ou na posição competitiva de Desvantagem e as condições da estrutura de mercado são mantidas, ao passo que um incremento no nível de desempenho será apurado, caso a posição competitiva da firma seja de Vantagem.

Na próxima seção são apresentados os resultados da estimação dos parâmetros do modelo.

$$
\begin{aligned}
& \mathrm{ROE}=\beta_{1} \mathrm{DIN}+\beta_{2} \mathrm{RIV}+\beta_{3} \mathrm{CONC}+\beta_{4} \mathrm{PAR}+\beta_{5} \mathrm{DES} \\
& +\beta_{6} \mathrm{TAM}+\varepsilon
\end{aligned}
$$

\section{Onde:}

ROE = Retorno sobre o patrimônio (Return on Equity)

DIN $=$ Dinamismo

RIV $=$ Rivalidade

CONC $=$ Concentração

PAR = Paridade competitiva (variável dummy)

DES = Desvantagem competitiva (variável dummy)

TAM $=$ Tamanho da firma (variável de controle)

$\varepsilon=$ Termo de erro aleatório

A análise de regressão múltipla foi utilizada como técnica para o processamento dos dados, com o objetivo de testar as hipóteses propostas. Para todas as equações finais apresentadas foram confirmadas as suposições de normalidade e homocedasticidade por meio da análise de resíduos, validando os modelos apresentados. Já a suposição de autocorrelação dos resíduos não foi considerada nestes 
modelos, haja vista que os dados não foram obtidos de modo sequencial em um mesmo processo, mas como resultados oriundos de diferentes firmas, tornando a ordem dos dados, e consequentemente este passo da análise, desnecessário. Para todos os casos considerou-se um nível de significância de $5 \%(\alpha=0,050)$ e as análises foram efetuadas com o uso do software IBM SPSS 19 ®.

\section{RESULTADOS}

Observando-se os resultados da estimação dos parâmetros, o modelo proposto apresentou elevada capacidade explicativa da variância do Retorno Sobre o Patrimônio (ROE), de 71,80\% em 2007, de 50,70\% em 2008 e de $64,60 \%$ em 2009. A variável de controle Tamanho da firma (TAM) se mostra estatisticamente significante em todos os períodos.

No ano de 2007 as variáveis Dinamismo e Concentração não apresentam significância estatística, ao passo que a variável Rivalidade apresenta efeito positivo $(\beta=0,528$; $\mathrm{p}$-valor $<0,100)$. Tais resultados apontam para uma maior influência da Rivalidade no desempenho da firma, ao passo que o Dinamismo e o grau de Concentração não se mostram fatores relevantes para a determinação da variação do desempenho das firmas. Em 2008, o Dinamismo continua a não apresentar efeito estatisticamente significante, a Rivalidade aumenta seu efeito positivo $(\beta=0,885$; $p$-valor $<0,050)$ no desempenho, que também passa a sofrer a influência negativa da Concentração ( $\beta=-0,866$; p-valor < 0,050). Tais resultados indicam que quanto maior a Rivalidade e menor a Concentração de mercado, maior será o Retorno sobre o Patrimônio. Já em 2009, o Dinamismo passa a exercer influência negativa no desempenho $(\beta=-0,801$; p-valor < $0,010)$, com incremento dos efeitos da Rivalidade $(\beta=$ $1,782$; p-valor $<0,010)$ e da Concentração $(\beta=-1,487$; pvalor $<0,010)$.

\section{1 - Análise das Hipóteses}

Tendo em vista que a estrutura de mercado mais favorável é caracterizada por um maior nível de Dinamismo (sinal positivo do coeficiente), um menor nível de Rivalidade (sinal negativo) e uma menor Concentração (sinal negativo), os resultados apresentados levam à rejeição da primeira hipótese de pesquisa $\left(H_{1}-\right.$ Quanto mais favorável a estrutura de mercado (mensurada em termos de dinamismo, concentração e rivalidade), maior o desempenho da firma (mensurado em termos de Retorno sobre o Patrimônio), para os três períodos em análise, em função tanto da não significância estatística do efeito do Dinamismo no desempenho, nos anos de 2007 e 2008, quanto do sinal negativo do efeito apurado no ano de 2009 , além da não significância estatística do efeito da Concentração no ano de 2007 e do sinal positivo do efeito estatisticamente significante da Rivalidade no desempenho, para os três períodos em consideração.

Quanto às influências da posição competitiva no desempenho da firma, apuradas por meio das influências das variáveis PAR e DES, os parâmetros negativos e estatisticamente significantes estimados para os três períodos em análise permitem a não rejeição da segunda hipótese $\left(\mathrm{H}_{2}-\right.$ Quanto mais favorável a posição competitiva da firma (identificada em termos de vantagem, desvantagem $e$ paridade competitiva), maior o seu desempenho (mensurado em termos de Retorno sobre o Patrimônio), para os três períodos em análise.

A posição competitiva da firma foi mensurada por meio de variáveis dummy, com a posição de vantagem competitiva como referência, ou seja, identificada quando as variáveis PAR e DES assumem valor zero. Assim, os coeficientes negativos apurados para as variáveis PAR e DES apontam para a redução do nível de desempenho, quando a firma está na posição competitiva de Paridade ou na posição competitiva de Desvantagem e as condições da estrutura de mercado são mantidas, ao passo que um incremento no nível de desempenho será apurado, caso a posição competitiva da firma seja de Vantagem, anulando os efeitos das outras variáveis dummy.

\section{CONCLUSÃO}

O processamento dos dados de firmas americanas de capital aberto, por meio de regressões múltiplas, para os anos de 2007, 2008 e 2009, foi possível responder à pergunta de pesquisa: Quais os efeitos da estrutura de mercado e da posição competitiva no desempenho de firmas americanas de capital aberto?

Os resultados apontam para uma influência significativa da Rivalidade do mercado no desempenho da firma nos três períodos analisados, indicando a maior relevância de aspectos ligados à atuação dos rivais na busca por uma maior parcela no orçamento dos consumidores, em relação ao Dinamismo e à Concentração do mercado, quando considerada a determinação da variação do retorno sobre o patrimônio. Também foi identificada a influência da posição competitiva no desempenho da firma, nos três períodos analisados, com as posições de Desvantagem e Paridade competitiva exercendo influência negativa e significativa na variação do desempenho; consequentemente a posição de Vantagem competitiva exerce influência positiva no desempenho.

Como sugestão para pesquisas futuras tem-se a realização da análise das interações entre a estrutura de mercado e a posição competitiva, além da consideração de outros períodos na pesquisa.

\section{REFERÊNCIAS BIBLIOGRÁFICAS}

AMIT, R.; LIVNAT, J. A concept of conglomerate diversification. Journal of Management, v. 14, n. 4, p. 593-604, 1988.

AMIT, R.; SCHOEMAKER, P. J. H. Strategic assets and organizational rent. Strategic Management Journal, v. 14, n. 1, p. 33-46, 1993.

BARNEY, J. B. Types of competition and the theory of strategy: toward an integrative framework. Academy of Management Review, v. 11, n. 4, p. 791-800, 1986.

BETTIS, R. A. Performance differences in related and unrelated diversified firms. Strategic Management Journal, v. 2, n. 4, p. 379-393, 1981.

BRIDOUX, Flore et al. A resource-based approach to performance and competition: an overview of the connections between resources and competition. UCL, 2004.

BRITO, L. A. L. A multilevel analysis of firm performance the effect of firm size. In: ENCONTRO NACIONAL DE PROGRAMAS DE PÓS-GRADUAÇÃO EM ADMINISTRAÇÃO, 30, 2006, Salvador (BA). Anais...Rio de Janeiro: ANPAD, 2006. 
BRITO, R. P. Criação de valor, vantagem competitiva e seu efeito no desempenho financeiro das empresas. 2011. 156p. Tese (Doutorado) - Escola de Administração de Empresas de São Paulo, Fundação Getúlio Vargas, São Paulo, 2011.

BRITO, R. P. de; BRITO, L. A. L. Vantagem competitiva, criação de valor e seus efeitos sobre o desempenho. RAE - Revista de Administração de Empresas [online], v.52, n.1, pp.70-84, 2012. ISSN 0034-7590. http://dx.doi.org/10.1590/S003475902012000100006 .

COMBS, J. G.; CROOK, T. R.; SHOOK, C. L. The dimensionality of organizational performance and its implications for strategic management research. In: KETCHEN, JR. D.; BERGH, D. D. Research Methodology in Strategy and Management. Elsevier: Kidlington, UK, 2005.

CUBBIN, J.; LEECH, D. Growth versus profit-maximization: a simultaneous-equations approach to testing the marris model. Managerial and Decision Economics, v. 7, n.2, 123-131, 1986. doi: 10.1002/mde.4090070209.

DESS, G. G.; BEARD, D.W. Dimensions of Organizational Task Environments. Administrative Science Quarterly. v. 29, n. 1, p. $52-73,1984$.

DIAS, A. T. Análise do papel das estratégias corporativas nas relações entre ambiente e desempenho. 2009. 184p. Tese (Doutorado) - Centro de Pós-graduação e Pesquisa em Administração, Faculdade de Ciências Econômicas, Universidade Federal de Minas Gerais, Belo Horizonte, 2009.

DUNCAN, R. B. Characteristics of organizational environments and perceived environmental uncertainty. Administrative Science Quarterly, v. 17, n. 3, p. 313-327, 1972.

FOSS, N. J.; KNUDSEN, T. The resource-based tangle: towards a sustainable explanation of competitive advantage. Managerial \& Decision Economics, v. 24, n. 4, p. 291-307,2003.

HENDRIKSEN, E. S.; VAN BREDA, M. F. Teoria da contabilidade. 5. ed. São Paulo: Atlas, 1999.

HILL, C. W. L.; HANSEN, G. S. A longitudinal study of the cause and consequences of changes in diversification in the U.S. pharmaceutical industry 1977-1986. Strategic Management Journal, v. 12, n. 3, p. 187-199, 1991.

HUNT, S. D.; ARNETT, D. B. Market Segmentation Strategy, Competitive Advantage, and Public Policy: Grounding Segmentation Strategy in Resource-Advantage Theory. Australasian Marketing Journal (AMJ), v. 12, n. 1, p. 7-25, jan. 2004.

HUNT, S. D.; DAVIS, D. F. Grounding supply chain management in Resource-Advantage Theory: in defense of a Resource-Based View of the firm. Journal of Supply Chain Management, v. 48, n. 2, p. 12, 2012.

KEATS, B. W. Diversification and business economic performance revisited: issues of measurement and causality. Journal of Management, v. 16, n. 1, p. 61-72, 1990.

LIPCZYNSKI, J.; WILSON, J. The economics of business strategy. Prentice Hall - Financial Times, 2004.

MINTZBERG, H.; QUINN, J. B. The Strategy Process: Concepts, Contexts and Cases. Upper Saddle River, NJ: PrenticeHall, 1996.

PALEPU, K. G.; HEALY P. M. Business Analysis \& Valuation: Using Financial Statements, $4^{\circ}$ ed. Thomson South-Western, 2008.

PENROSE, E.. The theory of the growth of the firm (3th ed.). Oxford, UK: Oxford University Press, 1959.
PEREIRA, J. A.; BÁNKUTI, S. M. S. Estrutura de Mercado e Estratégia: um Estudo na Indústria Brasileira de Baterias Automotivas. Revista Ibero-Americana de Estratégia, v. 15, n. 1, p. 97-115, 2016.

PETERAF, M. A. The cornerstones of competitive advantage: a resource-based view. Strategic Management Journal, v. 14, n. 3, p. 179-191, 1993.

PETERAF, M. A.; BARNEY, J. B. Unraveling the resource-based tangle. Managerial and Decision Economics, v. 24, n. 4, p. 309323, 2003.

PORTER, M. E. Estratégia competitiva: técnicas para análise de indústrias e da concorrência. 12. ed. Rio de Janeiro: Campus, 2004.

POWELL, T. C. Competitive advantage: logical and philosophical considerations. Strategic Management Journal, v. 22, n. 9, p. 875-888, 2001.

PRIEM, R. L. A consumer perspective on value creation. Academy of Management Review, v. 32, n. 1, p. 219-235, 2007. doi: 10.5465/AMR.2007.23464055.

REED, R.; DEFILLIPPI, R. J. Causal ambiguity, barriers to imitation, and sustainable competitive advantage. Academy of Management Review, v. 15, n. 1, p. 88-102, 1990.

RICHARD, P. J.; DEVINNEY, T. M.; YIP, G. S.; JOHNSON, G. Measuring organizational performance: towards methodological best practice. Journal of Management. v. 25, n. 3, p. 718-804, 2009.

RUMELT, R. P. Corporate diversification strategies and financial performance. Working Paper MGL-54, Managerial Studies Center, University of California Los Angeles, 1977.

RUMELT, R. P. Diversification strategy and profitability. Strategic Management Journal, v. 3, n. 4, p. 359-369, 1982.

RUMELT, R. P. Theory, strategy and the entrepreneurship. In: TEECE, D. J. The competitive challenge: strategies for industrial innovation and renewal. Cambridge, MA : Harper and Row, 1987. p. 137-158.

SCHERER, F. M; ROSS, D. Industrial market structure and economic performance. EUA: Houghton Mifflin Company, 1990.

SIMERLY, R. L.; LI. M. Environmental dynamism, capital structure and performance: a theoretical integration and an empirical test. Strategic Management Journal. v. 37, p. 686-697, 2000.

SLATER, M. The managerial limitation to a firm's rate of growth. The Economic Journal, v. 90, n. 359, p. 520-528, 1980.

SOUTH, S. E. Competitive advantage: the cornerstone of strategic thinking. The Journal of Business Strategy, v. 1, n. 4, p. 15-25, 1981.

STIMPERT, J.L., DUHAIME, I. M. Seeing the big picture: the influence of industry, diversification, and business strategy on performance: Academy of Management Journal, v. 40, n. 3, p. 560-583, 1997.

VASCONCELOS, F. C.; BRITO, L. A. L. Vantagem competitiva: o construto e a métrica. RAE - Revista de Administração de Empresas, v. 44, n. 2, p. 70-82, 2004.

WERNERFELT, B. The Resource Based View of the firm. Strategic Management Journal, v.5, n.2, p.171-180, 1984.

\section{COPYRIGHT}

Direitos autorais: Os autores são os únicos responsáveis pelo material incluído no artigo. 


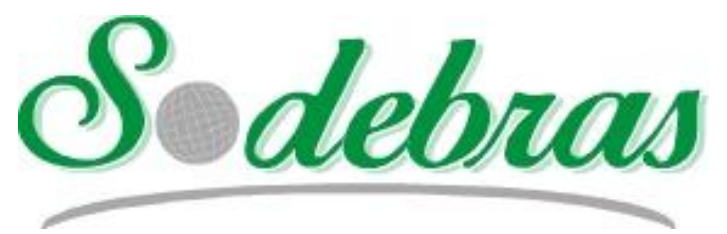

Volume $14-\mathrm{N}^{\mathrm{o}} 159$ - Março/2019.

XL International Sodebras Congress

10 a 12 de dezembro de 2018 - Vitória - ES.

\title{
GESTÃO E AVALIAÇÃO DO DESEMPENHO DE EMPREGADOS: SOLUÇÕES PARA UMA SOCIEDADE DE ECONOMIA MISTA DE GRANDE PORTE
}

\author{
MANAGEMENT AND ASSESSMENT' PERFORMANCE OF EMPLOYEES: \\ SOLUTIONS FOR A LARGE JOINT CAPITAL COMPANY
}

\author{
UERLEI VALDOMIRO ARAUJO'; ROQUEMAR DE LIMA BALDAM ${ }^{12}$; THALMO DE PAIVA COELHO \\ JUNIOR $^{1,2}$; LEONARDO CARNEIRO DA COSTA ${ }^{1}$
}

\section{1 - UNIVERSIDADE FEDERAL DO ESPÍRITO SANTO - UFES; 2 - INSTITUTO FEDERAL DO ESPÍRITO SANTO - IFES;}

uerlei.araujo.uva@gmail.com; roquemar.baldam@ifes.edu.br; thalmo@ifes.edu.br; leonardocarneirocosta@gmail.com

\begin{abstract}
Resumo - Este artigo consiste em um estudo de caso da gestão e avaliação do desempenho dos empregados de uma sociedade de economia mista de grande porte. Trata-se de um estudo exploratório qualitativo de um processo de melhoria ocorrido na empresa pesquisada e uma revisão sistemática que visa à proposiçãa de soluções para o processo de gestão e avaliação de desempenho dos empregados em relação aos problemas que persistiram nas avaliações de desempenho após um processo de melhoria implementado pela organização. Para a coleta dos dados foram utilizadas as técnicas de grupo focal, observação $e$ pesquisa documental.

Palavras-chave: Desempenho individual, Avaliação de

desempenho, Gestão do Desempenho.
\end{abstract}

\begin{abstract}
This article consists in a case study of employees' performance management and assessment in a large mixed economy company. This is an exploratory qualitative study of an improvement process in the employees' performance assessment, that happened at the company, and a systematic review that aim the proposition of solutions about the problems that continue existing in the employees' performance management and assessment process even after the improvement implemented by the organization. For data collect, were used the techniques of focal group, observation and documental research.
\end{abstract}

Keywords: Individual performance, Performance assessment, Performance management.

\section{INTRODUÇÃO}

A gestão do desempenho possibilita identificar e mapear obstáculos para o crescimento da empresa e ajuda a racionalizar tomadas de decisão por parte de seus gestores. Quando tratamos de organizações públicas, de acordo com de Souza (2002), o governo considera como estratégico para tornar-se um modelo gerencial controlador de resultados, ao invés de um modelo burocrático controlador de processos -, capacitar seus servidores, valorizar a função pública e realizar avaliações de desempenho regulares. Akim e Mergulhão (2015) afirmam que a medição do desempenho, neste contexto, é um campo emergente que necessita ser pesquisado.
Klein e Mascarenhas (2016), ao analisarem os modelos desenvolvidos por Porter e Lawler (1968) e Locke e Latham (2002) relacionando metas, esforço, desempenho e recompensas, explicam que as recompensas externas, quando atreladas a desempenhos, podem gerar satisfação nos empregados. Segundo os autores, um fator extrínseco, quando associado aos desafios de superar uma meta e de atingir elevado desempenho, pode gerar sensação de realização, promovendo, assim, motivação intrínseca. Depreendemos dessa análise que a combinação eficaz de fatores motivacionais extrínsecos e intrínsecos tem o potencial de promover satisfação e aumentar o desempenho individual do empregado.

O presente estudo analisa o processo de melhoria da avaliação de desempenho de uma sociedade de economia mista brasileira, identifica os problemas que ainda persistiram após o trabalho desenvolvido e, posteriormente, propõe soluções baseadas em estudos de outros pesquisadores sobre o tema.

\section{METODOLOGIA}

Tendo em vista o objetivo de propor melhorias no processo de gestão de desempenho ao departamento de recursos humanos da organização estudada, optou-se por desenvolver pesquisa descritiva através da abordagem exploratória e qualitativa utilizando o estudo de caso para confrontar a prática com a teoria e uma revisão sistemática sobre o tema com opiniões de pesquisadores clássicos e contemporâneos.

O presente estudo de caso divide-se em três etapas distintas baseadas em Yin (2014): I) seleção do caso e elaboração de protocolo para estudo; II) condução do estudo (coleta e análise dos dados e elaboração do relatório do caso); III) interpretação dos dados à luz da teoria selecionada e da empresa pesquisada.

Para atingir o objetivo proposto, seria prioritário identificar: quais problemas a empresa procurou combater melhorando as avaliações de desempenho dos seus 
funcionários; quais as mudanças propostas para a solução desses problemas; e o que a empresa procurava ganhar com tais mudanças. Após a coleta desses dados, seria necessário identificar quais problemas persistiram na avaliação e gestão do desempenho dentro da organização para, enfim, propor soluções. Schramm apud Yin $(2014$, p.31) corroboram com estas questões ao afirmar que a principal tendência em todos os tipos de estudos de caso é a tentativa de se esclarecer uma decisão, ou conjunto de decisões, ou seja, o que motivou essas decisões, como foram implementadas e quais os resultados obtidos.

Sequencialmente, depois de analisados os dados, sua interpretação foi realizada a partir da revisão de literatura sobre "Avaliação e Gestão do Desempenho". Esta interpretação contribuiu para identificar problemas que persistiram nas avaliações de desempenho. Através de pesquisa bibliográfica, foram identificados autores que pesquisaram sobre problemas encontrados em processos de gestão e avaliação de desempenho, conforme destacado mais adiante no item 3 deste artigo.

$\mathrm{Na}$ coleta de dados, utilizou-se mais de uma fonte, com o objetivo de realizar uma triangulação dos dados coletados (BARRAT; CHOI; Li, 2011). Para tanto, foram utilizadas 03 (três) técnicas distintas: grupo focal, observação direta e pesquisa documental.

\section{RESULTADOS E DISCUSSÕES}

Neely, Gregory e Platts (2005) afirmam que o desempenho de uma empresa é a função entre sua eficiência e sua eficácia. Eles definem 'Medição do Desempenho' como o processo de quantificação da eficiência e da eficácia de uma ação; 'Medida de Desempenho' como a métrica utilizada para quantificar a eficiência e a eficácia de uma ação; e 'Sistema de medição de desempenho' como o conjunto de métricas utilizadas para a quantificação da eficiência e da eficácia das ações.

Para Snell, Morris e Bohlander (2015), “a Gestão do Desempenho é o processo de criar um ambiente de trabalho no qual as pessoas possam realizar o melhor de suas habilidades, a fim de alcançar as metas da empresa". Segundo estes autores, tal processo possui 6 etapas essenciais e pode ser esquematizado conforme Figura 01.

Figura 01: Etapas do processo de Gestão do Desempenho.

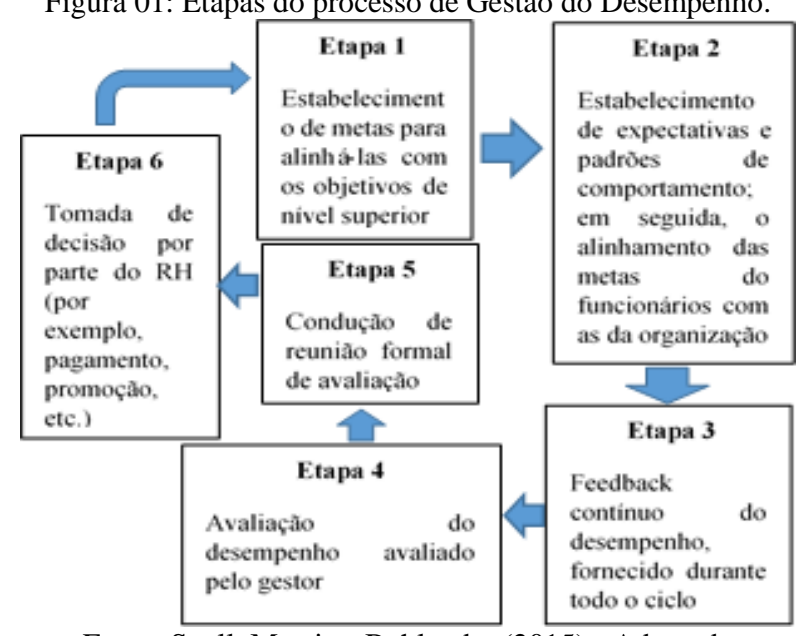

Fonte: Snell, Morris e Bohlander (2015) - Adaptado

De acordo com Taticchi, Balachandran e Tonelli (2012), a medição e a gestão do desempenho funcionam como facilitadores para que as empresas possam estabelecer metas e estratégias para o sucesso, executar atividades tomando decisões que reflitam nos resultados, monitorar os resultados e apontar melhoramentos a serem realizados.

Akim e Mergulhão (2015) apresentaram, através de pesquisa bibliométrica, um panorama da produção intelectual no campo da medição do desempenho na gestão pública entre 1980 e fevereiro de 2013. Suas bases foram a ISI Web of Science e a Scielo, de forma a refletir as pesquisas internacionais sobre o tema. As palavras-chave na base ISI Web of Science foram: performance measurement, performance measure, performance evaluation, performance assessment, performance appraisal, associadas às palavras-chave da área de gestão pública: public sector, public service, public organization e public management. Essa pesquisa resultou em uma amostra de 268 artigos, dentre os quais, 48 concentram $68 \%$ das citações. Desses 48, ao analisarmos os 10 mais citados, nenhum dos artigos diz respeito à avaliação de desempenho do indivíduo e, sim, das organizações públicas como um todo, programas públicos, etc. Tal constatação nos motivou a utilizar base nacional e internacional diversa da utilizada pelos autores. Considerando que o foco da presente pesquisa é a avaliação de desempenho individual do empregado em uma sociedade de economia mista.

Assim, para a realização de uma pesquisa bibliográfica mais específica sobre o assunto, utilizou-se base de dados nacional e internacional e palavras-chave diversas das utilizadas pelos autores: a busca foi realizada na base de dados Science Direct (Elsevier), Scielo e plataforma CAPES com as seguintes palavras-chave: "Individual Performance"; "Individual performance assessment"; "Individual performance appraisal”; $e$ "Individual performance evaluation". Após a busca na referida base de dados, foram aplicados 03 (três) filtros com a finalidade de aproximar os resultados do objetivo desta pesquisa bibliográfica. Os filtros foram aplicados na seguinte ordem: "Journal"; "Organization" e "Employee".

As palavras-chave e os filtros foram aplicados para que conseguíssemos identificar artigos (journal) sobre o tema de avaliação (evaluation; assessment; appraisal) de desempenho individual (individual performance) dos empregados (employee) dentro das organizações (organization).

Os resultados desta pesquisa estão demonstrados na tabela 01 abaixo:

Tabela 01: Resultados da pesquisa bibliográfica

\begin{tabular}{|c|c|c|c|c|c|}
\hline \multicolumn{6}{|c|}{ Science, Direct e CAPES } \\
\hline Palavras-chave & $\begin{array}{l}\text { № de } \\
\text { Resultados }\end{array}$ & $\begin{array}{l}\text { 10 filtro - } \\
\text { Jounal }\end{array}$ & $\begin{array}{l}\text { 2o filtro - } \\
\text { Organization }\end{array}$ & $\begin{array}{l}\text { 3o filtro - } \\
\text { Employee }\end{array}$ & $\begin{array}{l}2010 \text { a } \\
2016\end{array}$ \\
\hline Individual Performance & 1.172 .678 & 1.063 .294 & 5.415 & 273 & 102 \\
\hline $\begin{array}{l}\text { Individual Performance } \\
\text { Assesment }\end{array}$ & 436.838 & 392.633 & 2.688 & 131 & 47 \\
\hline $\begin{array}{l}\text { Individual Performance } \\
\text { Appraisal }\end{array}$ & 43.306 & 36.814 & 931 & 84 & 26 \\
\hline $\begin{array}{l}\text { Individual Performance } \\
\text { Evaluation }\end{array}$ & 521.912 & 471.152 & 2.979 & 150 & 58 \\
\hline
\end{tabular}

Fonte: Autores, 2018

Com a utilização do recurso de sugestões de leitura disponibilizado pela base de dados Science Direct, Scielo e CAPES, foi possível acessar outros artigos relacionados ao tema da presente pesquisa e que não faziam parte dos resultados da busca inicial. 
De maneira similar, Gruman e Saks (2011) desenvolveram uma pesquisa em 2011, fundamentando suas propostas em literatura sobre o tema. Eles apresentaram um modelo de gestão de desempenho no qual o engajamento do empregado seria um ponto chave para a melhoria do seu desempenho e discutiram elementos que poderiam promover tal engajamento.

Portanto, baseado nas propostas de Gruman e Saks (2011) e nos ensinamentos dos demais autores que fundamentam a presente pesquisa, passamos a apresentar nossas propostas de soluções para os problemas encontrados nas avaliações de desempenho individual dos empregados de uma sociedade de economia mista de grande porte.

\section{- Indicadores e metas impostos aos empregados}

Muitas empresas, atualmente, enfatizam seus sistemas de gestão do desempenho para melhorar os níveis de engajamento e, consequentemente, de desempenho dos seus empregados (GRUMAN; SAKS, 2011).

Para Gruman e Saks (2011), as metas devem ser condizentes com os objetivos da organização, porém, quando se permite que os empregados tenham voz no estabelecimento das metas, estas se alinham aos seus interesses e valores, produzindo bem-estar e gerando engajamento. Kim, McDuffie e Pil (2010), nessa vertente, afirmam que, a alta influência da voz do empregado aumenta o potencial de alavancar resultados. Para Leewu e Berg (2011), sem uma boa definição e uma boa implementação das métricas de desempenho, é difícil acarretar em ganho de desempenho para a organização.

Dessa forma, concluímos que seria importante empresa e empregados, em conjunto, construírem novos indicadores e metas. Esta medida melhoraria a motivação dos empregados, seu engajamento e, logo, seu desempenho (GRUMAN; SAKS, 2011). A implementação dessa medida poderia ser realizada, primeiramente, pela escolha de um setor ou uma unidade para um projeto piloto e, em caso de resultados positivos, expandi-lo para o restante da organização progressivamente.

- Não há acompanhamento dos indicadores por parte dos empregados

Liu et al. (2007) pesquisaram sobre desempenho organizacional baseado na influência do comportamento dos empregados através de práticas de gestão do desempenho. Quanto aos indicadores, os autores relacionam dois aspectos a serem observados: devem proporcionar uma visão balanceada e completa da performance dos empregados; e dar à direção da empresa uma visão imediata dos gargalos operacionais.

Liu et al. (2007) destacaram a importância do empregado acompanhar os resutados atingidos com seus indicadores diariamente - para melhorar e permanecer motivado. Nesse ponto a empresa pesquisada precisa melhorar, pois, constatou-se, por pesquisa documental e observação, que nenhum de seus indicadores podem ser acompanhados de forma recorrente pelos empregados.

A falta de informações ao longo do período de avaliação prejudica o desempenho do funcionário, pois este, por desconhecimento de que seus resultados estão aquém do esperado, não altera seu comportamento (SNELL; MORRIS; BOHLANDER, 2015).

- Ausência de critérios objetivos no estabelecimento de metas e falta de clareza nos objetivos
Taticchi, Balachandran e Tonelli (2012) apontam, como uma das principais intervenções para empresas que desejam aumentar a efetividade de um Sistema de Medição e Gestão do Desempenho (Performance Measurement and Management System - PMM System), que os modelos PMM incorporem inter-relações lógicas de causa e efeito entre ações e resultados. Segundo os autores, as empresas têm dificuldades de interpretar informações advindas da medição dos processos operacionais e reconhecem que a tarefa de compreender a cadeia de valor e a relação de causa e efeito nos diversos tipos de organizações é um desafio para este campo de pesquisa. Dada a complexidade do tema, Neely, Gregory e Platts (2005) incluíram em seu trabalho, como agenda de pesquisa, algumas questões relacionadas à medição de desempenho individual do empregado, quais sejam:

$>$ A medida do desempenho deveria focar no processo, no resultado do processo ou em ambos?

$>$ Como a medição do desempenho pode ser desenhada de forma a encorajar a cooperação interfuncional?

$>$ Como a medição do desempenho pode ser desenhada de forma a encorajar um comportamento apropriado?

Desse modo, a necessidade de aumentar a objetividade dos critérios para estabelecimento de metas e clareza nos objetivos abre oportunidades para que sejam realizados estudos adicionais sobre a formação de critérios e construção de indicadores objetivos dentro das diversas áreas da empresa como indicadores específicos para as áreas administrativas e operacionais, por exemplo.

- Remuneração variável de acordo com o desempenho da empresa

$\mathrm{Na}$ empresa pesquisada, a remuneração variável baseia-se no EBITDA (Sigla de índice financeiro que quer dizer "Earning Before Interests, Taxes, Depreciation and Amortization", ou seja, lucros antes dos juros, impostos, depreciação e amortização) e não há recompensa financeira individual ou por equipes, que varie de acordo com o desempenho dos empregados. Aguines e Bradley (2015) afirmam que esse tipo de sistema desmotiva os empregados de alto desempenho porque não terão seus esforços recompensados, e beneficia os empregados de baixo desempenho porque poderão almejar algum ganho financeiro mesmo sem ter feito por merecer (conhecido como "carona", ou freerider).

Sugerimos que seja estudada pela empresa, a implantação de um sistema de remuneração variável por desempenho (Peformance-Related Pay - PRP). Apesar de haver limitações impostas pelo próprio setor público, estudos indicam a possibilidade da implantação de sistemas PRP dentro da administração pública ter efeitos positivos (Alliger et al., 2015).

Lau e Roopnarain (2014) afirmam que mensuração baseada nos resultados é mais indicada e adequada em função da sua objetividade. Por outro lado, Snell, Morris e Bohlander (2015) salientam que avaliar a produção de um funcionário numa linha de produção é relativamente fácil e pode ser feito de forma objetiva, porém, quando se trata de funcionário da área administrativa, é mais difícil e subjetiva. Esse é, portanto, um ponto a ser observado pela empresa na discussão com os empregados sobre indicadores e metas a serem utilizados em seus respectivos setores. 
- Recompensas baseadas apenas no que foi realizado pelo empregado

Aguines e Bradley (2015) incentivam as empresas a implementar sistemas de gestão do desempenho ao invés de simplesmente aplicar uma avaliação anual e uma revisão. Para os autores, os gerentes deveriam adotar mecanismos de recompensas por metas específicas - que agregam valor à organização. Desta forma, tiram o foco da recompensa por ano trabalhado e enfatizam recompensa por ações específicas produzidas pelos empregados, fazendo com que se sintam mais motivados. Essas mudanças deixam de recompensar o que foi realizado para focar no que será produzido.

Observou-se, realmente, que a empresa pesquisada recompensa somente pelo que foi realizado pelo empregado. Portanto, adicionalmente ao que foi proposto na solução anterior, deve-se fomentar a discussão entre empregados e gestores para estudar formas de estabelecimento de recompensas por metas individuais e por equipes que visam premiar, além do que foi realizado pelo empregado, o cumprimento de metas e ações específicas que agreguem valor para a empresa. Uma das formas de premiar com esse novo foco é a realização de concursos internos entre os empregados para incentivar a proposição de inovações em seus processos, por exemplo. Os melhores trabalhos seriam transformados em projetos piloto e recompensados após a confirmação de sua aplicabilidade.

\section{- Feedback falho}

Gabelica et al. (2014) afirmam que dar o feedback às equipes é uma ferramenta poderosa para incrementar seu aprendizado e seu desempenho. Para Ford, Lathan e Lennox (2011), a maioria das empresas opta por fixar um intervalo de tempo para se realizar as reuniões de feedback sobre o desempenho. Porém, sendo assim, como se pode avaliar o desempenho continuamente se as reuniões são programadas em períodos previamente fixados? Não tem como os gerentes avaliarem todo o período sem se esquecerem de alguma coisa. Os empregados podem relaxar durante o início do período avaliativo e aumentar seus esforços quando se aproxima da data da avaliação final do ciclo. Entretanto, quando não há previsibilidade da data da avaliação e do feedback, a tendência é que os empregados permaneçam engajados durante todo o período. Neste cenário, concluímos que os problemas de feedback na empresa estudada seriam minimizados caso se adotassem as seguintes medidas:

- Alteração do cronograma de avaliação e feedback do desempenho do empregado, deixando de ser fixo para ter uma programação menos previsível, conforme sugere Ford, Lathan e Lennox (2011);

- O feedback deve ser contínuo, ou seja, ao longo do período a ser avaliado, possibilitando que o empregado corrija seu comportamento e seu desempenho antes da avaliação propriamente dita (SNELL; MORRIS; BOHLANDER, 2015);

- Os gerentes devem adotar a prática de coaching e mentoring com os empregados (FORD; LATHAN; LENNOX, 2011), os auxiliando na obtenção da melhora no desempenho;

- Utilizar os empregados de alto desempenho como "coachs" e "mentors" (AGUINES; BRADLEY, 2015; RUSSEL et al., 2015).

\section{- Falta de estrutura}

Taticchi, Balachandran e Tonelli (2012) sugerem que as condições necessárias para a utilização de um modelo PMM deve ser provido pela empresa, ou seja, ferramentas de Tecnologia da Informação (TI) adequadas para extrair, agrupar e elaborar dados que caracterizem seus negócios. Segundo os autores, sistemas como ERP (Enterprise Resource Planning) e BI (Business Inteligence) podem contribuir significativamente para auxiliar os modelos PMM. Ressalta-se que a empresa em foco possui um sistema ERP, mas a falta de comunicação entre avaliadores e avaliados persiste em decorrência da precariedade estrutural em algumas unidades.

Segundo Bedarkar e Pandita (2014), a falha na comunicação interna da empresa, ou a falta dela, provoca o desengajamento do empregado e, por consequência, a perda de desempenho. Portanto, será necessário alterar a estrutura física em algumas instalações visando oferecer condições mínimas de trabalho aos empregados, além da aquisição de equipamentos e novas tecnologias para adequar os ambientes profissionais ao processo de avaliação e, com isso, melhorar a comunicação entre líderes e liderados.

- Responsabilidade das avaliações de desempenho a cargo somente das chefias imediatas

Diversos autores pesquisados criticaram os sistemas de gestão do desempenho no qual a responsabilidade da avaliação incide apenas na chefia imediata do avaliado: Segundo Lotta (2002) esse tipo de modelo de avaliação restringe a visão em relação ao avaliado e pode haver um julgamento que não seja por parte do avaliador; Snell, Morris e Bonlander (2015) afirmam que fatores como preconceitos ou bom relacionamento podem ser aumentados; acrescenta-se que, outro fator negativo desse tipo de avaliação é que, em equipes maiores, o superior hierárquico imediato deve assumir várias funções o que não permite que ele preste atenção em todos os funcionários de forma a garantir justiça no julgamento dos mesmos (SNELL; MORRIS; BOHLANDER, 2015).

As sugestões de Snell, Morris e Bohlander (2015) corroboram com Taticchi, Balachandran e Tonelli (2012) que identificaram os marcos presentes em um sistema ideal de gestão do desempenho, dentre os quais se destacam as considerações das diferentes perspectivas das partes interessadas. Segundo esses autores, é importante que os sistemas de gestão de desempenho de uma organização levem em consideração as perspectivas de seus colaboradores.

Em um primeiro momento, propõe-se que seja adotada, em toda a empresa, a auto avaliação dos empregados que, segundo Snell, Morris e Bohlander (2015), contribui para que o empregado reflita sobre seus pontos fortes e fracos. Em seguida, propõe-se a formação de Grupo de Trabalho para estudar a implantação de novos sistemas de avaliação, como o $360^{\circ}$. Sugere-se também a realização de benchmarking (LEEWU; BERG, 2011) em Sociedades de Economia Mista que tenham características similares de tamanho, estrutura e dispersão geográfica de suas unidades.

- Falta de treinamento de avaliadores para implementação da nova avaliação

A observação direta revelou não haver, na empresa estudada, treinamento dos avaliadores para implementação das mudanças nas avaliações de desempenho. 
Sikora e Ferris (2014) afirmam que, normalmente, são os gerentes de linha os responsáveis pelas práticas de RH na organização e que o nível de qualidade na implementação destas tem relação positiva com o clima organizacional, satisfação dos empregados e seus desempenhos e relação negativa com a intenção de turnover (rotatividade) do empregado. Portanto, se a prática de RH é bem implementada, os resultados operacionais são incrementados e reduz o risco de perder empregados de alto desempenho para o mercado de trabalho.

Conforme já citamos anteriormente neste relatório, as avaliações são de responsabilidade das chefias imediatas, ou seja, os gerentes de linha são também avaliadores e devem saber utilizar a nova avaliação de desempenho.

Considerando que a gestão do desempenho é um processo crítico para as organizações e que menos de um terço dos empregados costumam acreditar que o processo de avaliação do desempenho ajuda a incrementar seus desempenhos (GRUMAN; SAKS, 2011), para a implementação dessas mudanças nas avaliações de desempenho dentro da empresa deve haver o máximo de cautela por parte das pessoas envolvidas.

Segundo Aguines e Bradley (2015), é importante identificar e treinar indivíduos de quem o desempenho é primordial para os resultados estratégicos da empresa. Certamente, os avaliadores se enquadram nesse tipo de indivíduos. Nesse caso, propomos que sejam realizados treinamentos principalmente com os avaliadores para reduzir ao máximo a possibilidade de insucesso na implementação das mudanças.

- Não há relação entre as avaliações de desempenho, o clima organizacional e a satisfação dos empregados

Se analisarmos conjuntamente os trabalhos de Russel et al. (2016) e Livi et al. (2015), podemos tirar conclusões e adotar medidas na empresa pesquisada que podem implicar em melhora do clima organizacional, melhora do desempenho de empregados com baixo rendimento além de refletir na possibilidade de diminuição de turnover, especialmente, dos profissionais de alto desempenho.

Livi et al. (2015) identificaram em seus estudos que o positivismo dos empregados contribui para o seu desempenho individual. Mais que isso, os autores também identificaram que pessoas com baixo positivismo melhoram seu desempenho quando participam de equipes que possuem pessoas com alto positivismo. Russel et al. (2015) por sua vez, destacam como tem aumentado o número de empregados que são subutilizados dentro das organizações. Esses autores sugerem que, quando as organizações oferecem oportunidades para os empregados super qualificados se desenvolverem na carreira (como lideranças informais ou atividades de mentoring, por exemplo), esses profissionais irão aproveitar essas oportunidades e utilizar suas habilidades, qualidades e experiência para dar contribuições únicas à organização, proporcionando recursos humanos valorizados para a empresa. Segundo Russel et al. (2015), ao dar essas oportunidades (e desafios) aos empregados melhores qualificados, a empresa proporciona resultados positivos para os empregados (maior satisfação no trabalho e melhora na reputação em relação aos outros empregados), e para a própria organização.

Desta forma, com base nas literaturas citadas, sugerimos que sejam inseridas questões nos formulários de avaliação de desempenho que permitam trazer informações sobre o clima organizacional e sobre a satisfação dos empregados com suas atividades.

\section{CONCLUSÃO}

O processo de melhoria ocorrido na empresa contribuiu para a evolução da prática da gestão e avaliação de desempenho de seus empregados e foram identificadas possibilidades de avanços. Entretanto, por se tratar de uma empresa formada em sua maioria, por capital público, dependerá de vontade política para a implementação dessas sugestões.

Foi demonstrado que a Gestão e a Avaliação do Desempenho é um desafio em vários países e em várias organizações públicas e privadas. Ainda não há resposta para todas as questões de forma simples e objetiva, mas com essa pesquisa, percebe-se que a solução para os problemas enfrentados pelas organizações no processo de gestão e avaliação de desempenho dos empregados pode estar na produção cientifica com estudos de aplicabilidade prática sobre o tema.

Segundo Yadav e Dabhade (2013), as aferições, em um ciclo de avaliação de desempenho, são normalmente realizadas duas vezes por ano em uma organização, sob a forma de revisões médias de ciclos anuais que são realizadas no final do exercício financeiro. Neste processo, o gestor primeiro oferece as análises auto preenchidas no formulário de autoavaliação e também descreve suas realizações ao longo de um período de tempo em termos quantificáveis. Após a autoavaliação, os julgamentos finais devem ser fornecidos pelo avaliador com as conquistas quantificáveis e mensuráveis do empregado sendo avaliado. Todo o processo de revisão busca uma participação ativa, tanto do empregado quanto do avaliador, para analisar as causas das falhas no desempenho e como isso pode ser superado e, isso deve ser discutido numa reunião de feedback de desempenho.

Assim, propomos uma análise crítica da Gestão e Avaliação de Desempenho dos colaboradores de uma organização de economia mista de grande porte. Ao analisarmos os métodos de avaliação aplicados, entendemos que a revisão com alguns ajustes de melhoria podem contribuir para a melhor mensuração do desempenho, aumentando a produtividade, a qualidade do serviço, a satisfação do colaborador avaliado e do gestor avaliador. Sugerimos um modelo mais amplo de avaliação, onde aumenta-se as responsabilidades do avaliador e do avaliado para a transparência do processo e para o atingimento das metas propostas pela organização para cada empregado, unidade, setor, gerência, departamento e diretoria.

\section{REFERÊNCIAS BIBLIOGRÁFICAS}

AGUINIS, Herman; BRADLEY, Kyle J. The secret sauce for organizational success: Managing and producing star performers. Organizational Dynamics, v. 44, n. 3, p. 161$168,2015$.

AKIM, Érica Kushihara; MERGULHÃO, Ricardo Coser. Panorama da produção intelectual sobre a medição de desempenho na gestão pública. Revista de Administração Pública, v. 49, n. 2, p. 337-366, 2015.

ALLIGER, George M. et al. Team resilience. Organizational Dynamics, v. 44, p. 176-184, 2015. 
BARRATT, Mark; CHOI, Thomas Y.; LI, Mei. Qualitative case studies in operations management: Trends, research outcomes, and future research implications. Journal of Operations Management, v. 29, n. 4, p. 329-342, 2011.

BEDARKAR, Madhura; PANDITA, Deepika. A study on the drivers of employee engagement impacting employee performance. Procedia-Social and Behavioral Sciences, v. 133, p. 106-115, 2014

DE LEEUW, Sander; VAN DEN BERG, Jeroen P. Improving operational performance by influencing shopfloor behavior via performance management practices. Journal of Operations Management, v. 29, n. 3, p. 224-235, 2011.

DE SOUZA, Vera Lúcia. Gestão de desempenho: julgamento ou diálogo. FGV Editora, 2002.

FORD, Robert C.; LATHAM, Gary P.; LENNOX, Gwen. Mystery shoppers. Organizational Dynamics, v. 3, n. 40, p. 157-164, 2011.

GABELICA, Catherine et al. The effect of team feedback and guided reflexivity on team performance change. Learning and Instruction, v. 34, p. 86-96, 2014.

GRUMAN, Jamie A.; SAKS, Alan M. Performance management and employee engagement. Human Resource Management Review, v. 21, n. 2, p. 123-136, 2011.

KIM, Jaewon; MACDUFFIE, John Paul; PIL, Frits K. Employee voice and organizational performance: Team versus representative influence. human relations, v. $63, \mathrm{n}$. 3, p. 371-394, 2010.

KLEIN, Fabio Alvim; MASCARENHAS, André Ofenhejm. Motivação, satisfação profissional e evasão no serviço público: o caso da carreira de especialistas em Políticas Públicas e Gestão Governamental. Revista de Administração Pública, v. 50, n. 1, p. 17-39, 2016.

LAU, Chong M.; ROOPNARAIN, Ketvi. The effects of nonfinancial and financial measures on employee motivation to participate in target setting. The British accounting review, v. 46, n. 3, p. 228-247, 2014.

LIU, Yongmei et al. The value of human resource management for organizational performance. Business horizons, v. 50, n. 6, p. 503-511, 2007.

LIVI, Stefano et al. Positivity within teamwork: Cross-level effects of positivity on performance. Personality and Individual Differences, v. 85, p. 230-235, 2015.

LOCKE, Edwin A.; LATHAM, Gary P. Building a practically useful theory of goal setting and task motivation: A 35-year odyssey. American psychologist, v. 57, n. 9, p. $705,2002$.

LOTTA, Gabriela Spanghero. Avaliação de desempenho na área pública: perspectivas e propostas frente a dois casos práticos. RAE-eletrônica, v. 1, n. 2, p. 1-12, 2002.

NEELY, Andy; GREGORY, Mike; PLATTS, Ken. Performance measurement system design: A literature review and research agenda. International journal of operations \& production management, v. 25 , n. 12 , p. 1228-1263, 2005.
PORTER, Lyman W.; LAWLER, Edward E. Management attitudes and performance. Homewood IL.: Richard D. Irwin Company, 1968.

RUSSELL, Zachary A. et al. Overqualified human resources, career development experiences, and work outcomes: Leveraging an underutilized resource with political skill. Human Resource Management Review, v. 26, n. 2, p. 125-135, 2016.

SIKORA, David M.; FERRIS, Gerald R. Strategic human resource practice implementation: The critical role of line management. Human Resource Management Review, v. 24, n. 3, p. 271-281, 2014.

SNELL, Scott; MORRIS, Shad; BOHLANDER, George W. Managing human resources. Nelson Education, 2015.

TATICCHI, Paolo; BALACHANDRAN, Kashi; TONELLI, Flavio. Performance measurement and management systems: state of the art, guidelines for design and challenges. Measuring Business Excellence, v. 16, n. 2, p. 41-54, 2012.

YADAV, Rajesh K.; DABHADE, Nishant. Performance management system in Maharatna Companies (a leading public sector undertaking) of India-a case study of BHEL, Bhopal (MP). International Letters of Social and Humanistic Sciences, v. 4, n. 49, p. 49-69, 2013.

YIN, R. K. Estudo de Caso - 5.Ed.: Planejamento e Métodos. Porto Alegre: Bookman, 2014.

\section{COPYRIGHT}

Os autores são os únicos responsáveis pelo material incluído no artigo. 


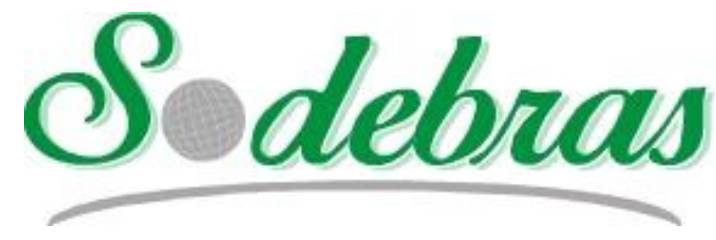

Volume 14 - No 159 - Março/2019.

XL International Sodebras Congress

10 a 12 de dezembro de 2018 - Vitória - ES.

\title{
O PLANEJAMENTO ESTRATÉGICO NA EDUCAÇAO A DISTÂNCIA NO INSTITUTO FEDERAL DE RONDÔNIA
}

\author{
THE STRATEGIC PLANNING IN DISTANCE EDUCATION AT THE FEDERAL \\ INSTITUTE OF RONDÔNIA
}

\author{
SEBASTIÃO GONÇALVES NEVES ${ }^{1}$; SAMUEL DOS SANTOS JUNIO ${ }^{1}$; ALOIR PEDRUZZI JUNIOR ${ }^{1}$; \\ JONIMAR SILVA SOUZA'.
}

\section{1 - IFRO - INSTITUTO FEDERAL DE EDUCAÇÃO, CIÊNCIA E TECNOLOGIA DE RONDÔNIA.}

neves_pt@hotmail.com,samuel.santos@ifro.edu.br,aloir.pedruzi@ifro.edu.br,jonimar.souz@ifro.edu.br

\begin{abstract}
Resumo - O presente trabalho tem por objetivo fazer uma análise da contribuição do planejamento estratégico em uma instituição de ensino a distância, por entender que esse modelo de ensino tem crescido na preferência de uma parcela significativa da população. $O$ conhecimento a distância surge nas primeiras décadas do século $X X$ e continua sua expansão no século XXl. Entender o motivo desse crescimento, quais as ferramentas que o sistema se apropria para tornar o ensino eficaz, foi o principal motivo que incentivou a pesquisa. Ressaltar a sua importância e função, com destaque para os benefícios que proporciona ao desenvolvimento das atividades e de que maneira o planejamento estratégico contribui para a atuação das funções administrativas e para o alcance dos resultados almejados. Apresenta-se, também, as características e elementos que o planejamento possui para indicar sua presença e aplicação no ambiente organizacional, bem como os fatores que são utilizados como referenciais para a sua classificação $e$ para o seu dimensionamento no tempo e no espaço. A Educação a Distância (EaD) tem sido o modelo de ensino mais procurado entre pessoas que trabalham, com idade acima dos trinta anos, e precisam aprimorar conhecimentos mediante a adequação do espaço e tempo disponível. Neste contexto, priorizou-se a discursão acerca da avaliação da aprendizagem EaD, fato que norteou boa parte do trabalho. Portanto a pesquisa foi realizada dentro de uma abordagem qualitativa de caráter bibliográfico, procurando responder os fundamentos que envolvem a Educação a Distância. $O$ resultado mostrou que esse modelo de ensino acompanhou o desenvolvimento do sistema educacional do Brasil.
\end{abstract}

Palavras-chave: Educação a Distância. Planejamento Estratégico. Resultados.

Abstract - The purpose of this study is to analyze the contribution of strategic planning in a distance learning institution, since it is understood that this model of education has grown in the preference of a significant portion of the population. Distance learning arose in the early decades of the twentieth century and continues its expansion in the 21 st century. Understanding the reason for this growth, which tools the system appropriates to make teaching effective, was the main motivation for the research. Emphasize its importance and function, highlighting the benefits it provides to the development of activities and how strategic planning contributes to the performance of the administrative functions and to the achievement of the desired results. It also presents the characteristics and elements that the planning has to indicate its presence and application in the organizational environment, as well as the factors that are used as references for its classification and for its dimensioning in time and space. EaD has been the most sought-after teaching model among working people, over the age of thirty, and needs to improve knowledge by adapting space and time available. In this context, prioritized the discourse about the evaluation of learning EaD, fact that guided much of the work. Therefore, the research was carried out within a qualitative bibliographical approach, trying to answer the fundamentals that involve Distance Education. The result showed that this teaching model followed the development of the educational system of Brazil.

Keywords: Distance Education. Strategic planning. Results.

\section{INTRODUÇÃO}

A Educação a Distância é um tema bastante discutido atualmente, devido sua incalculável importância em atender uma significativa quantia de alunos, que a cada dia se identificam com essa modalidade de ensino. A EaD ao longo de sua história traçou uma trajetória de grandes avanços, ao ponto de ser capaz de atender e oferecer capacitação para a melhoria no desenvolvimento das atividades profissionais em nosso país e no mundo.

A constituição Federal da República Federativa do Brasil de 1988, garante ao cidadão o direito mínimo necessário para usufruto da dignidade humana. Conforme a redação do art. 205 da carta magna de 1988, diz: a educação, direito de todos e dever do Estado e da família, visa o pleno desenvolvimento da pessoa, seu preparo para o exercício da cidadania e sua qualificação para o trabalho.

A Educação a Distância fundamenta-se em um histórico de formação e capacitação de profissionais que se tornaram desejosos em adquirir conhecimento rápido, de forma prática e acessível através das tecnologias de informação e comunicação especialmente desenvolvida para a metodologia EaD. Nesse contexto, a EaD torna-se um instrumento fundamental de promoção de oportunidade, possibilitando o indivíduo apropriar-se do método EaD para concluir um curso superior e abraçar novas oportunidades. Somando-se a isso, a metodologia da Educação a Distância, possui uma relevância social muito importante, quando inclui pessoas do processo educacional que já se encontravam excluídos pelo sistema presencial. 
Apesar do progresso da Educação a Distância, estudos mostram que muitas estratégias ainda precisam ser discutidas para melhoria do ensino a distância, envolvendo a sociedade e em especial os governos, federal, estadual e municipal, pesquisadores, alunos e professores. Destaca-se como fator chave, os avanços tecnológicos que tornaram visíveis o desenvolvimento da $\mathrm{EaD}$, no final do século $\mathrm{XIX}$ e no início do século XX. O Brasil foi considerado um país propulsor da metodologia da Educação a Distância.

Com base nos estudos, o presente trabalho fez uma reflexão sobre o avanço dessa modalidade de ensino, mencionando suas principais características, métodos e atores envolvidos, sua eficácia na formação e capacitação profissional em todos os níveis do ensino, como também analisou o motivo pelos quais leva um indivíduo a acreditar e se tornar um aluno desse modelo de ensino chamado Educação a Distância.

\section{METODOLOGIA}

Torna-se cada vez mais necessário aprender a estudar, seja na educação a distância, seja no ensino presencial. A sociedade exige que o indivíduo possa aprender por conta própria, ou seja, que seja de alguma maneira autodidata. $\mathrm{O}$ crescimento cada vez maior da educação a distância criou as possibilidades para que qualquer pessoa possa aprender o que quiser, no entanto, para isso, precisa adquirir essa capacidade de aprender a estudar e principalmente a gerenciar nossos estudos.

Vivendo nessa realidade, a EaD ainda é compreendida por muitos professores e alunos como um espaço para a "folga" e para o descompromisso. Para eles, parece difícil compreender que é possível educar quando os alunos estão distantes fisicamente, ou quando não estão todos reunidos no mesmo lugar. Isso é compreensível, pois precisa conhecer e vivenciar processos nesta modalidade, assim como em outras, para compreender as possibilidades de ensino e de aprendizagem que a constituem.

Portanto, o ambiente de educação a distância deve favorecer uma aprendizagem significativa. Esses ambientes, chamados de colaboração e aprendizagem, dispõe basicamente dos mesmos recursos da internet em geral. É possível utilizar fóruns, correios eletrônicos, bate papos, conferencias, bancos de dados, e diversas fermentas que despertam o interesse do aluno no intuito de possibilitar o aprendizado em questão.

Segundo Vilma A. G. Cruz (2011), O crescimento e a convergência do potencial das tecnologias da informação e da comunicação fazem com que a educação a distância, contribua para a expansão do ensino superior no Brasil, além de favorecer a transformação dos métodos tradicionais e ensino mediante uma proposta inovadora pedagógica.

Na linha de raciocínio da autora, o ensino a distância está apoiado em fortes pilares que garantem o autodesenvolvimento, permitindo que os estudantes ampliem seus conhecimentos teóricos, ao mesmo tempo em que aprendem a partir de suas experiências, desenvolvendo a capacidade de analisar o mundo ao seu redor

\section{BREVE HISTÓRICO SOBRE A EDUCAÇÃO A DISTÂNCIA}

As primeiras experiências de Educação a Distância foram registradas no primeiro século da era cristã, são as conhecidas cartas do apóstolo Paulo, que segundo Araújo (2010) tinham como finalidade fortalecer a fé cristã, porém foram significativas para as pessoas que tinham acesso a esse ensinamento. Se considerar as sagradas cartas paulinas como uma forma de ensino, mesmo de caráter escolástico, chega à conclusão que a Educação a Distância é bastante antiga. Araujo (2010 p. 2) faz a seguinte descrição:

Desde os primórdios bíblicos neotestamentários, onde foi evidenciada por meio das cartas. Até os dias de hoje por meio das tecnologias da informação, ela apresenta-se como forma alternativa de superar as carências socioeducacionais da humanidade na aquisição de conhecimento.

Diante das mudanças devido o aparecimento de tecnologia, o Ensino a Distância tem sua característica em estreitar as relações dos povos no mundo. O século $\mathrm{XV}$, marcado na história pelas grandes descobertas dos continentes, os colonizadores utilizaram o ensino dos evangelhos cristãos como forma de ensinar uma convivência social e espiritual, e a base desses ensinamentos eram as cartas de Paulo, e os professores eram os padres jesuítas, e tinha a missão de ensinar segundo os interesses da coroa portuguesa. Como registra a bíblia, as cartas do apóstolo Paulo levaram ensinamentos a muitos povos, eram de grande valia na sua época, e até hoje, estão inseridas no livro sagrado, norteando uma significativa parte da população mundial em nossos dias atuais.

Segundo Carvalho (2001). Os jesuítas tiveram um papel fundamental no processo de colonização no Brasil, possibilitando o governo português alcançar seus objetivos, alicerçando uma educação junto aos nativos, que gerassem obediência e produtividade a coroa portuguesa. Como são conhecidos, os jesuítas deixaram uma herança de um modelo educacional no Brasil e seus traces permanece até hoje.

No século XVlll, denominado de século das luzes, termo que nasce com a corrente filosófica iluminista que tinha como lema a proliferação do conhecimento pela ciência e pela educação, tinha como ideário o estandarte da democratização da educação da massa, .somando a esse movimento, destaca os benefícios produzidos graças a revolução industrial ocorrido também no século XV1ll, que exigia a qualificação da mão de obra para produzir o máximo possível e atingir os patamares do crescimento econômico, tal exigência permitia o aprimoramento dos meios tecnológicos e informativos, dos quais os trabalhadores passaram a ter acesso ao conhecimento profissional e adequar-se as exigências do mercado de trabalho.

Ainda no século XV1ll, nos Estados Unidos, surge o material impresso e, com o apoio dos correios, a modalidade do Ensino a Distância, passa a oferecer os primeiros cursos por correspondência.

Sobre a abrangência do Ensino a Distância, é notório a contribuição desse modelo de ensino nos Séculos, XV1ll, XIX e XX. Com o surgimento da industrialização, através das tecnologias, surgem também equipamentos modernos e potentes de grande capacidade de produção industrial, com capacidade de transformar a matéria prima em produto para ser comercializado em grande escala, exigindo qualificação para manusear com essas máquinas. Diante das transformações, os países industrializados não contavam com mão de obra qualificada devido à maioria dos 
trabalhadores não ter acesso à escola. Para manter o processo de produção, as indústrias necessitavam de mão de obra e pessoas qualificadas, logo os empresários perceberam a necessidade de qualificar pessoas para atuarem no setor de produção. Diante das necessidades os países em desenvolvimento passaram a depender de uma modalidade de ensino que pudesse atender a demanda do mercado de trabalho, no início houve grande dificuldade de reciclar pessoas devido a falta de tecnologia e estabelecimento adequado, também vale considerar que a maioria das pessoas moravam no campo, em pequenos vilarejos, não tenha acesso as informações que estavam surgindo nas cidades

O Ensino a Distância teve um avanço significativo, no século $\mathrm{XlX}$ e $\mathrm{XX}$, com invenção do rádio e avião, esses instrumentos permitiram o desnvolvimento do Ensino a Distância pela facilidade de acesso as locais distantes e inacessíveis. Como relata Araújo (2010, p. 3)

$\mathrm{O}$ ensino por correspondência em alguns países, contou com o apoio do rádio e até do avião. O ensino a distância tornou-se ainda mais importante para pessoas que moravam em colônias como os britânicos, por exemplo, que tinha nessa modalidade a oportunidade de se prepararem para os exames da universidade de Londres.

\section{FUNÇÃO DO PLANEJAMENTO ESTRATÉGICO NA ORGANIZAÇÃO EaD}

O ensino a distância vem crescendo e profissionalizado a medida do tempo, tornando um importante mecanismo na proliferação do conhecimento, tornando também uma área de investimento de capital público e privado. O governo federal tem contribuído com esse crescimento, dando uma atenção especial na criação de leis, ferramentas, incentivos e outros mecanismos que possam tornar o conhecimento a distância mais eficiente e eficaz. Devido ao crescimento as intuições necessitam de implementar um modelo de gestão que posso manter o nível interno e externo. Segundo Mil (2002) a gestão educacional é um campo de extrema importância para se compreender o conjunto do processo de ensino-aprendizagem na educação básica ou superior e, também, na educação presencial ou a distância.

Planejar tem sido a função de gestores que demonstram sua preocupação com o futuro de uma organização Oliveira (2013). Precisa ser continuo, um exercício diário, independente da vontade especifica de um indivíduo. Planejar é uma atividade complexa em decorrência natural, envolve uma ação continua para obter uma noção do futuro, entrelaçando diversas etapas que apontam pontos fortes e fracos das organizações.

O planejamento estratégico é uma ferramenta da administração, é considerada a mola mestra da arte de planejar, vem de origem grega e remete ao significado de a arte do geral. Segundo Oliveira (p.17) faz a seguinte descrição:

Planejamento estratégico é o processo administrativo que proporciona sustentação metodológica para se estabelecer a melhor direção a ser seguida pela empresa, visando ao otimizado grau de interação com os fatores externos não controláveis e atuando de forma inovadora e diferenciada.
Djalma de Pinho Rebouças de Oliveira nos leva a entender a importância do planejamento estratégico para as instituições do ensino a distância, quando considera o planejamento estratégico como uma ferramenta da administração, capaz de proporcionar sustentação e estabelecer uma direção ao método de administrar e buscar eficácia, ou seja, fazer a coisa certa e o que precisa ser feito. Nos sistemas EaD, a aplicação de uma boa metodologia de ensino faz com que alunos e professores possam interagir e melhorar o entendimento sobre os temas que estão disponíveis no ambiente virtual. O sistema do ensino a distância tem como característica a utilização de métodos onde o professor não está presente em sala de aula. Outra contribuição do planejamento estratégico no EaD, está relacionado com a criação dos polos de ensino. Visto internamente, esses polos passam uma sensação de inoperância, incapacidade, principalmente quando comparados as instituições presenciais que se montam dentro de uma estrutura gigantescas como é o caso das universidades. No entanto, estudos mostram que a importância dessa extensão de ensino tem sido a sustentação do método do ensino a distância.

\section{CONTRIBUIÇAO DA GESTÃO ESTRATÉGICA NA $\mathrm{EaD}$}

Quando trata de gestão, está nos referindo a mais complexa função atualmente de uma instituição de ensino, quer seja de nível médio ou superior, presencial ou a distância, no Brasil ou em todo mundo. Gestão nas instituições de ensino a distância torna-se mais complexas devido a ramificação nas camadas populacionais, parcerias utilizadas, implantação de pólos, modelo pedagógico eficiente, metodologia eficaz, enfim, pode considerar que trata de um ambiente minado que precisa de muito cuidado para manter-se nesse ambiente que se moderniza e modifica a cada dia. Segundo Chiavenato (2009, p. 422) nos leva a entender essa mudança nas organizações, com o seguinte raciocínio:

\begin{abstract}
As organizações e as pessoas que nelas trabalham estão em constante mudança. Novos objetivos são estabelecidos, enquanto velhos objetivos são revistos e modificados; novos departamentos são criados e os velhos reestruturados; as pessoas saem da organização ou mudam de cargos; novas pessoas são admitidas; os produtos sofrem alterações profundas; a tecnologia avança inexoravelmente. As pessoas também se desenvolvem, aprendem novas coisas, modificam seu comportamento e suas atitudes, desenvolvem novas motivações e criam novos problemas.
\end{abstract}

Chiavenato colabora com o entendimento sobre o planejamento estratégico quando pensa no sistema de toda organização, no conjunto que integra toda a empresa. Relata as constantes mudanças não só do sistema como também de toda a estrutura da organização. Segundo oliveira (2013. P, 38) "o planejamento estratégico não deve ser considerado apenas como uma afirmação das aspirações de uma empresa, pois inclui, também, o que deve ser feito para tornar essa aspiração em realidade". Oliveira e Chiavenato compartilham das mesmas observações, quando questiona o que deve fazer para que as aspirações de uma organização se transformem em realidade. Portanto o que observa é a teoria 
e a prática, sendo que a prática e uma virtude do planejamento estratégico que responde como fazer, quando fazer, pra quem fazer e onde fazer.

As instituições que ministram o ensino $\mathrm{EaD}$ precisam entender a responsabilidade quanto a gestão de suas unidades, em especial os polos, por estarem afastados dos grandes centros urbanos, sendo na maioria a única alternativa para pessoas que precisam concluir um curso superior. Precisam funcionar como uma orquestra totalmente em sintonia e em harmonia. Os setores da tecnologia da informação precisam estar em consonância com as necessidades especificas dessa instituição de ensino, focando não só as necessidades internas da organização, mas principalmente o suporte às funcionalidades de seus sistemas e ferramentas para o bom uso dos alunos da instituição.

Apesar dos avanços tecnológicos, hoje, disponíveis nos ambientes virtuais de aprendizagem através da internet tais como: metodologia abrangente, planejamento estratégico, professores qualificados e outros, não restam dúvida que o Ensino a Distância precisa passar por uma discursão mais abrangente para melhorar a qualidade do ensino EaD. Segundo Magnol (2009, p.337) entende que:

Apesar do processo recente da educação a distância, muitos dos seus principais pontos estratégicos ainda não foram discutidos com a profundidade necessária. Pode-se destacar como ponto ainda controverso na $\mathrm{EaD}$, os seus objetivos, a forma de transmissão, os provedores de tecnologia, a população alvo dos cursos ofertados, a formação e organização dos projetos pedagógicos, os métodos de avaliação de aprendizagem, entre tantos outros.

Concorda-se com os ajustes para tornar ensino EaD mais eficiente, porém, ressalta que a tecnologia de comunicação e informação tem contribuído para o desenvolvimento do método $\mathrm{EaD}$, através dos materiais de apoio, propostas que permitem o desenvolvimento de habilidades e competências e outros. Segundo Formiga e Litto (2009, p. 39). “ÀEaD está intrinsicamente ligado às TICs por se construir setor altamente dinâmico e prodígio em inovação, que transforma, moderniza e faz caducar termos técnicos e expressões linguísticas em velocidade alucinante.” Em síntese a EAD conta com várias opções que fortalecem os conceitos, e fundamenta a prática do ensino e aprendizado, deixando um legado para todos que estudam pelo modelo de Ensino a Distância.

\section{A EaD NO SÉULO XXI}

No começo do milênio, o mundo sofre mudanças tecnológicas constantes que por sua vez afetam nossas relações sociais. Tais relações têm sido moldadas pela globalização que tomou forma ao presenciar as nações do mundo vivenciando um intercâmbio econômico, social, cultural, religioso, tecnológico e educativo. Instituições educacionais e empresas dos cinco continentes têm ofertado cursos na modalidade a distância por meio do uso das novas tecnologias da informação: internet, satélite, vídeo conferência, CDROM entre outros. A utilização de mídias digitalizadas no processo ensino-aprendizagem é denominada de tecnologia educacional. Cavalcente (2007).

No contexto geral, analisa a globalização como um fenômeno em que se observa uma maior comunicação e intercâmbio de bens e serviços entre os diversos países do mundo. Existem vários autores e teóricos que sustentam que a globalização é sinônimo de internacionalização, ou seja, com ela os humanos adquirem a oportunidade de viver em um mundo sem fronteiras.

O Ensino a Distância é considerado um produto da Globalização, pauta-se nas relações de trocas de conhecimento, tornado uma rede de expansão do saber. Instituições governamentais e não governamental tomam posse dessa modalidade de ensino com a finalidade de promover a capacitação de seus colaboradores. Dessa forma, esforços são empenhados no aperfeiçoamento e aprendizagem através dos cursos compatível com a organização.

Para transmitir esse conhecimento é necessário envolver inúmeros fatores dos quais se insere: conteúdos programáticos, professores, tecnologias de informação e comunicação, fermentas virtuais e outros, no entando, destaca a função do tutor, por entender que o trabalho desenvolvido por esse profissional é um dos principais pilares que sustentam o adequado funcionamento da EAD, possibilitando que o aluno não se sinta isolado no processo de ensino aprendizagem, mesmo estando separado fisicamente dos colegas e do professor.

Como foi dito, ele é responsável pela mediação pedagógica de percurso de aprendizagem junto aos estudantes. $\mathrm{O}$ tutor têm a competência de organizar e estimular o aprendizado, acompanhar o desenvolvimento do estudante, envolver os alunos em suas aprendizagens e no trabalho, trabalhar em equipe, participar da gestão dos processos educacionais, utilizar as novas tecnologias, enfrentar os deveres e os dilemas éticos da profissão e gerir sua própria formação contínua.

São diversos os desafios das práticas de tutoria, considerando como um campo de demandas múltiplas e exige competência para o exercício da função. Nesse sentido, a capacitação de tutores para ministrar o Ensino a Distância tornou-se indispensável para o sucesso e qualidade dos cursos oferecidos, que por sua vez, refletirá definitivamente no desempenho dos alunos por intermédio da didática inovadora, contida na metodologia da Educação a Distância.

O conhecimento a distância é conhecido como uma modalidade de ensino que é capitaneado por tecnologias em que alunos e professores estão separados, ou seja, não estão no mesmo ambiente físico, mesmo assim, estão unidos dentro de um ambiente virtual de aprendizagem, que permite a interação para transmissão do conhecimento. É por isso que a metodologia $\mathrm{EaD}$ é considerada o grande marco na construção do ensino no século XXI, no entanto, vale lembrar que o avanço das tecnologias da informação foram ferramentas decisivas para consolidação do método EaD. Neves et al (2018).

A tecnologia digital tem crescido muito no Brasil e faz presença em diversos setores da sociedade. A partir da popularização da internet e, com isso, o seu acesso a boa parte da população, as Tecnologias da Informação e Comunicação (TICs) se tornam disponíveis no dia a dia por meio de computadores, notebooks, tablets e smartphones. Segundo Moran diante desse cenário:

Precisa reinventar a forma de ensinar e aprender, presencial e virtualmente, diante de tantas mudanças na sociedade e no mundo do trabalho. Os modelos tradicionais são cada vez mais inadequados. Educar com novas tecnologias é um desafio que até agora não foi enfrentado com profundidade e apenas adaptações, pequenas mudanças. 
Agora, na escola e no trabalho, pode aprender continuamente, de forma flexível, reunidos numa sala ou distantes geograficamente, mas conectados através de redes. (MORAN, 2015, p.1).

É importante abrir novos caminhos para a educação. Deve-se procurar transformar o sistema educacional em um processo cada vez mais flexível e aberto. Que cumpra com o objetivo principal, que é ensinar, mas adaptando-o às diferentes realidades de cada aluno e região. A educação a distância é considerada como meio muito afetivo de se propagar conhecimento com facilidade e abrangência. No entanto deve-se certificar de que isso está sendo feito sem abdicar-se da qualidade do ensino, que precisa ser tratado com propriedade absoluta.

\section{CONCLUSÃO}

A consolidação da Educação a Distância se dá mediante inúmeras ferramentas que contém sua metodologia, engloba um conjunto de processos pelas quais torna possível reconhecer uma determinada realidade, produzir determinado objeto ou desenvolver certos procedimentos ou comportamentos. A Educação a Distância não teria sucesso sem englobar dois termos importantes, método e técnica. Sem o método o aluno e professor não completariam as etapas de uma pesquisa, e a técnica é a instrumentação específica da ação de uma pesquisa.

A Educação a Distância fundamenta-se na pesquisa para alcançar o objetivo, disponibilizando ao aluno várias ferramentas através da internet, sem as quais seria impossível a eficácia de seu método.

O trabalho possibilitou uma visão concreta das diferentes partes que configuram a modalidade de Ensino a Distância, esclarece através da pesquisa, o real entendimento dos temas da palavra chave, dos quais foi o norte da pesquisa. Diante do entendimento pode afirmar que o Ensino a Distância e composto por inúmeras características que promovem o auto desenvolvimento do indivíduo, permitindo a ampliação do conhecimento através da metodologia EaD.

A Educação a Distância descaracterizou o pragmatismo, ou seja, é visto nos dias atuais como uma pedagogia moderna que engloba um conjunto de técnicas, princípios, métodos, e estratégias da educação e do ensino, podendo ser julgado pelo que realmente é, e não pela que deveria ser levantando dúvidas da eficácia do seu método.

$\mathrm{Na}$ trajetória da pesquisa, descobriu-se que a Educação a Distância é muito antiga, que no início foi guiada pela corrente empírica e passou por várias transformações até chegar à nova filosofia da ciência defendida por Kunh (1922-1966), onde afirma que a metodologia é instrumento que precisa ser partilhada entre alunos professores e cientistas.

A Educação a Distância superou todas as expectativas com o poio das tecnologias da informação e comunicação, alcançando o objetivo através de planejamento e estratégia, contribuindo com o desenvolvimento dos setores econômico, político e social, considerados o tripé do desenvolvimento. Ressalta o papel da EaD quando resgata o indivíduo da margem social e coloca no meio social, permitindo que uma pessoa possa tornar-se aluno e ter uma profissão. Juntando a fatores positivos destaca o empenho do Governo Federal na criação de mecanismos que estruturaram o Ensino a Distância, possibilitando o interesse da iniciativa privada e órgãos não governamentais em acreditarem no sucesso desse modelo de ensino.

As políticas públicas de expansão da EAD estão ligadas aos critérios fixados no decorrer de sua implementação: credenciamento, recredenciamento, supervisão e avaliação das suas Instituições e Cursos. Para tanto, apresenta um quadro histórico de decretos presidenciais que garantiram a construção da EAD no Brasil e os recentes documentos oficiais de 2017.

Hoje, a Educação a Distância é conceituado por diversos autores e cada um destes enfatiza alguma característica especial de seu conceito, passando mais credibilidade para as pessoas que estão e os que ingressarão nessa modalidade de ensino. Em suma o trabalho apresenta um breve histórico sobre a $\mathrm{EaD}$, prova que durante séculos esse modelo de ensino vem deixando um legado para o cidadão desde alfabetização ao curso superior, tem acompanhado as mudanças e se adequando através de sua inovada metodologia.

\section{REFERÊNCIAS BIBLIOGRÁFICAS}

ALVES, J. P. M. A Educação a Distância no Brasil. instituto de pesquisas avançadas em educação, Brasil, 2007. ALVES, L. Educação a Distância: conceitos e história no Brasil e no mundo. V. 10 - 2001.

ALMEDA, S. C. D. Educação a Distância. Curitiba: Fael, 2012.

ARAUJO, e al. A Gestão da Inovação na Educação a Distância. São Carlos: v. 20. 2013.

BRASIL. Constituição (1988). Constituição da República Federativa do Brasil. Brasília: Senado Federal, 1988.

BRASIL. Decreto 5622, de 19 de Dezembro de 2005. Regulamenta o artigo 80 da lei no 9.394 , de 20 de Dezembro de 1996, que estabelece as diretrizes e bases da educação nacional. Diário oficial da república federativa do Brasil. Brasília, DF, 20 de dez. 2005. Disponível em: http://www.planalto.gov.br/ccivil 03/_Ato2004.2006/200st Decreto/D5622,htm Acesso em 15 dez. 2017.

BOTELHO, J. M.: CRUZ, V. A. G. Metodologia científica. São Paulo: Pearson Education do Brasil, 2013.

CARVALHO, F. V. Os jesuítas no Brasil colônia. Jul. 2011. Disponível em: http://frankvcarvalho.blogspot.com/2011/06/05-jesuitas-eeducação-no-brasil. Acesso em 17 dez. 2017.

CHIAVENATO, I. Recursos humanos: o capital humano das organizações. 9. ed. - Rio de Janeiro: Elsevier, 2009.

Decreto $\mathbf{n}^{\circ} \mathbf{9 . 0 5 7}$, de 25 de maio de 2017 . Regulamenta o art. 80 da Lei $\mathrm{n}^{\circ} 9.394$, de 20 de dezembro de 1996, que estabelece as diretrizes e bases da educação nacional.

GRAEML, K. S. Tecnologias de Informação e Comunicação no Ensino Superior. Curitiba: Fael, 2012. HACK, J. R. Introdução à Educação a Distância. Florianópolis: LLV/CCE/UFSC, 2011.

LOPES, M. C. L. P. et al. A Educação a Distância no Ensino Superior: uma possibilidade concreta de inclusão social. Rev. Dialogo Educacional. Curitiba.: V. 10, n. 29. p. 191-204, jan./abr. 2010. Disponível em: http://www.redalyc.org/pdf/1891/189114444011.pdf.

Acesso em 28 dez. 2017.

LIBÂNEO, J. C. Pedagogia e pedagogos, para quê? 6, ed, - São Paulo. Cortez, 2002. 
LITTO, F. M.: FORMIGA, M. Educação a Distância: o estado da Arte. São Paulo. Pearson Education do Brasil, 2009.

MAGNOL, M. A Educação a Distância no Brasil: conceitos e fundamentos. Rev. Diálogo Educ. Curitiba. v. 9 n. 27 , p. 335 - 349, maio/ago. 2009.

MATTOS, O. M. S. Organização Política e Legislativa do Ensino Superior. Curitiba: Fael, 2012.

CRUZ, Vilma Aparecida Gimenes. Metodologia da pesquisa cientifica. São Paul: Pearson Prentice Hall, 2011.

MILL, D. Estudos sobre processos de trabalho em EaD mediada por tecnologias da informação e da comunicação. Belo Horizonte: FAE/UFMG. 2002. 193p. Dissertação (Mestrado em Educação) -Faculdade de Educação, Universidade Federal de Minas Gerais, Belo Horizonte, 2002.

MORAM, J. M. Educação inovadora presencial e a distância. São Paulo, Loyola, 2003. Disponível em: http://www.eca.usp.br/prof/moram/dist.htm. Acesso em 26 ago. 2016.

MORAN, J. M. Educação inovadora presencial e a distância. Disponível em: http://www.eca.usp.br/prof./moran/site/texto/tecnologias.ed ucaçao/inov.pdf. Acesso em 20 abr. 2018.

OLIVEIRA, D. P. R. Planejamento estratégico: conceitos, metodologia e práticas. 31. ed. São Paulo: Atlas, 2013.

PAUlA, R. A. M. Processos Interativos: ProfessorAluno-Conhecimento. Curitiba: Fael, 2012.

PRETI, O. et al. Educação a Distância: sobre discurso e prática. Brasília: Liber livro Editora, 2005.

RODERO, R, P. Práxis na EAD. Curitiba. ed. Fael, 2012.

VERMELHO, S. C. S. D. Práxis no Ensino Superior. Curitiba: Fael, 2012.

\section{COPYRIGHT}

Direitos autorais: $\mathrm{O}(\mathrm{s})$ autor(es) é(são) o(s) único(s) responsável(is) pelo material incluído no artigo. 


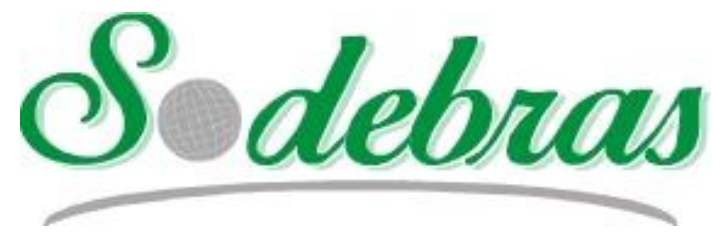

Volume 14 - No 159 - Março/2019.

XL International Sodebras Congress

10 a 12 de dezembro de 2018 - Vitória - ES.

\title{
SAUBARA: TERRITÓRIO E IDENTIDADE
}

\author{
SAUBARA: TERRITORY AND IDENTITY
}

\author{
VALDIR SILVA DA CONCEIÇÃO ${ }^{1 / 2}$; ANGELA MACHADO ROCHA ${ }^{1}$; SILVIO LIBERATO DE MOURA \\ FILHO $^{1}$
}

\section{1 - UNIVERSIDADE FEDERAL DA BAHIA - UFBA}

valdirconceicao@gmail.com,anmach@gmail.com, silvioliberatomoura@gmail.com

\begin{abstract}
Resumo - O espaço de uma comunidade tradicional de pesca constitui-se em um fator de formação territorial $e$ na conformação da identidade social e territorial do município, além da interação entre o espaço e o território. A pesquisa realizada foi do tipo exploratória e qualitativa acerca do município de Saubara, que fica geograficamente na Baía de Todos os Santos e no Recôncavo Baiano. A comunidade tradicional tende a ficar excluída do processo político e econômico hegemônico, assim como fica a margem das políticas públicas, que se apropria do espaço no qual está inserido, não possuindo representatividade fora da comunidade. A identidade e o território criam uma perspectiva de apropriação, pertencimento e permanência do sujeito da comunidade no seu local de origem na medida em que se sente parte integrante da comunidade tradicional.

Palavras-chave: Território. Identidade. Saubara.
\end{abstract}

\begin{abstract}
The space of a traditional fishing community constitutes a factor of territorial formation and the conformation of the social and territorial identity of the municipality, in addition to the interaction between space and territory. The research was of the exploratory and qualitative type about the municipality of Saubara, that is geographically in the Bay of All the Saints and in the Recôncavo Baiano. The traditional community tends to be excluded from the hegemonic political and economic process, as is the margin of public policies, which appropriates the space in which it is inserted, having no representation outside the community. Identity and territory creates a perspective of ownership, belonging and permanence of the subject of the community in its place of origin insofar as it is am integral part of the traditional community.
\end{abstract}

Keywords: Territory. Identity. Saubara.

\section{INTRODUÇÃO}

A sociedade moderna vive um momento em que a globalização e o avanço tecnológico influenciam e modificam o comportamento das pessoas, principalmente os mais jovens, inclusive na identidade e na cultura de um local ou região, o que suscita muitos estudos por parte das academias no campo das ciências humanas (HALL, 2015).

Essas atividades laborais tem um significado identificário e cultural para a comunidade, além do saberfazer que se constitui em uma tradição passada de geração para geração, o que aflora o sentimento de pertencimento como local, associado com essas atividades. Entretanto, as jovens nos dias atuais não demonstram interesse no aprendizado dessa arte, o que pode no futuro deixar de existir.
No município de Saubara, localizado no Recôncavo da Bahia, a renda de bilro é um artesanato que ganhou fama internacional, sendo produzido a partir de cruzamentos e entrelaçamento de linhas, fundamentalmente por mulheres, ofício passado de geração a geração que se perpetuam a história e a ancestralidade com a transmissão dos saberes e resistindo aos movimentos históricos de dominação. (AMORIM, 2010; SILVA, 2017) A Associação das Rendeiras de Saubara conta com cerca de 110 associadas e data dos anos 80, desde quando o grupo começa a se organizar e a ter apoio de entidades e do poder público. O trabalho da Associação baseia-se na preservação de aspectos culturais, como o uso de linha de algodão de cor branca, formato tradicional da renda, e trabalho solidário como princípio definido por todas as rendeiras (AMORIM, 2010)

O presente trabalho tem como objetivo observar o trabalho artesanal feita pelas mulheres do município de Saubara, no Recôncavo Baiano, que tem como principal ocupação a mariscagem, que proporciona um ganho financeiro imediato e que serve para a subsistência, sendo que algumas delas são filiadas a Associação das Rendeiras e complementam a renda exercendo atividades artesanais como a confecção da renda de bilro e o trançado de palha.

O tema surgiu após o trabalho executado no grupo de pesquisa que tem como objetivo o registro da Indicação Geográfica (IG) da renda de bilro de Saubara perante o Instituto Nacional de Propriedade Industrial (INPI), o que vai proporcionar uma maior visibilidade para o produto e que consequentemente poderá servir como um instrumento de incentivo para as jovens da comunidade.

No desenvolvimento do trabalhou optou-se por uma pesquisa do tipo exploratória, utilizando como base dissertações, teses, trabalho de conclusão de curso e reportagens nos meios de comunicação e nas redes sociais.

\section{METODOLOGIA}

Para Gil (2006) um bom pesquisador precisa além do conhecimento sobre um determinado assunto, ter curiosidade, criatividade, integridade intelectual e sensibilidade. A pesquisa tem de ser pragmática e com condições de desenvolver um método científico, tendo como objetivo descobrir respostas para os problemas levantados.

Neste artigo foi utilizado dados secundários obtidos através da pesquisa bibliográfica, incluindo dissertações, 
artigos científicos, teses e trabalhos de conclusão de cursos, além de pesquisa em órgãos governamentais, IBGE e no site da prefeitura.

A metodologia utilizada foi a pesquisa exploratória documental com abordagem do tipo qualitativa, baseado no levantamento bibliográfico acerca do assunto, estudo de casos similares, além de se utilizar de fontes secundárias coletados de diversas fontes públicas, privadas, de caráter nacional, regional ou local, como pesquisas de site como o IBGE cidades, com a exploração do tema de forma que se possa permitir fazer uma análise e compreensão do problema, além de fornecer subsídios para que se tenha um conhecimento mais amplo e detalhado acerca do problema. Todas as fontes consultadas encontram-se listadas nas referências.

\section{RESULTADOS}

\section{SAUBARA}

A sua história remonta a um tempo anterior a colonização portuguesa, pois era habitada pelos índios Tupis, e o seu nome deriva da formiga "saúva" que era abundante no local e teve como nome "Sauvara" que significa terra dos comedores de formiga, e quando foi colonizada pelos espanhóis teve a variação do nome para Saubara. (BARROS, 2017).

O povoado de Saubara surgiu em 1550, num local chamado Ponta de Saubara, próximo ao mar. O município teve papel relevante na origem do município de Santo Amaro, do qual foi um dos primeiros aglomerados urbanos. O município teve sua constituição como povoado a partir da construção de uma igreja dedicada a São Domingos de Gusmão da Saubara, construída pelos moradores da Ponta de Saubara - região a beira-mar fundada pelo fidalgo português Braz Fragoso em 1685 - para que os protegessem em alto mar (JESUS, 2011).

A igreja foi constituída de pedras e óleo de baleia, trazidos por jesuítas espanhóis da Ilha de Itaparica, junto com a imagem do santo. Ela serviu de quartel general nas lutas pela Independência da Bahia, onde do seu alto podia-se avistar os portugueses vindos do mar para o ataque.

Sua localização, às margens da Baía de Todos os Santos e próximo a foz do rio Paraguaçu, possibilitou a formação de um povo voltado para os mistérios das águas e para as possibilidades de sobrevivência que o mar oferecia, o que caracterizou uma subsistência vinculada a pesca e à coleta de marisco. A variedade de peixes, mariscos e crustáceos propiciou o surgimento de atividades pesqueiras.

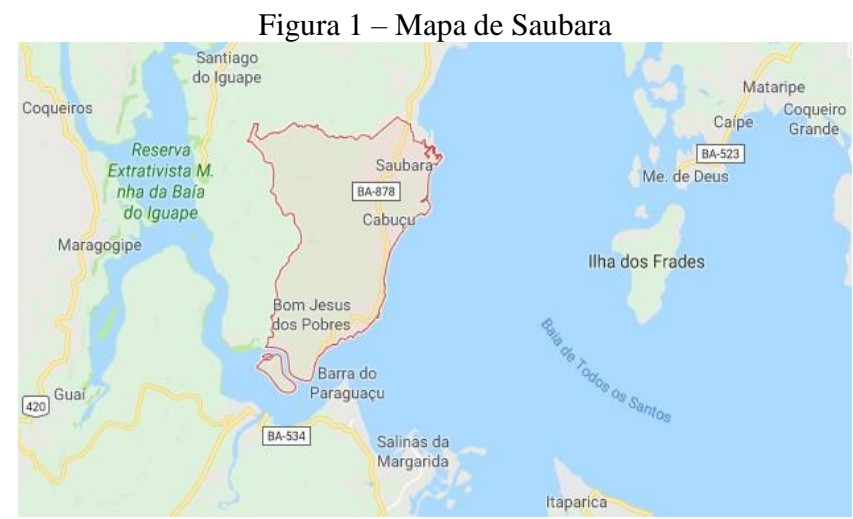

Fonte: Google Maps, 2018
A superfície é de $163,50 \mathrm{~km}^{2}$, altitude de $10 \mathrm{~m}$, coordenadas geográficas sexagesimais a $12^{\circ} 44^{\prime} 16^{\prime \prime}$ de latitude Sul e 38 46'09" de longitude Oeste. Faz limite com os municípios de Salvador, São Francisco do Conde e Madre de Deus (E); Santo Amaro (N); Cachoeira (W); e Maragogipe e Salina das Margaridas (S). O seu clima varia de úmido a subúmido, com temperatura média anual em torno de $23,4^{\circ} \mathrm{C}$ e pluviosidade média anual entre $1139 \mathrm{~mm}$. Faz parte da Mesorregião Metropolitana de Salvador e da Microrregião de Santo Antonio de Jesus. A população estimada em 2018 é de 11.978 pessoas e Índice de Desenvolvimento Humano (IDH) de 0,617 (IBGE, 2018)

O município de Saubara, até 1989, era um distrito que pertencia a Santo Amaro, cuja atividade estava relacionada com o ciclo da cana de açúcar e os seus engenhos. Os moradores nativos eram os índios tupis, a partir do século XVII foi colonizado pelos portugueses e devido a necessidade de mão de obra para os engenhos e para a lavoura, ocorreu a vinda dos negros africanos que foram escravizados, portanto, na formação do município ocorreu essa miscigenação de povos e consequentemente a influência dessas três etnias na formação cultural e do conhecimento, sendo que dos índios foi a culinária e os instrumentos de coleta dos mariscos, além da cultura ambiental; dos portugueses os métodos; dos negros os utensílios

A tradição dessa mistura, comum no Recôncavo, é originária da cozinha afrodescendente, na qual se destaca o uso do dendê em moquecas, feijões, legumes, folhas, tudo refogado e banhado no epô, como chamam os iorubá o nosso dendê. A tradição tem um significado para cada geração, que com a evolução natural do mundo e a modernidade desperta sentimentos, compreensão e olhares diferentes e o desinteresse das novas gerações pode comprometer a perpetuação da tradição e o saber-fazer (JESUS, 2011).

O município de Saubara é composto de três distritos: Saubara que corresponde a sede; Bom Jesus dos pobres e Cabuçu. As comunidades residentes são formações socioespaciais variadas como comunidades agrícolas, pesqueiras, sítios, casas de veraneio.

\section{TERRITÓRIO E IDENTIDADE}

O território é um fator gerador de raiz e identidade de um povo, não havendo possibilidade da tentativa de entendimento de uma população sem que a mesma se encontre inserida em um determinado território, pois a identidade sociocultural de uma comunidade está intimamente ligada aos atributos adquiridos no espaço territorial, não podendo haver dissociação entre eles (SOUZA, 2001). Serve como elemento gerador de recursos, como fonte de recursos naturais e materiais, além de servir como local de abrigo e de proteção para a comunidade, sendo distinto conforme o seu construtor, que pode ser o indivíduo, os grupos sociais e culturais, as instituições, os entes públicos e privados, que exercem um determinado controle nesse território ao qual pertence, agindo de forma política e relacional com os indivíduos e de acordo com as manifestações humanas (HAESBAERT, 2012).

No exercício das atividades da confecção das rendas de bilro e do artesanato de palha, além da atividade principal executada por essas mulheres, como a mariscagem, ocorre uma construção do saber-fazer, que se constitui em uma cultura distinta e específica, o que demonstra uma 
determinada identidade social e territorial no exercício dessas atividades.

Figura 2 - Renda de bilro e trançado de palha

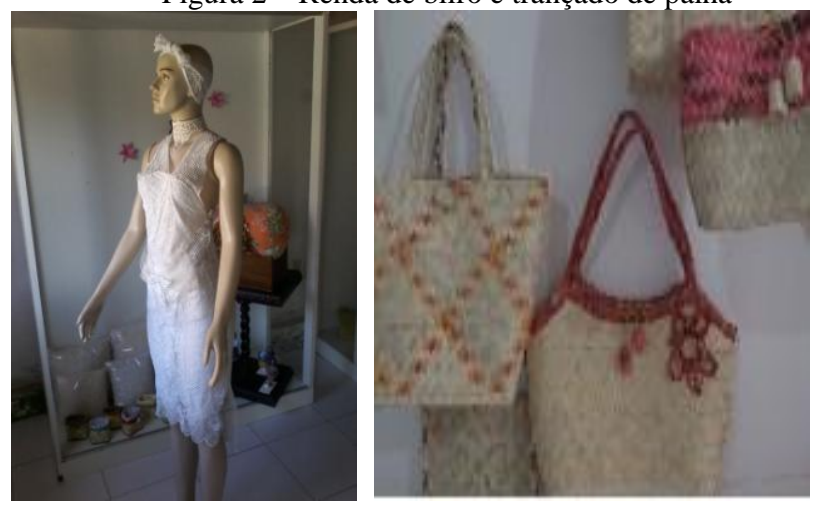

Fonte: Autoria própria, 2018

A identidade possui uma formação diversificada, podendo ser por meio da contagem de histórias da cultura popular, baseada nas origens, tradição e valores, podendo estar relacionada com a ocupação e apropriação do território, o que normalmente ocorre no desenvolvimento das atividades exercidas por essas mulheres (HALL, 2015).

Por se constituir em um grupo cuja atividade principal é a cata de marisco, o decreto $\mathrm{n}^{\circ} 6.040$, de 7 de fevereiro de 2007, considera-o como uma comunidade tradicional, que ocupa um território tradicional, utiliza recursos naturais para a sua subsistência e de forma organizada difunde e reproduz de forma natural a sua cultura rica em costumes e crenças, a religiosidade e a ancestralidade, utilizando como ferramenta o conhecimento, as inovações e as práticas geradas e transmitidas de forma tradicional de geração para geração.

A marisqueira, que é uma atividade de atribuição feminina, decorrente da hierarquia estabelecida pela divisão de gênero, da relação de poder e respaldada no determinismo genético, contribui para o desenvolvimento do município, que é considerado como um local de veraneio devido a beleza natural das suas praias. Elas levam uma vida simples e modesta, com história de vida de muito trabalho, tirano dos manguezais o seu sustento e da sua família, com o ofício sendo transmitido de geração a geração, que ao longo do tempo vai passando por uma ressignificação (JESUS, 2015). Ela tem um papel muito importante na cadeia produtiva, sendo um dos pilares da complementação da renda das famílias, com algumas delas tendo como papel principal a manutenção do sustento familiar, inclusive, algumas são registradas como marisqueira perante os órgãos governamentais (TORRES, 2014). A atividade também é realizada por pessoas idosas, que são as pessoas que detém o saber e transmitem o conhecimento para os mais jovens.

Figura 3 - Marisqueiras de Saubara

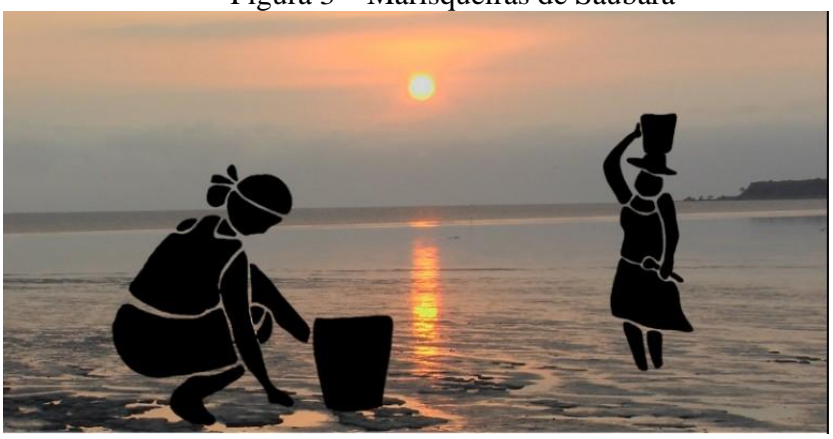

Fonte: Souza, 2018
A atribuição de cunho estritamente feminino vem passando por modificações ao longo do tempo, principalmente com o empoderamento das mulheres nesse mundo globalizado, com a ocorrência de muitos conflitos de gênero e conquistas, principalmente relacionados ao trabalho em diferentes espaços e segmentos, a religiosidade e também devido as questões culturais.

A atividade está fortemente interligada com o ambiente marinho, consistindo na captura de crustáceos e moluscos dos manguezais como o caranguejo, guaiamum, lambreta, sururu etc., o que contribui para a construção do território e da identidade ligada ao ambiente marinho.

$O$ processo de mariscagem envolve as etapas de captura, beneficiamento e comercialização. A primeira etapa consiste na ida ao manguezal ou a praia (no caso de alguns mariscos), quando a maré se encontra na vazante (ritmo e horário da maré estabelecido pela fase da lua), para buscar o caranguejo ou marisco. A segunda etapa elas se dirigem para as suas respectivas residências para o beneficiamento do produto catado, que consiste no cozimento e retirada do marisco da casca, normalmente feito no quintal, onde ocorre a conversa e a troca de experiência entre as catadoras. A etapa final consiste na lavagem, embalagem, pesagem, refrigeração e comercialização do produto de porta em porta, feira livre da cidade vizinha como Santo Amaro, Salvador e Feira de Santana, para as barracas de praia, bares, restaurantes, moradores e veranistas (MORAIS, 2010)

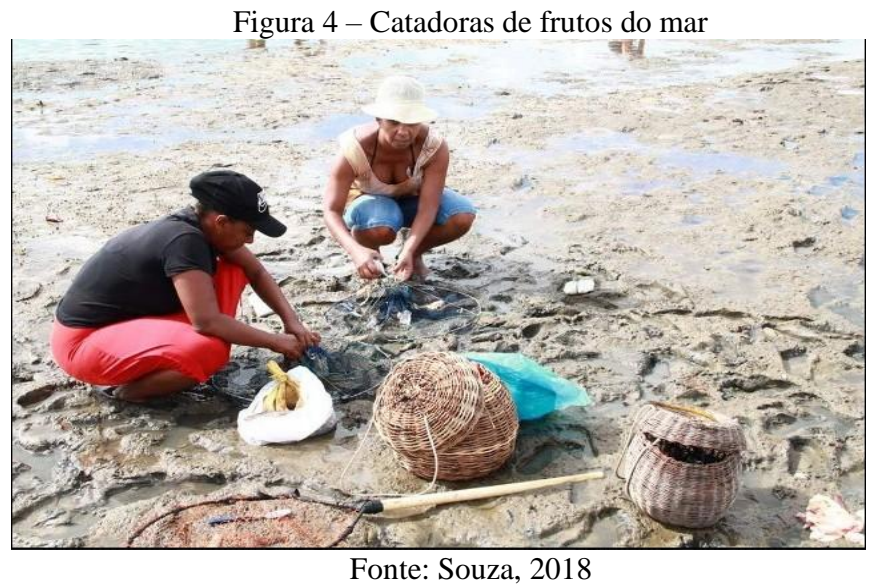

O trabalho envolve todo o seio familiar, como os filho(a)s, sobrinho(a)s, primo(a)s, neto(a)s etc., desde a captura até a comercialização, porém no exercício dessa atividade não são assalariados. As marisqueiras ficam expostas aos raios solares, utilizam ferramentas rudimentares e arcaicas por ser tratar de uma atividade artesanal e unitária, não utilizam roupas e protetores adequados para evitar essa exposição, assim como luvas e calçados adequados para evitar cortes nas mãos e nos pés ao tocar no marisco e/ou andar sobre pedras. A posição postural para a captura dos moluscos não é ergonomicamente correta, podendo a longo prazo acarretar problemas de saúde.

O conhecimento da comunidade tradicional em relação aos ciclos da natureza, a maré, o clima e as técnicas são adquiridos e passados por meio da oralidade, pela convivência, e pela experiência, nas formas produtivas (apetrecho apropriado para cada um dos itens a serem catados), organizacionais e culturais (processada no sentido vertical pela tradição e na forma horizontal pelo meio), 
como o aprendizado do manejo dos recursos naturais, o que garante a manutenção do grupo social, fazem uso de tecnologia simples e reduzida acumulação de capital. Também ocorre o conhecimento empírico como o apetrecho que deve ser utilizado na captura, o tamanho e a quantidade do material a ser capturado (JESUS, 2015).

$\mathrm{O}$ aprendizado não ocorre de forma letrada e nem formal, mas de forma cotidiana com a observação e a utilização da prática e do conhecimento tradicional, sendo passado entre os membros da família ou da vizinhança, do mais velho para o mais novo, como um processo lúdico que vai se interiorizando e criando uma identidade própria, além de ser fundamental para a socialização das crianças, e, que vai se moldando com o passar do tempo e criando habilidades próprias e readaptações individuais baseadas nos seus costumes, crenças e valores. Essa transmissão do conhecimento, o saber-fazer, caracteriza-se como um saber tradicional, que tem como função assegurar a transmissão do conhecimento a seus descendentes (TORRES, 2014).

O modo de viver da comunidade é feito de rotinas cotidianas, o que reforça os laços e a compreensão do outro, fazendo um elo entre a experiência de vida de um indivíduo com a dos outros componentes da comunidade, onde as relações são construídas e reforçadas e dotados de sentimentos, comportamentos, atitudes e significados diários. O cotidiano como uma manifestação da realidade é um fator responsável pela concretização do conhecimento e do saber, sendo representativo, identitário para o grupo e mantenedor da tradição.

A mariscagem proporciona uma vivência cotidiana, com produção de significados, principalmente relacionado ao fazer, ao compartilhamento das ideias, a preservação dos costumes tradicionais, além de exercer outras atividades e práticas produtivas para complementar a renda, fazendo atividades constantes como o artesanato de palha e a renda de bilro. As atividades esporádicas ocorrem na época do defeso, como serviços temporários, que não demandam escolaridade ou auxílio disponibilizado pela Prefeitura Municipal (JESUS, 2015).

A atividade inicia normalmente na infância, quer seja por necessidade ou por curiosidade, quando são introduzidas nessa atividade pela mãe, por parente próximo ou outras pessoas da vizinhança que exerçam a atividade. Nessa idade inicial, a mariscagem tem uma conotação de uma atividade divertida e não uma obrigação, sendo que na idade adulta, passa a ser uma responsabilidade e um meio de sustento e de ajuda na renda da família (TORRES, 2014).

Os meninos e meninas ficam até a idade de 12 anos acompanhando a mãe na mariscagem e após essa idade, apenas as meninas continuam desenvolvendo essa atividade e os meninos normalmente passam a exercer outras atividades, de cunho "masculino", acompanhando o cotidiano do pai ou de outros membros da família ou da comunidade do sexo masculino (CARVLHO et al., 2014; JESUS, 2015).

A estação do verão é o melhor período para aumentar a renda familiar, pois, os distritos aumentam a sua população devido a afluência de turistas e veranistas (moradores sazonais), principalmente vindos de Salvador, Feira de Santana e da região do Recôncavo Sul, enquanto que no inverno há uma redução nessa atividade. Para a coleta do marisco e do caranguejo os apetrechos utilizados são o balde, as mãos, as linhas, as armadilhas e as redes (JESUS, 2015).

\section{POLÍTICAS PÚBLICAS}

As políticas públicas sempre foram ineficientes para preservar os recursos pesqueiros e a reprodução social da comunidade. O meio ambiente de trabalho saudável é um item de reivindicação das marisqueiras, com o objetivo de obter melhorias nas condições trabalhistas das comunidades afetadas por problemas ambientais na Baía de Todos os Santos (BTS), como já ocorreu no passado com a comunidade de Saubara que foi vítima de um fenômeno denominado "maré vermelha", em 2007, que foi causada pelo lançamento de esgoto doméstico sem tratamento na BTS e essa condição ainda não foi resolvida pelos entes públicos, o que poderá ocorrer novamente. O fenômeno aconteceu no entorno da foz do rio Paraguaçu, com reflexo nas águas adjacentes ao município de Salinas das Margaridas. Nesse período ocorreu a mortandade de mais de 50 toneladas de peixes, assim como de aves, tartarugas, gatos e cachorros, além de intoxicação humana, o que levou os órgãos públicos a proibir a pesca e o consumo de frutos do mar. Foi observado que as águas estavam com a coloração alterada (ATARDE, 2007).

A contaminação ambiental da BTS ocorrida ao longo do tempo tem afetado diretamente o meio ambiente, as condições trabalhistas e de subsistência das marisqueiras, o que consequentemente afeta o sustento de suas famílias, porque ocorre uma redução no quantitativo e tamanho dos produtos catados pela comunidade. Entre os fatores que contribuíram encontra-se o despejo de cadmio, Chumbo e Zinco, que foram despejados diretamente no Rio Subaé durante 30 anos por uma empresa localizada no município de Santo Amaro. Outro elemento responsável foi o despejo de esgoto sem tratamento e os resíduos dos estaleiros na Barra do Paraguaçu diretamente no Rio Paraguaçu (CARVALHO et al., 2014).

A comunidade sabe que tem direito a um ambiente saudável e que essa condição é necessária para a continuidade da atividade voltada para a coleta de produtos do mar, que são necessárias para a sobrevivência da marisqueira e de seus familiares, pois a contaminação não é resultado da ação da natureza, mas pelas ações continuas e duradouras das industrias, que em parte pode ter sido decorrente da omissão dos órgãos responsáveis pela fiscalização, pela recuperação da degradação do meio ambiente e pela falta de uma rede de saneamento básico, que é uma das mais importantes fontes de contaminação (CARVALHO et al., 2014).

\section{CONCLUSÃO}

A comunidade tradicional das marisqueiras do município de Saubara apropria-se de uma identidade própria e característica devido a historicidade das pessoas que habitam o território e possuem a mesma atividade, que normalmente é exercida apenas pelas mulheres a partir dos 12 anos de idade, como uma forma de subsistência e continuidade da tradição local. Verifica-se também a relação espaço-sujeito e sujeito-território, que se revela como um conteúdo identitário e histórico, com as suas interconexões a partir da vivência de um modo particular, peculiar e tradicional, que representa no território uma expressão de ser e de agir, tendo como dimensão o local, o espaço e o seu entorno, que pode ser medida a partir da conduta social na relação entre o indivíduo e a natureza. 
Saubara é um município que tem uma identidade com o ambiente marinho no qual se encontra encravado, além de estimular a condição de pertencimento ao lugar e constituição do espaço da comunidade como território. A sua formação territorial tem uma longa trajetória e historicidade, com o seu povoamento ligado a lavoura canavieira, principalmente decorrente da povoação a partir do século XVI, com a constituição das cidades e com os engenhos tendo um papel fundamental como centro do poder local, o controle político e administrativo, tendo como pano de fundo a modelagem da cultura e dos costumes dos povos que habitavam essas terras constituídos de colonizadores, povos negros escravizados e os donos da terra, os indígenas.

A realidade espacial dos indivíduos no território é um fator determinante para a condição de pertencimento, não só do local, mas como indivíduo pertencente a comunidade tradicional que faz parte, principalmente quando se percebe que a sua constituição é feita em sua maioria por pretos e pardos, que ocupam o seu espaço com uma trajetória cultural e de adaptações de ajuste socioespacial dos seus moradores constituídos de pescadores, marisqueiras e artesãos.

As marisqueiras transitam de forma natural no processo de identificação e de forma silenciosa em relação a outras formas identitárias, principalmente em relação ao gênero, que por ser uma identidade feminina ainda se encontra em uma condição de "submissão" em relação ao universo masculino, que com o seu protagonismo altera a significação costumeira nas relações entre homem e mulher.

A identidade territorial é gerada pela convivência e apropriação dos elementos do espaço, no trabalho tradicional exercido pelos sujeitos da comunidade, no sentimento de pertencimento socioterritorial.

\section{REFERÊNCIAS BIBLIOGRÁFICAS}

AMORIM, M. C. Arte Brasil: Maria do Carmo Amorim. 2010. Disponível em:

<https://www.youtube.com/watch?v=VZim0fH5Ioo>. Acesso em: 10 out. 2018.

ANDRADE, Maíza. Maré vermelha causou mortandade de peixes. A TARDE, Salvador, 4 abr. 2007. Disponível em: $<$ http://atarde.uol.com.br/bahia/salvador/noticias/1268329-marevermelha-causou-mortandade-de-peixes $>$. Acesso em: 30 out. 2018.

BARRoS, J. S. Ponto de Cultura: Saubara em Movimento. 2017. Bahia. Disponível em: <http://marujadadesaubara.org.br/wpcontent/uploads/2013/07/Catalogo_PontodeCUltura_SaubaraemM Ovimento.pdf>. Acesso em 10 fev. 2018.

BRASIL, Instituto Brasileiro de Geografia e Estatística. Disponível em: <https://cidades.ibge.gov.br/brasil/ba/saubara>. Acesso em 02 out. 2018.

CARVALHO, Ingrid Gil Sales; RÊGO, Rita de Cássia Franco; LARREA-KILLINGER, Cristina; ROCHA, Júlio César de Sá da; PENA, Paulo Gilvane Lopes; MACHADO, Louise oliveira Ramos. Por um diálogo de saberes entre pescadores artesanais, marisqueiras e o direito ambiental do trabalho. Ciênc. saúde coletiva [online]. 2014, v. 19, n. 10, p. 4011-4022. ISSN 14138123. Disponível em: <http://www.scielo.br/pdf/csc/v19n10/14138123-csc-19-10-4011.pdf>. Acesso em: 03 nov. 2018.

Gil, Antonio Carlos. Métodos e técnicas de pesquisa social. 5 ed. São Paulo: Atlas, 2006
HAESBAERT, Rogério. Territórios alternativos. 3. ed. Niterói, RJ: São Paulo, SP: Contexto; EDUFF, 2012. 186 p.

HALL, Stuart. A identidade cultural na pós-modernidade. 12. ed. Rio de Janeiro, RJ: Lamparina, 2015. 52 p.

JESUS, Roseni Santana de. Pescador e marisqueira: identidades em conflito. In: SEMINÁRIO DA PÓS-GRADUAÇÃO EM CIÊNCIAS SOCIAIS: CULTURA, DESIGUALDADE E DESENVOLVIMENTO, 5., 2015, Cachoeira. Disponível em: $\langle$ https://www3.ufrb.edu.br/sppgcs2015/images/roseni.pdf $>$.

Acesso em 02 nov. 2018.

JESUS, Rosenaide Santos; PROST Catherine. Importância da atividade artesanal de mariscagem para as populações nos municípios de Madre de Deus e Saubara, Bahia. GEOSUP Espaço e Tempo [online], São Paulo, n. 30, p. 123-137, 2011. Disponível em: $\langle$ http://www.revistas.usp.br/geousp/article/view/74236>. Acesso em: 03 nov. 2018.

MORAIS, Lorena. Saubara: Encanto da Baía de Todos os Santos. Recôncavo [online]. Disponível em: $<$ http://moraislorena.blogspot.com/2010/11/saubara-encantos-dabaia-de-todos-os.html>. Acesso em: 02 nov. 2018.

SANTOS, Rodrigo Herles dos. Entre águas e gente: vivências e (in)visibilidade nos territórios do litoral de Sergipe. 2015. $334 \mathrm{f}$. Tese (Doutorado em Geografia) - Universidade Federal de Sergipe, São Cristóvão, 2015. Disponível em: <https://www.sigaa.ufs.br/sigaa/public/programa/defesas.jsf?lc=pt \&id=137>. Acesso em 2 nov. 2018.

SILVA, D. B. P. Educação, resistências e tradição oral: a transmissão de saberes pela oralidade de matriz africana nas culturas populares, povos e comunidades tradicionais. 2017. $217 \mathrm{f}$. Dissertação (Mestrado em Educação) — Universidade de Brasília, UNB, Brasília, 2017. Disponível em: <http://repositorio.unb.br/bitstream/10482/24411/1/2017_DanielaB arrosPonteseSilva.pdf $>$. Acesso em: 27 out. 2018.

SOUZA, Marcelo José Lopes de. O território: sobre espaço e poder. Autonomia e desenvolvimento. In CASTRO, I. E. de; GOMES, P. C. da C.; CORRÊA, R. L. (Orgs.). Geografia: conceitos e temas. Rio de Janeiro: Bertrand Brasil, 2001, p.77116.

SOUZA, Gabrielle. Marisqueiras. Disponível em: $<$ http://batepapocomnetuno.blogspot.com/2018/03/marisqueiras.ht $\underline{\mathrm{ml}}>$. Acesso em 02 nov. 2018

TORRES, Ronilse Pereira Aquino. O sentido de ser pescador: signos e marcas no povoado Pedreiras - São Cristóvão/SE. 2014 140 f. Dissertação (Mestrado em Geografia) - Universidade Federal de Sergipe, São Cristovão, 2014. Disponível em: $<$ https://ri.ufs.br/bitstream/riufs/5598/1/RONILSE_PEREIRA_AQ UINO TORRES.pdf>. Acesso em: 02 nov. 2018.

\section{COPYRIGHT}

Direitos autorais: Os autores são os únicos responsáveis pelo material incluído no artigo. 
Volume 14 - No 159 - Março/2019.

XL International Sodebras Congress

10 a 12 de dezembro de 2018 - Vitória - ES.

\section{Área: Ciências Agrárias e Biológicas}

\begin{tabular}{|c|c|}
\hline $4-4$ & 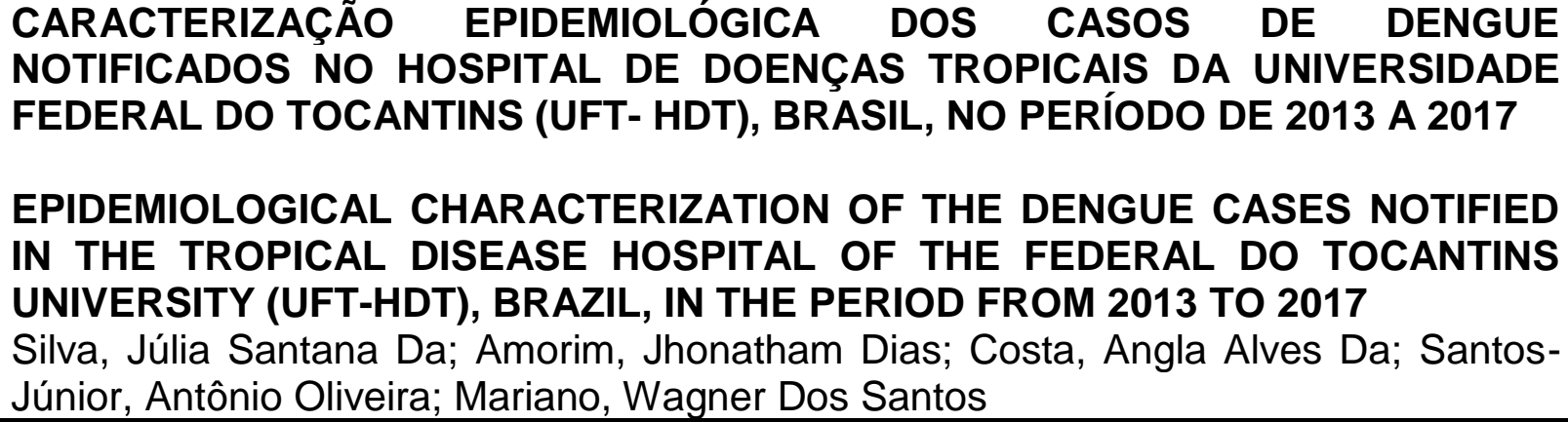 \\
\hline $4-4$ & $\begin{array}{l}\text { ANSENÍASE: CARACTERIZAÇÃO CLÍNICA-EPIDEMIOLÓGICA DOS CASOS } \\
\text { OTIFICADOS NO HOSPITAL DE DOENÇAS TROPICAIS DA UNIVERSIDADE } \\
\text { EDERAL DO TOCANTINS (UFT- HDT), BRASIL, NO PERÍODO DE } 2013 \text { A } 2017 \\
\text { ANSENIASIS: CLINICAL AND EPIDEMIOLOGICAL CHARACTERIZATION OF } \\
\text { HE NOTIFIED CASES IN THE TROPICAL DISEASE HOSPITAL OF THE } \\
\text { EDERAL DO TOCANTINS UNIVERSITY (UFT-HDT), BRAZIL, IN THE PERIOD } \\
\text { ROM } 2013 \text { TO } 2017 \\
\text { ampaio, Ana Cristina Mendanha; Mariano, Wagner Dos Santos; Silva, Júlia Santana } \\
\text { a Silva; Cavalcante, Patrícia Alves De Mendonça; Rocha, Marceli Diana Helfenstein } \\
\text { lbeirice Da Rocha }\end{array}$ \\
\hline $4-4$ & 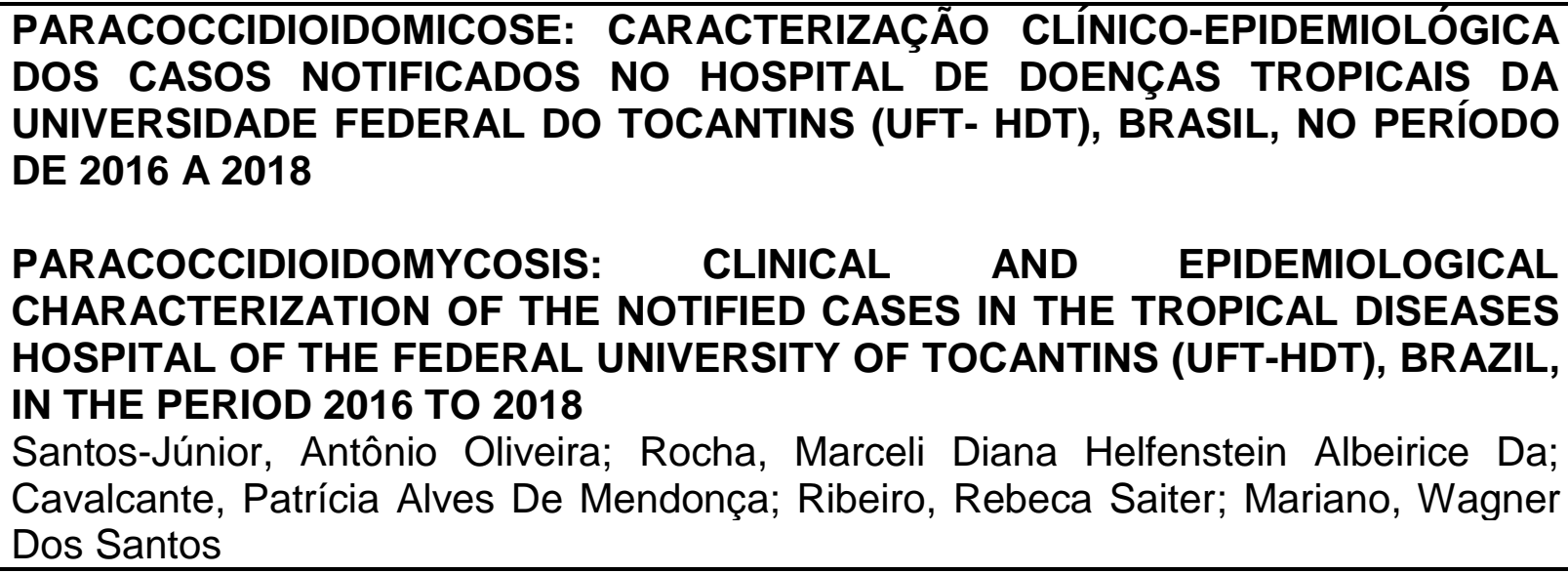 \\
\hline
\end{tabular}




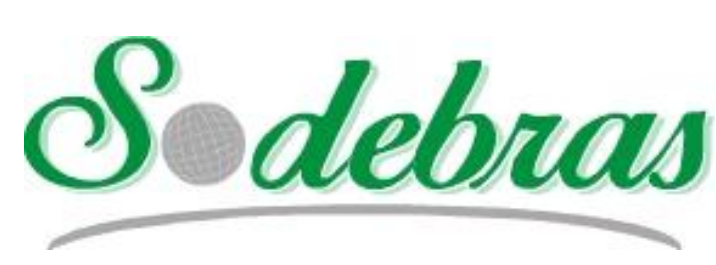

\author{
XL International Sodebras Congress
}

10 a 12 de dezembro de 2018 - Vitória - ES.

\title{
CARACTERIZAÇÃO EPIDEMIOLÓGICA DOS CASOS DE DENGUE NOTIFICADOS NO HOSPITAL DE DOENÇAS TROPICAIS DA UNIVERSIDADE FEDERAL DO TOCANTINS (UFT- HDT), BRASIL, NO PERÍODO DE 2013 A 2017
}

\author{
EPIDEMIOLOGICAL CHARACTERIZATION OF THE DENGUE CASES \\ NOTIFIED IN THE TROPICAL DISEASE HOSPITAL OF THE FEDERAL DO \\ TOCANTINS UNIVERSITY (UFT-HDT), BRAZIL, IN THE PERIOD FROM 2013 \\ TO 2017
}

\author{
SILVA, JÚLIA SANTANA DA ${ }^{1}$; AMORIM, JHONATHAM DIAS ${ }^{1}$; COSTA, ANGLA ALVES DA ${ }^{1}$; \\ SANTOS-JÚNIOR, ANTÔNIO OLIVEIRA ${ }^{2}$; MARIANO, WAGNER DOS SANTOS ${ }^{3}$
}

1 - Acadêmicos do curso de Licenciatura em Biologia e Bolsistas do PET Ciências Naturais da Universidade Federal do Tocantins (UFT). 2 - Graduado em Medicina, Mestrando em Sanidade Animal e Saúde Pública nos Trópicos da Universidade Federal do Tocantins (UFT); Gerente de Ensino e Pesquisa do Hospital de Doenças Tropicais da UFT. 3 - Docente dos cursos: Licenciatura em Biologia; Pós-Graduação em Sanidade Animal e Saúde Pública nos Trópicos; Pós-Graduação em Ensino de Ciências e Matemática da Universidade Federal do Tocantins (UFT); Chefe do Setor de Ensino do Hospital de Doenças Tropicais da UFT.

$$
\text { wagner.mariano@ebserh.gov.br }
$$

\section{INTRODUÇÃO}

A dengue é atualmente a arbovirose com maior disseminação em saúde pública no mundo (BRASIL, 2006). Esta doença tem reemergido em grande magnitude nos países tropicais infestados com Aedes aegypti, onde dois ou mais sorotipos do vírus dengue circulam (LIMACAMERA, 2016). No Brasil a dengue é hoje uma das doenças mais frequentes, atingindo a população em todos os estados, independente da classe social (MUNIZ et al 2011). A notável associação dos mosquitos vetores com o homem e o ambiente urbano e considerado um grande desafio para ciência moderna. (CONSOLI \& OLIVEIRA, 1994). O controle eficiente desses mosquitos tem sido desafiador.

Este estudo foi realizado com o objetivo de caracterizar o perfil sociodemográfico e epidemiológico dos casos de dengue registrados no Hospital de Doenças Tropicais da Universidade Federal do Tocantins (HDTUFT), entre os anos de 2013 e 2017.

\section{METODOLOGIA}

O presente estudo foi realizado com base em dados secundários, oriundos do Sistema de Informação de Agravos de Notificação (SINAN), que é alimentado pela notificação de casos de doenças e agravos que constam da lista nacional de doenças de notificação compulsória.
Aqui, foram incluídos todos os casos notificados pelo Hospital de Doenças Tropicais - HDT-UFT - desde o ano de 2013 a 2017.

\section{RESULTADOS E DISCUSSÃO}

Entre 2013 e 2017 foram registrados no HDT-UFT 144 casos de dengue. Entre 2013 e 2014, houve uma leve queda no número de registros (de 17 para 7), mas esse valor aumentou em 2015 (para 49), voltando a apresentar queda nos anos seguintes (39 casos em 2016 e 32 em 2017). Do total dos casos notificados, 44,4\% ( $n=64)$ acometeram o sexo masculino e $55,5 \% \quad(n=80)$ acometeram o sexo feminino, com apenas 1 caso sendo de paciente no $2^{\circ}$ trimestre de gestação. Em 70,8\% dos casos, $(n=102)$ os infectados são pardos, enquanto $27,1 \%(n=39)$ são brancos. Todas as faixas etárias foram atingidas (entre 1 dia de vida e os 85 anos de idade), porém percebe-se que $65,27 \%$ dos casos $(n=94)$ acometem adultos na faixa etária dos 25 aos 64 anos. De acordo com a literatura, esta faixa etária é a mais atingida por ser a mais economicamente ativa, onde prevê-se a maior probabilidade de contágio pela doença na rotina de trabalho. Do total de registrados com a doença, 29,8\% dos casos apresenta apenas o Ensino Médio completo $(\mathrm{n}=43)$, enquanto $16,6 \% \quad(\mathrm{n}=24)$ apresentam Ensino Fundamental incompleto e $25 \% \quad(n=36)$ já chegaram ao Ensino Superior. 


\section{CONCLUSÕES}

Como apresentado por diversos estudos, fatores sociais relacionados à incidência de doenças devem ser avaliados com cuidado. Estudos de levantamentos da distribuição geográfica da dengue dentro do perímetro urbano já demonstraram aumento do número de casos em bairros onde a condição de vida é intermediária ou elevada moradores apresentam renda e índice de escolaridade relativamente elevados - de modo atribuir e fazer generalizações sobre a relação da ocorrência da doença com determinada condição de renda e/ou nível de escolaridade podem trazer prejulgamento sobre determinado grupo de pessoas.

\section{REFERÊNCIAS BIBLIOGRÁFICAS}

CANARA, T.N.L. Arboviroses emergentes novos desafios para a saúde pública no Brasil. Revista de Saúde Pública, São Paulo, p1-7, 2016.

BRASIL. Ministério da Saúde. Secretária de Vigilância em Saúde. Boletim Situação Epidemiológica da Dengue. Brasília: Ministério da Saúde, 2006.

MUNIZ, E.R; CINTRA, N.M; COUTO, M.S.D.S; BARROS, V.F.A. Análise do Avanço da Dengue no Município de Inhumas. Anais/Resumos da $62^{\mathrm{a}}$ Reunião Anual da SBPC, v. 63, p. 05, 2011.

CONSOLI, R.A.G.B; OLIVEIRA, R.L. Principais mosquitos de importância sanitária no Brasil. Rio de Janeiro, FIOCRUZ, v. 1, p. 228, 1994.

SOUTO, M.C.S. Coeficiente de incidência da dengue e sua relação com os diferentes intra-urbanos segundo condições de vida no município de Natal, Rio Grande do Norte. Dissertação (Mestrado) - Universidade Federal do rio Grande do Norte. Programa Regional de pósgraduação em desenvolvimento e meio ambiente. Disponível em: https://repositorio.ufrn.br/jspui/bitstream/123456789/1826 0/1/MariaCSS.pdf.

\section{COPYRIGHT}

Direitos autorais: $\mathrm{O}(\mathrm{s})$ autor(es) é(são) o(s) único(s) responsável(is) pelo material incluído no artigo. 


\title{
HANSENÍASE: CARACTERIZAÇÃO CLÍNICA-EPIDEMIOLÓGICA DOS CASOS NOTIFICADOS NO HOSPITAL DE DOENÇAS TROPICAIS DA UNIVERSIDADE FEDERAL DO TOCANTINS (UFT- HDT), BRASIL, NO PERÍODO DE 2013 A 2017
}

\section{HANSENIASIS: CLINICAL AND EPIDEMIOLOGICAL CHARACTERIZATION OF THE NOTIFIED CASES IN THE TROPICAL DISEASE HOSPITAL OF THE FEDERAL DO TOCANTINS UNIVERSITY (UFT-HDT), BRAZIL, IN THE PERIOD FROM 2013 TO 2017}

\author{
SAMPAIO, ANA CRISTINA MENDANHA ${ }^{1}$; MARIANO, WAGNER DOS SANTOS ${ }^{2}$; SILVA, JÚLIA \\ SANTANA DA SILVA ${ }^{3}$; CAVALCANTE, PATRÍCIA ALVES DE MENDONÇA4; ROCHA, MARCELI \\ DIANA HELFENSTEIN ALBEIRICE DA ROCHA ${ }^{4}$
}

1 - Graduada em Medicina; Mestranda do Programa de Pós-Graduação em Sanidade Animal e Saúde Pública nos Trópicos-Universidade Federal do Tocantins (PPGSaspt); Coordenadora do Serviço de Dor do Hospital Regional de Araguaína; Coordenadora do Serviço de Anestesiologia e Dor do Hospital de Olhos do Tocantins. 2 - Docente dos cursos: Licenciatura em Biologia; PPGSaspt; Pós-Graduação em Ensino de Ciências e Matemática da Universidade Federal do Tocantins (UFT); Chefe do Setor de Ensino do Hospital de Doenças Tropicais (HDT) da UFT. 3 - Acadêmicos do curso de Licenciatura em Biologia e Bolsistas do PET Ciências Naturais da Universidade Federal do Tocantins (UFT). 4 - Graduadas em Enfermagem. Unidade de Vigilância em Saúde do HDT-UFT.

\begin{abstract}
wagner.mariano@ebserh.gov.br; julia_santana@uft.edu.br; patrícia.mendonça3@gmail.com;
\end{abstract} marcelialbeirice@yahoo.com.br

\section{INTRODUÇÃO}

A hanseníase é causada pelo bacilo Mycobacterium lepra, sendo transmitida pelo ar através do contato íntimo, prolongado e frequente com doentes, manifestando-se com sinais e sintomas dermatoneurológicos (FREITAS et al., 2016). Esta patologia continua sendo uma doença de grande preocupação em saúde pública, constituindo-se um agravo infectocontagioso que possui poder incapacitante e estigmatizante. O Brasil é classificado como o segundo país com maior número de casos e primeiro na América, e o Estado do Tocantins (região norte do país) é considerado hiperendêmico, ocupando o primeiro lugar na detecção de casos novos no país, no ano de 2016 (coeficiente de 88, 1/100.000hab). Presume-se uma relação do processo endêmico da doença com a ocupação de novos lugares, visto que o Tocantins é um estado extenso em área de fronteiras agrícolas e os movimentos migratórios e o crescimento demográfico para o desbravamento de áreas virgens de mecanizações parecem promover o aumento da incidência da doença (MONTEIRO, et al, 2017; MONTEIRO, et al., 2015).
O conhecimento das características clínicasepidemiológicas dos casos de hanseníase contribui para a realização de um diagnóstico eficaz, com realização oportuna do tratamento e consequente diminuição das sequelas. Em crianças, o diagnóstico exige exame criterioso diante da dificuldade de aplicação e interpretação dos testes de sensibilidade (FREITAS, 2017).

O presente estudo tem por objetivo apresentar a caracterização clínica-epidemiológica dos casos em um hospital universitário de referência em Araguaína (TO), Brasil, no período de 2013 a 2017.

\section{METODOLOGIA}

O município de Araguaína (Figura 1) é o segundo maior em população do Tocantins e está localizado na região norte do estado.

As informações epidemiológicas desta pesquisa foram adquiridas na base em dados secundários referentes ao período de 2013 a 2017, oriundos do Sistema de Informação de Agravos de Notificação (SINAN), que é alimentado pela notificação de casos de doenças e agravos 
que constam da lista nacional de doenças de notificação compulsória. Os dados tabulados foram norteados pela ficha de notificação preconizada pelo SINAN.

O HDT-UFT é o primeiro hospital-escola do estado, localizado no município de Araguaína-TO, que é referência em doenças infecto-parasitárias, emergentes, reemergentes e negligenciadas. Aqui, foram incluídos todos os casos notificados pelo HDT-UFT, entre os anos de 2013 a 2017.

Figura 1 - Área de estudo delimitada, cidade de Araguaína, no estado do Tocantins, Brasil.

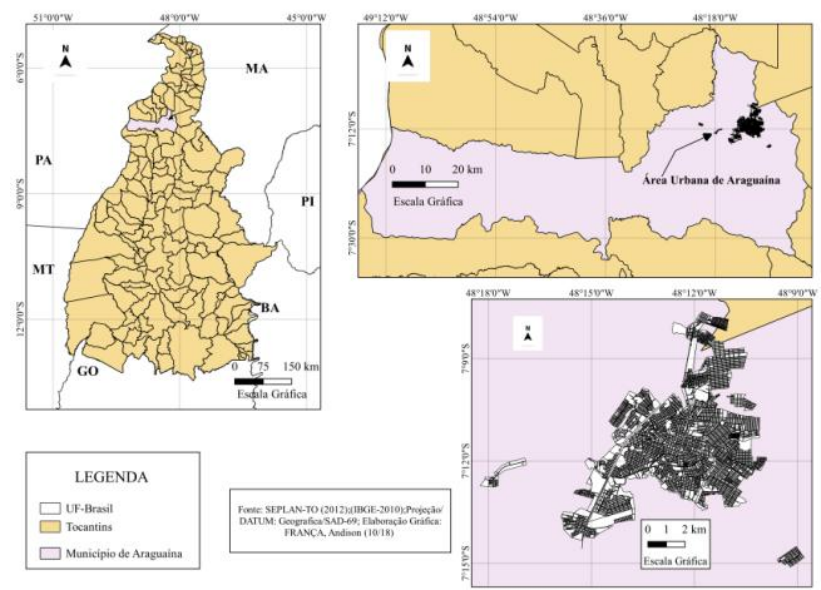

Fonte: França, 2018.

\section{RESULTADOS E DISCUSSÃO}

Dados da OMS (Organização Mundial de Saúde) de 2016 mostram uma taxa de detecção mundial de hanseníase de 3,0 casos/100.000 habitantes, 94\% dos casos notificados de hanseníase eram habitantes de apenas 13 países, dentre eles o Brasil. Neste mesmo ano o Brasil apresentava uma taxa de detecção de 12,2 casos/100.000 habitantes, sendo o segundo país com o maior número de casos novos registrados (SALES, 2018). Nos últimos anos a Região Norte do Brasil exibiu uma das maiores taxas médias de detecção geral (34,26/100.000 habitantes) e o estado do Tocantins apresentou a maior taxa de detecção de casos novos de hanseníase no último boletim epidemiológico divulgado pelo Ministério da Saúde (69,13 casos/100.000habitantes) (BRASIL, 2017).

No período estudado foram notificados, no HDTUFT, 753 casos de hanseníase. 89,37\% dos casos $(n=673)$ foram nos pacientes adultos, e 10,62\% $(n=80)$ dos casos em menores de 15 anos de idade. A faixa etária mais atingida se encontra entre os 30 e 39 anos, apresentando, com 150 casos. 62\% (n=467) dos casos são do sexo masculino, enquanto $38 \% \quad(n=286)$ acometem o sexo feminino. $\mathrm{Na}$ literatura verificamos que a hanseníase atinge homens e mulheres, mas alguns trabalhos apontam para prevalência da enfermidade no sexo masculino (SILVA, et al., 2018). A quantidade de notificações também é maior para aqueles que se identificam de raça parda, com $84,1 \%(n=634)$ dos casos e 58,3\% dos acometidos pela doença $(n=439)$ apresentam baixa escolaridade. Souza e colaboradores (2018) verificaram Anais do XL International Sodebras Congress que em área endêmica da região nordeste a maioria dos casos notificados ocorreram no sexo masculino, por pessoas analfabetas ou que estudaram até a quarta série incompleta, são da cor parda e estão entre 30 e 44 anos de idade.

No Brasil as quatro formas de manifestação da hanseníase são INDETERMINADA, TUBERCULOIDE, quando há poucos bacilos presentes, DIMORFA E VIRCHOWIANA, quando há uma grande carga bacilar presente nas lesões (SILVA, et al., 2017). Este estudo verificou que $30 \%(n=226)$ dos casos apresentaram lesão única, $28 \%(\mathrm{n}=202)$ apresentaram de 2 a 5 lesões, 15,1\% $(\mathrm{n}=114)$ apresentaram mais que 5 lesões. A forma clínica mais comum de notificação foi dimorfa, totalizando $36,5 \%(n=275)$ casos, seguida pela forma tuberculoide, com $32,9 \%(n=248)$. Quanto ao modo de entrada, $80,53 \%$ $(n=542)$ constaram como casos novos, enquanto os recidivos constaram apenas $0,30 \%(n=2)$. Quanto ao modo de detecção, 63,45\% (n=421) dos casos foram através de encaminhamentos da Rede de Atenção à Saúde.

Nos 80 casos de hanseníase registrados em menores de 15 anos, 58,75\% ( $\mathrm{n}=47)$ ocorreu entre 10 e 14 anos, $95 \%(n=76)$ eram pardos e 73,7\% (n=59) do sexo masculino. A forma clínica de notificação mais frequente $(47,5 \%, n=38)$ foi tuberculoide, 96,2\% $(n=77)$ foram classificados como caso novo, e 56,5\% ( $\mathrm{n}=45)$ tiveram saída por cura. Silva, et. al. (2018) salientam que a forma tuberculoide, dentre outras, se dá possivelmente pelo diagnóstico tardio, o que pode ter ocasionado com os pacientes neste estudo apresentados.

Souza e colaboradores (2018) salientam que o comportamento da doença em suas diferentes regiões reafirma o padrão de distribuição heterogênea, geralmente associado à vulnerabilidade social e que os riscos desiguais para a ocorrência da hanseníase podem estar associados a fatores demográficos, genéticos, ambientais, socioeconômicos e culturais superpostos geograficamente ao padrão de ocorrência observado. Comentam também que as precárias condições de vida e o não acesso aos serviços de saúde interferem na distribuição da hanseníase (SOUZA, et.al, 2018).

\section{CONCLUSÕES}

A hanseníase mantém-se como um problema de saúde pública, negligenciada, e com alta prevalência, principalmente, em regiões tropicais, mesmo levando-se em consideração a introdução do tratamento específico e eficaz contra o agravo. Assim, o diagnóstico precoce ainda é a melhor estratégia, impedindo a progressão dos sintomas que podem levar a sequelas motoras e sensitivas, bem como diminuir a incidência de casos novos. A finalidade dos programas de combate à Hanseníase visa o diagnóstico precoce, prevenção de incapacidades, à cura da doença e a quebra da cadeia de transmissão. 


\section{REFERÊNCIAS BIBLIOGRÁFICAS}

BRASIL. MINISTÉRIO DA SAÚDE. Secretaria de Vigilância em Saúde. Departamento de Vigilância das Doenças Transmissíveis. Guia prático sobre a hanseníase [recurso eletrônico]. Brasília: Ministério da Saúde, 68 p.2017.

FREITAS, BRUNA HINNAH BORGES MARTINS; CORTELA, DENISE DA COSTA BOAMORTE; FERREIRA, SILVANA MARGARIDA BENEVIDES. Tendência da hanseníase em menores de 15 anos em Mato Grosso(Brasil), 2001-2013. Rev. Saúde Pública, V. 51, n. 28, 2017.

MONTEIRO, LORENA DIAS, MOTA, ROSA MARIA, SALANI, MARTINS-MELO, FRANCISCO ROGESLÂNDIO; ALENCAR CALROS HENRIQUE; HEUKELBACK, JORGE Determinantes sociais da hanseníase em um estado hiperendêmico da região norte do Brasil. Rev. Saúde Pública, V. 51, n. 70, 2017.

MONTEIRO, LORENA DIAS; MARTINS-MELO, FRANCISCO ROGESLÂNDIO; BRITO, ALINE LIMA; ALENCAR CARLOS HENRIQUE; HEUKELBACK, JORGE. Padrões espaciais da hanseníase em um estado hiperendêmico no norte do Brasil, 2001-2012. Rev. Saúde Pública, V. 49, n. 84, 2015.

SALES, ORCÉLIA PEREIRA; MARTINS, FABRICIO JHONATTON DOS SANTOS; AMARAL, JOÃO BATISTA LOPES DA CRUZ. Hanseníase um Problema de Saúde Pública no Tocantins: O Que Revelam Os Dados de Domínio Público de 2011-2015. Revista Humanidades e Inovação v.5, n. 2, 2018.

SILVA, L.A.; CONCEIÇÃO, HAYLA NUNES; RODRIGUES; FREITAS, ANADA SANTOS; LEMOS, LANNA MARCELLA E SILVA; CÂMARA, JOSENEIDE TEIXEIRA. Aspectos epidemiológicos dos casos de hanseníase em um munícipio no interior do Maranhão. R. Interd. V.10, 2017.

SILVA, DAVID DARNIS BEZERRA; TAVARES; TAVARES, CLODIS MARIA; GOMES, NATALY MAYARA CAVALCANTE; CARDOSO, ALINE COSTA; ARCÊNCIO, RICARDO ALEXANDRE; NOGUEIRA, PAULO SACHA FROTA. A Hanseníase na população idosa de Alagoas. Rev. Bras. Geriatr. Gerontol, Rio de Janeiro, V. 21, n. 5. 2018.

SOUZA, ELIANA, AMORIM; FERREIRA, ANDERSON FUENTES; BOIGNY, REAGAN NZUNDU; ALENCAR, CARLOS HENRIQUE; HEUKELBACK, JORG; MARTINS-MELO, FRANCISCO ROGERLÂNCIO; BARBOSA, JAQUELINE CARACAS; RAMOS-JR, ALBERTO NOVAES. Hanseníase e gênero no Brasil: tendências em áreas endêmicas da região nordeste, 2001-2014. Rev. Saúde Pública, V:52, n.20, 2018.

\section{COPYRIGHT}

Direitos autorais: $\mathrm{O}(\mathrm{s})$ autor(es) é(são) o(s) único(s) responsável(is) pelo material incluído no artigo. 
Volume $14-\mathrm{N}^{\mathrm{o}} 159$ - Março/2019. XL International Sodebras Congress

10 a 12 de dezembro de 2018 - Vitória - ES.

\title{
PARACOCCIDIOIDOMICOSE: CARACTERIZAÇÃO CLÍNICO- EPIDEMIOLÓGICA DOS CASOS NOTIFICADOS NO HOSPITAL DE DOENÇAS TROPICAIS DA UNIVERSIDADE FEDERAL DO TOCANTINS (UFT- HDT), BRASIL, NO PERÍODO DE 2016 A 2018
}

\author{
PARACOCCIDIOIDOMYCOSIS: CLINICAL AND EPIDEMIOLOGICAL \\ CHARACTERIZATION OF THE NOTIFIED CASES IN THE TROPICAL \\ DISEASES HOSPITAL OF THE FEDERAL UNIVERSITY OF TOCANTINS \\ (UFT-HDT), BRAZIL, IN THE PERIOD 2016 TO 2018
}

\author{
SANTOS-JÚNIOR, ANTÔNIO OLIVEIRA ${ }^{1}$; ROCHA, MARCELI DIANA HELFENSTEIN ALBEIRICE \\ DA $^{2}$; CAVALCANTE, PATRÍCIA ALVES DE MENDONÇA ${ }^{2}$; RIBEIRO, REBECA SAITER ${ }^{3}$; MARIANO, \\ WAGNER DOS SANTOS ${ }^{4}$;
}

1 - Graduado em Medicina; Mestrando do Programa de Pós-Graduação em Sanidade Animal e Saúde Pública nos Trópicos-Universidade Federal do Tocantins (PPGSaspt); Gerente de Ensino e Pesquisa do Hospital de Doenças Tropicais da UFT (HDT-UFT). 2 - Graduadas em Enfermagem. Mestres. Unidade de Vigilância em Saúde do HDT-UFT. 3 - Graduada em Enfermagem. Especialista. Serviço de Saúde Ocupacional e Segurança do Trabalho (SOST). 4 - Docente dos cursos: Licenciatura em Biologia; PPGSaspt; Pós-Graduação em Ensino de Ciências e Matemática da Universidade Federal do Tocantins (UFT); Chefe do Setor de Ensino do HDTUFT

antonio.ojunior@ebserh.org.br; marcelialbeirice@yahoo.com.br; patrícia.mendonça3@gmail.com; rebecasaiter@gmail.com; wagner.mariano@ebserh.org.br

\begin{abstract}
Resumo - A paracoccidioidomicose (PCM) ou blastomicose sulamericana, classifica-se como uma doença causada pelo fungo dimorfo, sendo uma micose profunda. Objetivou-se caracterizar o perfil sociodemográfico e epidemiológico dos casos notificados no Hospital de Doenças Tropicais da Universidade Federal do Tocantins HDT-UFT, no período de 2016 a 2018. Realizou-se estudo com base nos dados do Sistema de Informação de Agravos de Notificação (SINAN). Do total de 46 pacientes notificados, $86,96 \%(n=40)$ eram do sexo masculino; $89,13 \%(n=41)$ eram pardos; e 58,7\% (n=27) possuíam baixa escolaridade. $80,4 \%$ $(n=37)$ dos casos foram confirmados; $e 4,35 \%(n=2)$ dos pacientes evoluíram a óbito, sendo um deles relacionado ao agravo estudado. $O$ diagnóstico precoce torna-se imprescindível a fim de prevenir as formas mais avançadas e mutilantes dessa doença, bem como o óbito.
\end{abstract}

Palavras-chave: Paracoccidiodomicose. Doenças negligenciadas. Notificação.

Abstract - Paracoccidioidomycosis (PCM) or South American Blastomycosis, is classified as a disease caused by the fungus dimorfo, being a deep Mycosis. The objective was to characterize the socio-demographic and epidemiological profile of reported cases in the Tropical Diseases Hospital at the Federal University of Tocantins HDT-UFT, from 2016 to 2018. A study was carried out based on from the Information System for Notifiable Diseases (SINAN). From the amount of 46 reported patients, $86.96 \%(n=$ 40) were male; $89.13 \%(n=41)$ were Brown; and $58.7 \%(n=27)$ had low education. $80.4 \%(n=37)$ of the cases were confirmed; and $4.35 \%(n=2)$ of the patients died, one of them being related to the further studied. Early diagnosis becomes essential in order to prevent death and the more advanced and mutilanting forms of this disease.

Key words: Paracoccidiodomycosis. Neglected diseases. Notification.

\section{INTRODUÇÃO}

A blastomicoce sul-americana corresponde a uma micose sistêmica ocasionada pelo fungo Paracoccidioides brasiliensis. É classificada a infecção fúngica mais relevante da América Latina, onde a grande maioria dos casos confirmados acontece em regiões tropicais e subtropicais. $\mathrm{O}$ Brasil é considerado um centro endêmico dessa doença, com maior incidência nas regiões sul, sudeste e centro-oeste. A infecção causada por esse fungo acomete tanto homens quanto mulheres, e em geral afeta os trabalhadores oriundos de atividades rurais (CASTRO, 2018).

A Paracoccidioides spp. têm ocupado diferentes nichos ecológicos, os quais contribuem para a evolução e especiação do fungo, tendo em vista que muitos organismos podem ocupar mais de um nicho ecológico durante seu ciclo de vida. Vaz (2014) explica que a forma filamentosa não patogênica do fungo é a saprobiótica, na qual há a alimentação da matéria em decomposição encontrada no solo, seja ela animal ou vegetal. Através da inalação de propágulos micelianos ou de conídios pelo hospedeiro, o fungo se diferencia na forma leveduriforme, iniciando assim a infecção. 
A Figura 1 exemplifica o ciclo de propagação de Paracoccidioides brasiliensis, no qual os fungos da PCM podem ter dois diferentes perfis de disseminação, apresentados por: uma fase saprobiótica, na qual o patógeno sofre a influência de diferentes condições resultantes dos fatores ambientais em que estão expostos, como alterações na temperatura e competição com outros micro-organismos; e uma fase patogênica, leveduriforme, na qual o fungo passa por adaptação a condições diversas, tais como aumento da temperatura, influência hormonal e resposta imune do hospedeiro (SHIKANAI-YASUDA, 2018; VAZ, 2014).

Figura 1: Ciclo de Propagação de Paracoccidioides brasiliensis

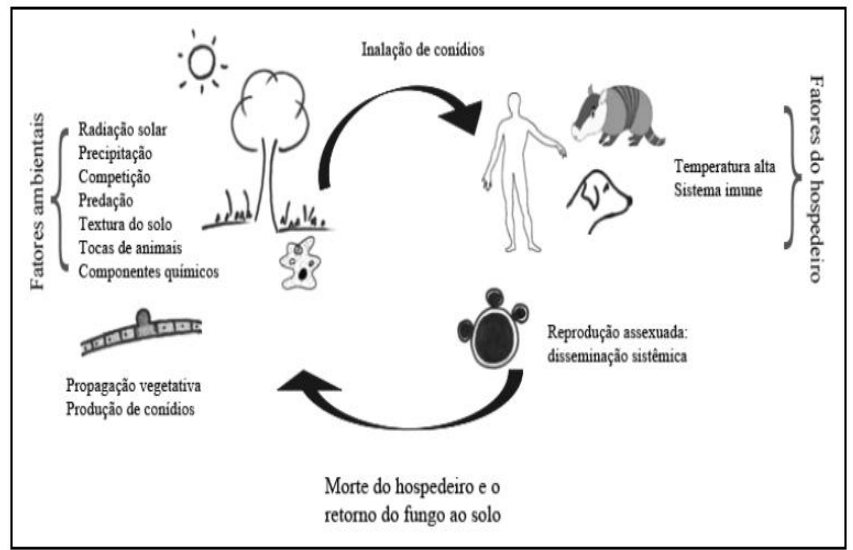

Fonte: Vaz (2014).

Recentemente houve a descoberta de uma nova espécie, o Paracoccidioides lutzii ( $P$. lutzii), em Rondônia, local onde a doença alcançou níveis epidêmicos. Acredita-se que a mudança na ecoepidemiologia do PCM, pode estar relacionada a alguns fatores como: urbanização, a abertura de novas fronteiras, derrubada de florestas e produção de café (CASTRO, 2018; SHIKANAI-YASUDA, 2018).

Os mesmos autores supracitados indicam que a PCM está como a oitava causa de mortalidade por doença infecciosa predominantemente crônica entre as doenças infecciosas e parasitárias, sendo esta taxa, inclusive, maior que a da mortalidade por leishmanioses, e a mais alta entre as micoses sistêmicas.

A PCM é um agravo de interesse estadual no Tocantins desde a publicação da Portaria SESAU/TO nº 236 de 09 de março de 2016, porém, no Brasil, não se constitui em doença de notificação compulsória e por isto não se tem dados precisos sobre sua incidência, o que torna de extrema importância a investigação epidemiológica sobre tal. Acredita-se que sua incidência em zonas endêmicas varie de 3 a 4 novos casos/milhão até 1 a 3 novos casos por $100 \mathrm{mil}$ habitantes ao ano. Além disso, as estimativas de incidência anual no Brasil descrevem a existência de 0,71 caso a 3,70 casos por 100 mil hab. (SHIKANAI-YASUDA, 2018).

O padrão ouro para diagnóstico da PCM é a visualização de elementos fúngicos sugestivos de Paracoccidioides spp em exame a fresco de escarro ou outro espécime clínico e/ou fragmento de biópsia de órgãos supostamente acometidos (CASTRO, 2018; SHIKANAI-YASUDA, 2018). Os demais exames de diagnóstico são: exames hematológicos, sorológicos, de detecção de antígenos, de biologia molecular, funcionais e de imagem (AMBRÓSIO et al, 2014).
São muitos os desafios a serem enfrentados em relação à PCM, de modo que seja realizado o estabelecimento do diagnóstico de forma oportuna e para a disponibilização de antígenos que tenham reatividade com os soros dos pacientes.

Este estudo objetiva realizar a caracterização sociodemográfica e epidemiológica dos casos de paracoccidioidomicose notificados no Hospital de Doenças Tropicais da Universidade Federal do Tocantins (HDTUFT), no período de 2016 a 2018.

\section{METODOLOGIA}

Estudo com base em dados secundários, oriundos do Sistema de Informação de Agravos de Notificação (SINAN). Foram incluídos todos os casos notificados pelo HDT-UFT no período de 2016 a 2018.

O Hospital de Doenças Tropicais da Universidade Federal do Tocantins (HDT-UFT) está situado na cidade de Araguaína - Tocantins, sendo uma Unidade especializada e referência em doenças tropicais, com enfoque em doenças infectocontagiosas, parasitárias e acidentes com animais peçonhentos e silvestres para todo estado e para a Região Norte do Brasil.

\section{RESULTADOS}

No período estudado, foram notificados 46 pacientes e, destes, 86,96\% ( $\mathrm{n}=40)$ são do sexo masculino; 89,13\% (n= 41) são pardos; $58,7 \%(n=27)$ possuem baixa escolaridade; e $86,96 \%(n=40)$ dos casos aconteceram em pessoas com idade economicamente ativa relacionada a atividade rural, com idade de 20 a 69 anos.

Estudos descrevem que a infecção é prioritariamente adquirida nas duas primeiras décadas de vida, com um pico de incidência entre 10 e 20 anos de idade, porém a apresentação de manifestações clínicas ou a evolução para doença é incomum neste grupo, ocorrendo mais frequentemente em adultos entre 30 e 50 anos (reativação de foco endógeno latente). A razão de acometimento da PCM em adultos varia entre 10 a 15 homens para uma mulher (SHIKANAI-YASUDA, 2018; MILLINGTON, 2018).

Verificou-se que $80,4 \% \quad(n=37)$ foram casos confirmados (Figura 2). Em 39,13\% ( $\mathrm{n}=18$ ) a patologia apresentou relação com o trabalho. Nesse sentido, há consenso de que as práticas de trabalho exercem grande fator de risco para aquisição da infecção. As atividades que se relacionam ao manejo do solo contaminado com o fungo, tais como atividades agrícolas, terraplenagem, preparo de solo, práticas de jardinagens, transporte de produtos vegetais, tornam-se vulneráveis ao desenvolvimento da PCM (CASTRO, 2018; SHIKANAI-YASUDA, 2018). 
Figura 2 - Distribuição dos casos de Paracoccidiodomicose segundo critério de confirmação, no período de 2016 a 2018.

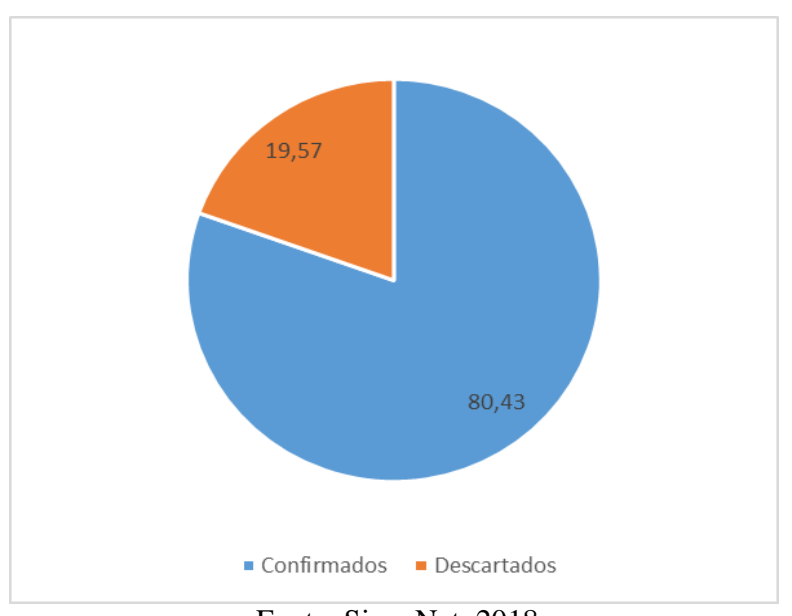

Fonte: SinanNet, 2018.

Sabe-se que para o diagnóstico de PCM, são fundamentais a anamnese e o exame físico que, se bem realizados, podem "mostrar o grau de envolvimento multissistêmico da doença; a presença de linfadenomegalia em várias cadeias linfáticas, de lesões cutâneas, da hepatoesplenomegalia ou de massas abdominais". Outros sintomas também podem ser percebidos nesse momento, como presença de icterícia, de ascite e de edema periférico, além de sintomas relacionados à parte gastrointestinal, tais como dor abdominal, diarreia crônica e vômitos. Febre e perda de peso podem estar associados e completam o quadro clínico (MILLINGTON, 2018; SHIKANAI-YASUDA, 2018).

Dessa forma, afirma-se que o diagnóstico de PCM pode ser realizado a partir de critério clínico-epidemiológico e não apenas com confirmação laboratorial. Em Rondônia, um estudo realizado aponta que aproximadamente um terço dos pacientes foi diagnosticado com base nos critérios clínicoepidemiológicos (SHIKANAI-YASUDA, 2018).

Neste estudo, a confirmação diagnóstica laboratorial aconteceu em $67,39 \% \quad(n=31)$ dos casos, conforme demostrado na Figura 3.

Figura 3 - Incidência dos casos confirmados de Paracoccidiodomicose, no período de 2016 a 2018.

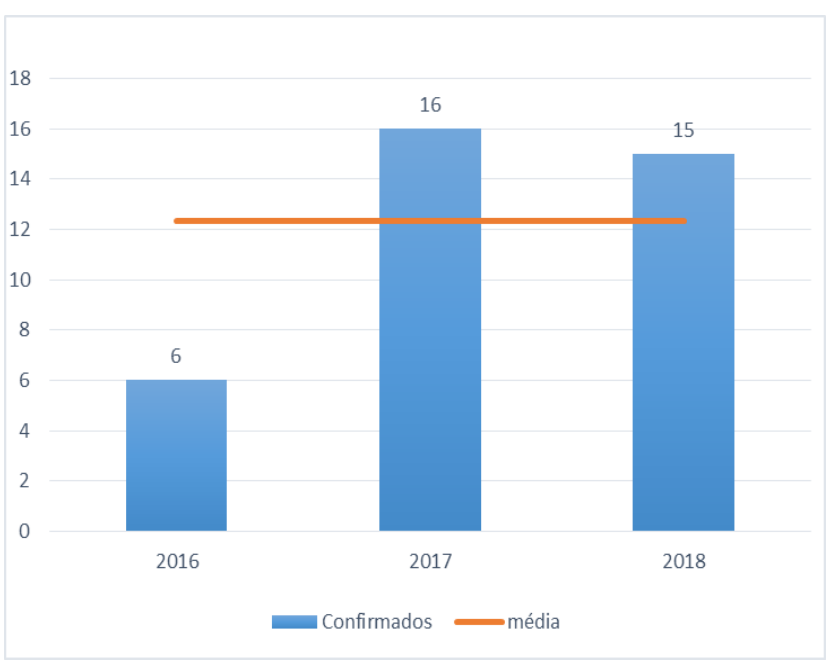

Fonte: SinanNet, 2018.
A Figura 3 demonstra a incidência de casos no período estudado, constatando que o ano de 2017 apresentou um aumento de $166 \%$ em relação ao ano anterior e de $33,3 \%$ em relação à média no período estudado. Essa elevação do número de casos notificados pode estar relacionada a inclusão da PCM como notificação compulsória de interesse estadual em 2016, bem como à melhoria nos processos de trabalho executados pelo Núcleo de Vigilância do HDTUFT, visto que as atividades de revisão de prontuário e busca ativa de pacientes se tornou mais sistemática e criteriosa.

Dos casos notificados, 4,35\% $(\mathrm{n}=2)$ evoluíram à óbito, e apenas um caso foi ocasionado pelo agravo estudado, conforme demonstrado na Figura 4.

Um estudo realizado em 2002 investigou a mortalidade relacionada à PCM e registrou 3.181 casos de óbito no Brasil, entre 1980 e 1995, resultando em taxa de mortalidade por PCM de 1,45 caso por milhão de habitantes (2,59 para a região Sul; 2,35 para o Centro Oeste; 1,81 para o Sudeste; 1,08 para o Norte; e 0,20 para o Nordeste) (COUTINHO et al, 2002). Outro estudo realizado em São Paulo, entre 1985 e 2005, sobre a tendência da mortalidade à paracoccidioidomicose, verificou a ocorrência de 950 óbitos, sendo a PCM a causa básica de morte em 164 59,7\% $(n=1164)$ e uma causa associada de morte em $40,3 \%$ $(n=786)$. Nesse período, os autores observaram um declínio do coeficiente de mortalidade pela causa básica de 59,8\% e pela causa associada, de 53,0\% (SANTO, 2005; TRISTÃO, 2017).

Figura 4 - Distribuição dos casos de Paracoccidiodomicose, segundo critério de evolução clínica, no período de 2016 a 2018.

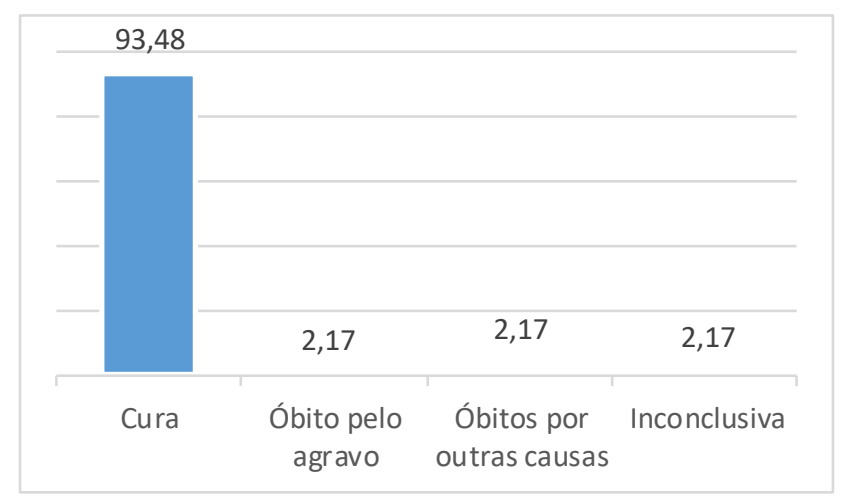

Fonte: SinanNet, 2018.

\section{CONCLUSÃO}

A maioria dos casos notificados neste estudo ocorreu em trabalhadores rurais adultos, do gênero masculino, estando de acordo com as demais literaturas.

Embora constitua uma doença inflamatória que corresponde de forma satisfatoriamente à terapêutica antifúngica, a paracoccidiodomise é considerada a micose que mais leva a óbitos, tendo em vista que a orientação do diagnóstico rápido e preciso desta enfermidade constitui-se uma possibilidade para evitar o aumento do dano aos pulmões e à disseminação deste fungo para outros órgãos.

Deste modo, o diagnóstico precoce é importante a fim de serem evitadas as formas mais avançadas e mutilantes dessa doença. 


\section{REFERÊNCIAS BIBLIOGRÁFICAS}

AMBRÓSIO, Alexandre Vasconcellos Alvim et al. Paracoccidioidomicose (doença de Lutz-SplendoreAlmeida): propedêutica complementar, diagnóstico diferencial, controle de cura. Rev Med Minas Gerais. Minas Gerais: 2014. Disponível em: <http://www.rmmg.org/artigo/detalhes/606>. Acesso em: 20 de novembro de 2018.

CASTRO, Delson Marcelino De. Paracoccidioidomicose: Formas Clínicas E Diagnósticas Uma Revisão De Literatura. [Monografia]. Porto Velho: 2018.

COUTINHO, ZF et al. Paracoccidioidomycosis mortality in Brazil (1980-1995). Cad Saúde Pública. 2002 SepOct/18(5):1441-54.

MILLINGTON, Maria Adelaide et al. Paracoccidioidomicose: abordagem histórica e perspectivas de implantação da vigilância e controle. Epidemiol. Serv. Saude, Brasília: 2018 Disponível em: >https://scielosp.org/article/ress/2018.v27nspe/e0500002/>. Acesso em: 03 de novembro de 2018.

SANTO, AH. Tendência da mortalidade relacionada à paracoccidioidomicose, Estado de São Paulo, Brasil, 1985 a 2005: estudo usando causas múltiplas de morte. Rev Panam Salud Publica. 2008;23(5):313-24.

SHIKANAI-YASUDA, Maria Aparecida et al . II Consenso Brasileiro em Paracoccidioidomicose - 2017. Epidemiol. Serv. Saúde, Brasília , v. 27, n. spe, e0500001, 2018. Disponível em <http://www.scielo.br/scielo.php?script=sci_arttext\&pid=S2 237-96222018000700200\&lng=pt\&nrm=iso>. Acesso em 26 nov. 2018.

TRISTÃO, Gabriel Brum. As Informações Sobre Paracoccidioidomicose Disponíveis em Websites Brasileiros São de Qualidade e Confiáveis? Multi-Science Journal, v. 1, n 7. (2017) p. 23-33. Disponível em: https://www.ifgoiano.edu.br/periodicos/index.php/multiscie nce/article/view/347/271. Acesso em: 03 de novembro de 2018.

VAZ, Alessandro Fernandes. Análise Proteômica Comparativa do Processo de Diferenciação Celular do Fungo Patogênico Paracoccidioides brasiliensis [manuscrito]. 2014. $22 \mathrm{p}$.

\section{COPYRIGHT}

Direitos autorais: $\mathrm{O}(\mathrm{s})$ autor(es) é(são) o(s) único(s) responsável(is) pelo material incluído no artigo. 
Volume 14 - No 159 - Março/2019.

XL International Sodebras Congress

10 a 12 de dezembro de 2018 - Vitória - ES.

\section{Área: Ciências Exatas e Engenharias}

\begin{tabular}{|c|c|}
\hline $1-2$ & $\begin{array}{l}\text { MODELAGEM DE DADOS PLUVIOMÉTRICOS EM BRASÍLIA-DF: UMA } \\
\text { APLICAÇÃO DE CADEIAS DE ORDEM VARIÁVEL } \\
\text { MODELING OF PLUVIOMETRIC DATA IN BRASÍLIA-DF: AN APPLICATION OF } \\
\text { VARIABLE ORDER CHAINS } \\
\text { Lucas Moreira; Matheus Ferreira Marques Cavacante }\end{array}$ \\
\hline $1-3$ & $\begin{array}{l}\text { ESQUEMA ARGUMENTATIVO EM TEXTOS: ENCONTRAR DEFINIÇÃO } \\
\text { CONCEITUAL NO TEXTO ACADEMICO E GERAR QUESTÕES QUE A } \\
\text { JUSTIFICA } \\
\text { ARGUMENTATIVE SCHEME IN TEXTS: FIND CONCEPTUAL DEFINITION IN } \\
\text { THE ACADEMIC TEXT AND GENERATE QUESTIONS THAT JUSTIFY IT } \\
\text { Koichi Sanoki; Ítalo Santiago Vega }\end{array}$ \\
\hline $1-3$ & $\begin{array}{l}\text { SISTEMA DE REALIDADE VIRTUAL PARA TREINAMENTO DE OPERADORES } \\
\text { DE LOCOMOTIVAS } \\
\text { VIRTUAL REALITY SYSTEM FOR TRAINING LOCOMOTIVE OPERATORS } \\
\text { Pablo Pereira E Silva; Rodrigo Varejão Andreão; Mário Mestria }\end{array}$ \\
\hline $1-6$ & $\begin{array}{l}\text { EM BUSCA DA SUSTENTABILIDADE: CÉLULA SOLAR PRODUZIDA COM } \\
\text { CORANTE EXTRAÍDO DA MORUS NIGRA } \\
\text { IN PURSUIT OF SUSTAINABILITY: SOLAR CELL PRODUCED WITH DYE } \\
\text { EXTRACTED FROM MORUS NIGRA } \\
\text { Julianno Pizzano Ayoub; Gideã Taques Tractz; Everson P. Banczek; Paulo R. P. } \\
\text { Rodrigues }\end{array}$ \\
\hline 3-3 & $\begin{array}{l}\text { AVALIAÇÃO DO CONSERVADORISMO DO MÉTODO DE ANÁLISE TÉRMICA } \\
\text { DO PRCI QUANTO AO RISCO DE PERFURAÇAO NO REPARO COM } \\
\text { SOLDAGEM EM OPERAÇAO DE OLEODUTO COM BAIXA ESPESSURA } \\
\text { EVALUATION THE CONSERVATIVENESS OF PRCI'S THERMAL ANALYSIS } \\
\text { METHOD REGARDING THE BURN-THROUGH RISK DURING IN-SERVICE } \\
\text { WELDING REPAIRS OF LOW THICKNESS OIL PIPELINE } \\
\text { Higor José Bravim; André Gustavo De Sousa Galdino; Temistocles De Sousa LuZ }\end{array}$ \\
\hline 3-3 & $\begin{array}{l}\text { MODOS DE RUPTURA DE LIGAÇÃO MADEIRA LAMINADA COLADA } \\
\text { CRUZADA E CONCRETO } \\
\text { CROSSED AND CONCRETE WOUNDED LAMINATED WOOD CONNECTION } \\
\text { RUPTURE } \\
\text { Ramos, F. M. G.; Carrasco, E. V. M.; Rodrigues, F. C. }\end{array}$ \\
\hline
\end{tabular}




\begin{tabular}{|c|c|}
\hline 3-4 & $\begin{array}{l}\text { INTEGRAÇÃO DE FERRAMENTAS DE MODELAGEM E SIMULAÇÃO DE } \\
\text { SISTEMAS UTILIZANDO O PROTOCOLO OPC-UA } \\
\text { INTEGRATION OF MODELING AND SIMULATION TOOLS USING OPC-UA } \\
\text { PROTOCOL } \\
\text { Alex Brandão ROSSOW }\end{array}$ \\
\hline $3-4$ & $\begin{array}{l}\text { EFICIÊNCIA LUMÍNICA EM INSTITUIÇÕES DE ENSINO SUPERIOR - UM } \\
\text { ESTUDO DE CASOS NA UNIVERSIDADE FEDERAL DA BAHIA (UFBA) } \\
\text { LIGHTING EFFICIENCY IN HIGHER EDUCATION INSTITUTIONS - A CASE } \\
\text { STUDY IN THE FEDERAL UNIVERSITY OF BAHIA (UFBA) } \\
\text { Maria Fabiana Baldoino Da Paixão; Antonio Santos Sánchez; Miguel Angel Iglesias } \\
\text { Duro }\end{array}$ \\
\hline $3-4$ & $\begin{array}{l}\text { LOCALIZAÇÃO EFICIENTE DE ESTAÇÕES DE CARREGAMENTO DE } \\
\text { VEÍCULOS ELÉTRICOS NUMA REGIAO METROPOLITANA UTILIZANDO } \\
\text { METAHEURÍSTICA CRO E TRAJETOS VEICULARES REAIS } \\
\text { EFFICIENT PLACEMENT OF ELECTRIC VEHICLE CHARGING STATIONS IN A } \\
\text { METROPOLITAN AREA UTILIZING CRO AND REALISTIC VEHICLE ROUTING } \\
\text { INFORMATION } \\
\text { Danilo Cesar Azeredo Silva; Mário Mestria }\end{array}$ \\
\hline $3-4$ & $\begin{array}{l}\text { PLANEJAMENTO ESTRATEGICO NO SETOR ELÉTRICO: UMA MODELAGEM } \\
\text { UTILIZANDO A MATRIZ DE ATRATIVIDADE DE MERCADO X FORÇA } \\
\text { COMPETITIVA } \\
\text { STRATEGIC PLANNING ON ENERGY SECTOR: AN MODELING USING } \\
\text { ATTRACTIVENESS VERSUS COMPETITIVENESS MATRIX } \\
\text { Flávio Dayrell Miserani Nunes; Petr lacovlevitch Ekel; Rose Mary De Souza Batalha }\end{array}$ \\
\hline 3-4 & $\begin{array}{l}\text { SELEÇÃO DE CARACTERISTICAS DE SINAIS CEREBRAIS PARA USO EM } \\
\text { APLICAÇÕES DE INTERFACE CÉREBRO-COMPUTADOR } \\
\text { FEATURE SELECTION OF BRAIN SIGNALS FOR USE IN BRAIN-COMPUTER } \\
\text { INTERFACE APPLICATIONS } \\
\text { Alex Brandão RosSOw; Anibal Cotrina }\end{array}$ \\
\hline $3-5$ & $\begin{array}{l}\text { ANÁLISE DA ACIDEZ DA SOLUÇÃO EXTRATORA PARA PRODUÇÃO DE } \\
\text { CORANTES EMPREGADOS EM CÉLULAS SOLARES DE TERCEIRA GERAÇÃO } \\
\text { ANALYZE OF DYE ACIDIFIED SOLUTION USED IN THIRD GENERATION OF } \\
\text { SOLAR CELLS PRODUCTION } \\
\text { Julianno Pizzano Ayoub; Gideã Taques Tractz; Douglas Kais Silva; Paulo R. P. } \\
\text { Rodrigues }\end{array}$ \\
\hline $3-5$ & $\begin{array}{l}\text { MODELAGEM CINEMÁTICA DO ROBÔ COLABORATIVO UR5 } \\
\text { KINEMATIC MODELING OF THE COLLABORATIVE ROBOT UR5 } \\
\text { Alexandre G. Soares; Felipe A. A. Macedo; Leonardo César De O. Marques; Luiz } \\
\text { Paulo G. Ribeiro }\end{array}$ \\
\hline $3-5$ & $\begin{array}{l}\text { RESOLUÇÃO DA CINEMÁTICA INVERSA DE ROBÔS INDUSTRIAIS POR } \\
\text { ALGORITMOS DE OTIMIZAÇÃO } \\
\text { INVERSE KINEMATICS RESOLUTION OF INDUSTRIAL ROBOTS THROUGH } \\
\text { OPTIMIZATION ALGORITHMS } \\
\text { Michel Alba; Alexandre G Soares; Luiz Ribeiro; Jose Herskovits }\end{array}$ \\
\hline
\end{tabular}




\begin{tabular}{|c|c|}
\hline \multirow[t]{2}{*}{$3-7$} & $\begin{array}{l}\text { AVALIAÇÃO DE RISCO ECOTOXICOLÓGICO COM BASE EM RESULTADOS } \\
\text { DO MODELO USETOX® PARA O TRICLOSAN PARA AS REGIÕES } \\
\text { HIDROGRÁFICAS BRASILEIRAS }\end{array}$ \\
\hline & $\begin{array}{l}\text { EVALUATION OF ECOTOXICOLOGICAL RISK BASED ON RESULTS OF THE } \\
\text { USETOX® MODEL FOR TRICLOSAN FOR THE BRAZILIAN HYDROGRAPHIC } \\
\text { REGIONS } \\
\text { Pedro Henrique Bolanho Simões; Biagio Fernando Giannetti; Lucas Alegretti; } \\
\text { Maurea Nicoletti Flynn }\end{array}$ \\
\hline $3-7$ & $\begin{array}{l}\text { CONFLITOS DE USO DO SOLO DE ÁREAS DE PRESERVAÇÃO PERMANENTE } \\
\text { DA BACIA HIDROGRÁFICA DA SERRA DA MANTIQUEIRA - UGRHI } 1 \\
\text { SOIL USE CONFLICTS OF PERMANENT PRESERVATION AREAS OF THE } \\
\text { SERRA DA MANTIQUEIRA WATERSHED - UGRHI } 1 \\
\text { SILVA, M.H.; TRANNIN, I. C. B.; CATELANI, C. S. }\end{array}$ \\
\hline \multirow[t]{2}{*}{$3-7$} & $\begin{array}{l}\text { DIAGNÓSTICO E PROPOSIÇÃO DE MEDIDAS PARA O CONTROLE DAS } \\
\text { PERDAS DE ÁGUA NO SISTEMA DE ABASTECIMENTO DE GUARATINGUETÁ } \\
\text { (SP) }\end{array}$ \\
\hline & $\begin{array}{l}\text { DIAGNOSIS AND PROPOSAL OF MEASURES FOR CONTROLLING WATER } \\
\text { LOSSES IN THE SUPPLY SYSTEM GUARATINGUETÁ (SP) } \\
\text { YOSHIMOTO, M. K.; TRANNIN, I. C. B. }\end{array}$ \\
\hline $3-7$ & $\begin{array}{l}\text { PROPOSTA PARA APROVEITAMENTO DE RESÍDUOS DA CONSTRUÇÃO } \\
\text { CIVIL GERADOS EM CANTEIROS DE OBRAS } \\
\text { PROPOSAL FOR USE OF WASTE FROM CIVIL CONSTRUCTION SITES } \\
\text { PERINA, J.M.; TRANNIN, I. C. B. }\end{array}$ \\
\hline $3-8$ & $\begin{array}{l}\text { O USO DO BIG DATA NO ESTUDO DO MERCADO CONSUMIDOR, } \\
\text { POTENCIALIDADES PARA APLICAÇÃO NO BRASIL } \\
\text { THE USE OF BIG DATA IN THE CONSUMER MARKET STUDY, POTENTIAL } \\
\text { FOR THE APPLICATION IN BRAZIL } \\
\text { Alex Brandão ROSSOW }\end{array}$ \\
\hline $3-8$ & $\begin{array}{l}\text { USO GERENCIAL DAS FERRAMENTAS DA QUALIDADE PARA TOMADA DE } \\
\text { DECISÃO: UM ESTUDO DE CASO SOBRE O ELEVADO ÍNDICE DE } \\
\text { DEVOLUÇÃO NA DISTRIBUIÇÃO LOGISTICA E A CRIAÇÃO DA ÁREA DE } \\
\text { CUSTOMER SERVICE }\end{array}$ \\
\hline & $\begin{array}{l}\text { OF QUALITY TOOLS FOR DECISION MAKING: A CASE } \\
\text { RETURN INDEX OF LOGISTICAL DISTRIBUTION AND } \\
\text { STOMER SERVICE AREA } \\
\text { pos; José Elmo De Menezes }\end{array}$ \\
\hline
\end{tabular}




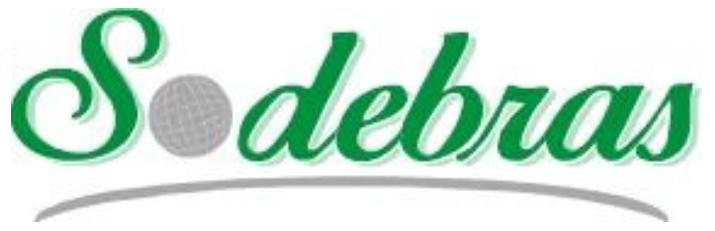

Volume 14 - $\mathrm{N}^{\mathrm{o}} 159$ - Março/2019.

XL International Sodebras Congress

10 a 12 de dezembro de 2018 - Vitória - ES.

\title{
MODELAGEM DE DADOS PLUVIOMÉTRICOS EM BRASÍLIA-DF: UMA APLICAÇÃO DE CADEIAS DE ORDEM VARIÁVEL
}

\author{
MODELING OF PLUVIOMETRIC DATA IN BRASÍLIA-DF: AN \\ APPLICATION OF VARIABLE ORDER CHAINS
}

\author{
LUCAS MOREIRA $^{1}$; MATHEUS FERREIRA MARQUES CAVACANTE ${ }^{1}$
}

\section{1 - UNIVERSIDADE DE BRASÍLIA}

\author{
lmoreira@unb.br;mat.fmc@gmail.com
}

\begin{abstract}
Resumo - Neste trabalho obtemos modelos meteorológicos na região do Distrito Federal. Mais especificamente, obtemos modelos de pluviosidade para cidade de Brasília. Para tanto, os modelos considerados foram as cadeias de ordem variável. Esses modelos foram introduzidos originalmente em Rissanen (1983), onde foram denominados fontes de memória finita ou máquinas de árvores. Rissanem chamou de contexto a parcela do passado necessária para predizer o próximo símbolo. Como nenhum contexto pode ser representado como sufixo de outro contexto, é possivel representar o conjunto de todos os contextos por uma árvore probabilística. Nesse artigo, propomos modelos de ordens dois e três para obter as chances de que, dado o histórico de chuvas, num determinado dia não chova, chova moderadamente ou chova forte. Adicionalmente, verificamos que houve uma mudança no regime de chuvas na cidade de Brasília após os anos 2.000 .
\end{abstract}

Palavras-chave: Cadeias de Ordem Variável, Árvores de Contextos, Modelos Meteorológicos.

Abstract - In this work we obtain meteorological models in the Federal District. More specifically, we obtain rainfall models for Brasilia city. For this, the models considered were the chains of variable order. These models were originally introduced in Rissanen (1983), where they were called finite memory sources or tree machines. Rissanem called context the part of the past necessary to predict the next symbol. Since no context can be represented as a suffix of another context, it is possible to represent the set of all contexts by a probabilistic tree. In this article, we propose models of orders two and three to obtain the chances that, given the rainfall history, on a given day it does not rain, it rains moderately or it rains heavily. In addition, we verified that there was a change in the rainfall regime in the city of Brasilia after 2000 years.

Keywords: Variable Order Chains, Context Trees, Meteorological Models.

\section{INTRODUÇÃO}

Segundo Quintino e Moreira (2015), a motivação inicial deste trabalho foi a obtenção de modelos meteorológicos na região do Distrito Federal. Mais especificamente, obtemos modelos de pluviosidade para cidade de Brasília. Para tanto, os modelos considerados foram as cadeias de ordem variável.
As cadeias de ordem variável combinam a riqueza de informação das Cadeias de Markov com a parcimônia almejada na Teoria da Informação, ao se considerar somente a parcela relevante do passado para realizar previsões. Esses modelos foram introduzidos originalmente em Rissanen (1983), onde foram denominados fontes de memória finita ou máquinas de árvores. Rissanem chamou de contexto a parcela do passado necessária para predizer o próximo símbolo. Como nenhum contexto pode ser representado como sufixo de outro contexto, é possível representar o conjunto de todos os contextos por uma árvore probabilística.

Por considerarem dependências estruturais, o que culmina em uma memória variável, esses modelos são mais econômicos e flexíveis que um modelo de Cadeia de Markov. Mais tarde, esses modelos também são chamados de Cadeias de Markov de Ordem Variável (VLMC), termo que ficou popular na literatura estatística.

As cadeias de ordem variável são consideradas em diversas áreas. Para aplicações desses modelos em teoria da informação, recomendamos a leitura de Rissanen (1983). Modelagens de dados linguísticos, são apresentadas em Galves et al. (2012), Moreira e Bomfim (2016), Moreira e Bomfim (2017). Para modelos meteorológicos de temperatura de memória variável, recomendamos a leitura de Moreira e Quintino (2015).

Os algoritmos de estimação da árvore de contextos podem ser divididos em duas famílias. A primeira, deriva diretamente do Algoritmo Contexto, introduzido em Rissanen (1983), e se destaca por realizar a poda de uma árvore dita completa. Isto é, dada uma medida de discrepância para o ramo podado, é determinando se ele deve ser removido da árvore ou não. A segunda família de estimadores se baseia na máxima verossimilhança penalizada. Para cada árvore possível é calculado um critério que combina o ajustamento com a complexidade do modelo. Esse procedimento é derivado do Princípio da Descrição de Comprimento Mínimo (Minimum Description Length Principle - MDL). Podemos também utilizar essa abordagem por meio do Critério de Informação Bayesiana (Bayesian Information Criterion - BIC) para estimação da árvore de contextos. 
Neste trabalho, analisamos dados pluviométricos de Brasília-DF para calcularmos a probabilidade de que em um determinado dia não chova, chova moderadamente ou chova forte, a partir do histórico de chuvas nessa cidade. Adicionalmente, verificamos que houve uma mudança no regime de chuvas nessa cidade de Brasília após os anos 2.000 .

Para estimar as árvores de contextos subjacentes aos conjuntos de dados analisados consideramos o Algoritmo Contexto Modificado, apresentado em Collet et al (2008). Destacamos que toda a parte de estatística computacional foi realizada no ambiente $\mathrm{R}$ ( $\mathrm{R}$ Core Team, 2018).

Este trabalho está dividido da seguinte forma: na Seção II, apresentamos as notações e conceitos básicos. Na Seção III, apresentamos a metodologia utilizada. Em seguida, na Seção IV, consideramos o regime de chuvas em BrasíliaDF. Seção V, apresentamos os resultados obtidos bem como as discussões dos mesmos. Na Seção VI, são expostas as considerações finais.

\section{NOTAÇÕES E DEFINIÇÕES}

Considere o alfabeto $A=\left\{0,1_{v} \cdots_{n} N-1\right\}$ com tamanho $|A|=N$. Dados dois inteiros $m \leq n$ denotamos $a_{m}^{n}$ a sequência de símbolos $a_{m} a_{m+1} \cdots a$ de $A$ e $A_{m}^{n}$ o conjunto de tais sequências. $O$ comprimento da sequência será $l\left(a_{m}^{n}\right)=n-m+1$. Caso $n<m, a_{m}^{n}=\emptyset$ e $l\left(a_{m}^{n}\right)=0$.

$\mathrm{O}$ conjunto de todas as sequências semi-infinitas e o conjunto de todas as sequências de símbolos de tamanho finito são denotados, respectivamente, por

$$
A_{-\infty}^{-1}=A^{-2}-1,-1 \text { e } A=j=000 A_{-j}^{-1},
$$

em que para $j=0$ corresponde ao conjunto das sequências vazias $\emptyset$.

Dadas duas sequências $w$ e $v$, com $l(w)<+\infty$, denotamos por $v w$ a sequência de comprimento $l(v)+l(w)$ obtida pela concatenação das duas sequências. Por exemplo, para $\nu=\cdots v_{-n-2} v_{-n-1}$ e $w=w_{-n}{ }^{\cdots} w_{-2} w_{-1}$, a sequência obtida pela concatenação de $v$ e $w$ será $\cdots v_{-n-2} v_{-n-1} w_{-n}{ }^{m} w_{-2} w_{-1}$. Note que, para o caso em que $v=\emptyset$ obtêm-se $v w=\emptyset w=w$. Analogamente ocorre para $w=\emptyset$.

Uma sequência $u$ é dita ser um sufixo de $w$ se existir $s$, com $l(s) \geq 1$, tal que $w=s u$ e será denotada por $u$ lla $w$. Caso $u$ 固w ou $u=w$, será denotado por $u \leq w$. Dada uma sequência finita $w$ denotamos por suf $(w)$ o maior sufixo de $w$.

Ao longo desse trabalho consideramos os processos $X=X_{t}, t \in Z, Y=Y_{t}, t \in Z$ e $Z=Z_{t}, t \in Z$ estacionários e ergóticos sobre o alfabeto $A=\{0,1, \cdots, N-1\}$. Assumimos que o processo $\mathbf{X}$ é compatível com a probabilidade de transição $p_{X}\left(v_{*}\right)$, ou seja,

$p_{X}(a \mid w)=P\left(X_{0}=a \vee X_{-1}=w_{-1}, X_{-2}=w_{-2} w^{\cdots}\right),(2.1)$ para todo $w \in A_{-\infty}^{-1}$ e para todo $a \in A$. Para $w \in A_{-j}^{-1}$ probabilidade estacionária do cilindro definida por essa sequência será denotada por

$\mu_{X}(w)=P\left(X_{-j}^{-1}=w\right)$.

Com intuito de estimarmos a árvore de contextos de um processo $\mathbf{X}$, dada uma amostra contaminada desse processo, consideramos que $\mathbf{X}$ satisfaz as seguintes definições.

Definição 1.1 Dizemos que um processo $\mathbf{X}$ é não-nulo se satisfaz

$$
\alpha_{X}=\inf p_{X}(a \mid w) ; a \in A_{s} w \in A_{-\infty}^{-1}>0 \text {. }
$$

Definição 1.2 Dizemos que um processo $\mathbf{X}$ possui taxa de continuidade somável se

$\beta_{X}=\sum_{k=0}^{+\infty} \beta_{k X}<+\infty$

onde a sequência $\beta_{k, X} \quad{ }_{k \in N}$ é definida por

$\beta_{k, X}=\left|1-\frac{p_{X}(a \mid w)}{\left.p_{X}^{(a} \mid v\right)}\right| ; a \in A, v, w \in A_{-\infty}^{-1} \quad c o m w_{-k}^{-1}=v_{-k}^{-1}$.

A sequência $\beta_{k, X} \quad k_{k \in N}$ é chamada taxa de continuidade do processo $\mathbf{X}$. Note que, a condição de não-nulidade do processo $\mathbf{X}$ é necessária para que possamos definir a taxa de continuidade do processo por (2.5). A taxa de continuidade é uma propriedade esperada para o processo $\mathbf{X}$, pois, desejamos que dois passados coincidindo nos últimos $k$ símbolos tenham a mesma influência na predição do próximo símbolo da sequência, a medida que $k$ cresce.

Rissanen (1983) chamou de contexto a porção do passado necessária para predizer o próximo símbolo do processo, sendo o tamanho desta sequência é função do próprio passado. Um contexto infinito é uma sequência semi-infinita tal que nenhum dos seus sufixos é um contexto. O conjunto de todos os contextos satisfaz a propriedade do sufixo, isto é, nenhum contexto é sufixo de outro contexto. Esta propriedade permite representar o conjunto de todos os contextos (finito ou infinito enumerável) como uma árvore probabilística com raiz e rótulos. Esta árvore é chamada árvore de contextos do processo $\mathbf{X}$. A seguir definiremos de maneira mais formal um contexto.

Definição 1.3 Dizemos que uma sequência $w \in A_{-j}^{-1}$ é um contexto do processo $\mathbf{X}$ se para toda sequência semi-infinita $x_{-\infty}^{-1} \in A_{-\infty}^{-1}$ tendo $w$ como sufixo satisfazer

$P\left(X_{0}=a \vee X_{-\infty}^{-1}=x_{-s o}^{-1}\right)=p_{X}(a \vee w)$

e nenhum sufixo de $w$ satisfaz esta equação.

Denotamos por $d(T)$ a profundidade da árvore $T$, ou seja,

$d(T):=\max l(w): w \in T$.

Uma árvore $T$ é dita completa se qualquer sequência em $A_{-\infty}^{-1}$ pertence a $T$ ou tem sufixo que pertence a $T$. Dizemos que a árvore de contextos é limitada se o comprimento do maior contexto é finito. Caso contrário, $T$ é dita ilimitada.

Dizemos que uma árvore é irredutível se nenhuma sequência pode ser substituída por um sufixo sem violar a propriedade sufixo.

A seguir definiremos de maneira mais formal uma árvore probabilística de contextos e uma Cadeia de Ordem Variável.

Definição 1.4 Uma árvore probabilística de contextos em $\mathcal{A}$ é um par ordenado $\left(T, p^{p}\right)$ que satisfaz

(1) $T$ é uma árvore irredutível.

(2) $p=p(\mid w), w \in T$ é uma família de probabilidades de transição sobre $A$.

Definição 1.5 Dizemos que o processo $\mathbf{X}$ é compatível com a árvore probabilística de contextos $(T, p)$ se satisfaz

(1) $T$ é a árvore de contextos do processo $\mathbf{X}$.

(2) Para qualquer $w \in T$ e $a \in A_{v} p_{X}(a \mid w)=p(a \mid w)$.

Se $\mathbf{X}$ é compatível com a árvore probabilística de contextos $(T, p)$, dizemos que $\mathbf{X}$ é uma Cadeia de Ordem Variável e denotamos a árvore de contextos de $\mathbf{X}$ por $T_{X}$. 
Em alguns casos podemos estar interessados não na árvore de contextos do processo $\mathbf{X}$, mas na utilização desta árvore com uma restrição no tamanho da maior sequência. Seja $K$ esta restrição. Neste caso, chamaremos de árvore truncada no nível $K$. Dessa forma, se definirmos $K \geq d\left(\begin{array}{ll}T & \end{array}\right)$, estaremos considerando a própria árvore de contextos do processo $\mathbf{X}$.

Definição 1.6 Dado um inteiro $K$, defina a árvore de contextos truncada no nível $K$ por

$T{ }_{k} \quad x=w \in T_{X}: l(w) \leq K \cup w: l(w)=K e w<$ uparaalgumu $\in T_{X}$

Considere $Z$ um processo tomando valores num alfabeto finito $A=\left\{0,1_{x}, \ldots{ }_{x} N-1\right\}$. Seja $Z_{1}, Z_{2}, \cdots, Z_{n}$ uma amostra aleatória do processo $\mathbf{Z}$. Para toda sequência finita $w$, com $l(w) \leq n$, denotamos por $N_{n}(w)$ o número de vezes que observou-se a sequência $w$ na amostra, ou seja,

$N_{n}(w)=\sum_{t=0}^{n-[t w]} 1_{\left[z_{L+1}^{i+1}(w)=w\right]}$.

Para todo elemento $a \in A$ e para toda sequência finitaw a probabilidade de transição empírica é dada por $\hat{p}_{Z}(a \mid w)_{n}=\frac{N_{n}(w a)+1}{N_{n}(w)+[A]}$.

Observe que a definição de $\hat{p}_{X}(a \mid w)_{n}$ é conveniente, pois, é assintoticamente equivalente ao Estimador de Máxima Verossimilhança que é $\frac{N_{n}(w a)}{N_{n}(w-)}$ e evita-se uma definição adicional no caso $N_{n}(w \cdot)=0$.

Antes de apresentar o estimador da árvore de contextos, definido na Seção II, é necessário definirmos o seguinte operador

$\Delta_{n}(w):=\max _{a \in A}\left|\hat{p}_{Z}(a \mid w)_{n}-\hat{p}_{X}(a \mid \operatorname{suf}(w))_{n}\right|^{x}$

para qualquer sequência finita $w \in A$.

Note que operador $\Delta_{n}(w)$ computa a distância entre as probabilidades de transição empíricas para uma sequência $w$ e a sequência associada suf $(w)$.

\section{METODOLOGIA}

Utilizamos o ambiente $\mathrm{R}$ de computação estatística ( $\mathrm{R}$ Core Team, 2018) para programar o estimador de árvore de contextos.

O algoritmo de estimação da árvore de contextos utilizado nesse trabalho foi proposto por Galves e Leonardi (2008) e é uma modificação do Algoritmo Contexto de Rissanem (1983). Apresentamos a seguinte definição com base no operador $\Delta_{n}(w)$ apresentado na Equação (2.9) da Seção II.

Definição 3.1 (Galves e Leonardi, 2008) Para todo $\delta>0 \mathrm{e}$ $d<$ na árvore de contextos estimada $\hat{T}_{n}^{b_{d} d}$ é o conjunto contendo todas as sequências $w \in i=1 d A_{-i}^{-1}$ tais que $\Delta_{n}(\operatorname{asuf}(w))>\delta$ para algum $a \in A$ e $\Delta_{n}(u w) \leq \delta$ para todo $u \in i=1 d-l(w) A_{-i}^{-1}$.

Observe na Definição 3.1 que as constantes $\delta>0$ e $d<n$ são fundamentais para o estimador, pois, inicialmente é considerada a árvore de contextos maximal, assim cada sequência $w$ candidata a contexto possui comprimento $l(w)=d$, ou seja, $w \in A_{-d}^{-1}$. Em seguida, o estimador reduz o comprimento das sequências $w$ que não satisfazem o critério de poda, apresentado nesta definição, tomando suf $(u)$ como novo candidato a contexto. Este procedimento é repetido até que a condição de parada seja satisfeita para todas as sequências $w \in \widehat{T}_{n}^{b, d}$.

\section{REGIME DE CHUVAS EM BRASÍLIA}

Nesta seção trazemos algumas informações climáticas de Brasília-DF. Em particular, caracterizamos o regime de chuvas nessa cidade.

O clima de Brasília é tropical. Na estação seca as temperaturas médias mensais são superiores a $18^{\circ} \mathrm{C}$. O índice pluviométrico anual é de 1.480 milímetros $(\mathrm{mm})$, sendo que as chuvas são concentradas entre os meses de outubro a abril. Durante a estação de seca, compreendida entre os meses de maio a setembro, é comum os que os níveis de umidade relativa dor ar fiquem abaixo de $30 \%$. A Figura 1 traz informações do clima de Brasília obtidas através estação Brasília-A001. Tais dados podem ser acessados através do portal eletrônico do INMET ${ }^{1}$.

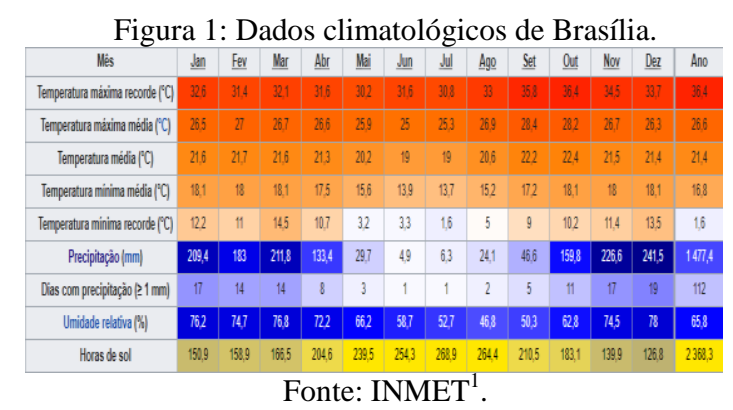

A partir da Figura 1, observamos que $92 \%$ das chuvas em Brasília ocorrem entre os meses de outubro e abril, que é o período da estação chuvosa em Brasília. Com base nessas informações, na Seção V, propomos modelos de previsão de pluviosidade em Brasília.

\section{MODELOS PLUVIOMÉTRICOS DE MEMÓRIA VARIÁVEL}

Nesta seção propomos modelos pluviométricos de ordem variável para o regime de chuvas de Brasília. Mais especificamente, a partir do histórico de chuvas, calculamos a probabilidade de que em um determinado dia não chova, chova moderadamente ou chova forte.

Para nossa aplicação de Cadeias de Memória Variável utilizamos dados de chuva diários de Brasília. As medições de pluviosidade em milímetros $(\mathrm{mm})$ correspondem ao período de 22/08/1961 a 07/05/2018. Assim, o tamanho da amostra utilizado foi de 20.415. Tais informações sobre precipitações de chuva em Brasília-DF foram obtidas através do portal eletrônico do INMET (http://www.inmet.gov.br/portal/), correspondentes à estação BRASILIA - DF (OMM: 83377). 
Figura 2: Árvore de contextos estimada com profundidade $\mathrm{d}=2$

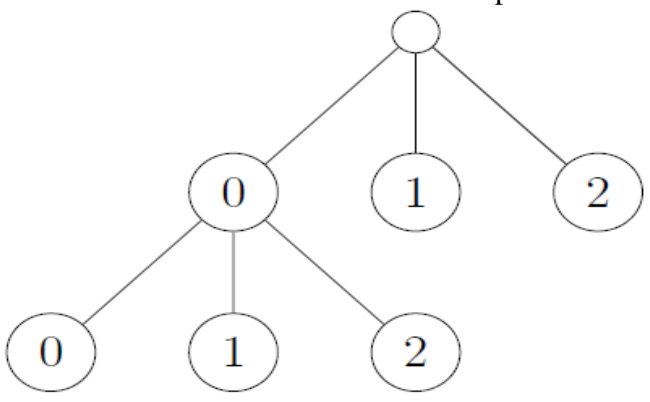

Fonte: Os autores.

Figura 3: Árvore de contextos estimada com profundidade $d=3$

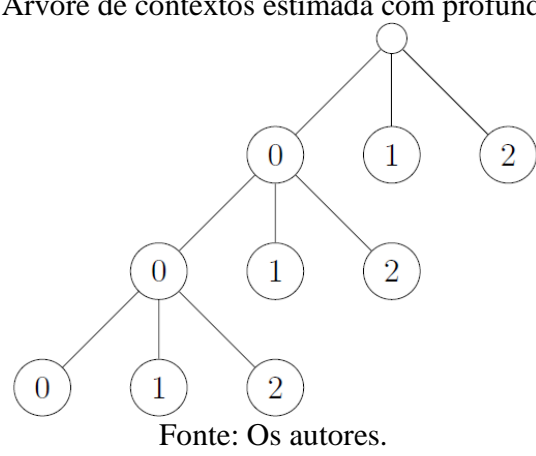

Para distinguir entre dias sem chuva, com chuva moderada ou com chuva forte adotamos o seguinte critério: se num determinado dia a precipitação de chuva foi menor que $1 \mathrm{~mm}$, então consideramos que não houve chuva; se a precipitação de chuva foi maior ou igual a $1 \mathrm{~mm}$ e menor do que $25 \mathrm{~mm}$, consideramos que houve chuva moderada; se a precipitação de chuva foi acima de $25 \mathrm{~mm}$, consideramos que houve chuva forte.

Seja $\mathbf{X}$ a cadeia de memória variável que representa a quantidade de chuva em um dia em Brasília. De acordo com nosso critério, $\mathbf{X}$ assume os valores 0,1 e 2 se em um determinado dia não choveu, choveu moderadamente e choveu forte, respectivamente.

Para a estimação das árvores de contextos $T_{X}$ do processo $\mathbf{X}$ utilizamos a versão do Algoritmo Contexto apresentada na Definição 3.1 da Seção III. Fixando a memória máxima do modelo como sendo 2 e 3 obtemos as árvores estimadas representadas nas Figuras 2 e 3 , respectivamente. As Tabelas 1 e 2 trazem as probabilidades de transição estimadas para as árvores estimadas representadas nas Figuras 2 e 3.

Uma característica das cadeias de ordem variável é que, em muitas aplicações, a correspondente árvore de contextos tem uma interpretação natural e informativa. Por exemplo, pela Figura 2, podemos dizer se o próximo dia irá chover ou não, apenas considerando, no máximo dois dias anteriores. A partir dessa árvore, podemos dizer que se hoje houve chuva moderada, não é necessário olhar qual foi o tipo de chuva que ocorreu ontem para afirmar que há $47 \%$ de chances de chover moderadamente amanhã, de acordo com a Tabela 1. Da mesma forma, a probabilidade de que amanhã chova forte dado que hoje choveu moderadamente é de apenas 9,6\%. Agora, se hoje não choveu, para determinar a probabilidade de que amanhã chova moderadamente é necessário olhar o que aconteceu ontem. Caso também não tenha chovido ontem, a chance de que não chova amanhã é de $87,7 \%$, pela Tabela 1. Interpretações e previsões semelhantes podem ser obtidas pelas Figura 3 e Tabela 2.
Tabela 1: Probabilidades de Transição Estimadas da Figura 2.

\begin{tabular}{|c|c|c|c|}
\hline \multirow{2}{*}{$\hat{p}\left(\left.a\right|_{w}\right)_{n}$} & \multicolumn{3}{|c|}{$\mathrm{A}$} \\
\cline { 2 - 4 } & 0 & 1 & 2 \\
\hline 00 & 0,877 & 0,104 & 0,017 \\
\hline 10 & 0,587 & 0,338 & 0,074 \\
\hline 20 & 0,532 & 0,393 & 0,074 \\
\hline 1 & 0,433 & 0,470 & 0,096 \\
\hline 2 & 0,366 & 0,504 & 0,130 \\
\hline \multicolumn{3}{|c}{ Fonte: Os autores. }
\end{tabular}

Tabela 2: Probabilidades de Transição Estimadas da Figura 3.

\begin{tabular}{|c|c|c|c|}
\hline \multirow{2}{*}{$\hat{p}(a \mid w)_{n}$} & \multicolumn{3}{|c|}{$\mathrm{A}$} \\
\cline { 2 - 4 } & 0 & 1 & 2 \\
\hline 000 & 0,9049437 & 0,08236305 & 0,01269326 \\
\hline 100 & 0,6930380 & 0,25712025 & 0,04984177 \\
\hline 200 & 0,6153846 & 0,32307692 & 0,06153846 \\
\hline 10 & 0,5876337 & 0,3384472 & 0,07391911 \\
\hline 20 & 0,5327869 & 0,3934426 & 0,7377049 \\
\hline 1 & 0,4338443 & 0,4701493 & 0,096006450 \\
\hline 2 & 0,3660000 & 0,5040000 & 0,13000000 \\
\hline
\end{tabular}

Fonte: Os autores.

\section{MUDANÇA NO REGIME DE CHUVAS}

Nessa seção mostramos que houve alteração no regime de chuvas de Brasília nos últimos dezoito anos, quando comparado com o comportamento histórico do regime de chuvas nos anos anteriores. Para tanto, analisamos os dados de chuva até e depois do início dos anos 2000.

Figura 4: Árvore de contextos estimada até 2.000.

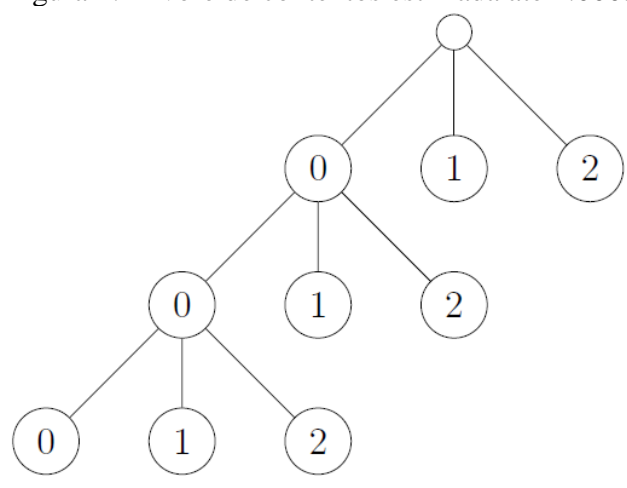

Fonte: Os autores.

Figura 5: Árvore de contextos estimada após 2.000.

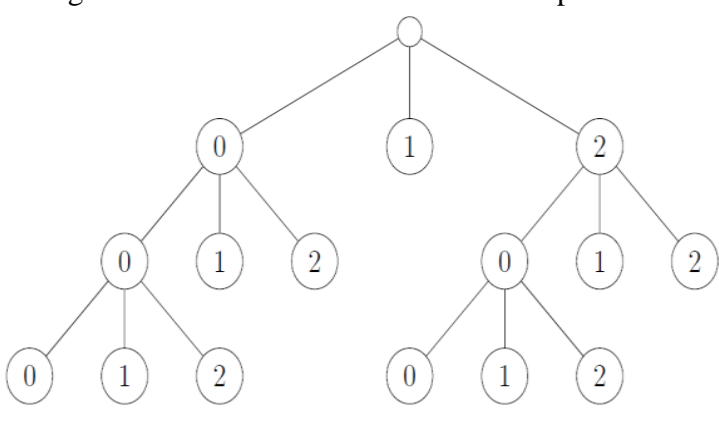

Fonte: Os autores

As Figuras 4 e 5 trazem as árvores de contextos estimadas, com profundidade $\mathrm{d}=3$, para o período até o início dos anos 2.000 e após os anos 2.000, respectivamente. As correspondentes probabilidades de transição são dadas pelas Tabelas 3 e 4 . 
Tabela 3: Probabilidades de Transição Estimadas da Figura 4.

\begin{tabular}{|c|c|c|c|}
\hline \multirow{2}{*}{$\hat{p}(a \mid w)_{n}$} & \multicolumn{3}{|c|}{$\mathrm{A}$} \\
\cline { 2 - 4 } & 0 & 1 & 2 \\
\hline 000 & 0,9030416 & 0,08236305 & 0,01269326 \\
\hline 100 & 0,6882217 & 0,25712025 & 0,04984177 \\
\hline 200 & 0,5899281 & 0,32307692 & 0,06153846 \\
\hline 10 & 0,5976536 & 0,3384472 & 0,07391911 \\
\hline 20 & 0,5408560 & 0,3934426 & 0,07377049 \\
\hline 1 & 0,4360518 & 0,4701493 & 0,09600645 \\
\hline 2 & 0,3813056 & 0,5040000 & 0,13000000 \\
\hline
\end{tabular}

Fonte: Os autores.

Pelos modelos dados nas Figuras 4 e 5 vemos que, no período até os anos 2.000, a informação de que hoje choveu forte era suficiente para dizer qual as chances de chover forte novamente amanhã, que são de $13 \%$. Isso não ocorre após os anos 2.000, ou seja, dado que hoje choveu forte, para dizer quais as chances de chover forte novamente amanhã, devemos olhar o que aconteceu ontem e/ou anteontem. Assim, com base em nosso modelo de ordem $\mathrm{d}=3$, podemos afirmar que houve mudança no regime de chuvas de Brasília após os anos 2.000. a árvore é diferente para os períodos antes de 2000 e após 2000. Para determinar se um dia irá chover forte é necessário olhar para mais dias anteriores, o que não acontece com o período até 2000. Mais especificamente, precisamos ver se no dia anterior choveu ou não, caso não, precisamos ir mais um dia antes.

\section{CONCLUSÃO}

Neste trabalho consideramos Cadeias de Ordem Variável tomando valores no alfabeto $\mathrm{A}=\{0,1,2\}$. Com base nessa classe de modelos, propomos modelos pluviométricos para a cidade de Brasília-DF. Mais especificamente, obtemos modelos de ordens dois e três obter as chances de que, dado o histórico de chuvas nessa cidade, num determinado dia não chova, chova moderadamente ou chova forte.

Adicionalmente, verificamos que houve uma mudança no regime de chuvas na cidade de Brasília após os anos 2.000. Concluímos que a partir desse ano, para prever as chances de chuva em um determinado dia, é necessário observamos a quantidade de chuvas em mais dias no histórico da cidade, quando comparado ao período até o início dos anos 2.000. Esse aumento de "incerteza", pode ser explicado pelo crescimento na emissão de monóxido de carbono no DF nas últimas décadas, devido ao aumento da frota de veículos na região. Além disso, Brasília tem vivenciado nos últimos anos um grande aumento na densidade demográfica e do consequente aumento do desmatamento.

Em trabalhos futuros, pretendemos obter modelos de previsão com ordens superiores. Adicionalmente, pretendemos obter modelos de previsão pluviométrica distintos para os períodos de estiagem e de chuva.

\section{REFERÊNCIAS BIBLIOGRÁFICAS}

COLLET, P., GALVES A., LEONARDI, F., Random Perturbations of Stochastic Processes with Unbounded Variable Length Memory. Electron. J. Probab. 13(538). 2008.

GALVES, A., LEONARDI, F., Exponential inequalities for empirical unbounded context trees. Progress in Probability 60. Birkhauser: 257-70.2008.

MOREIRA, L., BOMFIM, A. B. A., Desempenho de Estimadores de árvores de Contextos. Revista Sodebras [on line].v. 11 n.132, p. 207-211, 2016.

MOREIRA, L., BOMFIM, A. B. A., Estudo comparativo entre o português brasileiro e europeu: uma aplicação de árvores de Contexto. Revista Sodebras [on line]. v. 12 n. 136, p. 176-181, 2017.

MOREIRA, L., QUINTINO, F. S., Cadeias de Ordem Variável Estocasticamente Perturbadas: Aplicações a Dados Climáticos. RevistaSodebras [on line] v. 10 n.117,p.141146, 2015.

RISSANEN, J., A Universal Prior for Integers and Estimation by Minimum Description Length. The Annals of Statistics 11 (2): 416-431, 1983.BAIGORRI, A. R., GONÇALVES, C.

\section{COPYRIGHT}

Direitos autorais: Os autores são os únicos responsáveis pelo material incluído no artigo. 


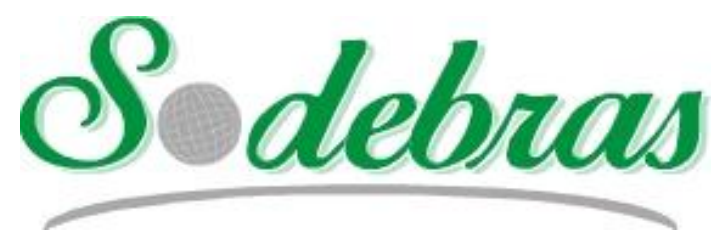

Volume 14 - No 159 - Março/2019.

XL International Sodebras Congress

10 a 12 de dezembro de 2018 - Vitória - ES.

\title{
ESQUEMA ARGUMENTATIVO EM TEXTOS: ENCONTRAR DEFINIÇÃO CONCEITUAL NO TEXTO ACADÊMICO E GERAR QUESTÕES QUE A JUSTIFICA
}

\author{
ARGUMENTATIVE SCHEME IN TEXTS: \\ FIND CONCEPTUAL DEFINITION IN THE ACADEMIC TEXT AND \\ GENERATE QUESTIONS THAT JUSTIFY IT
}

\author{
KOICHI SANOKI; ÍTALO SANTIAGO VEGA \\ PONTIFÍCIA UNIVERSIDADE CATÓLIGA - SÃO PAULO \\ koichisanoki00091587@gmail; italo@pucsp.br
}

\begin{abstract}
Resumo - O propósito deste artigo é apresentar um algoritmo computacional que valida às questões geradas das partes de um texto acadêmico em relação às questões geradas a partir do resumo. $O$ procedimento metodológico inicia-se com a obtenção do texto nos ficheiros de repositórios acadêmicos, particionado-o em palavras, em períodos gramaticais e frases. As palavras serão identificadas a partir de sua classe gramatical, definidas assim como todos os tipos de períodos gramaticais presentes armazenados em uma base de dados, denominada Corpus de Questões do Texto. Como resultado, esse algoritmo mostrará uma relação de questões, acrescido de pronomes interrogativos ou de advérbios de tipos de argumentos encontrados entre o resumo e as outras partes do texto, também sua relação com as palavras-chave, e a frequência destas nos tópicos do texto.

Palavras-chave: Corpus. Períodos gramaticais. Pronomes interrogativos.
\end{abstract}

Abstract - The purpose is to not only present a computational algorithm capable of generating questions from an argument structure but also validate the knowledge of the questions generated from items after comparing the questions generated from each sentence of the abstract. The process begins with a function to acquire data from a Portuguese text for input in the file system repository and split them into in words and grammatical sentences. These words will be defined and stored according to their word classes and the entire grammatical sentences with their morphology and the semantic grammatical features in a database called the Corpus Questions of the Text. The result, an algorithm that generates a series of questions, including some of the seven key questions adjusted according to the structure arguments, finally highlights the possibility of validating the relationship between the abstract and the items of the text, as well as the number of occurrences of keywords in these text items.

Keywords: Corpus. Grammar in a Sentence. Seven Key Questions.

\section{INTRODUÇÃO}

Este artigo tem como propósito mostrar algoritmo que mostrará para a atividade de leitura de textos acadêmicos uma ideia principal (RINO, 1996) de um texto acadêmico para pesquisador que queira desenvolver uma dissertação, uma tese ou um artigo, e que busca eficácia no resultado e na utilização do tempo dedicado. Uma contribuição de destaque deste artigo será em mostrar um algoritmo computacional que poderá gerar as questões automaticamente a partir dos períodos gramaticais do texto de origem.

Este artigo apresenta e discute a principal estratégia que subsidia as preocupações envolvidas no desenvolvimento de tal algoritmo. Esta estratégia terá várias etapas, e a primeira delas será a interação com o pesquisador, que deverá informar o texto e o objetivo da sua pesquisa através de palavras-chave.

A segunda etapa do algoritmo será a inserção desse texto em um meio computacional (caso este ainda não esteja inserido) para, a partir dos itens da referência bibliográfica, procurar os artigos referenciados e correlatos em periódicos ou repositórios disponíveis, e então criar uma base de dados que se chamará Corpus de Questões do Texto e que, por sua vez, dará suporte ao mesmo. Na criação do Corpus serão gerados os significados morfológicos e semânticos de todas as palavras do texto e dos artigos referenciados, e terá a ferramenta WordSmith como instrumento para análise (SARDINHA, 2000).

Este Corpus segue uma ordem de armazenamento, a ser obedecida com a finalidade de obter melhor resultado na consulta (Query) a ser feita à base de dados. A ordem de armazenamento (CODD, 1970) será: sequência dentro do texto, sequência do período, tipo de sequenciador (conjunção ou operador), verbo transitivo (Yes), Pronomes Interrogativos $(5 \mathrm{~W} 2 \mathrm{H})$, Word, dados morfológicos, dados semânticos.

A etapa seguinte do algoritmo será a criação de relações entre os tipos de palavras do texto e o conteúdo do Corpus, levando em consideração as características de cada palavra. $\mathrm{Na}$ fase de relacionamentos semânticos entre as orações do texto e o Corpus será preciso montar um texto de orações, sentenças e frases. A partir dos significados morfológicos e semânticos das palavras serão estabelecidas as relações com os advérbios de modo e pronomes demonstrativos, o que permitirá a elaboração de questionamentos objetivos. 
A etapa principal do algoritmo será a de reconstrução das orações ou sentenças, agregando $O$ quê, Quando, Porque, Onde, Qual, Quem, Como, Quanto, ou advérbios de tipos de argumentos. O resultado da aplicação dessas etapas será um algoritmo para o engendramento de questionários, na forma de indagações, acerca de determinados períodos gramaticais do texto acadêmico, e dará um bom motivo para a realização de leituras de esclarecimento, ou não.

\section{METODOLOGIA}

O processo do aplicativo computacional terá várias funções:

\section{1 - Adquirir o texto acadêmico}

A primeira função é a obtenção do texto do tipo pdf nos ficheiros de repositórios acadêmicos.

\section{2 - Separar em oração}

A próxima função é a separação desse texto em palavras sempre que houver coincidência de caracteres, conforme Tabela 1, e a identificação de cada palavra a partir de sua classe gramatical, como sugerido neste artigo (SANOKI; VEGA, 2017), onde o resultado é morfologia e semântica. O uso da ferramenta TreeTagger é sugerido para anotação de texto com informações de parte da fala e do lema; foi desenvolvido por Helmut Schmid (1994) no projeto TC (Cooperação Técnica) do Instituto de Linguística Computacional da Universidade de Stuttgart, onde os resultados foram a morfologia e as formas de classes semânticas (SANOKI, 2017).

Tabela 1 - Caracteres que encerram uma oração

\begin{tabular}{ll}
\hline Final das palavras & Caracters \\
\hline espaço & 6 \\
ponto final & $\cdot$ \\
ponto e virgula & $;$ \\
reticencia & $\ldots$ \\
ponto de interrogação & $?$ \\
ponto de exclamação & $!$ \\
\hline
\end{tabular}

Nesta mesma função, caso se identifique tratar-se de uma das palavras-chave, há de se montar dinamicamente a tabela 2. E então detectar se essa palavra se apresenta em uma das partes do texto, como: resumo, introdução, método, resultados, discussão e conclusão (CHEMIN, 2015), conforme tabela 3 e discussão (CHEMIN, 2015);

Tabela 2 - Palavras-chave do texto

\begin{tabular}{l}
\hline keywords \\
\hline <empty>
\end{tabular}

Tabela 3 - Itens do texto

\begin{tabular}{l}
\hline Item \\
\hline Abstract \\
Resumo \\
Introdução \\
Método \\
Metodologia \\
Discussão \\
Conclusão \\
\hline
\end{tabular}

\section{3 - Divisão por períodos}

Identificação dos períodos gramaticais conforme tabela 4, e as suas características apresentadas, como: conjunções, operadores argumentativos ou operadores lógicos
(CANÇADO, 2009), de acordo com a tabela 5, de conjunções, e com a tabela 6 , de tipos de argumentos lógicos localizados no sequenciador dentro do período, por sua vez de acordo com a tabela de tipos de argumentos.

a) Além disso, os verbos transitivos usados dentro dos argumentos para criar uma questão de compreensão são identificados e assimilados dinamicamente na Tabela 5 para gerar questões de conteúdo, que primeiro incluem a associação das sentenças com as sete questões-chave apresentadas na Tabela 7;

Tabela 4 - Caracteres de finais de período gramatical

\begin{tabular}{ll}
\hline Final & Caracters \\
\hline Ponto final & $\cdot$ \\
Reticencia & $\ldots$ \\
Ponto de interrogação & $?$ \\
Ponto de exclamação & $!$ \\
\hline
\end{tabular}

Tabela 5 - Conjunções

\begin{tabular}{|c|c|}
\hline Con & Orações coordenadas \\
\hline $\begin{array}{l}\text { e; nem; também; } \\
\text { bem como; não } \\
\text { só... mas também }\end{array}$ & $\begin{array}{l}\text { Sindéticas aditivas transmitem } \\
\text { uma ideia de adição à oração } \\
\text { anterior. }\end{array}$ \\
\hline $\begin{array}{l}\text { mas; porém; contı } \\
\text { todavia; entretant }\end{array}$ & $\begin{array}{l}\text { Sindéticas adversativas } \\
\text { transmitem uma ideia de } \\
\text { oposição à oração anterior. }\end{array}$ \\
\hline $\begin{array}{l}\text { ou; ou... ou; } \\
\text { já... já; ora... ora; } \\
\text { quer... quer; seja... seja; } \\
\text { nem... nem }\end{array}$ & $\begin{array}{l}\text { Sindéticas alternativas } \\
\text { transmitem uma ideia de } \\
\text { alternância em relação à oração } \\
\text { anterior. }\end{array}$ \\
\hline $\begin{array}{l}\text { logo; pois; portanto; } \\
\text { assim; por isso; desse } \\
\text { modo; por } \\
\text { consequência }\end{array}$ & $\begin{array}{l}\text { Sindéticas conclusivas } \\
\text { transmitem a conclusão de uma } \\
\text { ideia expressada na oração } \\
\text { anterior. }\end{array}$ \\
\hline $\begin{array}{l}\text { que; porque; porquant } \\
\text { pois; na } \\
\text { verdade; isto é; ou } \\
\text { seja; a saber }\end{array}$ & $\begin{array}{l}\text { Sindéticas explicativas } \\
\text { transmitem a explicação de } \\
\text { uma ideia expressada na oração } \\
\text { anterior. }\end{array}$ \\
\hline
\end{tabular}

Tabela 6 - Operadores argumentativos

\begin{tabular}{|c|c|}
\hline Operador & Argumentativos \\
\hline $\begin{array}{l}\text { Mesmo; até; até } \\
\text { mesmo; inclusive }\end{array}$ & $\begin{array}{l}\text { Estabelecem a hierarquia dos } \\
\text { elementos numa escala, } \\
\text { assinalando o argumento mais } \\
\text { forte para uma conclusão. }\end{array}$ \\
\hline $\begin{array}{l}\text { ao menos; pelo menos; } \\
\text { no mínimo }\end{array}$ & $\begin{array}{l}\text { Introduzem argumentos } \\
\text { deixando subentendida a } \\
\text { existência de uma escala com } \\
\text { outros argumentos mais fortes. }\end{array}$ \\
\hline $\begin{array}{l}\text { e; também; nem (igual a } \\
\text { “e não"); não só... mas } \\
\text { também }\end{array}$ & $\begin{array}{l}\text { Somam argumentos a favor de } \\
\text { uma mesma conclusão, ou seja, } \\
\text { que fazem parte de uma mesma } \\
\text { classe argumentativa. }\end{array}$ \\
\hline $\begin{array}{l}\text { portanto; logo; por } \\
\text { conseguinte; pois; } \\
\text { em decorrência de }\end{array}$ & $\begin{array}{l}\text { Introduzem uma conclusão } \\
\text { relativa, assim como } \\
\text { argumentos apresentados em } \\
\text { enunciados anteriores. }\end{array}$ \\
\hline $\begin{array}{l}\text { ou; ou então; quer... } \\
\text { quer; seja... seja }\end{array}$ & $\begin{array}{l}\text { Introduzem argumentos } \\
\text { alternativos que levam a } \\
\text { conclusões diferentes ou } \\
\text { opostas. }\end{array}$ \\
\hline $\begin{array}{l}\text { mais que; menos que; } \\
\text { tão... como }\end{array}$ & $\begin{array}{l}\text { Estabelecem relações de } \\
\text { comparação entre elementos, } \\
\text { visando uma determinada } \\
\text { conclusão. }\end{array}$ \\
\hline porque; que; já que; pois & $\begin{array}{l}\text { Introduzem uma justificativa } \\
\text { ou explicação relativa ao }\end{array}$ \\
\hline
\end{tabular}




\begin{tabular}{|c|c|}
\hline $\begin{array}{l}\text { mas; porém; contudo; } \\
\text { todavia; no entanto }\end{array}$ & $\begin{array}{l}\text { Indicam oposição entre } \\
\text { elementos semânticos, } \\
\text { explícitos ou implícitos. }\end{array}$ \\
\hline já; ainda; agora & $\begin{array}{l}\text { Têm por função introduzir ao } \\
\text { enunciado conteúdos } \\
\text { pressupostos. }\end{array}$ \\
\hline $\begin{array}{l}\text { Um pouco; pouco; } \\
\text { quase; apenas; só; } \\
\text { somente }\end{array}$ & $\begin{array}{l}\text { Distribuem-se em escalas } \\
\text { opostas, onde um deles } \\
\text { funciona numa escala orientada } \\
\text { para a afirmação total. }\end{array}$ \\
\hline aliás; além do mais & $\begin{array}{l}\text { Introduzem um argumento } \\
\text { decisivo, a título de acréscimo, } \\
\text { como se fosse desnecessário. }\end{array}$ \\
\hline $\begin{array}{l}\text { isto é; quer dizer; se; ou } \\
\text { seja; ou; ou melhor; de } \\
\text { fato }\end{array}$ & $\begin{array}{l}\text { Em outras palavras, visam } \\
\text { esclarecer, retificar, ou } \\
\text { desenvolver um enunciado } \\
\text { anterior. }\end{array}$ \\
\hline $\begin{array}{l}\text { tudo; todos; nada; } \\
\text { nenhum }\end{array}$ & $\begin{array}{l}\text { São usados para dar sequência } \\
\text { ao discurso quando se tem } \\
\text { escalas no sentido da afirmação } \\
\text { ou da negação plenas. }\end{array}$ \\
\hline
\end{tabular}

\section{Tabela $7-5 \mathrm{~W} 2 \mathrm{H}$}

Questões

What (O quê)

When (Quando)

Where (Onde)

Which (Qual)

Who (Quem)

Why (Porque)

How (Como)

How Much (Quantos)

\section{4 - Armazenar sentenças}

A próxima função é o armazenamento da gramática em sentenças, com suas sequências dentro do texto; as partes em que estão inseridas e as características da ordem de armazenamento (CHEMIN, 2015) são identificadas com a palavra sequencial no texto. Além disso, o tipo de conexões (uma conjunção ou o operador argumentativo), o tipo de item conforme Tabela 3 , os verbos transitivos existentes conforme Tabela 5, as sete questões-chave e oração (sem o caractere final) ou sentença (sem o caractere final), os dados morfológicos e os dados semânticos são posteriormente identificados.

\section{5 - Construir as perguntas}

Esta função presente será a construção das orações ou sentenças, começando com o que, quando, por que, onde, quem, como, quanto, ou os advérbios do operador argumentativo apresentado na Tabela 7 , e mudando a ordem do verbo com o sujeito.

\section{6 - Relacionamentos}

Por fim, a relação entre as questões levantadas no resumo com os demais itens do texto são identificados a partir das conjunções ou operadores lógicos e dos argumentativos contidas nas conexões (MARTINO, 2014), e armazenadas em um banco de dados, as Questões Corpus de o Texto (SARDINHA, 2006). Isso garantirá que o algoritmo computacional seja consistente e coerente para uso em relação a textos acadêmicos (QUARESMA et al, 2006).

\section{RESULTADOS}

Os resultados desse algoritmo é apresentar uma relação de questões geradas pelo item 2.6 sobre o conteúdo em relação aos itens do texto;

\section{1 - Resultados da Simulação}

No resumo deste artigo aparece propósito, o mesmo que está relacionado no item "INTRODUÇÃO", e neste caso será gerada uma questão do tipo: "Qual é o propósito desse artigo?".

\section{2 - Resultados dos Ensaios}

A resposta que o algoritmo deverá responder: "propósito mostrar algoritmo que mostrará para a atividade de leitura de textos acadêmicos...”.

\section{CONCLUSÃO}

O algoritmo apresentará uma relação de questões baseadas em combinações e associações com as tabelas, acrescidas de pronomes interrogativos (5W2H) na montagem do Corpus.

A análise realizada pelo algoritmo a partir das questões poderá corresponder ao esperado dos tipos de argumentos encontrados nos períodos gramaticais através de sequenciadores como conjunções, operadores lógicos e argumentativos do texto de origem.

A última ação do algoritmo é o engendramento de questionários, na forma de indagações, acerca de um determinado texto acadêmico, que acarretará um bom motivo para a realização de leituras de esclarecimento, e por fim poder-se conhecer a ligação entre o resumo e as outras partes do texto, sua relação com as palavras-chave, e a frequência destas nos tópicos do texto.

\section{REFERÊNCIAS BIBLIOGRÁFICAS}

CANÇADO, M. Argumentos: complementos e adjuntos. 2009. ALFA: Revista de Linguística, Brazil, ISSN: 19815794.

CHEMIN, B. F. Manual da univates para trabalhos acadêmicos: Planejamento, elaboração e apresentação. [S.1.]: 2015. Editora UNIVATES, Lajeado, Brazil, ISBN 978-85-8167-102-4.

CODD, E. F. A relational model of data for large shared data banks. Communications of the ACM, ACM, v. 13, n. 6, p. 377-387, 1970.

QUARESMA, P. et al. Um sistema de Pergunta-Resposta para uma base de Documentos. Letras de Hoje, v. 41,n. 2, 2006. ISSN 1984-7726.

MARTINO, A. Português esquematizado: gramática,interpretação de texto, redação oficial, redação discursiva.[S.1.]: 2014, 2013. ISBN 978-85-02-21376-0.

RINO, L. H. modelagem de discurso para o tratamento da concisão e preservação da ideia central. Tese (Doutorado) — Instituto de Física de São Carlos, 1996. Disponível em: <http://www.teses.usp.br/teses/disponiveis/76/76132/tde07012009-095918/en.php>. Citado na página 12.

SANOKI, K. Generating key questions from academic texts. 2017 12th Iberian Conference on Information System and 
Technologies (CISTI), p. 1-4, 2017. ISBN 978-989-96247-

4-0.

SANOKI, K.; VEGA, I. S. Esquema Argumentativo Em Textos Acadêmicos: Identificação Algorítmica De Conceitos. 2017. XXXVIII International Sodebras Congress, v. 13, n. 147, p. 108-111, 2018. ISSN 1809-3957.

SARDINHA, T. B. Linguística de corpus: histórico e problemática. Delta, SciELO Brasil, v. 16, n. 2, p. 323-367, 2000 .

\section{COPYRIGHT}

Direitos autorais: Os autores são os únicos responsáveis pelo material incluído no artigo. 


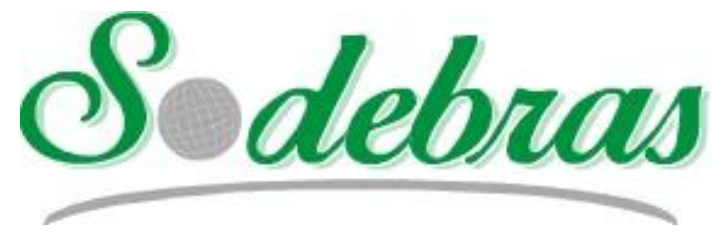

Volume 14 - No 159 - Março/2019.

XL International Sodebras Congress

10 a 12 de dezembro de 2018 - Vitória - ES.

\title{
SISTEMA DE REALIDADE VIRTUAL PARA TREINAMENTO DE OPERADORES DE LOCOMOTIVAS
}

\section{VIRTUAL REALITY SYSTEM FOR TRAINING LOCOMOTIVE OPERATORS}

\author{
PABLO PEREIRA E SILVA ${ }^{1} ;$ RODRIGO VAREJÃO ANDREÃO ${ }^{1} ;$ MÁRIO MESTRIA $^{1}$
}

1 - INSTITUTO FEDERAL DO ESPÍRITO SANTO

pablops08@gmail.com; rodrigova@ifes.edu.br; mmestria@ifes.edu.br

\begin{abstract}
Resumo - Nas últimas décadas, o uso de sistemas de Realidade Virtual (RV) para treinamento tem sido impulsionado por uma evolução tecnológica contínua, pela busca de processos mais lucrativos e sustentáveis, pela busca por treinamentos mais envolventes e outros. Além disso, o treinamento usando a $R V$ permite que os usuários absorvam o conhecimento sem serem expostos a procedimentos que envolvam riscos. $O$ objetivo deste artigo é apresentar a criação de um sistema de treinamento de Realidade Virtual utilizando técnicas de gamificação para treinar condutores de locomotivas.
\end{abstract}

Palavras-chave: realidade virtual, gamificação, treinamento.

Abstract - In the last decades, the usage of Virtual Reality (VR) systems for training has been driven by a continuing technological evolution, the search for more profitable and sustainable processes, the search for more engaging trainings, and others. Also, training using VR enable users to absorb knowledge without being exposed to procedures that involve risks. The purpose of this article is to introduce the creation of a virtual reality training system to train drivers with gamification strategies.

Keywords: virtual reality, gamification, training.

\section{INTRODUÇÃO}

A Realidade Virtual (RV) é uma ferramenta utilizada nos treinamentos para compreensão e simulação de processos produtivos industriais através de jogos sérios que possuem vantagens em relação aos treinamentos nos ambientes reais. São denominados jogos sérios aqueles cuja proposta principal transcende o entretenimento, disponibilizando ao usuário algum tipo de conhecimento ou treinamento (MICHAEL e CHEN, 2005). Algumas vantagens desses jogos são: redução de custos, tempo de execução, alta disponibilidade de realização, garantia de realizar repetições com muito mais facilidade e disponibilidade de aplicar mecanismos de avaliação (PINHEIRO et al., 2016). Além disso, outra vantagem de destaque é a capacidade de realizar treinamentos de processos que possuem uma grande importância para a empresa, sob o ponto de vista econômico ou estratégico, ou estão inseridos em ambientes de alto risco.

De acordo com Sousa et al. (2010), o aumento da complexidade técnica dos equipamentos e das máquinas exige uma maior qualificação dos funcionários. $\mathrm{O}$ aumento nos custos operacionais, demandas cada vez maiores nos processos produtivos e esforços que são exigidos de técnicos fizeram com que as empresas procurassem novos métodos e ferramentas para realizar treinamentos com menores investimentos.

A atual tendência na educação mostra que o treinamento através de Realidade Virtual possibilita a absorção de conhecimento de forma rápida e eficiente pelos estudantes se comparado aos treinamentos tradicionais utilizando livros, fotos e vídeos. Com o passar dos anos, tem sido observado que estudantes aprendem melhor quando é usada uma variedade de métodos. As técnicas de ensino baseadas em Realidade Virtual têm o potencial de revolucionar o processo educacional quando usadas em conjunto com técnicas de ensino contemporâneas. Essas técnicas educacionais são mais atraentes para os estudantes, pois são flexíveis, atraentes e fáceis de entender, por exemplo, na indústria mineradora, onde processos são complexos e difíceis de explicar de outras formas (MITRA, HEBBLEWHITE e SAYDAM, 2015).

A gamificação pode ser descrita como o uso de elementos desenvolvimento de jogos em outras atividades que não são relacionadas aos jogos com o intuito de tornálas mais atrativas (DETERDING et al., 2011). Logo, seu uso em sistemas de treinamento em Realidade Virtual pode despertar um interesse maior nos usuários. Exemplos de elementos usados são a narrativa do jogo, objetivos e regras, níveis de dificuldade, sistema de compensação e sistemas de feedback (FARDO, 2013).

Segundo Tichon (2007) a condução de trens é uma tarefa complexa que envolve um grande número de dificuldades e desafios, sendo necessário o conhecimento de dinâmica do trem e procedimentos emergenciais como combate ao incêndio e treinamento de evacuação. Logo, a Realidade Virtual aplicada a esses sistemas pode trazer benefícios quando se pensa em visualização de procedimentos e treinamento de condutores. $\mathrm{O}$ treinamento desses condutores utilizando a Realidade Virtual pode melhorar as habilidades de condução e melhorar as ações tomadas em situações de risco. Isso é um fator importante já que um grande número de acidentes em ferrovias está ligado aos erros de desempenho humano.

Neste trabalho, apresentamos resultados do desenvolvimento de um sistema computacional de Realidade Virtual aplicado no treinamento de condutores de locomotivas utilizando técnicas de gamificação. Os ambientes utilizados fazem parte da logística de uma 
empresa de mineração. Essa pesquisa tem abrangência exploratória e estudo de campo com experimentos empíricos.

Este artigo possui, além da introdução, outras sete seções: A seção 2 apresenta os trabalhos relacionados que envolvem treinamento, Realidade Virtual e sistemas ferroviários encontrados na literatura. A seção 3 apresenta a metodologia utilizada. A seção 4 apresenta os resultados obtidos no desenvolvimento. A seção 5 apresenta as considerações finais e os trabalhos futuros que serão realizados pela pesquisa. Por fim, a seção 6,7 e 8 apresentam, respectivamente, as referências bibliográficas, agradecimentos e direitos autorais.

\section{TRABALHOS RELACIONADOS}

Nessa seção serão mostrados os trabalhos realizados que envolvem treinamento, Realidade Virtual e sistemas ferroviários.

O artigo de Naweed, Hockey e Clarke (2013) apresenta um estudo de caso que descreve o desenvolvimento de um simulador de condução de trens chamado de ATREIDES (Adaptive Train Research Enhanced Information Display \& Environment Simulator). No ATREIDES, o condutor possui o controle da aceleração e da frenagem, e a tarefa central é percorrer o trajeto levando passageiros através de uma condução ótima de acordo com os parâmetros de conforto, tempo de permanência e eficiência energética. Um sistema automático supervisório também é incorporado ao simulador, que monitora o desempenho e a operação segura do condutor. Esse sistema gera mensagens quando velocidades excessivas são atingidas, e se necessário, aciona os freios para retornar à velocidade permitida. A interface desenvolvida para o ATREIDES é bastante simples e apresenta gráficos de distância-velocidade, informação de consulta, painel de alarmes, dados de estados do trem, topografia do trajeto e contorno do trajeto.

No trabalho de Dorrian et al. (2007) relaciona a Realidade Virtual com a saúde do operador na condução de trens. Uma das motivações para a realização da pesquisa são as investigações sobre falta de sono e fadiga, fatores que contribuem para inúmeros acidentes em ferrovias. Logo, o objetivo principal do trabalho é investigar os efeitos da falta de sono e fadiga no desempenho de usuários em um simulador ferroviário. $\mathrm{O}$ trabalho analisa o desempenho de 20 condutores de trem no simulador submetido a situações de baixo, moderado e alto nível de fadiga. Para compor a pesquisa, são realizados questionários e adquiridos diversos dados nas sessões no simulador, como uso de combustível, tempo de viagem, erros de frenagem e aceleração e violações de condução. Foi concluído no trabalho que altos níveis de fadiga podem resultar em desligamento cognitivo das tarefas de direção, e então, aumentar o risco de acidentes ferroviários.

Barbosa et al. (2011) apresenta um sistema de Realidade Virtual de simulação multiusuário constituído por computadores trabalhando interconectados em uma arquitetura de rede que permite a conexão entre os módulos de treinamento que passam a interagir dentro de uma malha viária completa. Esse trabalho descreve a segunda versão do simulador, onde a metodologia utilizada é centralizada na expansão da capacidade de treinamento e introdução de inovações, como a inclusão do modelo dinâmico do veículo completo. Foi utilizado o software de desenvolvimento
Unity capaz de gerar visualizações tridimensionais (3D) de alta qualidade e desempenho.

O trabalho de Barbosa et al. (2010) aborda o desenvolvimento do simulador do trem numa fase anterior, onde cita que o sistema é capaz de simular a condução normal de um trem ou reproduzir as condições adversas de operação. Esse simulador é capaz de representar os controles, painéis e mostradores presentes na locomotiva real. O sistema reproduz também a geometria da linha férrea e a visualização do ambiente contendo a topografia do terreno e sons locais, além de simular as variações climáticas.

O artigo escrito por Tichon (2007) não apresenta o desenvolvimento ou estudo em um sistema de Realidade Virtual aplicado a sistemas ferroviários, porém ele utiliza um método de análise para ampliar o conhecimento das ações corretas e errôneas realizadas em alguns incidentes em ferrovias. Os resultados encontrados neste trabalho, utilizando o conhecimento de oito condutores e instrutores experientes, apoiam o desenvolvimento de sistemas de treinamento, com foco nas situações críticas de segurança ferroviária.

Como vimos diversos trabalhos utilizando Realidade Virtual foram desenvolvidos verificando variáveis e métricas para sistemas ferroviários. Desta forma, mostra que a Realidade Virtual é uma ferramenta promissora para treinar e avaliar sistemas produtivos.

\section{METODOLOGIA}

O sistema foi construído na game engine Unity com o auxílio dos softwares 3Ds Max e Substance Painter. O 3Ds Max é um programa de propriedade da Autodesk voltado para modelagem, renderização, animação e visualização de ambientes e objetos tridimensionais, sendo ele um dos mais abordados na literatura em processos de criação de modelos para Realidade Virtual. O Substance Painter é um software de pintura 3D e texturização. A plataforma Unity é amplamente utilizada para criação de jogos, tanto para o entretenimento, quanto para as áreas educacionais, industriais e de saúde. Essa plataforma foi escolhida, pois além de disponibilizar uma versão gratuita, para fins não comerciais, se destaca no quesito iluminação, física e facilidade de desenvolvimento.

\section{1-Modelos $3 D$}

O sistema é composto de um trecho de linha férrea contendo objetos de construção civil, vegetação, topografia, sinalização, chamados de objetos 3D notáveis, e um modelo tridimensional de uma central de manutenção de vagões ferroviários real de uma empresa mineração.

Os modelos 3D foram desenvolvidos utilizando um workflow de modelagem apresentado no artigo de SILVA et al. (2018). Esse processo foi importante para a criação de modelos com características semelhantes ao real contendo em sua estrutura uma quantidade reduzida de polígonos, garantindo o desempenho adequado da game engine. $\mathrm{O}$ modelo da central de manutenção de vagões no sistema de treinamento pode ser visualizado na Figura 1.

O modelo da locomotiva também foi desenvolvido seguindo o workflow citado, e apresenta os principais controles presentes nas locomotivas da série SD produzidas pela General Motors Electro-Motive Division (EMD). Outros modelos 3D desenvolvidos e inseridos no sistema 
foram: estação ferroviária, pátio de abastecimento de locomotivas e cabines de sinalização.

\section{2 - Construção do sistema}

O sistema desenvolvido no Unity é composto basicamente das geometrias 3D, descritas no tópico anterior, códigos em linguagem de programação C\# (Csharp) e objetos de game (game objects) desenvolvidos no próprio Unity. Exemplos de game objects são: terrenos, iluminação, câmera, telas de visualização e telas de menu interativas.

Figura 1 - Modelo da central de manutenção no sistema de treinamento

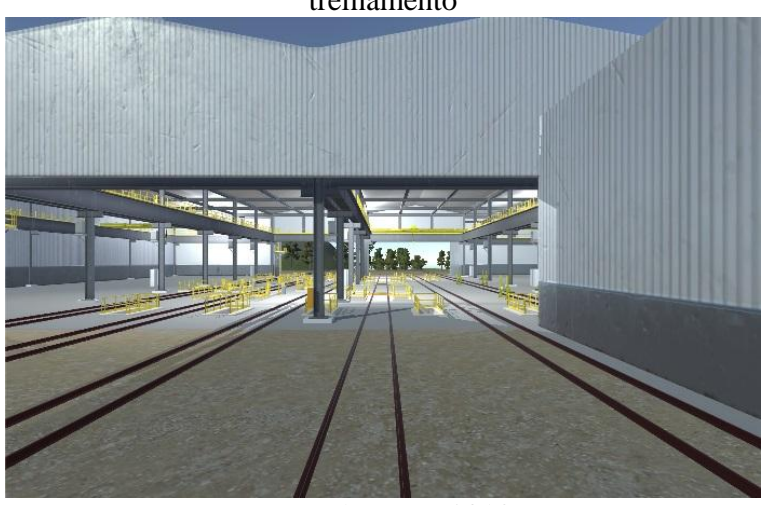

Fonte: Autores, 2018.

As geometrias 3D desenvolvidas a partir do workflow de modelagem são importadas para a game engine, associadas aos seus respectivos materiais e posicionadas no ambiente. Algumas, como o caso da locomotiva, são objetos dinâmicos no sistema e precisam ser associadas com códigos em $\mathrm{C \#}$ e receber características de corpos rígidos (rigidbody).

Os principais códigos em linguagem C\# desenvolvidos são:

- Código de controle da locomotiva;

- Código do tutor ou assistente de treinamento, responsável por disponibilizar na tela do usuário as orientações durante a execução. Além disso, compara as ações do usuário com dados de condução definidas como ideal e contabiliza os acertos;

- Código que armazena os dados de condução definidas como ideais;

- Códigos de controle do menu inicial, menu de resultados e de ranking.

\section{3 - Tutor ou assistente de treinamento}

O tutor é composto basicamente de uma tela de visualização na parte superior esquerda, que no decorrer da execução do treinamento poderá fornecer os seguintes dados:

- Controle que deverá ser alterado;

- Para qual valor deverá ser alterado;

- Distância até o ponto ideal de execução. Onde apresenta valores positivos em verde quando o ponto de execução está à frente, e caso contrário, apresenta valores negativos em vermelho;

- Observações sobre a necessidade da execução da ação, como "Curva a frente" ou "Cruzamento à frente";

- Valor atual de pontos obtidos (score);

- Vida do usuário referente ao número máximo de erros que podem ser cometidos.
O tutor disponibiliza as ações conforme o nível de dificuldade escolhido no menu inicial. Ele segue a lógica de quanto mais difícil o nível escolhido, menos orientações serão disponibilizadas para o usuário. Sendo que no nível mais fácil, todas as ações que devem ser executadas pelo usuário e convertidas na nota final são apresentadas as devidas orientações pelo tutor.

A nota final (número de pontos obtidos ou score) é computada a partir das ações executadas corretamente, sendo que, quanto maior o nível escolhido pelo usuário, maior será o peso de cada ação na nota final. Isso é realizado com a multiplicação da nota unitária de cada ação por um fator de dificuldade, que assume valores entre 1 e 2 , dependendo no nível escolhido.

O usuário só poderá perder 5 vidas no decorrer da execução. Caso as 5 vidas se esgotem, o treinamento é finalizado. Uma vida é perdida quando o usuário deixa de executar alguma ação definida como ideal, contabilizada como um erro cometido pelo usuário. Uma vida pode ser recuperada se o usuário executar 3 ações corretas de forma consecutiva.

Na Figura 2 são apresentados, através do gráfico, as ações definidas como ideais num trecho de 5 quilômetros para o treinamento de condução. Pelo gráfico pode ser identificado o ponto ideal para execução de cada ação.

Figura 2 - Valores ideais no treinamento de condução Outros Controles

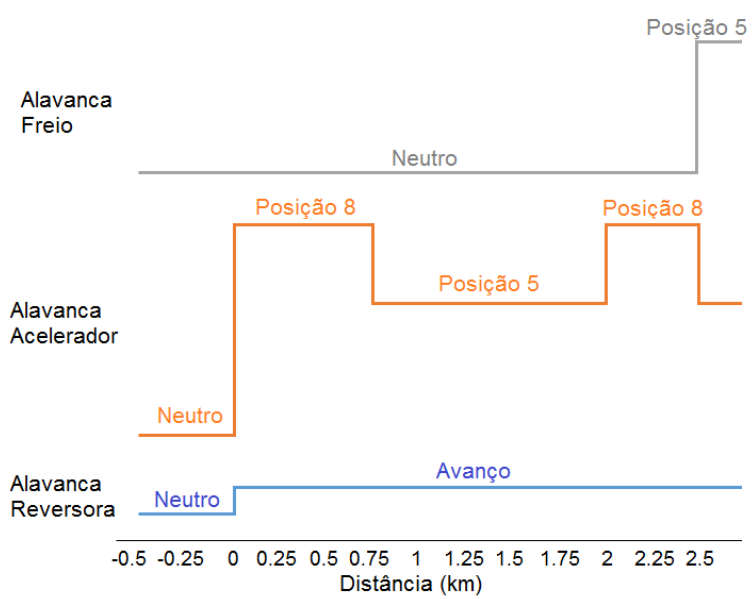

Outros Outros
Controles
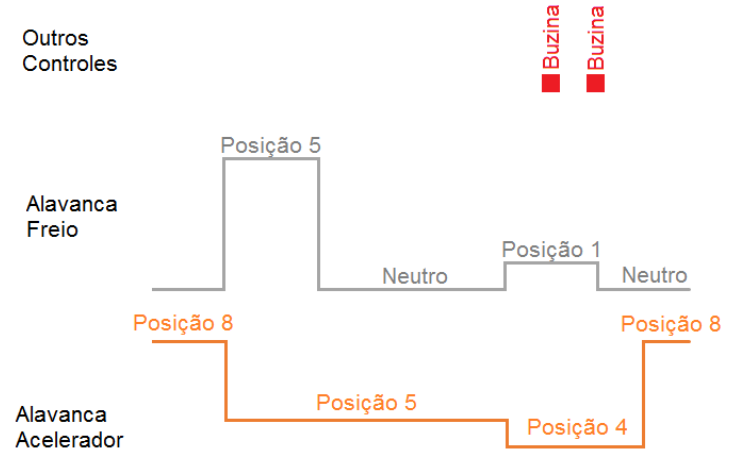

Alavanc Reversora $\begin{array}{llllllllllll}2.25 & 2.5 & 2.75 & 3 & 3.25 & 3.5 & 3.75 & 4 & 4.25 & 4.5 & 4.75 & 5\end{array}$ Distância $(\mathrm{km})$

Fonte: Autores, 2018. 


\section{4 - Gamificação}

A partir da revisão de literatura foram identificadas algumas técnicas de gamificação e incorporadas no sistema:

- Pontuação referente aos acertos do usuário e ponderadas de acordo com o nível do treinamento;

- Vida do usuário referente ao número máximo de erros que podem ser cometidos;

- $\quad$ Níveis de dificuldades de execução do treinamento;

- Menu principal com entrada para o nome do usuário, nível de fase e escolha do tipo de treinamento;

- Assistência na execução das ações através do tutor de treinamento;

- Apresentação dos pontos obtidos no final do treinamento e ranking dos dois tipos de treinamento.

A Figura 3 mostra o menu principal, sendo uma tela inicial ou de apresentação do jogo, e outra com a entrada dos dados pelo usuário. A tela de entrada de dados é acessada quando o usuário clica na opção "Treinamentos". A tela de "Controle de som" já foi desenvolvida para ser utilizada no futuro.

Figura 3 - Menu principal de apresentação do jogo (esquerda) e de entrada de dados do usuário (direita).

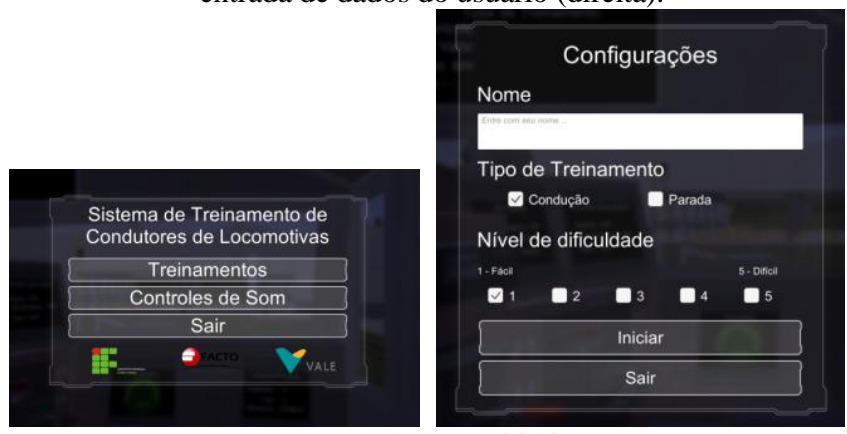

Fonte: Autores, 2018.

A tela com os resultados do usuário após a realização do treinamento e o ranking geral dos treinamentos de condução e de parada são mostradas na Figura 4 e Figura 5, respectivamente.

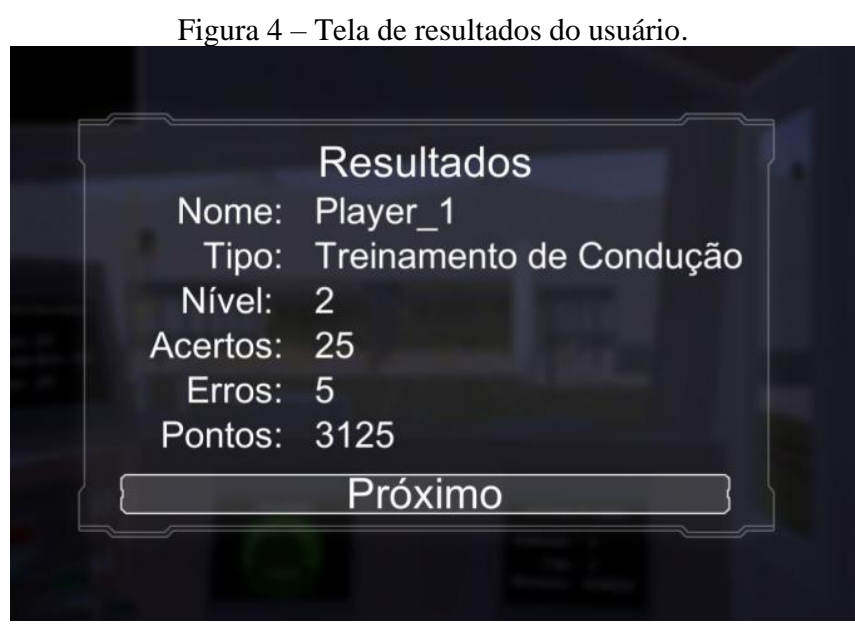

Fonte: Autores, 2018.

Todas as telas de menu de interação com o usuário do sistema podem ser manipuladas através dos comandos do teclado, pelas setas, ou através do mouse do computador.

A imagem do sistema durante a execução de um treinamento é mostrada na Figura 6.

\section{$3.5-$ Controles}

Os controles principais da locomotiva no sistema de treinamento foram desenvolvidos baseados nas alavancas do Controlador Mestre, um dos equipamentos responsáveis para a condução do trem. O Controlador Mestre possui 3 alavancas: freio dinâmico, acelerador e reversora. No sistema foram configurados 8 níveis para o freio dinâmico e acelerador, além da posição de neutro. A alavanca reversora, responsável por comandar a direção da força de tração, foi configurada com 3 níveis: avanço, neutro e retorno.

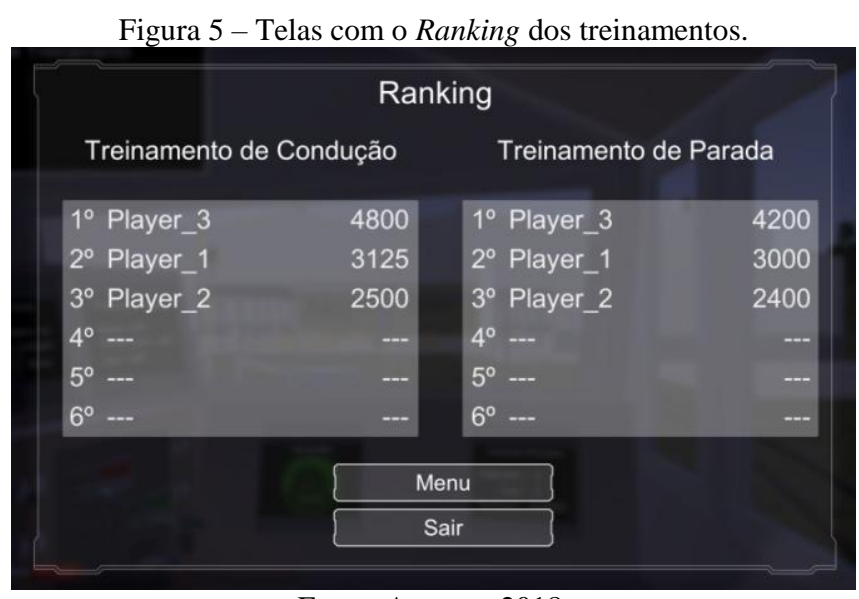

Fonte: Autores, 2018.

Figura 6 - Imagem vista pelo usuário durante um treinamento de condução.

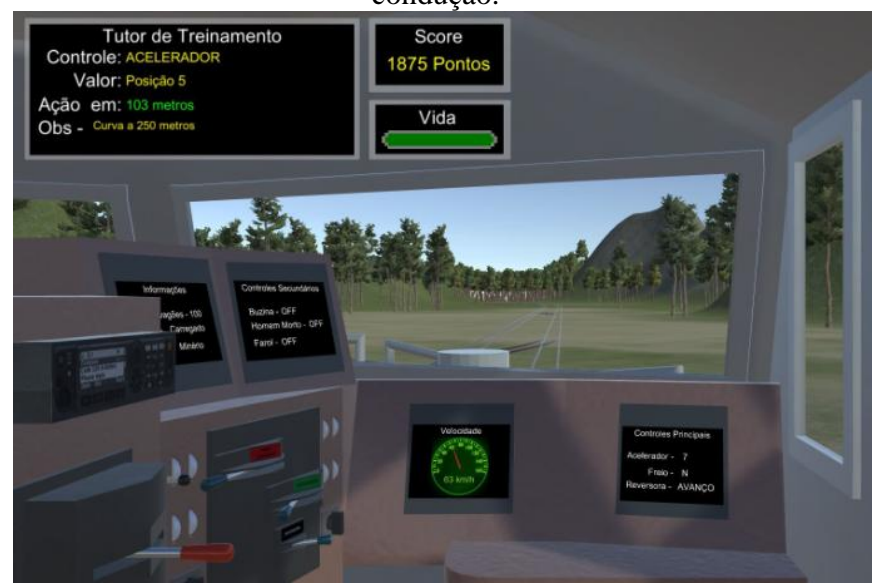

Fonte: Autores, 2018.

Esses controles e outros, como o acionamento da buzina e farol, foram configurados para serem utilizados com as teclas de um teclado comum para computador. Porém, todos os controles possuem seu modelo 3D associado ao modelo da cabine da locomotiva para futura aplicação com os óculos de RV e acionamento através de controles para as mãos.

\section{RESULTADOS}

Para demonstrar o sistema em operação foi realizado uma execução do treinamento de parada e uma execução do treinamento de condução.

A Figura 7 e a Figura 8, apresentam os gráficos com as comparações entre as execuções e os valores ideais de operação nos dois tipos de treinamento para um determinado trecho.

Pode ser observado na Figura 7 que o usuário executou todas as ações corretamente no treinamento de condução 
para a alavanca de freio e alavanca reversora. Porém, na alavanca do acelerador, o usuário deixou de efetuar a mudança da posição 8 para a posição $5 \mathrm{em}$ dois pontos. Esses 2 erros nesse trecho levaram ao usuário perder 2 vidas e deixar de somar pontos ao seu score referentes a essas ações.

Figura 7 - Comparação entre as ações do usuário e os valores ideais no treinamento de condução

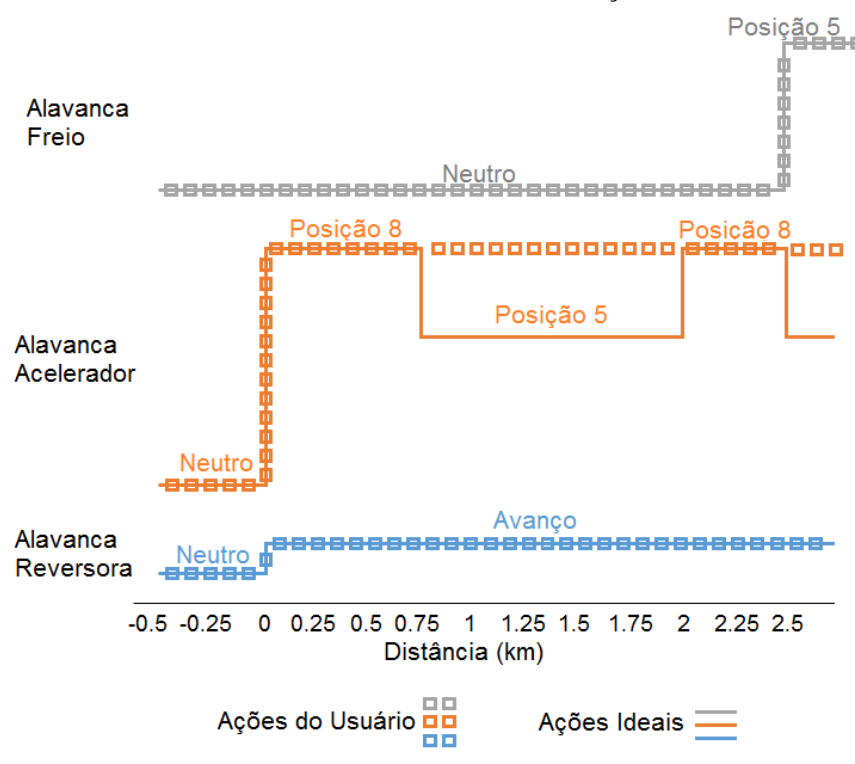

Fonte: Autores, 2018.

Figura 8 - Comparação entre as execuções e os valores ideais no treinamento de parada

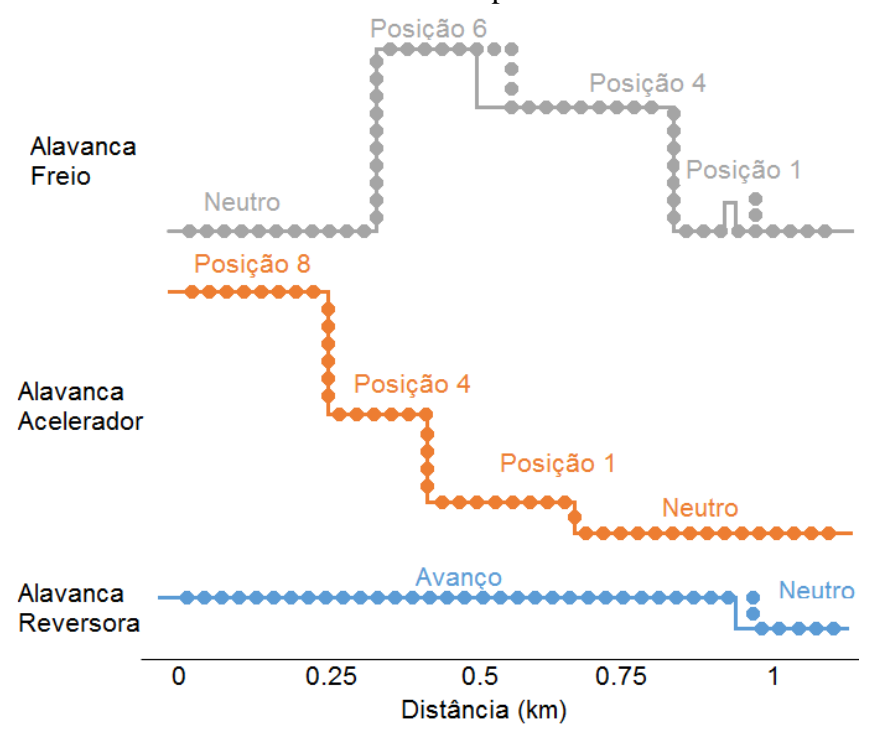

Ações do Usuário $\because \quad$ Ações Ideais

Fonte: Autores, 2018.

Na Figura 8, o usuário somente executou todas as ações corretas no treinamento de parada na alavanca do acelerador. Nas alavancas de freio e reversora, o usuário realizou as mudanças nos valores fora da posição ideal, o que acarretou num total de 4 erros cometidos e na parada da locomotiva a alguns metros à frente do local definido.

\section{CONCLUSÃO}

Em decorrência da busca por alternativas de treinamentos que necessitam de menores investimentos para serem executados, que possuam uma maior disponibilidade e capacidade de realizar repetições, o presente trabalho teve como objetivo descrever o desenvolvimento de um sistema computacional de Realidade Virtual aplicado no treinamento de condutores de locomotivas.

O sistema simula a condução de trens em ambientes ferroviários, dando a possibilidade ao usuário de escolher entre treinamento de parada em pátios de manutenção e treinamento de condução num trecho de linha férrea.

A utilização de técnicas de gamificação na construção do sistema gera a possibilidade de um maior engajamento dos usuários nos treinamentos apresentados. Isso ocorre com a introdução de conceitos, já presentes no ambiente de jogos, como o ranking dos usuários, assistente na realização de ações, contagem de pontos e vidas.

O sistema retorna ao usuário seu desempenho com a contabilização de acertos, erros e quantidade de pontos, que pode ser utilizado para mensurar o aprendizado do usuário após realizar várias execuções.

Como trabalhos futuros será aplicado um questionário, já desenvolvido e submetido ao comitê de ética e de pesquisa da instituição de ensino (CAAE 97105218.1.0000.5072), para realizar a avaliação qualitativa do sistema de treinamento. Ele é composto de 17 perguntas que serão respondidas por no mínimo 40 alunos da instituição após utilizarem o sistema. $\mathrm{O}$ foco desse questionário será mensurar o impacto da presença de objetos 3D na qualidade da simulação e desempenho dos usuários.

Para agregar mais ao sistema será incorporado sons referentes ao ambiente $\mathrm{e}$ as operações realizadas nos treinamentos. Também será desenvolvido a opção de condução em diferentes condições climáticas e horários do dia, como: chuva, neblina, condução de dia e de noite. Além disso, serão inseridos novos modelos $3 \mathrm{D}$ de outras construções civis presentes nesse ambiente ferroviário.

Finalmente, será desenvolvido uma aplicação para ser utilizado em óculos de Realidade Virtual, onde a manipulação dos controles internos da cabine da locomotiva será realizada através dos controles para as mãos.

\section{REFERÊNCIAS BIBLIOGRÁFICAS}

BARBOSA R. S. et al. Sistemas de Realidade Virtual para Simulação de Equipamentos de Movimentação e Treinamento de Operadores. In: II Encontro de Ferrovias, ANTF, 2010.

BARBOSA R. S. et al. Sistema de Realidade Virtual de Simulação Multiusuários de Trens em Malha Ferroviária para Treinamento de Operadores. In: III Encontro de Ferrovias, ANTF, 2011.

DETERDING, S. et al. From game design elements to gamefulness: defining gamification. In: Proceedings of the 15th International Academic MindTrek Conference: Envisioning Future Media Environments. ACM, 2011, pp. 9-15.

DORRIAN, J. et al. Simulated train driving: Fatigue, selfawareness and cognitive disengagement. Applied Ergonomics, v. 38, n. 2, p. 155-166, 2007.

FARDO, M. L. A gamificação aplicada em ambientes de aprendizagem. RENOTE, vol. 11, jul. 2013. 
MICHAEL, D. R.; CHEN, S. L. Serious Games: Games That Educate, Train, and Inform. Education. Boston: Thomson Course Technology PTR, 2005.

MITRA, R.; HEBBLEWHITE, B.; SAYDAM, S. Improving Mine Safety and Mining Education through use of virtual reality. In: 36th International Conference of Safety in Mines Research Institute, 2015.

NAWEED, A.; HOCKEY, G. R. J.; CLARKE, S. D. Designing simulator tools for rail research: the case study of a train driving microworld. Applied ergonomics, v. 44, n. 3, p. 445-454, 2013.

PINHEIRO, E. B. et al. Requirements for Development of a Low Cost Portable Simulator for Shooting Skill Training. In: Virtual and Augmented Reality (SVR), 2016 XVIII Symposium on. IEEE, 2016. p. 234-238.

SILVA, P. P. et al. Fluxo de trabalho para otimização de modelos 3D para desenvolvimento de jogos. In: Virtual and Augmented Reality (SVR), 2018 XX Symposium on. IEEE, 2016. p. 234-238.

SOUSA, M. P. A. et al. Maintenance and operation of a hydroelectric unit of energy in a power system using virtual reality. International Journal of Electrical Power \& Energy Systems, v. 32, n. 6, p. 599-606, jul. 2010.

TICHON, J. G. The use of expert knowledge in the development of simulations for train driver training. Cognition, Technology \& Work, v. 9, n. 4, p. 177-187, 2007.

\section{AGRADECIMENTOS}

Agradecemos o apoio financeiro recebido através do convênio Ifes/FACTO/Vale dentro do projeto "Plano de pesquisa e capacitação em Operação e Manutenção Logística", código Ifes de número PJ00003647 e processo FACTO de número 4600037859 com Vale ITV.

\section{COPYRIGHT}

Direitos autorais: Os autores são os únicos responsáveis pelo material incluído no artigo. 


\title{
EM BUSCA DA SUSTENTABILIDADE: CÉLULA SOLAR PRODUZIDA COM CORANTE EXTRAÍDO DA MORUS NIGRA
}

\section{IN PURSUIT OF SUSTAINABILITY: SOLAR CELL PRODUCED WITH DYE EXTRACTED FROM MORUS NIGRA}

\author{
JULIANNO PIZZANO AYOUB ${ }^{1}$; GIDEÃ TAQUES TRACTZ ${ }^{1}$; EVERSON P. BANCZEK ${ }^{1}$; PAULO R. P. \\ RODRIGUES $^{1}$
}

\section{1 - UNIVERSIDADE ESTADUAL DO CENTRO OESTE.}

\begin{abstract}
juliannopa@hotmail.com; gide.tractz@hotmail.com; edopradobanczek@yahoo.com.br; prprodrigues@gmail.com
\end{abstract}

\begin{abstract}
RESUMO - Energia solar é uma alternativa para reduzir a emissão de gases poluentes. Corantes naturais, podem ser aplicados em células solares sensibilizadas por corante (CSSC) para a redução de custos. Este trabalho tem como objetivo caracterizar uma célula solar de $\mathrm{TiO}_{2}$ sensibilizada com o corante extraído da amora, rica em antocianinas. As técnicas de caracterização empregadas são: Espectroscopia no UV-VIS, medidas do potencial de circuito aberto em função do tempo $\left(E_{c a}\right)$, medidas de fotocronoamperometria (j-t) e curvas de densidade de corrente em função do potencial (j-E).
\end{abstract}

Palavras-chave: Energia renovável. Corante natural. CSSC.

\begin{abstract}
Solar energy is an alternative to reduce the emission of polluting gases. Natural dyes can be applied to dyesensitized solar cells (DSSC) to reduce costs. This work aims to characterize a solar cell of TiO2 sensitized with the dye extracted from the blackberry, rich in anthocyanins. The characterization techniques used are: UV-VIS spectroscopy, open-circuit potential as a function of time (Voc), photocronoamperometry (j-t) and measurements and current density curves as a function of potential $(j-V)$.
\end{abstract}

Keywords: Renewable energy. Natural dye. DSSC.

\section{INTRODUÇÃO}

Em busca da sustentabilidade, novas metodologias energéticas surgem, frente como forma alternativa, para a redução da emissão de gases poluentes e também para suprir a demanda mundial. Dentre essas, pode-se citar a energia solar [1].

A célula fotovoltaica, é a responsável por captar a energia solar e transformar esta em corrente elétrica e, dentre as várias classes de sistemas sendo desenvolvidos e produzidos, as células de terceira geração são aquelas definidas teoricamente como as capazes de ultrapassarem o limite de Shockley Queisser [2].

Sua produção baseia-se no uso de um óxido semicondutor nanocristalino em tamanho nanométrico, sensibilizada por um corante, sendo este último impregnado na superfície do óxido. Quando a luz solar incide no dispositivo, elétrons do corante são ejetados para a banda de

Anais do XL International Sodebras Congress condução do semicondutor, gerando assim um fluxo de elétrons e consequentemente uma corrente elétrica [3].

Figura 1. Esquema de montagem da célula solar em formato sanduíche.

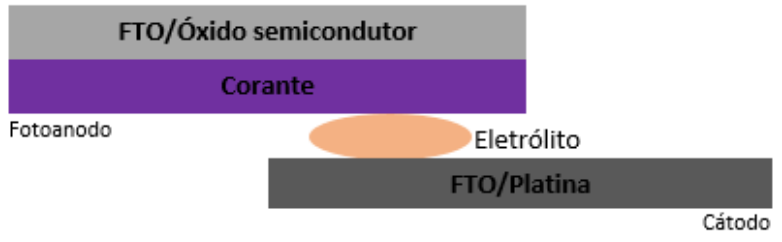

Fonte: O autor (2018)

Os corantes mais utilizados hoje, são os derivados de rutênio, que como demonstrado por Hangfeldt e colaboradores (2010), são capazes de absorverem em um amplo espectro eletromagnético [4]. Apesar de apresentarem características bastante promissoras, seu custo é bastante elevado, o que acarreta na pesquisa por novos fotosensibilizadores, dentre esses, os produtos naturais.

Este trabalho tem como objetivo produzir e caracterizar uma célula solar de $\mathrm{TiO}_{2}$ com corante extraído da amora.

\section{METODOLOGIA}

Óxido de titânio $\left(\mathrm{TiO}_{2}\right)$ em morfologia anátase foi utilizado como óxido semicondutor, e como fotossensibilizante, o corante extraído da amora (Morus Nigra) em solução etanoica acidificada com ácido cítrico $(3 \% \mathrm{~m} / \mathrm{m})$ durante 24 horas à $5{ }^{\circ} \mathrm{C}$. $\mathrm{O}$ anodo de $\mathrm{TiO}_{2}$ foi produzida com FTO (óxido de estanho dopado com flúor) através da metodologia descrita por Tractz e colaboradores (2018), e a impregnação do corante foi realizada pela submersão do FTO na devida solução por 24 horas [5]. Platina eletrodepositada foi utilizada como cátodo e o par redox de triiodeto como intermediador de cargas [5]. A célula foi montada em formato sanduíche do fotoanodo e do cátodo como representado na Figura 1, com área ativa de 0,2 $\mathrm{cm}^{2}$ e com intermediador de cargas contendo par redox $\mathrm{I}^{-} / \mathrm{I}_{3}{ }^{-}$. 
As verificação da faixa de absorção no espectro eletromagnético foi realizada por espectroscopia no UVVIS, em um espectrofotômetro UV-VIS 320G Gehaka, com feixe duplo a $25^{\circ} \mathrm{C}$, numa faixa de varredura de $400 \mathrm{~nm}$ a $700 \mathrm{~nm}$. As medidas eletroquímicas da célula produzida foram realizadas em um potenciostato Zhenium Zahner®, com sistema de simulação solar Lot Oriel LS0106 controlado por um potenciostato auxiliar Xpot, com lâmpada de Xenônio e intensidade solar de $100 \mathrm{~mW} \mathrm{~cm}{ }^{-2}$, com espectro padrão de AM 1.5G [6].

\section{RESULTADOS E DISCUSSÃO}

A região de absorção no espectro eletromagnético do corante extraído é mostrado na Figura 2.

Figura 2. Espectro UV-VIS para o corante da amora extraído em solução etanoica acidificada com ácido cítrico.

1

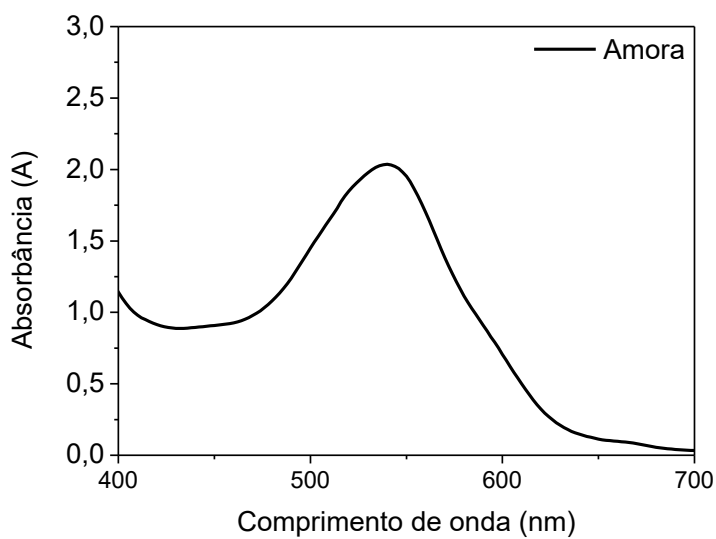

Na Figura 2 nota-se que o corante extraído da amora, apresenta uma maior absorção na faixa dos $550 \mathrm{~nm}$ característica das antocianinas presentes [5].

Os corantes derivados de produtos naturais, quando comparado a corantes sintéticos, possuem menor eficiência, porém, sua disponibilidade, simplicidade no preparo, e custo relativamente baixo tornam o uso de corantes naturais, viável [7].

Observa-se também, que há a limitação de absorção na região do visível para este sistema, diferente de como ocorre quando há o uso de corantes com base em rutênio, que atingem a região do infra vermelho e consequentemente geram células mais eficientes [8].

Outras metodologias de extração, capazes de gerar espécies ativas em maiores concentrações e deslocarem a faixa do comprimento de onda, não foram utilizadas $[5,8]$.

Para verificar o potencial da célula produzida foi utilizada a técnica do potencial de circuito aberto, onde a corrente é nula, e a iluminação constante como mostra a Figura 3.
Figura 3. Potencial de circuito aberto em relação ao tempo para o sistemaanalisado.

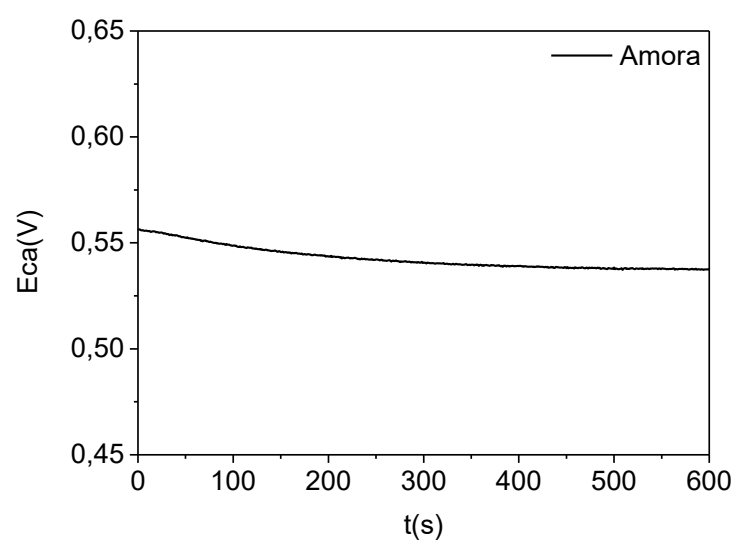

$\mathrm{Na}$ Figura 3 percebe-se que o sistema apresenta pequena variação até que a temperatura se estabilize, devido a incidência luminosa, permanecendo próximo a $550 \mathrm{mV}$, sendo encontrado valor semelhante na literatura para células de $\mathrm{TiO}_{2}$ com corantes naturais [9] [10].

O potencial do sistema é utilizado para verificação dos efeitos de recombinação de cargas que ocorrem no sistema, e como células solares de Gratzel, que foram as primeiras a serem desenvolvidas, e ainda são a base dos dispositivos com maior eficiência apresentam um potencial maior $(700 \mathrm{mV})$, quando comparada a célula aqui desenvolvida, sugere-se que o sistema aqui produzido, possui efeitos de recombinação mais pronunciáveis [11].

$\mathrm{Na}$ Figura 4, encontra-se a fotocronomperometria para a célula produzida.

Figura 4. Fotocronoamperometria para o sistema analisado sob iluminação de $1000 \mathrm{Wcm} 2$

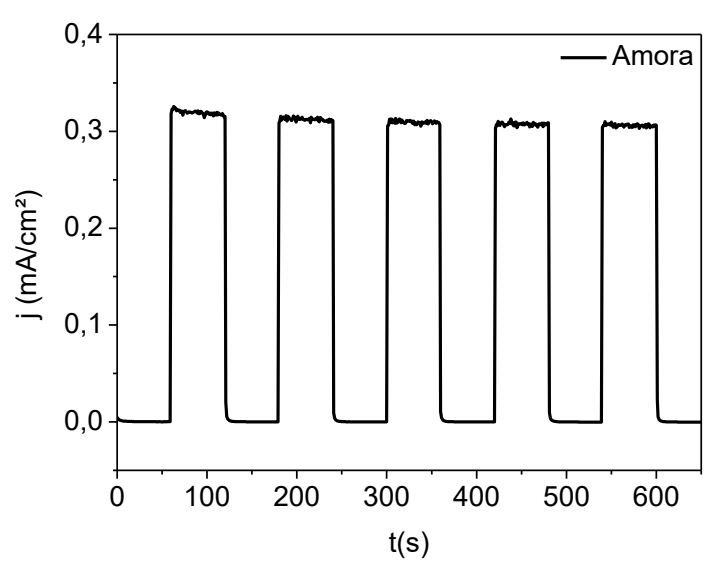

A célula produzida foi fotossensível, pois com inserção de luz no dispositivo houve um aumento instantâneo da corrente $\left(\mathrm{j}=0,32 \mathrm{~mA} \mathrm{~cm} \mathrm{~cm}^{-2}\right.$ e quando a lâmpada foi desligada a corrente produzida foi nula. Verifica-se também um ótimo carregamento/descarregamento do dispositivo, com a inserção/interrupção da luz, comprovando que célula produzida apresenta a altas velocidades de resposta na presença de luz [5].

Como demonstrado no Trabalho de Tractz e colaboradores (2018), o $\mathrm{TiO}_{2}$ apresenta um jcc próximo a $0,13 \mathrm{~mA} \mathrm{~cm}$, sendo possível calcular o fator de 
recobrimento ( $\Theta$ ), também chamada de eficiência fotocronoamperométrica, empregando-se a Equação 1 [8].

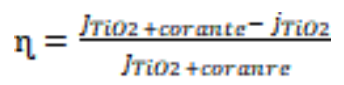

Em que, $\mathrm{j}_{\mathrm{TiO} 2}$ representa a fotocorrente do semicondutor e $\mathrm{j}_{\mathrm{TiO} 2+c o r a n t e}$ representa a fotocorrente do sistema sensibilizado.

Empregando-se a equação 1, adquire-se um valor $0,59 \%$, menor quando comparado a sistemas com antocianinas em maiores quantidades, mas também maior para alguns corantes, como exemplo o urucum [8].

Na Figura 5 seguir encontra-se a curva de densidade de corrente em função do potencial, fornecendo os parâmetros para cálculo da eficiência em conversão energética, utilizando-se da Equação 2 [4].

$$
\eta=\frac{J_{\text {cr } F F E} E_{\text {can }}}{P_{\text {in }}}
$$

Em que, $j_{c c}$ equivale a corrente de curto circuito, FF o fator de preenchimento, $\mathrm{E}_{\mathrm{ca}} \mathrm{o}$ potencial de circuito aberto e $\mathrm{P}_{\text {in }}$ a potência incidente.

Figura 5. Curva de fotocorrente em função do potencial para o sistema analisado e na tabela 1 , os parâmetros fotoeletroquímicos obtidos.

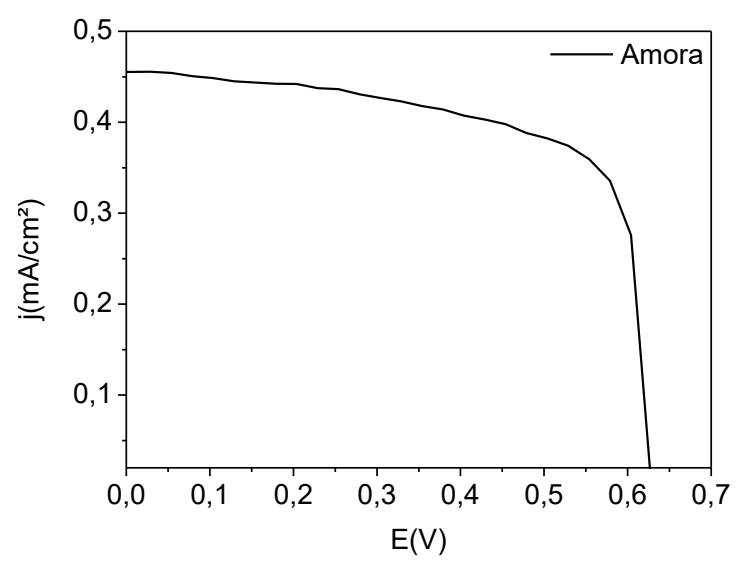

Tabela 1. Parâmetros fotoeletroquímicos para a célula de $\mathrm{TiO}_{2}+$ corante da amora.

\begin{tabular}{llllll}
\hline Corante & $\begin{array}{l}\mathbf{j}_{\mathbf{c c}} \\
\left.\mathbf{c m}^{-2}\right)\end{array}$ & $(\mathbf{m A}$ & $\mathbf{F F}$ & $\mathbf{E}_{\mathbf{c a}}(\mathbf{V})$ & $\mathbf{\eta}(\mathbf{\%})$ \\
Amora & $0,391 \pm 0,09$ & $0,634 \pm 0,08$ & $0,587 \pm 0,06$ & $0,150 \pm 0,07$ \\
\hline
\end{tabular}

Observa-se na Tabela 1, que o sistema apresentou uma

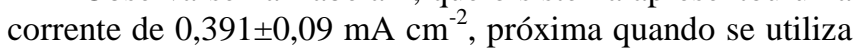
corantes naturais para a fabricação destes sistemas. Com relação ao corante N719 (Di- tetrabutilamônio cis-bis (isotiocianato) bis (2,2'-bipiridil-4,4' dicarboxilato) rutênio (II)) [4][11], com base em rutênio, apresenta uma densidade de corrente inferior, sendo devido à ausência de grupos auxocromos e cromóforos, como SCN, COOH, COOTBA (tetrabutilamônio), entre outros [4]. Estes grupos presentes nos corantes comerciais, além de absorverem energia na região do infravermelho, se ancoram com facilidade em uma angulação adequada na superfície do $\mathrm{TiO}_{2}$, gerando células com altas correntes [12] [13].
O fator de preenchimento encontrado para o dispositivo foi promissor, equivalente a 0,634 , e próximo ao relatado com o uso do corante N719 [11].

O potencial para a célula com corante, se estabilizou próximo a $0,587 \mathrm{~V}$, gerando uma célula com eficiência de $\eta=0,150 \%$. Essa eficiência encontrada, se aproxima do uso de corantes naturais, e seu valor está relacionado a absorção dos raios solares, pois como visto na Figura 1, a célula tem uma eficiência limitada devido a região de absorção no espectro [14].

Apesar das células apresentarem uma eficiência baixa, na literatura raramente são evidenciados sistemas com $\eta \geq 1 \%$ para corantes naturais, mostrando que a célula aqui produzida se aproxima dos valores literários encontrados $[9,12]$.

\section{CONCLUSÕES}

A disponibilidade de produtos naturais, simplicidade no preparo, e custo relativamente baixo, torna viável o uso de corantes naturais para fabricação de células solares sensibilizadas por corante. O dispositivo foi fotossensível, com um excelente tempo de carga/descarga, apresentando uma fotocorrente próxima de $\mathrm{j}=0,32 \mathrm{~mA} \mathrm{~cm}^{-2}$.

\section{AGRADECIMENTOS}

O presente trabalho foi realizado com o apoio da coordenação de aperfeiçoamento de pessoal de nível superior-Brasil (Capes) código de financiamento 001. Os autores agradecem a FAU/UNICENTRO pelo apoio financeiro, e também ao CNPq, FINEP, Fundação Araucária e SETI/UGF.

\section{REFERÊNCIAS BIBLIOGRÁFICAS}

[1] PAURUSSUlO, A. L. A. Conceitos supramoleculares e morfologia interfacial em células solares de $\mathrm{TiO}_{2}$. Tese de Doutorado, São Paulo, 2013.

[2] GRATZEL, M. Dye sensitized solar cells. Journal of photochemistry and photobiology C: Photochemistry Reviews. V. 4, Jul./2003, pg 145-153

[3] GRATZEL, M. Photoelectrochemical Cells. Nature, V. 414, p. 338-345, 2001.

[4] HAGFELDT, A; BOSCHLOO, G; SUN, L; KLOO, L; PETTERSON, Henrike. Dye Sensitized solar cells. Chemistry reviews. V. 110, 2010, pg 6595-6663.

[5] TRACTZ, G. T.; MAIA, G. A. R.; DIAS, B. V.; IGNACHEWSKI, F.; Rodrigues, P.R.P.; Avaliação da adsorção e estudo eletroquímico de células solares sensibilizadas com corante do Hibisco. Química Nova, v.41, pg. 512-518, 2018.

[6] TRACTZ, G. T.; MAIA, G. A .R.; DIAS, B. V.; BANCZEK, E. P.; CUNHA. M. T.; RODRIGUES, P. R. P. Estudo de células solares híbridas de $\mathrm{TiO} 2$ com corantes naturais. Revista Virtual de Química. 2018, 10, 4, pg. 1074-1086.

[7] PATROCÍNIO, A. O. T; ILHA, N. Y. M., "Em busca da sustentabilidade: Células solares sensibilizadas por extratps 
natuais", Química Nova, v.33, n.03, pp. 574-578, Fev. 2010.

[8] TRACTZ, G. T.; MAIA, G. A .R.; DIAS, B. V.; BANCZEK, E. P.; CUNHA. M. T.; RODRIGUES, P. R. P. Estudo de células solares híbridas de $\mathrm{TiO} 2$ com corantes naturais. Revista Virtual de Química. 2018, 10, 4, pg. 1074-1086.

[9] KUMARA, N.T. R. N; LIM, A; LIM, C. M; PETRA, M. I; EKANAYAKE, Piyasiri. Recent progress and utilization of natural pigments in dye sensitized solar cells. A review. Renewable and sustainable energy reviews. V, 78, 207, pg 301-317.

[10] Tractz, G.T.; VIOMAR, A.; MATHEUS, A. P. C.; MAIA, G. A. R.; BANCZEK, E.; CUNHA, M. T.; RODRIGUES, P. R. P. Produção de célula solar com corante natural extraído da Acacia Decurrens. Sodebras. V.13,Mar/ 2018.

[11] VIOMAR, A; MAIA, G. A. R; SCREMIN, F. R; KHALIL, N. M; CUNHA, M. T; ANTUNES, A. C; RODRIGUES, P. R. P. Influencia do método de obtenção de partículas de $\mathrm{Nb} 2 \mathrm{O} 5$ empregadas em células solares sensibilizadas por corante composta de $\mathrm{TiO}_{2} / \mathrm{Nb} 2 \mathrm{O} 5$. Revista Virtual de Química, v. 8, 2016, pg 889-900.

[12] WONGCHAREE, K; MEEYOO, V; CHAVADEJ, S. Dye sensitized solar cell using natural dye extracted from rosella and blue pea flowers. Solar energy materials and solar cells. V.91, Jan./2007, pg 566-571.

[13] ALWANI, M. A. M; MOHAMAD, A. B; LUDIN, N. A; KHADUN, A. A. H; SOPIAN, K. Dye sensitized solar cells: Development, structure, operation principles, electron kinects, characterization, synthesis materials and natural photosensitizers. Renewable and sustainable energy reviews. V, 65, 2016, pg 183-213.

[14] Hamadaian, M; Ghomi, J. S; Hosseinpour, M; Masoomi, R; Jabbaru, V. Uses of new natural dye photosensitizers in fabrication of high potential dye sensitized solar cells (DSSCs). Materials science in semiconductor processing, v.27, p. 733-739, 2014.

\section{COPYRIGHT}

Direitos autorais: Os autores são os únicos responsáveis pelo material incluído no artigo. 


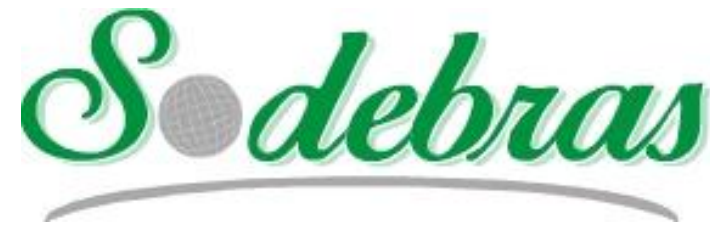

Volume $14-\mathrm{N}^{\mathrm{o}} 159$ - Março/2019. XL International Sodebras Congress

10 a 12 de dezembro de 2018 - Vitória - ES.

\title{
AVALIAÇÃO DO CONSERVADORISMO DO MÉTODO DE ANÁLISE TÉRMICA DO PRCI QUANTO AO RISCO DE PERFURAÇAO NO REPARO COM SOLDAGEM EM OPERAÇAO DE OLEODUTO COM BAIXA ESPESSURA
}

\author{
EVALUATION THE CONSERVATIVENESS OF PRCI'S THERMAL ANALYSIS \\ METHOD REGARDING THE BURN-THROUGH RISK DURING IN-SERVICE \\ WELDING REPAIRS OF LOW THICKNESS OIL PIPELINE
}

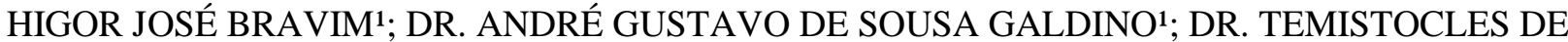 \\ SOUSA LUZ ${ }^{2}$ \\ 1 - INSTITUTO FEDERAL DE ENSINO, CIÊNCIA E TECNOLOGIA DO ESPÍRITO SANTO, \\ PROGRAMA DE PÓS-GRADUAÇÃO EM ENGENHARIA METALÚRGICA E DE MATERIAIS- \\ VITÓRIA, ES, BRASIL; 2 - UNIVERSIDADE FEDERAL DO ESPÍRITO SANTO, DEPARTAMENTO DE \\ ENGENHARIA MECÂNICA-VITÓRIA, ES, BRASIL;
}

higor.bravim@hotmail.com; andreg28@gmail.com; t.luz@ct.ufes.br

\begin{abstract}
Resumo - O objetivo deste trabalho foi avaliar o grau de conservadorismo do método de análise térmica do PRCI, criado pelo EWI, na avaliação do risco de ocorrência do fenômeno de perfuração. Para o experimento, foi construída uma bancada de testes para simular 6 condições de soldagem em operação distintas, onde se variou a espessura do tubo e a velocidade de soldagem. Foram realizadas soldagens na direção longitudinal sobre tubos contendo água como fluido interno, utilizando-se o processo automático MIG/MAG (GMAW) com o modo de transferência metálica em curto circuito com posterior avaliação do risco de perfuração pelo modelo de análise térmica do PRCI e pelo modelo de abordagem experimental. Os resultados corroboraram com estudos existentes, mostrando que a avaliação do risco de perfuração, em soldagem em operação, pelo método de análise térmica do PRCI é realmente conservadora.
\end{abstract}

Palavras-chave: Soldagem em operação 1. Perfuração 2. Análise Térmica PRCI 3.

Abstract - The objective of the present work was to evaluate the degree of conservativeness of the PRCI's thermal analysis method, created by the EWI, to evaluate the burn-through phenomenon risk of occurrence. For the experiment, a test bench was constructed to simulate 6 different in-service welding conditions, where the tube thickness and the welding speed were varied. All welds were carried out in the longitudinal direction of tubes containing water as internal fluid, using the automatic MIG / MAG (GMAW) weld process with metallic transfer mode in short circuit with subsequent evaluation of the burn-through risk by the PRCI's thermal analysis model and by the experimental approach model. The results corroborated with the existing studies showing that the evaluation of the burn-through risk during in-service welding repairs of pipeline systems using the PRCI's thermal analysis method is indeed conservative.

Keywords: In-service welding 1. Burn-through 2. PRCI's Thermal Analysis 3.

\section{INTRODUÇÃO}

Entre os meios de condução utilizados na movimentação de petróleo e derivados, os dutos tornaram-se o preferencial. Essa preferência é explicada por ser o meio mais econômico de conduzir óleo e gás. Contudo, a economia só se justifica se o transporte por dutos for realizado com confiabilidade e segurança operacional, evitando prejuízos econômicos e, principalmente, ambientais. Por meio deles interligam-se as fontes de extração, terminais de armazenamento, refinarias e centros de consumo (FREIRE, 2009).

Os tubos mais utilizados em malhas dutoviárias responsáveis pelo transporte de petróleo e seus derivados são os da especificação API 5L (API, 2012). Além de serem aceitos pela principal norma de projeto de oleodutos, ASME B31.4 (ASME, 2006), sua aplicação é vantajosa por possuir elevada resistência mecânica, quando comparada aos tubos de outros materiais. Essa elevada resistência mecânica proporciona o uso de tubos de menor espessura, que torna, na grande maioria das vezes, o projeto final de uma malha de oleoduto mais econômico, em comparação ao mesmo projeto com o uso de outros tubos.

A extensa malha de dutos existente em território nacional é composta, em parte, de plantas com mais de 40 anos de operação, que necessitam de constantes reparos. Um dos reparos mais comuns é a reconstituição da resistência de tubos com perda de espessura localizada, gerada principalmente por corrosão externa.

É muito vantajoso, economicamente, que esse reparo seja realizado sem a interrupção do fluxo do produto, ou seja, com o duto em operação. Caso esse reparo seja possível, não haveria perdas com lucro cessante, nem o incômodo de purga do produto, inertização e selagem dos tubos, que elevariam os custos do serviço. 
Entre os reparos existentes, considerados permanentes, os mais utilizados são os com o uso da soldagem, são eles: o uso de dupla calha, o uso de chapa sobreposta e o reparo por deposição direta (PETROBRAS, 2014). Entre os citados, o Reparo por Deposição Direta possui algumas vantagens quando comparada aos demais. Em seções curvas ou em acessórios, onde a aplicação da dupla calha é dificultada ou impossível, sua aplicação tende a ser ainda mais justificável. Trata-se de um reparo de aplicação direta, não requerendo acessórios extras, como chapas ou calhas, apenas os consumíveis de soldagem. Sendo assim, um reparo mais barato, e por isso, mais atrativo (BRUCE; AMEND, 2009).

Quando se pretende soldar regiões do tubo com pequenas espessuras, a trinca a frio e a perfuração da parede do tubo pelo arco apresentam maior probabilidade de ocorrerem, exigindo cuidados maiores na especificação e no controle dos procedimentos e das condições de soldagem (API 1104, 2013) (PETROBRAS, 2016).

A perfuração ocorre quando a espessura de parede abaixo da poça de fusão não tem a resistência mecânica suficiente para conter a pressão interna do tubo. $\mathrm{O}$ aço, quando exposto a elevadas temperaturas, como as associadas ao fenômeno de soldagem, tem sua resistência mecânica muito reduzida, explicado assim a possibilidade de ocorrer a perfuração (BORING, 2012).

Ao longo dos anos, os métodos para avaliação dos riscos de perfuração foram evoluindo. O primeiro método utilizado para a avaliação da perfuração foi o de abordagem experimental, o qual baseia-se na avaliação da seção transversal da solda, a qual é dada como insegura se a região de grãos grosseiros da zona termicamente afetada propagar para a superfície interna do tubo ou se ocorrer uma protuberância nessa mesma superfície (BORING, 2012). Posteriormente com o desenvolvimento dos computadores, os modelos de análise térmica e termomecânicos foram criados.

$\mathrm{Na}$ indústria, pela rápida resposta computacional quando comparada ao modelo termomecânico, o modelo mais utilizado para avaliar o risco de perfuração em cordão de solda por deposição direta é o PRCI Thermal Analysis Model for Hot-Tap Welding - V 4.2. Trata-se de um modelo de análise térmica, criado pelo Edison Welding Institute (EWI), que usa uma solução numérica em duas dimensões (2D) para resolver a equação de transferência de calor para prever a temperatura na superfície interna do tubo abaixo da região do cordão de solda. Os dados de entrada para análise são: dados do material (composição química), dados geométricos (diâmetro, tipo da junta), dados operacionais (tipo, vazão, pressão manométrica, temperatura do fluido e temperatura ambiente) e dados da soldagem (tensão, corrente e rendimento térmico ou energia de soldagem e rendimento térmico) (BRUCE; CITTERBERG, 2002).

$\mathrm{O}$ critério que define os parâmetros seguros quanto ao risco de perfuração são os que produzem uma temperatura de superfície interna do tubo, abaixo do cordão de solda, menor que um certo limite. Usando eletrodo de baixo hidrogênio, a temperatura limite da superfície interna para o qual a solda é considerada segura é $1800^{\circ} \mathrm{F}\left(982^{\circ} \mathrm{C}\right)$ e quando usando eletrodo celulósico o limite é $1400^{\circ} \mathrm{F}\left(760^{\circ}\right.$ C). Esses limites foram baseados em uma série de experimentos, no qual observou-se que a perfuração tendia a ocorrer quando a temperatura da superfície interna excedia o valor de $1260^{\circ} \mathrm{C}$ (BORING; ZHANG; BRUCE, 2008).
A diferença de temperatura de $278^{\circ} \mathrm{C}$, para eletrodo de baixo hidrogênio, foi introduzida como uma margem de segurança (BRUCE; AMEND, 2009).

Os modelos de análise térmica têm previsto parâmetros de soldagem seguros, porém os resultados tende a ser excessivamente conservativos para aplicações em tubos de baixas espessuras, conforme apresentado em Boring e Bruce (2008).

A proposta do presente trabalho é avaliar o grau de conservadorismo do método de análise térmica criado pelo PRCI, na avaliação do risco de ocorrência do fenômeno de perfuração, o qual já foi citado em Boring, Zhang e Bruce (2008).

Não há dúvidas, que é preciso aprofundar as pesquisas em soldagem em operação, que permitam a aplicação de modo seguro e otimizado, em tubos com paredes cada vez mais finas, justificado pela crescente aplicação de materiais de alta resistência e da perda de espessura de dutos com longas campanhas de operação. É nesse contexto que o presente trabalho se insere e se justifica.

\section{METODOLOGIA}

Neste trabalho realizou-se 6 deposições de soldas num tubo de 6" com especificação API 5L Gr. B PLS 2, em faixas de espessuras e velocidades de soldagem diferentes, tendo todas as demais variáveis pertinentes como fixas, conforme figura 1.

Figura 1 - Parâmetros fixos e variáveis da soldagem em operação.

\section{SOLDAGEM EM OPERAÇÃO}

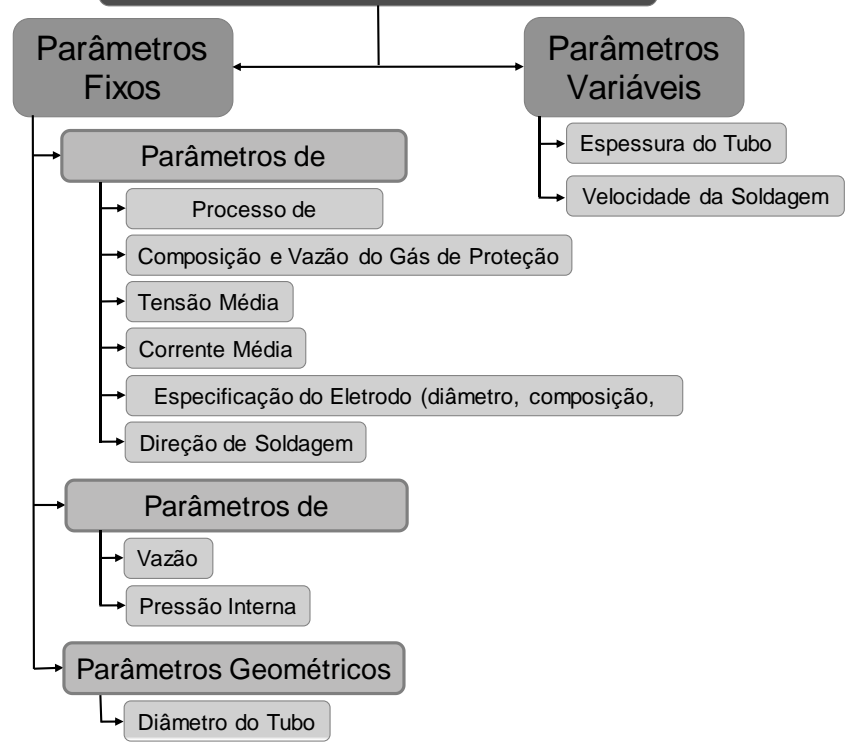

Fonte: Autores.

Programou-se estudar as espessuras respeitando os seguintes limites: máximo de 6,3 mm e mínimo de 3,2 mm. O motivo da adoção do limite máximo é que a tecnologia existente e a experiência na soldagem em operação estão relacionadas principalmente com o reparo de tubos de parede espessa (acima de 6,3 $\mathrm{mm}$ ) e além disso, o risco de perfuração para soldas executadas acima dessa espessura tem um risco muito baixo de perfurar, quando adotado um procedimento qualificado de soldagem. $\mathrm{O}$ motivo da adoção do limite mínimo é que muitas indústrias proíbem a execução de soldagem em operação abaixo dessa espessura, inclusive as empresas do sistema Petrobras (PETROBRAS, 
2016), por considerarem um processo de alto risco. Logo, adotou-se variar as espessuras na seguinte progressão, de $3,2,4,0$ e $4,8 \mathrm{~mm}$. Contudo as espessuras reais verificadas no local de onde executou-se a soldagem foram de 3,2, 4,0, 5,0 e 5,3 mm, já que as mesmas foram obtidas por meio do rebaixamento por usinagem de tubos com espessura original de 7,1 mm, sendo esse o motivo dessa divergência. Usou-se as velocidades de soldagem de 15 e $20 \mathrm{~cm} / \mathrm{min}$ com a justificativa de ser os extremos praticados em soldagens manuais em geral.

Dessa forma, as 6 condições de soldagem realizadas estão apresentadas na figura 2 .

Figura 2 - Condições de soldagem em operação executadas na bancada

CONDIÇŌES DE SOLDAGEM EM OPERAÇÃO

\begin{tabular}{|c|c|c|c|c|c|}
\hline$\downarrow$ & I & t & I & I & \\
\hline Condição 1 & Condição 2 & Condição 3 & Condição 4 & Condição 5 & Condição 6 \\
\hline $\begin{array}{c}\text { Espessura: } \\
3,2 \mathrm{~mm}\end{array}$ & $\rightarrow \begin{array}{c}\text { Espessura: } \\
3,2 \mathrm{~mm}\end{array}$ & $\rightarrow \begin{array}{c}\text { Espessura: } \\
4,0 \mathrm{~mm}\end{array}$ & - Espessura: & \begin{tabular}{|c} 
Espessura: \\
$5,0 \mathrm{~mm}$
\end{tabular} & - $\begin{array}{c}\text { Espessura: } \\
5,3 \mathrm{~mm}\end{array}$ \\
\hline $\begin{array}{c}\text { Velocidade } \\
\text { de } \\
\text { Soldagem: } \\
15 \mathrm{~cm} / \mathrm{min}\end{array}$ & $\rightarrow \begin{array}{l}\text { Velocidade } \\
\text { de } \\
\text { Soldagem: } \\
20 \mathrm{~cm} / \mathrm{min}\end{array}$ & $\rightarrow \begin{array}{c}\text { Velocidade } \\
\text { de } \\
\text { Soldagem: } \\
15 \mathrm{~cm} / \mathrm{min}\end{array}$ & $\rightarrow \begin{array}{l}\text { Velocidade } \\
\text { de } \\
\text { Soldagem: } \\
20 \mathrm{~cm} / \mathrm{min}\end{array}$ & $\begin{array}{l}\rightarrow \quad \begin{array}{l}\text { Velocidade } \\
\text { de } \\
\text { Soldagem: } \\
15 \mathrm{~cm} / \mathrm{min}\end{array}\end{array}$ & $\rightarrow \begin{array}{l}\text { Velocidade } \\
\text { de } \\
\text { Soldagem: } \\
20 \mathrm{~cm} / \mathrm{min}\end{array}$ \\
\hline
\end{tabular}

Fonte: Autores.

Foi criada uma bancada para simulação da soldagem em operação no laboratório de soldagem da UFES, conforme figura 3 , para que durante todo o processo de soldagem o fluxo contínuo de água a temperatura ambiente fosse mantido no interior do tubo, simulando um reparo com soldagem em operação.

Figura 3 - Bancada para simular soldagem em operação.

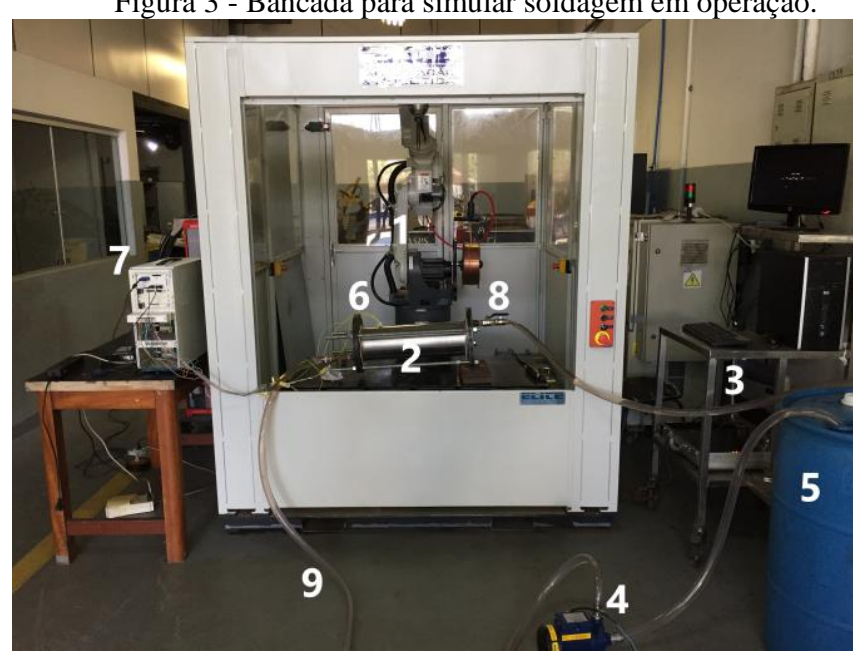

Fonte: Autores

Os componentes principais contidos na bancada criada para simular as 6 condições de soldagem em operação, enumerados na figura 3, são: robô de soldagem (1), tubo API 5L Gr. B PSL2 (2), sistema SAP para coletar os parâmetros de soldagem (3), bomba centrífuga (4), reservatório de água (5), termopares para coleta de temperatura (6), sistema LABVIEW utilizado para receber os dados de temperatura coletados pelo termopar (7), válvula de bloqueio (8) e tubos flexíveis (9). Convém citar que não se utilizou os componentes 6 e 7 neste estudo proposto.

Os parâmetros de soldagem e operacionais que se fixou no estudo estão apresentados nas tabelas 1 e 2, respectivamente.
Tabela 1 - Parâmetros de Soldagem fixos.

Processo de Soldagem GMAW - Curto-circuito / polaridade direta
Máquina de Soldagem
Panasonic - TM 1400WGIII

Robô de Soldagem

Composição do gás de proteção

Vazão do gás de proteção

Especificação do arame eletrodo

Velocidade do arame eletrodo

Stick Out

Direção de Soldagem

Tensão Média

Corrente Média

80\% Argônio - 20\% CO2

$15 \mathrm{~L} / \mathrm{min}$

AWS 5.18 - ER70S-6

(diâmetro de $1 \mathrm{~mm}$ )

$3,69 \mathrm{~m} / \mathrm{min}$

$15 \mathrm{~mm}$

Longitudinal

17,1 V (valor inserido na máquina de soldagem) 102 A (valor inserido na máquina de soldagem)

Fonte: Autores.

Tabela 2 - Parâmetros Operacionais Fixos.

\begin{tabular}{lc}
\hline \multicolumn{1}{c}{ Fluido } & Água \\
\hline Pressão do Fluido $\left(\mathrm{kg} / \mathrm{cm}^{2}\right)$ & 0,2 \\
Vazão do Fluido $(\mathrm{L} / \mathrm{s})$ & 0,5 \\
Velocidade de Escoamento do Fluido $(\mathrm{m} / \mathrm{s})$ & 0,001 \\
Número de Reynolds & 152 \\
Regime de Fluxo & Escoamento \\
& Laminar \\
\hline
\end{tabular}

Fonte: Autores.

Após realização de cada condição de soldagem, retirou-se um corpo de prova da seção transversal de cada região soldada, totalizando-se em 6 corpos de prova.

Nesses corpos de prova realizou-se as análises metalográficas (macrográficas e micrográficas) e medição de perfil de dureza. Além disso, retirou-se uma amostra do tubo para realização do ensaio de espectrometria óptica para obtenção da composição química do mesmo, que é um dado necessário para utilização do software de analise térmica do PRCI.

A macrografia foi realizada para identificar as regiões e extensão da ZTA, bem como a existência de descontinuidades internas. As amostras foram cortadas, lixadas, polidas e atacadas com solução de Nital 3\% por aproximadamente 20 segundos.

A micrografia óptica na microestrutura da ZTA teve a função de mostrar a evolução do tamanho de grão (crescimento e refino) após a soldagem em operação.

Foi realizado o perfil de microdureza com a carga de $0,2 \mathrm{kgf} / \mathrm{cm}^{2}$ (ASTM, 2017). Esse perfil foi medido ao logo da direção vertical, conforme figura 4, para contribuir na distinção entre as regiões presentes na ZTA, principalmente a de grão grosseiros. 
Figura 4 - Croqui do Perfil de Microdureza.

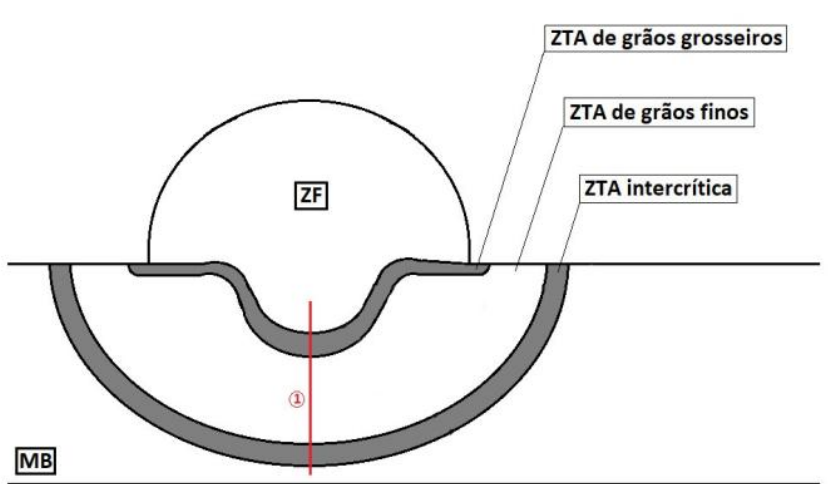

Fonte: Autores

\section{RESULTADOS}

Segue a apresentação dos resultados:

\section{1 - Resultados da Espectrometria óptica}

Segue, na tabela 3, a composição química do tubo, obtido por meio do ensaio de espectrometria óptica. Essa composição química está de acordo com os limites estabelecidos para enquadrar na especificação API 5L Gr. B PSL2.

Tabela 3 - Composição química do tubo.

\begin{tabular}{ccc}
\hline Elementos & Ensaio & $\begin{array}{c}\text { Norma API 5L Gr B } \\
\text { PSL2 }\end{array}$ \\
\hline $\mathrm{C}(\%)$ & 0,1971 & máx. 0,24 \\
$\mathrm{Si}(\%)$ & 0,2269 & máx. 0,40 \\
$\mathrm{Mn}(\%)$ & 0,4844 & máx. 1,20 \\
$\mathrm{P}(\%)$ & 0,0101 & máx. 0,025 \\
$\mathrm{S}(\%)$ & 0,0027 & máx. 0,015 \\
$\mathrm{Cr}(\%)$ & 0,041 & máx. 0,30\% \\
$\mathrm{Mo}(\%)$ & 0,0179 & máx. 0,15\% \\
$\mathrm{Ni}(\%)$ & 0,0077 & máx. 0,30\% \\
$\mathrm{Nb}(\%)$ & 0,0007 & $\mathrm{Nb}+\mathrm{V} \leq 0,06 \%$ \\
$\mathrm{~V}(\%)$ & 0,0002 & \\
$\mathrm{Ti}(\%)$ & 0,0003 & máx. 0,04 \\
$\mathrm{Cu}(\%)$ & 0,0035 & máx. 0,50\% \\
\hline
\end{tabular}

Fonte: Autores.

\section{2 - Corpos de Prova.}

Seguem, na figura 5, as seções transversais retiradas das diferentes condições de soldagem em operação, que deram origem aos corpos de prova. Para facilitar seu manuseio nos ensaios, os mesmos foram embutidos a quente. Para cada um estabeleceu-se uma numeração, para se ter a devida rastreabilidade.
Figura 5 - Corpos de Prova.

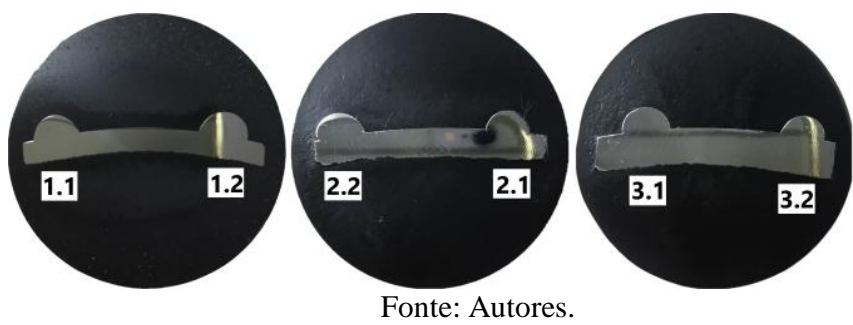

\section{3 - Resultado das micrografias.}

Seguem, nas figuras 6 e 7, as micrografias dos corpos de prova 1.1 e 1.2 , respectivamente. Devido ao objetivo do estudo, deu-se ênfase na região abaixo do cordão de solda.

Figura 6 - Micrografia do corpo de prova 1.1.

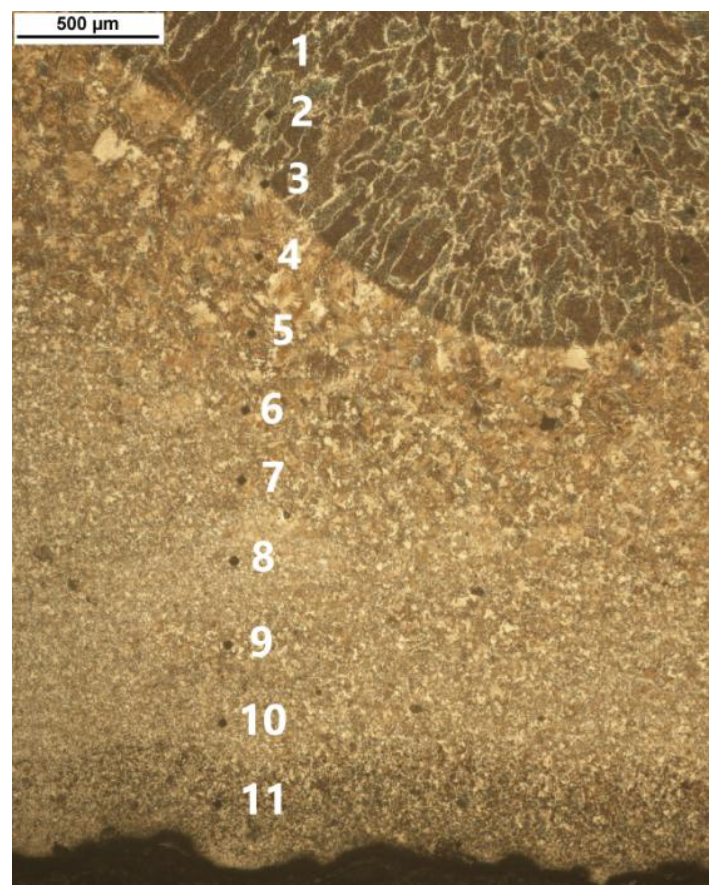

Fonte: Autores.

Figura 7 - Micrografia do corpo de prova 1.2.

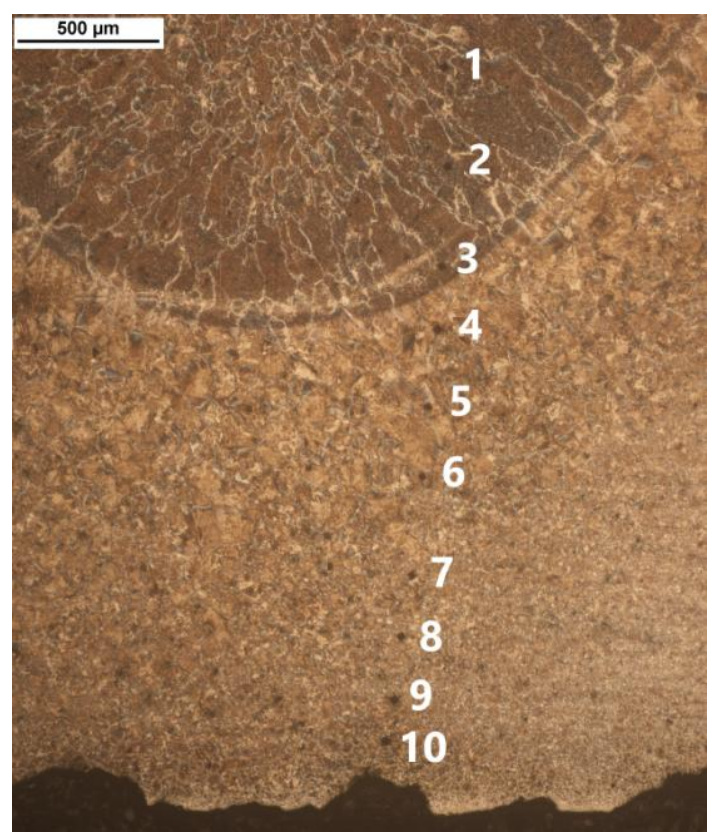

Fonte: Autores. 


\section{4 - Resultado dos Perfis de Microdureza.}

Seguem, na figura 8 , os resultados do perfil de microdureza nos corpos de prova 1.1 e 1.2 , onde a aparece a separação das regiões da solda: zona fundida $(\mathrm{ZF})$ e zona termicamente afetada (ZTA). A localização dos pontos de medição de microdureza estão rastreados nas figuras 6 e 7 . Utilizou-se a carga $0,2 \mathrm{kgf}$ e o mesmo foi realizado na direção vertical.

Figura 8 - Perfil de dureza dos corpos de prova 1.1 e 1.2.

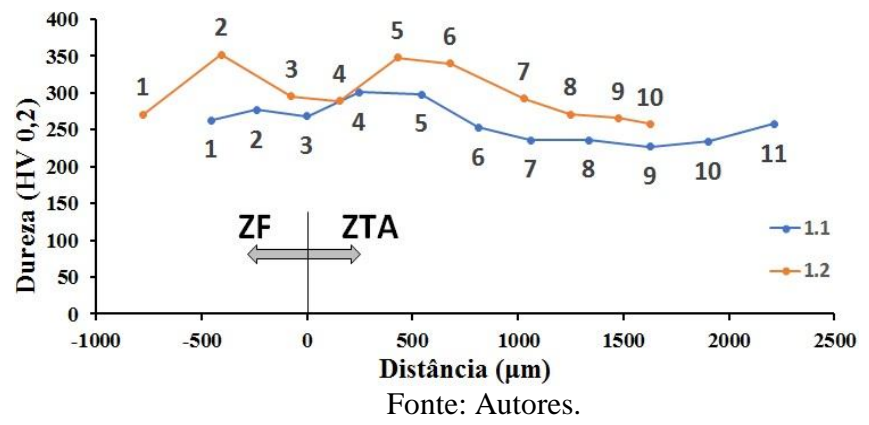

3.5 - Resultados das Macrografias.

Seguem, na figura 9, os resultados das macrografias realizadas nos 6 corpos de prova.

Figura 9 - Macrografias dos corpos de prova.

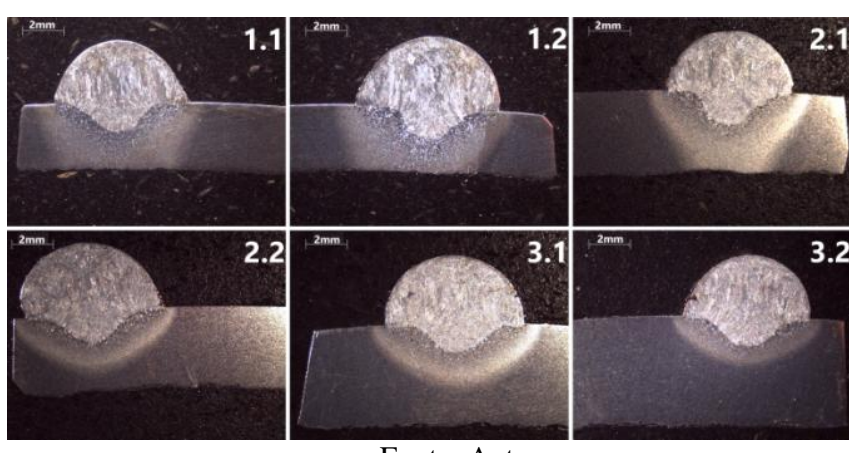

Fonte: Autores.

\section{6 - Resultados dos Parâmetros de Soldagem}

Os parâmetros de soldagem coletados, tensão média (Um) e corrente média (V), para cada condição simulada, durante a soldagem em operação na bancada estão apresentados na tabela 4 , onde também a parecem as informações corpo de prova (CP), espessura (e), velocidade de soldagem (v) e energia de soldagem total (Et).

Tabela 4 - Parâmetros de soldagem coletados durante a soldagem em operação.

\begin{tabular}{cccccc}
\hline $\mathbf{C P}$ & $\begin{array}{c}\mathbf{e} \\
(\mathbf{m m})\end{array}$ & $\begin{array}{c}\mathbf{U m} \\
(\mathbf{V})\end{array}$ & $\begin{array}{c}\mathbf{I m} \\
(\mathbf{A})\end{array}$ & $\begin{array}{c}\mathbf{v} \\
(\mathbf{c m} / \mathbf{m i n})\end{array}$ & $\begin{array}{c}\mathbf{E t} \\
(\mathbf{k J} / \mathbf{m m})\end{array}$ \\
\hline 1.1 & 3,2 & 16,7 & 102,7 & 15 & 0,69 \\
1.2 & 3,2 & 16,7 & 99,7 & 20 & 0,50 \\
2.1 & 4,0 & 16,7 & 103,3 & 15 & 0,69 \\
2.2 & 4,0 & 16,7 & 101,6 & 20 & 0,51 \\
3.1 & 5,0 & 16,7 & 102,6 & 15 & 0,69 \\
3.2 & 5,3 & 16,7 & 100,8 & 20 & 0,51 \\
\hline \multicolumn{5}{c}{ Fonte: Autores }
\end{tabular}

Volume 14 - No 159 - Março/2019.
O cálculo da Energia de Soldagem Total (Et) é dado pela equação (1):

$$
E t=(U m \cdot \operatorname{Im}) / v
$$

\section{7 - Resultados da Simulação no PRCI.}

Seguem, na tabela 5, os resultados das simulações do modelo de análise térmica do PRCI para as condições de soldagem em operação de cada corpo de prova.

Tabela 5 - Resultado da Simulação do PRCI.

\begin{tabular}{cc}
\hline Corpo de Prova & $\begin{array}{c}\text { Temperatura da Superfície } \\
\text { Interna }\left({ }^{\circ} \mathbf{C}\right)\end{array}$ \\
\hline 1.1 & 1220 \\
1.2 & 1128 \\
2.1 & 990 \\
2.2 & 891 \\
3.1 & 780 \\
3.2 & 647 \\
\hline
\end{tabular}

Fonte: Autores.

\section{DISCUSSÃO DOS RESULTADOS}

Segue a análise do risco de perfuração durante a soldagem em operação nas condições da bancada, para cada corpo de prova, utilizando 2 métodos distintos: a abordagem experimental e análise térmica pelo PRCI.

\section{1 - Abordagem Experimental}

Segundo (BORING, 2012), o critério de aceitação desse método baseia-se na análise da seção transversal da solda, referente a presença de abaulamento na parede do tubo ou a proximidade da zona termicamente afetada pelo calor (ZTA) da superfície interna do tubo. As soldas são consideradas tipicamente seguras se não houver a presença de abaulamento e a região de grãos grosseiros da ZTA não englobar a superfície interna do tubo.

Conforme citado em Pérez (2005), o limite da ZTA visível é dado pela temperatura de transformação dinâmica, linha Ac1. As temperaturas críticas para um determinado aço são, geralmente, determinadas experimentalmente. Entretanto, em Mascarenhas (2005) apresentou-se uma fórmula empírica que mostra o efeito dos elementos de liga nas temperaturas críticas e equivale a aproximadamente a temperatura de $725^{\circ} \mathrm{C}$, para a composição do aço estudado.

Já o limite da região de grãos grosseiros da ZTA, dado pela interface com a região de grãos refinados, é de aproximadamente $1200^{\circ} \mathrm{C}$ (MARQUES et al., 2016).

Assim sendo, usou-se a micrografia óptica dos corpos de prova, que faz a distinção das regiões da solda, para estimar a distribuição de temperatura, em regiões específicas, ao longo da espessura do tubo abaixo do cordão de solda. Verificou-se que o critério para ocorrência do fenômeno de perfuração adotado na abordagem experimental está em acordo com a temperatura limite da superfície interna, verificada numa série de experimentos, conforme citado em Bruce e Amend (2009).

Analisando os resultados das macrografias dos corpos de prova, na figura 9, percebe-se que não houve abaulamento em nenhuma das seções de solda. 
Além disso, para os corpos de prova 2.2, 3.1 e 3.2, o resultado de macrografia assegura que não houve a evolução da região de grão grosseiro da ZTA para a superfície interna, sendo assim consideradas seguras quanto ao risco de perfuração nas condições operacionais simuladas.

Para os corpos de prova 1.1, 1.2 e 2.1, apenas a análise das macrografias não são suficientes. Porém, como os corpos de 1.1 e 1.2 , por terem menor espessura, tendem a ser mais críticos quanto ao risco de perfuração. Para esses 2 corpos de prova complementou-se a análise com a realização das micrografias, conforme figuras 6 e 7, e com os perfis de microdureza, conforme figura 8 .

Sabe-se que a região de grãos grosseiros da ZTA tende a ter maior dureza da região da solda (KOU, 2003). Assim sendo, ao longo do perfil vertical evidenciou-se que os valores de maior dureza se dão antes da superfície interna do tubo. Logo, a região de crescimento de grão grosseiro da ZTA não propagou para a região da superfície interna do tubo.

Assim sendo, tem-se que a região de grãos grosseiros da ZTA não propagou para a superfície interna do tubo em nenhuma das 6 condições de soldagem, e com isso todas as soldas não apresentaram risco de perfurar durante as soldas em operação simuladas em bancada.

\section{2 - Análise térmica pelo PRCI}

A avaliação do risco de perfuração durante a soldagem em operação será realizada com o resultado da avaliação do risco de perfuração pelo modelo de análise térmica do PRCI na tabela 5 e considerando o critério de aceitação referente a temperatura limite de $982^{\circ} \mathrm{C}$ para superfície interna do tubo, dado que o processo de soldagem utilizado foi um de baixo hidrogênio, conforme citado em Possebon (2009).

Os corpos de prova 2.2, 3.1 e 3.2, que caracterizam determinada condição de soldagem, não correm o risco de perfurar na condição do estudo proposto em laboratório. Já para os outros corpos de prova o modelo apresentou não ser uma condição segura para se realizar o reparo, caso se mantenha todos os parâmetros de soldagem e operacionais da bancada.

Assim sendo, essa análise reprova as condições de soldagem representados pelos corpos de prova 1.1, 1.2 e 2.1, considerando que as mesmas são inseguras, onde as mesmas apresentam o risco de perfurar durante a execução da solda em operação.

\section{CONCLUSÃO}

O modelo de análise térmica do PRCI para avaliação do risco de perfuração mostra-se realmente conservador em relação ao método de avaliação pela abordagem experimental, quando utilizado em soldagem por deposição direta em oleodutos com pequena espessura de parede e em operação.

\section{REFERÊNCIAS BIBLIOGRÁFICAS}

AMERICAN PETROLEUM INSTITUTE (API). Specification for Line Pipe, API 5L. 45. ed. Washington, 2012.

AMERICAN PETROLEUM INSTITUTE (API). Welding of Pipelines and Related Facilities, API 1104. 21. ed. Washington, 2013.
AMERICAN SOCIETY FOR MECHANICAL ENGINEERS. Pipeline Transportation Systems for Liquid Hydrocarbons and Other Liquids, ASME B31.4. New York, 2006.

AMERICAN SOCIETY FOR TESTING AND MATERIALS (ASTM). Standard Test Method for Microindentation Hardness of Materials E384-17, United States, 2017.

BORING, M. A.; ZHANG W.; BRUCE W. A. IMPROVED BURNTHROUGH PREDICTION MODEL FOR INSERVICE WELDING APPLICATIONS. 7th International Pipeline Conference. Alberta, Canada, 2008.

BORING, M. A; BRUCE, W.A. THE EFFECT OF HOOP STRESS ON THE BURNTHROUGH SUSECPTIBILITY DURING IN-SERVICE WELDING OF THIN-WALLED PIPELINES. 7th International Pipeline Conference. Alberta, Canada, 2008.

BORING, M. A. BURNTHROUGH PREDICTION FOR IN-SERVICE WELDING - PAST, PRESENT AND FUTURE. EWI. Ohio, USA, 2012.

BRUCE, W. A.; AMEND, W.E. GUIDELINES FOR PIPELINE REPAIR BY DIRECT DEPOSITION OF WELD METAL. WTIA/APIA Welded Pipeline Symposium, Australia, 2009.

BRUCE, W. A.; LI, V.; CITTERBERG, R. PRCI Thermal Analysis Model for Hot-Tap Welding - V 4.2. Edison Welding Institute, 2002.

FREIRE, José Luiz De França. Engenharia de Dutos. ABCM, Rio de Janeiro, 2009.

KOU, S. Welding metallurgy. Second Edition, WileyInterscience, New Jersey, 2003.

MARQUES, P. V.; MODENESI, P. J.; BRACARENSE, A. Q. - SOLDAGEM: Fundamentos e Tecnologia. $4^{\mathrm{a}}$ edição, 2016.

MASCARENHAS, L. A. B. Estudo da Aplicação do Processo TIG Alimentado para a Soldagem em Operação. Santa Catarina. Florianópolis, 2005.

PÉREZ, G. E. G. - ESTABELECIMENTO DE CRITÉRIOS PARA EVITAR A PERFURAÇÃO NA SOLDAGEM DE TUBULAÇÕES EM OPERAÇÃO DE PEQUENA ESPESSURA. Universidade Federal de Santa Catarina, Santa Catarina, 2005.

PETROBRAS. NORMA N-2737: Manutenção de Oleoduto e Gasoduto Terrestre. REV.B. Brasil, 2014.

PETROBRAS. NORMA N-2163: Soldagem e trepanação em equipamentos, tubulações e dutos e operação. Brasil, 2016.

POSSEBON, S. Utilização de MIG/MAG com CurtoCircuito Controlado na Soldagem em Operaçao. Porto Alegre, Rio Grande do Sul, 2009.

\section{COPYRIGHT}

Direitos autorais: Os autores são os únicos responsáveis pelo material incluído no artigo. 


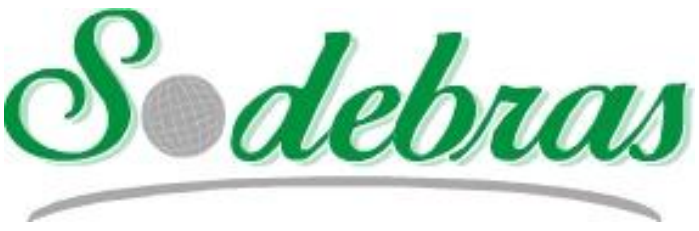

Volume 14 - No 159 - Março/2019.

XL International Sodebras Congress

10 a 12 de dezembro de 2018 - Vitória - ES.

\title{
MODOS DE RUPTURA DE LIGAÇÃO MADEIRA LAMINADA COLADA CRUZADA E CONCRETO
}

\section{CROSSED AND CONCRETE WOUNDED LAMINATED WOOD CONNECTION RUPTURE}

\author{
RAMOS, F. M. G. ${ }^{1, A^{*}}$, CARRASCO, E. V. M. ${ }^{1, \mathrm{~B}}$, RODRIGUES, F. C. ${ }^{1, \mathrm{C}}$ \\ ${ }^{1}$ ESCOLA DE ARQUITETURA, UNIVERSIDADE FEDERAL DE MINAS GERAIS, BELO HORIZONTE, \\ MG, BRASIL \\ afmgramos2@gmail.com, ${ }^{b}$ mantilla@dees.ufmg.br, ${ }^{c}$ francisco@dees.ufmg.br
}

\begin{abstract}
Resumo - Este trabalho apresenta um modelo de análise para ensaios de ligações de madeira através pinos metálicos Esse modelo é conhecido como Modelo de Escoamento Europeu, European Yeld Model (EYM). O EYM serve de base para o dimensionamento das ligações com pinos solicitadas a forças laterais em várias normas internacionais de estruturas de madeira, tais como: as americanas National Design Specification (NDS) (1991), (1997) e (2001), Load and Resistance Factor Design (LRFD) (1996), a Européia EUROCODE 5 (1994) e a canadense CSA - Canadian Standards Association (1994). Esse modelo é mundialmente conhecido por "Teoria do Escoamento" (Yield Theory-YM) ou "Modelo de Escoamento Europeu" (European Yield Model" - EYM). O EYM é utilizado para estimar a resistência lateral de uma ligação com um pino, com um e com dois planos de corte. Foi desenvolvido por Johansen (1949) que supõe que o estado-limite da ligação pode ser alcançado devido ao embutimento do pino na madeira ou pela flexão do pino com a formação de uma ou mais rótulas plásticas. Essas suposições fornecem seis modos de ruptura para ligações com um plano de cisalhamento e quatro modos de ruptura para ligações com dois planos de cisalhamento. Apresenta-se os modos de ruptura e descreve-se qualitativamente o mecanismo resistente e qual foi o fator determinante da resistência da ligação em cada caso.

Palavras-chave: Conexões de Madeira e Concreto. Sistema Construtivo Misto. Madeira Laminada Colada Cruzada. Ligação madeira Laminada Colada Cruzada e laje de Concreto
\end{abstract}

\begin{abstract}
This work presents an analysis model for testing wood bonding through metallic pins. This model is known as the European Yeld Model (EYM). The European Yield Model (EYM) serves as the basis for the sizing of the pin connections requested to lateral forces in several international standards of wood structures, such as the American National Design Specification (NDS) (1991) (1994) and the European CSA (Canadian Standards Association) (1994). In this paper, we present the results of the study. This model is known worldwide as "Yield Theory-YM" or "European Yield Model" (EYM). EYM is used to estimate the lateral resistance of a (1949) which assumes that the boundary state of the bond can be reached due to the inlaying of the pin in the wood or by the bending of the pin with the formation of one or more plastic hinges. Assumptions provide six modes of rupture for connections with a shear plane and four modes of rupture for connections with two planes of shear. Disruption modes are presented and the resistant mechanism is described qualitatively and what was the determinant of the resistance of the shear plane. connection in each case.
\end{abstract}

Keywords: Wood and Concrete Connections. Mixed Construction System. Laminated Wood Crossed. Linking Laminated Wood Crossed and Concrete Slab

\section{INTRODUÇÃO}

O Brasil, com seu imenso território continental cultivável, possui um enorme potencial madeireiro. Este poderoso potencial madeireiro aliado às tecnologias de produção de madeira laminada colada desenvolvidas atualmente na Europa, tanto madeira laminada colada (MLC) quanto madeira laminada colada cruzada (CLT), esta desenvolvida mais recentemente, veio viabilizar a sua utilização em larga escala na construção civil. A diferença entre um e outro processo de fabricação, MLC e CLT, é que na fabricação do painel MLC as fibras das lâminas de madeira são dispostas no mesmo sentido, sendo que no CLT as fibras são cruzadas possibilitando um melhor desempenho estrutural do produto, sobretudo na fabricação de painéis.

Por outro lado, a cultura do concreto armado, quer seja moldado no local ou pré-fabricado, já se encontra consolidada no nosso país. Estudar conectores e elementos de ligação adequados ao uso em um sistema construtivo que contemple o uso dos painéis CLT com lajes maciças préfabricadas de concreto armado, parece um caminho viável e com enorme potencial de uso no âmbito da construção de edificações no país.

São apresentadas aqui algumas pesquisas realizadas nos últimos anos por pesquisadores em instituições de pesquisas nacionais e estrangeiras, que proporcionam uma visão geral dos conceitos mais importantes pertinentes ao tema, com destaque para alguns pontos significativos que devem ser levados em conta. Nesse sentido, tornam-se muito importante a forma de realizar os ensaios destrutivos, em quais normas se apóiam e quais os procedimentos adotados. Duarte (2004), apresenta um estudo experimental de ligações rígidas entre vigas de madeira laminada colada (MLC) no qual utiliza parafusos auto-atarraxantes e chapas metálicas, solicitadas a momento fletor e esforço cortante. A madeira utilizada na fabricação da MLC foi a Eucalyptus grandis. Foram realizados ensaios não destrutivos para caracterização da madeira. Esses procedimentos iniciais são muito importantes para a montagem da viga de MLC, uma vez que, permitem a disposição seletiva das tábuas na 
montagem da viga, resultando em um aumento da qualidade, um melhor aproveitamento e, principalmente, uma diminuição nas variações das propriedades da madeira utilizada. Segundo a autora, a escolha do arranjo de ligação e do parafuso auto-atarraxante foi fundamental no desenvolvimento do seu trabalho. Ela se baseou na execução dos seus ensaios no European Yield Model (EYM), que serve de base para o dimensionamento de ligações com pinos solicitadas a forças laterais em várias normas internacionais de estruturas de madeira. O EYM é utilizado para estimar a resistência lateral de uma ligação com um pino, com um e com dois planos de corte. Nesse mesmo trabalho são citados os autores Soltis, Hubbard e Wilkinson (1986), que supõem que o estado-limite da ligação pode ser alcançado devido ao embutimento do pino na madeira ou pela flexão do pino com a formação de uma ou mais rótulas plásticas. Essas suposições fornecem seis modos de ruptura para ligações com um plano de cisalhamento e quatro modos de ruptura para ligações com dois planos de cisalhamento conforme mostrados na Figura 1.

Figura 1 - Modos de ruptura das ligações

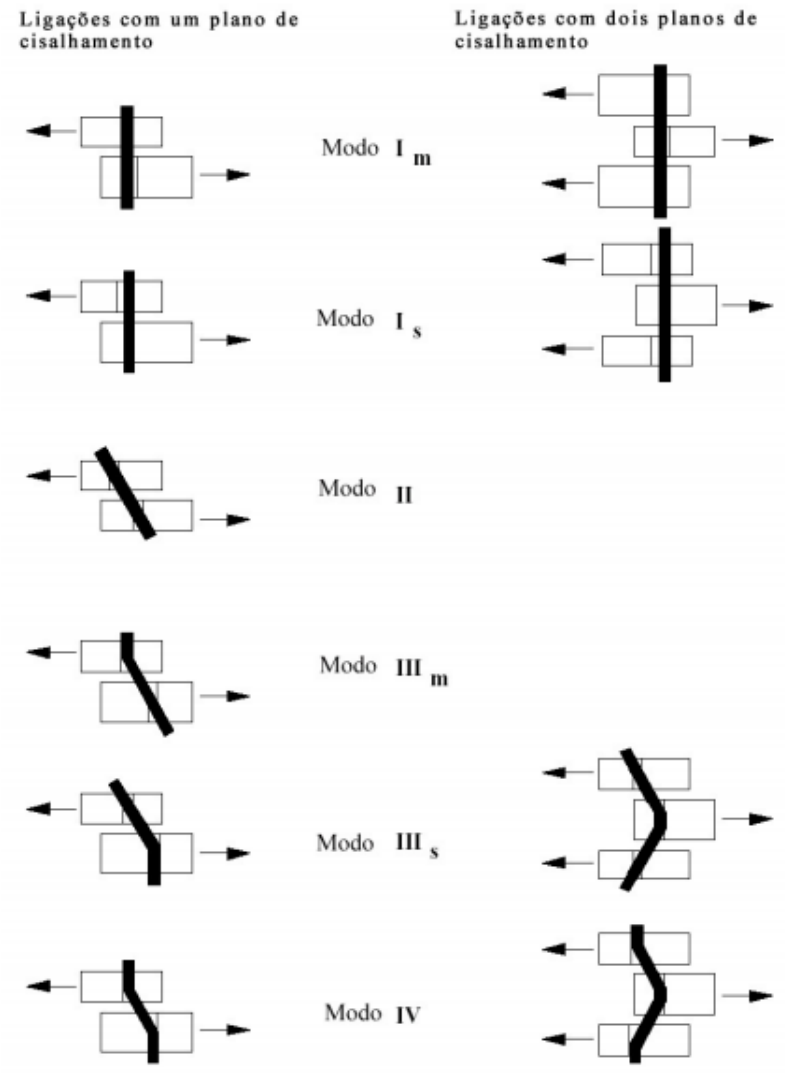

Fonte: Duarte (2004)

Os modos de ruptura $I_{m}$ e $I_{g}$ representam o embutimento do pino na peça principal (índice $\mathrm{m}$ ) e lateral(ais) respectivamente (índice(s) s). O modo de ruptura $I I$ representa a rotação do pino sem flexão e o embutimento do pino em ambas as peças. O modo de ruptura $I I I_{m}$ representa o embutimento do pino na peça principal e a flexão do pino na(s) peça(s) lateral(ais). o modo de ruptura $I I I_{s}$, representa o embutimento do pino na(s) peça(s) lateral(ais) e a flexão do pino na peça principal. O modo de ruptura $I V$ representa a flexão do pino nas peças principal e lateral(ais). A cada modo de ruptura, está relacionada uma equação para a determinação da resistência lateral da ligação. O modo que resultar na menor resistência é considerado como determinante da resistência lateral teórica da ligação.

Branco (2009) avaliou a precisão da metodologia proposta no EUROCODE 5 para conexões pré-carregadas lateralmente de madeira e concreto. Num primeiro momento o autor analisou e discutiu a adequação da metodologia proposta pelo EUROCODE 5 usando madeira de Pinus Pinaster. Através de ensaios de push-out, com ligações tipo cavilha, utilizando-se pinos quadrados e redondos lisos, em cisalhamento simples e duplo. Num segundo momento, o autor analisou e discutiu os resultados de ensaios nos quais utilizou metodologia semelhante e mesmo tipo de elementos de fixação, para ligações de madeira e concreto. $\mathrm{O}$ uso e a influência da concretagem com forma permanente também são investigados. $\mathrm{O}$ autor comenta no seu trabalho, que o modelo de escoamento europeu (MEJ) ou (EYM), originalmente proposto por Johansen (1949), que pode ser encontrado no EUROCODE 5, é geralmente aceito para a determinação da capacidade de suporte de carga lateral utilizando-se elementos de fixação tipo pinos, especialmente para falhas dúcteis. As equações com base nessa teoria, prevêem a capacidade de carregamento de um único conector por plano de corte, colocado perpendicular ao seu eixo e dependem das propriedades do material (madeira), dos elementos de fixação e da geometria da ligação. O comportamento de deformação dessas ligações é baseado no módulo de deslizamento de um único conector por plano de corte e os resultados podem ser conseguidos por meio de ensaios de acordo com a EN 26891, 1991, ou seja, calculada usando expressões propostas no EUROCODE 5. Embora pesquisas realizadas utilizando-se ligações de madeira e concreto tenham obtido bons resultados, nenhum método de análise específico é apresentado no EUROCODE 5 para conectores tipo pino em ligações de madeira e concreto. No EC 5, parte 2, presume-se que o módulo de deslizamento nas ligações de madeira e concreto será o dobro em comparação com sistemas semelhantes de ligações madeira e madeira. Segundo Branco (2009), para a quantificação da capacidade de carga de conexões de concreto e madeira, nenhum modelo particular ou expressão simplificada é apresentada pelo EUROCODE 5. A curva de carga/deslocamento completa, continua o autor, alcançada nos ensaios realizados no âmbito de pesquisas realizadas, não só proporcionou a carga de ruptura da ligação mas, também, deu informação adicional sobre a rigidez e ductibilidade da ligação. Demonstrou-se que o comportamento mecânico das estruturas mistas, tais como os elementos compostos de madeira e concreto, é mais freqüientemente influenciado pelo módulo de deslizamento da junção do que pela capacidade máxima de carga de ruptura da junta Em geral, deve-se afirmar que as propriedades de resistência e rigidez das conexões mistas de madeira e concreto devem ser avaliadas por ensaios. O EUROCODE 5, parte 2, contém poucas informações sobre o comportamento e o projeto de conexões mistas de madeira e concreto. Sem o apoio de resultados experimentais, o EC 5, sugere ter em conta um valor do módulo de deslizamento duplo do que o de uma conexão semelhante de madeira com madeira. Isso não parece ser razoável.

No modelo de escoamento europeu, tanto para a madeira quanto para o conector são assumidos um comportamento rígido-plástico. Enquanto esta suposição 
possibilita uma simplificação considerável da análise, provoca, ao mesmo tempo, um pequeno impacto sobre os resultados finais. $\mathrm{O}$ autor citou os modos de falha previstos no EC 4, já vistos na Figura 1. Tendo como base a distribuição de tensão e o equilíbrio procurado, é possível quantificar a capacidade de suporte de carga associada a cada modo de falha. No EUROCODE 5 são mostradas as equações para um plano de corte e para dois planos de corte.

Pretende-se nesse trabalho, comentar os modos de falha previstos no EUROCODE 5 e descrever qualitativamente o mecanismo resistente e qual foi o fator determinante da resistência da ligação em cada caso.

\section{METODOLOGIA}

Neste artigo foi analisado o EUROCODE 5, em especial no que tange a ligações de madeira com madeira, usando-se o modelo de escoamento europeu (MEJ) e seus modos de falha previstos. Esse modelo é utilizado para estimar a carga lateral de uma ligação com pino, com um ou dois planos de corte. Foram analisados os modos de ruptura das ligações (Figura 1) e foram descritos qualitativamente o mecanismo resistente e qual foi o fator determinante da resistência da ligação em cada caso.

\section{RESULTADOS}

Nesse trabalho, foi considerado o modelo de escoamento europeu EYM. Com a utilização desse modelo, o estado-limite da ligação pode ser alcançado pelo embutimento do pino na madeira ou pela flexão do pino com a formação de uma ou mais rótulas plásticas. Essas suposições fornecem seis modos de rupturas para ligações com um plano de cisalhamento e quatro modos de ruptura para ligações com dois planos de cisalhamento. Esses modos são mostrados na Figura 1.

Descrevemos a seguir os modos de falha da ligação e descrição qualitativa do mecanismo resistente e qual é o fator determinante da resistência da ligação em cada caso:

Os modos de ruptura Im e Is representam o embutimento do pino na peça principal (índice $\mathrm{m}$ ) e lateral(is) respectivamente (índice(s) s).

No modo de ruptura I m, para ligações com um plano de cisalhamento, o pino de aço se comporta como corpo rígido, não se deforma, e provoca um esmagamento da madeira na peça principal. O fator determinante do modo é devido à resistência ao embutimento da peça lateral ser maior do que a da peça principal e à elevada capacidade resistente do pino ao escoamento.

No modo de ruptura I m, para ligações com dois planos de cisalhamento, o pino de aço também se comporta como corpo rígido, não se deforma, e provoca um esmagamento da madeira na peça lateral. $O$ fator determinante do modo é devido à resistência ao embutimento das peças principais ser maior do que a da peça lateral e à elevada capacidade resistente do pino ao escoamento.

No modo de ruptura I s, para ligações com um plano de cisalhamento, o pino de aço se comporta como corpo rígido, não se deforma, e provoca um esmagamento da madeira na peça lateral. O fator determinante do modo é devido à resistência ao embutimento da peça principal ser maior do que a da peça lateral e à elevada capacidade resistente do pino ao escoamento.
No modo de ruptura I s, para ligações com dois planos de cisalhamento, o pino de aço também se comporta como corpo rígido, não se deforma, e provoca um esmagamento da madeira nas peças laterais. $O$ fator determinante do modo é devido à resistência ao embutimento das peças laterais ser menor do que a da peça principal e à elevada capacidade resistente do pino ao escoamento.

O modo de ruptura II representa a rotação do pino sem flexão e o embutimento do pino em ambas as peças.

No modo de ruptura II, para ligações com um plano de cisalhamento, o pino de aço se comporta como corpo rígido, não se deforma, e provoca um esmagamento da madeira nas peças lateral e principal. $\mathrm{O}$ fator determinante do modo é devido à resistência ao embutimento das peças principal e lateral ser menor do que a capacidade resistente do pino ao escoamento.

O modo de ruptura III m é o embutimento do pino na peça principal e a flexão do pino na(s) peça(s) lateral(is)

No modo de ruptura III m, para ligações com um plano de cisalhamento, o pino já não mais se comporta como corpo rígido; houve a formação de uma rótula plástica na ligação com a peça lateral, e provoca o esmagamento da madeira tanto na peça lateral como na principal. O fator determinante do modo é devido à capacidade resistente da barra de aço não suportar a força aplicada, provocando o escoamento e a formação de uma rótula plástica, e a resistência ao embutimento das peças principal e lateral não ser capaz de evitar o esmagamento das duas peças.

O modo de ruptura III s representa o embutimento do pino na(s) peça(s) lateral(is) e a flexão do pino na peça principal

No modo de ruptura III s, para ligações com um plano de cisalhamento, o pino de aço escoa, provoca a formação de uma rótula plástica na ligação com a peça principal, com pequeno esmagamento na madeira e um esmagamento da madeira na peça lateral. O fator determinante do modo é devido à resistência ao embutimento da peça lateral ser menor que a capacidade resistente do pino e à capacidade de resistência da peça principal ser maior do que a do aço, provocando uma rótula plástica e pequeno esmagamento da madeira.

No modo de ruptura III s, para ligações com dois planos de cisalhamento, o pino de aço escoa, provoca a formação de uma rótula plástica na ligação com a peça principal, com pequeno esmagamento e um esmagamento da madeira nas peças laterais. $O$ fator determinante do modo é devido à resistência ao embutimento das peças laterais ser menor do que a capacidade resistente do pino e a capacidade de resistência da peça principal ser maior do que a do aço, provocando uma rótula plástica e pequeno esmagamento da madeira.

O modo de ruptura IV representa a flexão do pino nas peças principal e lateral(is)

No modo de ruptura IV, para ligações com um plano de cisalhamento, o pino de aço escoa e provoca a formação de duas rótulas plásticas nas ligações com a peça principal e lateral, com pequeno esmagamento da madeira em ambas. $\mathrm{O}$ fator determinante do modo é devido à capacidade resistente do pino não suportar a força aplicada e provocar a formação das duas rótulas plásticas e pequeno esmagamento da madeira tanto na peça principal quanto na lateral. 
No modo de ruptura IV, para ligações com dois planos de cisalhamento, o pino de aço escoa e provoca a formação de três rótulas plásticas nas ligações com a peça principal e laterais, com pequeno esmagamento da madeira em todas elas. $\mathrm{O}$ fator determinante do modo é devido à capacidade resistente do pino não suportar a força aplicada e provocar a formação das três rótulas plásticas e pequeno esmagamento da madeira tanto na peça principal quanto nas laterais.

É importante salientar que, no caso desse artigo em tela, considera-se que uma das peças será de concreto armado.

Outras alternativas foram apresentadas em pesquisas realizadas sobre o tema, entre as quais a de Carvalho (2008), que enriquecem as possibilidades de solução para o caso.

Segundo Carvalho (2008), citando estudos desenvolvidos por Dias (2005), para as ligações madeiraconcreto, dos 6 modos de ruptura apresentados pelo EUROCODE, somente ocorreram os 3 modos mostrados na Figura 2, devido às restrições promovidas pelo concreto.

Figura 2 - Modos de ruptura para ligações madeiraconcreto
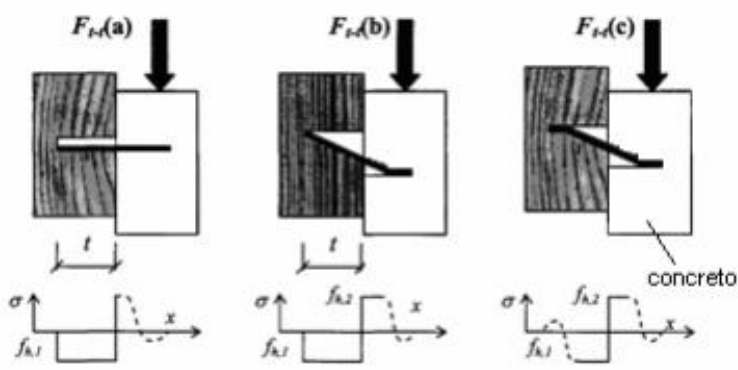

Fonte:DIAS (2005)

Continua Carvalho (2008), citando Dias (2005), a principal limitação desse modelo de madeira-madeira, para avaliar o comportamento concreto-madeira, é a consideração do comportamento elasto-plástico perfeito para ambos os materiais. A plasticidade no concreto é limitada e ele mostra um comportamento frágil, usualmente resultante em esmagamento. $\mathrm{Na}$ realidade, os resultados experimentais mostraram que o concreto sob o pino é danificado, diminuindo sua resistência. Uma alternativa é considerar o comportamento do concreto como completamente rígido, e adotar os modelos para ligações entre peças de aço espessas e madeira. Neste caso, três diferentes modos de ruptura podem ser considerados, conforme Figura 3.
Figura 3 - Modos de ruptura para ligações madeira-aço.
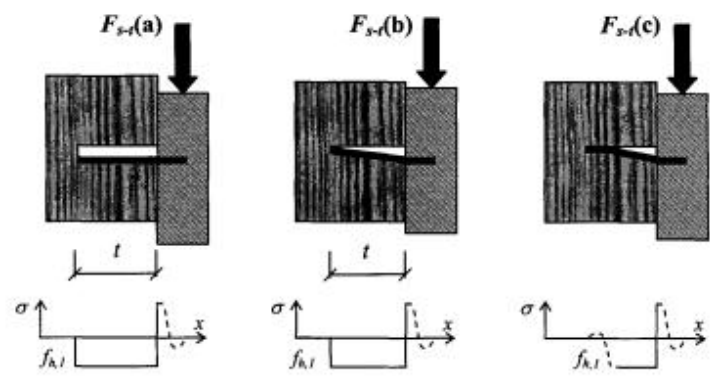

Fonte: DIAS (2005)

Carvalho (2008) continua, porém, segundo o autor, a consideração de engastamento perfeito do pino, no concreto, não representa totalmente a realidade, uma vez que sempre existe algum dano localizado. $\mathrm{O}$ uso desses modelos desconsidera esses fenômenos, superestimando a capacidade resistente do concreto. Argumenta que, diante das considerações apontadas, DIAS (2005) desenvolveu um estudo com objetivo de comparar os resultados teóricos, calculados a partir dos modelos propostos, com resultados experimentais. DIAS (2005) executou ensaios de cisalhamento de acordo com a EN 26891(1991) e utilizou barras de aço de 8,0 mm e de 10,0 mm de diâmetro. O autor concluiu que o modelo aço-madeira foi o que apresentou resultados mais próximos aos experimentais. Além disto, os pinos mostraram uma grande capacidade de deformação plástica, para todas as amostras. $\mathrm{O}$ modo de ruptura foi caracterizado pelo escoamento das barras de aço em dois pontos, com a formação de duas rótulas plásticas e esmagamento da madeira. Não foi observado nenhum movimento axial do pino com relação ao concreto e à madeira. Os danos que o pino provocou no concreto com alta resistência foram pequenos e podem ser considerados desprezíveis, quando comparados com os danos na madeira. Nestes casos, o concreto atuou como um engaste perfeito e o esmagamento da madeira apresentou uma importância muito maior.

\section{CONCLUSÃO}

Neste artigo foi analisado o EUROCODE 5, em especial no que tange a ligações de madeira com madeira, usando-se o modelo de escoamento europeu (MEJ) e seus modos de falha previstos. Esse modelo é utilizado para estimar a carga lateral de uma ligação com pino, com um ou dois planos de corte. Foram analisados os modos de ruptura das ligações $\mathrm{e}$ foram descritos qualitativamente $\mathrm{o}$ mecanismo resistente e qual foi o fator determinante da resistência da ligação em cada caso.

Espera-se que seja possível verificar que os modos de ruptura das ligações podem ser aplicados também a uma ligação de madeira com concreto, tal como a estudada na pesquisa ora em andamento (RAMOS, 2018), É importante salientar que nessa pesquisa uma das peças é de concreto armado. A estratégia a ser adotada será a de considerar para o concreto um comportamento análogo ao da peça de madeira, mas considerando a sua resistência à compressão, $f_{c k}$, verificada por meio de ensaios de compressão.

Espera-se que os danos que o pino provocará no concreto de alta resistência sejam pequenos e que poderão ser considerados desprezáveis, quando comparados com os danos na madeira. 
Neste caso, o concreto atuará como um engaste perfeito e o esmagamento da madeira apresentará uma importância muito maior.

\section{REFERÊNCIAS BIBLIOGRÁFICAS}

BRANCO, Jorge M.; CRUZ, Paulo J.S.; Piazza Maurício Experimental Analysis of Laterally Loaded Nailed Timberto-Concrete Connections. Artigo (Constrution and Building Materials - no $23,2009$.

CARVALHO, Eliene Pires - Avaliação do Comportamento mecânico ao Cisalhamento de Conectores de Barras de Aço com Ganchos em Vigas Mistas de Madeira Laminada Colada e Concreto -Tese Doutorado, Universidade Federal de Minas Gerais, Maio 2008.

DIAS AMPG. Mechanical behaviour of timber-concrete joints. PhD thesis; 2005. ISBN 90-9019214-X.

DUARTE, Renata S. Avaliação do Comportamento de Ligações com Parafusos Auto-Atarraxantes em Vigas de MLC. Dissertação (Mestrado em Engenharia de Estruturas). Escola de Engenharia da Universidade Federal de Minas Gerais. Belo Horizonte, 2004.

EN 26891:1991. Timber structures - joints made with mechanical fasteners - general principles for the determination of strength and deformation characteristics. ISO 6891-1983 (E).

EUROCODE 5- partes 1 e 2 (drafts 2002 e 2003) - Desing of timber structures - General rules and rules for builings, Brussels.

JOHANSEN, K.W.; Theory of Timber Connections International Association of Bridge and Structural Engineering Publications (1949) vol. 9, pag 249-62.

RAMOS, Fernando. M. G.; Conector de Aço para Ligações entre Painéis de Madeira Laminada Colada Cruzada e entre painéis de Madeira Laminada Colada Cruzada com Laje de Concreto Pré-Fabricado - Projeto de Tese. Programa de Pós-Graduação em Engenharia de Estruturas da UFMG, 2018.

SOLTIS, Lawrence A.; HUBBARD, Finn K.; WILKINSON, Thomas L. Bearing strength of bolted timber joints. Journal of Structural Engineering, Sept. 1986, p. 2141-2154.

\section{COPYRIGHT}

Direitos autorais: $\mathrm{O}(\mathrm{s})$ autor(es) é(são) o(s) único(s) responsável(is) pelo material incluído no artigo. 


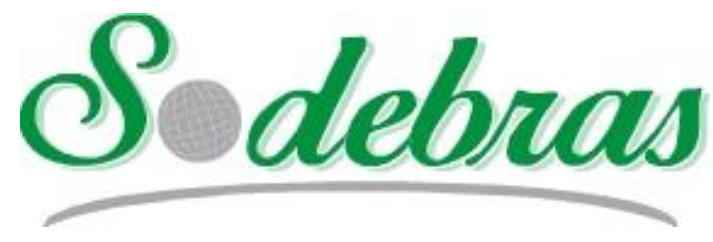

Volume 14 - No 159 - Março/2019.

XL International Sodebras Congress

10 a 12 de dezembro de 2018 - Vitória - ES.

\title{
INTEGRAÇÃO DE FERRAMENTAS DE MODELAGEM E SIMULAÇÃO DE SISTEMAS UTILIZANDO O PROTOCOLO OPC-UA
}

\author{
INTEGRATION OF MODELING AND SIMULATION TOOLS USING OPC-UA \\ PROTOCOL
}

\author{
ALEX BRANDÃO ROSSOW \\ INSTITUTO FEDERAL DO ESPÍRITO SANTO
}

alex.rossow@ifes.edu.br

\begin{abstract}
Resumo - Este artigo apresenta a integração de ferramentas de modelagem e simulação de sistemas, com finalidade educacional, utilizando o protocolo OPC-UA. Este estudo realizou a integração do programa de modelagem de sistemas OpenModelica com a ferramenta de simulação de sistemas de controle Xcos do Scilab. Ambas as ferramentas são disponibilizadas como software livre. Para a programação do cliente UPC-UA para o Xcos utilizou-se a biblioteca Open62541. Como resultado observou-se que a comunicação é possível, porém apresenta limitações para a simulação de sistemas em malha fechada. Observou-se que existe potencial para a integração de diferentes ferramentas de modelagem e simulação pelo protocolo OPC-UA em aplicações onde o tempo de resposta não seja crítico, como sistemas chaveados.
\end{abstract}

Palavras-chave: Xcos. OpenModelica. OPC-UA. Open62541. Redes industriais. Modelagem de sistemas.

Abstract - This paper presents the integration of modeling and simulation tools, for educational purposes, using the OPC-UA protocol. This study executed the integration of the OpenModelica systems modeling program with the Scilab Xcos control system simulation tool. Both tools are available as free software. For programming the UPC-UA client for Xcos, the Open62541 library was used. As a result, it was observed that the communication is possible, but presents limitations for the simulation of closed-loop systems. It was observed that there is potential for the integration of different modeling and simulation tools by the OPC-UA protocol in applications where the response time is not critical, such as switched systems.

Keywords: Xcos. OpenModelica. OPC-UA. Open62541. Industrial networks. Systems modeling.

\section{INTRODUÇÃO}

As ferramentas de simulação são recursos importantes para a modelagem de sistemas e projeto de controladores, pois permitem a visualização do comportamento do sistema de interesse de forma ágil e a consequência de alterações dos parâmetros do sistema. Sem as ferramentas de simulação a análise dos projetos se baseia apenas na análise de equações, o que pode dificultar o entendimento e a identificação de erros de projeto.

Com a popularização dos computadores, as ferramentas de modelagem e simulação se tornaram amplamente disponíveis, existindo opções comerciais ou disponibilizadas como software livre.
Existem programas especializados em determinadas áreas, como na análise de circuitos elétricos ou de sistemas mecânicos. Essas ferramentas apresentam a vantagem de permitir a implementação de funcionalidades complexas para atender usuários áreas específicas. Entretanto, o fato de muitos sistemas existentes serem descritos por equações diferenciais possibilita e existência de sistemas de modelagem e simulação genéricos.

Os diferentes programas de modelagem podem ter funções específicas. Portanto, a integração de ferramentas distintas pode ser útil para aumentar a capacidade de análise no momento de modelar sistemas e projetar sistemas de controle.

Este artigo tem por objetivo apresentar os resultados da implementação da integração entre o OpenModelica e o Xcos, que é uma ferramenta do Scilab, por meio do protocolo OPC-UA. Adotou-se esses dois programas por apresentarem funções que podem se complementar e estarem disponíveis sem custos. Para a implementação da comunicação por OPC-UA adotou-se a biblioteca Open62541, também disponível como software livre. Os programas utilizados neste estudo estão disponíveis para Windows e Linux.

\section{METODOLOGIA}

Este trabalho apresenta um modelo mecânico simples, composto por um bloco, uma mola e um amortecedor, que é uma configuração normalmente usada no estudo de modelagem de sistemas.

Foram realizadas simulações em malha aberta e em malha fechada com controle proporcional. As simulações foram executadas através do Xcos. A planta analisada foi modelada através do OpenModelica, sendo a integração das duas ferramentas realizada pelo protocolo OPC-UA. Para comparação, foi executada a simulação simultânea de uma planta idêntica modelada diretamente pelo Xcos.

\section{1 - Revisão bibliográfica}

Esta seção apresenta as ferramentas utilizadas no desenvolvimento deste estudo, que são o OpenModelica, o $\mathrm{Xcos}$ o protocolo OPC e a biblioteca Open62541. 
O OpenModelica é uma implementação da linguagem de programação Modelica destinada ao uso industrial e acadêmico (OPEN MODELICA, 2018).

Modelica é uma linguagem não proprietária, orientada a objetos, baseada em equações para modelar convenientemente sistemas físicos complexos contendo, por exemplo, subcomponentes mecânicos, elétricos, eletrônicos, hidráulicos, térmicos, de controle, de energia elétrica ou orientados a processos (MODELICA, 2018). Pode-se, por exemplo, modelar um sistema que inclua um circuito eletrônico acionando um motor elétrico que esteja acoplado a um sistema mecânico.

A linguagem Modelica permite a descrição de um sistema diretamente pelas equações diferenciais que regem o seu comportamento. O OpenModelica possui em seu conjunto de funcionalidades a ferramenta OMEdit, que possibilidade a modelagem gráfica de sistemas pela conexão de blocos que representam as partes do sistema.

O Xcos é um editor gráfico, integrado ao Scilab, para projetar modelos de sistemas dinâmicos híbridos. Os modelos podem ser projetados compilados e simulados (SCILAB, 2018). O Xcos complementa o Scilab fornecendo a função de modelagem de sistemas pela ligação de blocos que representam as partes do sistema. No Xcos, os sistemas são normalmente representados pela sua função de transferência no domínio de Laplace. O Xcos é bastante útil no projeto de controladores, podendo ser usado para a simulação de controle em malha fechada com compensadores, como os controladores proporcionais integrais derivativos (PID), por exemplo.

Pelo exposto, observa-se que o OpenModelica apresenta maior potencial para a modelagem de sistemas e o Xcos é mais adequado para o projeto e teste de sistemas de controle em malha fechada com uso de compensadores. A integração dessas duas ferramentas ilustra como pode ser útil a associação de programas que apresentem potencialidades que se complementam.

O OPC é um padrão de interoperabilidade para a troca segura e confiável de dados no espaço industrial. Ele é independente de plataforma e garante o fluxo de informações entre dispositivos de vários fornecedores. $\mathrm{O}$ padrão OPC é uma série de especificações desenvolvidas por fornecedores do setor, usuários finais e desenvolvedores de software. Essas especificações definem formas de interface entre clientes e servidores, bem como entre vários servidores, incluindo acesso a dados em tempo real, monitoramento de alarmes e eventos, acesso a dados históricos e outros aplicativos (OPC FOUDATION, 2018).

Inicialmente, o padrão $\mathrm{OPC}$ era restrito ao sistema operacional Windows. Com o surgimento de novas necessidades, foram desenvolvidas as especificações do OPC-UA, que fornece uma arquitetura de plataforma aberta, não se limitando a um único sistema operacional.

O open62541 é uma implementação em código livre do OPC-UA. É uma biblioteca compatível com os principais compiladores e que fornece as ferramentas necessárias para a implementação de clientes e servidores OPC-UA dedicados, ou para incluir a capacidade de comunicação baseada em OPC UA em aplicativos existentes. A biblioteca open62541 é independente da plataforma (OPEN62541, 2018).

Apesar de o OPC-UA tradicional não ser usado para aplicações que demandem grande velocidade, existem novas funcionalidades sendo implementadas no protocolo que visam preencher essa lacuna. Uma das novas capacidades em estudo é a troca de mensagens utilizando o protocolo UDP como camada de transporte, em uma estrutura chamada PubSub (referência a Publish-Subscribe) (UNIFIED AUTOMATION, 2018). Existem estudos associando esse padrão PubSub do OPC-UA a redes do tipo TSN (time sensitive network), que é uma extensão do padrão ethernet para aplicações em tempo real (BRUCKNER et al, 2018).

O OpenModelica é uma ferramenta que possui de forma nativa a capacidade de executar um servidor OPC-UA para comunicação durante a simulação (JOHANSSON, 2017). Por outro lado, o Xcos não possui entre suas funções a capacidade de comunicação por OPC-UA, sendo necessário utilizar um bloco genérico, disponível no Xcos, para implementar a comunicação por OPC-UA. A programação do bloco genérico do Xcos foi realizada em linguagem $\mathrm{C}$, utilizando a biblioteca Open62541.

\section{2 - Sistema modelado}

Para a análise feita neste estudo foi adotado um sistema simples, composto por um bloco uma mola e um amortecedor, apresentado na Figura 1, com os seguintes parâmetros: massa do bloco $\mathrm{M}=1 \mathrm{~kg}$, constante da mola $\mathrm{k}$ $=3 \mathrm{~N} / \mathrm{m}$ e coeficiente de amortecimento $\mathrm{b}=0,3 \mathrm{Ns} / \mathrm{m}$.

Figura 1 - Sistema mecânico modelado.

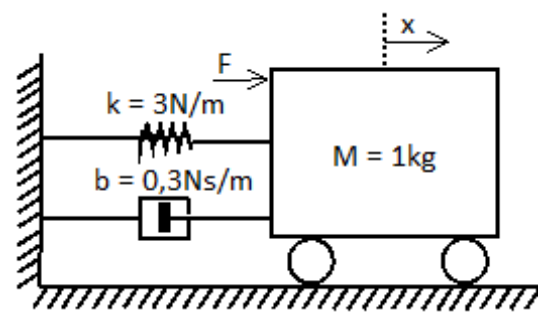

Fonte: Autor, 2018.

O objetivo da simulação dessa planta modelada é observar o comportamento do posicionamento " $\mathrm{x}$ " do bloco em função da força " $F$ " exercida. Aplicando a segunda lei de Newton ao sistema é obtida a equação (1), que descreve o comportamento do sistema.

$$
M \cdot d^{2} x / d t^{2}=F-k \cdot x-b \cdot d x / d t
$$

A equação (1) pode ser implementada diretamente no domínio do tempo pelo OpenModelica, como apresentado na Figura 2. 
Figura 2 - Implementação do sistema com o OpenModelica.

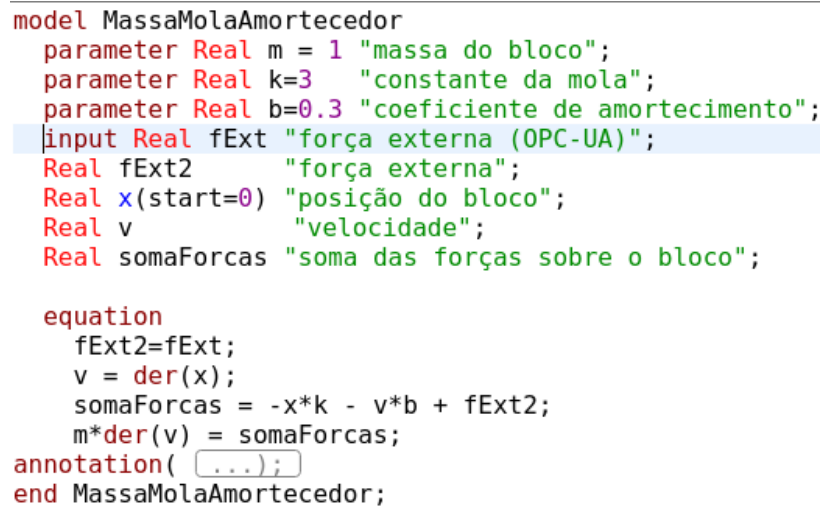

Fonte: Autor, 2018.

Para a simulação pelo Xcos deve-se realizar a transformada de Laplace da equação (1) para obter a função de transferência que relaciona a posição " $x$ " com a força " $F$ " aplicada sobre o bloco. Considerando o sistema inicialmente em repouso, tem-se a planta representada pela função de transferência G(s) apresentada na equação (2)

$$
G(s)=X(s) / F(s)=1 /\left(M . s^{2}+b . s+k\right)
$$

\section{3 - Arranjos para simulação}

A simulação foi realizada em dois contextos. A primeira análise foi da simulação com a planta em malha aberta, ou seja, aplicando-se uma força e observando o comportamento do sistema. A segunda avaliação se deu em uma configuração de malha de controle fechada com realimentação negativa, aplicando uma referência de posição "R" e gerando a força "F", exercida sobre o bloco, através de um controle proporcional. Em ambos os casos foi realizada a simulação da planta modelada diretamente pelo Xcos, representada por sua função de transferência, e da planta modelada no OpenModelica, com comunicação por OPC-UA. O arranjo para a simulação em malha aberta é apresentado na Figura 3.

Figura 3 - Simulação em malha aberta, por função de transferência e por bloco de comunicação OPC-UA.

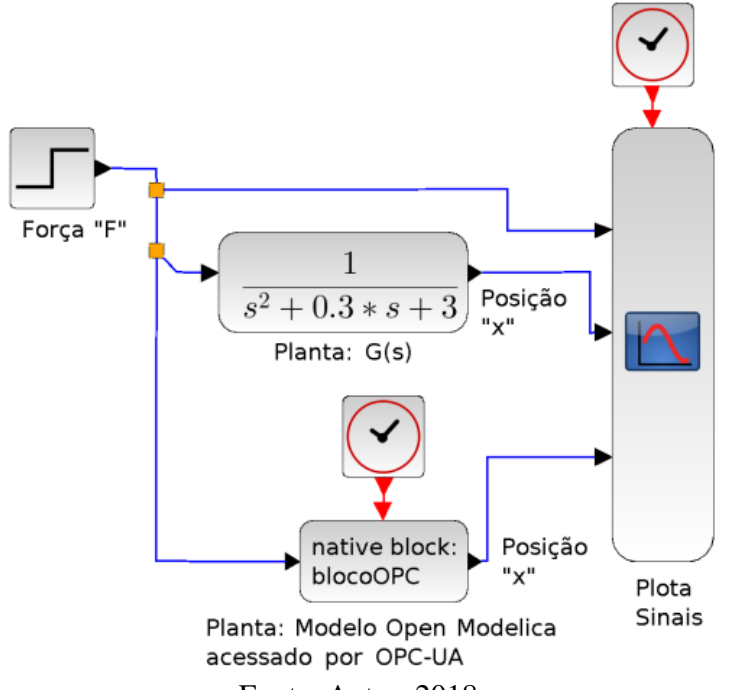

Fonte: Autor, 2018.

O arranjo para simulação em malha fechada é apresentado na Figura 4.
Figura 4 - Simulação em malha fechada, por função de transferência e por bloco de comunicação OPC-UA.

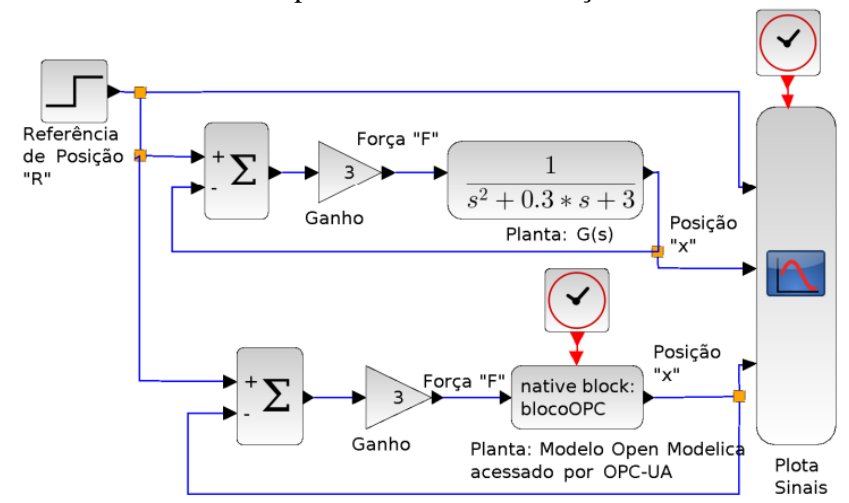

Fonte: Autor, 2018.

Para a utilização do bloco genérico do Xcos é necessária a criação de um programa executável com o uso da estruturação e das bibliotecas próprias do Scilab. Também é necessária a configuração do bloco genérico do Xcos, a configuração utilizada é apresentada na Figura 5.

Figura 5 - Configuração do bloco genérico do XCos.

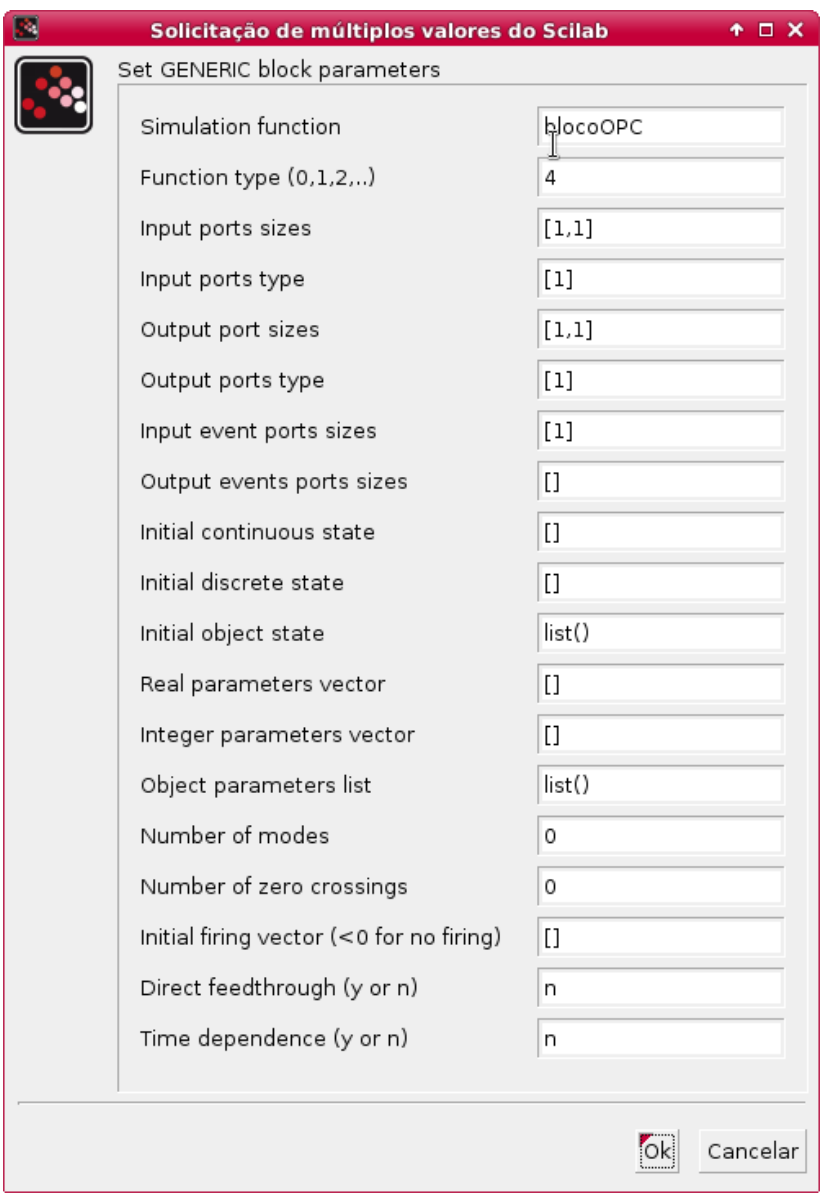

Fonte: Autor, 2018

\section{RESULTADOS}

Esta seção apresenta os resultados das simulações em malha aberta e em malha fechada.

\section{1 - Simulação em malha aberta}

Pela simulação em malha aberta, aplicando-se uma força do tipo degrau com amplitude $1 \mathrm{em} \mathrm{t}=2$ segundos, observa-se que os modelos apresentam comportamento semelhante, conforme apresentado na Figura 6. 
Pelos gráficos da posição "x", observa-se que o modelo simulado através do OpenModelica apresenta um pequeno atraso.

Figura 6 - Resultado da simulação em malha aberta.
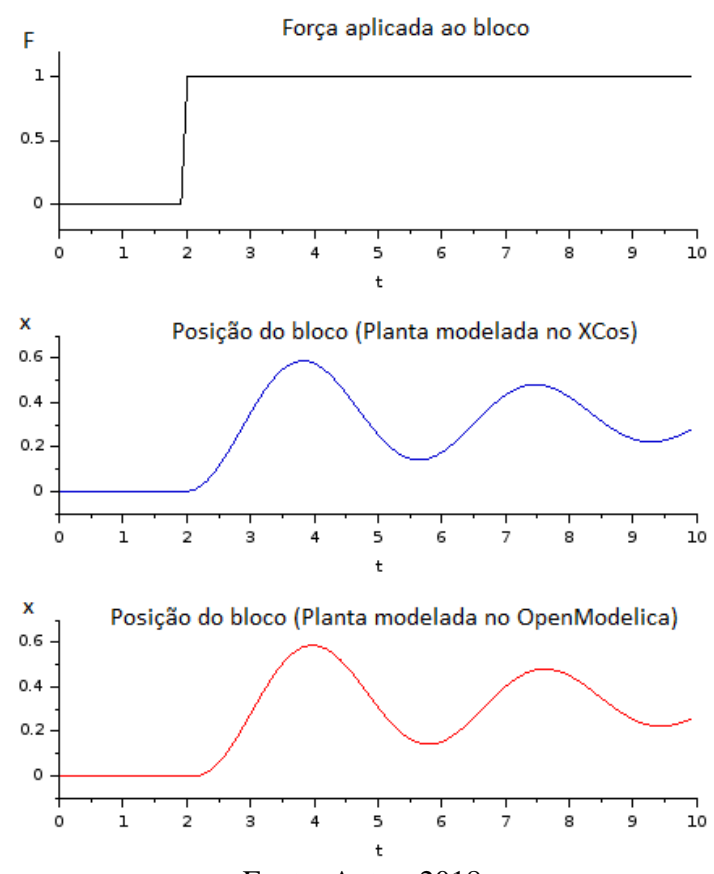

Fonte: Autor, 2018.

\section{2 - Simulação em malha fechada}

A simulação em malha fechada apresenta de forma mais evidente o efeito do atraso introduzido pelo tempo de acesso ao modelo que é executado pelo OpenModelica.

Observa-se, pela Figura 7, que apesar de o sistema modelado diretamente no Xcos ser estável em malha fechada, o modelo simulado através do OpenModelica se tornou instável, devido ao atraso introduzido no processo de comunicação pelo protocolo OPC-UA. Essa instabilidade é demonstrada pela oscilação com amplitude crescente. Observou-se a ocorrência da instabilidade para o ganho presente na malha maior que dois.

Figura 7 - Resultado da simulação em malha fechada.
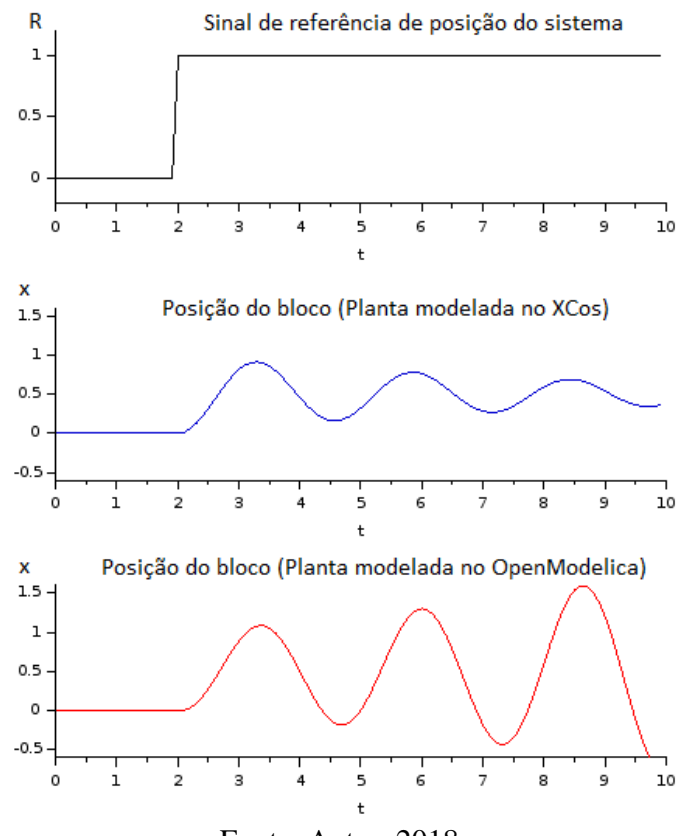

Fonte: Autor, 2018.

\section{CONCLUSÃO}

Este estudo mostrou a viabilidade da comunicação de duas ferramentas de modelagem e simulação pelo protocolo UPC-UA. O fato de o OpenModelica possuir a capacidade de integração por OPC-UA de forma nativa facilita a integração. A necessidade de utilizar um bloco genérico do Xcos, programado em C com a biblioteca Open62541, mostrou que a implementação de um cliente OPC-UA é simples, podendo ser uma solução para outros programas que disponibilizam essa capacidade de criação de blocos com funções personalizadas.

$\mathrm{Na}$ simulação em malha aberta observou-se que o modelo simulado pelo OpenModelica e acessado pelo protocolo OPC-UA apresentou resposta muito próxima àquela apresentada pela planta simulada diretamente pelo Xcos. Os gráficos de posição do bloco mostram que a resposta do modelo executado no OpenModelica apresenta um pequeno atraso, menor que 0,5 segundo. Esse atraso pode ser tolerável em determinados problemas, como em simulações onde o controlador envia comandos de chaveamento para a planta simulada.

$\mathrm{Na}$ simulação em malha fechada, observou-se que o pequeno atraso introduzido pelo tempo de troca de informações pode levar à instabilidade do sistema. Essa constatação indica que a integração feita não é adequada para a implementação de controle em malha fechada. De fato, o protocolo UPC-UA não foi desenvolvido para substituir os barramentos de campo, que são os que apresentam características adequadas para aplicações de controle em malha fechada.

Pode-se estudar a possibilidade de compartilhamento do relógio para sincronização das duas ferramentas de simulação. Caso esse compartilhamento seja possível, tornase viável a simulação em malha fechada, pelo fato do relógio compartilhado eliminar o atraso na comunicação.

Pelo resultado alcançado, pode-se concluir que a integração de ferramentas de modelagem e simulação de sistemas pode ser útil em aplicações onde o tempo de resposta não seja crítico. Pode-se aproveitar o potencial de modelagem de sistemas complexos do OpenModelica para representar plantas reais utilizando a capacidade de integração por OPC-UA para o desenvolvimento de sistemas de controle que envolvam comandos de chaveamento e intertravamentos.

Uma área onde a capacidade de comunicação por OPC-UA pode ser explorada é a comunicação entre plantas simuladas e dispositivos reais, como controladores lógicos programáveis (CLPs) ou microcontroladores. Essa capacidade pode permitir ao projetista realizar correções, ajustes e otimizações antes de o sistema ser ligado à planta real, onde erros podem ocasionar grandes prejuízos.

Pelos resultados obtidos neste artigo e a análise da evolução do padrão OPC-UA com sua convergência para aplicações em tempo real, com a arquitetura PubSub e o uso de redes do tipo TSN, pode-se concluir que a integração de diferentes ferramentas e até mesmo a integração entre modelos simulados e controladores reais podem ser viáveis no futuro, aumentando as possibilidades para estudantes e projetistas.

\section{REFERÊNCIAS BIBLIOGRÁFICAS}

BRUCKNER, D. et al. OPC UA TSN - A new Solution for Industrial Communication, California: Moxa, 2018. 
<https://www.moxa.com/doc/white_papers/opc-ua-tsn.pdf〉. Acesso em: 20 set. 2018.

JOHANSSON, Christoffer F OpenModelica Interactive Simulation using an OPC UA client. Bachelor thesis Department of Computer and Information Science, Linköping University, Linköping, 2017.

MODELICA, Modelica and the Modelica Association, 2018. Disponível em: <https://www.modelica.org/>. Acesso em: 22 set 2018 .

OPC FOUDATION, What is OPC?, 2018. Disponível em: <https://opcfoundation.org/about/what-is-opc/>. Acesso em: 22 set. 2018

OPEN62541, Release notes. 2018. Disponível em: <https://open62541.org/>. Acesso em: 22 set 2018.

OPEN MODELICA, OpenModelica - Introduction, 2018. Disponível em: <https://openmodelica.org/>. Acesso em 22 set 2018 .

SCILAB, Xcos - Dynamic systems modeler and simulator in discrete and continuous time domains. 2018. Disponível em: <http://scilab.io/products/xcos/>. Acesso em: 22 set 2018.

UNIFIED AUTOMATION, OPC UA Publish-Subscribe (Pub/Sub) - IoT becomes easier, 2018. Disponível em: $<$ https://www.unified-automation.com/news/newsdetails/article/opc-ua-publish-subscribe-pubsub-iotbecomes-easier.html>. Acesso em : 25 set. 2018.

\section{COPYRIGHT}

Direitos autorais: O autor é o único responsável pelo material incluído no artigo. 


\author{
Volume $14-\mathrm{N}^{\mathrm{o}} 159$ - Março/2019. \\ XL International Sodebras Congress \\ 10 a 12 de dezembro de 2018 - Vitória - ES.
}

\title{
EFICIÊNCIA LUMÍNICA EM INSTITUIÇÕES DE ENSINO SUPERIOR - UM ESTUDO DE CASOS NA UNIVERSIDADE FEDERAL DA BAHIA (UFBA)
}

\author{
LIGHTING EFFICIENCY IN HIGHER EDUCATION INSTITUTIONS - A CASE \\ STUDY IN THE FEDERAL UNIVERSITY OF BAHIA (UFBA)
}

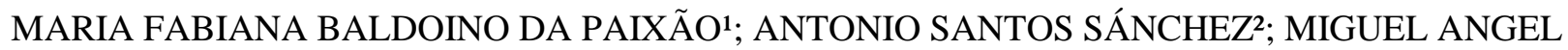 \\ IGLESIAS DURO ${ }^{1}$

\section{1 - UNIVERSIDADE FEDERAL DA BAHIA - PROGRAMA DE PÓS-GRADUAÇÃO EM ENGENHARIA INDUSTRIAL; 2- UNIVERSIDADE FEDERAL DE OURO PRETO - DEPARTAMENTO DE ENGENHARIA DE PRODUÇÃO}

mariafabiana.bp@gmail.com; sanchezbahia@gmail.com miguel.iglesias@ufba.br

\begin{abstract}
Resumo - Em uma edificação universitária, os sistemas de iluminação oferecem oportunidades para redução de despesas elétricas. O objetivo deste estudo de caso na Escola Politécnica da Universidade Federal da Bahia (EP-UFBA) é avaliar o desempenho energético da instituição e dos sistemas de iluminação atuantes nas salas de aula. Para tanto, foi calculado $o$ indicador de desempenho energético do edifício, Energy Use Intensity (EUI) e foram aferidos dados de iluminância em 12 salas de aula através da instrumentação (Luxímetro). Os resultados do EUI na instituição correspondem $65,5 \mathrm{kWh}$ $/ \mathrm{m}^{2} /$ ano, ao passo que $58 \%$ das salas apresentam zonas de baixa iluminância. Os retrofits dos sistemas de iluminação configuram uma alternativa apropriada para esta instituição visando economia de energia, melhoria do indicador e também expansão do conforto lumínico nas salas de aula.

Palavras-chave: Eficiência Energética. Edificação Universitária. Energy Use Intensity. Conforto Lumínico.
\end{abstract}

Abstract -In a university building, lighting systems offer opportunities for energy savings. The aim of this case study at the Polytechnic School of the Federal University of Bahia (EP$U F B A$ ) is to evaluate the institution's energy performance as well as lighting performance in classrooms. For this, it was calculated the building's energy performance indicator, Energy Use Intensity (EUI) of building and it was measured data of illuminance of 12 classrooms through the instrumentation apparatus (Luximeter). As a result, this paper presents the EPUFBA's EUI value of $65.5 \mathrm{kWh} / \mathrm{m}^{2} /$ year and indicates low illuminance conditions in $58 \%$ classrooms, suggesting that lighting systems retrofit are appropriate for this institution targeting energy savings, Energy Use Intensity improvement and also better lighting comfort in classrooms.

Keywords: Energy Efficiency. University Buildings. Energy Use Intensity. Light Comfort.

\section{INTRODUCTION}

In Brazil, the residential and non-residential buildings are together responsible for the third highest percentage of energy consumption by sector (MME, 2017). Energy consumption in buildings occurs in five phases: manufacturing of building materials, transport of these materials from production plants to building sites, construction of the building, operation and demolition of the building (SBCI, 2009). Most energy is consumed during the use phase in which energy is used for heating, cooling, lighting, cooking and ventilation (HUOVILA, 2007; ALKHATATBEH; MA'BDEH, 2017) which frame existing buildings in the use phase as propitious for energy savings.

Public sector buildings are currently being targeted to reduce energy consumption, save energy costs and demonstrate new technologies, providing incentives to the private sector to follow energy efficiency practices (HARRIS et al, 2004). In Brazil, energy issues are recognized by the Ministry of Mines and Energy (MME), which stablished in 2016 the Energy Efficiency Program $(P E E)$ regulated by the National Electric Energy Agency (ANEEL), targeting the implementation of projects to combat energy waste. In the year of implementation, the projects were destined to Research and Development (P\&D), while in 2017 it focused on Energy Efficiency in Public Service typologies, which include Federal Universities (ANEEL, 2016; ANEEL, 2018).

Despite national incentives on reducing energy demand, electric bill was the third highest expense group in Brazilian Federal Universities in the year 2015. These expenses are connected (among other factors) to the use of inefficient equipment and to the lack of efficient and rational use of energy by occupants (ANEEL, 2016). In the Federal University of Bahia (UFBA) the electricity expenses paid to the concessionaire - Companhia de Eletricidade do Estado de Bahia (COELBA) - increased by $82 \%$ between 2009 and 2017 (MINISTÉRIO, 2018). This scenario highlights need of reducing energy demand in Federal Universities to reach the national efforts on energy savings.

Existing university buildings are generally old and are adapted to current technologies installation in order to meet the diverse uses. This leads to the constantly increase of energy consumption and reflects the need to explore its energy savings potential (CHUNG; RHEE, 2014). In this sense, energy efficiency is presented as an alternative for the purpose of energy savings. Energy efficiency is associated to the use of less energy to result the same amount of 
response in a service, work or useful output (CHUG et al., 2006). A case study in a Korean university campus presented a potential for energy conservation between $6 \%$ and $29 \%$ through the implementation of strategies for improving energy efficiency (CHUNG; RHEE, 2014).

The energy efficiency indicators are used to designate the energy-consumption performance level of systems (CHUG et al., 2006). For energy use analysis in buildings, a commonly metric used is the Energy Use Intensity (EUI) that expresses the energy use per square foot per year and can be calculated through the overall energy consumption divided by the total floor area. This quotient can be measured yearly, considering the energy consumption in a time period of one year, and it can vary among buildings according to the location, type of building and building activity (TECHNOLOGY, 2011; NUS, 2016; ENERGY STAR, 2012).

The energy benchmarking is associated to the development of metrics that predict the energy performance of a building through references of similar buildings. It ensures the identification of indicators of energy assessments that express opportune aspects for energy improvements in a building (KHOSHBAKHT et al., 2018).

There are several aspects that influence energy consumption in higher education institutions and offer opportunities for interventions targeting energy efficiency, such as the building design, the components and devices, and behavior of its occupants (SBCI, 2009; GUL; PATIDAR, 2015; JAFARY et al., 2016).

\section{1 - Building Design}

The building design (or envelope) is an important aspect facing energy efficiency once it influences the amount of energy required to heat, cool and ventilate spaces during the use phase. The building design is also associated to the use of ventilation and natural lighting, as well as with the use of the equipment/infrastructure necessary to guarantee users comfort conditions (MISSAOUI; MOURTAD, 2010). An adequate building design can significantly reduce energy consumption once it requires less cooling and heating equipment use to guarantee comfort levels inside (HARVEY, 2009; SOZER, 2010).

Dimoudi and Kostarela (2009) concluded that an adequate energy design of school buildings has two main benefits, energy savings and the creation of indoor comfort conditions, which is necessary for the proper operation of the educational system. Newer projects contemplate aspects of thermal comfort, lighting for visual comfort and ventilations for indoor quality in order to require low energy demand.

When it comes to indoor areas it is necessary to allow the use of lighting and natural ventilation conditions offered in construction. A case study regarding a nursery and an elementary school building showed that measures to archive energy efficiency contemplates low-cost ones, as the installation of louvers for better solar and daylight control, the improvement of window air-tightness, providing better lighting control. These measures aim the maximum use of sunlight replacing the use of artificial lights (THEODOSIOU; ORDOUMPOZANIS, 2008).

\section{2 - Occupant's Behavior}

Educational buildings contemplate higher education institutions and different sized schools (elementary, primary, secondary school buildings) which have different educational level, occupation densities and time-table occupation, leading to different levels of energy consumption (PEREIRA, 2014). In the use phase, occupant's behavior has a direct impact on the assessment of the energy usage. First, because energy is used to provide indoor comfort (thermal and light) for occupants and second because of energy waste caused by them. As long as the space is occupied, higher amounts of energy are used and also wasted, which explains a direct relation between users and occupied period. The type of occupancy also influences energy consumption: by the time transient occupancy require more energy intensive services (e.g. ventilation), sedentary occupation the energy consumption can be less intense as a result of a moderate cooling and heating systems use (CIBSE, 2018).

The direct relation between energy consumption and users is agreed and discussed by many authors. Masoso and Grobler (2010) mentioned that the waste of energy from poor occupants' behavior requires attention when facing goals in improving energy efficiency and reinforced the existence of measures to promote better occupant behavior as energy awareness campaigns, incentives and punitive measures. Other studies reinforce the importance of changing energy-use behaviors aiming energy efficiency improve (Egging, 2013; González et al, 2012). Salleh et al. (2015) also points that user behavior influences the pattern of energy consumption in a building and reinforces the importance to consider the user factor for measuring building's energy efficiency.

\section{3 - Components and Devices}

The total amount and share of electricity consumed in non-residential buildings is high due to the use of electronic equipment and the increased use of existing technologies (CBECS, 2018). Despite the specificities of each educational building it is possible to evaluate the energy consumption by end use in each one and evaluate the distribution of energy use for each system. The energy end use in Brazilian public buildings is illustrated in Figure 1.

Figure 1 - Brazil typical end use in public buildings

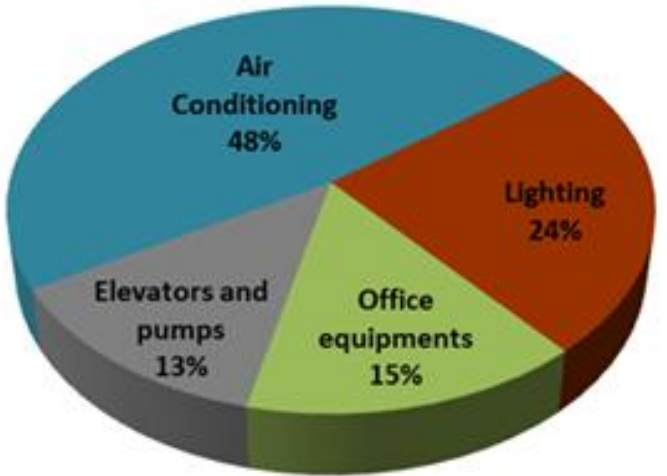

Source: MAGALHÃES, 2001.

The air conditioning system is responsible for the highest share of energy use in Brazilian public buildings. As well as the HVAC (Heating, Ventilating, and Air Conditioning) are used to ensure the user's internal thermal comfort, the lighting systems are indispensable for the performance of activities in a higher education institution. They are responsible for the second highest share of energy use they also offer opportunities for energy savings. 


\subsection{3 - Lighting systems and energy efficiency}

Generally, older public buildings do not present good lighting projects, or excessive standardization that does not consider several new uses and work equipment (JANNUZZI, 2010). Light systems require an adequate design to reach the purpose of an adequate illumination level while using minimum amount of electricity. They ensure comfort, productivity and safety, and concentrate potential opportunities for improving energy efficiency and promote energy savings (STEFANO, 2000; MAHLIA et al., 2011).

The technological advances in lighting systems have developed over the years and they ensure the possibility of reducing installed capacity of lighting systems using more efficient luminaires, lamps and reactors. Savings of the order of $50 \%$ of installed capacity have been obtained with technologies improvements lighting systems (DANELLA, M. et al., 2006).

Lighting systems power consumption is associated with the types of lighting devices (CHUNG; RHEE, 2014). Each lighting type has specific characteristics which make them adequate for specific uses and purpose. Some of these characteristics are lifetime and the efficacy which is a measure of how well a light source turns input power into the desired output, which the unit is lumens/Watt (DOE, 2011; EIA, 2012). This relation is shown in Table 1.

Table 1 - Lamps Efficacies and Lifetimes

\begin{tabular}{c|c|c} 
Current Technology & $\begin{array}{c}\text { Efficacy } \\
\text { (lumens/Watt) }\end{array}$ & $\begin{array}{c}\text { Typical Rated } \\
\text { Lifetime (hours) }\end{array}$ \\
\hline Fluorescent - T8 & $35-87$ & $7,500-20,000$ \\
Compact Fluorescent & $40-70$ & 10,000 \\
Mercury Vapor & $25-50$ & 29,000 \\
Metal Halide & $50-115$ & $3,000-20,000$ \\
Halogen & $14-20$ & $2,000-3,500$ \\
LED & $20-100$ & $15,000-50,000$
\end{tabular}

Source: Adapted from DOE, 2011; IEA, 2012.

As a parameter, the theoretical maximum luminous efficacy of white light is 220 lumens/Watt (DOE, 2011). Fluorescent lamps are those in which light is increased by an electric discharge containing a gas or an internal vapor. To promote illumination, a small amount of mercury is introduced into the tube and a special phosphorus material responsible for converting ultraviolet light into visible light. The Light Emitter Diode (LED) lamp consists of semiconductor devices filled with gases and coated with different phosphorus materials (SANTOS et al., 2015). Even though LED lamps cost is higher than the other lamps (fluorescent and incandescent), this technology has been expanding in the market due to, among other factors, its efficiency. LED lamps are more efficient than the fluorescent ones, and have longer duration, requiring a less substitution and consequently less maintenance expenses (SANTOS et al., 2015).

Lighting technologies offer opportunities for an efficient use, they also allow indoor comfort conditions for users, which is fundamental for educational purpose. The human perception of environmental comfort can promote reactions such as relaxation or greater productivity for its user's. The environmental comfort contemplates the luminous comfort which is the major motivation for lighting a building, once it is associated with various aspects of the use phase such as expansion of visual tasks and suppression of damage eyesight (BLANCO, 2007; OLIVEIRA, 2016).

In classrooms the illumination system must provide adequate conditions to the development of activities as reading and writing (YENER, 2002). As a way quantify and qualify lighting parameters in a work place, the Brazilian standard NBR 8995-1 (Lighting of workplace) indicates the illuminance parameter. Illuminance corresponds to the incident light flux per illuminated area, its unit of measure is lux (ABNT, 2013; MOREIRA, 1999). The parameters of illuminance in classrooms may vary according to each country codes of lighting and it can vary between 200 and 500 lux (YU; SU, 2015).

The aim of this case study is to evaluate the illuminance performance in the classrooms of a Brazilian Higher Education Institution, the Polytechnic School of the Federal University of Bahia (EP-UFBA) and calculate the energy performance indicator (Energy Use Intensity) of this institution.

\section{METHODOLOGY}

The methodology adopted in this case study is divided in two parts:

I) Calculus of an energy performance indicator, the Energy Use Intensity (EUI) - energy consumption per gross floor area per year $\left(\mathrm{Kwh} / \mathrm{m}^{2} /\right.$ year $)$ - of the higher education institution Polytechnic School of Federal University of Bahia (EP-UFBA), achieved through the data of electricity consumption between the years 2017 and 2018 and the gross floor area measured according to Royal Institution of Chartered Surveyors (RICS) parameters of gross internal area (GIA);

II) Gauge of the illuminance (quantitative parameter of the light environment) of the classrooms of the EP-UFBA. For this purpose, it was used the instrumentation of illuminance measurement, the Luximeter, foreseen in ISO 50002: 2014 (Energy audits - Requirements with guidance for use). The illuminance data were collected in 12 classrooms at night with the luminaires connected. For each classroom, 10 to 20 measurements were performed with the instrumentation, and the desk was adopted as a reference point in the horizontal plane. It was presented graphical and statistical analysis by boxplot.

\section{RESULTS}

The EP-UFBA was built in the 1950s in Salvador, located in a tropical rainforest (Af) climatic zone. The eight floors construction allocates seven departments, forty laboratories, twenty-seven classrooms, and one library (ESCOLA POLITÉCNICA, 2018). Figure 2 illustrates the institution's front view. 
Figure 2 - EP-UFBA

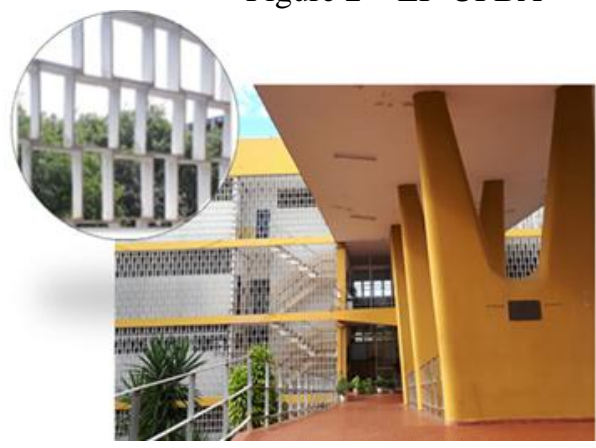

Source: Author, 2018

Although the architectural structure of the building favors the natural ventilation and lighting (through hollow façades positioned to the coast) there are air-conditioning systems operating in classrooms the whole year (due to the climate conditions) and also lighting systems operating during the night classes.

The operation of the institution during the years 2017 and 2018 leaded to an Energy Use Intensity equals to 65.5 $\mathrm{kWh} / \mathrm{m}^{2} /$ year. To benchmark the EUI, the value was compared to the Chartered Institution of Building Services Engineers (CIBSE) parameters, which presents a benchmarking of electricity Energy Use Intensity according to the building type (CIBSE, 2012). The averages of Energy Use Intensity $\left(\mathrm{kWh} / \mathrm{m}^{2} / \mathrm{year}\right)$ in educational building are rated as a good practice and a typical practice for each compartment of the institution. Figure 3 illustrates EPUFBA performance compared to CIBSE parameters.

Figure 3 - Energy Use Intensity ( $\mathrm{kWh} / \mathrm{m}^{2} /$ year) benchmarks: EPUFBA x CIBSE Higher Educational Buildings

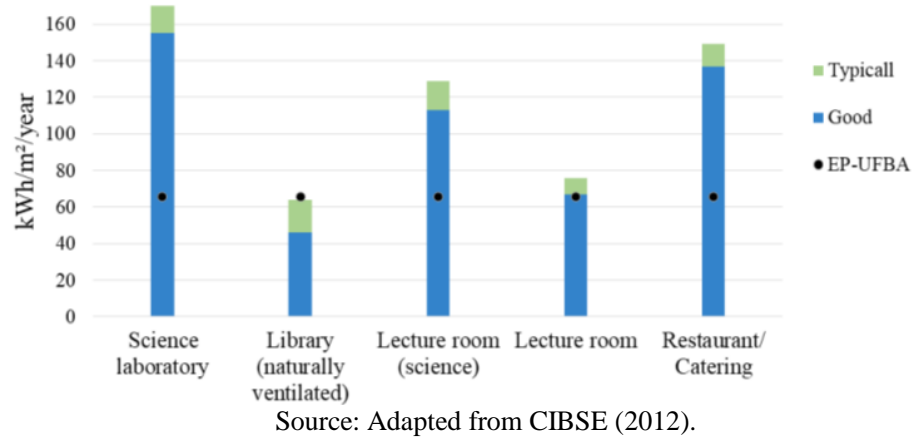

The EP-UFBA operates within a range of Energy Use Intensity of $65.5 \mathrm{kWh} / \mathrm{m}^{2} /$ year mostly considered good for an educational building energy use. This indicator is a result of the overall building's electric consumption, considering the operation of the diverse accommodations. For this reason, the indication of the EP-UFBA is rated according to the diverse accommodations of an educational building by CIBSE parameters.

The institution light system is mostly composed by fluorescent lamps model $\mathrm{T} 860 \mathrm{~cm}$. This illuminance apparatus operates in the classrooms during night journey where the classes are conducted. The illuminance performance in classrooms is shown in Figure 4 through the statistical graph boxplot.
Figure 4 - Illuminance distribution in classrooms (EP-UFBA).

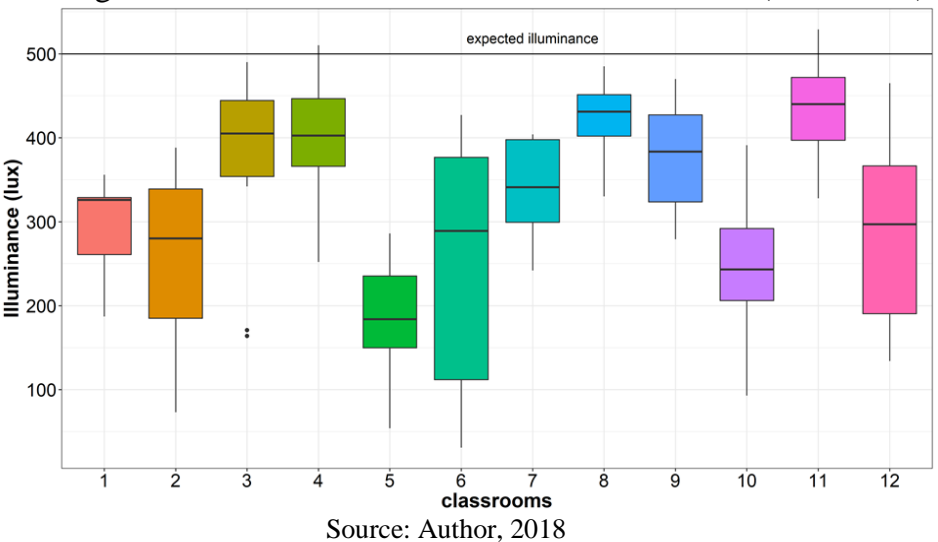

The standard NBR 8995-1 recommends that the maintained illuminance in classrooms during night journey must be 500 lux, and in areas where continuous work is performed, the illuminance maintained may not be less than 200 lux (ABNT, 2013). The classrooms 1, 2, 3, 5, 6, 10, 12 presented areas with illuminance lower than 200 lux which corresponds to $58 \%$ of classes evaluated. Two classrooms presented areas with illuminance values superior than the indicated by the standard, which were classroom number 4 (one-point equals $510 \mathrm{lux}$ ) and classroom number 11 (onepoint equals 529 lux), corresponding $17 \%$ of samples evaluated.

When evaluating the 12 samples exposure it is notable an ununiformed distribution of illuminance among them, indicating that each classroom performed in a particular condition, noticed through the comparison of each sample's median. This performance may vary in each classroom according to its area and the distribution of illumination apparatus inside.

When evaluating the performance of each classroom it is notable high amplitude of illuminance values (variation between maximum and minimum values), which is clearer in the classrooms 2, 3, 6 and 12. This performance can be justified by two aspects: a. In these classrooms there are a few luminaries in LED lamps model T8 $60 \mathrm{~cm}$ replacing old fluorescent lamps model T8 $60 \mathrm{~cm}$ out of operation, conducting to this ununiformed performance of illuminance inside classrooms; b. A discontinuous and random allocation of illuminance apparatus inside classrooms.

The qualitative analysis indicates a notable discontinue distribution of illuminance of classrooms evaluated, through the recognition of extremely bright areas and others poorly lit in the same classroom, which is perceptible by observers. In this sense the positioning of luminaires is an important aspect once an inadequate allocation can promote loss of illuminance for pillars and walls surface, which absorb illuminance from the light points (MOREIRA, 1999).

\section{CONCLUSION}

There are several ways to reduce energy demand in educational buildings which include interventions in building design, components and devices improvements and user's behavioral aspects. Measures on building envelope are appropriate for new constructions in which energy efficiency must be considered in planning phase, however interventions can be done on existing buildings allowing the use of natural light and ventilation which results in energy savings. Occupant's behavior can contribute to energy 
consumption reduction especially when students are engaged on energy issues. By this point of view, it is important for institutions to stimulate energy awareness through seminars, lectures and sharing energy usage historic. The HVAC and lighting systems are responsible for the highest amount of energy by end use in Brazilian public institutions and offer opportunities for energy savings.

The classrooms evaluated allow the use of natural lighting and ventilation, however during the nocturnal activities it is necessary the use artificial lighting. The lighting systems are fundamental to ensure propitious light comfort for reading and writing activities. The illumination distribution of classrooms during the night journey showed that $58 \%$ of classrooms presented zones of illuminance lower than required by the standard NBR 8995-1 which is 200 lux. These results are not only due to the lamps typology, but also due to the positioning of lamps in the internal environments, resulting in several zones with low illuminance. However, when evaluating the building's Energy Use Intensity, it operates within a range of 65.5 $\mathrm{kWh} / \mathrm{m}^{2} /$ year mostly considered typical for classrooms building category.

This study suggests that lighting retrofits are opportune at EP-UFBA, they can result on energy savings, EUI performance improvement, and in addition it can promote light comfort which is deeply important for the development of academic activities.

\section{REFERENCES}

ABNT NBR ISO/CIE 8995-1: Iluminacao de ambientes de trabalho. Associação Brasileira de Normas Técnicas, Rio de Janeiro, 2013

AL-KHATATBEH, B. J.; MA'BDEH, S. N. Improving visual comfort and energy efficiency in existing classrooms using passive daylighting techniques. Energy Procedia, v. 136, p. 102-108, 2017.

ANEEL - Agencia Nacional de Energia Elétrica. Chamada 001/2016: Eficiência Energética e Minigeração em Instituições Públicas de Educação Superior. Disponível em: <www.aneel.gov.br> Acesso em: 3 mai.2018.

ANEEL - Agencia Nacional de Energia Elétrica. Programa de Eficiência Energética. Disponível em:

<www.aneel.gov.br> Acesso em: 3 fev.2018.

BLANCO, M. A. O conforto luminoso como fator de inclusão escolar do portador de baixa visão nas escolas públicas regulares do Distrito Federal. Dissertação (Mestrado em Arquitetura e Urbanismo) - Universidade de Brasília, 2007.

CBECS - Commercial Buildings Energy Consumption Survey, (2012) "Energy Usage Summary". Disponível em: $<$

https://www.eia.gov/consumption/commercial/reports/2012/ energyusage/>. Acesso em: 10 Jan.2018.

CHUNG, M. H.; RHEE, E. K. Potential opportunities for energy conservation in existing buildings on university campus: A field survey in Korea. Energy and Buildings, v. 78, p. 176-182, 2014.

CHUNG, W.; HUI, Y. V.; LAM, Y. M. Benchmarking the energy efficiency of commercial buildings. Applied Energy, v. 83, n. 1, p. 1-14, 2006.
CIBSE. Efficiency in further and higher education: Cost effective low energy buildings Energy Consumption Guide 54. Disponível em: <http://www.cibse.org/getmedia/f944f3e0-e047-4c62-af8543f02533f2de/ECG54-Energy-Use-in-Further-HigherEducation-Buildings.pdf> Acesso em: 11 abr.2018

CIBSE. Guide F: Energy efficiency in buildings 3rd ed. The Chartered Institution of Building Services Engineers (CIBSE), London, UK, 2012.

DANELLA, M. et al. Projeto de Eficiência Energética no Hospital de Clinicas da UNICAMP. XVII Seminario Nacional de Distribuicao de Energia Eletrica, 2006

DIMOUDI, A.; KOSTARELA, P. Energy monitoring and conservation potential in school buildings in the $\mathrm{C}^{\prime}$ climatic zone of Greece. Renewable Energy, v. 34, n. 1, p. 289-296, 2009.

DOE - Departament of Energy. 2011 Buildings Energy Data Book. Department of Energy, U.S. , 2011.

EGGING, R. Drivers, trends, and uncertainty in long-term price projections for energy management in public buildings. Energy Policy, v. 62, p. 617-624, 2013.

EIA- Energy Information Administration. Trends in Lighting in Commercial Buildings. Disponível em: $<$ https://www.<eia.gov/consumption/commercial/reports/20 12/lighting/>. Acesso em: 4 ago.2018

ENERGY STAR. Data Trends - Energy Use Benchmarking. Disponível em: < https://www.energystar.gov/sites/default/files/buildings/tool s/DataTrends_Energy_20121002.pdf>. Acesso em: 24 jul. 2018.

ESCOLA POLITÉCNICA. Estrutura. Disponível em: $<$ http://www.eng.ufba.br/laboratorios?page=2>. Acesso em: 2 fev. 2018.

GONZÁleZ, A. B. R.; DÍAZ, J. J. V.; WILBY, M. R. Dedicated tax/subsidy scheme for reducing emissions by promoting innovation in buildings: The EcoTax. Energy policy, v. 51, p. 417-424, 2012.

GUL, M. S.; PATIDAR, S. Understanding the energy consumption and occupancy of a multi-purpose academic building. Energy and Buildings, v. 87, p. 155-165, 2015.

HARRIS, J. P. et al. Energy-Efficient Purchasing by State and Local Government: Triggering a Landslide down the Slippery Slope to Market Transformation. 2004.

HARVEY, L. D. Reducing energy use in the buildings sector: measures, costs, and examples. Energy Efficiency, v. 2, n. 2, p. 139-163, 2009.

HUOVILA, P. Buildings and climate change: status, challenges, and opportunities. United Nations Environment Programme (UNEP), 2007

JAFARY, M. et al. Understanding Campus Energy Consumption - People, Buildings and Technology. 2016 IEEE Green Technologies Conference (GreenTech), p. 68-72, 2016.

JANNUZZI, G. M. Estudo 50: Eficiência Energética no Setor Público. Perspectivas dos Investimentos Sociais no Brasil (PIS), 2010 
KHOSHBAKHT, M.; GOU, Z.; DUPRE, K. Energy use characteristics and benchmarking for higher education buildings. Energy and Buildings, v. 164, p. 61-76, 2018.

MAGALHÃES, L. C. Orientações Gerais para Conservação de Energia em Prédios Públicos. ELETROBRÁS PROCEL. Brasília, p. 53, 2001.

MAHLIA, T. M. I.; RAZAK, H. A.; NURSAHIDA, M. A. Life cycle cost analysis and payback period of lighting retrofit at the University of Malaya. Renewable and Sustainable Energy Reviews, v. 15, n. 2, p. 1125-1132, 2011.

MASOSO, O. T.; GROBLER, L. J. The dark side of occupants' behaviour on building energy use. Energy and buildings, v. 42, n. 2, p. 173-177, 2010.

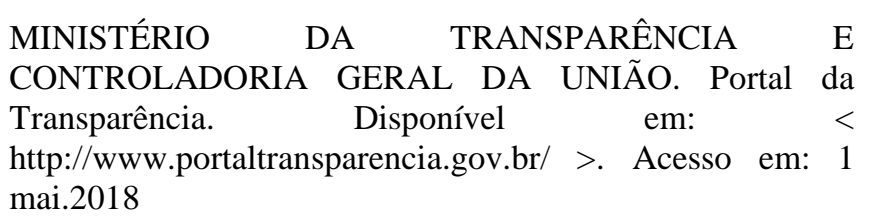

MISSAOUI, R.; MOURTADA, A. Instruments and Financial Mechanisms of energy efficiency measures in building sector. World Energy Council \& ADEME, v. 58, 2010 .

MME- Ministério das Minas e Energia. Balanço Energético Nacional: relatório síntese 2017. Disponível em: $<$ https://ben.epe.gov.br/downloads/S\%C3\%ADntese\%20do $\% 20$ Relat\%C3\%B3rio\%20Final_2017_Web.pdf>. Acesso em: 6 jul.2018.

MOREIRA, V. A. Iluminação Elétrica. Edgar Blucher, v. 1, 1999.

NUS - National University of Singapore. Sustainability Report 2016. National University of Singapore, 2016

OLIVEIRA, A. L. A. Avaliação das condições de desempenho acústico, lumínico, e térmico em edificações de porte monumental: um estudo de caso da biblioteca central e do restaurante universitário da Universidade de Brasília. Dissertação (Mestrado em Arquitetura e Urbanismo) - Universidade de Brasília, 2016.

PEREIRA, L. D. et al. Energy consumption in schools-A review paper. Renewable and Sustainable Energy Reviews, v. 40, p. 911-922, 2014.

SALLEH, M. N. M. et al. Users' Perception of Energy Efficiency in School Design. Procedia-Social and Behavioral Sciences, v. 170, p. 155-164, 2015.

SANTOS, T. S.et al. Análise da eficiência energética, ambiental e econômica entre lâmpadas de LED e convencionais. Eng Sanit Ambient, v. 20, n. 4, p. 595-602, 2015.

SBCI, U. N. E. P. Buildings and climate change: Summary for decision makers. United Nations Environmental Programme, Sustainable Buildings and Climate Initiative, Paris, pp. 1-62, 2009

SOZER, H. Improving energy efficiency through the design of the building envelope. Building and Environment, v. 45, n. 12, p. 2581-2593, 2010.
STEFANO, J. D. Energy efficiency and the environment: the potential for energy efficient lighting to save energy and reduce carbon dioxide emissions at Melbourne University, Australia. Energy, v. 25, n. 9, p. 823-839, 2000.

TECHNOLOGY RESEARCH AND DEVELOPMENT SUBCOMMITTEE. Submetering of building energy and water usage: Analysis and recommendations of the subcommittee on buildings technology research and development. Technology Research and Development Subcommittee, 2011

THEODOSIOU, T. G.; ORDOUMPOZANIS, K. T. Energy, comfort and indoor air quality in nursery and elementary school buildings in the cold climatic zone of Greece. Energy and Buildings, v. 40, n. 12, p. 2207-2214, 2008.

YENER, A. K. Daylight analysis in classrooms with solar control. Architectural Science Review, v. 45, n. 4, p. 311 316, 2002.

YU, X.; SU, Y. Daylight availability assessment and its potential energy saving estimation-A literature review. Renewable and Sustainable Energy Reviews, v. 52, p. 494-503, 2015.

\section{ACKNOWLEDGMENT}

This study was financed in part by the Coordenação de Aperfeiçoamento de Pessoal de Nível Superior - Brasil (CAPES) - Finance Code 001.

\section{COPYRIGHT}

Direitos autorais: $\mathrm{O}(\mathrm{s})$ autor(es) é(são) o(s) único(s) responsável(is) pelo material incluído no artigo. 
Volume $14-\mathrm{N}^{\mathrm{o}} 159$ - Março/2019.

XL International Sodebras Congress

10 a 12 de dezembro de 2018 - Vitória - ES.

\title{
LOCALIZAÇÃO EFICIENTE DE ESTAÇÕES DE CARREGAMENTO DE VEÍCULOS ELÉTRICOS NUMA REGIÃO METROPOLITANA UTILIZANDO METAHEURÍSTICA CRO E TRAJETOS VEICULARES REAIS
}

\author{
EFFICIENT PLACEMENT OF ELECTRIC VEHICLE CHARGING STATIONS \\ IN A METROPOLITAN AREA UTILIZING CRO AND REALISTIC VEHICLE \\ ROUTING INFORMATION
}

\author{
DANILO CESAR AZEREDO SILVA ${ }^{1}$; MÁRIO MESTRIA ${ }^{1}$
}

1 - INSTITUTO FEDERAL DO ESPÍRITO SANTO

danilo@ifes.edu.br;mmestria@ifes.edu.br

\begin{abstract}
Resumo - Neste trabalho, um modelo matemático de otimização foi utilizado para localizar estações comerciais de carregamento de veículos elétricos (ECVEs) na região metropolitana da Grande Vitória, ES, de forma a minimizar seu custo de implantação, bem como os custos de deslocamento dos usuários de veículos elétricos (VEs) às ECVEs mais próximas a eles. Diversos cenários de utilização foram criados, selecionando-se locais típicos onde ECVEs têm sido instaladas em diversos países, bem como trajetos reais entre VEs e ECVEs, obtidos programaticamente de serviços de mapeamento da Internet. Para a determinação eficiente da localização das ECVEs, foram utilizados métodos exatos, além da metaheurística Chemical Reaction Optimization. Os resultados obtidos poderão auxiliar a futura implantação de ECVEs em áreas metropolitanas.
\end{abstract}

Palavras-chave: Veículos Elétricos. Chemical Reaction Optimization. Estações de carregamento de Veículos Elétricos.

\begin{abstract}
In the present work, a mathematical optimization problem was used for placing commercial electric vehicle charging stations (ECVEs) in the metropolitan area of Grande Vitória, ES, Brazil, in order to minimize their deployment costs, as well as the cost of electric vehicles (VEs) operators to drive to their nearest stations for recharging. Several utilization scenarios have been created, selecting typical locations where ECVEs have been installed in several countries, as well as realistic routes between VEs and ECVEs, which were programmatically obtained from Internet-based mapping services. To efficiently determine the location of ECVEs, exact methods were used in addition to the Chemical Reaction Optimization metaheuristic. Results could help future deployment of ECVEs in metropolitan areas.
\end{abstract}

Keywords: Electric Vehicles. Chemical Reaction Optimization. Commercial electric vehicle charging stations.

\section{INTRODUÇÃO}

A melhoria da qualidade do ar nas áreas metropolitanas dependerá, em grande parte, da redução de emissões produzidas por veículos de combustão interna. Uma forma mais eficiente para atingir a redução de emissões é a da intensificação da circulação de veículos elétricos (VEs), o que também poderá aliviar a dependência do petróleo e reduzir a emissão de gases causadores do efeito estufa.
No Brasil, em 2015, 65,6\% da energia elétrica produzida foi de origem hidráulica e eólica (EMPRESA DE PESQUISA ENERGÉTICA, 2016), constituindo-se em fontes de energia renovável, o que torna ainda mais atraente a eletrificação de nossos sistemas de transporte, em relação a outros países.

Embora existam diversas maneiras de recarregar baterias de VEs, estações de carregamento comerciais de veículos elétricos (ECVEs) deverão ser a principal fonte de energia de recarga, devido às dificuldades para o carregamento residencial em grandes centros urbanos (WU et al., 2010). Desse modo, a introdução de VEs em tais áreas dependerá da implantação otimizada de ECVEs, em termos de custo e localização. Se as ECVEs não estiverem presentes em número suficiente e convenientemente próximas aos futuros proprietários de VEs, a adoção da tecnologia poderá ser desestimulada. Além disso, as mesmas deverão estar suficientemente dispersas, de modo os VEs possam circular sem restrições por toda a cidade (LAM; LEUNG; CHU, 2013). Do ponto de vista dos futuros proprietários de ECVEs, o seu custo de implantação e operação deverá ser minimizado, a fim de tornarem-se atrativas financeiramente.

Um modelo matemático de otimização foi utilizado para localizar ECVEs na região da Grande Vitória, ES, com o objetivo de minimizar tanto os custos de implantação das estações quanto os custos dos usuários de VEs para se deslocarem às estações mais próximas.

O modelo, proposto por Baouche e colaboradores (2014), foi formulado como um problema de programação inteira e toma como entrada um conjunto de locais candidatos a tornarem-se ECVEs, bem como um conjunto de centros de consumo, além de outros dados descritos no item 2.2, e retorna um subconjunto de locais candidatos a receberem ECVEs, cuja localização é ótima ou próxima da ótima.

O modelo foi resolvido por métodos matemáticos exatos e um método heurístico. A resolução por métodos exatos possibilitou a obtenção dos valores ótimos para as instâncias propostas, porém a um custo computacional relativamente 
alto. A utilização de um método heurístico permitiu que as mesmas instâncias fossem resolvidas de forma quase ótima a um custo computacional mais baixo, aumentando a possibilidade de que a solução possa ser empregada mais efetivamente na avaliação de diferentes cenários de utilização.

A metaheurística Chemical Reaction Optimization (CRO), proposta recentemente por LAM e LI (2012), foi adaptada para resolver o problema de otimização escolhido.

Finalmente, uma base de dados contendo locais candidatos a receberem ECVEs, bem como centros de consumo, foi criada a partir de rotas reais de deslocamento veicular obtidos de sistemas de mapeamento e navegação, disponíveis na Internet, para a região da Grande Vitória. Locais candidatos a receber ECVEs foram selecionados tomando-se como base locais em que estações são comumente instaladas em países cuja eletrificação parcial da frota de veículos já é uma realidade. A utilização de distâncias reais de percurso, também obtidas dos mesmos serviços de navegação, permitiu uma representação mais precisa das necessidades de consumo de energia dos VEs, em relação ao uso de distâncias euclidianas ou geodésicas.

\section{METODOLOGIA}

\section{1 - Definição dos cenários de carregamento de VEs}

Para avaliar o desempenho do modelo de otimização e a eficácia da adaptação do CRO na resolução do mesmo, uma base de dados contendo locais candidatos a receberem ECVEs em um centro metropolitano foi criada, utilizando o serviço online de mapeamento Google Maps API (GOOGLE INC., 2018). O centro escolhido foi o da Grande Vitória, ES. O mesmo compreende sete cidades e possuía, em 2016, cerca de 870.000 carros (CONFEDERAÇÃO NACIONAL DO TRANSPORTE, 2016).

Inicialmente, foram selecionados, programaticamente, 547 locais candidatos a instalação de ECVEs, buscando-se por pontos de interesse que correspondem a locais típicos onde ECVEs têm sido instaladas nos Estados Unidos (MCCAULEY, 2018). Em seguida, foram efetuadas triagens manuais visando eliminar locais inapropriados, de onde 272 pontos de interesse foram selecionados para criação da base dados descrita no item 2.4. Tais pontos correspondem a postos de gasolina, hospitais, estacionamentos comerciais, shopping centers, além do aeroporto de Vitória.

Devido a eletrificação da frota brasileira de automóveis ser praticamente inexistente, foram utilizados alguns valores típicos, baseados em informações disponíveis na literatura:

- Frota: 100 a 1000 VEs, correspondendo de 0,01\% a $0,1 \%$ da frota atual estimada da Grande Vitória (1 milhão).

- VEs: Baterias com capacidade de 24kWh, correspondente a menor capacidade de bateria dentre os VEs puros a venda nos EUA, em 2018 (EVADOPTION, 2018). Consumo de energia combinado (cidade e estrada) de $0,1865 \mathrm{kWh} / \mathrm{Km}$, correspondente a média dos 14 principais VEs puros a venda nos EUA, em 2018.

- ECVEs: Estações com carregadores de nível 3 (carga rápida em corrente contínua), por permitirem o carregamento completo das baterias da maioria dos VEs em menos de 30 minutos. Cada ECVE permite o carregamento de oito VEs simultaneamente. A capacidade total de fornecimento é de $400 \mathrm{kWh}$, com disponibilidade de $12 \mathrm{~h}$ diárias, perfazendo uma capacidade total diária de $4.800 \mathrm{kWh}$, por ECVE. O custo total estimado é 600.000 Reais (AGENBROAD; HOLLAND, 2014).

\section{2 - Modelo de otimização para localização de ECVEs}

O modelo escolhido para localização de ECVEs foi proposto por Baouche e colaboradores (2014). A razão da sua escolha se deve ao fato do mesmo retratar com bastante fidelidade as necessidades tanto do ponto de vista dos usuários de EVs, quanto dos futuros proprietários de ECVEs. O mesmo é baseado nos modelos clássicos FCLP - Fixed Charge Location (BALINSKI, 1965) e p-dispersion (KUBY, 1987). Os autores se concentraram em minimizar o custo total das viagens entre zonas de demanda e ECVEs. A demanda é representada por agrupamentos de EVs, localizados em pontos selecionados. O custo fixo de instalação das estações propriamente ditas também faz parte do modelo, assim como a manutenção de uma distância mínima entre as mesmas. Sua formulação é mostrada a seguir:

\section{Variáveis de decisão:}

$$
\begin{gathered}
x_{j}=\left\{\begin{array}{c}
1, \text { se a estação candidata } j \text { é selecionada } \\
\text { ou } 0 \text {, do contrário }
\end{array}\right\} \\
y_{i j}=\left\{\begin{array}{c}
1 \text { se o centro de demanda i é coberto } \\
\text { pela estaçâo } j \text { ou } 0, \text { do contrảrio }
\end{array}\right\}
\end{gathered}
$$

\section{Função de otimização:}

$$
\operatorname{Min} \sum_{j \in J} f_{j} x_{j}+\propto \sum_{i \in I} \sum_{j \in J} n_{i}^{(e v)} d_{i j} y_{i j}
$$

Sujeito a:

$\sum_{j=1}^{n} y_{i j}=1, \forall i \in I$

$$
y_{i j}-x_{j} \leq 0, \forall i \in I, \forall j \in J
$$

$$
\sum_{i \in I} n_{i}^{(e v)}\left(D i+d_{i j}\right) y_{i j} \leq C_{j} x_{j}, \forall j \in J
$$

$$
\begin{gathered}
r x_{i} x_{j} \leq \text { dist }_{i j}, \forall i, j \in J \\
x_{j} \in\{0,1\}, \forall j \in J, r>0 \\
y_{i j} \in\{0,1\}, \\
\forall i \in I, \forall j \in J
\end{gathered}
$$

\section{Onde:}

$J$ : conjunto de locais candidatos a receber ECVEs;

$I$ : conjunto de centros de demanda de energia;

$f_{j}$ :custo para se situar uma ECVE no local candidato $j$;

$D_{i}$ : demanda de energia no centro de consumo $i$;

$d_{i j}$ : energia necessária para um veículo se deslocar de um centro de consumo $i$ a uma estação de carregamento $j$;

$r$ : distância mínima entre duas estações de carregamento; $d_{i s t_{i j}}$ : distância entre a estação $i$ e a estação $j$; $C_{j}$ : capacidade da estação de carregamento $j$; 
$\alpha$ : custo do quilowatt-hora, que pode ser multiplicado por um período de tempo $T$, necessário para obtenção de lucro; $n_{i}^{(e v)}$ : número médio de veículos se deslocando para um centro de consumo $i$;

A função Erro! Fonte de referência não encontrada. representa a função de otimização. O objetivo é minimizar o custo total de instalação e manutenção das ECVEs, bem como a energia total dispendida por todos os veículos para chegar às ECVEs designadas. As restrições Erro! Fonte de referência não encontrada. e Erro! Fonte de referência não encontrada. asseguram que cada agrupamento de demanda seja coberto por uma ECVE. A restrição Erro! Fonte de referência não encontrada. garante que a demanda atribuída a estação $j$ não esteja além da capacidade $\mathrm{C}_{j}$, daquela ECVE. A restrição não-linear Erro! Fonte de referência não encontrada. é derivada do problema de pdispersão (KUBY, 1987), e força cada ECVE a estar separada por uma distância mínima $r$. A mesma pode ser simplificada para uma restrição (10):

$$
\begin{gathered}
r+\left(M-\text { dist }_{i j}\right) x_{i}+\left(M-d_{i s t i j}\right) x_{j} \leq 2 M- \\
\text { dist }_{i j}
\end{gathered}
$$

Onde $M$ é uma constante de valor alto, como $\operatorname{Max}\left(\right.$ dist $\left._{i j}\right), \forall i, j \in J$. Finalmente, as restrições Erro! Fonte de referência não encontrada. e Erro! Fonte de referência não encontrada. definem $y_{i j}$ e $x_{j}$ como binários (0 ou 1) e $r$ como sendo maior que 0 .

Uma vez que Baouche e colaboradores (2014) não atribuíram um nome específico a seu modelo, no presente trabalho, o mesmo será denominado FCLP Baouche.

\section{3 - Metaheurística Chemical Reaction Optimization (CRO)}

Lam e Li (2012) propuseram uma metaheurística para solução de problemas de otimização inspirada na natureza das reações químicas, denominado de Chemical Reaction Optimization (CRO). A reação química é um processo natural que transforma substâncias instáveis em estáveis. Esta característica é incorporada ao CRO, a fim de resolver problemas de otimização.

Um sistema de reação química consiste de substâncias químicas, composta de moléculas, em um ambiente. Moléculas possuem energia potencial e cinética. Uma reação química ocorre quando o sistema é instável, possuindo energia excessiva. Todos os sistemas de reação química tendem a alcançar um estado de equilíbrio, no qual a energia potencial cai a um mínimo. O CRO simula esse fenômeno convertendo energia potencial em energia cinética, pela transferência gradual da energia das moléculas para o ambiente, através de passos consecutivos, ou sub-reações, passando por vários estados de transição, que resultam em produtos mais estáveis e com energia mínima. É um processo iterativo em busca do ponto ideal.

Uma alteração química em uma molécula é desencadeada por uma colisão. O CRO utiliza quatro tipos de colisões: colisão ineficaz com a parede, decomposição, colisão ineficaz intermolecular e síntese. As duas colisões ineficazes implementam busca local (intensificação), enquanto que a decomposição e a síntese dão o efeito de diversificação. As reações moleculares elementares estão resumidas na
Figura 1. Soluções são manipuladas através de uma sequência aleatória de reações. Uma mistura adequada de intensificação e diversificação permite fazer uma busca efetiva do mínimo global dentro do espaço de soluções.

\begin{tabular}{|c|c|c|}
\hline \multirow{2}{*}{$\begin{array}{c}\text { Extensão da } \\
\text { mudança }\end{array}$} & \multicolumn{2}{|c|}{ Número de moléculas envolvidas } \\
\hline & 1 molécula & 2 moléculas \\
\hline Maior & Decomposição & Síntese \\
\hline Menor & $\begin{array}{c}\text { Colisão ineficaz } \\
\text { com a parede }\end{array}$ & $\begin{array}{l}\text { Colisão ineficaz } \\
\text { intermolecular }\end{array}$ \\
\hline
\end{tabular}

Tabela 1 - Características das quatro reações elementares

Figura 1 - Quatro reações elementares do CRO

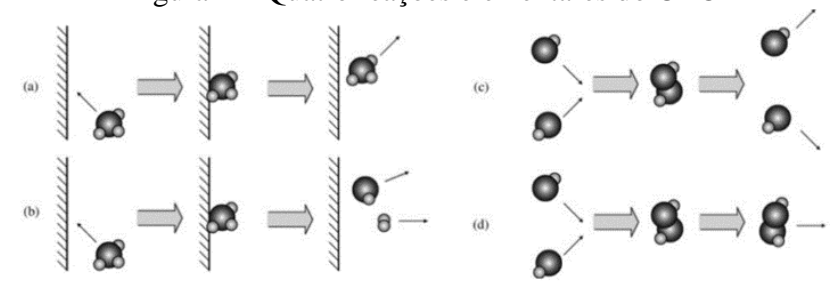

(a) Colisão ineficaz com a parede; (b) Decomposição;

(c) Colisão ineficaz intermolecular; (d) Síntese. Fonte: Lam e Li, 2012

A adaptação da metaheurística CRO para resolução do modelo FCLP Baouche requereu a criação de estruturas de dados para representar o conjunto de moléculas participantes de uma reação química, bem como a implementação de algoritmos, denominados operadores, responsáveis pela implementação das colisões moleculares. A molécula, que é a unidade básica do CRO, foi definida como uma classe de uma linguagem de programação orientada a objetos (C\#) e seu pseudocódigo mostrado na Figura . Contém os seguintes atributos:

- Identificador da Molécula (MolID): identifica uma molécula na população de moléculas.

- Estrutura molecular $(\omega)$ : armazena uma solução viável para o problema, ou seja, o valor da função objetivo, além das variáveis de decisão $x$ (1) e $y$ Erro! Fonte de referência não encontrada.

- Energia potencial $(\boldsymbol{P E})$ : é definida como o valor da função objetivo da solução correspondente $(\omega)$.

- Energia cinética $(\boldsymbol{K} \boldsymbol{E})$ : é um número não negativo que quantifica a tolerância do sistema em aceitar uma solução pior do que a existente.

- Número de colisões (NumHit): número total de colisões que uma molécula já sofreu.

- Estrutura mínima (MinStruct): é a solução $(\omega)$ com a menor $(P E)$, que uma molécula atingiu, até um dado momento (melhor solução).

- Energia potencial mínima (MinPE): é o PE correspondente ao MinStruct.

- Número mínimo de colisões (MinHit): é o número da colisão em que a molécula atingiu o MinPE.

Tabela 1 e ilustradas na 
Figura 2-A Classe Molécula

\begin{tabular}{|l}
\hline classe Molecula \{ \\
Atributos: \\
MolID, $\omega$, PE, KE, NumHit, MinStruct, MinPE, MinHit \\
Métodos: \\
// Construtor \\
Molecula (molID, solucãoInicial, KEinicial ) \{ \\
MolID $\leftarrow$ molID; \\
$\omega \leftarrow$ initialSolution; \\
PE $\leftarrow$ f $\omega) ;$ \\
KE $\leftarrow$ KEinicial; \\
NumHit $\leftarrow 0 ;$ \\
MinStruct $\leftarrow \omega ;$ \\
MinPE $\leftarrow P E ;$ \\
MinHit $\leftarrow 0 ;\}\}$
\end{tabular}

Os algoritmos referentes aos operadores foram adaptados de algoritmos de intensificação e diversificação disponíveis na literatura, e estão descritos a seguir:

- Colisão ineficaz com a parede: ocorre quando uma molécula colide com a parede de um recipiente e então é rebatida, sem se partir, permanecendo uma única molécula. Neste tipo de colisão, a solução existente, $\omega$, é perturbada e se torna uma solução $\omega^{\prime}$, i.e., $\omega \rightarrow \omega^{\prime}$. Isto é feito gerando-se uma solução $\omega^{\prime}$ que esteja na vizinhança de $\omega$, através de um operador baseado no mecanismo $\lambda$ interchange, proposto por Osman e Christofides (1994).

- Colisão ineficaz intermolecular: Ocorre quando duas moléculas colidem entre si e, em seguida, se afastam. O número de moléculas permanece inalterado, i.e., $\omega_{1}+\omega_{2} \rightarrow$ $\omega_{1}^{\prime}+\omega_{2}^{\prime}$. Utiliza o mesmo operador do item anterior.

- Decomposição: Ocorre quando uma molécula $(\omega)$ colide com uma parede e, em seguida, quebra-se em duas partes, produzindo $\omega^{\prime}{ }_{1}$ e $\omega^{\prime}{ }_{2}$, i.e., $\omega \rightarrow \omega_{1}^{\prime}+\omega_{2}^{\prime}$. Para esta operação, utilizou-se o algoritmo Half-total change, proposto por Lam e Li (2012).

- Síntese: É o oposto da decomposição. Ocorre quando duas moléculas colidem uma contra a outra e se fundem, isto é: $\omega_{1}+\omega_{2} \rightarrow \omega$ '. O operador empregado foi o Distance Preserving Crossover (DPX), proposto por Merz e Freisleben (1997) para resolução do problema de assinalamento quadrático por Algoritmo Genético.

\section{4 - Base de dados contendo locais candidatos a ECVES}

Conforme descrito no item 2.1, uma base de dados mapeamento Google Maps API. A mesma é composta de 5 instâncias, com tamanhos entre 50 e 250 vértices, que servem tanto como locais candidatos quanto centros de consumo. A candidato foi obtida através do serviço Google Maps Distance Matrix API, que que fornece a distância e o tempo de percurso para uma matriz de origens e destinos (GOOGLE INC., 2018). As instâncias foram nomeadas de vixnnn, onde nnn representa o número de vértices (estações/consumidores), variando entre 50 e 250, em intervalos de 50 vértices, ou seja, vix050, vix100, vix150, vix200 e vix 250

\section{RESULTADOS}

\subsection{Adaptação do CRO para o modelo FCLP Baouche}

Para a avaliação da adaptação da metaheurística CRO para o modelo FCLP Baouche, cada uma das cinco instâncias da base vix foi resolvida, de forma exata, utilizando o denominada vix, foi criada a partir de consultas ao serviço distância entre cada centro de consumo e cada local otimizador IBM CPLEX (IBM, 2017) na versão 12.6. A

seguir, na mesma plataforma computacional, cada instância foi resolvida 30 vezes pelo CRO, utilizando-se a mesma configuração para todos os problemas. Os resultados foram, então, comparados, em termos de gaps e tempos de execução, com os obtidos pelo CPLEX. Gap é definido como a diferença percentual entre o resultado obtido pelo CRO e o seu respectivo valor ótimo ou o valor da melhor solução viável conhecida (MSV), na resolução de um problema.

A plataforma computacional utilizada foi um PC, com processador Intel i7, $2.3 \mathrm{GHz}, 16 \mathrm{~GB}$ RAM e Windows 10.0.

A configuração dos parâmetros operacionais do CRO utilizada na resolução dos problemas foi obtida empiricamente, na forma de tentativa e erro, sendo a seguinte: PopSize $=10$, KELossRate $=0,8$, MoleColl $=0,1$, InitialKE $=1.000 .000 .000, \alpha=10, \beta=100.000 .000$, buffer $=0$. Como critério de parada, limitou-se o número máximo de iterações em 10.000 e o número máximo de iterações sem melhorias em 5.000. Além disso, o CRO foi configurado para terminar caso o valor ótimo ou a MSV para a instância fosse atingido.

Devido a eletrificação da frota brasileira de automóveis ser praticamente inexistente, valores constantes foram atribuídos à alguns dos dados de entrada do modelo FCLP Baouche, como se segue:

- $D i=24 k W h, \forall i \in I$

- $r=5000 m$

- $n_{\mathrm{i}}^{\left[\mathrm{iev}^{\mathrm{j}}\right]}=4, \forall i \in I$

- $f_{j}=600.000$ Reais, $\forall j \in J$

- $c_{j}=4.800 \mathrm{kWh}, \forall j \in J^{*}$

- $\propto=540$, correspondente à um período $T$ de 3 anos $(1080$

dias) multiplicado pelo custo aproximado do kWh no estado do Espirito Santo (R\$ 0,50 / kWh) (AGÊNCIA

NACIONAL DE ENERGIA ELÉTRICA, 2017).

A Tabela 2 apresenta os resultados da resolução das instâncias vix pelo CPLEX. A coluna vix ID representa a identificação da instância, de vix050 a vix250. A coluna $p$ exibe o número de ECVEs selecionados pelo CPLEX. A coluna MSV exibe a melhor solução viável (MSV) encontrada, sendo que os valores em negrito representam valores ótimos. Por fim, a última coluna (TE) mostra os tempos de execução, em segundos.

A Tabela 3 exibe os resultados obtidos pelo CRO. São mostrados o número mínimo e máximo de ECVEs selecionadas (Min $p$ e Max $p$ ) nas 30 execuções, o gap e o tempo de execução médios, o percentual de atingimento do MSV, o melhor gap atingido, o desvio padrão, além do número médio de iterações realizadas.

Tabela 2 - Resultados obtidos pelo CPLEX para as instâncias vix

\begin{tabular}{c|c|c|c}
\hline Instância & \multicolumn{3}{c}{ CPLEX 12.6 } \\
\hline vix ID & $\boldsymbol{p}$ & MSV & TE(s) \\
\hline 050 & 9 & $\mathbf{1 0 6 7 0 9 6 0}$ & 0,14 \\
100 & 14 & $\mathbf{1 6 6 1 7 4 1 2}$ & 1,06 \\
150 & 14 & $\mathbf{2 1 7 4 9 6 3 4}$ & 4,95 \\
200 & 16 & $\mathbf{2 7 0 3 9 3 8 7}$ & 50,27 \\
250 & 21 & 34605868 & 7222,47 \\
Média & & $\mathbf{1 4 5 5 , 7 8}$ \\
\hline \multicolumn{4}{c}{ Fonte: Autores, 2017 }
\end{tabular}

Volume $14-\mathrm{N}^{\mathrm{o}} 159$ - Março/2019. 
Tabela 3 - Resultados obtidos pelo CPLEX para as instâncias vix

\begin{tabular}{|c|c|c|c|c|c|c|c|c|}
\hline Inst & \multicolumn{8}{|c|}{ CRO } \\
\hline $\begin{array}{l}v i x \\
I D\end{array}$ & $\begin{array}{c}\mathbf{M} \\
\mathbf{i} \\
\mathbf{n} \\
p\end{array}$ & $\begin{array}{c}\mathbf{M} \\
\mathbf{a} \\
\mathbf{x} \\
\boldsymbol{p}\end{array}$ & $\begin{array}{c}\text { gap } \\
\text { Med. } \\
(\%)\end{array}$ & $\begin{array}{c}\text { Tempo } \\
\text { Médio } \\
\text { Exec. } \\
\text { (s) }\end{array}$ & $\begin{array}{c}\mathbf{M} \\
\mathbf{S} \\
\mathbf{V} \\
(\%) \\
\end{array}$ & $\begin{array}{l}\text { Me- } \\
\text { lhor } \\
\text { gap } \\
(\%)\end{array}$ & $\begin{array}{c}\text { Desvio } \\
\text { Padrão }\end{array}$ & $\begin{array}{l}\text { Med } \\
\text { Iter. }\end{array}$ \\
\hline 050 & 9 & 9 & 0,00 & 0,27 & 100 & 0,00 & 0,00 & 32 \\
\hline 100 & 14 & 14 & 0,00 & 5,41 & 100 & 0,00 & 0,00 & 668 \\
\hline 150 & 14 & 14 & 0,00 & 21,96 & 100 & 0,00 & 0,00 & 1827 \\
\hline 200 & 16 & 19 & 0,45 & 248,23 & 0 & 0,05 & 70529,47 & 8200 \\
\hline 250 & 21 & 26 & 0,98 & 385,89 & 0 & 0,72 & 135124,68 & 8153 \\
\hline \multicolumn{3}{|c|}{ Médias } & 0,29 & 132,35 & & 0,15 & & \\
\hline
\end{tabular}

O CRO foi capaz de atingir a otimalidade nas três primeiras instâncias (vix050 a vix150), porém, com tempos de execução um pouco maiores que os obtidos pelo CPLEX.

Na resolução da instância vix200, o CRO não atingiu a otimalidade em nenhuma das execuções de teste. Porém, o menor gap foi de apenas $0,05 \%$, sendo a média de $0,45 \%$. O CRO foi 197.96s mais lento que o CPLEX.

Na instância vix250 o CRO obteve nítida vantagem no tempo de execução em relação ao CPLEX. Durante a resolução desta instância, o otimizador da IBM se mostrou instável, causando travamento do sistema operacional, por falta de memória, após cerca de três horas de execução. Assim, sua execução foi limitada a 7200s (2 horas). Portanto, o valor da função objetivo informado para o CPLEX não é o ótimo, mas o da MSV. Da mesma forma, o CRO não atingiu a otimalidade em nenhuma das execuções de teste. O menor gap, em relação a MSV, foi de $0,72 \%$ e a média, $0,98 \%$. O tempo médio de execução ficou em torno de 6 min $(385,89 \mathrm{~s})$.

Em média, o CRO foi 1323,43 s mais rápido que o CPLEX, em grande parte devido à instância vix250. Os gaps médios apresentados pelo CRO estiveram sempre abaixo de $1 \%$ em relação aos valores ótimos ou MSV.

Apesar de não ter sido o método mais rápido ou mais preciso nesta comparação, os autores acreditam que a presente adaptação do CRO possa ter uma vantagem competitiva em aplicações que devam ser executadas em plataformas de hardware mais modestas, como aquelas usadas em sistemas embarcados ou dispositivos móveis. A razão é que o CRO requer um tamanho de memória pequeno (<64 MB) e é processado em um único núcleo, enquanto a maioria dos otimizadores comerciais, como o CPLEX, exigem grandes quantidades de memória (geralmente acima de 4GB) e CPUs multicore para atingir um bom desempenho. $\mathrm{O}$ alto custo de licenciamento de um otimizador comercial também pode ser um fator limitante, dependendo da aplicação. Por fim, os gaps e tempos de execução obtidos pelo CRO podem ser aceitáveis em muitas aplicações.

\subsection{Modelo FCLP Baouche na localização de ECVEs}

Para a avaliação do comportamento do modelo FCLP Baouche, na localização de ECVEs na região da Grande Vitória, ES, utilizando a metaheurística CRO, experimentos foram realizados utilizando a instância vix100, composta de 100 vértices, representando tanto locais candidatos a receber ECVEs como centros de consumo.

Utilizando a mesma plataforma computacional e parâmetros de configuração do CRO do item 3.1, a instância vix100 foi resolvida para diferentes tamanhos de frota circulante de VEs necessitando de recarga, de forma a simular diferentes taxas de penetração de VEs na frota da Grande Vitória. O objetivo desta análise de sensibilidade foi o de observar o comportamento do modelo FCLP Baouche na localização de estações à medida que o número de VEs em circulação, necessitando recarga, crescia.

Nos testes, a taxa de penetração de VEs foi variada entre $0,01 \%$ e $0,1 \%$ da frota atual de automóveis estimada da Grande Vitória (1 milhão), em intervalos de 0,01\%. Para tanto, o número de veículos necessitando recarga,

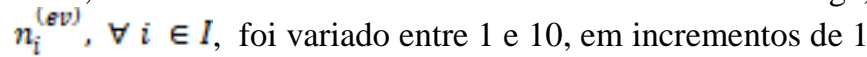
unidade, o que corresponde a tamanhos de frota entre $100 \mathrm{e}$ 1000 VEs, já que a instância vix100 possui 100 centros de consumo (vértices). Os demais valores relativos ao conjunto de dados de entrada permaneceram os mesmos do item 3.1.

Para cada valor distinto de $n^{\text {[evs }}$, o problema resultante foi resolvido 10 vezes pelo $\mathrm{CRO}$, sendo aproveitado o melhor resultado, i.e., aquele com o menor valor de função objetivo.

A

Tabela mostra os resultados da análise de sensibilidade efetuada. Para cada tamanho de frota de VEs (FVE) são mostrados o número de estações selecionadas $(p)$, o melhor valor da função objetivo alcançado (MO) e respectivo tempo de execução (TMO), além dos índices $\tilde{j}, \forall j \in J$, para os quais $x_{j}=1$, correspondente às estações selecionadas no modelo FCLP Baouche (1).

Como esperado, o número de estações aumenta com a taxa de penetração, exceto para as configurações de 600 e 700 VEs, onde as mesmas estações são selecionadas. As Figuras 3, 4 e 5 exibem, no mapa da Grande Vitória, os locais onde as estações de carregamento foram localizadas, para frotas de 100, 500 e 1000 VEs, respectivamente. Os círculos representam os centros de consumo, onde estão concentradas as demandas de carregamento, e os marcadores numerados em forma de gota, as estações de carregamento selecionadas.

A partir de uma análise visual dos mapas de localização de estações, pode-se concluir que, em quase todos os experimentos, ECVEs foram localizadas próximas aos centros de consumo. Apenas no mapa com apenas 5 estações abertas (Figura 3), alguns centros de consumo, nos munícipios de Fundão e Viana ficaram distantes das estações mais próximas, o que poderia inviabilizar a operação de VEs em tais locais. 
Figura 3 - Localização de ECVEs, para frota de 100 EVs

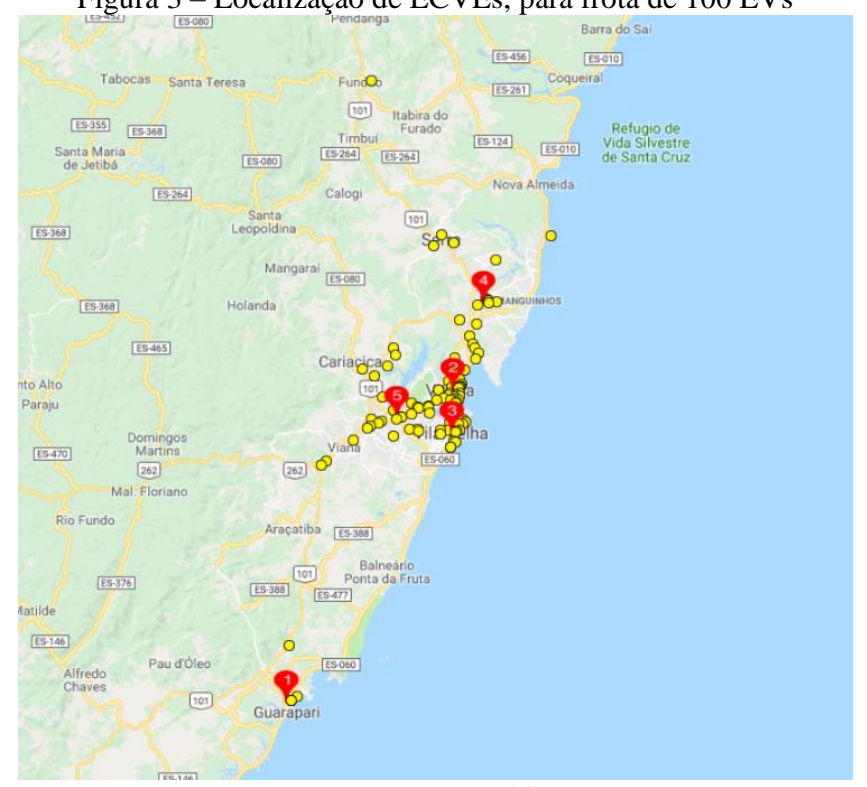

Fonte: Autores, 2017

Figura 4 - Localização de ECVEs, para frota de 500 EVs

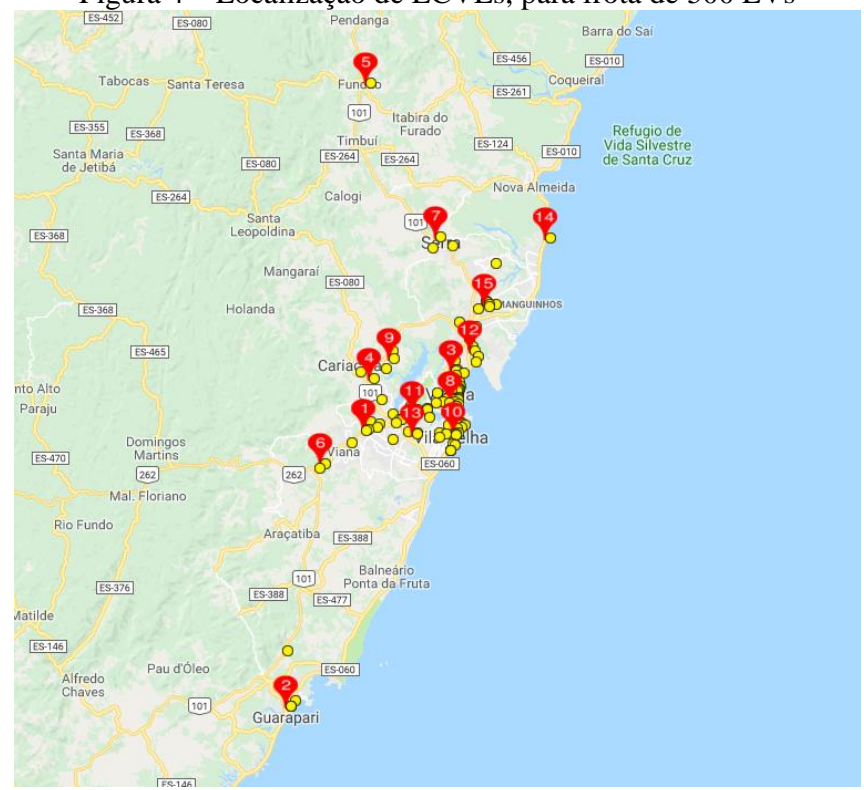

Fonte: Autores, 2017

Figura 5 - Localização de ECVEs, para frota de 1000 EVs

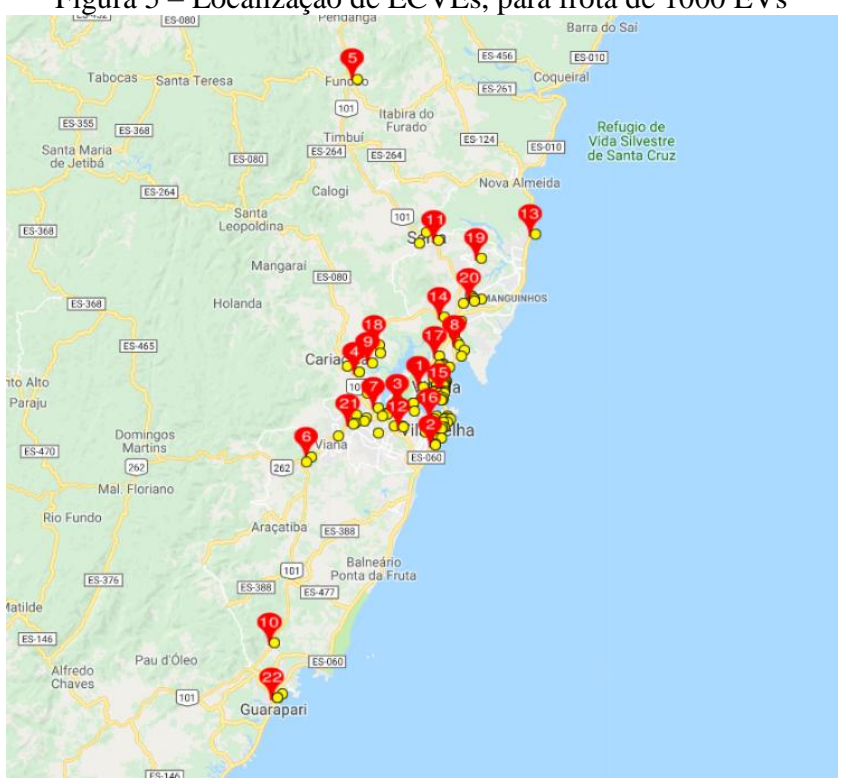

Fonte: Autores, 2017
Este problema poderia ser mitigado, atribuindo-se a locais mais distantes da capital, ECVEs de menor capacidade e custo. No entanto, à medida que o número de VEs circulando nos locais mais distantes aumenta, estações passam a ser localizadas nos locais mais extremos, como mostram as Figuras 3 e 4, incluindo pontos ao longo do litoral e na rodovia BR-101, próximo a Guarapari (Figura 4).

Tabela 4 - ECVEs selecionadas em função da frota, para vix100

\begin{tabular}{|c|c|c|c|c|}
\hline FVE & $p$ & MO & TMO & $\begin{array}{c}\text { ECVEs } \\
\text { selecionadas }\end{array}$ \\
\hline 100 & 5 & 7575639 & 0,374 & $5,55,71,74,95$ \\
\hline 200 & 8 & 11289168 & 0,283 & $5,22,33,55,71,74,76,95$ \\
\hline 300 & 12 & 14267546 & 0,361 & $\begin{array}{l}2,5,10,20,21,22,24,25,30,33, \\
71,74\end{array}$ \\
\hline 400 & 14 & 16617412 & 2,702 & $\begin{array}{l}5,10,20,21,22,25,28,30,33, \\
35,41,46,71,74\end{array}$ \\
\hline 500 & 15 & 18960773 & 36,066 & $\begin{array}{l}2,5,10,16,20,21,22,25 \\
26,27,28,30,41,46,74\end{array}$ \\
\hline 600 & 17 & 22051351 & 75,433 & $\begin{array}{l}2,7,10,16,20,21,22,25,26 \\
28,30,38,41,46,50,74,89\end{array}$ \\
\hline 700 & 17 & 24936058 & 109,974 & $\begin{array}{l}2,7,10,16,20,21,22,25,26 \\
28,30,38,41,46,50,74,89\end{array}$ \\
\hline 800 & 18 & 28185688 & 122,428 & $\begin{array}{l}6,7,16,20,21,22,26,28,30,35 \\
38,41,46,48,50,58,74,89\end{array}$ \\
\hline 900 & 21 & 31907376 & 105,743 & $\begin{array}{l}6,7,16,20,21,22,23,26, \\
28,30,38,41,46,47,48, \\
50,58,65,74,76,89 \\
6,7,12,16,20,21,23,30\end{array}$ \\
\hline
\end{tabular}

$10002243191941242,735 \quad 33,38,40,41,46,47,48$, $50,58,59,65,74,76,89$

Fonte: Autores, 2017

\section{CONCLUSÃO}

Nesse trabalho, um modelo matemático de otimização para localização de ECVEs foi utilizado para situar, de forma eficiente, estações na Grande Vitória, ES. A metaheurística CRO foi adaptada para a resolução dos problemas de uma base de dados contendo locais candidatos a receber ECVEs e centros de consumo, contendo VEs necessitando de recarga.

Quanto a adaptação do CRO para solução do problema de localização, pode-se concluir que a metaheurística também é aplicável ao mesmo, uma vez que foi capaz de obter soluções de boa qualidade com baixo tempo computacional.

No que tange a eficiência do modelo de Baouche e colaboradores (2014) na localização de estações de carregamento na Grande Vitória, o mesmo provou ser adequado, concentrando ECVEs próximas às áreas de maior densidade urbana, sem deixar de atender a locais mais distantes, à medida em que a penetração de EVs aumentava.

Espera-se que o presente trabalho possa auxiliar futuros esforços de implantação de ECVEs em áreas metropolitanas do Brasil.

\section{REFERÊNCIAS BIBLIOGRÁFICAS}

AGENBROAD, Josh; HOLLAND, Ben. RMI: What's the true cost of EV charging stations? Disponível em: <https://www.greenbiz.com/blog/2014/05/07/rmi-whats-truecost-ev-charging-stations>. Acesso em: 18 fev. 2018. 
AGÊNCIA NACIONAL DE ENERGIA ELÉTRICA. Tarifas - ANEEL. Disponível em: <http:// www.aneel.gov.br/dados/tarifas>. Acesso em: 2 abr. 2018.

BALINSKI, M L. Integer Programming: Methods, Uses, Computations. Management Science, v. 12, n. 3, p. 253313, 1965.

BAOUCHE, Fouad et al. Efficient Allocation of Electric Vehicles Charging Stations: Optimization Model and Application to a Dense Urban Network. IEEE Intelligent Transportation Systems Mag., v. 6, n. 3, p. 33-43, 2014.

CONFEDERAÇÃO NACIONAL DO TRANSPORTE. Anuário CNT do transporte. 2016. Disponível em: <http://anuariodotransporte.cnt.org.br/2017/>. Acesso em: 14 mar. 2018.

EMPRESA DE PESQUISA ENERGÉTICA. Anuário Estatístico de Energia Elétrica. 2016. Disponível em: <http://www.epe.gov.br/AnuarioEstatisticodeEnergiaEletrica /Forms/Anurio.aspx>. Acesso em: 8 fev. 2017.

EVADOPTION. EV Statistics of the Week: Range, Price and Battery Size of Currently Available (in the US) BEVs - EV Adoption. Disponível em: <http://evadoption.com/evstatistics-of-the-week-range-price-and-battery-size-ofcurrently-available-in-the-us-bevs/>.Acesso em: 20 mar. 2018.

GOOGLE INC. Google Maps API. 2018. Disponível em: <https://developers.google.com/maps>

IBM. IBM CPLEX Optimizer. Disponível em: <https://www.ibm.com/analytics/cplex-optimizer>.

KUBY, Michael J. Programming Models for Facility Dispersion: The p-Dispersion and Maxisum Dispersion Problems. Geographical Analysis, v. 19, n. 4, p. 315-329, 1987.

LAM, Albert Y S; LEUNG, Yiu-wing; CHU, Xiaowen. Electric Vehicle Charging Station Placement. IEEE Smart Grid Comm, p. 510-515, 2013.

LAM, Albert Y S; LI, Victor O K. Chemical Reaction Optimization: A tutorial. Memetic Computing, v. 4, n. 1, p. 3-17, 2012.

MERZ, Peter; FREISLEBEN, Bernd. A genetic local search approach to the quadratic assignment problem. In: Proceedings of the 7th international conference on genetic algorithms, 7., 1997, Michigan. Anais... Michigan: Springer-Verlag. 1997. p. 1-1.

MCCAULEY, Ryan. Building Out Electric Vehicle Infrastructure: Where Are the Best Locations for Charging Stations? Disponível em: <http://www.govtech.com/fs/Building-Out-Electric-VehicleInfrastructure-Where-Are-the-Best-Locations-for-ChargingStations.html>. Acesso em: 19 mar. 2018.

OSMAN, Ibrahim H.; CHRISTOFIDES, Nicos. Capacitated clustering problems by hybrid simulated annealing and tabu search. International Transactions in Operational Research, v. 1, n. 3, p. 317-336, 1994.

WU, Chunyang et al. A method for electric vehicle charging infrastructure planning. Dianli Xitong Zidonghua /

Automation of Electric Power Systems, v. 34, n. 24, 2010.

\section{COPYRIGHT}

Os autores são os únicos responsáveis pelo material incluído no artigo. 
Volume $14-\mathrm{N}^{\mathrm{o}} 159$ - Março/2019.

XL International Sodebras Congress

10 a 12 de dezembro de 2018 - Vitória - ES.

\title{
PLANEJAMENTO ESTRATÉGICO NO SETOR ELÉTRICO: UMA MODELAGEM UTILIZANDO A MATRIZ DE ATRATIVIDADE DE MERCADO X FORÇA COMPETITIVA
}

\section{STRATEGIC PLANNING ON ENERGY SECTOR: AN MODELING USING ATTRACTIVENESS VERSUS COMPETITIVENESS MATRIX}

\author{
FLÁVIO DAYRELL MISERANI NUNES; PETR IACOVLEVITCH EKEL; ROSE MARY DE SOUZA \\ BATALHA
}

\author{
PUC-MG, DEPARTAMENTO DE ENGENHARIA ELÉTRICA, BELO HORIZONTE - MINAS GERAIS
}

\author{
fldayrell@terra.com.br; pekel@superig.com.br; batalha@pucminas.br
}

\begin{abstract}
Resumo - Neste artigo foi realizado um estudo de caso de uma Companhia, utilizando o modelo de distribuição de energia elétrica no Reino Unido. Foi analisado o modelo regulatório e a situação do mercado de distribuição de energia elétrica e gás britânico. Foram avaliados os dados dos contratos de consumidores $e$ estruturado uma matriz de atratividade de mercado versus força competitiva como modelagem das estratégias da empresa para crescimento do faturamento. Com base na matriz foi possível demonstrar a importância para priorização dos investimentos da Companhia para os próximos anos.

Palavras-chave: Fornecimento de Energia. Mercado Regulatório de Energia. Planejamento Estratégico. Atratividade de Mercado. Força Competitiva.
\end{abstract}

Abstract - This study presents the importance of the market attractiveness and competitiveness matrix for prioritizing investments on competitive markets. A study was conducted in the British energy market, a highly competitive market.

Keywords: Energy Supply. Regulatory Energy Market. Strategic Planning. Market Attractiveness. Competitive Strength.

\section{INTRODUÇÃO}

Em cenários de crise econômica, empresas buscam otimizar seus negócios utilizando técnicas para redução de custos, eficiência operacional, planejamento estratégico, dentre outros. O planejamento estratégico pode ser considerado um dos mais utilizados para priorização dos investimentos na companhia (Fischmann e Almeida, 1991).

Estratégia, de acordo com Meyer (1997), pode ser descrito como um conjunto de atividades que define prioridades nas ações dos gestores da companhia, com o único objetivo de atingir as metas estabelecidas no planejamento, e a utilização da matriz atratividade de mercado versus força competitiva da empresa, é uma das técnicas de estratégia largamente utilizada.

Setores da economia onde o número de empresas concorrentes é elevado, por exemplo, o setor de varejo e o setor de distribuição de energia elétrica do Reino Unido (Giulietti, Price e Waterson, 2005), utiliza-se do planejamento estratégico para direcionar os investimentos e a força competitiva em clientes visando maior atratividade de mercado.

O setor de distribuição de energia elétrica no Reino Unido, é considerado altamente competitivo devido ao número elevado de distribuidoras e pela liberdade de entrada de novas empresas no mercado. Nos últimos 8 anos a redução das margens de lucro no setor comercial e industrial foi de aproximadamente 5\%. (Ofgem, 2017)

Neste sentido, este artigo tem o objetivo de demonstrar a importância da matriz que correlaciona a força competitiva à atratividade do mercado de uma companhia de distribuição de energia e gás do Reino Unido e as estratégias para priorização dos investimentos.

\section{O MODELO DE DISTRIBUIÇÃO DE ENERGIA ELÉTRICA BRITÂNICO}

\section{1 - Legislação}

Em 1986, o governo privatizou empresas anteriormente nacionalizadas de gás através do "Gas Act" 1986 e, em 1989, empresas de eletricidade através do "Electricity Act" 1989. Isto foi seguido por liberalização gradual do mercado. Os mercados de fornecimento foram totalmente abertos à concorrência a partir de 1998 e os controles de preços para os consumidores comuns foram removidos em 2002.

Até 2000, dois órgãos reguladores eram responsáveis pela supervisão dos mercados de gás e eletricidade, o Escritório de Regulamentação de Eletricidade (OFFER) e o Escritório de Fornecimento de Gás (Ofgas). Eles foram fundidos pela "Utilities Act 2000" para formar a Ofgem "Agência de Mercado de Gás e Energia Elétrica", que recebeu poderes para regular ambos os mercados, incluindo os monopólios da rede. (Ofgem, 2017)

Atualmente, o setor de energia elétrica do Reino Unido é regulado pela Agência Regulatória de Gás e Mercado de Energia Elétrica (GEMA). Suas responsabilidades é garantir que todos os consumidores sejam atendidos no mercado de energia elétrica conforme regulamenta as leis e diretrizes estabelecidas na legislação britânica. (Ofgem, 2018) 
Sob supervisão da GEMA, o órgão Ofgem é responsável pelo controle e fiscalização das empresas distribuidoras de energia e gás atuando em prol dos consumidores, sejam pessoas físicas, sejam pessoas jurídicas.

\section{2 - Mercado de Energia}

O mercado de energia e gás é considerado altamente competitivo devido ao crescente número de distribuidoras. $\mathrm{O}$ número de distribuidores de energia para consumidores domésticos cresceu aproximadamente $250 \%$ ao longo dos últimos 3 anos, conforme pode-se verificar na Figura 1. (Ofgem, 2018b)

Figura 1 - Crescimento de distribuidores de energia elétrica no Reino Unido

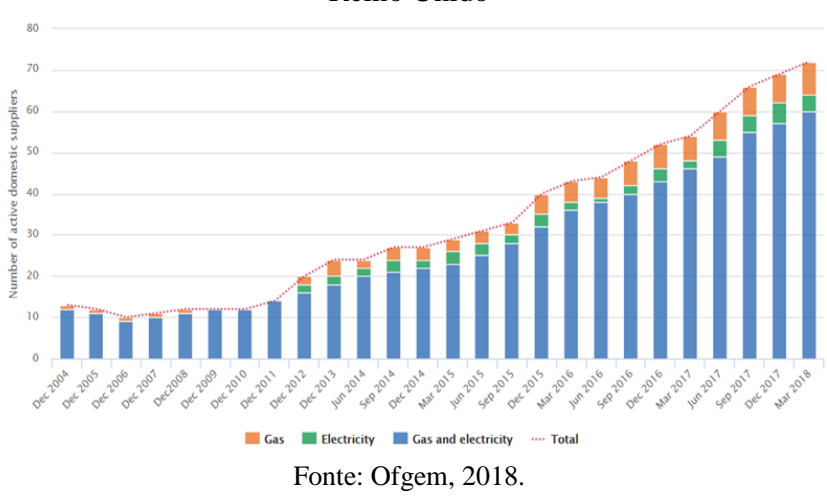

De acordo com o Ofgem, as principais empresas de fornecimento de energia elétrica para consumidores residenciais e comerciais são: British Gas, Coop, E.On, EDF, First Utility, Npower, OVO, ScottishPower, SSE e Utility Warehouse.

\section{3 - Competitividade}

As empresas que fornecem energia elétrica e gás natural para o setor comercial, enfrentam uma constante redução da margem líquida nos últimos anos, conforme pode-se verificar na Figura 2. (Ofgem, 2018a)

Figura 2 - Evolução das margens de retorno líquidas das maiores distribuidoras de energia elétrica do Reino Unido.

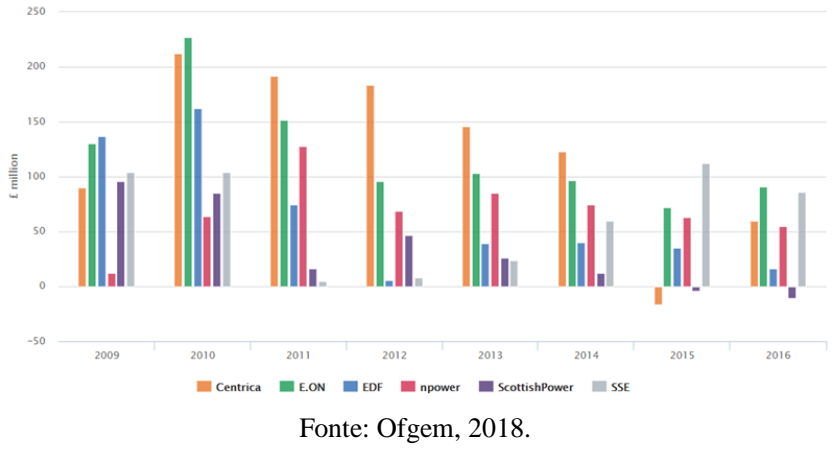

\section{PLANEJAMENTO ESTRATÉGICO}

Planejamento estratégico, de acordo com Meyer (1997), pode ser considerado como um modelo de condução racional das empresas para seguir objetivos definidos. No que tange as ações estratégicas da organização, Megginson, Mosley, e Pietri Junior (1986), define o planejamento como a adaptabilidade da empresa às condições externas de mudança.
Nos níveis de planejamento estratégico, de acordo com Ferreira, Reis e Pereira (1997), as decisões se encontram direcionadas no nível estratégico da organização se ramificando para todas as demais áreas da companhia.

Este artigo aborda a importância da análise da atratividade de mercado versus força competitiva em cenários competitivos e foi estruturado em cinco etapas, sendo elas:

a) Pesquisa da situação atual do mercado;

b) Levantamento da situação atual da empresa;

c) Definição de estratégias;

d) Revisão da força competitiva; e

e) Elaboração do estudo de caso.

Figura 3 - Iniciativas do Planejamento do Estratégico

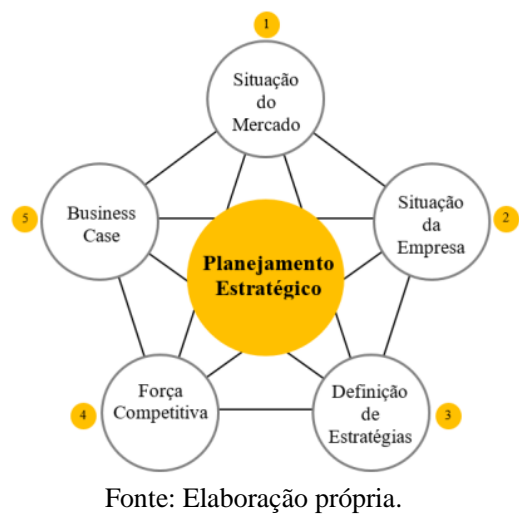

\section{1 - Situação do Mercado}

A análise das tendências de mercado foi realizada com o objetivo de identificar as necessidades dos consumidores, a dinâmica atual do mercado e as tendências futuras que poderão impactar na habilidade da empresa em atingir a meta estimada no planejamento estratégico.

Pode-se perceber na Figura 4 que, no mercado de energia e gás no Reino Unido, existem empresas com foco em diferentes segmentos, sejam eles SME (Pequenas e Médias Empresas) e I\&C (Empresas Comerciais e Industriais) (Ofgem, 2017).

Figura 4 - Representatividade dos consumidores no mercado de energia comercial por competidor.

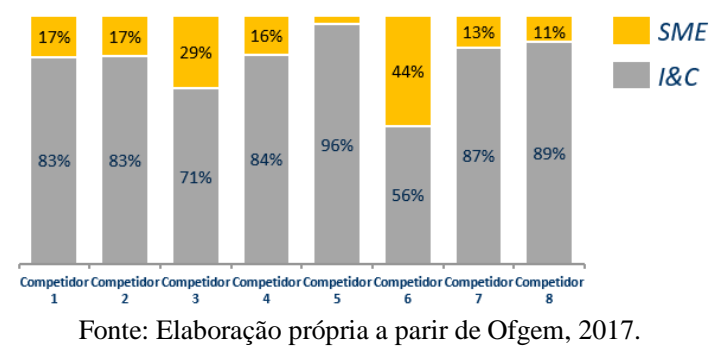

A pressão sobre a margem de lucro, entretanto, faz com que as tendências de mercado e as necessidades dos consumidores alterem significativamente. Em cenário de crise a demanda por serviços de gestão de consumo, transparência e eficiência se torna essencial para redução dos custos operacionais e a previsão para os investimentos nesta área vem crescendo significativamente desde 2008, vide Figura 5. (Department of Energy and Climate Change, 2014) 
Figura 5 - Evolução da venda de serviços de eficiência energética no Reino Unido.

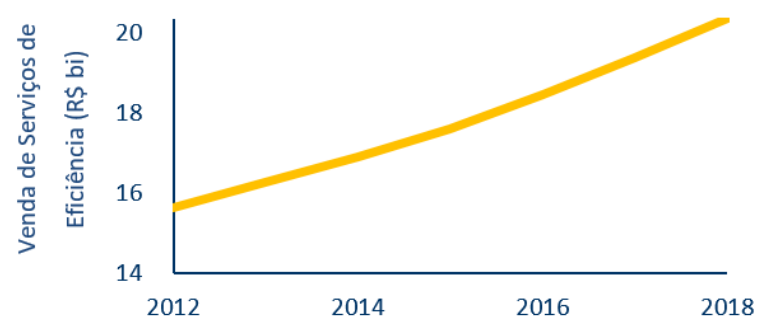

Fonte: Department of Energy \& Climate Change, 2014.

\section{2 - Situação da Empresa}

O levantamento da situação atual da Companhia foi realizado com objetivo de identificar as potenciais áreas para priorizar os investimentos e compreender os diferenciais entre os demais concorrentes.

Através da base de contratos dos clientes comerciais e industriais foi possível compilar todos os dados de consumo e demanda contratados, margem de lucro, setor da economia de cada cliente, entre outras informações relacionadas ao desenvolvimento deste artigo.

Com a base compilada, foi realizado a estratificação dos clientes em onze macro setores da economia, sendo eles:
a) Administração Pública
b) Serviços Professionais
c) Acomodação, Alimentos e Recreação
d) Setor Imobiliário
e) Agricultura
f) Telecomunicações e Serviços Financeiros
g) Comércio
h) Transporte
i) Construção e Mineração
j) Utilidades
k) Indústria de Manufaturas

A categorização de cada cliente da Companhia foi definida com base no consumo de energia e gás, em GWh, disponível nos contratos firmados, sendo:
a) SME: menor que $0,1 \mathrm{GWh}$
b) I\&C Low: de 0,1 a 20GWh
c) I\&C Medium: de 20 a 50GWh
d) I\&C High: acima de 50GWh

Os setores com maior lucratividade para a empresa, de acordo com os dados contratuais, são os setores de administração pública, comércio, telecomunicações e serviços financeiros, conforme pode-se verificar na Figura 6.

\section{Figura 6 - Distribuição dos clientes da Companhia por setor da} economia e por margem de lucro.

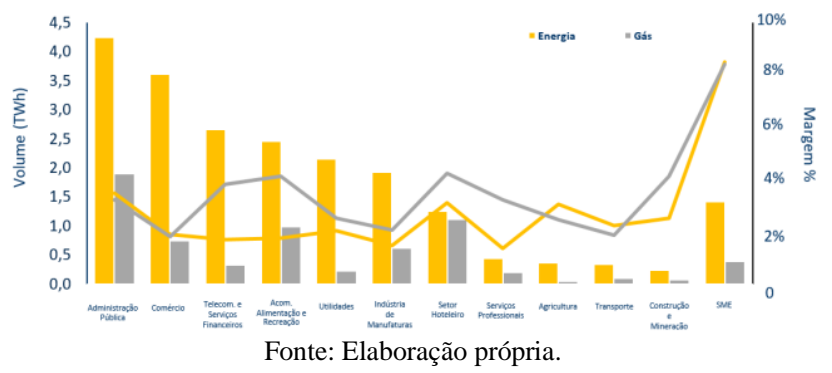

Não obstante à atratividade do mercado de energia, deve-se analisar a força competitiva atual da empresa. Para isto foi realizada uma pesquisa junto aos clientes e aos principais gerentes responsáveis pelos contratos da Companhia nos diversos setores da economia e para variados tamanhos de empresa, cujo resultado identificou as fraquezas e potenciais melhorias existentes no fornecimento dos serviços. A pesquisa realizada para cada critério definido, obteve-se o seguinte resultado:

Figura 7 - Resultado da avaliação das capacidades da Companhia.

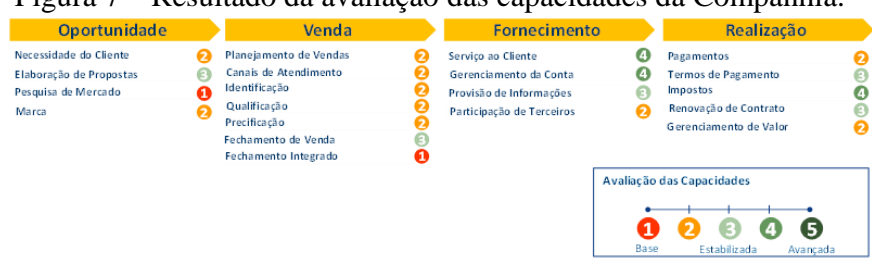

Fonte: Elaboração própria

\section{3 - Definições de Estratégias}

Os resultados da Companhia nos últimos anos demonstram uma crescente redução no faturamento, resultado da elevada competividade no mercado. Em um dos cenários considerados pela Companhia, o faturamento permanece reduzindo caso não seja realizada atividades de estratégia. No segundo cenário, o faturamento se estabiliza e com leve aumento de produtividade. No terceiro cenário a meta de crescimento do faturamento utilizada foi de aproximadamente $50 \%$ se comparado ao momento atual da Companhia, conforme pode-se verificar na Figura 8.

Figura 8 - Cenários de faturamento da Companhia com a meta do planejamento estratégico.

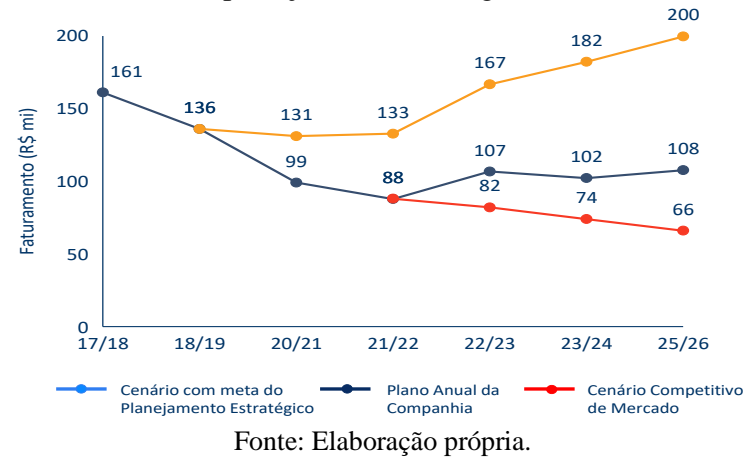

Com a meta de faturamento estabelecida pela empresa para os próximos 5 anos, considerando o cenário de planejamento estratégico, a definição de estratégias, priorizando investimentos em setores com maior atratividade e maior força competitiva, estrutura as iniciativas da empresa para atingir seus objetivos.

Através de ponderação de critérios definidos para atratividade de mercado e força competitiva foi elaborado uma matriz onde é possível visualizar para cada setor da economia e tamanho da empresa o quão atrativo é aquele setor e quão apto a empresa está em atender a demanda dos consumidores.

Estratificando o gráfico em quatro quadrantes pode-se priorizar os investimentos sejam eles na revisão da força competitiva, maximização de resultados e diferenciação no mercado, vide Figura 9. 
Figura 9 - Matriz de atratividade de Mercado versus força competitiva.

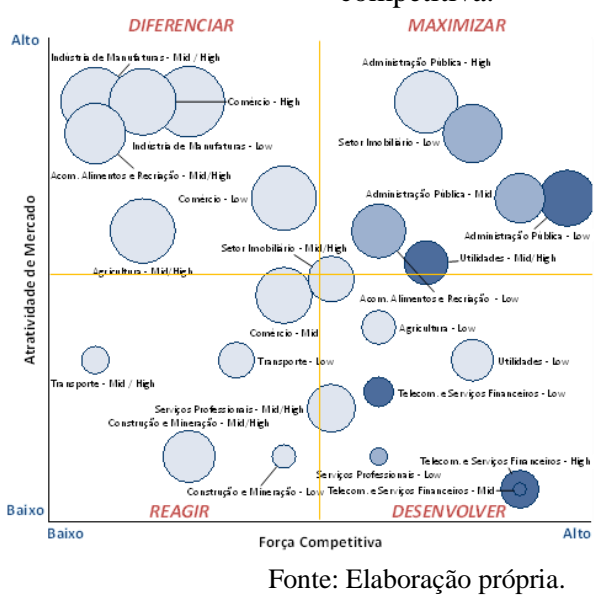

O tamanho dos círculos na Figura 8 representa o volume de receita do setor no mercado enquanto a densidade da cor representa o quão presente a companhia está naquele setor analisado.

Analisando os setores, pode-se identificar que a administração pública, por exemplo, é, para a Companhia, um setor altamente atrativo e com elevada chance de atendimento visto a força competitiva robusta da empresa.

Ao contrário do setor de administração pública, o setor de construção e mineração não apresenta atratividade para a empresa. Os contratos firmados possuem margem de lucro baixa e o atual perfil da empresa não está apto às demandas dos consumidores.

Para cada um dos três principais quadrantes, desenvolver, diferenciar e maximizar, foram elaboradas estratégias diferenciadas considerando:

\section{a) Necessidades dos Consumidores \\ b) Potencial Futuro \\ c) Prospecções Futuras \\ d) Passos para o Sucesso}

Com a análise e o entendimento do consumo diário dos clientes da empresa é possível identificar quais as principais exigências e reais necessidades para a uma adequada prestação dos serviços.

As prospecções futuras procuram identificar os potenciais consumidores comerciais e industriais cujas cotações para fornecimento de energia e demanda estão sendo renovadas. Estas informações foram obtidas através do histórico de cotações perdidas com o prazo de vencimento de cada contrato. Exemplificando para o setor hoteleiro as prospecções futuras poderá gerar um incremento de 608,45 GWh.

Figura 10 - Potenciais clientes com base na base de cotações da

\begin{tabular}{ccc} 
Cliente & $\begin{array}{c}\text { Companhia. } \\
\text { Data de } \\
\text { Renovação }\end{array}$ & $\begin{array}{c}\text { Volume Estimado } \\
\text { (GWh) }\end{array}$ \\
\hline Cliente A & $31 / 08 / 2018$ & 263,14 \\
Cliente B & $30 / 09 / 2018$ & 220,15 \\
Cliente C & $30 / 09 / 2018$ & 67,35 \\
Cliente D & $30 / 09 / 2018$ & 37,6 \\
Cliente E & $31 / 03 / 2019$ & 20,21 \\
\hline
\end{tabular}

Fonte: Elaboração própria.
Com base nos potenciais clientes, foi possível quantificar o ganho para cada setor da economia. Após o levantamento dos potencias clientes foi possível definir os passos necessários a serem realizados pela Companhia, para o faturamento definido no planejamento estratégico.

\section{4 - Força Competitiva}

Com base na pesquisa realizada sobre a força competitiva atual da empresa e os resultados apurados de acordo com cada nível de maturidade, foi possível priorizar as áreas de maior dispêndio de investimentos necessários para o fortalecimento da competitividade da empresa no mercado.

Dentre as capacidades pesquisadas, três foram consideradas no estudo de caso para avaliar o crescimento da empresa através das estratégias estabelecidas, vide Figura 11 .

Figura 11 - Principais capacidades da Companhia avaliadas.

$$
\text { Capacidade }
$$
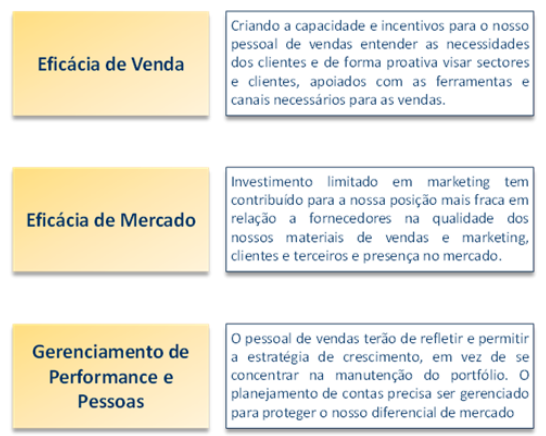

Fonte: Elaboração própria visão do Cliente
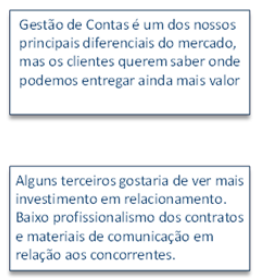

e materiais de coos concorrentes.
rela

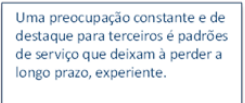

Desta forma, foi possível priorizar os investimos nos setores da companhia para aprimorar a força competitiva com objetivo de atingir a meta estratégica no estudo de caso.

\section{5 - Estudo de Caso}

Com base nas estratégias definidas para cada setor da economia em conjunto com as iniciativas estruturadas na avaliação da força competitiva da empresa, foi definido os investimentos necessários para aumento do faturamento considerando:
a) Treinamento
b) Sistemas
c) Marketing
d) Desenvolvimento Futuro

O investimento com treinamento visa preparar a equipe de vendas a atenderem os clientes de acordo com reais necessidades. Aprimorar o sistema de marketing da empresa perante o mercado, visa atrair novos consumidores. Sistemas são necessários para desenvolvimento das iniciativas de gestão do consumo e demanda dos consumidores visando aumento de eficiência operacional e atendimento às demandas de smart meterings. $\mathrm{O}$ desenvolvimento nos recursos humanos da empresa visa atender o avanço da tecnologia e aprimora a capacidade de interlocução entre usuários.

Foi definido o estudo de caso da Companhia considerando o cenário de planejamento estratégico e valores hipotéticos aos quais se correlacionam com os 
investimentos necessários e os benefícios esperados. Os resultados esperados ao longo dos próximos anos podem ser verificados na Figura 12.

Figura 12 - Estudo de caso considerando a meta do planejamento estratégico.

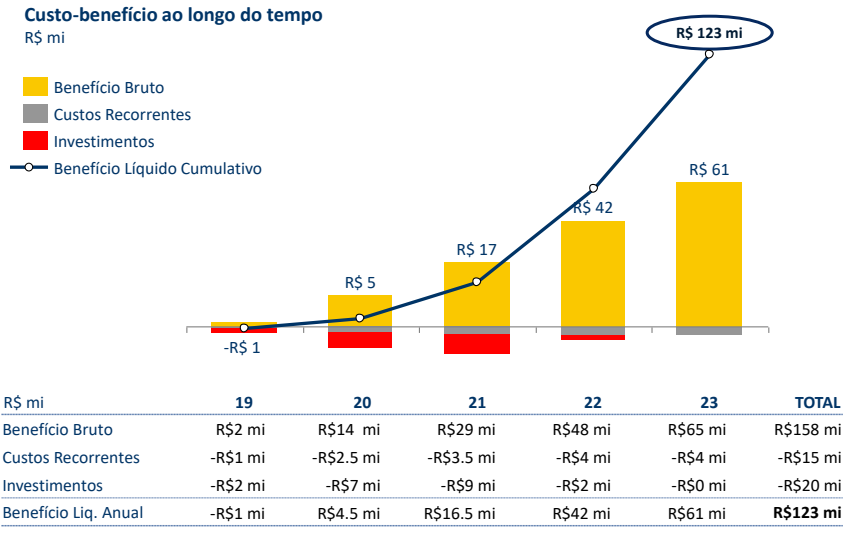

Fonte: Elaboração própria.

\section{CONCLUSÕES}

O mercado de energia do Reino Unido é um dos setores mais competitivos do mercado britânico. A utilização de técnicas de estratégias propicia às empresas o foco em investimentos necessários para incremento de sua representatividade no mercado.

O planejamento estratégico, utilizando a matriz de atratividade de mercado versus força competitiva, pode ser considerado um aliado em momentos de crise econômica.

$\mathrm{O}$ estudo de caso, demonstrou que o levantamento da situação de mercado, do posicionamento da empresa perante seus consumidores e dos dados de clientes da Companhia é essencial para identificação dos principais setores da economia onde a Companhia possui maior capacidade de atendimento e força de mercado.

Não obstante ao mercado de energia elétrica do Reino Unido, a matriz pode ser utilizada nos diversos setores da economia onde a competitividade é intrínseca à atividade econômica.

\section{REFERÊNCIAS BIBLIOGRÁFICAS}

Department of Energy \& Climate Change, "UK National Energy Efficiency Action Plan”, 2014, Disponível em: $<$ https://ec.europa.eu/energy/sites/ener/files/documents /2014_neeap_united-kingdom.pdf> Acesso em 01 set. 2018.

FERREIRA, A. A.; REIS, A. C. F.; PEREIRA, M. I. Gestão empresarial: de Taylor aos nossos dias - evolução e tendências da Moderna Administração de Empresas. São Paulo: Pioneira Thomson Learning, 1997.

FISCHMANN, A. A.; ALMEIDA, M. I. R. (1991). Planejamento estratégico na prática. São Paulo, Atlas.

GEMA, Gas and Electricity Markets Authority, 2018.

Giulietti, M. Price, C. W. and Waterson, M. (2005), Consumer Choice and Competition Policy: a Study of UK Energy Markets. The Economic Journal, 115: 949-968. doi:10.1111/j.1468-0297.2005.01026.x

MEGGINSON, L. C.; MOSLEY, D. C.; PIETRI JUNIOR, H. P. (1986). Administração: conceitos e aplicações. São Paulo, Harbra Ltda.
MEYER, C. A. (1997). Planejamento formal e seus resultados: um estudo de caso. Caderno de pesquisas em Administração, v.2, vo 5, p. 39-46.

OFGEM, State of the energy market report, 2017.

OFGEM, "Non-domestic supply profits in $£$ million by supplier", 2018, Disponível em: <https://www.ofgem.gov.uk/gas/retail-market/retail-marketmonitoring/understanding-profits-large-energy-suppliers> Acesso em 01 set. 2018.

OFGEM, "Number of active domestic suppliers by fuel type (GB)", 2018, Disponível em: <https://www.ofgem.gov.uk/data-portal/retail-marketindicators> Acesso em 01 set. 2018.

\section{COPYRIGHT}

Direitos autorais: Os autores são os únicos responsáveis pelo material incluído no artigo. 


\title{
SELEÇÃO DE CARACTERÍSTICAS DE SINAIS CEREBRAIS PARA USO EM APLICAÇÕES DE INTERFACE CÉREBRO-COMPUTADOR
}

\author{
FEATURE SELECTION OF BRAIN SIGNALS FOR USE IN BRAIN- \\ COMPUTER INTERFACE APPLICATIONS
}

\author{
ALEX BRANDÃO ROSSOW ${ }^{1}$; ANIBAL COTRINA ${ }^{1}$ \\ 1 - INSTITUTO FEDERAL DO ESPÍRITO SANTO \\ alex.rossow@ifes.edu.br; acotrin@protonmail.com
}

\begin{abstract}
Resumo - Atualmente, dispositivos com grande número de canais $e$ altas frequências de amostragem para registro de sinais cerebrais estão disponíveis. Esse fato representa uma enorme vantagem na análise de sinais cerebrais; no entanto, quando não há informações prévias sobre quais canais e frequências escolher, pode ser difícil obter um desempenho aceitável para aplicações de BCI. Este trabalho propõe um algoritmo para selecionar os canais e frequências mais discriminantes para distinguir os movimentos realizados e imaginados dos punhos esquerdo e direito. Para isso, consideraram-se sinais de EEG em 64 canais de movimentos realizados $e$ imaginados dos punhos. $O$ resultado obtido no modo off-line com 90 características, após redução com análise de componentes principais, ficou próximo ao resultado com 140 características; $43.5 \%$ e $43.7 \%$ de taxa de acerto, respectivamente, com classificador SVM.
\end{abstract}

Palavras-chave: Eletroencefalograma. Interface cérebrocomputador. PCA. SVM.

Abstract - Nowadays, devices with great number of channels and high sample frequencies for recording electroencephalographic brain signals are available. It represents an enormous advantage in brain signal analysis; however, when there is no previous information about which channels and frequencies to choose, it can be difficult to achieve an acceptable performance to $B C I$ applications. This work proposes an algorithm to select most discriminant channels and frequencies to distinguish performed and imagined movements of left and right fists. For this aim, 64channel signals of performed and imagined movements of fists was considered. The result obtained in offline mode with 90 features, after reduction with principal component analysis, was close to the result with 140 features; $43.5 \%$ and $43.7 \%$ of accuracy, respectively, with SVM classifier.

Keywords: Brain computer interface. Electroencephalogram. PCA. SVM.

\section{INTRODUÇÃO}

A evolução das técnicas de processamento de sinais, ocorrida nas últimas décadas, oferece um amplo campo de estudo relacionado ao uso de sinais cerebrais para interface com computadores (Brain Computer Interface, BCI). Pessoas com deficiências motoras podem se beneficiar do desenvolvimento de equipamentos que possam ser comandados diretamente por sinais cerebrais (WOLPAW et al., 2000). Um requisito para os sistemas de BCI é a escolha dos melhores canais, que correspondem ao posicionamento dos eletrodos sobre o couro cabeludo, e faixas de frequência para a identificação de comandos.

Este artigo tem por objetivo apresentar o estudo de um algoritmo para seleção dos melhores canais e faixas de frequência dos sinais cerebrais para aplicações de BCI.

Foi utilizado o banco de dados EEG Motor Movement/Imagery Dataset criado e distribuído através do repositório de sinais biológicos para pesquisa PhysioNet (GOLDBERGER et al., 2000). Esse banco de dados consiste no registro do eletroencefalograma (EEG) de 114 voluntários, enquanto executam atividades previamente definidas, com duração de quatro segundos. Neste estudo foram avaliadas as seguintes atividades: execução de movimento com o punho direito, execução de movimento com o punho esquerdo, imaginação de movimento com o punho direito e imaginação de movimento com o punho esquerdo. A partir do registro do eletroencefalograma é feita a tentativa de reconhecimento do comando executado pelo voluntário.

Para compor os vetores de características utilizados para identificar as tarefas realizadas, o algoritmo desenvolvido neste trabalho classificou cada frequência de todos os canais de acordo com sua capacidade de isolar uma classe das demais. As melhores combinações de frequência e canal dos registros foram escolhidas para compor os vetores de características. Na sequência, foi usada a técnica de Análise de Componentes Principais (PCA) para reduzir a dimensão dos vetores de características. Foram realizados testes de desempenho de classificação, medidos pela taxa de acerto, com os vetores de características originais e reduzidos. Os testes foram realizados através dos classificadores KNN (K-Nearest Neighbor) e SVM (Support Vector Machine).

\section{METODOLOGIA}

Esta seção apresenta informações sobre o banco de dados utilizado e descreve o algoritmo desenvolvido neste trabalho.

\section{1 - Registro da atividade cerebral}

Os registros dos sinais cerebrais, eletroencefalograma, usados nas pesquisas de BCI normalmente seguem o sistema 
internacional 10-20 de posicionamento dos eletrodos no couro cabeludo. Cada uma das posições mapeadas pelo sistema 10-20 constitui um canal. A caracterização das atividades cerebrais, normalmente, utiliza as bandas de frequência beta $(>13 \mathrm{~Hz})$, alfa $(8-13 \mathrm{~Hz})$, teta $(4-8 \mathrm{~Hz})$ e delta $(0,5-4 \mathrm{~Hz})$ (TEPLAN, 2002).

Cada atividade cerebral pode resultar em sinais de maior amplitude em determinadas faixas de frequência e ser mais perceptível em canais específicos do eletroencefalograma. À medida que as pesquisas evoluem, as informações sobre os melhores canais e faixas de frequência para o reconhecimento de atividades cerebrais específicas passam a ser conhecidas. No entanto, quando não há informações prévias é necessário pesquisar todos os canais e bandas de frequência para identificar as combinações que fornecem informações mais relevantes para a identificação da atividade desejada.

Devido à dificuldade de distinguir diferentes atividades cerebrais, é comum que se trabalhe com um número reduzido de classes. Alguns trabalhos relacionados limitam o número de atividades a serem identificadas através do EEG. Pode-se, por exemplo, limitar-se a movimentos realizados, distinguindo entre a mão esquerda e a mão direita (ALOMARI, SAMAHA e ALKAMHA, 2013). Outra possibilidade é a distinção entre duas classes, onde o primeiro grupo consiste em movimentos realizados ou imaginados com o punho esquerdo e o segundo grupo consiste em movimentos realizados ou imaginados do punho direito (LOBODA, A. et al, 2014).

\section{2 - Banco de dados utilizado}

O banco de dados utilizado, EEG Motor Movement/Imagery Datase, consiste no registro do eletroencefalograma de 114 voluntário que executaram tarefas de movimento ou imaginação de movimento dos membros. O EEG registrado consiste em 64 canais capturados com uma taxa de amostragem de $160 \mathrm{~Hz}$. Cada voluntário realizou 14 seções do experimento, conforme descrito a seguir:

- Duas linhas de base de um minuto (uma com os olhos abertos, outra com os olhos fechados),

- Três execuções de dois minutos executando uma das quatro tarefas a seguir:

1) Um alvo aparece no lado esquerdo ou direito da tela, então o voluntário abre e fecha o punho correspondente até que o alvo desapareça. Então o voluntário relaxa.

2) Um alvo aparece no lado esquerdo ou direito da tela, então o voluntário imagina abrir e fechar o punho correspondente até que o alvo desapareça. Então o voluntário relaxa.

3) Um alvo aparece na parte superior ou inferior da tela, então voluntário abre e fecha ambos os punhos (se o alvo estiver na parte superior) ou ambos os pés (se o alvo estiver na parte inferior) até que o alvo desapareça. Então o voluntário relaxa.

4) Um alvo aparece na parte superior ou inferior da tela. O voluntário imagina abrir e fechar ambos os punhos (se o alvo estiver na parte superior) ou ambos os pés (se o alvo estiver na parte inferior) até que o alvo desapareça. Então o voluntário relaxa.

Cada tarefa é executada por quatro segundos. O conjunto de dados é rotulado, de forma que seja conhecida a amostra inicial do trecho de quatro segundos da execução de uma tarefa e o tipo da tarefa executada, através de um código que informa o membro envolvido.

Este trabalho utilizou os registros que seguem o mesmo padrão, cada registro corresponde a um voluntário. Os seguintes registros foram descartados por apresentavam algum experimento executado com menos de 14 seções registradas ou algum registro de tarefa com menos de quatro segundos: 34, 37, 41, 51, 64, 72, 73, 74, 76, 100, 102, $104 \mathrm{e}$ 106.

\section{3 - Algoritmo de seleção de frequências e canais para classificação}

Os trechos do sinal com quatro segundos foram isolados e agrupados em oito classes, correspondentes às tarefas realizadas. Neste trabalho foram utilizadas as quatro classes, correspondentes ao movimento imaginado do punho direito, movimento imaginado do punho esquerdo, movimento realizado com punho direito e movimento realizado com o punho esquerdo. Os registros das outras tarefas não foram utilizados.

Metade das amostras foi utilizada para realizar a busca das características mais discriminantes e, posteriormente, para treinar os classificadores. A outra metade foi usada no teste de desempenho.

$\mathrm{O}$ processo de seleção das características mais discriminantes foi realizado através das seguintes etapas:

(1) Separação dos 64 canais EEG que compõem o registro de cada voluntário no banco de dados.

(2) Divisão dos sinais em períodos correspondentes às tarefas de movimento realizado ou imaginado. Esses períodos consistem em aproximadamente quatro segundos de registro (665 amostras com uma taxa de amostragem de $160 \mathrm{~Hz}$ ).

(3) Separação dos registros de tarefas em dois conjuntos, um para ser usado na seleção das características e treinamento dos classificadores, conjunto de treino, e outro para ser usado no teste de desempenho.

(4) Cálculo da Transformada Rápida de Fourier (Fast Fourier Transform - FFT) de cada registro de quatro segundos no conjunto de treino.

(5) Cálculo da média, para cada canal, do resultado obtido pela FFT para cada uma das classes. A Figura 1 apresenta o gráfico da média calculada nesta etapa para o canal 59. O canal 59 foi tomado como exemplo, o mesmo cálculo foi feito para todos os canais.

(6) Cálculo da distância entre as médias da FFT, obtidas na etapa anterior, das diferentes classes. Sendo registrado o menor valor para cada classe, que corresponde à distância para a classe mais próxima.

Na Figura 1 é possível ver, na faixa de frequência em torno dos $10 \mathrm{~Hz}$ do canal 59, que a média do espectro de potência da classe "movimento imaginado do punho esquerdo" se distancia das demais classes.

(7) Normalização das distâncias, obtidas na etapa anterior, dividindo-as pela média da densidade de potência, do mesmo canal, de todas as classes. Essa normalização tem por função impedir que canais que apresentam sinais de menor amplitude sejam descartados, mesmo apresentando potencial para diferenciar as classes possíveis.

A Figura 2 apresenta o detalhe da mínima distância normalizada para a classe "movimento imaginado do punho esquerdo", no canal 59. Nessa figura é possível observar que o distanciamento da média do espectro de potência, visto na 
Figura 1, é percebido como um pico no gráfico da mínima distância normalizada.

(8) Para cada classe, escolha da combinação de canal e frequência das " $n$ " maiores distâncias normalizadas, calculadas no passo anterior, para compor os vetores de características. Para não selecionar frequências próximas em um mesmo canal, foi respeitada uma margem de $2 \mathrm{~Hz}$ em torno de cada frequência selecionada.

(9) Composição dos vetores de características com dimensão " $4 \mathrm{n}$ ". Cada característica consiste na soma da densidade espectral de potência em uma faixa de $4 \mathrm{~Hz}$ centrada em uma das frequências selecionadas na etapa anterior. As características foram ordenadas da mais discriminante para a menos discriminante, de modo que os vetores de características pudessem ser reduzidos pela escolha dos primeiros elementos.

Figura 1 - Média da densidade espectral de potência (conjunto de treino). Detalhe da faixa de frequência em torno de $10 \mathrm{~Hz}$ do canal 59.

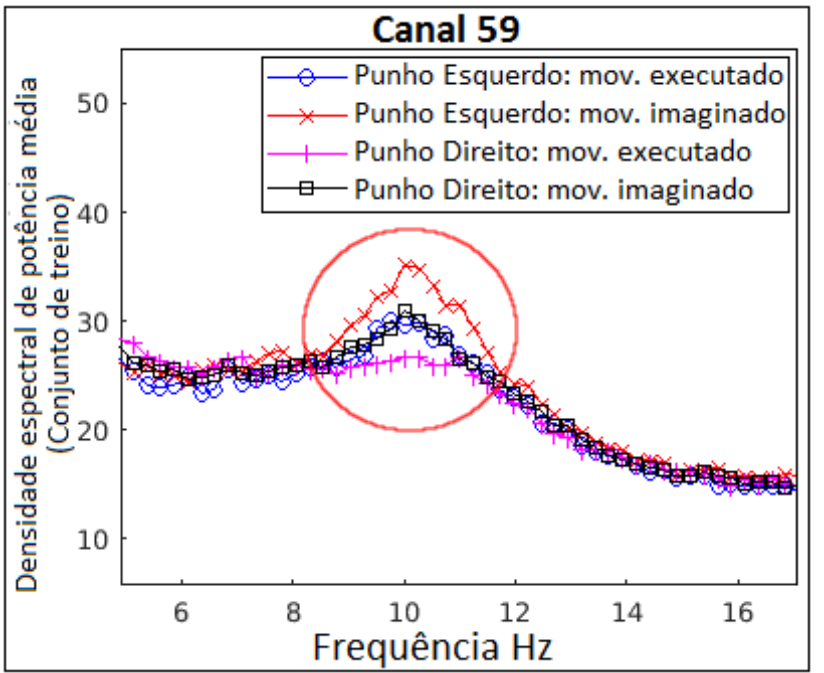

Fonte: Autores, 2018.

No exemplo apresentado na Figura 1, é possível ver que a densidade espectral de potência em torno da frequência de $10 \mathrm{~Hz}$, no canal 59, fornece uma melhor capacidade de discriminação do movimento imaginado do punho esquerdo do que as demais frequências. Isso indica que a densidade espectral de potência em uma faixa de frequência em torno de $10 \mathrm{~Hz}$ do canal 59 pode ser selecionada para compor os vetores de características devido à sua capacidade de caracterizar o movimento imaginado do punho esquerdo.

Para analisar todos os canais e escolher as bandas de frequência mais discriminantes para distinguir uma classe das demais, nas etapas 6 e 7 calculou-se a distância mínima normalizada da média da densidade espectral de potência de cada classe para as demais. A Figura 2 mostra essa distância para a classe "movimento imaginado do punho esquerdo" para o mesmo canal e faixa de frequência vistos na Figura 1.
Figura 2 - Mínima distância normalizada da média da densidade espectral de potência da classe "Punho esquerdo: movimento imaginado" para as demais (conjunto de treino).

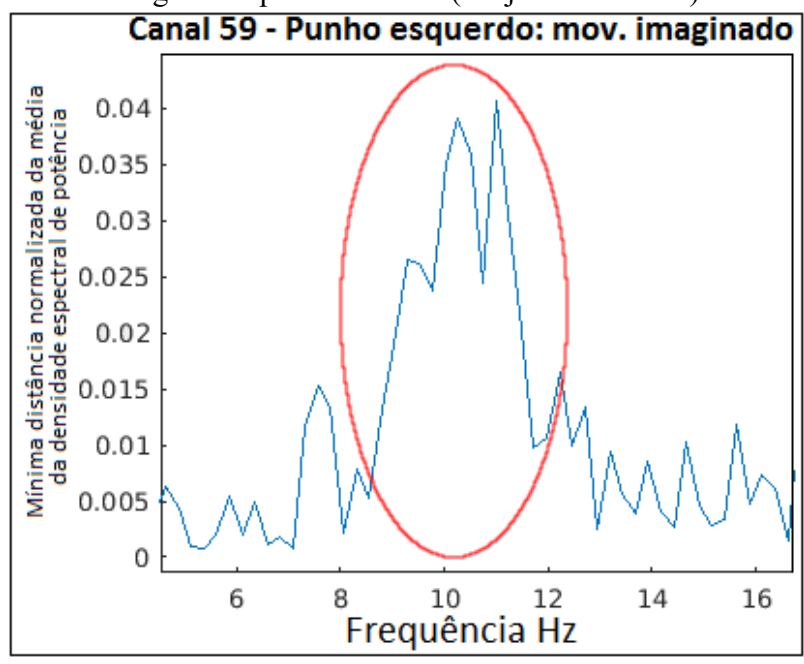

Fonte: Autores, 2018.

A normalização, executada no passo 7, da distância calculada no passo 6 foi realizada para comparar distâncias entre bandas de frequências e canais que possuam densidades espectrais de potência diferentes. Sem a normalização, os vetores de características são compostos apenas pelas frequências e canais com grande densidade espectral de potência, o que reduz a taxa de acerto na classificação.

\section{4 - Redução da dimensão dos vetores de características}

Após a seleção das características mais discriminantes, foram realizados testes de desempenho, medido pela taxa de acerto, com diferentes dimensões dos vetores de características. A dimensão dos vetores de características foi escolhida para maximizar o desempenho do classificador SVM, conforme apresentado na Figura 3. Os melhores resultados foram obtidos com a dimensão em torno de 140 características.

Figura 3 - Teste de tamanho dos vetores de características sem a aplicação do PCA.

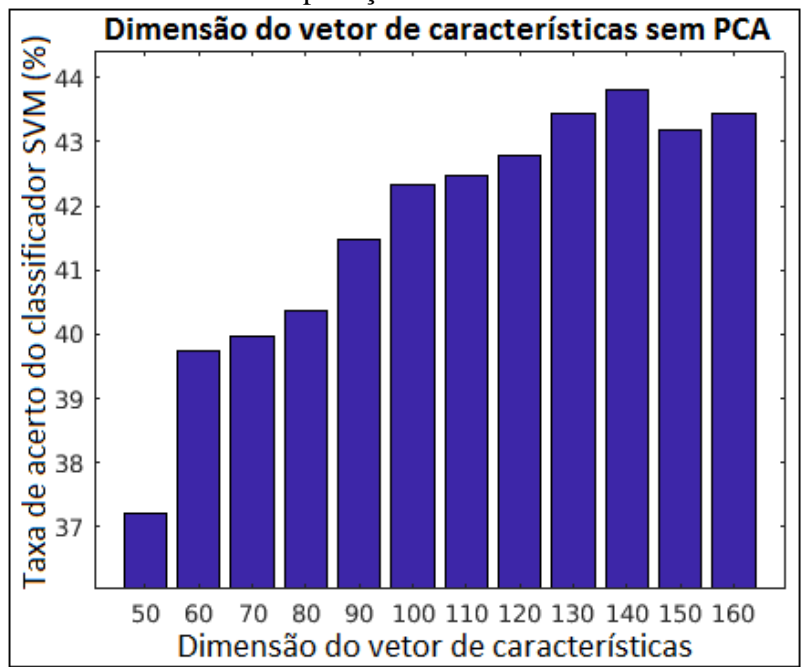

Fonte: Autores, 2018.

Como muitas dessas características podem ser correlacionados, foi utilizada a Análise de Componentes Principais (PCA) para gerar novos vetores de características 
com componentes menos correlacionadas (ILIN e RAIKO, 2010). Ao aplicar o PCA, foi possível reduzir a dimensão dos vetores de características de 140 para 90, sem redução no desempenho, conforme mostrado na Figura 4.

Figura 4 - Teste de tamanho dos vetores de características com a aplicação do PCA.

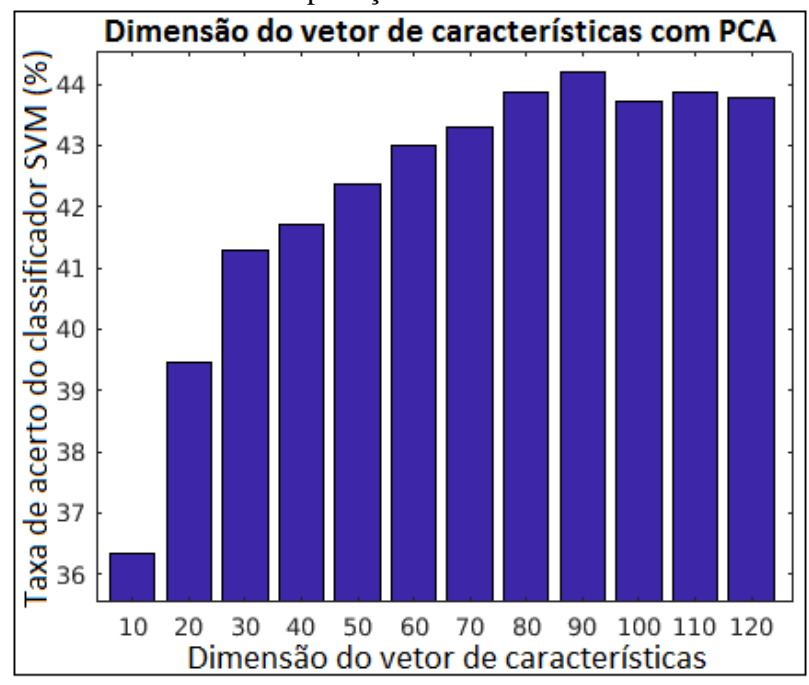

Fonte: Autores, 2018.

\section{RESULTADOS}

Foram realizadas duas rodadas de treinamento e teste. Em cada rodada, metade dos registros de cada classe foi usada para a seleção de características discriminantes e treinamento dos classificadores, a outra metade dos registros foi usada para avaliação de desempenho.

Foram utilizados os classificadores K-Nearest Neighbor (KNN) (IMANDOUST e BOLANDRAFTAR, 2013) e Support Vector Machine (SVM) (SRIVASTAVA, D.K. e BHAMBHU, 2010). Os parâmetros desses classificadores foram configurados na primeira rodada de testes, com o objetivo de maximizar a taxa de acerto. Os mesmos conjuntos de treinamento e teste foram usados para ambos os classificadores.

$\mathrm{Na}$ segunda rodada de testes, a configuração dos classificadores e a dimensão dos vetores de característica foram mantidas inalteradas a partir da primeira rodada. A Tabela 1 apresenta os resultados sem uso do PCA.

Tabela 1 - Taxa de acerto sem a aplicação do PCA (Vetor de características com dimensão 140)

\begin{tabular}{ccc}
\hline & SVM & KNN \\
\hline Primeira rodada & $43.7992 \%$ & $37.3438 \%$ \\
Segunda rodada & $43.6835 \%$ & $36.7654 \%$ \\
\hline & Fonte: Autores, 2018.
\end{tabular}

A partir da Tabela 1, pode-se observar que o classificador SVM apresentou um desempenho melhor que o KNN.

A classificação realizada com a aplicação da Análise de Componentes Principais e a redução da dimensão dos vetores de características de 140 para 90 foi realizada com o mesmo conjunto de dados, a precisão da classificação neste caso é apresentada na Tabela 2.
Tabela 2 - Taxa de acerto com a aplicação do PCA (Vetor de características com dimensão 90)

\begin{tabular}{ccc}
\hline & SVM & KNN \\
\hline Primeira rodada & $44.1925 \%$ & $37.3670 \%$ \\
Segunda rodada & $43.4521 \%$ & $36.7654 \%$ \\
\hline \multicolumn{3}{c}{ Fonte: Autores, 2018. }
\end{tabular}

Durante a implementação deste trabalho, observou-se que a escolha correta de canais e frequências para compor os vetores de características é importante para aumentar a precisão da classificação. Testando diferentes tipos de medidas de discriminação para compor os vetores de características, verificou-se que essas escolhas afetam significativamente o desempenho.

O uso da Análise de Componentes Principais (PCA) após a seleção das características provou ser bastante eficaz para reduzir a presença de informações redundantes, causada pela correlação entre alguns canais do eletroencefalograma.

O uso do PCA foi útil para reduzir a dimensão do vetor de características, sem redução no desempenho. O classificador SVM teve um desempenho superior ao do classificador KNN, o que mostra que o SVM tem uma maior capacidade de generalização, ou seja, classificar corretamente os dados que não foram usados para treinar o classificador.

\section{CONCLUSÃO}

Este estudo confirmou que a escolha de canais e faixas de frequência dos sinais de EEG para aplicações de BCI pode ser realizada pela análise espectral de potência.

Observou-se que, devido à correlação entre os canais do eletroencefalograma, é possível a redução da presença de informações redundantes pela aplicação da técnica de análise de componentes principais, sem diminuição no desempenho dos classificadores.

As taxas de acerto encontradas indicam que a utilização simultânea dos quatro comandos testados não é adequada para aplicações BCI através a técnica testada. Em estudos futuros, pode-se avaliar o efeito da redução do número de atividades classificadas no desempenho do sistema. Por exemplo, realizar apenas a distinção entre movimentos executados pelos punhos esquerdo e direito, excluindo os movimentos imaginados.

Como pesquisa futura, é possível criar uma estrutura com objetivo de reduzir a redundância de informações antes de compor os vetores de características. Isso pode ser conseguido pela avaliação da correlação entre os canais do electroencefalograma diretamente no espaço de tempo, isto é, antes do cálculo da densidade espectral de potência pela FFT. Com a redução de redundância, espera-se um melhor desempenho na classificação.

\section{REFERÊNCIAS BIBLIOGRÁFICAS}

ALOMARI, M.H.; SAMAHA, A.; ALKAMHA K. Automated classification of $l / r$ hand movement eeg signals using advanced feature extraction and machine learning. International Journal of Advanced Computer Science and Applications (IJACSA), n. 4(6), p. 207-212, 2013.

GOLDBERGER, A. L. et al. Physiobank, physiotoolkit, and physionet: Components of a new research resource for 
complex physiologic signals. Circulation, 101(23): e215e220, 2000.

ILIN , A.; RAIKO, T. Practical approaches to principal component analysis in the presence of missing values. Journal of Machine Learning Research, n. 11, p. 1957-2000, 2010.

IMANDOUST, S. B.; BOLANDRAFTAR, M. Application of k-nearest neighbor (knn) approach for predicting economic events: Theoretical background. Journal of Engineering Research and Applications, n. 3, p. 605-610, 2013.

LOBODA, A. et al. Discrimination of eeg-based motor imagery tasks by means of a simple phase information method. International Journal of Advanced Research in Artificial Intelligence(IJARAI), n. 3(10), p. 11-15, 2014.

SRIVASTAVA, D.K.; BHAMBHU, L. Data classification using support vector machine. Journal of Theoretical and Applied Information Technology, n. 12, p. 1-7, 2010.

TEPLAN, M. Fundamentals of EEG measurement. Measurement Science Review, n. 2, p.1-11, 2002.

WOLPAW, J. et al. Braincomputer interface technology: A review of the first international meeting. IEEE Transactions on Rehabilitation Engineering, IEEE, n. 8, p. 164-173, 2000 .

\section{COPYRIGHT}

Direitos autorais: Os autores são os únicos responsáveis pelo material incluído no artigo. 


\title{
ANÁlISE DA ACIDEZ DA SOLUÇÃO EXTRATORA PARA PRODUÇÃO DE CORANTES EMPREGADOS EM CÉLULAS SOLARES DE TERCEIRA GERAÇÃO
}

\author{
ANALYZE OF DYE ACIDIFIED SOLUTION USED IN THIRD \\ GENERATION OF SOLAR CELLS PRODUCTION
}

\author{
JULIANNO PIZZANO AYOUB $^{1}$; GIDEÃ TAQUES TRACTZ ${ }^{1}$; DOUGLAS KAIS SILVA ${ }^{1}$; PAULO \\ R. P. RODRIGUES ${ }^{1}$
}

\section{1 - UNIVERSIDADE ESTADUAL DO CENTRO OESTE.}

juliannopa@hotmail.com; gide.tractz@hotmail.com;douglasks@gmail.com; prprodrigues@gmail.com

\begin{abstract}
RESUMO - Células solares sensibilizadas por corante, são uma alternativa para a redução de gases poluentes e a diminuição dos custos de conversão energética. Este trabalho tem como objetivo caracterizar uma célula solar de $\mathrm{TiO}_{2}$ sensibilizada com o corante extraído batata doce roxa, sob solução etanoica acidificada a diferentes valores de $\mathrm{pH}$. As técnicas de caracterização empregadas são: Espectroscopia no UV-VIS, medidas do potencial de circuito aberto em função do tempo $\left(E_{c a}\right)$, medidas de fotocronoamperometria (j-t), curvas de densidade de corrente em função do potencial (j-V), e espectroscopia de impedância eletroquímica (EIE)
\end{abstract}

Palavras-chave: Sustentabilidade. Células de Gratzel. Antocianinas.

ABSTRACT - Dye sensitized solar cells (DSSC) are an alternative method to reduce polluent gas and the production costs of energetic conversion. This work aims to characterize a solar cell of $\mathrm{TiO} 2$ sensitized with the dye extracted from the purple sweet potato, extracted in different $\mathrm{pH}$ values. The characterization techniques used are: UV-VIS spectroscopy, open-circuit potential as a function of time (Eca), photocronoamperometry (j-t) measurements, current density curves as a function of potential $(j-V)$ and electrochemical impedance spectroscopy (EIE).

Keywords: Sustentability. Gratzel Cell. Anthocyanins.

\section{INTRODUÇÃO}

Os dispositivos fotovoltaicos desempenham a função de captar a luz solar e gerar corrente elétrica, através do efeito fotoelétrico [1] [2]. Dentre as classes de dispositivos solares produzidas hoje no mercado, encontram-se as células solares de terceira geração, pertencentes a esta classe as chamadas células solares híbridas, as células de perovskitas, as células solares por sensibilizadas por pontos quânticos e as células solares sensibilizadas por corante (CSSC), foco deste trabalho [3].

Descobertas em 1991 por Gratzel, baseiam-se no uso de um semicondutor de elevada porosidade, sendo nele Anais do XL International Sodebras Congress depositado um material fotossensibilizador. Quando a luz solar incide no dispositivo, elétrons do corante são ejetados para a banda de condução do óxido, e as espécies oxidadas/reduzidas, são regeneradas pelo uso de um intermediador de cargas (eletrólito), propiciando assim um fluxo de elétrons, ou seja, uma corrente elétrica [4].

Devido ao custo elevado dos corantes utilizados, novas pesquisas surgem, com o intuito de viabilizar a produção destes dispositivos em larga escala. Os corantes extraídos de produtos naturais, podem ser aplicados nestes dispositivos, e os mais utilizados são os ricos em antocianinas, moléculas capazes de absorver na região do visível, como a berinjela, beterraba, uva, entre outros [5].

As antocianinas, são facilmente extraídas em solução etanoica, e segundo Lopes (2007) a acidificação da solução facilita a extração de espécies ativas, porém o $\mathrm{pH}$ da solução, pode vir a interferir na degradação da interface $\mathrm{TiO}_{2} /$ corante [6].

Este trabalho tem como objetivo, produzir e caracterizar eletroquimicamente, uma célula solar de terceira geração, composta de $\mathrm{TiO}_{2}$ e corante natural extraído da beterraba roxa, sob solução etanoica acidificada com ácido cítrico e ácido clorídrico, verificando assim, qual metodologia de extração gera células mais eficientes.

\section{METODOLOGIA}

O fotoanodo foi produzido com $\mathrm{TiO}_{2}$ depositado via Doctor Blading em FTO (óxido de estanho dopado com flúor) e calcinadas a $450^{\circ} \mathrm{C}$ [7]. As soluções do corante foram produzidas sob solução etanoica acidificada em ácido clorídrico $(\mathrm{pH}=1,2)$ e ácido cítrico $(\mathrm{pH}=5,3)$ da batata doce roxa (Ipomoea Batatas). Para a preparação do fotoanodo, a placa de $\mathrm{TiO}_{2}$ foi mergulhada na solução do corante, por 24 horas para garantir uma perfeita adsorção das espécies ativas na superfície do óxido, como mostra a Figura 1 [8]. 
Figura 1. Fotoanodo de $\mathrm{TiO}_{2}$ com corante da batata doce roxa, extraído em solução, a) etanoica acidificada com ácido cítrico e b) etanoica acidifica com ácido clorídrico.

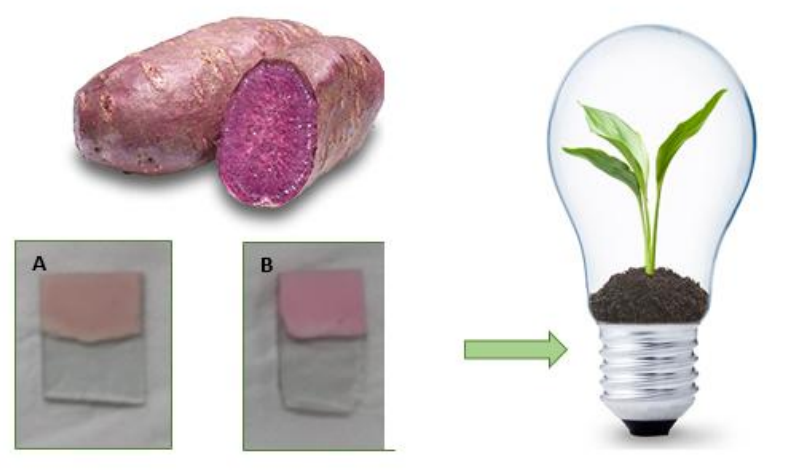

Fonte: O autor (2018).

Platina eletrodepositada foi utilizada como cátodo e a intermediação das cargas foi realiza pelo par redox $\mathrm{I}_{3}{ }^{-} / 3 \mathrm{I}^{-}$ [4]. A célula foi montada em formato sanduíche do fotoanodo e do cátodo, com uma área ativa de $0,2 \mathrm{~cm}^{2}$ [9].

As medidas eletroquímicas foram realizadas em um potenciostato Zhenium Zhaner com simulador solar XPOT, utilizando lâmpada de Xenônio, com um espectro solar padrão de AM 1.5G e potência incidente de $100 \mathrm{~mW} \mathrm{~cm} \mathrm{~cm}^{-2}$ $[7,9]$.

\section{RESULTADOS E DISCUSSÃO}

Na Figura 2, encontram-se as medidas de UV-VIS para a solução dos corantes.

Figura 2. Espectro UV-VIS para a solução dos corantes analisadas.

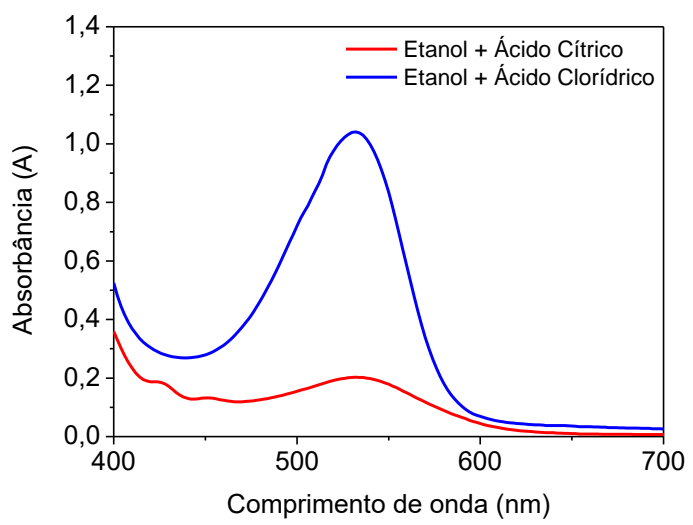

Observa-se na Figura 2, que ambos os corantes analisados absorvem na região do visível, característica essa fundamental para o funcionamento de uma célula de terceira geração, pois como demonstrado por Hangfeldt e colaboradores (2010), o $\mathrm{TiO}_{2}$ apresenta a capacidade de absorção apenas na região do ultra violeta [10].

Percebe-se também na Figura 2, que o corante extraído sob solução etanoica acidificada com ácido clorídrico, apresentou uma banda de maior absorção na Anais do XL International Sodebras Congress região próxima a $550 \mathrm{~nm}$, esta característica se da, devido a presença de antocianinas na composição do corante. Nota-se também, que em valores menores de $\mathrm{pH}$, as antocianinas são extraídas em maiores quantidades, o que aumenta a banda de absorção do espectro eletromagnético [10].

O fato das amostras não absorverem energia na região do espectro eletromagnético, também é um fator que limita parcialmente a conversão energética da célula, como relatado por Tractz e colaboradores (2018) [11].

As curvas de potencial de circuito aberto em função do tempo, como mostra a Figura 3, mostram os dados de potencial fornecido pela célula, e também, como descrito por Viomar et al. (2016) apresentam estimativas básicas dos efeitos de recombinação de cargas no dispositivo, efeito esse que impede a passagem da corrente e gera perdas por calor [12].

Figura 3. Curvas de potencial em circuito aberto em função do tempo, para o sistema analisado.

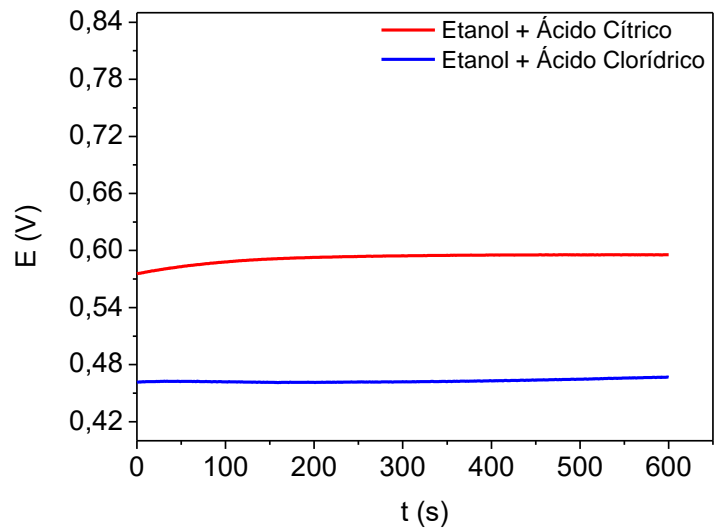

Percebe-se na Figura 3, que a célula produzida com corante extraído em solução etanoica acidificada com ácido cítrico, apresentou um maior valor de potencial, consequentemente sugerindo reações de recombinação menos pronunciáveis quando comparados a célula com corante extraído em $\mathrm{pH}=5,3[7,12]$. Este resultado amostra, que apesar de soluções de ácidos fortes, gerarem corantes com maior banda de absorção no espectro eletromagnético, gera células com menores valores de potencial.

$\mathrm{Na}$ Figura 4, é mostrado a técnica de fotocronoamperometria para ambos os sistemas analisados, onde é possível verificar o perfil de carregamento e descarregamento da célula, e também os valores de densidade de corrente produzida no sistema. 
Figura 4. Curvas fotocronoamperométricas para os sistemas analisados.

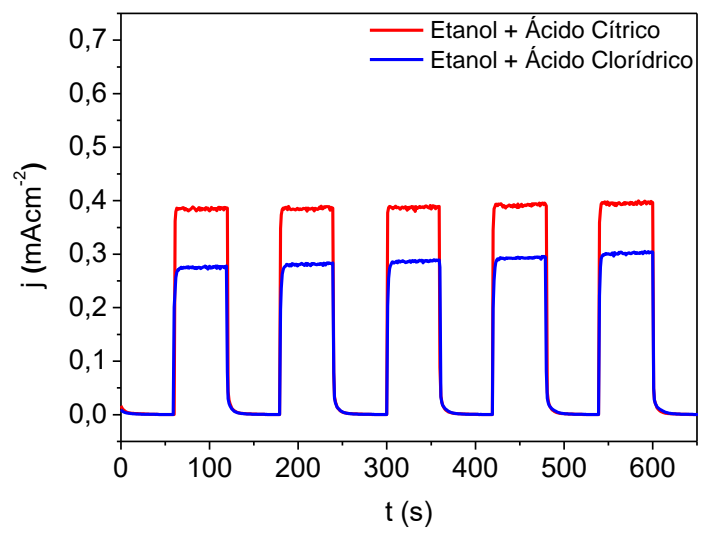

Figura 4 mostra que o sistema produzido com o corante extraído com uso do ácido cítrico, apresentou uma densidade de corrente próxima a $\mathrm{j}=0,40 \mathrm{mAcm}^{-2}$, enquanto aquele que faz uso de um ácido mais forte, um valor próximo a $\mathrm{j}=0,30 \mathrm{mAcm}^{-2}$. Este resultado também comprova $\mathrm{o}$ anterior, que soluções fracamente acidificadas geram células com maiores parâmetros fotoeletroquímicos [8].

Ambos os dispositivos analisados, apresentaram um ótimo perfil de carregamento/descarregamento, pois quando houve a incidência de luz o aumento da corrente foi instantâneo e quando a luz foi interrompida, o sistema apresentou um valor nulo [13]

Utilizando-se das medidas fotocronoamperométricas, é possível estimar a eficiência de recobrimento, obtendo sugestões sobre a adsorção do corante na superfície do $\mathrm{TiO}_{2}$, como relato no trabalho de Tractz et al (2018)[7]. Foi obtido para este sistema, valores de $\Theta$ (eficiência de recobrimento) de 0,68 e 0,55, para os corantes extraídos com ácido cítrico e ácido clorídrico respectivamente, sugerindo que o uso do ácido clorídrico, dificulta a adsorção do corante na superfície do óxido [7].

A medida de densidade de corrente em função do potencial (Figura 5) fornece os parâmetros fotovoltaicos para cálculo da eficiência do dispositivo, como relatado por Narayan et al.(2014)[14], e encontram -se na Tabela 1.

Figura 5.Curvas de j-E para os sistemas analisados.

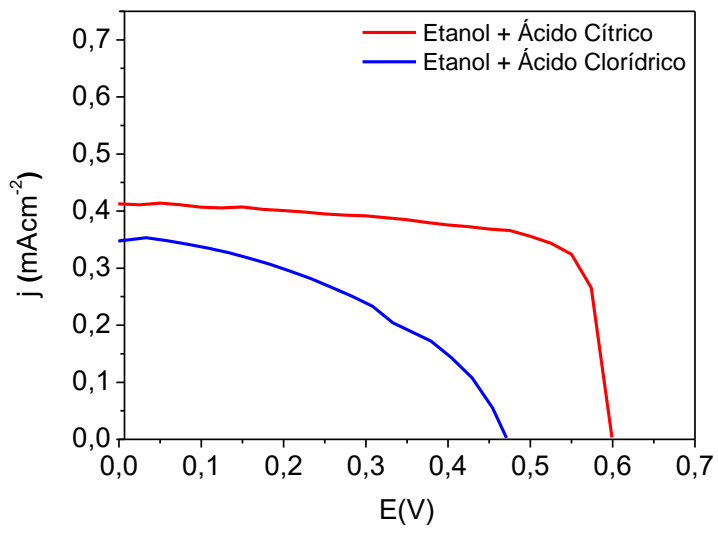

Tabela 1. Parâmetros fotovoltaicos dos sistemas analisados, obtidos sob iluminação de $100 \mathrm{~mW} \mathrm{~cm}^{-2}$.

\begin{tabular}{lllll}
\hline Extração & $\begin{array}{l}\mathbf{j}_{\mathbf{c c}}(\mathbf{m A} \\
\left.\mathbf{c m}^{-2}\right)\end{array}$ & Eca $(\mathbf{V})$ & $\mathbf{F F}$ & $\mathbf{\eta ( \% )}$ \\
$\begin{array}{l}\text { Ácido } \\
\text { Cítrico }\end{array}$ & $0,43 \pm 0,02$ & $0,59 \pm 0,01$ & $0,72 \pm 0,01$ & $0,18 \pm 0,01$ \\
$\begin{array}{l}\text { Ácido } \\
\text { Clorídrico }\end{array}$ & $0,34 \pm 0,02$ & $0,503 \pm 0,04$ & $0,54 \pm 0,02$ & $0,09 \pm 0,02$ \\
\hline \multicolumn{5}{c}{ Fonte: O autor (2018). }
\end{tabular}

Nota-se na Tabela 1, que a célula com corante extraído sob solução acidificada com ácido cítrico apresenta maiores valores de densidade de fotocorrente $(0,43 \pm 0,02$ $\left.\mathrm{mA} \mathrm{cm}{ }^{-2}\right)$, potencial de circuito aberto $(0,59 \pm 0,01 \mathrm{~V})$ e fator de preenchimento $(0,72 \pm 0,01)$, gerando consequentemente, células com maior eficiência $(0,18 \pm 0,01 \%)$ em aproveitamento de energia quando comparado ao uso do $\mathrm{HCl}$ [14]. Devido aos resultados obtidos, sugere-se que quanto maior a força do ácido utilizado, a adsorção das moléculas de antocianinas na superfície do $\mathrm{TiO}_{2}$ são dificultadas, gerando células menos eficientes [7].

Grande ênfase é dada no valor de preenchimento encontrado para a célula com corante extraído do ácido cítrico, pois quando há o uso de corantes comerciais na produção destes sistemas, que são referências na absorção em uma ampla região do espectro eletromagnético, valores menores de FF são encontrados, comprovando que o uso de ácidos fortes, para extração de corantes naturais aplicados em CSSC, geram células próximas a idealidade [12].

Para a verificação das resistências das células produzidas, na Figura 6 é mostrada os resultados da espectroscopia de impedância eletroquímica.

Figura 6. Diagramas de Bode, para os sistemas analisados.

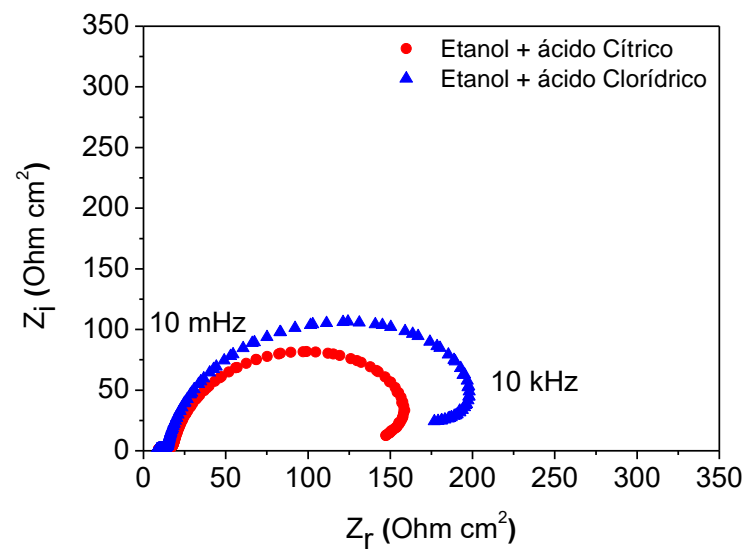

Nota-se a formação de dois arcos, sendo o menor relatado como os processos oriundos no contra eletrodo $(\mathrm{Pt})$, e os processos de menor frequência relativos a interface anódica $\mathrm{FTO} / \mathrm{TiO}_{2} /$ Corante, como relatado por Guimaraes et al (2017) [15].

Verifica-se também na Figura 6, que a célula com $\mathrm{HCl}$, apresenta um maior arco capacitivo, comprovando que o sistema apresenta uma maior resistividade $e$ consequentemente uma dificuldade a passagem de corrente, 
quando comparada ao sistema com ácido cítrico, fato este comprovado pelas medidas anteriores [11].

\section{CONCLUSÕES}

A substituição de corante sintético por corante natural na produção de CSSC, é uma boa alternativa, devido ao custo mais baixo. O uso de ácidos fracos, que gera soluções com pH mais alto usados para a extração de corantes naturais, gera células mais eficientes, quando comparados a ácidos fortes, e este resultado, sugere-se estar relacionado com a adsorção das moléculas do corante na superfície do $\mathrm{TiO}_{2}$.

\section{REFERÊNCIAS BIBLIOGRÁFICAS}

[1] Gratzel, M. Photoelectrochemical Cells. Nature, V. 414, p. 338-345, 2001.

[2] Tractz, G.T.; VIOMAR, A.; MATHEUS, A. P. C.; MAIA, G. A. R.; BANCZEK, E.; CUNHA, M. T.; RODRIGUES, P. R. P. Produção de célula solar com corante natural extraído da Acacia Decurrens. Sodebras. V.13,Mar/ 2018.

[3] VITORETTI, A. B. F.; CORREA, L. B.; RAPHAEL, E.; PATROCINIO, A O. B.; NOGUEIRA, A. F.; SCHIAVON, M. A.; Células solares sensibilizadas por pontos quânticos. Química Nova, v.40, n.04, pg.436-446, 2017.

[4] GRATZEL, M. Dye sensitized solar cells. Journal of photochemistry and photobiology C: Photochemistry Reviews. V. 4, Jul./2003, pg 145-153.

[5] PATROCINIO, A. O. T; ILHA, N. Y. M. Em busca da sustentabilidade: Células solares sensibilizadas por extratos naturais. Química nova. V.33, n. 03, Fev./2010, pg 574578.

[6] LOPES, T. J; XAVIER, M. F; QUADRI, M. G. N; QUADRI, M. B. Antocianinas: uma breve revisão das características estruturais e estabilidade. Revista brasileira de agrociência. V.13. N. 3, 2007, pg 291-297.

[7] TRACTZ, G. T.; MAIA, G. A .R.; DIAS, B. V.; BANCZEK, E. P.; CUNHA. M. T.; RODRIGUES, P. R. P. Estudo de células solares híbridas de $\mathrm{TiO} 2$ com corantes naturais. Revista Virtual de Química. 2018, 10, 4, pg. 1074-1086.

[8] Tractz, G. T.; Maia, G. A. R.; Dias, B. V.; Ignachewski, F.; Rodrigues, P.R.P.; Avaliação da adsorção e estudo eletroquímico de células solares sensibilizadas com corante do Hibisco. Química Nova, v.41, pg. 512-518, 2018.

[9] TRACTZ, G. T.; MAIA, G. A. R.; DIAS, B. V.; BANCZEK, E.; MOLINARES, M. A.; CUNHA, M. T.; RODRIGUES, P. R. P.; Influence of deposition methodology and heating treatment on dye sensitized solar cell with natural extract. Orbital: The electronic journal of chemistry. V.10, n. 03, pg. 204-210, 2018.

[10] HAGFELDT, A; BOSCHLOO, G; SUN, L; KLOO, L; PETTERSON, Henrike. Dye Sensitized solar cells. Chemistry reviews. V. 110, 2010, pg 6595-6663..

[11] TRACTZ, G .T.; VIOMAR, A.; DIAS, B.; LIMA, C. A.; BANCZECK, E.; CUNHA, M. T.; ANTUNES, R. M.;
RODRIGUES, P. R. P.; Recombination study of natural dye sensitized solar cells. Journal of the Brazilian chemical society. 2018.

[12] VIOMAR, A; MAIA, G. A. R; SCREMIN, F. R; KHALIL, N. M; CUNHA, M. T; ANTUNES, A. C; RODRIGUES, P. R. P. Influencia do método de obtenção de partículas de $\mathrm{Nb} 2 \mathrm{O} 5$ empregadas em células solares sensibilizadas por corante composta de $\mathrm{TiO}_{2} / \mathrm{Nb} 2 \mathrm{O} 5$. Revista Virtual de Química, v. 8, 2016, pg 889-900

[13] DIAS, B.; TRACTZ, G. T.; VIOMAR, A.; MAIA, G. A R.; CUNHA, M. T.; RODRIGUES, P. R. P.; Photoelectrochemical behaviour of the cell FTO/TiO2/CeO2/N19 obtained from the pechinni and precipitation of cerium oxide methods. Journal of electronic Materials. V.47, n.09, 2018

[14] Hamadaian, M; Ghomi, J. S; Hosseinpour, M; Masoomi, R; Jabbaru, V. Uses of new natural dye photosensitizers in fabrication of high potential dye sensitized solar cells (DSSCs). Materials science in semiconductor processing, v.27, p. 733-739, 2014.

[15] GUIMARAES, R.R.; PARUSSULO, A. L. A.; MATIAS, T. A.; TOMA, H. E.; ARAKI, K.; Electrostatic blocking barrier as an effective strategy to inhibit electron recombination in DSSCs. Electrochimica acta. V. 255, pg.92-98, 2017.

\section{AGRADECIMENTOS}

O presente trabalho foi realizado com o apoio da coordenação de aperfeiçoamento de pessoal de nível superior-Brasil (Capes) código de financiamento 001. Os autores agradecem a FAU/UNICENTRO pelo apoio financeiro, e também ao CNPq, FINEP, Fundação Araucária e SETI/UGF.

\section{COPYRIGHT}

Direitos autorais: Os autores são os únicos responsáveis pelo material incluído no artigo. 


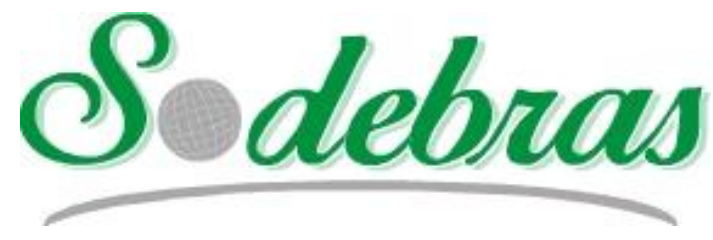

Volume 14 - No 159 - Março/2019.

XL International Sodebras Congress

10 a 12 de dezembro de 2018 - Vitória - ES.

\title{
MODELAGEM CINEMÁTICA DO ROBÔ COLABORATIVO UR5
}

\author{
KINEMATIC MODELING OF THE COLLABORATIVE ROBOT UR5
}

\author{
ALEXANDRE G. SOARES ${ }^{1}$; FELIPE A. A. MACEDO ${ }^{1}$; LEONARDO CÉSAR DE O. MARQUES ${ }^{1}$; \\ LUIZ PAULO G. RIBEIRO ${ }^{1}$
1 - INSTITUTO MILITAR DE ENGENHARIA / LABORATÓRIO DE ROBÓTICA INDUSTRIAL E DE DEFESA - IDR LAB

alexandregsoares@gmail.com; felipeaamacedo1@gmail.com; leonardomarques@prof.educacao.rj.gov.br; ribeiro@ime.eb.br

\begin{abstract}
Resumo - A crescente demanda por flexibilidade nos processos de fabricação e a evolução tecnológica dos sensores levou os fabricantes de robôs industriais ao desenvolvimento de manipuladores capazes de realizar tarefas em colaboração com humanos: os robôs colaborativos (cobots). Estes tipos de robôs possuem dispositivos que diminuem torque e velocidade quando em ambiente compartilhado, possibilitando a colaboração homem-robô nas células de trabalho de forma segura. Por se tratar de uma tecnologia relativamente recente, as aplicações dos cobots ainda estão em fase de discussão, o que incentiva a Pesquisa, Desenvolvimento e Inovação (PD\&I). Este trabalho objetiva apresentar a modelagem cinemática do robô colaborativo UR5 utilizando a Teoria dos Helicoides, passo inicial de PD\&I de um simulador que auxilie a análise do potencial de implementação dos cobots em atividades industriais. Palavras-chave: Cobots. Modelagem. Teoria dos Helicoides.
\end{abstract}

\begin{abstract}
The growing demand for flexibility in manufacturing processes and the technological evolution of sensors took the industrial robots' manufacturers to the development of manipulators capable of accomplish tasks in collaboration with humans: the collaborative robots (cobots). These kinds of robots possess gadgets that lows torque and velocity when in shared environment, allowing the safely man-robot collaboration in the workspace. As it is a relatively recent technology, the applications of cobots are still in a discussion stage, which encourages the Research, Development and Innovation (RD\&I). This paper aims to present the kinematic modeling of the collaborative robot UR5 using the Screw Theory, being the first step of $R D \& I$ of a simulator that supports the potential implementation analysis of cobots in industrial activities.
\end{abstract}

Keywords: Cobots. Modeling. Screw Theory.

\section{INTRODUÇÃO}

A utilização de robôs industriais nos processos de fabricação vem sendo feita desde a década de 1960 e possui uma série de benefícios associados à redução de custos, à padronização da qualidade, ao aumento de produtividade, da confiabilidade de entrega e da flexibilidade da mudança do tipo de lote dentro de uma mesma família de peças, devido ao fato de serem robustos e reprogramáveis. Assim sendo, alinham-se com os objetivos de desempenho industriais definidos por Slack e Lewis (2002), que levam ao aumento da produtividade total, o que implica em ganho estratégico de competitividade.
Todavia, existem diversos processos com complexidades inerentes que limitam a automação usando robôs industriais, o que ainda torna necessária a presença humana, mesmo que parcial, para viabilizar a execução de tarefas associadas a estes processos. Os seres humanos possuem um conjunto de atributos como destreza, criatividade e capacidade analítica de resolução de problemas, ausentes nas máquinas.

Por apresentarem riscos aos seres humanos, a utilização de robôs industriais está sujeita a normas de segurança rígidas. Dentre as recomendações necessárias consta que estes dispositivos devem estar enclausurados, a fim de reduzir os riscos de acidentes de trabalho. Entretanto, o aumento de demanda por flexibilidade e a busca de automatização de processos complexos vêm fazendo com que os fabricantes de robôs industriais busquem soluções para que o ambiente de trabalho dos robôs possa ser compartilhado com o homem. Neste sentido, em 1996 surgiu o primeiro protótipo de robô colaborativo (cobot).

Os cobots são manipuladores robóticos capazes de compartilhar o mesmo ambiente com seres humanos, de forma segura, pois incorporam dispositivos de sensoriamento em seu sistema ou no espaço de trabalho, que permitem a percepção de eventos que demandam limitação de torque e velocidade. Por se tratar de uma tecnologia relativamente recente, as aplicações desse tipo de manipulador robótico ainda estão em debate e análise, o que fornece oportunidades de PD\&I na busca de melhorias e vantagens competitivas.

Uma maneira de verificar a viabilidade de utilização de robôs na automatização de tarefas é através de análises por simulação com visualização de resultados em cenários virtuais. Assim sendo, é possível investigar, prever e comparar diferentes layouts, usando os modelos 3D da célula de trabalho, obtendo indicadores de desempenho, sem a necessidade do equivalente real.

As ferramentas computacionais de análise por simulação são consideradas estratégicas, pois além de proporcionar redução de tempo e de custos, auxiliam na confiabilidade da tomada de decisão e na aprendizagem e treinamento de operação do equipamento, como apresentado em Santos et al. (2017) e Galhardo e Ribeiro (2017). Podem também se tornar ferramentas úteis de auxílio à 
programação de robôs, dispensando parcialmente a operação manual do braço robótico. Entretanto, simular as capacidades colaborativas dos cobots demandam um nível maior de sofisticação do modelo, o que implica que haja entendimento das características e dos eventos associados a comportamentos presentes, a fim de serem implementados.

Este trabalho tem por objetivo: (i) realizar uma breve revisão bibliográfica a respeito de robôs colaborativos, analisando e identificando suas principais características; (ii) identificar os eventos/comportamentos associados aos modos de colaboração; e (iii) modelar matematicamente a cinemática direta do robô colaborativo UR5 usando fundamentos da Teoria dos Helicoides, o que caracteriza-se como passo inicial da metodologia de PD\&I de um simulador de cobots.

Este artigo está estruturado com uma análise do desenvolvimento histórico dos cobots na seção II. A seção III ressalta as necessidades da análise de riscos para utilização dos cobots e a seção IV identifica os eventos/comportamentos associados aos modos de operações colaborativas. $\mathrm{Na}$ seção $\mathrm{V}$, os fundamentos da Teoria dos Helicoides utilizados na modelagem cinemática de robôs são sumariamente apresentados, enquanto na seção VI, encontra-se a modelagem do cobot UR5. Finalmente, na seção VII constam as conclusões e perspectivas de trabalhos futuros.

\section{DESENVOLVIMENTO HISTÓRICO}

A origem dos robôs industriais decorreu, segundo Spong et al. (2004), do desenvolvimento e posterior união de duas tecnologias precedentes: $(i)$ a teleoperação, que se modernizou com a necessidade de manipular materiais radioativos durante a Segunda Guerra Mundial; e (ii) o CNC (Computer Numerical Control) cujo advento foi motivado pela necessidade de alta precisão na usinagem de componentes como os de aeronaves de alta performance.

De acordo com Fryman e Matthias (2012), a força hidráulica dos primeiros robôs industriais causou preocupações quanto à segurança em sua aplicação. $\mathrm{O}$ controle dessas máquinas não era totalmente confiável e a grande vantagem mecânica em relação aos outros dispositivos da época tornavam um risco em potencial ao operador. Entretanto, o grande avanço proporcionado à automação, justificavam sua utilização apesar dos riscos na operação, que foram reduzidos pelo enclausuramento do robô, ou seja, pela separação por meio de "barreiras" físicas (cercas), do espaço de trabalho do robô e do homem.

$\mathrm{O}$ desenvolvimento de sensores e microprocessadores, aliado à redução de custos dos mesmos, permitiu a implementação de sistemas de segurança cada vez mais sofisticados aos robôs industriais, possibilitando a interação direta entre humanos e robôs em operações colaborativas. A introdução do termo robô colaborativo foi feita por Colgate et al. (1996), que desenvolveu um protótipo que permitia a movimentação de um robô biaxial manualmente pelo usuário, ao restringir a movimentação do robô a determinado grau de liberdade, o que servia de guia ao movimento. Além disso o robô não aplicava força na direção do movimento, sendo passivo e intrinsecamente seguro.

O estudo da interação homem-robô levou ao desenvolvimento de novos sensores para este tipo de aplicação como apresentado em Lorenz et al. (1999), e por mecanismos capazes de adaptar a capacidade do protótipo original de Colgate a robôs mais complexos. Nos primeiros protótipos, os denominados cobots eram apenas dispositivos que auxiliavam na trajetória do movimento, enquanto que os humanos eram responsáveis por tracioná-los.

Tecnologias de assistentes robóticos foram mesclandose com os avanços dos robôs colaborativos com intuito de aprimorar a relação homem/máquina. Schraft et al. (2005) desenvolveram um assistente robótico industrial funcional, o PowerMate, que consistia em uma célula de trabalho com um robô industrial convencional que permitia, em parte do layout, o compartilhamento seguro entre homem e robô. $\mathrm{O}$ espaço de trabalho era monitorado por câmeras, sensores de força, cortinas de luz, scanners a laser, dentre outros dispositivos de segurança.

Atualmente os robôs colaborativos são definidos como sistemas robóticos que permitam uma operação colaborativa, ou seja, onde robô opere em cooperação direta com um ser humano em determinado ambiente de trabalho. Assim, um robô convencional pode ser considerado colaborativo desde que possua sistemas "assistentes", para o sensoriamento do ambiente e possibilite a interação segura do robô-operário.

Diversas empresas já fabricam linhas de manipuladores colaborativos, com sistema de sensores próprios incorporados, em que não são necessários a utilização de acessórios adicionais para a operação colaborativa. De acordo com Schäffer et al. (2007), após anos de desenvolvimento em conjunto com o centro aeroespacial alemão (DLR), em 2006, a KUKA inicia a comercialização de seu primeiro manipulador robótico colaborativo, o KUKA LBR 3, ainda com baixa taxa de produção. Em 2009, a Universal Robots inicia a venda internacional do UR5. Em 2015, a ABB lança sua linha de robôs colaborativos com dois braços, o YuMi, enquanto a FANUC lança o robô colaborativo com maior capacidade de carga do mercado até então, o CR-35iA. Em 2017, a Yaskawa lança o Motoman $\mathrm{HC} 10$, fazendo com que atualmente cinco das maiores fabricantes de robôs industriais possuam linhas de cobots em seus catálogos.

\section{ANÁLISE DE RISCOS}

Desde 1984 foram registrados pela Occupational Safety and Health Administration (OSHA, 2018), nos Estados Unidos, 38 acidentes de trabalho envolvendo robôs industriais. Deste total, $27(71,1 \%)$ foram fatais, o que ratifica a importância e o imprescindível cumprimento das normas de segurança.

Por se tratarem de robôs que estão em permanente contato com seres humanos, uma análise de risco da operação se faz necessária para utilização de robôs colaborativos, que se encontra bem documentada na norma ISO 10218 (2011), que trata dos requerimentos de segurança para trabalho com robôs industriais. Outra norma pertinente é a ISO/TS 15066 (2016) que trata especificamente de questões técnicas de robôs e dispositivos robóticos colaborativos.

De acordo com Hägele et al. (2002) para que um sistema robótico consiga realizar atividades colaborativas é necessário obter a redução de forças ou momentos, que podem ser obtidos através de:

- sistemas intrinsecamente passivos, como em Colgate (1996);

- monitoramento e controle de torques atuantes na estrutura do manipulador; 
- controle da célula de trabalho por sensores e monitoramento do movimento humano; e,

- redundância dos sistemas críticos de segurança.

É certo que os robôs colaborativos devem atuar com forças que não causem lesões em trabalhadores, não saindo do estágio de sensação de toque para o estágio de dor, o que ainda não é uma área completamente conhecida, e alguns estudos já estão sendo desenvolvidos para melhor compreensão da relação biomecânica entre homem e máquina, como mostra Cordero et al. (2014).

\section{ANÁLISE DE EVENTOS/COMPORTAMENTOS ASSOCIADOS À OPERAÇÃO COLABORATIVA}

De modo a permitir o desenvolvimento de um simulador é necessário identificar os modos de operação colaborativa entre homem e robô e suas características básicas, a fim de serem implementadas computacionalmente. Uma característica comum é a presença de um ambiente colaborativo previamente definido. Quatro eventos demandam implementação computacional no modelo do robô colaborativo, de modo a adequar-se à ISO 10218 (2011).

\section{1 - Se uma zona de segurança for violada pelo operador, então parar o robô}

Robôs colaborativos de parada de segurança monitorada possuem os freios de juntas acionados quando um ser humano entra em uma zona de segurança pré-estabelecida. Os robôs empregados nesse tipo de colaboração são normalmente robôs convencionais com dispositivos que detectam a presença do homem na célula de trabalho, sendo utilizado quando praticamente toda a atividade é feita pelo manipulador, havendo apenas a necessidade ocasional da presença de seres humanos.

Em ambientes com alta circulação de funcionários a implementação desse tipo de colaboração resulta em paralisação da produção, o que não é recomendado.

\section{2 - Se uma distância de separação for violada pelo operador, então reduzir a velocidade do robô}

Este tipo de operação colaborativa necessita que o ambiente de trabalho seja monitorado, através de sistemas a laser, ou de visão, com intuito de acompanhar a distância de separação entre o homem e o robô. As magnitudes de velocidade do cobot que são reduzidas progressivamente à medida que o funcionário se aproxima do manipulador, até um limite pré-estabelecido, onde os freios de atuadores de junta são acionados, parando o robô.

Ambientes industriais reduzidos e com fluxo de funcionários são indicados para implementação dessa operação colaborativa. Por não haver necessidade de deixar o robô completamente enclausurado, a necessidade de espaço é menor e a segurança é garantida através da diminuição da velocidade do manipulador. Robôs convencionais, com a devida adaptação na programação, podem ser empregados nesse tipo de operação colaborativa.

4.3 - Se as mãos do operador atuarem na garra, então movimentar o robô de modo que a garra seja guiada

$\mathrm{O}$ operador utiliza diretamente suas mãos para guiar a garra do cobot entre os pontos a serem ensinados, característica que auxilia na diminuição do tempo de programação, pois elimina parcialmente a utilização da
TPU (Teach Pendant Unit), unidade física que permite a operação, manobra e programação do manipulador.

Para implementação desse aspecto em robôs industriais convencionais é necessário a instalação de sensores de força entre o flange e a ferramenta (garra), além de possuir controlador com capacidade de percepção do sinal.

É fundamental a diminuição do tempo de programação de produtos de baixo ciclo de vida onde é necessário reprogramar a linha de produção para fabricação de novos modelos, como mostra Santos et al. (2016). Nesse sentido, torna-se importante a colaboração por operação manual, que ainda possui como vantagem diminuir a complexidade da tarefa de programação de robôs.

\section{4 -Se houver contato com o operador, então limitar força e potência do robô}

Robôs com capacidade de limitar força e potência são os mais associados a robôs colaborativos. São autossuficientes em relação a necessidade de dispositivos de percepção externos, pois possuem sensores de torque em cada junta, permitindo detectar valores anormais durante a operação (SCHÄFFER et al.; 2007) e ajustá-los a magnitudes determinadas por normas de segurança.

Outra vantagem é que podem detectar colisão, tornando-os capazes de operar tanto com seres humanos quanto com outras máquinas. São ideais em operações repetitivas que exigem forças e velocidades similares às feitas por humanos, com a vantagem de padronizar a qualidade, pois nunca se cansam, nem sofrem LER (Lesão por Esforço Repetitivo).

\section{FUNDAMENTOS DA MODELAGEM CINEMÁTICA}

Os robôs colaborativos, embora possuam capacidade de controlar sua movimentação em função de um sistema de sensoriamento, continuam tendo uma cadeia cinemática, que pode ser modelada através de metodologias tradicionais.

Assim, como primeiro passo para implementação dos modos de operação colaborativa em um simulador é necessário obter a resolução de sua cinemática. Nesta seção é apresentada de forma sumária as etapas para modelagem da cinemática direta por helicoides.

\section{1 - Fundamentos da Teoria dos Helicoides}

De acordo com Davidson e Hunt (2004), o helicoide, \$, é um ente geométrico definido por:

(1) um vetor unitário, $s$, da reta no espaço que representa a direção do eixo do helicoide, em torno do qual um corpo rígido rotaciona, ou ao longo do qual translada;

(2) um vetor $s_{0}$ ligando a origem do referencial absoluto a qualquer ponto pertencente ao eixo do helicoide;

(3) um ângulo $\theta$, que caracteriza a rotação em torno de $s$, e;

(4) um comprimento d cuja variação representa a translação ao longo da direção de $s$.

O Teorema de Chasles afirma que todo deslocamento espacial de um corpo rígido pode ser representado pela soma vetorial de duas parcelas: (i) uma rotação sobre o eixo do helicoide e (ii) uma translação; representados na Figura 1 . 
Figura 1: Deslocamento helicoidal.

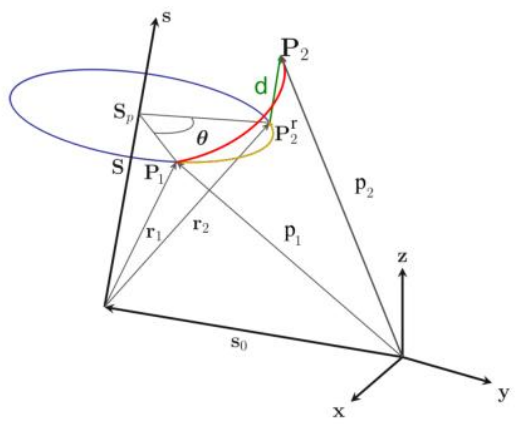

Fonte: Adaptado de Tsai, 1999.

Assumindo um ponto $P_{\mathbb{i}}$, pertencente a um corpo rígido, no instante de tempo $i$; e que no instante inicial encontra-se na posição de referência, $\operatorname{com} \theta$ e $d$ nulos, representado pelo vetor $p_{\text {Ref }}$. Associando outros valores aos parâmetros $\theta e d$, em instante distinto, o ponto $P_{\mathrm{i}}$ parte de $p_{1}=p_{\text {Ref }}$ deslocando-se para a posição alvo $p_{2}=p$, representado por:

$\stackrel{\infty}{p}=\left[\begin{array}{l}p \\ 1\end{array}\right]=T_{\$(4 \times 4)}\left[\begin{array}{c}p_{\text {Ref }} \\ 1\end{array}\right]=T_{\$} p_{\text {Ref }}$

onde, $T_{\$}$ é a Matriz de Transformação Homogênea $(4 \times 4)$ baseada nos parâmetros do helicoide, associada à localização de um corpo passível de deslocamento em relação a um referencial fixo, escrita em função de $s, s_{0}, \theta$ e d, dada por:

$$
T_{5}=\left[\begin{array}{cccc}
a_{11} & a_{12} & a_{13} & a_{14} \\
a_{21} & a_{22} & a_{23} & a_{24} \\
a_{31} & a_{32} & a_{23} & a_{34} \\
0 & 0 & 0 & 1
\end{array}\right]
$$

onde cada elemento é expresso por:

$$
\begin{aligned}
& a_{11}=\cos \theta+s_{x}^{2}(1-\cos \theta) \\
& a_{12}=s_{y} s_{x}(1-\cos \theta)-s_{z} \operatorname{sen} \theta \\
& a_{13}=s_{z} s_{x}(1-\cos \theta)+s_{y} \operatorname{sen} \theta \\
& a_{14}=d s_{x}+s_{0_{x}}-s_{0_{x}} a_{11}-s_{0_{y}} a_{12}-s_{0_{z}} a_{13} \\
& a_{21}=s_{x y} s_{y}(1-\cos \theta)+s_{z} \operatorname{sen} \theta \\
& a_{22}=\cos \theta+s_{y}^{2}(1-\cos \theta) \\
& a_{23}=s_{z} s_{y}(1-\cos \theta)-s_{x} \operatorname{sen} \theta \\
& a_{24}=d s_{y}+s_{0_{y}}-s_{0_{x}} a_{21}-s_{0_{y}} a_{22}-s_{0 z} a_{23} \\
& a_{31}=s_{x} s_{z}(1-\cos \theta)-s_{y} \operatorname{sen} \theta \\
& a_{32}=s_{y} s_{z}(1-\cos \theta)+s_{x} \operatorname{sen} \theta \\
& a_{33}=\cos \theta+s_{z}^{2}(1-\cos \theta) \\
& a_{34}=d s_{z}+s_{0_{z}}-s_{0_{x}} a_{31}-s_{0_{y}} a_{32}-s_{0_{x}} a_{33}
\end{aligned}
$$

\section{2 - Método dos Deslocamentos dos Helicoides Sucessivos}

Um robô industrial possui uma sucessão de corpos e juntas formando uma cadeia cinemática. A localização de cada corpo do robô serial depende do(s) helicoide(s) anterior(es), sendo necessário localizar múltiplos corpos rígidos no espaço. A metodologia dos deslocamentos dos helicoides sucessivos retorna um helicoide resultante que representa o deslocamento total, considerando cada contribuição devido à variação de $\theta$ e $d$ de cada helicoide da cadeia cinemática aberta, como ilustra a Figura 2, de uma posição de referência(inicial) para uma final (alvo).

Figura 2: Helicoides Sucessivos.

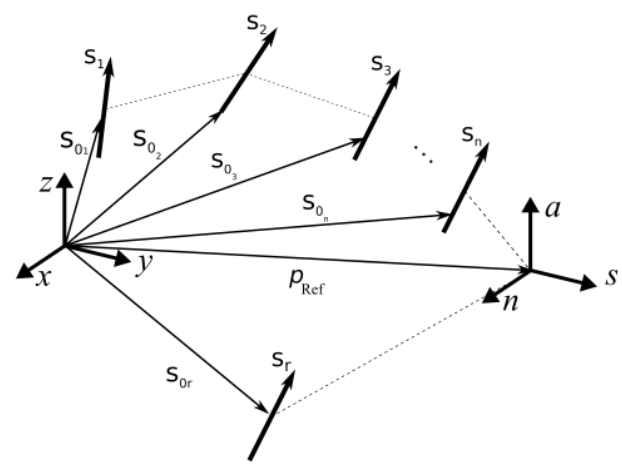

Fonte: Autores, 2018.

Assim sendo, cada corpo rígido da cadeia cinemática aberta, que compõe o robô serial, é conectado ao próximo por uma junta, havendo um helicoide associado que influencia os corpos sucessivos. Através de uma análise iniciada pela ferramenta (último corpo) em direção à base, tem-se que o helicoide $\$_{n}$ é passível de sofrer influência do helicoide $\$_{n-1} \cdots \$_{1}$. Sendo assim, é possível obter a posição alvo da ferramenta em função das posições de referência de cada helicoide da cadeia cinemática aberta, expresso pelo vetor $p$ :

$\stackrel{\infty}{p}=\left[\begin{array}{l}p \\ 1\end{array}\right]=T_{S_{k}} \stackrel{\infty}{p_{\text {Ref }}}$

onde $T_{S_{K}}$ é a Matriz de Transformação Homogênea resultante, obtida pelo produtório das $T_{\$ i}$, para $i=1 \cdots n$, dos helicoides sucessivos, ou seja:

$$
T_{S_{R}}=T_{S_{1}} T_{S_{2}} \ldots T_{S_{n-1}} T_{S_{n}}
$$

\section{MODELAGEM DO ROBÔ COLABORATIVO UR5}

$\mathrm{O}$ método supracitado aplicado à modelagem do robô colaborativo UR5 demanda identificar os parâmetros dos helicoides. Para tal, foram analisadas informações contidas no datasheet e no modelo CAD 3D disponibilizados pelo fabricante Universal Robots. $\mathrm{Na}$

Figura 3, encontram-se esquematizados os vetores $s$, e as componentes de $s_{0}$ dos helicoides de cada junta do UR5, na posição de referência. 
Figura 3: Helicoides na posição de referência do UR5.

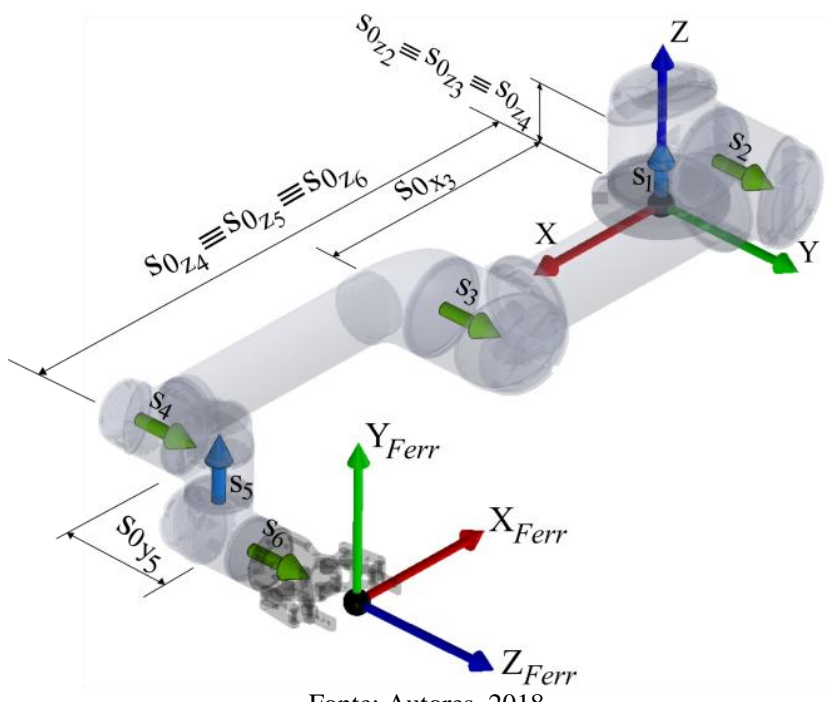

Fonte: Autores, 2018

A Tabela 1 apresenta os valores dos parâmetros $s, s_{0,} \theta$ e $d$ dos helicoides de cada junta, o que possibilita obter as $T_{\$ \bar{i}}$, sendo $i=1 \cdots 6$.

Tabela 1: Parâmetros associados ao UR5.

\begin{tabular}{|c|c|c|c|c|c|c|c|c|}
\hline \multirow{2}{*}{$\begin{array}{l}\text { Juntas } \\
\$_{i}\end{array}$} & \multicolumn{3}{|c|}{$s$} & \multicolumn{3}{|c|}{$s_{0}[\mathrm{~mm}]$} & \multirow{2}{*}{$\begin{array}{l}\theta \\
{[1]}\end{array}$} & \multirow{2}{*}{$\begin{array}{l}d \\
{[\mathrm{~mm}]}\end{array}$} \\
\hline & $s_{x}$ & $s_{y}$ & $s_{z}$ & $s_{0_{x}}$ & $s_{0 y}$ & $s_{0_{Z}}$ & & \\
\hline 1 & 0 & 0 & 1 & 0 & 0 & 0 & $\theta_{1}$ & 0 \\
\hline 2 & 0 & 1 & 0 & 0 & 0 & 89 & $\theta_{2}$ & 0 \\
\hline 3 & 0 & 1 & 0 & 425 & 0 & 89 & $\theta_{3}$ & 0 \\
\hline 4 & 0 & 1 & 0 & 817 & 0 & 89 & $\theta_{4}$ & 0 \\
\hline 5 & 0 & 0 & 1 & 817 & 109 & 0 & $\theta_{5}$ & 0 \\
\hline 6 & 0 & 1 & 0 & 817 & 0 & 0 & $\theta_{6}$ & 0 \\
\hline
\end{tabular}

Substituindo os valores dos parâmetros de cada helicoide na equação (2), é possível obter cada $T_{\$_{\text {[ }}}$, e finalmente a nova posição $p$ da ferramenta, em função dos ângulos $\theta_{1} \cdots \theta_{6}$, e do vetor $p_{\text {Ref }}$, conforme a equação (15).

\section{1 - Ajuste da orientação}

É comum encontrar o sistema de eixos coordenados da ferramenta com vetores unitários $n, s$ e $a$, como ilustrado na Figura 4 correspondentes aos eixos da ferramenta $X_{F e r y}$, $Y_{\text {Ferr }}$ e $Z_{\text {Ferr }}$, respectivamente. O centro do referencial da ferramenta é posicionado em um ponto central entre as superfícies de contato das extremidades da garra com a peça a ser manipulada, conhecido como TCP (Tool Center Point). Assim sendo, o TCP na posição de referência é representado pelo vetor $p_{\text {Ref }}$. Para incorporar estes ajustes basta pósmultiplicar a equação (16) por $T_{\text {Ferr }}$ Keff , dada por:

$$
T_{\text {Ferr }_{\text {Ref }}}=\left[\begin{array}{cccc}
n_{\text {Ref }} & s_{\text {Ref }} & a_{\text {Ref }} & p_{\text {Ref }} \\
0 & 0 & 0 & 1
\end{array}\right]
$$

Figura 4: Posição e orientação de referência da ferramenta.

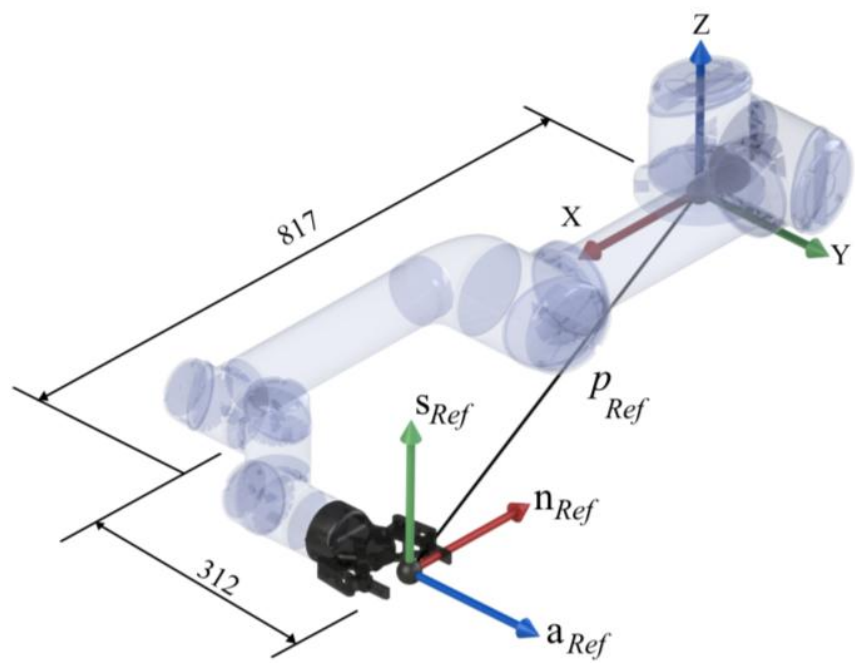

Fonte: Autores, 2018.

Para determinar numericamente $T_{\text {Ferr }}$ Bef , a Figura 4 apresenta os valores (em $\mathrm{mm}$ ) das componentes do vetor $p_{\text {Reff }}$ e a orientação do referencial da ferramenta. A direção do vetor $n_{\text {Ref }}$ (unitário de $X_{F e r r}$ ) na posição de referência, encontra-se na direção oposta ao vetor unitário do eixo $X$ do referencial absoluto. A direção do vetor $s_{\text {Ref }}$ (unitário de $Y_{\text {Ferry }}$ ) encontra-se na posição de referência alinhada com a direção do vetor unitário do eixo $Z$ do referencial absoluto; enquanto que a direção do vetor $a_{\text {Ref }}$ (unitário de $Z_{\text {Ferr }}$ ) na posição de referência, está alinhada com a direção do vetor unitário do eixo $Y$ do referencial absoluto. Assim sendo, é possível substituir os valores dos vetores na equação (17), obtendo:

$T_{\text {Ferr }}=\left[\begin{array}{cccc}-1 & 0 & 0 & 817 \\ 0 & 0 & 1 & 312 \\ 0 & 1 & 0 & 0 \\ 0 & 0 & 0 & 1\end{array}\right]$

Finalmente é possível reescrever a equação (15) em uma forma compacta alternativa obtendo $T_{\text {Ferr }}$, que permite calcular, além da posição, a orientação atualizada em função dos ângulos $\theta_{1} \cdots \theta_{6}$, e dos vetores $n_{\text {Ref }}, s_{\text {Ref }}, a_{\text {Ref }}$ e $p_{\text {Ref }}$, ou seja:

$T_{\text {FerY }}=\left[\begin{array}{llll}n & s & a & p \\ 0 & 0 & 0 & 1\end{array}\right]=T_{\$_{1}} T_{\$_{2}} \ldots T_{\$_{6}} T_{\text {Ferr }}$ Raf

\section{2 - Resultados obtidos}

Com o modelo da cinemática direta baseado em Helicoides apresentado na equação (19) é possível obter, portanto, a nova localização do TCP do UR5 para um conjunto de valores de ângulos de junta $q=\left[\begin{array}{lll}\theta_{1} & \cdots & \theta_{6}\end{array}\right]^{T}$. Uma postura particular denominada posição de HOME, definida como posição inicial do UR5 é alcançada para os ângulos de junta do vetor $q_{\text {Home }}=\left[0^{\circ}-90^{\circ} 0^{\circ} 0^{\circ}-90^{\circ} 0^{\circ}\right]^{T}$, ilustrado na Figura 5 (a). Diversas posturas intermediárias de uma trajetória que conduz o TCP para a posição de equidistância das extremidades da garra às superfícies laterais do bloco azul, encontram-se ilustradas na Figura 5 (b)-(d), contendo os respectivos ângulos de junta $q$ associados. 
Figura 5: Posturas do UR5 em diversas ângulos de juntas.

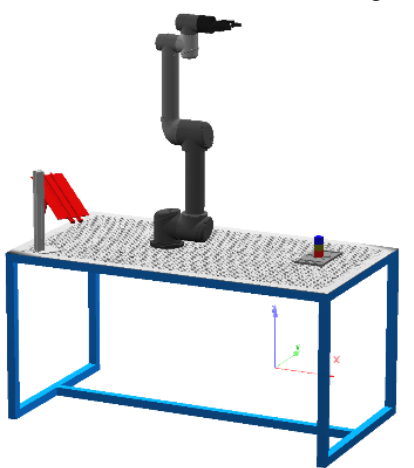

(a) $q_{\text {Home }}=\left[\begin{array}{lll}0^{\circ}-90^{\circ} & 0^{\circ} & 0^{\circ}-90^{\circ} 0^{\circ}\end{array}\right]^{T}$

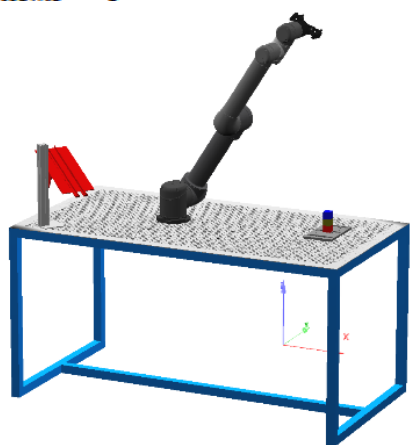

(b) $q=\left[87^{\circ}-57^{\circ} 0^{\circ} 0^{\circ}-90^{\circ} 0^{\circ}\right]^{T}$

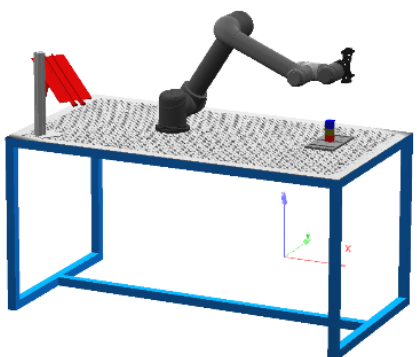

(c) $q=\left[87^{\circ}-57^{\circ} 79^{\circ}-112^{\circ}-90^{\circ} 0^{\circ}\right]^{T}$

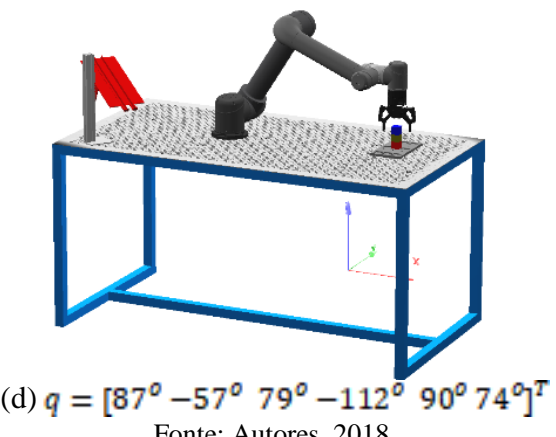

Fonte: Autores, 2018

A implementação computacional foi realizada na versão acadêmica do RAD Studio, integrada à biblioteca gráfica GLScene, que permite a visualização dos modelos em CAD 3D dos corpos em cenário virtual, sendo que para isso, foram devidamente convertidos para a extensão 3DS utilizando as versões acadêmicas do SolidWorks e 3DStudio Max.

Foram utilizados conceitos de Programação Orientada a Objetos (POO), com estrutura de classes implementada em Object Pascal. Conceitos adicionais de Cadeias Virtuais de Posicionamento foram utilizados de forma similar aos apresentados por Macedo et al. (2018), o que possibilitou montar um cenário virtual com o cobot UR5 e outros componentes (mesa, alimentador gravitacional de peças, pallets e blocos).

\section{CONCLUSÕES}

Este trabalho consiste na primeira etapa de PD\&I de um simulador de cobots, onde foram identificadas as características necessárias para a criação de um software capaz de simular os eventos/comportamentos dos modos de operação colaborativa, além de apresentar a modelagem cinemática baseada em helicoides.

A Teoria dos Helicoides se mostrou bastante eficaz na implementação computacional do cobot UR5, por ser robusta e amigável, permitindo ao usuário identificar com simplicidade os parâmetros dos helicoides do robô e permitir a localização de componentes, com visualização da simulação em cenário virtual.

Como perspectivas de trabalhos futuros, por se tratar de simulação de robôs que interagem diretamente com seres humano, torna-se necessário dar andamento a etapas, que contemplem a modelagem tridimensional de avatares, integrada com uma metodologia que permita a detecção de colisão entre modelos de robô-avatar, bem como, região colaborativa- avatar, modelando assim os eventos/comportamentos identificados.

\section{REFERÊNCIAS BIBLIOGRÁFICAS}

COLGATE, J. E; WANNASUPHOPRASIT, W.; PESHKIN, M. A.; COBOTS: Robots for Collaboration with Human Operators; Proceedings of the International Mechanical Engineering Congress and Exhibition, p. 433 439, 1996.

CORDERO, C. A.; CARBONE, G.; CECCARELLI, M.; ECHÁVARRI, J.; MUÑOZ, J. L.; Experimental tests in human-robot collision evaluation and characterization of a new safety index for robot operation; Mechanism and Machine Theory, p. 184 - 199, 2014.

DAVIDSON, J. e HUNT, K. Robots and Screw Theory. Oxford University Press, 2004.

FRYMAN, J; MATTHIAS, B.; Safety of Industrial Robots: From Conventional to Collaborative Applications; 7th German Conference on Robotic, p. 51-55, 2012.

GALHARDO, B. H. M.; RIBEIRO L. P. G.; OCOTS: Sistema de Treinamento de Operadores de Guindaste Offshore - Modelagem 3D de Cenário. Sodebras, Fortaleza, v. 12 , n. 141 , p. $208-213,2017$. ISSN - 1809-3957.

HÄGELE， M.; SCHAAF，W.; HELMS， E.; Robot Assistants at Manual Workplaces: Effective Cooperation and Safety Aspects; Proceedings of the 33rd ISR (International Symposium on Robotics). 2002.

LORENZ, W. A.; PESHKIN, M. A.; COLGATE, J. E.; New Sensors for New Applications: Force Sensor for Human/Robot Interaction; International Conference on Robotics \& Automation, p. 2855 - 2860, 1999.

OCCUPATIONAL SAFETY AND HEALTH ADMINISTRATION; Accidents with Robots. Disponível em: https://www.osha.gov/pls/imis/AccidentSearch. Acesso em 03 abril de 2018. 
SANTOS, L. M. F.; SANTOS, R. R.; RIBEIRO, L. P. G.; Fatores de Influência da Programação On-line no Tempo de Execução de uma Tarefa Realizada Pelo Robô Pegasus; Sodebras, Foz do Iguaçu, v. 11, n. 129, p. 174 - 179, 2016. ISSN 1809-3957.

SANTOS, L. M. F.; SANTOS, R. R.; MACEDO, F. A. A.; MARQUES, L. C. O.; RIBEIRO, L. P. G.; CAPRON: Avaliação da Eficiência do Simulador na Aprendizagem de Programação On-Line do Robô Pegasus; Sodebras, Fortaleza, v. 12, n. 141, p. 193 - 197, 2017. ISSN 18093957.

SCHÄFFER, A. A.; HADDADIN, S.; OTT, C.; STEMMER, A.; WIMBÖCK, T.; HIRZINGER, G.; The DLR lightweight robot: design and control concepts for robots in human environments; Industrial Robot: An International Journal, p. 376 - 385, 2007.

SCHRAFT, R. D.; MEYER, C.; PARLITZ, C.; HELMS, E.; PowerMate - A Safe and Intuitive Robot Assistant for Handling and Assembly Tasks; Proceedings of the 2005 IEEE International Conference on Robotics and Automation, p. 4074 - 4079, 2005.

SLACK, N.; LEWIS, M.; Operations Strategy, 1th ed., Pearson Education: Inglaterra, 2002.

SPONG, M. W.; HUTCHINSON, S.; VIDYASAGAR, M.; Robot Dynamics and Control; John Wiley \& Sons; Estados Unidos, 2004.

SSI-SWEDISH STANDARDS INSTITUTE. SS-ISO

10218-1:2011-Robots and Robotic Devices - Safety Requirements for Industrial Robots. Part 1: Robot, Stockholm, Sweden: Swedish, 2011.

INTERNATIONAL ORGANIZATION FOR STANDARDIZATION; ISO/TS 15066:2016, Robots and robotic devices - Collaborative robots; Genebra, 2016.

\section{AGRADECIMENTOS}

O presente trabalho foi realizado com o apoio do Exército Brasileiro, da Fundação de Amparo à Pesquisa do Estado do Rio de Janeiro - FAPERJ e da Coordenação de Aperfeiçoamento de Pessoal de Nível Superior - Brasil (CAPES) - Código de Financiamento 001.

\section{COPYRIGHT}

Direitos autorais: Os autores são os únicos responsáveis pelo material incluído no artigo. 


\author{
Volume 14 - No 159 - Março/2019. \\ XL International Sodebras Congress \\ 10 a 12 de dezembro de 2018 - Vitória - ES.
}

\title{
RESOLUÇÃO DA CINEMÁTICA INVERSA DE ROBÔS INDUSTRIAIS POR ALGORITMOS DE OTIMIZAÇÃO
}

\author{
INVERSE KINEMATICS RESOLUTION OF \\ INDUSTRIAL ROBOTS THROUGH OPTIMIZATION ALGORITHMS
}

\author{
MICHEL ALBA ${ }^{1}$; ALEXANDRE G SOARES ${ }^{1}$; LUIZ RIBEIRO ${ }^{1}$; JOSE HERSKOVITS ${ }^{1,2}$ \\ 1 - INSTITUTO MILITAR DE ENGENHARIA (IME); 2 - UNIVERSIDADE FEDERAL DO RIO DE \\ JANEIRO (UFRJ)
}

michel.alba@hotmail.com; alexandregsoares@gmail.com; ribeiro@ime.eb.br; jose@optimize.ufrj.br

\begin{abstract}
Resumo - Este trabalho apresenta a resolução da cinemática inversa de robôs industriais seriais através de duas metodologias usando algoritmos de otimização determinístico e estocástico, sendo o primeiro caso representado pelo algoritmo FDIPA (Feasible Directions Interior Point Algorithm), enquanto no segundo utiliza-se o algoritmo PSO (Particle Swarm Optimization). Para a validação das metodologias, um estudo de caso é apresentado utilizando o modelo do robô Amatrol Pegasus, formulado com base na Teoria dos Helicoides e no Método dos Deslocamentos dos Helicoides Sucessivos, no qual comparam-se os resultados de cada algoritmo para a resolução da cinemática inversa do robô. Por fim, são avaliados os aspectos característicos de cada método de otimização no contexto da robótica industrial.

Palavras-chave: Cinemática Inversa. Otimização. Robótica Industrial. FDIPA. PSO.
\end{abstract}

Abstract - This work presents the resolution of the inverse kinematics of serial industrial robots through two methodologies, using deterministic and stochastic optimization algorithms. The first case is represented by the Feasible Directions Interior Point Algorithm (FDIPA), while the second one uses the Particle Swarm Optimization algorithm (PSO). For the validation of the methodologies, a case study is presented using the Amatrol Pegasus robot model, which is formulated based on the Screw Theory and the Method of Successive Screw Displacements. The results of both algorithms are compared for the robot's inverse kinematics resolution. Finally, the main aspects of each optimization method in the context of industrial robotics are discussed.

Keywords: Inverse Kinematics. Optimization. Industrial Robotics. FDIPA. PSO.

\section{INTRODUÇÃO}

A Robótica Industrial e os métodos de otimização mostram-se atrativos para auferir vantagens aos processos de fabricação. $\mathrm{O}$ aumento da capacidade de processamento dos computadores em conjunto com a redução de custos de dispositivos eletrônicos vem permitindo a utilização de novas estratégias de modelagem e de métodos de otimização alternativos objetivando tornar os sistemas robóticos ainda mais eficientes.

Segundo Nocedal e Wright (2006), as propriedades que qualificam um bom algoritmo são:
- robustez: devem ter bom desempenho em uma grande variedade de problemas para todos valores razoáveis de ponto inicial.

- eficiência: devem necessitar de baixo tempo computacional de processamento e/ou armazenamento.

- precisão: devem ser capazes de identificar a solução com precisão, sem excessiva sensibilidade a erro nos dados ou de arredondamento quando implementado computacionalmente.

No âmbito de otimização, um dos aspectos que distingue um algoritmo do outro é a estratégia adotada para gerar uma nova iteração que estime a solução do problema. A maioria destas estratégias utiliza valores da função objetivo e das restrições, podendo utilizar as derivadas de primeira e segunda ordem destas funções, e ainda acumular informações coletadas em iterações prévias ou usar apenas informações obtidas na iteração atual.

O presente trabalho busca avaliar estas propriedades na utilização das técnicas de otimização no contexto de Robótica Industrial. Para isto são usados dois algoritmos que representam classes distintas de métodos de otimização: os determinísticos e os estocásticos.

Os algoritmos determinísticos possuem como característica o conhecimento prévio sobre os dados a serem calculados. Já os algoritmos estocásticos levam em consideração, para a obtenção das soluções, aspectos aleatórios ou probabilísticos, e possuem como vantagem a facilidade de implementação, entretanto, quando utilizados em problemas com muitas variáveis, em geral demandam alto custo computacional.

O algoritmo de otimização determinístico utilizado é o de pontos interiores e direções viáveis FDIPA (Feasible Direction Interior Point Algorith) apresentado sumariamente na seção II, enquanto o estocástico, apresentado na seção III, é o algoritmo de enxame de partículas PSO (Particle Swarm Optimization). Na seção IV são apresentados: os fundamentos teóricos de modelagem cinemática baseada na Teoria dos Helicoides; sua aplicação em um estudo de caso com o robô Amatrol Pegasus; e a formulação da resolução cinemática por otimização. Os resultados obtidos utilizando os algoritmos FDIPA e PSO são os apresentados e discutidos na seção V. Finalmente, as 
conclusões e perspectivas de trabalhos futuros constam na seção VI.

\section{ALGORITMO DETERMINÍSTICO FDIPA}

A classe de algoritmos determinísticos é usualmente aplicada a problemas em que o modelo matemático/físico é bem definido e completamente conhecido.

O algoritmo determinístico FDIPA (Feasible Direction Interior Point Algorithm), desenvolvido por Herskovits (1998), propõe uma abordagem por direções viáveis e pontos interiores para a minimização de funções suaves sob restrições suaves, que podem ser de igualdade e/ou de desigualdade.

A cada iteração, o FDIPA resolve um sistema linear de equações baseado nas condições de otimalidade de primeira ordem de Karush-Kuhn-Tucker, de modo a obter a solução das variáveis duais e primais (SHAPIRO, 1997). Esta solução gera uma direção de descida, ou seja, uma direção de busca na qual a função objetivo é minimizada. Em seguida, tal sistema linear é perturbado de forma que a direção de descida seja defletida, obtendo-se uma direção de descida viável.

Em uma segunda etapa é realizado um procedimento de busca linear, onde é calculado um comprimento de passo. Finalmente, um novo ponto interior é obtido de modo a garantir a convergência global.

Seja o problema de otimização com apenas restrições de desigualdade, definido como:

$\left\{\begin{array}{cc}\text { minimizar } & f(x) \\ \text { tal que } & g(x) \leq 0\end{array}\right.$

onde $f(x)$ é a função objetivo, $x \in R^{n}$ o vetor de variáveis de projeto e $g \in R^{m}$ o vetor de restrições de desigualdade, sendo pelo menos uma delas não-linear.

Desse modo, a estrutura do FDIPA para a resolução deste caso é apresentada no Algoritmo 1.

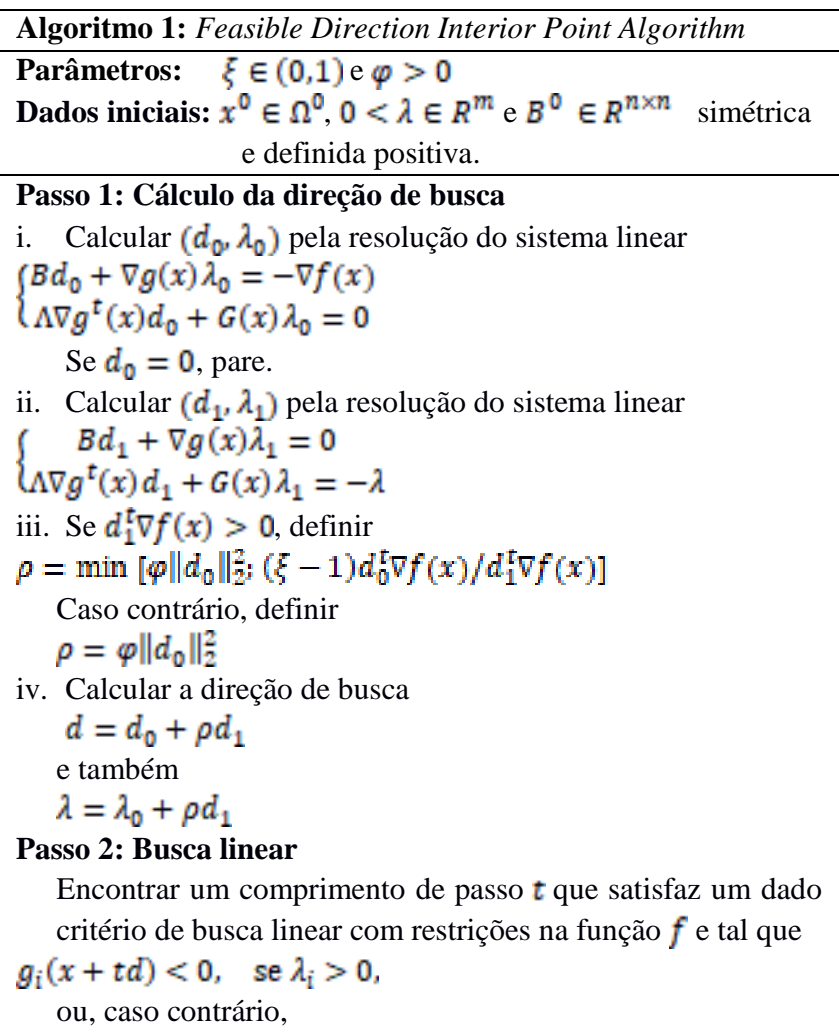

$g_{i}(x+t d) \leq g_{i}(x)$

Passo 3: Atualizações

i. Definir $x=x+t d$

e novos valores para $\lambda>0$ e $B$ simétrica e definida positiva. ii. Voltar ao Passo 1.

Definidas as funções objetivo, as funções de restrição e o ponto inicial $x_{0}$, o algoritmo executa iterativamente o cálculo da direção de busca e do comprimento de passo, obtendo novas estimativas de $x$ até que determinado critério de parada seja alcançado, garantindo a convergência para a solução ótima do problema.

\section{ALGORITMO ESTOCÁSTICO PSO}

Da classe de algoritmos estocásticos, o algoritmo PSO (Particle Swarm Optimization) é um método evolucionário proposto por Kennedy e Eberhart (1995), que utiliza conceitos de otimização por enxames. Segundo Colaço et al. (2006) a ideia original deste método veio da observação do comportamento social de populações de pássaros buscando um local ideal para aninhar-se.

O método visa equilibrar a individualidade e a sociabilidade da população para encontrar o local ótimo. Quando a individualidade aumenta, consequentemente a procura por locais alternativos para o aninhamento cresce. Entretanto, quando a individualidade da população fica muito alta, os indivíduos podem nunca encontrar o melhor local.

Por outro lado, quando a sociabilidade da população é aumentada, o indivíduo aprende mais com a experiência do vizinho e tende a não buscar novos locais para aninhar-se. Porém, se a sociabilidade fica muito alta, todos os indivíduos podem convergir para o primeiro local de mínimo encontrado, que possivelmente seja um mínimo local.

Assim, no PSO, os indivíduos, ou partículas, de uma população são constantemente melhoradas graças a experiência das partículas vizinhas, mas também permitindo que cada partícula busque novas soluções que podem ser melhores que a solução das outras.

Neste método são armazenadas as partículas responsáveis pelo melhor valor da função objetivo daquela posição (pbest) e da história (gbest), e varia-se a velocidade das partículas a cada iteração $k$, para tender à pbest e gbest, de forma que:

$$
\begin{aligned}
x_{i}^{k+1} & =x_{i}^{k}+v_{i}^{k+i} \\
v_{i}^{k+i} & =\alpha v_{i}^{k}+\beta_{1} r_{1}\left(\text { pbest }-x_{i}^{k}\right)+\beta_{2} r_{2 i}\left(\text { gbest }-x_{i}^{k}\right)
\end{aligned}
$$

onde, $x_{i}^{k}$ é o valor da partícula na iteração $k$ e $v_{i}^{k}$ é a velocidade da partícula $i$.

A velocidade inicial é $v_{i}^{0}=0$ em $k=0, r_{1}$ e $r_{2}$ são números aleatórios com distribuição uniforme entre 0 e 1 e também são definidos os parâmetros $\alpha$ entre 0 e 1 e $\beta$ entre 1 e 2. Desse modo, para otimizar uma função objetivo de $D$ variáveis, a estrutura do PSO é apresentada no Algoritmo 2:

\begin{tabular}{|l|}
\hline Algoritmo 2: Particle Swarm Optimization (PSO) \\
\hline Parâmetros: $\alpha \in(0,1)$ e $\beta_{1} \in \beta_{2} \in(1,2)$ \\
Dados: $n_{s} \in$ \\
\hline Passo 1: Criação da população \\
$\quad$ Inicializar vetor de $n$ partículas de dimensão $D$ com valores \\
$\quad$ aleatórios dentro do intervalo de restrição.
\end{tabular}


Passo 2: Avaliar a função objetivo de dimensão $D$ para cada partícula

Caso a função objetivo da partícula seja a melhor daquela posição, armazená-la em pbest. Caso seja a melhor entre todas as partículas da história, armazená-la também em gbest. Se gbest < e , parar o algoritmo.

Passo 3: Mudar a velocidade de cada partícula

Calcular aleatoriamente valores de $r_{1}$ e $r_{2} \in(0,1)$ e calcular a velocidade de cada partícula pela equação (3).

Passo 4: Alterar os valores de cada partícula

Utilizar a equação (2) para atualizar os valores de cada partícula e voltar para o Passo 2.

\section{CINEMÁTICA INVERSA POR OTIMIZAÇÃO}

A resolução cinemática de robôs industriais seriais estabelece relações entre as variáveis de junta e a localização da ferramenta, podendo ser abordada de forma direta ou inversa.

A cinemática direta fornece as variáveis do espaço operacional, ou seja, a localização da ferramenta, calculada em função dos parâmetros de entrada, que são as variáveis de junta do manipulador.

Já a cinemática inversa toma como parâmetros de entrada a posição da ferramenta e os cálculos são realizados com intuito de obter as respectivas variáveis de junta como parâmetros de saída. Devido à não-linearidade das equações, há a possibilidade de a solução não ser única e ainda dificuldade ou impossibilidade de obter soluções analíticas, necessitando assim recorrer-se a métodos numéricos (SICILIANO et al, 2009).

O objetivo deste artigo é utilizar métodos de otimização na resolução da cinemática inversa. Para isso, é fornecido um ponto alvo (desejado) da ferramenta e utiliza-se a cinemática direta para cálculo dos pontos obtidos com as estimativas de variáveis de junta. Dessa forma, calcula-se o erro entre as localizações desejada e obtida e os métodos de otimização são utilizados para que este erro seja minimizado, convergindo até uma tolerância estabelecida.

\subsection{Modelagem cinemática}

Nesta seção, encontram-se os fundamentos da Teoria dos Helicoides e o Método dos Deslocamentos dos Helicoides Sucessivos (TSAI, 1999; DAVIDSON E HUNT, 2004).

\subsubsection{Teoria dos Helicoides}

Partindo do Teorema de Chasles, que afirma que qualquer deslocamento de um corpo rígido no espaço pode ser realizado por meio de uma rotação do corpo em torno de um único eixo (chamada de eixo helicoidal ou do helicoide), acompanhada da uma translação paralela a este eixo. $O$ helicoide pode ser completamente definido por quatro parâmetros:

- $s=\left[\begin{array}{lll}s_{x} & s_{y} & s_{z}\end{array}\right]^{T}$ : vetor unitário do eixo helicoidal;

- $s_{0}=\left[\begin{array}{lll}s_{0_{x}} & s_{0_{y}} & s_{0_{z}}\end{array}\right]^{T}$ : vetor que conecta a origem do referencial absoluto a qualquer ponto do eixo helicoidal;

- $\quad \theta$ : magnitude do ângulo de rotação em torno do eixo;

- d: magnitude da translação ao longo do eixo.

Na Figura 1 encontram-se ilustrados estes parâmetros, onde pode ser observado o deslocamento helicoidal do ponto de $P_{[1]}$, no instante inicial na posição de referência, para $P_{(2)}$ no instante final (posição alvo), que ocorre devido à composição de deslocamentos de rotação $\theta$ e translação $d$.

Figura 1 - Deslocamento Helicoidal.

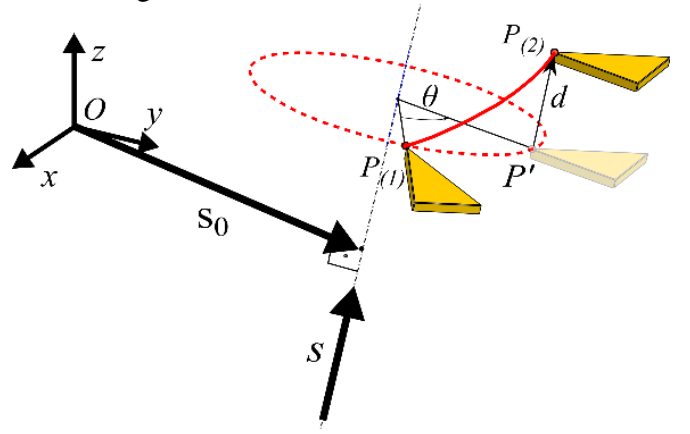

Fonte: Autores, 2018.

Primeiramente considera-se um movimento de rotação pura de magnitude $\theta$ para descrever o deslocamento do ponto $P_{[1]}$ ao ponto intermediário $\mathrm{P}^{r}$. Este movimento é descrito pela Fórmula de Rodrigues para deslocamento esférico, ou seja:

$$
P^{\prime}=P_{(1)} c \theta+(1-c \theta)\left(P_{(1)} s\right) s+\left(s \times P_{(1)}\right) s \theta
$$

onde: $\operatorname{si}=\operatorname{sen}(\theta)$ e $c \theta=\cos (\theta)$.

Reescrevendo-a na forma vetorial, seguindo o Teorema de Euler $\left(p_{(1)}=R_{\xi} p^{f}\right)$, chega-se à Matriz de Rotação $R_{\xi}$ baseada em Helicoides:

$$
\begin{aligned}
& R_{\xi}=\left[\begin{array}{cc}
c \theta+s_{x}^{2}(1-c \theta) & s_{y} s_{x}(1-c \theta)-s_{x} s \theta \\
s_{x} s_{y}(1-\cos \theta)+s_{z} s \theta & \cos \theta+s_{y}^{2}(1-c \theta) \\
s_{x} s_{z}(1-\cos \theta)-s_{y} s \theta & s_{y} s_{x}(1-c \theta)+s_{x} s \theta
\end{array}\right. \\
& \left.\begin{array}{c}
s_{z} s_{x}(1-c \theta)+s_{y} s \theta \\
s_{x} s_{y}(1-c \theta)-s_{x} s \theta \\
c \theta+s_{z}^{2}(1-c \theta)
\end{array}\right]
\end{aligned}
$$

De forma similar, utilizando somas vetoriais para determinação de $P_{[\mathbb{[ 1}\}}$ e $P_{[\{2]}$ e substituindo-as na Fórmula de Rodrigues para o caso do deslocamento helicoidal, adicionando a translação $q^{A}$, chega-se a:

$$
p_{(2)}=R_{\$} p_{(1)}+q^{A}
$$

em que,

$$
\left[\begin{array}{l}
q_{x}^{A} \\
q_{y}^{A} \\
q_{z}^{A}
\end{array}\right]=\left[\begin{array}{l}
d s_{x}+s_{0_{x}}\left(1-a_{11}\right)-s_{0 y} a_{12}-s_{0_{z}} a_{13} \\
d s_{y}-s_{0_{x}} a_{21}+s_{0 y}\left(1-a_{22}\right)-s_{0 z} a_{23} \\
d s_{z}-s_{0_{x}} a_{31}-s_{0 y} a_{32}+s_{0 z}\left(1-a_{33}\right)
\end{array}\right]
$$

onde os termos $a_{i j j}$, para $i_{v} j=1,2,3$ são os elementos da matriz de rotação $R_{\xi}$ descritos na equação (5).

Assim, a representação do deslocamento helicoidal pode ser feita por uma Matriz de Transformação Homogênea $(4 \times 4) T_{\$}$, que depende dos vetores $s$ e $s_{0}$ e das magnitudes $\theta$ e $d$, calculada por:

$$
T_{\xi}=\left[\begin{array}{cc}
R_{\$} & d s+\left[I-R_{\xi}\right] s_{0} \\
000 & 1
\end{array}\right]
$$

de modo que a posição de um ponto após o deslocamento helicoidal pode ser obtida por:

$$
\tilde{p}_{(2)}=\left[\begin{array}{c}
p_{(2)} \\
1
\end{array}\right]=\left[\begin{array}{cc}
R_{S} & q \\
0 & 1
\end{array}\right]\left[\begin{array}{c}
p_{(1)} \\
1
\end{array}\right]=T_{5} \tilde{p}_{(1)}
$$


4.1.2 Método dos Deslocamentos dos Helicoides Sucessivos

Associando um eixo helicoidal a cada junta de um manipulador, são assumidos dois casos particulares: juntas de rotação ( $d=0$ e $\theta$ como variável de junta) e juntas prismáticas $(\theta=0$ e $d$ como variável de junta), ou seja, juntas elementares com apenas um DOF, sendo que as variáveis de junta podem assumir qualquer valor dentro dos limites de junta.

Dessa forma, é possível estabelecer a relação entre um sistema de coordenadas móvel solidário à ferramenta, com origem em seu centro TCP (Tool Center Point), e o referencial absoluto, em função das variáveis de junta. O Método dos Deslocamentos dos Helicoides Sucessivos estabelece que esta relação é dada pelo produtório das MTH de cada junta, desde a base até o efetuador, gerando-se a matriz resultante:

$$
T_{\$_{T}}=T_{S_{1}} T_{\$_{2}} \ldots T_{S_{m-1}-1} T_{\$_{m}} T_{f}
$$

Na Figura 2 pode ser observado um modelo cinemático de robô serial de $n$ juntas através dos helicoides $\$ \$_{i}$ e o helicoide resultante, associado a $T_{S_{r}}$. Desse modo, calcula-se a localização da ferramenta na posição de referência como:

$$
T_{f}=\left[\begin{array}{cccc}
n & s & a & s_{0_{f}} \\
0 & 0 & 0 & 1
\end{array}\right]
$$

Figura 2 - Método dos Deslocamentos dos Helicoides Sucessivos.

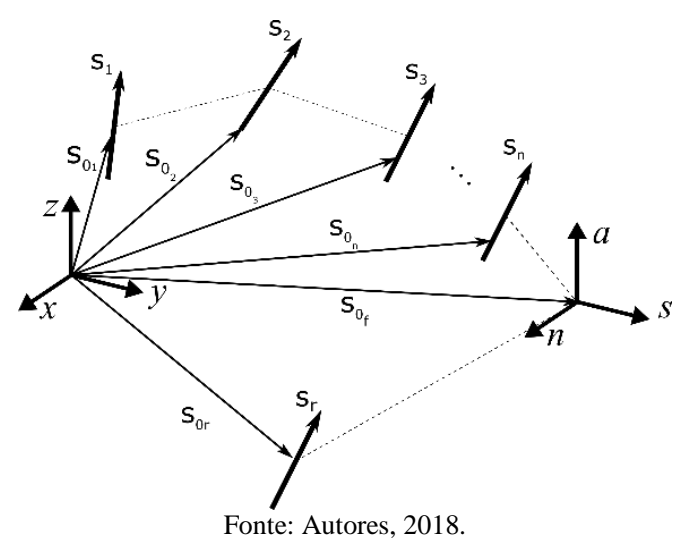

\subsubsection{Modelagem do robô Pegasus}

Com base nos conceitos apresentados, analisando o robô Pegasus na posição de referência (Home) é possível obter os parâmetros dos Helicoides de cada junta, apresentados na Tabela 1 e esquematizados na Figura 3.

\begin{tabular}{|c|c|c|c|c|c|c|c|c|}
\hline \multirow{2}{*}{ Juntas } & \multicolumn{3}{|c|}{$s$} & \multicolumn{3}{|c|}{$s_{0}[$ pol.] } & \multirow{2}{*}{$q_{i}$} & \multirow{2}{*}{$d$} \\
\hline & $\boldsymbol{x}$ & $y$ & $z$ & $x$ & $y$ & $z$ & & \\
\hline 1 & 0 & 0 & 1 & 0 & 0 & 0 & $\theta_{1}$ & 0 \\
\hline 2 & 1 & 0 & 0 & 0 & 0 & 12,50 & $\theta_{2}$ & 0 \\
\hline 3 & 1 & 0 & 0 & 0 & 0 & 21,50 & $\theta_{3}$ & 0 \\
\hline 4 & 1 & 0 & 0 & 0 & 9 & 21,50 & $\theta_{4}$ & 0 \\
\hline 5 & 0 & 1 & 0 & 0 & 9 & 21,50 & $\theta_{5}$ & 0 \\
\hline Ferramenta & - & - & - & 0 & 15 & 21,50 & - & - \\
\hline
\end{tabular}

Tabela 1: Parâmetros dos Helicoides das juntas do robô Pegasus.
Figura 3 - Componentes dos vetores $\boldsymbol{s}$ e $\boldsymbol{s}_{0}$ do robô Pegasus.

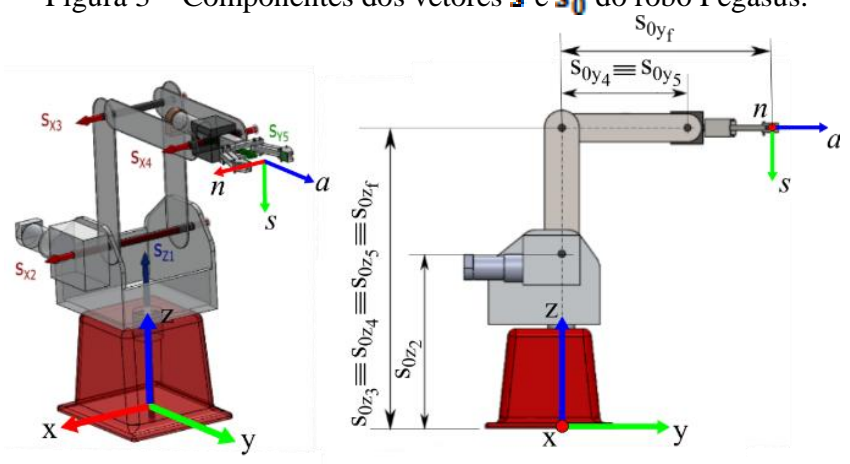

Fonte: Adaptado de Santos (2017).

Definidos os respectivos parâmetros, conforme apresentados na Tabela 1 , é possível estabelecer $T_{\$_{\bar{i}}}$ de cada junta e de $T_{f}$, correspondente ao ajuste do TCP, substituindo-os na equação (8). As matrizes obtidas em função das variáveis de junta encontram-se na Tabela 2. Assim sendo, basta calcular o produtório destas matrizes através da equação (10) e obtém-se a localização da ferramenta em função das 5 variáveis de junta de rotação $\theta_{i}$, para $i=1, \ldots, 5$.

Tabela 2: MTH das juntas e da ferramenta.

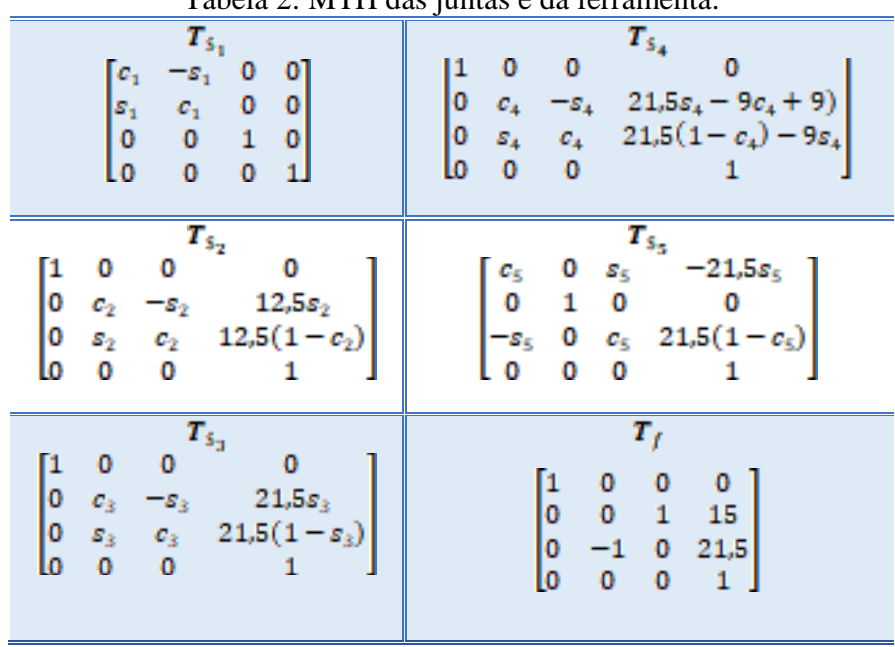

Tomando como exemplo a posição de Home, ou seja, todos as magnitudes das variáveis de junta iguais a zero $\left(q_{0}=\left[\begin{array}{lllll}0 & 0 & 0 & 0 & 0\end{array}\right]^{T_{\text {rad }}}\right)$, a MTH resultante $\left(T_{S_{\mathrm{T}}}(q)\right)$ resulta em:

$$
T_{S_{r}}=T_{\$_{1}} T_{\$_{2}} T_{S_{3}} T_{S_{4}} T_{S_{5}} T_{f}=\left[\begin{array}{cccc}
1 & 0 & 0 & 0 \\
0 & 0 & 1 & 15 \\
0 & -1 & 0 & 21,5 \\
0 & 0 & 0 & 1
\end{array}\right]
$$

Dessa matriz é possível extrair a localização do TCP do manipulador na posição de Home, sendo sua posição dada pelos três primeiros elementos da última coluna, ou seja:

$$
\left[\begin{array}{lll}
p_{x} & p_{y} & p_{z}
\end{array}\right]^{T}=\left[\begin{array}{lll}
0 & 15 & 21,5
\end{array}\right]^{T} \text { pol }
$$

A orientação é dada pela matriz $3 \times 3$ dos elementos $a_{i j}$, para $i_{s} j=1,2,3$, de $T_{S_{r}}$. Uma melhor visualização da orientação pode ser obtida se essa matriz for convertida na forma de ângulos de Euler RPY (SICILIANO et al, 2009), 
sendo então equivalente a três rotações sucessivas, em torno dos eixos absolutos $z, y$ e $x$, tal que:

$$
\left[\begin{array}{lll}
r_{x} & r_{y} & r_{z}
\end{array}\right]^{T}=\left[\begin{array}{lll}
-90^{\circ} & 0 & 0
\end{array}\right]^{T}
$$

A cada iteração os algoritmos de otimização geram uma nova estimativa para as variáveis de junta e, através da Cinemática Direta, calcula-se a respectiva localização da ferramenta, possibilitando monitorar o erro.

\subsection{Problema de Otimização}

A formulação do problema de otimização para a resolução da cinemática inversa de robôs seriais pode ser feita definindo o ponto alvo em termos de posição e orientação desejadas, dado pelo vetor $x^{d}=\left[\begin{array}{llllll}p_{x}^{d} & p_{y}^{d} & p_{z}^{d} & r_{x}^{d} & r_{y}^{d} & r_{z}^{d}\end{array}\right]^{Y}$.

Define-se como função objetivo a ser minimizada o erro de localização, calculado como a diferença entre a localização desejada e a obtida a cada iteração, ou seja:

$$
e(q)=\gamma_{1} e_{\text {pos. }}+\gamma_{2} e_{\text {orient }}
$$

em que

$$
\theta_{p a s}=\sqrt{\left(p_{x}^{q}-p_{x}(q)\right)^{2}+\left(p_{y}^{q}-p_{y}(q)\right)^{2}+\left(p_{z}^{q}-p_{z}(q)\right)^{2}}
$$

$\mathrm{e}$

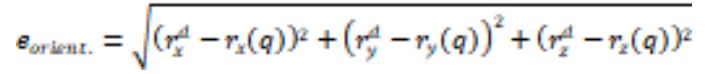

sendo $\quad p_{x}(q), p_{y}(q), p_{z}(q), r_{x}(q), r_{y}(q), r_{z}(q) \quad$ as coordenadas da ferramenta obtidas pelas variáveis de junta da iteração. Os fatores $\gamma_{1}$ e $\gamma_{2}$ são utilizados para atribuir pesos aos erros de posição e orientação, de forma a deixálos na mesma ordem de grandeza.

São impostas restrições sobre as variáveis, de tal forma que não ultrapassem os limites mecânicos de cada junta, tal que $q_{\mathrm{i}}^{\min } \leq q_{\mathrm{i}} \leq q_{\mathrm{i}}^{\max }$, sendo $i=1, \ldots, 5$.

Assim, é possível formular o seguinte problema de otimização: encontrar as variáveis de projeto $q$ que minimizem a função objetivo $\theta(q)$ - o erro expresso na equação (15) - tal que os valores de $q$ estejam dentro dos limites físicos das juntas do robô, ou seja:

$$
\left\{\begin{array}{cc}
\underset{q \in R^{n}}{\operatorname{minimizar}} & e(q)=\gamma_{1} e_{\text {pos. }}+\gamma_{2} e_{\text {orient }} \\
\text { tal que } & q_{\mathrm{i}}^{\min } \leq q_{\mathrm{i}} \leq q_{\mathrm{i}}^{\max }
\end{array}\right.
$$

\section{RESULTADOS E DISCUSSÃO}

Foi realizado um estudo de caso que consiste em resolver o problema de otimização formulado na equação (18), utilizando os algoritmos FDIPA e PSO, de modo a calcular a postura do robô, isto é, as variáveis de junta, $q=\left[\begin{array}{lllll}\theta_{1} & \theta_{2} & \theta_{3} & \theta_{4} & \theta_{5}\end{array}\right]^{T}$, que corresponda ao seguinte ponto alvo da ferramenta:

$$
p^{d}=\left[\begin{array}{llllll}
-2^{\mathrm{m}} & 11^{\mathrm{m}} & 15^{\mathrm{m}} & -70^{\mathrm{D}} & 0^{\mathrm{o}} & 10^{\mathrm{D}}
\end{array}\right]^{T}
$$

Os valores admissíveis para os ângulos de juntas estão no intervalo $\left[-180^{\circ}, 180^{\circ}\right]$ e os fatores de escala são definidos $\gamma_{1}=0,02$ e $\gamma_{2}=0,08$.
O critério de parada foi definido para quando o valor da função objetivo $e(q)$ estiver abaixo da tolerância $\epsilon=10^{-3}$, valor este baseado na repetibilidade do robô real.

As simulações foram realizadas em um mesmo computador com processador Intel Core i5 com 4 GB de memória RAM.

\subsection{Resultados FDIPA}

Para a resolução com o algoritmo FDIPA foram tomados os parâmetros iniciais $\varphi=1$ e $\xi=0,7$. As derivadas da função objetivo e das restrições foram calculadas pelo método de diferenças finitas progressivas. No procedimento de busca linear utilizou-se o critério de Armijo (LUENBERGER, 1984) e a atualização da matriz quasiNewton $B$ utilizando a regra BFGS modificada Powell (1978).

$\mathrm{Na}$ Tabela 3 encontram-se os valores obtidos em algumas iterações, da função objetivo $e(q)$, além dos respectivos ângulos de junta $\theta_{i}$ (em rad). Os resultados obtidos da função objetivo e dos erros (de posição e orientação) ao longo das iterações estão ilustrados respectivamente nos gráficos das Figuras 4 e 5 . O tempo computacional total para a convergência foi de $t=0,55 \mathrm{~s}$ e foram necessárias 24 iterações.

Tabela 3: Resultados obtidos com o algoritmo FDIPA.

\begin{tabular}{ccccccc}
\hline \hline Iter. & $\boldsymbol{e}(\boldsymbol{q}]$ & $\boldsymbol{\theta}_{\boldsymbol{i}}$ & $\boldsymbol{\theta}_{\boldsymbol{\Sigma}}$ & $\boldsymbol{\theta}_{\boldsymbol{z}}$ & $\boldsymbol{\theta}_{\boldsymbol{q}}$ & $\boldsymbol{\theta}_{\mathbf{5}}$ \\
\hline \hline 0 & 0,189019 & 0 & 0 & 0 & 0 & 0 \\
1 & 0,15375 & 0,0894 & $-0,0675$ & $-0,1405$ & $-0,0218$ & 0 \\
2 & 0,137081 & 0,2363 & $-0,1076$ & $-0,4531$ & $-0,0218$ & 0,0055 \\
$\vdots$ & & & $\vdots$ & & & $\vdots$ \\
24 & 0,000870081 & 0,1801 & $-0,2267$ & $-0,9443$ & 1,5142 & $-0,0073$ \\
\hline \hline
\end{tabular}

Figura 4 - Evolução da função objetivo pelo FDIPA.

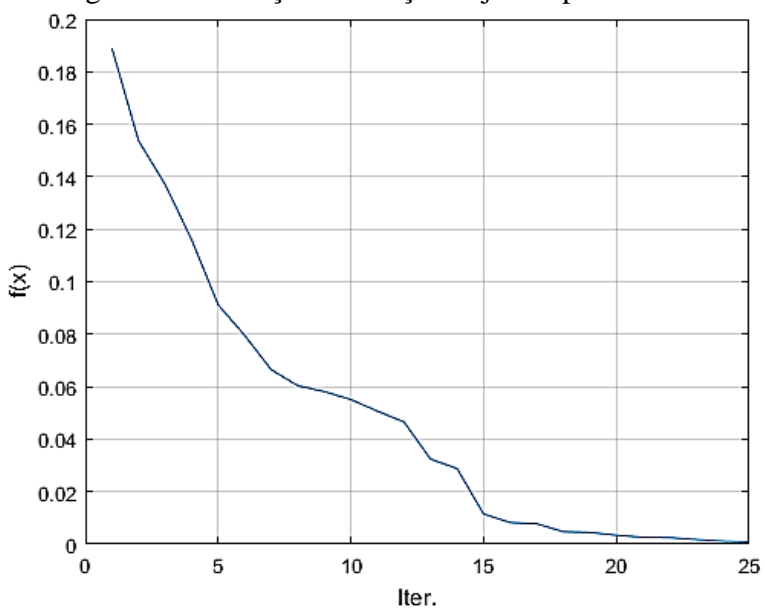

Fonte: Autores, 2018.

Figura 5 - Evolução do erro ao longo das iterações pelo FDIPA.

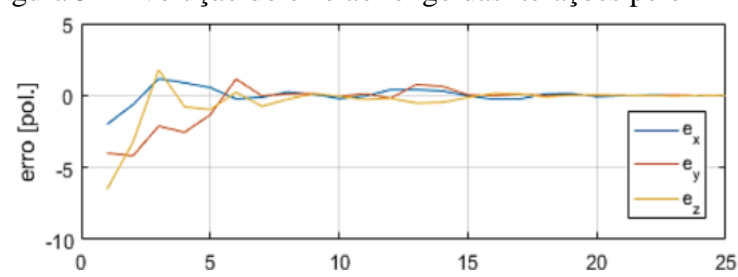

(a) erro de posição 


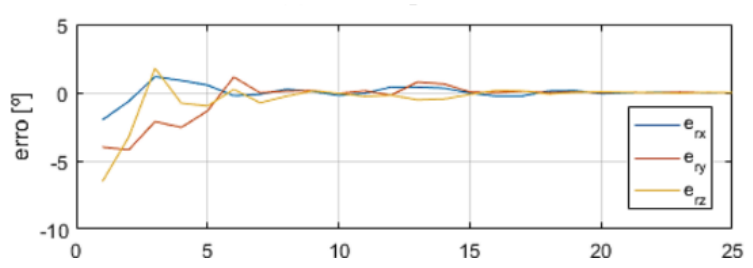

(b) erro de orientação

Fonte: Autores, 2018.

\subsection{Resultados PSO}

Para avaliação do PSO foram utilizados os parâmetros $\alpha=0,8, \beta_{1}=1$ e $\beta_{2}=1,5$ com uma população de $n=200$ partículas. Por se tratar de um algoritmo estocástico, a busca pela solução ocorre de maneira não uniforme, ou seja, o número de iterações para obter a solução varia, podendo inclusive não ser obtida. Vale ressaltar que o método gera a população inicial aleatoriamente dentro do espaço de busca, dispensando informar uma postura inicial do robô para executar o algoritmo.

No estudo de caso proposto, de forma a sempre garantir a convergência do método, uma abordagem de convergência forçada foi utilizada, executando o algoritmo repetidas vezes até ocorrer a convergência. Esse processo foi executado 100 vezes, sendo que em 88 delas houve convergência na primeira tentativa, e nas outras 12 foi necessário repetir a inicialização uma ou mais vezes para forçar a convergência.

Em média o tempo computacional total para a convergência foi de $t=0,7 \mathrm{~s}$, com, em média, 47 iterações.

Os resultados obtidos da função objetivo e dos erros (de posição e orientação) ao longo das iterações estão ilustrados respectivamente nos gráficos das Figuras 6 e 7, para uma amostra que levou à convergência.

Figura 6 - Evolução da função objetivo pelo PSO em uma amostra que convergiu.

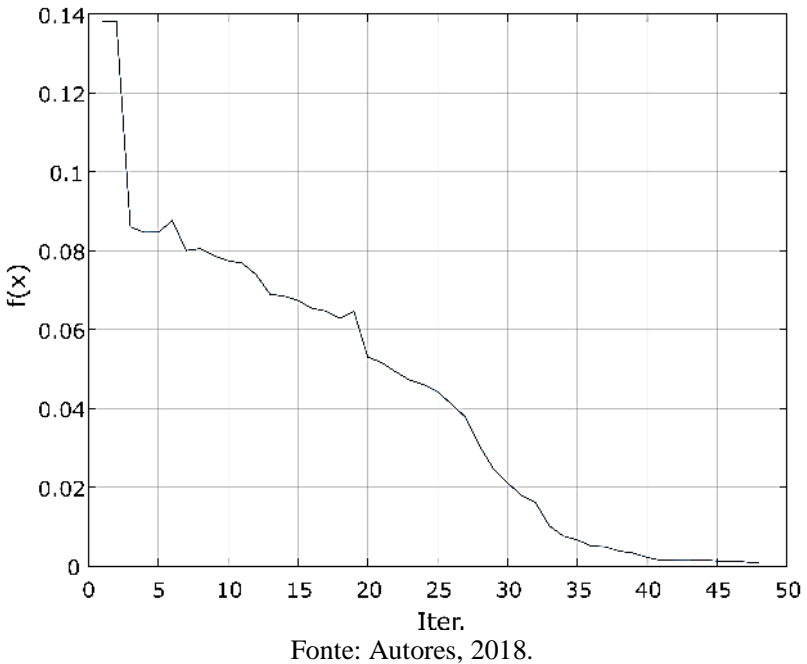

Figura 7 - Evolução do erro ao longo das iterações pelo PSO.

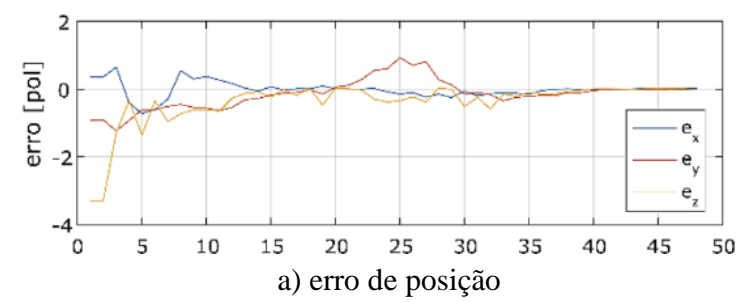

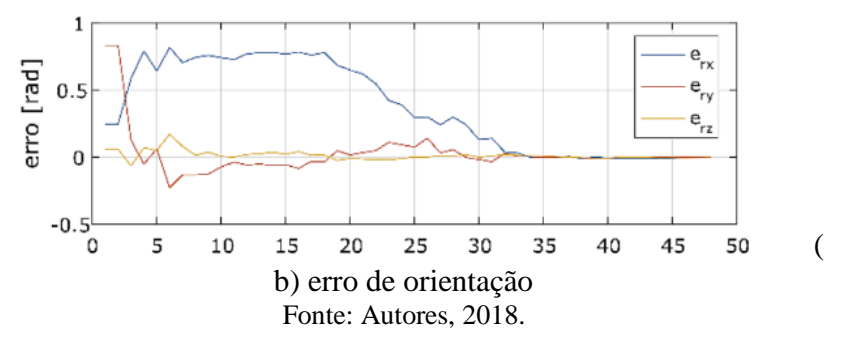

5.3 Análise Comparativa dos Resultados

Em função da característica probabilística do PSO, constata-se que o comportamento da função objetivo $e(q)$ não é necessariamente decrescente a cada iteração. Entretanto, com o algoritmo FDIPA, verifica-se que a cada iteração $\theta(q)$ é sempre decrescente.

Devido à complexidade de resolução do estudo de caso abordado, por considerar tanto posição quanto orientação do TCP, além de tratar de um robô espacial com $5 \mathrm{DOF}$, foi necessário utilizar um artifício de repetição para garantir convergência do método PSO, o que elevou seu tempo computacional médio. No FDIPA, manteve-se a estrutura original do método e necessitou de menor tempo.

$\mathrm{O}$ algoritmo PSO não demanda que o usuário especifique uma postura inicial do robô, o que ocorre de forma aleatória, podendo conduzir a múltiplas soluções, caso a geometria do robô permita, para uma mesma localização desejada do TCP. Como o FDIPA parte da estimativa inicial informada pelo usuário, a solução obtida é sempre a mesma.

\section{CONCLUSÃO}

Os resultados deste trabalho mostram a viabilidade da utilização de ambos algoritmos para resolução da cinemática inversa de robôs industriais no estudo de caso proposto. $\mathrm{O}$ algoritmo FDIPA mostrou-se mais eficiente, garantindo a convergência em menos tempo e com menor número de iterações que o PSO.

Como perspectivas de trabalhos futuro, há possibilidade de implementar no FDIPA o cálculo das derivadas analíticas da função objetivo e das restrições, o que possibilita diminuir ainda mais o custo computacional para a resolução.

\section{REFERÊNCIAS BIBLIOGRÁFICAS}

COLAÇO, M. J.; ORLANDE, H. R. B.; DULIKRAVICH, G. S.; Inverse and optimization problems in heat transfer. Journal of the Brazilian Society of Mechanical Sciences and Engineering, v. 28, n. 1, p. 1-24, 2006.

DAVIDSON, J. e HUNT, K. Robots and Screw Theory. Oxford University Press, 2004.

HERSKOVITS, J. Feasible Direction Interior-Point Technique for Nonlinear Optimization, JOTA - Journal of Optimization Theory and Applications, v. 99, pp. 121146, 1998.

KENNEDY, J; EBERHART, R. Particle swarm optimization. In: Proceedings of ICNN'95 - International Conference on Neural Networks, 1995.

LUENBERGER, D. G.: Linear and Nonlinear ( Programming, 2nd Edition, Addison-Wesley, Reading, Massachusetts, 1984. 
NOCEDAL, J., WRIGHT, S. J. Numerical Optimization. Springer, 2006.

POWELL, M. J. D. The Convergence of Variable Metric Methods for Nonlinearly Constrained Optimization Calculations, Nonlinear Programming 3, Academic Press, London, England, pp. 27-64, 1978.

SANTOS, F. L. Modelagem e Simulação de Robôs Seriais Baseadas em Helicoides. Instituto Militar de Engenharia, Rio de Janeiro. 2017.

SHAPIRO, A. On uniqueness of Lagrange multipliers in optimization problems subject to cone constraints, SIAM Journal on Optimization, v. 7, n. 2, pp. 508-518, 1997.

SICILIANO, B., SCIAVICCO, L., VILLANI, L. e ORIOLO, G. Robotics: Modelling, Planning and Control. London, England: Springer Science \& Business Media, 2009.

TSAI, L. W. Robot analysis: the mechanics of serial and parallel manipulators. Maryland, USA: John Wiley \& Sons, 1999.

\section{AGRADECIMENTOS}

O presente trabalho foi realizado com apoio da Fundação de Amparo à Pesquisa do Estado do Rio de Janeiro FAPERJ e da Coordenação de Aperfeiçoamento de Pessoal de Nível Superior - Brasil (CAPES) - Código de Financiamento 001.

\section{COPYRIGHT}

Direitos autorais: Os autores são os únicos responsáveis pelo material incluído no artigo. 


\author{
Volume $14-\mathrm{N}^{\mathrm{o}} 159$ - Março/2019. \\ XL International Sodebras Congress \\ 10 a 12 de dezembro de 2018 - Vitória - ES.
}

\title{
AVALIAÇÃO DE RISCO ECOTOXICOLÓGICO COM BASE EM RESULTADOS DO MODELO USETOX® PARA O TRICLOSAN PARA AS REGIÕES HIDROGRÁFICAS BRASILEIRAS
}

\section{EVALUATION OF ECOTOXICOLOGICAL RISK BASED ON RESULTS OF THE USETOX ${ }^{\circledR}$ MODEL FOR TRICLOSAN FOR THE BRAZILIAN HYDROGRAPHIC REGIONS}

\author{
PEDRO HENRIQUE BOLANHO SIMÕES ${ }^{1,3}$; BIAGIO FERNANDO GIANNETTI ${ }^{1}$, LUCAS ALEGRETTI $^{2}$ \\ ; MAUREA NICOLETTI FLYNN ${ }^{3}$

\section{1 - UNIVERSIDADE PAULISTA-UNIP; 2 - FACULDADE DE TECNOLOGIA UNIVERSIDADE ESTADUAL DE CAMPINAS - FT-UNICAMP; 3 - LISAM ECOADVISOR SYSTEMS}

simoes.pedro@hotmail.com; biafgian@unip.br; lucas.alegretti@gmail.com; maurea.flynn@lisam.com.

\begin{abstract}
Resumo - O objetivo do trabalho foi obter pela modelagem USEtox ${ }^{\circledR}$ os fatores de destino, exposição e caracterização do ingrediente Triclosan para avaliação do risco ambiental tendo como "endpoint" o quociente de risco (metodologia PEC/PNEC) calculado para as bacias hidrográficas nacionais. Para avaliação dos riscos ecológicos foi considerada uma emissão total de 200 toneladas por ano. O parâmetro de entrada do modelo USEtox mais sensível na composição do potencial de impacto ambiental é relativo aos valores de EC50. O Triclosan apresenta maior impacto quando se considera os PNECs de primeiro quartil, os mais baixos. Nesta situação o risco foi avaliado como médio nas áreas mais populosas e/ou com menor disponibilidade hídrica. $O$ resultado é corroborado pelas investigações de Montagner $e$ colaboradores (2014) para o estado de São Paulo, e reforça a necessidade da inclusão do Triclosan na lista de contaminantes prioritários para proteção da biota aquática.
\end{abstract}

Palavras-chave: Quociente PEC/PNEC, Modelagem, Risco Ambiental.

Abstract - This paper aims to obtain through USEtox ${ }^{\circledR}$ modelling, fate, exposure and characterization factors of Triclosan for environmental risk assessment. The chosen endpoint is the risk quotient (PEC/PNEC) calculated for national river basins. A total emission of 200 tons per year was considered for the risk assessment. The most sensitive input parameter of the USEtox model is related to EC50 values. Triclosan has a greater impact when PNECs first quartile, the lowest, are considered. In this situation, the risk was assessed as average in the most populated areas and/or with less water availability. The result is corroborated by the investigation of Montagner et al (2014) for the state of São Paulo and reinforces the need for inclusion of Triclosan in the list of priority contaminants related to aquatic biota protection.

Keywords: PEC/PNEC Ratio, Modelling, Environmental Risk

\section{INTRODUÇÃO}

Avaliações de risco realizadas têm demonstrado que o Triclosan em águas superficiais pode afetar uma grande variedade de organismos aquáticos, o que aumenta a preocupação em relação à sua permanência no ambiente, principalmente devido à possibilidade de que sofra biotransformação gerando compostos de maior toxicidade e persistência, como as dioxinas e os clorofenóis (TIBURTIUS; SCHEFFER, 2014).

Triclosan é um composto clorado aromático com unidade estrutural de fenol e éter utilizado em cosméticos e produtos de higiene pessoal como biocida, agente desodorante ou preservativo. Apesar do seu uso no Brasil ser regulamentado pela Resolução - RDC $\mathrm{N}^{\circ} 29$, de $1^{\circ}$ de junho de 2012 da Agência Nacional de Vigilância Sanitária (ANVISA), há um entendimento internacional de que os produtos de grande consumo devam ter padrão de certificação de uso diferenciado.

A associação francesa de normatização (ADEMEAFNOR) está testando o modelo USEtox ${ }^{\circledR}$ (ROSENBAUM et al.2008) indicado pela SETAC para o desenvolvimento de uma rotulagem ambiental para os produtos de amplo consumo com base nos resultados gerados de caracterização dos impactos humanos e ecotoxicológicos das substâncias químicas.

Este artigo tem como objetivo, obter pela modelagem USEtox $^{\circledR}$ os fatores de destino, exposição e caracterização do ingrediente Triclosan para avaliação do risco ambiental tendo como "endpoint" a fração de espécies com potencial de não ocorrência local e o quociente de risco (metodologia PEC/PNEC) calculado para as bacias hidrográficas nacionais.

\section{METODOLOGIA}

Para avaliação dos riscos ecológicos foi considerada uma emissão total de 200 toneladas por ano. Esse valor foi estabelecido baseado nas informações de importações ocorridas no Brasil do Triclosan da última década. Para análise da avaliação de risco o valor foi convertido para kg e considerando uma emissão diária constante. Para obtenção da emissão por região assumiu-se um uso uniforme de Triclosan e dessa maneira foi estabelecida uma taxa per capita de emissão diária dividindo o total anual importado de Triclosan pelo número estimado de habitantes do Brasil 
para o ano de 2015, 204.450.649 habitantes (IBGE, 2015). A taxa per capita de emissão foi igual 2,68E-06 $\mathrm{kg} / \mathrm{dia} /$ habitante ou 2,68 mg/dia/habitante (ZHANG et. al., 2015).

O Brasil é divido em 12 regiões hidrográficas e os dados referentes às proporções de área superficial, de volume de água disponível e habitantes por região hidrográfica apurados nas bases da ANA (2015).

O modelo considerou dois cenários: o "Default USEtox", cenário médio aplicável a qualquer região do mundo, e o "Brazil+", cenário aplicável ao Brasil incluído também a região da bacia amazônica pertencente a Venezuela, Bolívia e Peru.

Para obtenção das informações sobre o Triclosan $\left(\mathrm{N}^{\circ}\right.$ CAS: 3380-34-5) necessárias para a aplicação do modelo USEtox ${ }^{\circledR}$ foram utilizadas metodologias distintas. Para os parâmetros físico-químicos e ecotoxicológicos, utilizou-se a base ECHA, utilizando dados de trabalhos confiáveis e aceitos (confiabilidade 1 ou 2). Quando mais de um dado para o mesmo parâmetro é encontrado, utilizou-se a média dos valores encontrados. Para valores não disponíveis na base ECHA, optou-se pela utilização do programa de estimativas EPISuite®.

Com base nas concentrações de exposição modeladas, os potenciais riscos presentes podem ser mapeados usando a abordagem de quociente de risco (RQ). Esse quociente é calculado pela seguinte equação (1):

$$
R Q=P E C / P N E C
$$

Onde,

$\mathrm{RQ}=$ Quociente de risco

$\mathrm{PEC}=$ Predicted environmental concentration

PNEC $=$ Predicted no effect concentration

O valor de PEC a ser utilizado é dado pela equação (2):

$$
P E C=m e / V r
$$

Onde,

me $=$ Massa estimada

$\mathrm{Vr}=$ Volume regional de água doce.

O valor da massa estimada, quando a emissão é exclusivamente para água doce, é obtido através da multiplicação da quantidade da substância/ingrediente emitida diariamente em quilograma pelo Fator de Destino (FF - Fate Factor) do compartimento receptor. O volume regional pode ser encontrado na guia "Fate" do modelo USEtox ${ }^{\circledR}$ nos dados referentes a escala continental (CONTINENTAL ENVIRONMENT) linha $\mathrm{n}^{\circ} 147$ definida como "VOLUME fresh water compartment". O resultado usado é referente a região selecionada na guia "Run", segundo a equação (3):

$$
m e=\text { Emissão diária } \times \text { Fator de destino }
$$

O coeficiente de risco (RQ) traz a caracterização preliminar de risco (no caso, compartimento água), e se baseia na razão entre as concentrações ambientais encontradas (PEC) e as concentrações ambientais para as quais não se prevê a ocorrência de efeitos (PNEC) estimadas a partir de ensaios de toxicidade padrão.

O valor da PEC será obtido do resultado da massa esperada no compartimento água doce estimada pelo modelo USEtox ${ }^{\circledR}$. Essa concentração será comparada aos valores de concentração ambiental medidos (MEC) disponíveis na literatura.

A PNEC para o compartimento água, é calculada a partir de valores de EC50 obtidos em testes de toxicidade aguda (algas, Daphnia, peixe) e pela aplicação de fator de extrapolação (valor de 1000) que leva em conta a variabilidade em sensibilidade intra- e interespecíficas. A PNEC para compartimento água doce (PNECwat) pode ser determinada pela seguinte equação (4):

\section{PNECwat $=(E C 50$ ou LC50 $) / 1000$}

Critérios comuns para a interpretação do RQ em estudos de avaliação de risco estabelecem os níveis de risco, como consta na Tabela 1.

Tabela 1 - Critérios comuns para a interpretação do RQ.

\begin{tabular}{cc}
\hline RQ $($ PEC/ PNEC) & Risco \\
\hline $\mathrm{RQ}<0,01$ & Sem risco \\
$0,01 \leq \mathrm{RQ}<0,1$ & Risco baixo \\
$0,1 \leq \mathrm{RQ}<1$ & Risco médio \\
$\mathrm{RQ} \geq 1$ & Risco alto \\
\hline
\end{tabular}

Para a avaliação PEC/PNEC de risco serão considerados, com base nos valores de LC50 pesquisados, os valores respectivos de PNECs mínimos (primeiro quartil) PNECs médios (média geométrica) para minimização de erros em procedimentos tanto empíricos como de análise estatística.

\section{RESULTADOS}

Os dados de entrada gerados para o Triclosan e utilizados para alimentar o modelo USEtox ${ }^{\circledR}$ estão expostos na Tabela 2.

Tabela 2. Dados de entrada gerados para o Triclosan e utilizados para alimentar o modelo USEtox ${ }^{\circledR}$

\begin{tabular}{lcc}
\hline Parâmetro de entrada & Unidade & $\begin{array}{c}\text { Entrada } \\
\text { USEtox }\end{array}$ \\
\hline Kow & $\mathrm{L} / \mathrm{kg}$ & $5,94 \mathrm{E}+04$ \\
Koc & $9,27 \mathrm{E}+03$ \\
Constante de Henry & $\mathrm{Pa} \cdot \mathrm{m}^{3} \cdot \mathrm{mol}^{-1}$ & $1,72 \mathrm{E}-02$ \\
Pressão de vapor $25^{\circ} \mathrm{C}$ & $\mathrm{Pa}$ & $5,95 \mathrm{E}-04$ \\
Kdoc & $\mathrm{L} / \mathrm{kg}$ & $4,75 \mathrm{E}+03$ \\
Concentração perigosa à $50 \%$ & $\mathrm{mg} / \mathrm{L}$ & $-1,65 \mathrm{E}+00$ \\
\hline
\end{tabular}

Os valores de equilíbrio das concentrações modeladas do Triclosan em água estão listados na Tabela 3 considerando as duas configurações de região utilizadas no modelo USEtox ${ }^{\circledR}$, "Default USEtox" e "Brazil+", além de cada região hidrográfica. A partir de valores de LC50 levantados na base ECHA, foi calculado a PNEC do $1^{\circ}$ quartil, igual a $1,19 \mathrm{ng} / \mathrm{L}$, e a PNEC da média geométrica, igual a 15,8 ng/L. Com estes valores foram calculadas as razões PEC/PNEC para os diferentes cenários considerados (Tabela 3). 
Tabela 3. Valores de equilíbrio esperado das concentrações modeladas do Triclosan para cada cenário considerado (PECs), razão entre PEC e PNEC do $1^{\circ}$ Quartil e PEC/PNEC da Média Geométrica.

\begin{tabular}{lccc}
\hline \multicolumn{1}{c}{ Região Hidrográfica } & $\begin{array}{r}\text { PECs } \\
\text { (ng/L) }\end{array}$ & $\begin{array}{c}\text { PEC/ } \\
\text { PNEC } \\
\mathbf{1}^{\circ} \mathbf{Q t}\end{array}$ & $\begin{array}{c}\text { PEC/PNEC } \\
\text { Média }\end{array}$ \\
\hline "Default USEtox" & $3,6 \mathrm{E}-02$ & $3,0 \mathrm{E}-02$ & $2,3 \mathrm{E}-03$ \\
"Brazilt" & $1,8 \mathrm{E}-02$ & $1,5 \mathrm{E}-02$ & $1,1 \mathrm{E}-03$ \\
Amazônica (Am) & $1,8 \mathrm{E}-03$ & $1,5 \mathrm{E}-03$ & $1,2 \mathrm{E}-04$ \\
Atlântico Leste (AL) & $2,5 \mathrm{E}-01$ & $2,1 \mathrm{E}-01$ & $1,6 \mathrm{E}-02$ \\
Atlântico NE Oci.(ANO1) & $5,8 \mathrm{E}-02$ & $4,9 \mathrm{E}-02$ & $3,7 \mathrm{E}-03$ \\
Atlântico NE Ori. (ANO2) & $7,2 \mathrm{E}-01$ & $6,0 \mathrm{E}-01$ & $4,5 \mathrm{E}-02$ \\
Atlântico Sudeste (Ase) & $2,1 \mathrm{E}-01$ & $1,7 \mathrm{E}-01$ & $1,3 \mathrm{E}-02$ \\
Atlântico Sul (As) & $7,9 \mathrm{E}-02$ & $6,6 \mathrm{E}-02$ & $5,0 \mathrm{E}-03$ \\
Paraguai (Pa1) & $2,9 \mathrm{E}-02$ & $2,4 \mathrm{E}-02$ & $1,8 \mathrm{E}-03$ \\
Paraná (Pa2) & $1,4 \mathrm{E}-01$ & $1,2 \mathrm{E}-01$ & $9,1 \mathrm{E}-03$ \\
Parnaíba (Pa3) & $1,3 \mathrm{E}-01$ & $1,1 \mathrm{E}-01$ & $8,3 \mathrm{E}-03$ \\
São Francisco (SF) & $1,2 \mathrm{E}-01$ & $1,0 \mathrm{E}-01$ & $7,8 \mathrm{E}-03$ \\
Tocantins-Araguaia (TA) & $1,4 \mathrm{E}-02$ & $1,1 \mathrm{E}-02$ & $8,5 \mathrm{E}-04$ \\
Uruguai (Ur) & $2,3 \mathrm{E}-02$ & $1,9 \mathrm{E}-02$ & $1,5 \mathrm{E}-03$ \\
\hline
\end{tabular}

Pelos resultados das razões PEC/PNEC para as diferentes regiões hidrográficas brasileiras, considerando o PEC e PNEC do $1^{\circ}$ Quartil (Figura 1) e PEC/PNEC da Média Geométrica (Figura 2).

Figura 1 - Quociente de Risco pelas razões PEC/PNEC para as regiões hidrográficas brasileiras, considerando o PEC e PNEC do

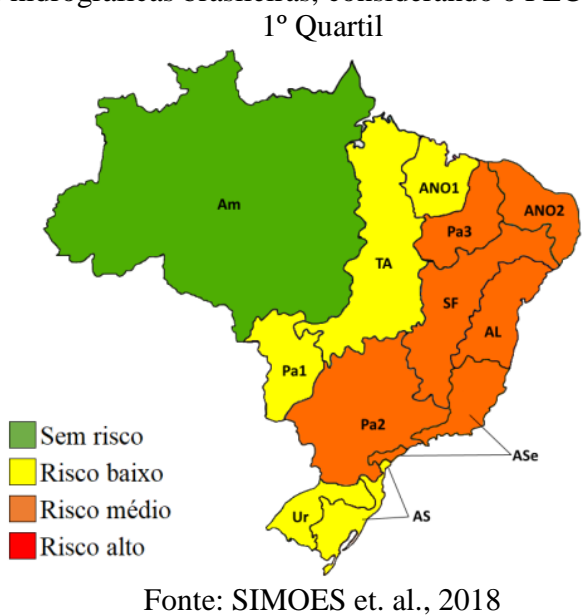

Figura 2 - Quociente de Risco pelas razões PEC/PNEC para as regiões hidrográficas brasileiras, considerando PEC/PNEC da

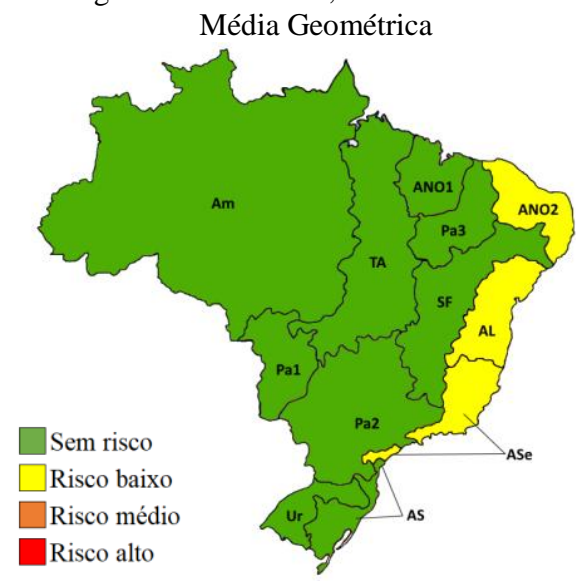

Fonte: SIMOES et. al., 2018

\section{CONCLUSÃO}

O estudo forneceu uma caracterização do impacto ecotoxicológico potencial ao sistema hídrico do Triclosan. O parâmetro de entrada do modelo USEtox ${ }^{\circledR}$, mais sensível na composição do potencial de impacto ambiental é relativo aos valores de EC50, isto porque este mantém uma relação direta com o Fator de Caracterização (CF) (inversamente proporcional ao log EC50), enquanto os outros parâmetros de entrada, parâmetros físico-químicos, são em sua maioria utilizados para o cálculo das matrizes de destino e exposição, tendo, portanto, efeito indireto. $\mathrm{O}$ mais importante destes últimos na composição do CF é a taxa de degradação em água $(\mathrm{kdegW})$. CF e kdegW seguem tendências opostas: quanto mais alta a taxa de degradação mais baixo é o valor de CF.

O Triclosan apresenta maior impacto quando se considera os PNECs de primeiro quartil, mais baixos. Nesta situação teríamos risco avaliado como médio nas áreas mais populosas e/ou com menor disponibilidade hídrica como, Atlântico Leste, Atlântico Nordeste Oriental, Atlântico Sudeste, Paraná, Parnaíba e São Francisco. O resultado é corroborado pelas investigações de Montagner e colaboradores (2014) para o estado de São Paulo. E reforça a necessidade da inclusão do Triclosan na lista de contaminantes prioritários de inclusão necessária na legislação brasileira referente a qualidade das águas, de modo a promover a proteção a biota aquática.

\section{AGRADECIMENTOS}

O presente trabalho foi realizado com apoio da Coordenação de Aperfeiçoamento de Pessoal de Nível Superior - Brasil (CAPES) - Código de Financiamento 001.

\section{REFERÊNCIAS BIBLIOGRÁFICAS}

ANA. Agência Nacional das Águas (2015). Conjuntura dos recursos hídricos no Brasil: regiões hidrográficas brasileiras - Edição Especial. Brasília - ANA. 163p. Disponível em: https://www.gtap.agecon.purdue.edu/resources/download/78 85.pdf . Acesso em 20 set. 2018

Affichage environnemental (ADEME-AFNOR). Disponível em: http://affichage-environnemental.afnor.org/. Acesso em 08 set. 2018

Agência Nacional de Vigilância Sanitária (ANVISA) Resolução - RDC $\mathbf{N}^{\circ}$ 29, de $1^{\circ}$ de junho de 2012. Disponível em: http://portal.anvisa.gov.br/. Acesso em 15 out. 2018 .

MONTAGNER, C.C.; JARDIM, W.F.; VON DER OHE, P.C; UMBUZEIRO, G.A. Occurrence and potential risk of triclosan in freshwaters of São Paulo, Brazil-the need for regulatory actions. Environ Sci Pollut Res, 21:1850-1858, 2014.

European Chemicals Agency (ECHA). Registered substances. Disponível em: http://echa.europa.eu/information-on-chemicals/registeredsubstances. Acesso em 08 mar. 2016.

ROSENBAUM, R.K., BACHMANN, T.M., GOLD, L.S., HUIJBREGTS, M.A.J., JOLLIET, O., JURASKE, R., KOEHLER, A., LARSEN, H.F., MACLEOD, M., MARGNI, M.D., MCKONE, T.E., PAYET, J., SCHUHMACHER, M., VAN DE MEENT, D., 
HAUSCHILD, M.Z., USEtox - The UNEP/SETACconsensus model: recommended characterisation factors for human toxicity and freshwater ecotoxicity in Life Cycle Impact Assessment. International Journal of Life Cycle Assessment, v. 13, n. 7, p. 532-546, 2008.

TIBURTIUS, E. R.L.; SCHEFFER, E. W.O. Triclosan: Destino no Meio Ambiente e Perspectivas no Tratamento de Águas de Abastecimento Público. Revista Virtual de Química, v. 6, n. 5, p. 1144-1159, 2014.

ZHANG, Q-Q.; YING, G-G.; CHEN, Z-F.; ZHAO, J-L; LIU, Y.S. Basin-scale emission and multimedia fate of triclosan in whole China. Environ Sci Pollut Res, v. 22, p. 10130-10143, 2015.

\section{COPYRIGHT}

Direitos autorais: $\mathrm{O}(\mathrm{s})$ autor(es) é(são) o(s) único(s) responsável(is) pelo material incluído no artigo. 


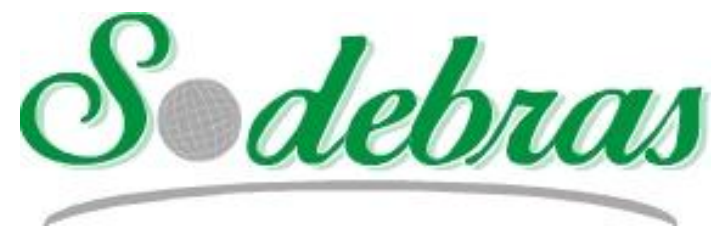

Volume $14-\mathrm{N}^{\mathrm{o}} 159$ - Março/2019. XL International Sodebras Congress

10 a 12 de dezembro de 2018 - Vitória - ES.

\title{
CONFLITOS DE USO DO SOLO DE ÁREAS DE PRESERVAÇÃO PERMANENTE DA BACIA HIDROGRÁFICA DA SERRA DA MANTIQUEIRA - UGRHI 1
}

\section{SOIL USE CONFLICTS OF PERMANENT PRESERVATION AREAS OF THE SERRA DA MANTIQUEIRA WATERSHED - UGRHI 1}

\author{
SILVA, M.H. ${ }^{1}$; TRANNIN, I. C. B. ${ }^{2}$; CATELANI, C. S. ${ }^{3}$ \\ 1;2;3 FACULDADE DE ENGENHARIA DE GUARATINGUETÁ, UNIVERSIDADE ESTADUAL \\ PAULISTA “JÚLIO DE MESQUISTA FILHO”
}

marcos_ambiental@yahoo.com.br; isatrannin@feg.unesp.br; cscatelani@gmail.com

\begin{abstract}
Resumo - A delimitação das áreas de preservação permanente (APPs) é uma ferramenta importante para a gestão dos recursos naturais e preservação de bacias hidrográficas. Neste estudo foram delimitadas as APPs hídricas e de declividade da bacia da Serra da Mantiqueira - UGRHI 1 e analisado o uso do solo em atendimento ao Novo Código Florestal, instituído pela Lei Federal 12.651/2012. Para a delimitação das APPs e verificação do uso conflitante foram analisados os mapas de uso e ocupação do solo, de rede de drenagem e de declividade, manipulados em SIG - ArcGIS® 10.1. As APPs cobrem 100,3 km ocupando 14,84\% da área da bacia, destes, $43,97 \mathrm{~km}^{2}$ não atendem ao Código Florestal, sendo ocupados, principalmente, com pastagens. Estas informações são imprescindiveis para subsidiar as políticas públicas em projetos e ações de intervenção visando o uso sustentável do solo.
\end{abstract}

Palavras-chave: Preservação Ambiental. Geoprocessamento. Código Florestal.

Abstract - The delimitation of permanent preservation areas (APPs) is an important tool for the management of natural resources and preservation of watersheds. This study delimited the hydrics and slopes APPs of the Serra da Mantiqueira watershed-UGRHI 1 and analyzed the soil use in compliance with the New Forest Code, established by Federal Law 12.651/2012. For delimitation of the APPs and verification of the conflicting use, maps of land use and occupation, drainage and slope were manipulated in GIS - ArcGIS ${ }^{\circledR} 10.1$ and analyzed. The APPs cover $100.3 \mathrm{~km}^{2}$ corresponding to $14.84 \%$ of the watershed area and $43.97 \mathrm{~km}^{2}$ not comply with the Forest Code being occupied mainly with pastures. This information is essential to support public policies in intervention projects and actions aimed at sustainable land use.

Keywords: Environmental Preservation. Geoprocessing. Forest Code.

\section{INTRODUÇÃO}

A ausência de planos de manejo e de gerenciamento dos recursos naturais de uma bacia hidrográfica tem como consequência o desenvolvimento de atividades em locais inapropriados, inclusive em áreas de preservação permanente (APPs), o que pode degradar e poluir o ambiente e afetar diretamente todo o ecossistema da bacia.

De acordo com o Código Florestal brasileiro, instituído pela Lei Federal no 12.651/12 (BRASIL, 2012), as APPs são áreas de grande importância ecológica, cobertas ou não, por vegetação nativa, que têm como função preservar os recursos hídricos, a paisagem, a estabilidade geológica, a biodiversidade, o fluxo gênico de fauna e flora, proteger o solo e assegurar o bem estar da população.

Legalmente, as APPs hídricas correspondem a áreas que estão diretamente ligadas aos cursos d'água, como as nascentes ou olhos d'água, locais onde a água aflora naturalmente, mesmo que de forma intermitente; os manguezais; a água subterrânea e as matas ciliares, que são formações vegetais das margens dos rios, córregos, lagos, represas e nascentes, que também são conhecidas como matas de galeria, matas de várzea, vegetação ou floresta ripária. As APPs de declividade compreendem as encostas com declividade superior a 45 graus. As APPs são protegidas pelo Código Florestal e devem ser preservadas e restabelecidas, sendo que o uso indevido é considerado crime ambiental, conforme a Lei Federal n ${ }^{\circ}$ 9.605/98.

A delimitação das APPs e o mapeamento do uso do solo de uma bacia hidrográfica, utilizando ferramentas de geoprocessamento é um mecanismo de extrema importância para a gestão e proteção dos recursos naturais de uma bacia hidrográfica (FERREIRA, 2011). Neste aspecto, a Mata Atlântica, que compõe a Serra da Mantiqueira é considerada patrimônio nacional pela Constituição Brasileira e como bioma insubstituível pela UNESCO (2011).

Neste contexto, a preservação dos recursos naturais é de grande importância para a Unidade de Gerenciamento dos Recursos Hídricos da Bacia Hidrográfica da Serra da Mantiqueira (UGRHI 1), composta pelos municípios paulistas de Campos do Jordão, Santo Antônio do Pinhal e São Bento do Sapucaí. Apesar disso, há décadas esta bacia tem sido submetida a intervenções antrópicas progressivas e até o momento não existem informações disponíveis sobre a delimitação e a caracterização do uso do solo em suas APPs.

Neste estudo foram delimitadas as APPs da bacia hidrográfica da Serra da Mantiqueira - UGRHI 1 e identificados os usos do solo conflitantes com o que estabelece o Código Florestal, visando fornecer informações que possam subsidiar as políticas públicas na gestão dos recursos naturais desta bacia hidrográfica. 


\section{METODOLOGIA}

A Unidade de Gerenciamento de Recursos Hídricos da bacia hidrográfica da Serra da Mantiqueira (UGRHI 1) está localizada na porção nordeste-leste do Estado de São Paulo, fazendo divisa com a bacia do Rio Paraíba do Sul e a oestenorte, com o Estado de Minas Gerais. Esta bacia possui uma área de $675,60 \mathrm{~km}^{2}$, que corresponde a 0,28\% do estado de São Paulo e é constituída pelos municípios de Campos do Jordão (290,00 km²), Santo Antônio do Pinhal (133,00 km²) e São Bento do Sapucaí $\left(252,60 \mathrm{~km}^{2}\right)$, com área urbanizada de 3.058,33 ha e uma população de 65.114 habitantes até o ano de 2011 (CBH-SM, 2012, SMA/CPLA, 2014).

No contexto internacional, a UGRHI 1 está inserida na bacia do rio da Prata e, no contexto nacional, na região hidrográfica do Paraná - RHPR, mais especificamente na bacia hidrográfica do Rio Grande, que contempla áreas nos estados de São Paulo e Minas Gerais (OEA/SRH, 2005). Devido a pequena extensão, condicionamento fisiográfico e ocupação, a UGRHI 1 foi dividida em duas unidades hidrográficas principais, a oeste, a Sapucaí-Mirim, sob influência dos municípios de Santo Antônio do Pinhal e São Bento do Sapucaí e, a leste, a Sapucaí-Guaçu, sob influência de Campos do Jordão. Estas duas unidades principais foram ainda subdivididas em bacias secundárias ou pequenas bacias municipais. De acordo com Kronka et al. (2005), os corpos hídricos cobrem uma área de 30,77 ha, distribuídos entre os municípios de Campos do Jordão, São Bento do Sapucaí e Santo Antônio do Pinhal.

A Serra da Mantiqueira é uma cadeia montanhosa que se estende pelos estados de São Paulo (30\%), Minas Gerais $(60 \%)$ e Rio de Janeiro (10\%). O maciço rochoso possui aproximadamente $500 \mathrm{~km}$ de extensão, formado principalmente por gnaisses, granitos, migmatitos e rochas cataclásticas (milonitos). Há terrenos cristalinos ígneometamórficos pré-cambrianos, suítes alcalinas mesozoicas e terrenos sedimentares mais recentes, predominantemente aluvionares sedimentares e sedimentos quaternários, considerando que esta bacia situa-se ao norte da bacia sedimentar do Paraíba do Sul (CBH-SM, 2012).

As altitudes variam de 886 metros em São Bento do Sapucaí, chegando a atingir 2000 metros na região de Campos do Jordão (CBH-SM, 2012). Devido a sua geomorfologia e características climáticas, o município de Campos do Jordão encontra-se na zona de risco de escorregamento, inundações e erosão e é um dos 19 municípios do estado de São Paulo com Plano Municipal de Redução de Risco (SMA/CPLA, 2014).

Com base nas informações obtidas no Plano de bacias da Serra da Mantiqueira, esta bacia é composta em toda a sua extensão por unidades de conservação, que incluem a Área de Proteção Ambiental (APA) da Serra da Mantiqueira. Pela classificação climática de Köppen, na região da Serra da Mantiqueira predomina o clima subtropical de altitude - $\mathrm{Cfb}$, mesotérmico médio e úmido, com temperatura média anual entre $13,4^{\circ} \mathrm{C}$ a $17^{\circ} \mathrm{C}$ e, devido às elevadas altitudes, ocasionalmente, podem ocorrer temperaturas inferiores a $0^{\circ} \mathrm{C}$ (CPTI, 2012). O total médio anual de precipitação pluviométrica é superior a $1500 \mathrm{~mm}$, com chuvas bem distribuídas em todos os meses do ano, decrescendo no período de inverno, quando ocorrem períodos de estiagem (SANTOS, 2009; CPTI, 2012).

De acordo com o mapa de uso e ocupação do solo da bacia hidrográfica da Serra da Mantiqueira fornecido pela Secretaria do Meio Ambiente/Instituto Florestal (2008), entre os usos do solo destacam-se a pastagem relacionada à pecuária (25.844,7 ha), o reflorestamento (4.791,78 ha), a vegetação de campo natural com perturbação antrópica (2.644,58 ha) e a agricultura (1.835,65 ha).

A delimitação das APPs hídricas e de declividade da bacia hidrográfica da Serra da Mantiqueira teve como referência o Código Florestal, instituído pela Lei Federal $n^{\circ}$ $12.651 / 12$, que estabelece a faixa de $30 \mathrm{~m}$ marginais ao longo dos cursos d'água com largura inferior a $10 \mathrm{~m}$; faixa de $50 \mathrm{~m}$ ao longo dos cursos d'água de 10 a $50 \mathrm{~m}$ de largura; o raio de $50 \mathrm{~m}$ ao redor das nascentes e a faixa marginal de $50 \mathrm{~m}$ em lagoas na zona rural com área inferior a 20 ha e para as APPs de declividade foram consideradas as encostas ou partes destas com declividade superior a $45^{\circ}$, equivalente a $100 \mathrm{~m}$ de projeção horizontal.

O mapa da rede de drenagem da bacia hidrográfica da Serra da Mantiqueira foi disponibilizado pelo Instituto Brasileiro de Geografia e Estatística (IBGE, 2008). O mapa das classes de declividade foi gerado pelo fatiamento da grade numérica da declividade em porcentagem (Tabela 1).

Tabela 1 - Correlação entre classes de declividade e relevo.

\begin{tabular}{cc}
\hline $\begin{array}{c}\text { Classes de } \\
\text { Declividade }(\%)\end{array}$ & Relevo \\
\hline A $(0-3)$ & Plano \\
B (3-5) & Plano a suave ondulado \\
C $(5-12)$ & Suave ondulado a ondulado \\
D $(12-20)$ & Ondulado e forte ondulado \\
E $(20-40)$ & Forte ondulado a montanhoso \\
F $(>40)$ & Montanhoso \\
\hline
\end{tabular}

Fonte: Elaborado pelos autores, conforme De Biase (1993).

Para gerar o mapa temático de classes de declividade da bacia da Serra da Mantiqueira (Figura 1) foi utilizado o conjunto de arquivos do projeto TOPODATA produzidos ao longo do processamento dos dados SRTM e realizado o fatiamento da grade numérica da declividade em porcentagem (VALERIANO, 2011), empregando-se o software SPRING (CÂMARA et al., 1996).

Figura 1 - Classes de declividade da bacia hidrográfica da Serra da Mantiqueira - UGRHI 1.

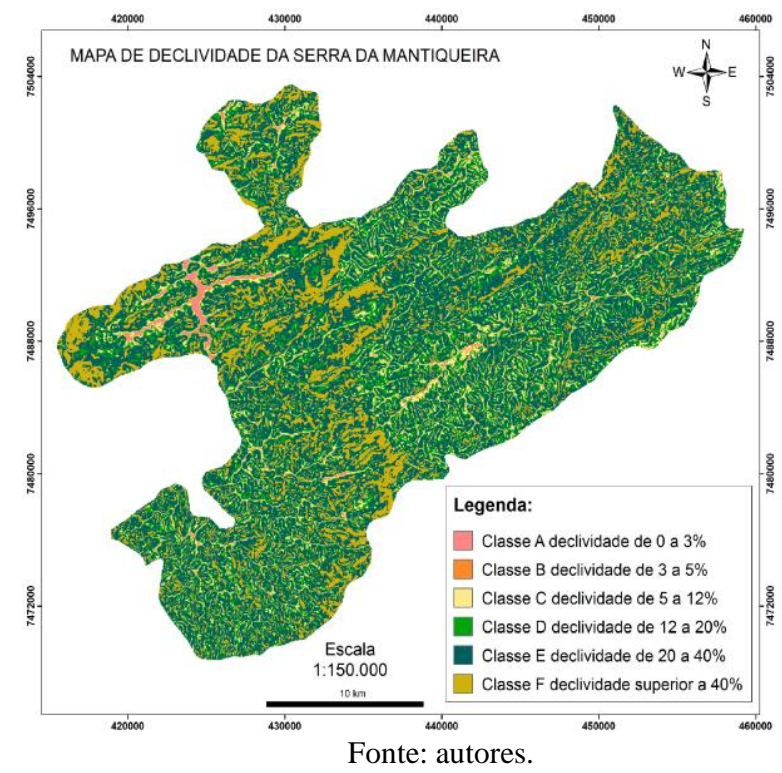


Na delimitação das APPs hídricas e de declividade foram considerados os parâmetros indicados na Lei 12.651/12, do Código Florestal e, por meio da ferramenta Buffer do software ArcGIS® 10.1 e extração das áreas de declividade com valor superior a $45^{\circ}$, foi possível quantificar o número de APPs hídricas e de declividade da bacia hidrográfica da Serra da Mantiqueira.

A caracterização pedológica da bacia da Serra da Mantiqueira teve como base o levantamento semidetalhado realizado em campo e o cruzamento das informações dos mapas de declividade e da rede de drenagem. A partir desta matriz foi feita a análise da topossequência e delimitação das classes de solos: Neossolos Litólicos (RL) e afloramentos rochosos, em terrenos com declividade forte ondulado a montanhoso, Cambissolos Háplicos (CX) e Cambissolos Húmicos $(\mathrm{CH})$ em terrenos ondulados a forte ondulados, sendo os últimos de ocorrência em áreas de matas e florestas, Neossolos Flúvicos (RU), em relevo plano e próximo à rede de drenagem.

Seguindo o modelo estabelecido por Andrade et al (1998) e Pinto et al. (2005), as classes de solos atualizadas pela Embrapa (2009) foram correlacionadas às classes de declividade (Tabela 2).

Tabela 2 - Correlação entre classes de declividade e classes de solo da bacia hidrográfica da Serra da Mantiqueira.

\begin{tabular}{cc}
\hline $\begin{array}{c}\text { Classes de } \\
\text { Declividade (\%) }\end{array}$ & Classes de Solo \\
\hline A $(0-3)$ & Latossolos \\
B (3-5) & Neossolos Flúvicos \\
C (5-12) & Latossolos \\
D $(12-20)$ & Solos com B textural \\
E $(20-40)$ & Solos com B textural e Cambissolos \\
F (>40) & Cambissolos e Neossolos Litólicos \\
\hline Fonte: Elaborada pelos autores, conforme modelo de Andrade et al. \\
(1998) e Pinto et al. (2005) e classes de solo da Embrapa (2009).
\end{tabular}

Após delimitar as APPs hídricas e de declividade foram consideradas sob uso conflitante com o que estabelece o Código Florestal, todas as áreas que não eram de vegetação nativa presentes nas APPs das nascentes, cursos d'água e encostas com declividade superior a $45^{\circ}$ e as áreas que não eram ocupadas com culturas permanentes nas classes de $20 \%$ a $45 \%$ de declividade, conforme metodologia de Bigarella e Mazuchowski (1985), empregada por Pinto et al. (2005).

Para a identificação do uso conflitante do solo nas áreas de $20 \%$ a $45 \%$ de declividade utilizou-se uma operação condicional cruzando-se os mapas de declividade e de uso do solo e para a obtenção do mapa de uso conflitante, cruzaram-se os mapas de APPs e de uso do solo. Para quantificar os tipos de uso do solo conflitante foram cruzados os mapas de uso conflitante com o de uso atual do solo a partir da função de tabulação cruzada do SPRING.

\section{RESULTADOS}

De acordo com o mapa apresentado na figura 2, as APPs hídricas e de declividade cobrem uma área de 100,3 $\mathrm{km}^{2}$ da bacia hidrográfica da Serra da Mantiqueira, o que corresponde a $14,84 \%$ de sua área total $\left(675,6 \mathrm{~km}^{2}\right)$.
Figura 2 - Áreas de preservação permanente (APPs) hídricas e de declividade da Bacia Hidrográfica da Serra da Mantiqueira (UGRHI 1).

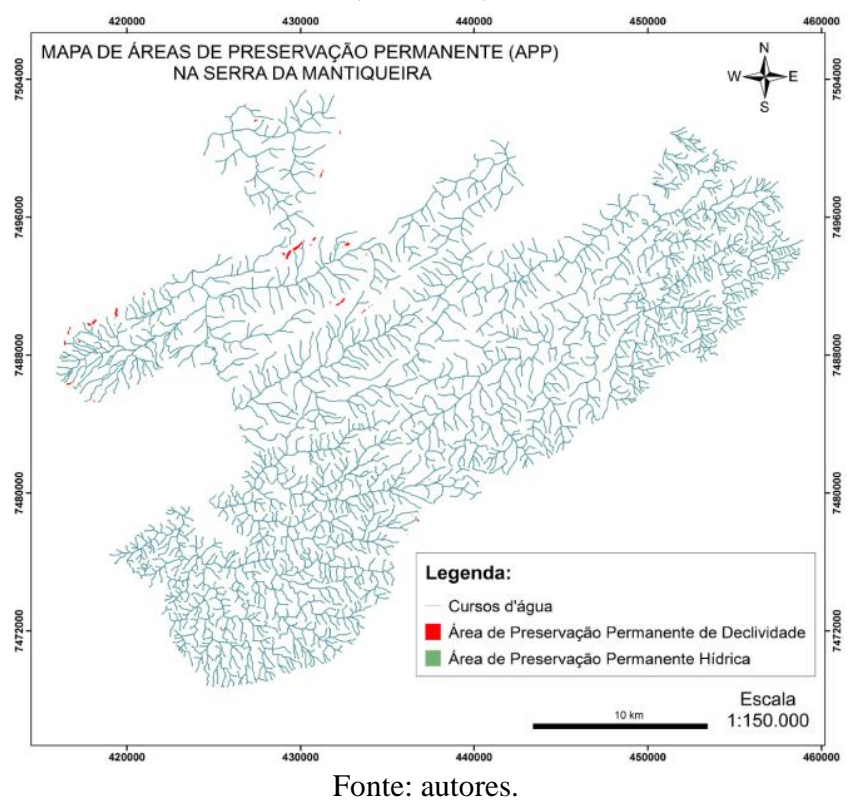

Como pode ser observado na tabela 3 , os principais usos do solo identificados nas APPs hídricas foram vegetação secundária em estágio médio $(41,58 \%)$, pastagens $(31,48 \%)$, vegetação secundária avançada $(11,49 \%)$ e reflorestamento $(5,29 \%)$ e, nas APPs de declividade, vegetação secundária em estágio médio $(71,01 \%)$, pastagens $(15,94 \%)$ e afloramento rochoso $(4,35 \%)$.

Tabela 3 - Áreas de Preservação Permanente (APPs) hídricas e de declividade da bacia da Serra da Mantiqueira - UGRHI 1.

\begin{tabular}{|c|c|c|c|c|}
\hline \multirow{2}{*}{$\begin{array}{l}\text { Uso e Ocupação do solo da } \\
\text { UGRHI } 1\end{array}$} & \multicolumn{2}{|c|}{$\begin{array}{l}\text { APPs } \\
\text { hídricas }\end{array}$} & \multicolumn{2}{|c|}{$\begin{array}{l}\text { APPs de } \\
\text { declividade }\end{array}$} \\
\hline & $\mathrm{km}^{2}$ & $\%$ & $\mathrm{~km}^{2}$ & $\%$ \\
\hline Afloramento rochoso & - & - & 0,03 & 4,35 \\
\hline $\begin{array}{l}\text { Campo natural com perturbação } \\
\text { antrópica }\end{array}$ & 1,12 & 1,12 & - & - \\
\hline $\begin{array}{l}\text { Campo natural sem perturbação } \\
\text { antrópica }\end{array}$ & 0,59 & 0,59 & - & - \\
\hline Corpo d'água & 0,12 & 0,12 & - & - \\
\hline Pastagem & 31,35 & 31,48 & 0,11 & 15,94 \\
\hline Reflorestamento & 5,27 & 5,29 & 0,01 & 1,45 \\
\hline Solo exposto & 0,01 & 0,01 & - & - \\
\hline Uso agrícola & 2,38 & 2,39 & 0,01 & 1,45 \\
\hline Araucária & 0,52 & 0,52 & - & - \\
\hline Vegetação de várzea & 0,48 & 0,48 & - & - \\
\hline $\begin{array}{l}\text { Vegetação secundária - estágio } \\
\text { avançado }\end{array}$ & 11,44 & 11,49 & 0,02 & 2,90 \\
\hline $\begin{array}{l}\text { Vegetação secundária - estágio } \\
\text { inicial }\end{array}$ & 1,21 & 1,21 & 0,02 & 2,90 \\
\hline $\begin{array}{l}\text { Vegetação secundária - estágio } \\
\text { médio }\end{array}$ & 41,41 & 41,58 & 0,49 & 71,01 \\
\hline Área urbanizada & 3,71 & 3,72 & - & - \\
\hline Total & 99,61 & 100 & 0,69 & 100 \\
\hline
\end{tabular}

Dos 43,84 $\mathrm{km}^{2}$ identificados com uso conflitante nas APPs hídricas, 71,5\% correspondem a pastagens, 12,02\% por reflorestamento, $8,46 \%$ por urbanização, $5,43 \%$ por agricultura, 2,56\% campo natural com perturbação antrópica e $0,02 \%$ com solo exposto. Nas APPs de declividade, dos $0,13 \mathrm{~km}^{2}$ identificados com usos conflitantes, $84,62 \%$ são 
ocupados por pastagens, 7,69\% por reflorestamento e 7,69\% com uso agrícola e não atendem ao que estabelece o Código Florestal brasileiro, instituído pela Lei 12.651/12 (Tabela 4).

Tabela 4 - Conflito do uso do solo nas APPs hídricas e de declividade da bacia hidrográfica da Serra da Mantiqueira UGRHI 1.

\begin{tabular}{|c|c|c|c|c|}
\hline \multirow{2}{*}{$\begin{array}{l}\text { Uso Conflitante do solo da } \\
\text { UGRHI } 1\end{array}$} & \multicolumn{2}{|c|}{$\begin{array}{l}\text { APPs } \\
\text { hídricas }\end{array}$} & \multicolumn{2}{|c|}{$\begin{array}{l}\text { APPs de } \\
\text { declividade }\end{array}$} \\
\hline & $\mathrm{km}^{2}$ & $(\%)$ & $\mathrm{km}^{2}$ & $(\%)$ \\
\hline Afloramento rochoso & - & - & - & - \\
\hline $\begin{array}{l}\text { Campo natural com } \\
\text { perturbação antrópica }\end{array}$ & 1,12 & 2,56 & - & - \\
\hline $\begin{array}{l}\text { Campo natural sem } \\
\text { perturbação antrópica }\end{array}$ & - & - & - & - \\
\hline Corpo d'água & - & - & - & - \\
\hline Pastagem & 31,35 & 71,50 & 0,11 & 84,62 \\
\hline Reflorestamento & 5,27 & 12,02 & 0,01 & 7,69 \\
\hline Solo exposto & 0,01 & 0,02 & - & - \\
\hline Uso agrícola & 2,38 & 5,43 & 0,01 & 7,69 \\
\hline Araucária & - & - & - & - \\
\hline Vegetação de várzea & - & - & - & - \\
\hline $\begin{array}{l}\text { Vegetação secundária - } \\
\text { estágio avançado }\end{array}$ & - & - & - & - \\
\hline $\begin{array}{l}\text { Vegetação secundária - } \\
\text { estágio inicial }\end{array}$ & - & - & - & - \\
\hline $\begin{array}{l}\text { Vegetação secundária - } \\
\text { estágio médio }\end{array}$ & - & - & - & - \\
\hline Área urbanizada & 3,71 & 8,46 & - & - \\
\hline Total & 43,84 & 100 & 0,13 & 100 \\
\hline
\end{tabular}

Verificou-se que os usos conflitantes relacionados às APPs ocupam 43,97\% de toda a área delimitada como APPs, dos quais somente $0,13 \%$ estão em APPs de declividade (Figura 3).

Figura 3. Conflito de uso e ocupação do solo em APPs hídricas e de declividade da bacia hidrográfica da Serra da Mantiqueira UGRHI 1.

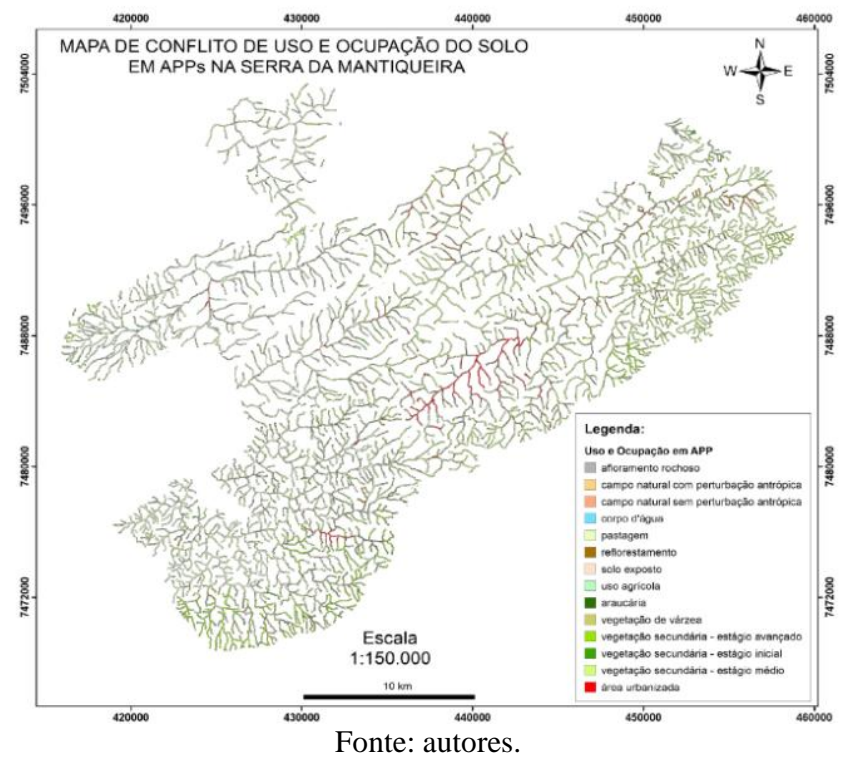

Na bacia hidrográfica da Serra da Mantiqueira, as pastagens representam o maior percentual de uso conflitante nas APPs hídricas e de declividade, evidenciando a destruição dos fragmentos florestais o que pode interferir diretamente no ciclo hidrológico, alterando o processo de infiltração de água nos solos e contribuir para a ocorrência dos processos erosivos e, consequentemente, para o assoreamento dos cursos d'água e escassez de água na bacia. É preciso destacar que a bacia hidrográfica da Serra da Mantiqueira apresenta cerca de $80 \%$ de sua área sobre relevo forte ondulado a montanhoso e uma precipitação total média anual superior a $1.500 \mathrm{~mm}$, fatores que facilitam o escoamento superficial e aumenta a necessidade de proteção das APPs.

Pinto et al. (2005) também verificaram que as pastagens representaram o uso predominante $(62,41 \%)$, na bacia hidrográfica do Ribeirão Santa Cruz, em Lavras (MG), sendo responsável por $84,57 \%$ dos $11,04 \%$ de uso conflitante nas APPs. Estes autores relataram que mais de $70 \%$ das APPs de declividade estavam sendo ocupadas por pastagem e que, apesar destas APPs representarem uma área restrita da bacia, são de extrema importância para a conservação do solo e da água. Neste sentido, Adami et al. (2012) aplicaram métodos de análise multicriteriais em SIG para a priorização de APPs visando à recuperação da vegetação, estabelecendo prioridade para as áreas de maior declividade, solos rasos e suscetíveis aos processos erosivos.

No caso da bacia da Serra da Mantiqueira é imprescindível a elaboração de um plano de recomposição vegetal das APPs, considerando que o uso inadequado do solo pode refletir na quantidade e na qualidade dos recursos naturais desta bacia.

\section{CONCLUSÃO}

As ferramentas do Sistema de Informações Geográficas (SIG) foram eficientes para delimitar espacialmente as APPs e para identificar e quantificar os usos do solo da bacia hidrográfica da Serra da Mantiqueira UGRHI 1, que não atendem ao Código Florestal.

As APPs ocupam uma área de $100,3 \mathrm{~km}^{2}$, que representam 14,84\% da área total da bacia hidrográfica da Serra da Mantiqueira - UGRHI 1, sendo que 43,97 $\mathrm{km}^{2}$ correspondem a usos conflitantes, ocupados principalmente por pastagens.

Dos 43,97 km² de APPs sob uso conflitante, 43,84 km² correspondem a APPs hídricas e estão sendo explorados de forma indevida, com $71,51 \%$ ocupados por pastagens, $12,02 \%$ por reflorestamento, $8,46 \%$ por urbanização, $5,43 \%$ por agricultura, $2,56 \%$ por campo natural com perturbação antrópica e $0,02 \%$ com solo exposto. Dos $0,13 \mathrm{~km}^{2}$ de uso conflitante em APPs de declividade, 84,62\% estão ocupados por pastagens, $7,49 \%$ por reflorestamento e $7,49 \%$ por agricultura.

A elaboração de um plano de recomposição vegetal das APPs da bacia hidrográfica da Serra da Mantiqueira UGRHI 1, é imprescindível e deve fazer parte da pauta das políticas públicas.

\section{REFERÊNCIAS BIBLIOGRÁFICAS}

ADAMI, S. F.; FRANCISCO, C. E. S.; COELHO, R. M.; TORRES, R. B. Análise multicriterial aplicada à priorização para recuperação de áreas de preservação permanente: uma implantação em Sistemas de Informações Geográficas. Bol. Camp. Geog., v.2, n.3, 2012.

ANDRADE, H.; ALVES, H. M. R.; VIEIRA, T. G. C.; RESENDE, R. J. T. P.; ESTEVES, D. R.; ROSA, E. R. Diagnóstico ambiental do Município de Lavras com base 
em dados do meio físico: III - Estratificação em classes de declive. In: CONGRESSO BRASILEIRO DE ENGENHARIA AGRÍCOLA, 27. Poços de Caldas, 1998. Anais... Lavras, Sociedade Brasileira de Engenharia Agrícola, 1998. v.4, p.356-358.

BIGARELLA， J. J.; MAZUCHOWSKI， J. Z. Visão integrada da problemática da Erosão. In: SIMPÓSIO NACIONAL DE CONTROLE DE EROSÃO, 3., Maringá, 1985. Anais...Curitiba, Associação Brasileira de Geologia de Engenharia/Associação de Defesa e Educação Ambiental, 1985. p.372.

BRASIL. Lei no 9.605, de 12 de fevereiro de 1998. Dispõe sobre as sanções penais e administrativas derivadas de condutas e atividades lesivas ao meio ambiente, e dá outras providências. Brasília, 1998.

BRASIL. Lei $\mathbf{n}^{\circ} \mathbf{1 2 . 6 5 1}$, de 25 de maio de 2012. Dispõe sobre a proteção da vegetação nativa; altera as Leis nos 6.938, de 31 de agosto de 1981, 9.393, de 19 de dezembro de 1996, e 11.428, de 22 de dezembro de 2006; revoga as Leis nos 4.771 , de 15 de setembro de 1965 , e 7.754 , de 14 de abril de 1989, e a Medida Provisória no 2.166-67, de 24 de agosto de 2001; e dá outras providências. Brasília, 2012.

CÂMARA, G.; SOUZA, R. C. M.; FREITAS, U. M.; GARRIDO, J. SPRING: Integrating remote sensing and GIS by object-oriented data modelling. v.20, n.3. Amsterdam, Computers \& Graphics, 1996. p.395-403.

COMITÊ DAS BACIAS HIDROGRÁFICAS DA SERRA DA MANTIQUEIRA - CBH-SM. Plano de Bacias Hidrográficas da Serra da Mantiqueira (UGRHI-1). São Paulo, 2012. p.354.

COOPERATIVA DE SERVIÇOS E PESQUISAS TECNOLÓGICAS E INDUSTRIAIS - CPTI. Relatório Técnico Final do Plano das Bacias Hidrográficas da Unidade de Gerenciamento de Recursos Hídricos da Serra da Mantiqueira - UGRHI 1. Relatório Técnico CPTI, 571, 2012.

DE BIASE, M. A. Carta clinográfica: os métodos de representação e sua confecção. Revista de geografia, 6:4560, 1993.

EMPRESA BRASILEIRA DE PESQUISA AGROPECUÁRIA - EMBRAPA. Sistema Brasileiro de Classificação de Solos. Centro Nacional de Pesquisa de Solos. Rio de Janeiro, 2009. 2ed. 412p.

FERREIRA, M. C. Proposta para o uso e manejo sustentável da bacia hidrográfica do ribeirão Guaratinguetá/SP. Guaratinguetá, Universidade Estadual Paulista "Julio de Mesquita Filho", 2011. 124p. (Dissertação de Mestrado)

INSTITUTO BRASILEIRO DE GEOGRAFIA E ESTATÍSTICA - IBGE. Rede de Drenagem do Estado de São Paulo. 2008.

KRONKA, F.J.N.; M.A. NALON, C.K. MATSUKUMA, M.M. KANASHIRO, M.S.S. YWANE, M. PAVÃO, G. DURIGAN, L.M.P.R. LIMA, J.R. GUILLAUMON, J.B. BAITELLO, S.C. BORGO, L.A. MANETTI, A.M.F. BARRADAS, J.C. FUKUDA, C.N. SHIDA, C.H.B. MONTEIRO, A.A.S. PONTINHA, G.G. ANDRADE, O. BARBOSA, A.P. SOARES, H.T.Z. COUTO, C.A. JOLY.
2005. Inventário Florestal da Vegetação Natural do Estado de São Paulo. São Paulo: Imprensa Oficial. 200 p.

ORGANIZAÇÃO DOS ESTADOS AMERICANOS OEA/SECRETARIA NACIONAL DE RECURSOS HÍDRICOS - SRH. Caderno Regional da Região Hidrográfica do Paraná. Relatório Parcial RT-3, 2005.

PINTO L. V. A.; FERREIRA, E.; BOTELHO, S. A.; DAVIDE, A. C. Caracterização física da bacia hidrográfica do Ribeirão Santa Cruz, Lavras, MG e uso conflitante da terra em suas áreas de preservação permanente. Cerne, 11:49-60, 2005.

SANTOS, A. M. D. Bacias Hidrográficas do município de Campos do Jordão: florestamento compensatório visando retenção de água no solo. Taubaté, Universidade de Taubaté, 2009. 135p. (Dissertação de Mestrado)

SECRETARIA DE ESTADO DE MEIO AMBIENTE SMA/INSTITUTO FLORESTAL DE SÃO PAULO - IF. Base georreferenciada para o mapeamento do uso e ocupação da terra e das unidades de conservação da bacia hidrográfica da Mantiqueira, São Paulo, 2008.

SECRETARIA DO MEIO AMBIENTE - SMA COORDENADORIA DE PLANEJAMENTO AMBIENTAL - CPLA. Meio ambiente paulista: relatório de qualidade ambiental 2014. 1a ed. São Paulo, 2014.

UNITED NATIONS EDUCATIONAL, SCIENTIFIC AND CULTURAL ORGANIZATION - UNESCO. Biosphere Reserve Information. Brazil. Mata Atlântica. 2011. Disponível em: <http://www.unesco.org/mabdb/br/brdir/directory/biores.asp ?mode $=$ all $\&$ code $=$ BRA+01 $>$ Accesso em: 15 nov. 2018

VAlERIANO, M. M.; ROSSETTI, D. F. Topodata: Brazilian full coverage refinement of SRTM data. Applied Geography (Sevenoaks), v.32, p.300-309, 2011.

\section{COPYRIGHT}

Direitos autorais: $\mathrm{O}(\mathrm{s})$ autor(es) é(são) o(s) único(s) responsável(is) pelo material incluído no artigo. 


\author{
Volume $14-\mathrm{N}^{\mathrm{o}} 159$ - Março/2019. \\ XL International Sodebras Congress \\ 10 a 12 de dezembro de 2018 - Vitória - ES.
}

\title{
DIAGNÓSTICO E PROPOSIÇÃO DE MEDIDAS PARA O CONTROLE DAS PERDAS DE ÁGUA NO SISTEMA DE ABASTECIMENTO DE GUARATINGUETÁ (SP)
}

\section{DIAGNOSIS AND PROPOSAL OF MEASURES FOR CONTROLLING WATER LOSSES IN THE SUPPLY SYSTEM GUARATINGUETÁ (SP)}

\author{
YOSHIMOTO, M. K. ${ }^{1}$; TRANNIN, I. C. B. ${ }^{2}$; \\ ${ }^{1 ; 2}$ FACULDADE DE ENGENHARIA DE GUARATINGUETÁ, UNIVERSIDADE \\ ESTADUAL PAULISTA “JÚLIO DE MESQUISTA FILHO”
}

monica.yoshimoto@gmail.com; isatrannin@feg.unesp.br

\begin{abstract}
Resumo - Diante da crise hídrica que o Brasil tem enfrentado nos últimos anos, a população deve adotar hábitos sustentáveis de consumo e as empresas de abastecimento precisam combater as perdas de água potável no sistema de distribuição. A perda econômica corresponde ao valor agregado ao produto água $e$ inclui custos com captação, tratamento e distribuição, resultando em prejuizo e menor disponibilidade de recursos financeiros para as empresas de saneamento investirem em soluções ambientalmente corretas. Este estudo diagnosticou o sistema de distribuição de água do município de Guaratinguetá (SP), para propor medidas de combate às perdas. As principais medidas propostas foram o monitoramento de perdas através de macro $e$ micromedidores, o planejamento para substituição das tubulações antigas e a conscientização da empresa e da população para o uso sustentável da água.

Palavras-chave:Recursos hídricos. Crise hídrica. Distribuição de água.
\end{abstract}

\begin{abstract}
In face of the water crisis that Brazil has experienced in recent years, the population must adopt sustainable consumption habits and the supply companies need to combat the losses of potable water in the distribution systems. The economic loss corresponds to the added value to water product and includes costs of catchment, treatment and distribution, resulting in reduction of financial resources for sanitation companies to invest in environmentally correct solutions. This study diagnosed the water distribution system of Guaratinguetá city in São Paulo State to propose measures to combat water losses. The main measures proposed were the monitoring of losses through macro and micro measurers, the planning to replace old pipes and the awareness of the company and the population for the sustainable use of water.
\end{abstract}

Keywords: Water resources. Water crisis. Water supply.

\section{INTRODUÇÃO}

No VIII Fórum Mundial da Água, realizado em março de 2018, foi discutido o fato do Brasil possuir $12 \%$ das reservas de água doce disponíveis no mundo e, ainda assim, alguns municípios brasileiros enfrentarem problemas de abastecimento público em períodos de estiagem.

Em 2014 o Brasil enfrentou uma das maiores crises hídricas de sua história e, de acordo com a Agência Nacional das Águas - ANA, para a região sudeste, essa foi a pior crise dos últimos 84 anos (ANA, 2015). Nos anos posteriores, os efeitos da crise hídrica brasileira, associados aos problemas de falta de infraestrutura e de planejamento, geraram sérios impactos ao abastecimento público, principalmente na região metropolitana de São Paulo.

O sistema de abastecimento público é a solução coletiva para a distribuição de água em quantidade e qualidade para o consumo humano, sendo constituído de unidades de captação, estações de tratamento, adutoras, estações elevatórias, reservatórios e redes de distribuição. O Internacional Benchmarking Network for Water and Sanitation Utilities, relatou que o Brasil perde cerca de 39\% de sua água tratada no sistema de distribuição pública, superando países como Vietnã, México, Rússia e China, que perdem, respectivamente, $31 \%, 24 \%, 23 \%$ e $22 \%$ (IBNET, 2011).

A água tratada é perdida no sistema de abastecimento, quando não chega ao consumidor. De acordo com Santos (2008), a perda de água pode ser real ou física, devido a vazamentos visíveis ou não visíveis nas adutoras, redes/ramais de distribuição e extravasamentos em reservatórios setoriais. No entanto, essa perda nem sempre é física. Do ponto de vista empresarial, se um produto for entregue e por alguma ineficiência não for faturado (como é o caso de fraudes, ligações clandestinas e erros de medição), os custos intrínsecos para sua produção e transporte acarretarão em prejuízos para a companhia. Portanto, além da perda física, tem-se o prejuízo causado pelos custos relacionados ao aspecto comercial do serviço prestado, que correspondem às perdas aparentes de água.

Dessa forma, um elevado índice de perdas de água indica redução no faturamento das empresas responsáveis pelo abastecimento público e, consequentemente, a diminuição da capacidade de investimento e de obtenção de financiamentos. Além disso, a perda de água gera danos ambientais devido ao esgotamento de reservatórios, o que obriga as empresas de saneamento a explorarem novos mananciais (ABES, 2013). Assim, o gerenciamento e a adoção de medidas de combate às perdas de água tratada nos sistemas de distribuição pública são imprescindíveis para o uso sustentável dos recursos hídricos. 
Tsutiya (2006) afirma que o sucesso das ações contínuas das companhias de saneamento para a redução das perdas de água tratada resulta em melhor performance econômica da companhia, revertendo tal benefício em tarifas mais baixas aos clientes e em postergação de novos investimentos na ampliação dos sistemas de produção, adução e reservação de água.

Neste estudo foi realizado o diagnóstico do sistema de distribuição de água no município de Guaratinguetá (SP), executado pela Companhia de Serviços de Água, Esgoto e Resíduos de Guaratinguetá (SAEG) e a análise do potencial de perdas, para a proposição de medidas mitigadoras e de conscientização da importância da atuação das políticas públicas na otimização do abastecimento público, para que os recursos hídricos sejam utilizados de forma sustentável.

\section{METODOLOGIA}

\section{1 - Localização e caracterização da Companhia de Abastecimento de Água de Guaratinguetá - SAEG}

Guaratinguetá é um município do Estado de São Paulo, localizado na região do Vale do Paraíba, possui importância turística, industrial e comercial e, em 2015, contava com 115 mil habitantes (IBGE, 2015). Com uma área urbana aproximada de $13,5 \mathrm{~km}^{2}$, este município, é dividido em cinco regiões:

- Zona Norte: Parque das Alamedas, Mirante, Portal das Colinas, Parque do Sol, Beira Rio I e II, Jardim do Vale I e II, Jardim Esperança, Nova Guará, Vila Paraíba, Jardim Pérola, entre outros menores.

- Zona Sul: São Benedito, Campinho, Santa Rita, Vila Santa Rita, Campo do Galvão, Pedreira, Chácara Selles, Jardim Tamandaré, Vila Santa Maria, Residencial Augusto Filippo, Jardim David Fernandes Coelho, entre outros menores.

- Zona Oeste: Pedregulho, Parque das Árvores, Jardim Rony, Vila Mollica, Vila Indiana, Parque São Francisco, Jardim Independência, Vila Comendador, Matadouro, Parque Santa Clara, Vila Municipal I e II, Vila dos Funcionários, entre outros menores.

- Zona Leste: Vila Rosa, Vila Guará, Vila Santa Mônica, Vila Angelina, Chácaras Paturi, Clube dos 500, Jardim Primavera, Nova República, entre outros menores.

- Centro: centro histórico e centro expandido.

A SAEG é responsável pelo abastecimento de água, esgotamento sanitário e manejo de resíduos do município. Possui uma economia mista, com sede e foro em Guaratinguetá.

Em 2015, a SAEG apresentou os seguintes indicadores de atendimento da população urbana de Guaratinguetá: $100 \%$ de abastecimento de água, com $597 \mathrm{~km}$ de rede; $91,7 \%$ de coleta e afastamento de esgoto, com $459 \mathrm{~km}$ de rede e $19 \%$ de tratamento de esgoto; $100 \%$ de coleta de resíduos sólidos urbanos, sendo $96 \%$ destes resíduos destinados a aterro sanitário e $50 \%$ da população atendida por coleta seletiva (SAEG, 2015).

Na principal Estação de Tratamento de Água (ETA) do município, mantida pelos ribeirões Guaratinguetá e Lemes, a água tratada abastece $87,17 \%$ da população, sendo o restante abastecido por poços artesianos e ETAs Compactas (SAEG, 2015).

De acordo com dados fornecidos pela Companhia, sua capacidade de produção no ano de 2015 era de $409 \mathrm{~L} \mathrm{~s}^{-1}$, o equivalente a $1.472,40 \mathrm{~m}^{3} \mathrm{~h}^{-1}$; com regime de operação de $21 \mathrm{~h} \mathrm{dia}^{-1}$; produzindo, em média, $30.920,40 \mathrm{~m}^{3} \mathrm{dia}^{-1}$.

\section{2 - Sistema municipal de abastecimento de água}

O sistema de abastecimento de água do município de Guaratinguetá adotado pela SAEG está em conformidade com a estrutura esquematizada na figura 1 , descrita a seguir.

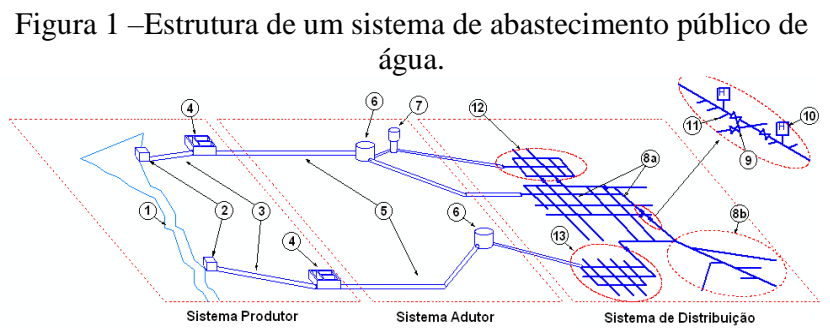

1. Manancial; 2.Captação; 3. Adutora de água bruta; 4. Estação de Tratamento de Água -ETA; 5. Adutora; 6. Reservatório superficial; 7. Reservatório elevado (Torre); 8. Rede de distribuição: (a) em anéis, (b) ramificada; 9. Válvula de isolamento (registro); 10. Hidrante; 11. Ramal domiciliar; 12. Zona alta; 13. Zona baixa.

Fonte: Misiunas (2005).

Captação: durante a realização desse estudo, o município era abastecido majoritariamente pela água captada do Ribeirão Guaratinguetá e, além deste, pela captação no Ribeirão Lemes. Estas duas captações se somam na ETA principal do sistema, localizada na sede da SAEG, na Rua Xavantes, 1880, Jardim Aeroporto. Além destes cursos d'água superficiais, o abastecimento público é complementado por seis poços artesianos implantados nos bairros: Comerciários, João Daniel, Santa Clara, Engenho d'Água, Vila Ofélia e Montes Verdes. O município conta também com duas ETAs compactas nos bairros, Rocinha e Pedrinhas.

Reservatórios: o sistema de abastecimento do município de Guaratinguetá contava com 29 Centros de Reservação (CR) no ano de 2015.

Macromedidores: em 2015, o sistema de distribuição de água do município contava com 12 macromedidores, localizados nos bairros: Engenho d'Água, Rocinha, Vila Ofélia, Santa Clara, Santa Luzia, São Manoel, João Daniel, Resedas, dois medidores no Pedregulho e dois nas Pedrinhas.

\section{3- Metodologia para a análise das perdas de água}

O diagnóstico qualitativo foi realizado junto ao setor de Combate a Perdas de Água da SAEG, por meio de levantamentos de campo no bairro Santa Luzia, selecionado para a análise, em agosto de 2015, com o objetivo de obter informações sobre o sistema de distribuição de água e a detecção de pontos de vazamento.

Para a detecção de vazamentos foi utilizada a haste de escuta mecânica, em cada residência deste bairro. Os funcionários responsáveis por este trabalho de campo foram treinados para identificar quando o som do equipamento correspondia a um provável vazamento. Quando havia suspeita de vazamento era utilizado o geofone, que também se baseia na acústica, mas apresenta maior sensibilidade e facilidade de locomoção. Desta forma, o vazamento pode ser localizado e consertado.

Para o diagnóstico quantitativo das perdas de água foi comparado o volume de água que saiu do reservatório que abastece o bairro Santa Luzia com o volume que chegou às residências. $\mathrm{O}$ volume de água disponibilizado foi medido 
por meio de um macromedidor disposto na saída do reservatório. Alguns macromedidores possuem sistemas automatizados que registram nos dias determinados o volume disponibilizado. No caso da SAEG, a leitura era feita por funcionários da Equipe de Combate às Perdas, que anotavam o valor no mesmo dia em que eram feitas as leituras dos hidrômetros das residências. $\mathrm{O}$ volume de água tratada que chegou às residências, gerado pela micromedição, foi obtido pelo Setor Comercial da SAEG, por meio do somatório dos valores obtidos dos hidrômetros dos usuários.

A análise de custo da exploração e do tratamento de água pela SAEG, em Guaratinguetá, teve como base os Indicadores Econômicos, definidos pelo Sistema Nacional de Informações sobre Saneamento (SNIS, 2014), conforme a equação (1):

$I N 026=F N 015 /(A G 011+E S 007)$

Em que:

IN026: Despesa de exploração por $\mathrm{m}^{3}$ faturado;

FN015: Despesas de exploração (DEX);

AG011: Volume de água faturado;

ES007: Volume de esgoto faturado.

O fator FN015 (DEX) corresponde à:

- Despesa com pessoal próprio;

- Despesa com produtos químicos;

- Despesa com energia elétrica;

- Despesa com serviço de terceiro;

- Água importada;

- Despesas fiscais ou tributárias computadas na DEX;

- Outras despesas de exploração;

- Esgoto exportado.

Com o valor obtido de IN026, foi possível estimar os custos mensais aproximados da empresa, considerando o Volume Micromedido (VMicro) e a média nacional de perdas no sistema de distribuição de 39\% (IBNET, 2011).

Inicialmente foi estimado o Volume Macromedido (VMacro) e, em seguida, o Volume de Perdas (Vp), utilizando a equação (2):

VMicro = VMacro - 0,39 VMacro $=0,61$ VMacro

De acordo com a Equação (2) para que VMacro fique em função de VMicro, obteve-se a equação (3):

VMacro $=$ VMicro/0,61

E, com os Volumes Macro e Micromedidos, calculouse o Volume de Perdas (Vp):

Vp = VMacro - VMicro

O custo mensal aproximado da empresa com as perdas no sistema, multiplicando o Volume de Perdas (Vp) pelo Índice de Despesa de exploração por $\mathrm{m}^{3}$ faturado (IN026).

\section{RESULTADOS}

\section{1 - Classificação do sistema de abastecimento de água de Guaratinguetá}

De acordo com dados obtidos da FUNASA (2014), o município de Guaratinguetá foi enquadrado na Classe 03 de sistema de abastecimento de água, por possuir a população urbana entre 100 e 500 mil habitantes, sendo recomendado o Sistema de Macromedição Quantitativo Mínimo, composto por:

- Macromedidor de Vazão para o Sistema de Produção: a instalação de um macromedidor deve ser feita na saída da caixa de reunião (Reunião das linhas adutoras do Ribeirão Guaratinguetá e Ribeirão Lemes). Para os seis poços artesianos, as medições devem ser realizadas em cada uma dessas captações de água.

- Macromedidor de Vazão para o Sistema de Distribuição: é prioritária a medição nas entradas de todos os reservatórios de distribuição, sendo recomendada a instalação de macromedidores nos 29 reservatórios distribuídos no município.

- Macromedidor de Pressão para o Sistema de Produção e Distribuição: deve ser instalado nos pontos de medição não permanentes na tubulação de sucção e na de descarga, com a instalação do medidor o mais próximo possível dos flanges. Além disso, recomenda-se localizar em cada zona de pressão, pontos de medição não permanentes de pressão nos trechos mais desfavoráveis da rede (ponto de pressão estática máxima e de dinâmica mínima). Recomenda-se a instalação de macromedidores de pressão na entrada e na saída de Válvulas Redutoras de Pressão (VRP), quando estas fizerem parte do sistema.

Apesar das recomendações da FUNASA (2014), até o momento da realização deste estudo, em 2015, não havia levantamento da localização e necessidade de instalação dos macromedidores nos referidos pontos. Embora tenha sido recomendada a instalação de 36 macromedidores, além do estudo dos pontos desfavoráveis da rede, somente 12 aparelhos haviam sido efetivamente instalados.

\section{2 - Custos do tratamento de água}

O custo para o tratamento de água na ETA principal de Guaratinguetá incluiu itens de despesa de exploração, abrangendo desde a energia elétrica consumida no sistema de abastecimento até a despesa com funcionários.

Utilizando os dados do SNIS (2014), o IN026, para a SAEG no ano de 2015, foi calculado conforme a Equação (1) e os valores obtidos para o fator FN015foram: Despesa com pessoal próprio: $\mathrm{R}$ \$ 6.092.911,93

Despesa com produtos químicos: $\mathrm{R} \$ 763.371,85$

Despesa com energia elétrica: $\mathrm{R} \$ 2.065 .421,46$

Despesa com serviço de terceiros: $\mathrm{R} \$ 11.011 .876,41$

Água importada: R $\$ 0,00$

Despesas fiscais ou tributárias computadas na DEX: R\$ $799.288,37$

Outras despesas de exploração: R 0,00

Esgoto exportado: R $\$ 0,00$

A soma dessas despesas resultou em FN015 de $\mathrm{R} \$ 20.732 .870,02$. Além dessas despesas a SAEG obteve os volumes faturados de água (AG011) e esgoto (ES007) de $8.523 .090,00 \mathrm{~m}^{-3}$ e $8.069 .700,00 \mathrm{~m}^{-3}$, respectivamente.

Com a aplicação da Equação (1), verificou-se que o IN026, ou seja, a despesa para a exploração da água pela SAEG foi de $\mathrm{R} \$ 1,25 \mathrm{~m}^{-3}$. 
De acordo com os dados apresentados na tabela 1 constatou-se que, no período avaliado, o custo para a exploração de água no município de Guaratinguetá de $\mathrm{R} \$$ $1,25 \mathrm{~m}^{-3}$ foi próximo aos custos médios de outros municípios do Vale do Paraíba, de $\mathrm{R} \$ 1,52 \mathrm{~m}^{-3}$, cujo número de habitantes e consumo per capita de água são semelhantes, cerca de $170 \mathrm{~L} \mathrm{hab}^{-1} \mathrm{dia}^{-1}$. Também foi observado que a SABESP apresentou o maior valor de indicador de despesa de exploração, enquanto o menor valor foi alcançado pela SAAE, de Jacareí.

Tabela 1 - Despesas com exploração de água (custo por $\mathrm{m}^{-3}$ ) dos municípios do Vale do Paraíba (SP).

\begin{tabular}{lcccc}
\hline Município & Empresa & $\begin{array}{c}\text { Mil } \\
\text { hab. }\end{array}$ & $\begin{array}{c}\text { Consumo } \\
\text { per capta } \\
\text { L hab }^{-1} \mathbf{d i a}^{-1}\end{array}$ & $\begin{array}{c}\text { Despesa } \\
\mathbf{R} \mathbf{\$} \mathbf{~ m}^{-3}\end{array}$ \\
\hline Guaratinguetá & SAEG & 115 & 169,70 & 1,25 \\
Caçapava & SABESP & 91 & 173,86 & 1,91 \\
Jacareí & SAAE & 187 & 198,47 & 1,15 \\
Lorena & SABESP & 87 & 155,73 & 1,46 \\
Pindamonhangaba & SABESP & 103 & 156,14 & 1,84 \\
\hline
\end{tabular}

Fonte: SNIS (2014)

\section{3 - Diagnóstico do setor de combate às perdas}

O setor de Combate às Perdas de Água da SAEG ainda estava no início de suas atividades em 2015. A aparelhagem e os equipamentos necessários haviam sido adquiridos, entretanto, eram subutilizados pela equipe.

As informações sobre as características das tubulações, como extensão, idade, material e diâmetro, não foram fornecidas para o presente estudo.

A pesquisa de campo realizada no bairro Santa Luzia, em agosto de 2015 e a análise dos dados de Macro e Micromedição disponibilizados, possibilitou diagnosticar a situação do sistema de distribuição de água do setor Santa Luzia.

O primeiro problema encontrado foi no macromedidor, pois analisando os volumes de água dos meses de abril, maio, junho e julho do ano de 2015, verificou-se que os valores registrados foram quatro vezes inferiores à somatória dos micromedidores, ou seja, o volume de água consumido foi quatro vezes maior que o volume fornecido, como pode ser observado na tabela 2 . Esse resultado indicou que o macromedidor utilizado apresentava defeito, o que pode ser devido ao elevado tempo de uso ou ao mau dimensionamento

Tabela 2 - Volumes Macro e Micromedidos de água no Bairro Santa Luzia, em Guaratinguetá

\begin{tabular}{|c|c|c|}
\hline \multirow[t]{2}{*}{ Mês } & Macromedição & Micromedição \\
\hline & \multicolumn{2}{|c|}{ 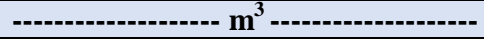 } \\
\hline Abril & 4579 & 15211 \\
\hline Maio & 3790 & 15487 \\
\hline Junho & 3622 & 15121 \\
\hline Julho & 3813 & 15343 \\
\hline
\end{tabular}

Fonte: SAEG (2015)

Para a estimativa das perdas de água no Bairro Santa Luzia, considerando a média brasileira de perda, de 39\%, e aplicando as equações (3) e (4), foram obtidos os volumes de perdas $(\mathrm{Vp})$ mensais apresentados na Tabela 3.
Tabela 3 - Volumes perdidos de água tratada no sistema de distribuição da SAEG, no Bairro Santa Luzia, em Guaratinguetá.

\begin{tabular}{|c|c|c|}
\hline \multirow[t]{2}{*}{ Mês } & $\begin{array}{c}\text { Volume } \\
\text { Micromedido }\end{array}$ & $\begin{array}{c}\text { Volume de } \\
\text { Perdas (VP) }\end{array}$ \\
\hline & \multicolumn{2}{|c|}{ 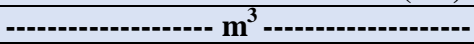 } \\
\hline Abril & 15211 & 9725,07 \\
\hline Maio & 15487 & 9901,52 \\
\hline Junho & 15121 & 9667,52 \\
\hline Julho & 15343 & 9809,46 \\
\hline
\end{tabular}

Fonte: autoras.

Considerando o Volume de Perda médio de 9.775,89 $\mathrm{m}^{3}$ mês ${ }^{-1}$ de água e aplicando o indicador de despesa de exploração IN026 = R $\$ 1,25 \mathrm{~m}^{-3}$, verificou-se que, somente no bairro Santa Luzia, o prejuízo devido à perda de água foi da ordem de R\$12.219,86 por mês. Estendendo essa estimativa para um ano, as perdas de água no sistema de abastecimento, podem resultar em um prejuízo para a SAEG de $\mathrm{R} \$ 146.638,32$.

Santos (2008) propôs a adequação do sistema de distribuição de água do setor Interlagos, no município de São Paulo, sob a responsabilidade da SABESP. Para isso, o autor caracterizou os consumos residencial, comercial e industrial e a infraestrutura da rede, considerando o diâmetro, o material, a extensão e a idade das tubulações. Com essa base de dados foi calculado o volume total macromedido em um ano, que corresponde ao ponto de partida para um estudo de controle de perdas de água no sistema de distribuição. Com a metodologia proposta para o combate às perdas d'água, que inclui instalação, substituição e monitoramento de válvulas redutoras de pressão, reativação de ligações inativas, troca de hidrômetros e mapeamento e conserto de vazamentos; esse autor estimou uma redução de 9\% da perda de água em 105 dias de operação.

No presente estudo, durante o levantamento sobre as perdas de água em algumas ruas do bairro Santa Luzia, foi verificado que na grande maioria das residências, os hidrômetros foram dispostos do lado interno e com muro fechado, dificultando a leitura dos dados. Além disso, muitos moradores estavam ausentes ou não abriram o portão para a equipe de controle de perdas de água da SAEG. Portanto, a visualização do medidor e, consequentemente, o levantamento dos pontos de vazamento, só foi realizado quando havia alguém em casa, o que impossibilitou a execução do trabalho de forma eficaz.

O diagnóstico quantitativo das perdas de água no sistema de distribuição da SAEG também foi dificultado por vários fatores. Entre estes, vale destacar que o tempo de análise foi pequeno, porque a coleta dos dados registrados pelos macromedidores foi iniciada somente após a instalação destes equipamentos, em março de 2015. Além disso, os maiores bairros de Guaratinguetá, que possuem volume macromedido e contam com tubulações mais antigas e mais propícias a vazamentos são os bairros Pedregulho e Santa Luzia, mas em ambos, os macromedidores apresentaram defeitos. Por outro lado, bairros como a Vila Ofélia, abastecidos por poço artesiano, não apresentam potencial de perda significativa de água, porque são contemplados com sistema de abastecimento fechado, não possuem grandes extensões, o índice de fraudes é baixo e contam com tubulação relativamente nova.

O setor de combate a perdas de água da SAEG possui funcionários capacitados por cursos certificados de controle 
e combate às perdas e equipamentos de pesquisa de vazamentos adequados. O que falta é a manutenção dos equipamentos, como macromedidores, que possibilitem o cálculo da diferença entre os volumes macromedidos e micromedidos, necessário para constatar a ocorrência de problemas no sistema.

Vale destacar que a perda de água no sistema de distribuição municipal é um assunto relativamente novo e não possui obrigatoriedade e fiscalização por parte do governo e, mesmo que existam projetos de modernização dos sistemas de abastecimento, cabe à própria empresa decidir se é importante ou não o investimento no combate às perdas de água.

\section{4 - Proposição de medidas de combate às perdas}

Como primeira medida proposta para o controle de perdas de água, é a medição dos volumes de água do sistema, pois apenas dessa forma é possível constatar o problema. Para um município como Guaratinguetá, com sistema de abastecimento de água classe 3 recomenda-se:

- Instalação de macromedidor na saída da caixa de reunião das linhas adutoras de água bruta na ETA;

- Instalação de macromedidor na entrada de todos os reservatórios de distribuição;

- Mudança dos hidrômetros residenciais para a parte frontal da casa, com proteção e lacre para evitar ligações clandestinas e fraudes;

- Monitoramento dos macromedidores instalados e conserto ou substituição dos que foram constatados defeituosos, como os dos bairros Santa Luzia e Pedregulho;

- Realizar pesquisas de vazamento nas ruas onde forem verificadas perdas significativas de água, procurando sempre uma eficiência nos consertos no quesito agilidade e qualidade do reparo.

- Realizar estudos de viabilidade para estabelecer novos Distritos de Medição e Controle;

- Aumentar a setorização do sistema e possibilitar a instalação de válvulas de redução de pressão;

- Substituir hidrômetros e mapear os vazamentos, como foi realizado no trabalho de Santos (2008)

A substituição de tubulações mal dimensionadas, com material inadequado ou com idade acima da recomendada, pode ser realizada seguindo a metodologia proposta por Sarzedas (2009), aplicada à Região Metropolitana de São Paulo. Este autor abordou itens importantes, como a taxa de fraturas em tubulações no período de onze anos e a variação mensal dos vazamentos reparados durante cinco anos, sendo verificado maior número de vazamentos nos meses de inverno. Também quantificou os vazamentos reparados por faixa de diâmetro, demonstrando que quanto menor o diâmetro, maior a ocorrência de vazamentos. Avaliou a taxa de quebra por década de implantação, por faixa de pressão da água, por material inadequado usado na tubulação, onde o cimento amianto foi o que apresentou maior taxa de quebra, apesar de pouco utilizado (2,7\% na região avaliada) e a taxa de quebra por via pública, sendo a maior taxa identificada em vias arteriais, de tráfego pesado a muito pesado. Este autor utilizou um modelo computacional para a previsão de falhas no sistema de abastecimento, baseado em um histórico de vazamentos, com modelo de previsão do tempo ótimo de substituição, cujo cálculo considera o custo mínimo, que resulta da soma do custo de manutenção e de implantação e um planejamento de longo prazo.

\section{CONCLUSÃO}

O potencial de perda de água tratada no sistema de distribuição do município de Guaratinguetá (SP) é elevado. Somente no bairro Santa Luzia, o volume de perda médio foi de $9.775,89 \mathrm{~m}^{3}$ de água mês ${ }^{-1}$, com prejuízo anual estimado em $\mathrm{R} \$ 146.638,32$, que poderia ser convertido pela SAEG em investimentos para a melhoria do sistema.

O controle de perda de água no sistema de abastecimento público do município de Guaratinguetá mostrou-se precário. Até o final de 2015, a SAEG não contava com um sistema de informações organizado, com as características e condições das tubulações da rede e previsão de substituição e, dos 36 macromedidores necessários ao controle de perdas do sistema, apenas 12 haviam sido instalados, alguns com defeitos.

As principais medidas propostas para que o sistema de abastecimento de água do município de Guaratinguetá tenha um controle eficaz das perdas de água foram: a instalação de macromedidores nos pontos recomendados; a substituição e padronização de hidrômetros defeituosos, com alocação na frente das residências e colocação de lacres para impedir fraudes; realização de pesquisa de vazamento nos setores que apresentarem grandes perdas; criação de distritos de medição e controle, para posterior instalação de válvulas redutoras de pressão; adequação das tubulações, por meio de planejamento de substituição e a produção e manutenção de uma base confiável de dados da rede, elaborada por funcionários capacitados para o monitoramento das perdas de água do sistema.

\section{REFERÊNCIAS BIBLIOGRÁFICAS}

AGENCIA NACIONAL DE ÁGUAS - ANA. Disponível em: <http://www2.ana.gov.br/Paginas/acessoainformacao/institu cional.aspx> Acesso em: 18/09/2015.

ASSOCIAÇAO BRASILEIRA DE ENGENHARIA SANITARIA E AMBIENTAL - ABES. Perdas em sistemas de abastecimento de água: diagnóstico, potencial de ganhos com sua redução e propostas de medidas para o efetivo combate. Relatório técnico. São Paulo, 2013. 45 p.

COMPANHIA DE SERVICO DE AGUA, ESGOTO E RESIDUOS DE GUARATINGUETA - SAEG. Disponível em:< http://www.saeg.net.br/saeg> Acesso em: 16/10/2015

FUNDAÇAO NACIONAL DE SAÚDE - FUNASA. Redução de Perdas em Sistemas de Abastecimento de Água. Brasília, 2014. 176 p.

INTERNATIONAL BENCHMARKING NETWORK FOR WATER AND SANITATION UTILITIES - IBNET. 2011. Country Profile Brazil. Disponívelem: $<\mathrm{http}: / /$ database.ibnet.org/country_profile?ctry $=119$ \&years $=2014,2013,2012,2$ $011,2010 \&$ type $=$ report $\&$ ent $=$ country \&mult $=$ true $\&$ table $=$ tru e\&chart=false \&chartType $=$ column\&lang=en\&exch $=1>$ Acesso em: 08/11/2015.

INSTITUTO BRASILEIRO DE GEOGRAFIA E ESTATISTICA - IBGE. Disponível em: <http://cidades.ibge.gov.br/painel/painel.php?codmun=3518 40> Acesso em: 16/11/2015.

MISIUNAS, D. Failure Monitoring and Asset Condition Assessment in Water Supply Systems. 2005. 349p. (Doctoral in Industrial Automation) Department of 
Industrial Electrical Engineering and Automation. Lund University. Lund, 2005.

SANTOS, R. B. Perdas de água no sistema para abastecimento publico. 2008. 68p. Trabalho de Conclusão de Curso (Graduação em Engenharia Civil) - Universidade Anhembi Morumbi, São Paulo, 2008.

SARZEDAS, G. L. Planejamento para a substituição de tubulações em sistemas de abastecimento de água. Aplicação na rede de distribuição de água da Região Metropolitana de São Paulo. 114 p. Dissertação (Mestrado em Engenharia Civil) - Escola Politécnica da Universidade de São Paulo, São Paulo, 2009.

SISTEMA NACIONAL DE INFORMAÇOES SOBRE SANEAMENTO - SNIS. Diagnóstico dos Serviços de Água e Esgotos. Brasília, 2014. 181 p.

TSUTIYA, M. T. Abastecimento de água. Departamento de Engenharia Hidráulica e Sanitária da Escola Politécnica da Universidade de São Paulo, São Paulo, 2006. 643p.

\section{COPYRIGHT}

Direitos autorais: $\mathrm{O}(\mathrm{s})$ autor(es) é(são) o(s) único(s)responsável(is) pelo material incluído no artigo. 


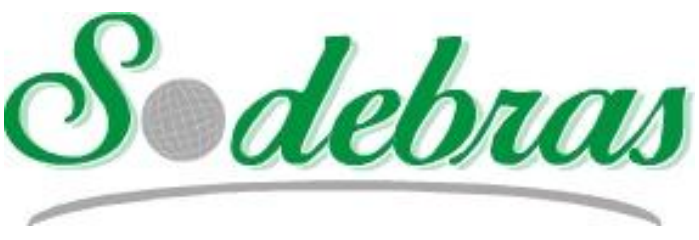

Volume 14 - No 159 - Março/2019.

XL International Sodebras Congress

10 a 12 de dezembro de 2018 - Vitória - ES.

\title{
PROPOSTA PARA APROVEITAMENTO DE RESÍDUOS DA CONSTRUÇÃO CIVIL GERADOS EM CANTEIROS DE OBRAS
}

\author{
PROPOSAL FOR USE OF WASTE FROM CIVIL CONSTRUCTION SITES
}

\author{
PERINA, J.M. ${ }^{1}$; TRANNIN, I. C. B. ${ }^{1}$; \\ 1 - FACULDADE DE ENGENHARIA DE GUARATINGUETÁ, UNIVERSIDADE ESTADUAL \\ PAULISTA "JÚLIO DE MESQUISTA FILHO"
}

julia.perina@hotmail.com;isatrannin@feg.unesp.br

\begin{abstract}
Resumo - A indústria da construção civil está entre as que mais impactam o ambiente, devido à elevada extração de recursos não renováveis e à disposição inadequada dos resíduos gerados. Neste estudo foram avaliados os resíduos gerados no canteiro de obras da Companhia de Desenvolvimento Habitacional e Urbano $(\mathrm{CDHU})$, de Pindamonhangaba (SP), no período de execução da alvenaria e revestimentos interno e externo, para propor formas de aproveitamento. Os principais resíduos gerados, concreto, blocos, argamassa, areia e pedras, apresentam elevado potencial de reutilização, na forma de agregados reciclados, no próprio canteiro ou em obras externas. Essa medida pode minimizar as perdas de materiais nos canteiros de obras, reduzir os impactos ambientais e agregar valor aos resíduos, transformando-os em recursos para construtoras e usinas de reciclagem, além de contribuir para o desenvolvimento sustentável deste setor.

Palavras-chave: Construção civil. Reciclagem. Sustentabilidade.
\end{abstract}

\begin{abstract}
The construction industry is among the most impacting of environment, due to the high extraction of natural resources and the inadequate disposal of waste generated. This study evaluated the waste generated at the construction site of Housing and Urban Development Company (HUDC), in Pindamonhangaba (SP), during the execution period of the masonry and internal and external coatings, to propose reuse or recycling of residues. The main residues generated were concrete, blocks, mortar, sand and stones, all with high potential for reuse, in form of recycled aggregates, in this construction site or in external works. This use can minimize material losses at construction sites, reduce environmental impacts and add value to waste, transforming them into resources for construction companies and recycling plants, contributing to the sustainable development of this sector.
\end{abstract}

Keywords: Civil construction. Recycling. Sustainability.

\section{INTRODUÇÃO}

A importância social e econômica da indústria da construção civil é mundialmente reconhecida, mas para o desenvolvimento sustentável deste setor é imprescindível a adoção de medidas que visem a redução do consumo de recursos naturais não renováveis e energia e a gestão adequada dos resíduos gerados.

O crescimento progressivo do setor construtivo e o consequente aumento na geração de resíduos da construção civil (RCC), que representam $50 \%$ a $70 \%$ dos resíduos sólidos urbanos (RSUs) tem trazido preocupações ambientais (PINTO; GONZÁLES, 2005; KLEIN;
GOLÇALVES-DIAS, 2017, VARGAS, 2018). Geralmente, os materiais perdidos em canteiros de obras e que contribuem para a geração de resíduos, correspondem em massa, a valores iguais ou superiores aos dos resíduos sólidos domiciliares. De acordo com Oliveira e Mendes (2008), ocorre um desperdício irracional de material desde a sua extração, passando pelo transporte, até a sua utilização na obra. Pinto (1999) constatou que com a quantidade de materiais desperdiçados em três obras é possível a construção de uma quarta, idêntica.

No Brasil ainda é incipiente a quantidade de empresas de construção civil que fazem a gestão dos resíduos gerados em canteiros de obras e desenvolvem ações planejadas para a redução ou aproveitamento dos RCC. A segregação, o acondicionamento e a disposição final adequada dos resíduos ainda não são realizados de forma adequada e integrada às atividades produtivas do canteiro de obra, considerando que a legislação que regulamenta a gestão dos RCC é, relativamente, recente em nosso país.

Os RCC são regulamentados pela Lei Federal $n^{\circ}$ 12.305/2010, que institui a Política Nacional de Resíduos Sólidos (PNRS), e estabelece instrumentos necessários à redução de resíduos na fonte geradora, bem como sua reciclagem, reutilização e correta destinação final, a fim de promover o desenvolvimento sustentável (BRASIL, 2010).

Outro instrumento importante de normatização dos RCC é a Resolução n 307/2002 do Conama, que determina critérios sobre a responsabilidade e necessidade de implementação dos planos de gerenciamento de resíduos da construção civil (PGRCC) nos municípios, e sua classificação em pequenos ou grandes geradores, instituindo ainda métodos adequados ao manejo dos resíduos (BRASIL, 2002).

Ao longo dos anos, a Resolução no 307/2002 foi alterada pela Resolução $n^{\circ} 348 / 2004$, que incluiu o amianto na classe D (resíduos perigosos); Resolução no 431/2011, que alterou a classificação do gesso, da classe $\mathrm{C}$ para a classe B; Resolução $n^{\circ}$ 448/2012, que estabeleceu as áreas de transbordo e triagem (ATT) de RCC e volumosos, bem como o plano municipal de gestão de RCC, como instrumento necessário a gestão dos RCC nos municípios; Resolução no 469/2015, que incluiu na classe B, embalagens vazias de tintas imobiliárias, considerando que estas 
apresentem apenas filme seco de tinta dentro do recipiente, bem como, a submissão de embalagens com tinta líquida ao sistema de logística reversa, de acordo com a PNRS.

A Resolução 307/2002 define RCC como resíduos oriundos de construções, reformas, reparos e demolições de obras, e os decorrentes da preparação e da escavação de terrenos, também conhecidos como entulhos de obras, caliça ou metralha (BRASIL, 2002). De acordo com esta Resolução, os RCC não podem ser dispostos em aterros de resíduos sólidos urbanos, encostas, corpos d'água, lotes vagos, áreas de bota-fora e em áreas protegidas por lei. O gerador deve se responsabilizar pelos resíduos e ter como principal objetivo a não geração. Secundariamente, estão a redução, reutilização, reciclagem, o tratamento e a disposição final, ambientalmente adequada, dos rejeitos.

Nesta resolução os RCC são divididos em 4 classes: A (reutilizáveis ou recicláveis como agregados); B (recicláveis para outras destinações); C (ainda não existem tecnologias ou aplicações economicamente viáveis que permitam a reciclagem ou recuperação) e $\mathrm{D}$ (perigosos, resultantes do processo de construção). A Resolução 307/2002 define a reutilização, como sendo a aplicação do resíduo, sem transformação e a reciclagem, como o aproveitamento do resíduo, após transformação.

Dentre os instrumentos federais vigentes, destacam-se ainda as normativas instituídas pela Associação Brasileira de Normas Técnicas (ABNT), que estabelecem normas específicas aos projetos, implantação e gestão dos resíduos: NBR 10.004/2004 - Resíduos sólidos - classificação; NBR 15.112/2004 - RCC e resíduos volumosos - áreas de transbordo e triagem (diretrizes para projetos, implantação e operação); NBR 15.113/2004 - RCC e resíduos inertes aterros (diretrizes para projetos, implantação e operação); NBR 15.114/2004 - RCC - áreas para reciclagem (diretrizes para projetos, implantação e operação); NBR 15.115/2004 - Agregados reciclados de RCC - execução de camada de pavimentação (procedimentos); NBR 15.116/2004 - Agregados reciclados de RCC - utilização em pavimentação e preparo de concreto sem função estrutural - requisitos.

Para atender a Lei Federal $\mathrm{n}^{\mathrm{o}}$ 12.305/10 da PNRS, o município de Pindamonhangaba, situado na região do Vale do Paraíba, Estado de São Paulo, assinou em agosto de 2014, o Termo de Cooperação Técnica com a Associação Pró-Gestão das Águas da Bacia Hidrográfica do Rio Paraíba do Sul (AGEVAP), que consiste na elaboração do Plano Municipal de Gestão Integrada de Resíduos Sólidos (PMGIRS). Um dos principais objetivos deste termo foi a implantação de programas de coleta seletiva, visando a reciclagem e o aproveitamento, em especial, de resíduos da construção civil.

Neste contexto, este estudo avaliou e propôs alternativas de aproveitamento para os principais resíduos gerados no canteiro de obras da CDHU, em Moreira César, distrito do município de Pindamonhangaba (SP), no período de execução da alvenaria estrutural e revestimentos interno e externo. Essa medida pode reduzir as perdas em canteiros de obras e os impactos ambientais da disposição inadequada dos RCC, além de agregar valor a estes resíduos, transformando-os em recursos para construtoras e usinas de reciclagem.

\section{METODOLOGIA}

O estudo avaliou os RCC gerados no canteiro da obra estadual da CDHU, em Moreira César, distrito do município de Pindamonhangaba (SP), na região do médio Vale do Paraíba. Esse distrito ocupa uma área de $234 \mathrm{~km}^{2}$, que corresponde a um terço da área do município e, em 2014 contava com uma população de cerca de 40.000 habitantes (IBGE, 2010).

O conjunto habitacional localiza-se na Rua Benedito Galvão de Castro, bairro Marieta Azeredo, no distrito de Moreira César, a cerca de $15 \mathrm{~km}$ do centro de Pindamonhangaba, com área total de $6.739,69 \mathrm{~m}^{2}$ e área construída de $1.584,07 \mathrm{~m}^{2}$. A obra foi iniciada em 16 de outubro de 2013 e consistiu de seis torres de quatro pavimentos, totalizando 94 apartamentos de $47 \mathrm{~m}^{2}$, um salão de festas e uma quadra poliesportiva (Figura 1).

Figura 1 - Planta do pavimento tipo da CDHU do Distrito de Moreira Cesar, no município de Pindamonhangaba (SP).

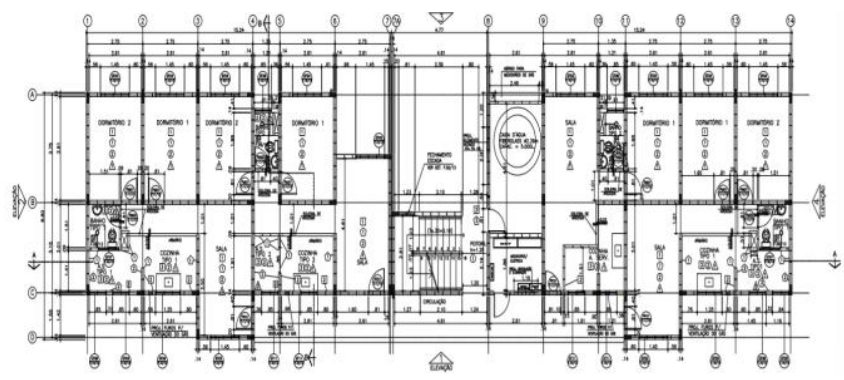

Fonte: Projeto de arquitetura da Companhia de Desenvolvimento Habitacional e Urbano do Estado de São Paulo (2013).

Para a identificação, quantificação e caracterização dos RCC gerados no canteiro de obras da CDHU foram considerados os resíduos coletados em caçambas e os entulhos dispostos no pátio, no período de abril a outubro de 2014, durante a execução da alvenaria estrutural e dos revestimentos interno e externo (Figura 2 ).

Neste período foram calculadas as quantidades de cada material gerado, sendo analisada a principal fonte geradora e a classificação segundo a NBR 10.004/2004 e as Resoluções do Conama 307/2002, 348//2004, 431/2011 e 469/2015, para a posterior análise do potencial de aproveitamento no próprio canteiro de obras ou em obras externas.

Figura 2 - Resíduos da construção civil, coletados no canteiro de obras da CDHU, em Pindamonhangaba (SP), no período de execução da alvenaria estrutural e revestimentos interno e externo.
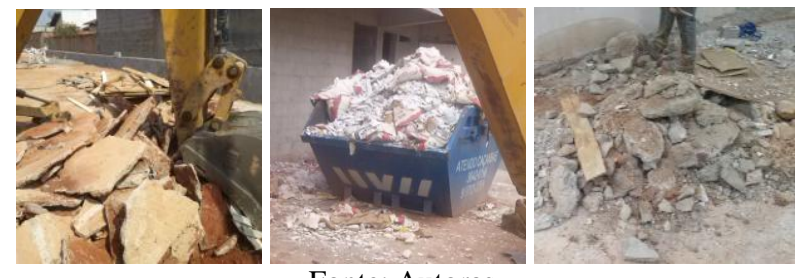

Fonte: Autoras.

Para a análise do potencial de aproveitamento e proposição de alternativas de reutilização e reciclagem foram consultadas a Lei Federal $\mathrm{n}^{\mathrm{o}} 12.305 / 2010$ da PNRS; as Resoluções do Conama: 307/2002, 348/2004, 431/2011; $448 / 2012$ e 469/2015 e as normas da ABNT NBR 
10.004/2004; NBR 15.112/2004; NBR 15.113/2004; NBR 15.115/2004 e NBR 15.116/2004.

Em adição à legislação e as normatizações brasileiras o estudo também se fundamentou na literatura disponível sobre o tema.

\section{RESULTADOS}

\section{1 - Quantificação e caracterização dos RCC da CDHU}

Durante os sete meses de acompanhamento da obra e avaliação dos RCC foram retiradas 107 caçambas de $5 \mathrm{~m}^{3}$ de resíduos do canteiro de obras da CDHU de Pindamonhangaba (SP), totalizando $535 \mathrm{~m}^{3}$ de resíduos enviados ao aterro municipal. Os principais componentes dos RCC, com as respectivas quantidades e classificação, conforme a Resolução Conama ${ }^{\circ}$ 307/2002 e resoluções complementares, podem ser observadas no quadro 1 .

Quadro 1 - Principais RCC gerados no canteiro de obras da CDHU de Pindamonhangaba (SP) na execução da alvenaria estrutural e dos revestimentos interno e externo, e respectivas classificações, conforme Resolução Conama n ${ }^{0}$ 307/02 e complementares.

\begin{tabular}{|c|c|c|c|}
\hline Resíduo & Volume, $\mathbf{~ m}^{\mathbf{3}}$ & Proporção, $\%$ & Classe \\
\hline Concreto e blocos & 149,8 & 28 & $\mathrm{~A}$ \\
\hline Argamassa & 101,65 & 19 & $\mathrm{~A}$ \\
\hline Solo e areia & 90,95 & 17 & $\mathrm{~A}$ \\
\hline Pedra & 16,05 & 3 & $\mathrm{~A}$ \\
\hline Gesso & 69,55 & 13 & $\mathrm{~B}$ \\
\hline Madeira & 64,2 & 12 & B \\
\hline Plástico & 26,75 & 5 & B \\
\hline Outros & 16,05 & 3 & - \\
\hline TOTAL & 535 & 100 & - \\
\hline \multicolumn{4}{|c|}{ Fonte: Autoras. } \\
\hline
\end{tabular}

Entre os principais componentes dos resíduos gerados na obra da CDHU no período de execução da alvenaria e de revestimentos interno e externo, verificou-se que $67 \%$ pertencem à classe $\mathrm{A}$ (concreto e blocos, argamassa, solo, areia e pedras), que apresentam elevado potencial de reciclagem na forma de agregados. Estudos de Pinto (1986), Brito Filho (1999), Quadros e Oliveira (2001), Nóbrega (2002), Vieira (2003), Lovato (2007) e Zordan (2014), realizados em diferentes canteiros de obras, em sete municípios brasileiros, relataram que os componentes dos RCC gerados em maior proporção foram os também encontrados no canteiro de obras da CDHU.

Cassa, Carneiro e Brum (2001) constataram que, dos $2.044 \mathrm{~m}^{3}$ dos RCC enviados diariamente ao aterro da cidade de Salvador (BA), cerca de $94 \%$ possuíam elevado potencial para reciclagem, destacando-se entre estes resíduos, 53\% de concreto e argamassa, $14 \%$ de material cerâmico, $5 \%$ de rocha e $22 \%$ de solo e areia, semelhantes aos resultados encontrados no canteiro de obras da CDHU.

Segundo Leite (2001), na composição dos RCC de Porto Alegre (RS) foi encontrada a proporção: rocha natural $(29,84 \%)$, argamassa $(28,26 \%)$, material cerâmico $(26,33 \%)$, concreto $(15,18 \%)$ e outros $(0,39 \%)$. Este autor afirmou que esses dados refletem os insumos com os maiores índices de desperdício no setor da construção civil.

Também foram avaliados os principais componentes dos RCC e as respectivas quantidades geradas mensalmente no canteiro de obras da CDHU, no período de abril a outubro de 2014 (Figura 3). Durante a execução da alvenaria, realizada entre os meses de abril a julho, predominaram os resíduos de concreto e bloco (51\%) usados na execução da estrutura, juntamente com a madeira (22\%), utilizada nas formas. Ainda no mês de julho deu-se início à etapa de revestimento externo com argamassa e revestimento interno com gesso, havendo no mês de agosto, predomínio dos componentes: argamassa (38\%), gesso $(26 \%)$ e solo e areia $(23 \%)$.

Figura 3 - Principais RCC gerados no canteiro de obras da CDHU de Pindamonhangaba (SP), nos meses de abril a outubro de 2014,

durante a execução da alvenaria estrutural e de revestimentos.

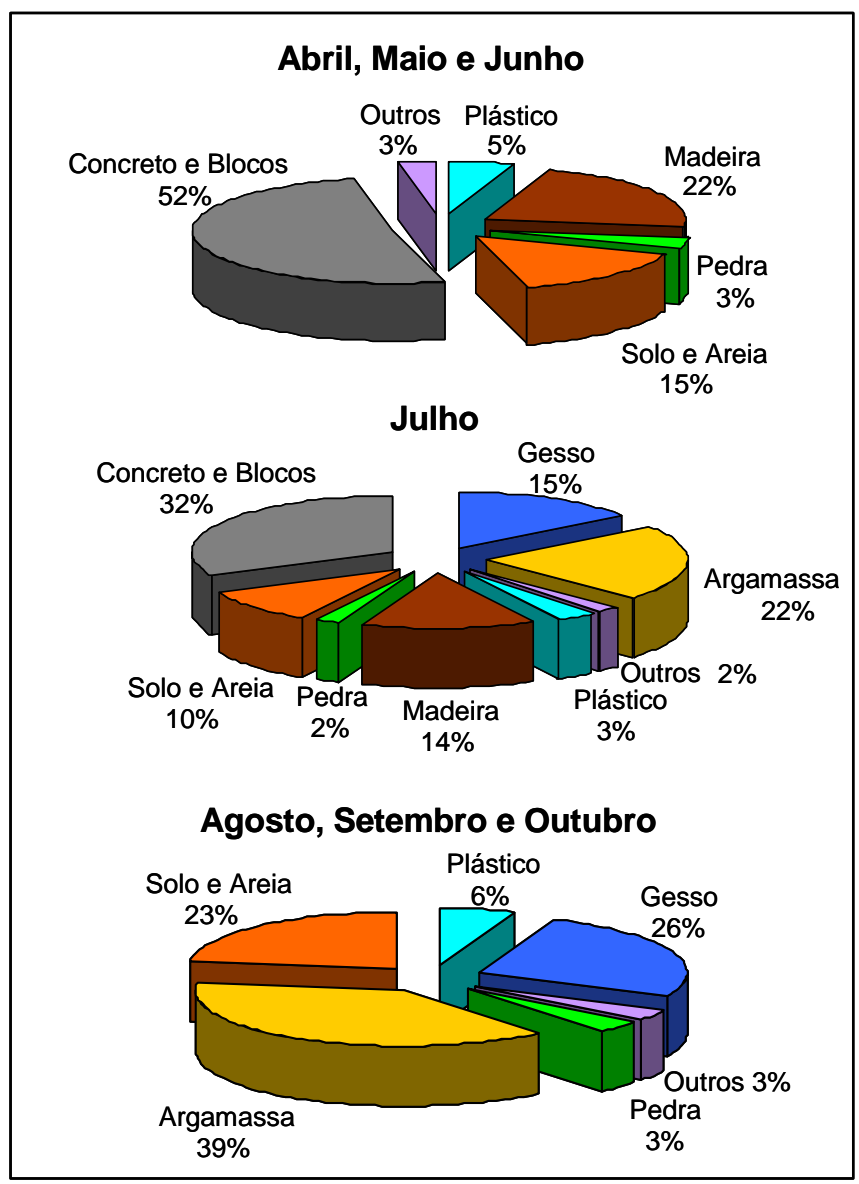

Fonte: Autoras.

Considerando a quantidade total de 107 caçambas por um período de sete meses, temos uma média de 15,28 caçambas por mês, com volume de $5 \mathrm{~m}^{3}$. Assim, obteve-se um volume médio de RCC de $76,42 \mathrm{~m}^{3}$ mês ${ }^{-1}$, equivalente a $2,55 \mathrm{~m}^{3} \mathrm{dia}^{-1}$. Adotando-se como massa específica o valor de $1200 \mathrm{~kg} \mathrm{~m}^{-3}$ (PINTO, 2005) para os RCC, na CDHU foram gerados 91,7 $\mathrm{t}$ mês ${ }^{-1}$ ou 3,05 $\mathrm{t} \mathrm{dia}^{-1}$.

Pinto (1999) encontrou valores estimados de geração per capta de RCC entre 230 a 760 kg hab $\mathrm{ano}^{-1}$. Considerando essa média de $495 \mathrm{~kg} \mathrm{hab}^{-1}$ ano $^{-1}$ obtida por este autor, estimou-se que o distrito de Moreira César, com uma população de 40.000 habitantes, tem potencial para produzir $19.800 \mathrm{t} \mathrm{ano}^{-1}$ ou $1.650 \mathrm{t} \mathrm{mês}^{-1}$. A geração de RCC na obra CDHU no período avaliado foi de $91,7 \mathrm{t} \mathrm{mês}^{-1}$, que representa $0,5 \%$ do total gerado no distrito.

John e Agopyan (2005) mostram que as estimativas de geração per capta de RCC variam de 130 a $3000 \mathrm{~kg}$ hab ${ }^{1}$ ano $^{-1}$. Essa grande amplitude dos valores ocorre devido à classificação dos resíduos, uma vez que alguns estudos incluem a remoção de solo enquanto outros não. Ainda assim, é preciso considerar a existência de diversas tecnologias de construção empregadas em diferentes países. 
De acordo com Careli (2008), as obras que utilizam processos construtivos convencionais, ou seja, estrutura de concreto armado juntamente com alvenaria de vedação, realizados com bloco de concreto ou cerâmico, geram entre 0,10 a $0,15 \mathrm{~m}^{3} \mathrm{~m}^{-2}$ de área construída de $\mathrm{RCC}$, sendo que desse volume de resíduo, $50 \%$ corresponde à alvenaria (concreto, argamassa e cerâmicos), 30\% à madeira, 10\% ao gesso, $7 \%$ ao papel, plástico e metais e $3 \%$ são constituídos de resíduos perigosos e outros resíduos não recicláveis. Com base nestas informações, cada apartamento da CDHU, com $47 \mathrm{~m}^{2}$, pode gerar 4,7 a 7,05 $\mathrm{m}^{3}$ de RCC, uma média de $5,87 \mathrm{~m}^{3}$ de RCC, resultando no volume total de $552 \mathrm{~m}^{3}$ de resíduos gerados na construção dos 94 apartamentos. No entanto, o volume de $535 \mathrm{~m}^{3}$ de RCC coletado somente no período de estudo, nas etapas de execução de alvenaria estrutural e de revestimentos interno e externo, já se aproximou do volume que deveria ser coletado em todo o período de construção, indicando que as perdas de materiais no canteiro de obras da $\mathrm{CDHU}$ foram superiores às normalmente identificadas em canteiros de obras.

Souza (2005) avaliou 50 unidades habitacionais populares de $44,52 \mathrm{~m}^{2}$, considerando uma massa específica média de $1288 \mathrm{~kg} \mathrm{~m}^{-3}$ e obteve $89,68 \mathrm{~kg} \mathrm{~m}^{-2}$ de RCC. Adotando esta massa específica para cada unidade habitacional da CDHU, obteve-se o valor de $151,14 \mathrm{~kg} \mathrm{~m}^{-2}$ de RCC, $61,46 \mathrm{~kg} \mathrm{~m}^{-2}$ a mais do que obtido por Souza (2005).

É importante observar que, além do apartamento da CDHU possuir 2,48 $\mathrm{m}^{2}$ a mais do que cada unidade habitacional avaliada por Souza (2005), outro fator que influenciou essa diferença entre as quantidades de RCC gerados é que naquele estudo não foi considerado o uso de formas de madeira, gesso, lajes de forros, áreas comuns e outros serviços que não são executados normalmente em obras populares, como a da CDHU. Além disso, este autor considerou o volume gerado durante a execução de toda a obra, enquanto o presente estudo avaliou somente o período de sete meses, durante as etapas de execução da alvenaria estrutural e dos revestimentos externo e interno, indicando novamente, que no canteiro de obras da CDHU as perdas foram muito superiores às normalmente relatadas na literatura.

Marques Neto e Schalch (2010) quantificaram os RCC gerados em 5 obras e obtiveram o valor de 137,02 $\mathrm{kg} \mathrm{m}^{-2}$ com uma massa unitária de $600 \mathrm{~kg} \mathrm{~m}^{-3}$. Aplicando esta massa unitária, de $600 \mathrm{~kg} \mathrm{~m}^{-3}$ ao volume de RCC coletados no canteiro da CDHU, obteve-se o valor de 70,41 $\mathrm{kg} \mathrm{m}^{-2}$ de RCC. No entanto, é importante ressaltar que essa massa específica proposta por estes autores é atípica comparada aos valores adotados em outros estudos.

$\mathrm{Na}$ execução deste estudo verificou-se a existência de diversas metodologias aplicadas à quantificação de RCC gerados em canteiros de obras, cada uma com características e particularidades distintas, devendo ser selecionada a que mais se ajusta a situação avaliada, para validação e confiabilidade na obtenção da taxa de geração de RCC.

Assim, para a quantificação dos RCC gerados no canteiro de obras da CDHU, foram obtidos diferentes valores decorrentes das diversas metodologias adotadas por cada autor. Ao aplicar a massa específica proposta por Marques Neto e Schalch (2010) aos dados coletados na CDHU, obteve-se uma taxa de 70,41 $\mathrm{kg} \mathrm{m}^{-2}$ de RCC. Para o valor de $1.288 \mathrm{~kg} \mathrm{~m}^{-3}$ proposto por Souza (2005), obteve-se a taxa de $151,14 \mathrm{~kg} \mathrm{~m}^{-2}$ de RCC. Entretanto, para as estimativas propostas por Careli (2008), adotando a massa específica de $1.200 \mathrm{~kg} \mathrm{~m}^{-3}$, obteve-se o valor de $149,87 \mathrm{~kg}$ $\mathrm{m}^{-2}$ de RCC na CDHU. A média dos valores obtidos com a massa específica proposta por estes três estudos, foi de $123,8 \mathrm{~kg} \mathrm{~m}^{-2}$ de RCC gerados na obra da CDHU no período de execução da alvenaria estrutural e revestimentos interno e externo.

\section{2 - Potencial de aproveitamento dos RCC}

De acordo com os dados coletados no canteiro de obras e na literatura foram propostas alternativas de aproveitamento dos principais componentes dos RCC gerados na obra da CDHU no período de execução de alvenaria estrutural e revestimentos interno e externo (Quadro 1).

Como alternativa de aproveitamento propõe-se que os resíduos brutos sejam aproveitados em obras para aterros, de forma simplificada, reconhecendo condições necessárias de compactação e estabilidade do terreno. É possível, também, utilizar as aparas de blocos para preencher vãos, na execução de vedações em alvenaria. Além disso, é possível britar estes resíduos para a homogeneização (produção dos agregados reciclados) empregados para enchimentos, estabilização de terrenos, sub-base e base de pavimentos, contrapisos, drenagens, produção de argamassas, concretos não estruturais, entre outros usos. A produção de agregados reciclados por meio de britagem, peneiramento $\mathrm{e}$ balanceamento granulométrico, pode estar relacionada ao processamento dos resíduos no próprio canteiro de obras ou em unidades de reciclagem externas.

$\mathrm{O}$ segundo componente dos RCC coletados em maior volume foi a fração solo e areia. No caso do solo, os aterros de RCC de classe A abrangem a recuperação de áreas degradadas pela atividade de mineração e serviços de regularização topográfica de terrenos, por meio de obras de engenharia com capacidade de receber resíduos, definidas por projetos específicos. Outra alternativa viável de aproveitamento na forma de agregados reciclados é a utilização da areia na produção de argamassas no próprio canteiro para assentamento de cerâmica e contrapiso.

As sobras da aplicação do gesso e aparas devem ser enviadas a empresas que concentram cargas para destinação final dos resíduos em indústrias de cimento. O material será utilizado nessas indústrias para controle da pega do cimento na fase de moagem do clínquer. Além disso, é importante observar que o gesso foi armazenado em caçamba individual, no canteiro de obras da CDHU (Figura 2). No Vale do Paraíba, a reciclagem do gesso só é realizada no município de Caieiras.

No caso da madeira, o procedimento ideal é reutilizar as peças exaustivamente e redimensioná-las para uso diversificado, preparando local próximo da carpintaria para formação dos estoques intermediários. Esgotadas as possibilidades de reuso em canteiro, a madeira deve ser destinada a unidades que trituram estes resíduos, transformando-os em cavacos utilizados como combustível em fornos e caldeiras em substituição à madeira virgem.

Os materiais plásticos, presentes em embalagens, lonas, telas, partes de tubulações e conduítes, entre outros, devem ser destinados às cooperativas ou empresas que comercializam resíduos plásticos para reciclagem, em um processo que envolve moagem, lavagem, secagem, aglutinação, extrusão, resfriamento, granulação e, 
finalmente, uso como insumo na produção de artefatos em plástico.

Para o aproveitamento dos metais como embalagens vazias, arames, partes de tubulações e vergalhões de metal, entre outros itens, estes também devem ser encaminhados às cooperativas ou empresas que comercializam sucatas metálicas, com destinação final na indústria siderúrgica.

\section{CONCLUSÃO}

Durante o período de execução da alvenaria estrutural, os principais resíduos gerados foram, concreto e bloco $(51 \%)$ e madeira (22\%). Na etapa de revestimento houve predomínio dos componentes: argamassa (38\%), gesso $(26 \%)$, solo e areia $(23 \%)$. Os resíduos, concreto, bloco e argamassa, corresponderam a $67 \%$ do total de RCC gerados no período do estudo e, como pertencem à Classe $\mathrm{A}$, apresentam elevado potencial de reciclagem, podendo ser utilizados como agregados na construção civil.

O canteiro de obras da CDHU de Pindamonhangaba gerou um volume médio de $76,42 \mathrm{~m}^{3}$ mês $^{-1}$ de RCC, equivalente a 2,55 $\mathrm{m}^{3} \mathrm{dia}^{-1}$. As 91,7 $\mathrm{tmês}^{-1}$ de RCC coletado no canteiro de obras da CDHU representaram $0,5 \%$ do total de RCC gerado no distrito de Moreira Cesar, que é de $1.650 \mathrm{t} \mathrm{mês}{ }^{-1}$, indicando que houve uma grande contribuição desta obra para os RCC enviados ao aterro municipal, com grandes perdas de materiais.

Para o aproveitamento dos RCC gerados no canteiro de obras da CDHU, em Pindamonhangaba (SP), no período de execução da alvenaria estrutural e revestimentos interno e externo foi proposta: a utilização dos resíduos de blocos e argamassa, em enchimento de degraus de escada e rasgos de paredes para tubulações hidráulicas e elétricas; em chumbamento de caixas elétricas e tubulações. Os resíduos de concreto, blocos, argamassa e areia, após beneficiamento e balanceamento granulométrico, em padrões que atendam as normas vigentes, podem ser utilizados na forma de agregados para concreto e argamassa de assentamento de blocos ou em revestimentos internos e externos, como chapisco e reboco; fabricação de blocos de vedação; camadas de base e sub-base de pavimentação entre outros, podendo esse aproveitamento ocorrer no próprio canteiro ou em obras externas.

\section{REFERÊNCIAS BIBLIOGRÁFICAS}

ASSOCIAÇÃO BRASILEIRA DE NORMAS TÉCNICAS. NBR 10.004: Resíduos sólidos - Classificação. Rio de Janeiro, 2004.

ASSOCIAÇÃO BRASILEIRA DE NORMAS TÉCNICAS. NBR 15.112: Resíduos da Construção Civil e resíduos volumosos - Áreas de Transbordo e Triagem - Diretrizes para projeto, implantação e operação. Rio de Janeiro, 2004.

ASSOCIAÇÃO BRASILEIRA DE NORMAS TÉCNICAS. NBR 15.113: Resíduos Sólidos da Construção Civil e resíduos Inertes - Aterros - Diretrizes para projeto, implantação e operação. Rio de Janeiro, 2004.

ASSOCIAÇÃO BRASILEIRA DE NORMAS TÉCNICAS. NBR 15.114: Resíduos Sólidos da Construção Civil Áreas de Reciclagem - Diretrizes para projeto, implantação e operação. Rio de Janeiro, 2004.

ASSOCIAÇÃO BRASILEIRA DE NORMAS TÉCNICAS. NBR 15.115: Agregados Reciclados de resíduos sólidos da Construção civil - Execução de camadas de pavimentação - Procedimentos. Rio de Janeiro, 2004.

ASSOCIAÇÃO BRASILEIRA DE NORMAS TÉCNICAS. NBR 15.116: Agregados Reciclados de resíduos sólidos da Construção civil - Utilização em pavimentação e preparo de concreto sem função estrutural - Requisitos. Rio de Janeiro, 2004.

BRASIL. Lei Federal $n^{\circ}$ 12.305, de 2 de agosto de 2010. Institui a Política Nacional de Resíduos Sólidos; altera a Lei $\mathrm{n}^{\circ}$ 9.605, de 12 de fevereiro de 1998; e dá outras providências. Diário Oficial da União, Brasília, 2 ago. 2010.

BRASIL. Ministério do Meio Ambiente. Resolução Conama $n^{\circ}$ 307, de 5 de julho de 2002. Estabelece diretrizes, critérios e procedimentos para a gestão dos resíduos da construção civil. Diário Oficial da União, Brasília, 17 jul. 2002.

BRASIL. Ministério do Meio Ambiente. Resolução Conama $n^{\circ}$ 348, de 16 de agosto de 2004. Altera a Resolução Conama ${ }^{\circ}$ 307, de 5 de julho de 2002, incluindo o amianto na classe de resíduos perigosos. Diário Oficial da União, Brasília, 17 ago. 2004.

BRASIL. Ministério do Meio Ambiente. Resolução Conama $n^{\circ} 431$, de 24 de maio de 2011. Altera o artigo $3^{\circ}$ da Resolução $n^{\circ}$ 307. Diário Oficial da União, Brasília, 25 mai. 2011.

BRASIL. Ministério do Meio Ambiente. Resolução Conama $n^{\circ}$ 448, de 19 de janeiro de 2012. Altera os artigos. $2^{\circ}, 4^{\circ}, 5^{\circ}, 6^{\circ}, 8^{\circ}, 9^{\circ}, 10$ e 11 da Resolução $n^{\circ} 307$. Diário Oficial da União, Brasília, 20 jan. 2012.

BRASIL. Ministério do Meio Ambiente. Resolução Conama $n^{\circ}$ 469, de 29 de julho de 2015. Altera a Resolução no 307 . Diário Oficial da União, Brasília, 20 jul. 2015.

BRITO FILHO, J. A. Cidades versus entulho. In: Seminário Desenvolvimento Sustentável e a Reciclagem na Construção Civil, Anais. São Paulo: Comitê Técnico do IBRACON; CT206 - Meio e Ambiente, p.56-67,1999.

CARELI, E. D. A Resolução CONAMA no 307/2002 e as Novas Condições para Gestão dos Resíduos de Construção e Demolição. 2008. 154 p. Dissertação (Mestrado em Engenharia Civil) - Centro Estadual de Educação Tecnológica Paula Souza, São Paulo, 2008.

CASSA, J.C.; CARNEIRO, A. P.; BRUM, I. A. S. Reciclagem de entulho para produção de materiais de construção: projeto entulho bom. Salvador: EDUFBA; Caixa Econômica Federal, 2001.312p.

CENSO DEMOGRÁFICO 2010. Características da população e dos domicílios: resultados do universo. Rio de Janeiro: IBGE, 2010. Estudos e pesquisas. Informação demográfica e socioeconômica, n. 28. Disponível em: http://www.ibge.gov.br/home/estatistica/populacao/censo20 10/caracteristica_da_populacao/resultados_do_universo.pdf. Acesso em: 16 nov. 2018.

JOHN, V. M.; AGOPYAN, V. Reciclagem de resíduos da construção. In: SEMINÁRIO DE RECICLAGEM DE RESÍDUOS SÓLIDOS DOMICILIARES. 2005, São Paulo. 
KLEIN, F.B.; GOLÇALVES-DIAS, S.L.F. A deposição irregular de resíduos da construção civil no município de São Paulo: um estudo a partir dos instrumentos de políticas públicas ambientais. Desenvolvimento e Meio Ambiente, v. 10, 2017, p. 483-506.

LEITE, M. B. Avaliação de propriedades mecânicas de concretos produzidos com agregados reciclados de resíduos da construção e demolição. Porto Alegre, 2001. 290p.Tese (Doutorado em Engenharia Civil) - Universidade Federal do Rio Grande do Sul. 2001.

LOVATO, P. S. Verificação dos Parâmetros de Controle de Agregados Reciclados de Resíduos de Construção e Demolição para Utilização em Concreto. Porto Alegre, 2007. 180p. Dissertação (Mestrado). Programa de PósGraduação em Engenharia Civil, Universidade Federal do Rio Grande do Sul.

MARQUES NETO, J. C.; SCHALCH, V. Gestão dos Resíduos de Construção e Demolição: Estudo da Situação na cidade de São Carlos-SP. Universidade Federal de São Carlos, São Carlos - SP, 2010.

NOBREGA, A. R. S. Contribuição ao diagnóstico da geração de entulho da construção civil no município de Campina Grande, PB. Dissertação (Mestrado). Universidade Federal de Campina Grande. Campina Grande, 2002.96p.

OLIVEIRA, E. G. O.; MENDES, O. Gerenciamento de resíduos da construção civil e demolição: estudo de caso da Resolução 307 do CONAMA. Goiana, 2008.

PINTO, T. P. Utilização de resíduos de construção: estudo do uso em argamassas. 1986. 140p. Dissertação (Mestrado) - Departamento de Arquitetura e Planejamento da Universidade de São Carlos - Universidade de São Paulo.

PINTO, T. P. Metodologia para a gestão diferenciada de resíduos sólidos da construção urbana. 1999. 189 f. Tese (Doutorado em Engenharia Civil) - Universidade de São Paulo, São Paulo, 1999.

PINTO, T. P. Gestão ambiental dos resíduos da construção civil: a experiência do SindusCon-SP. São Paulo: SindusCon, 2005.47p.

PINTO, T.P.; GONZÁLES, J.L.R. Manejo e gestão de resíduos da construção civil. Brasília: CEF, 2005. v. 1.196 p. (Manual de orientação: como implantar um sistema de manejo e gestão nos municípios, v.1).

QUADROS，B. E. C.; OLIVEIRA， A. M. V. Gestão diferenciada do entulho na cidade de Salvador. In: Reciclagem de entulho para a produção de materiais de construção / Organizado por Alex Pires Carneiro, Irineu Antônio Schadach de Brum e José Clodoaldo da Silva Cassa. Salvador: EDUFBA; 312 p.: 2001; p.116-141.

SOUZA, V. B. Avaliação da Geração de Entulho em Conjunto Habitacional Popular - estudo de caso. 2005 251 f. Dissertação (Mestrado em Engenharia Civil). Faculdade de Engenharia Civil da Universidade Federal de Uberlândia, Uberlândia, 2005.

VARGAS, C. Análise da gestão de resíduos da construção civil no Estado do Paraná e município de Cascavel-PR. 2018. 116p. Dissertação (Mestrado em
Ciências Ambientais). Universidade Estadual do Oeste do Paraná, Unioeste. Toledo, 2018.

VIEIRA, C. M. F.; CARDOSO, B. R.; MONTEIRO, S. N. Influência da adição de argila fundente em massa de cerâmica vermelha caulinítica. In: Jornadas SAM/CONAMET/SIMPÓSIO MATÉRIA 2003. Anais, p. 796-799.

ZORDAN; S. E. Entulho da indústria da construção civil. São Paulo: PCC-EPUSP, 2014. Disponível em: hppt//www.reciclagem.pcc.usp.br Acesso em: 15 nov. 2018.

\section{COPYRIGHT}

Direitos autorais: $\mathrm{O}(\mathrm{s})$ autor(es) é(são) o(s) único(s) responsável(is) pelo material incluído no artigo. 


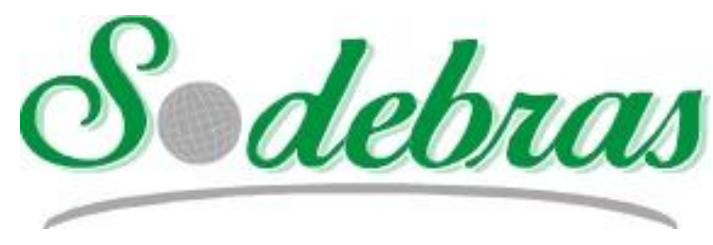

Volume 14 - No 159 - Março/2019.

XL International Sodebras Congress

10 a 12 de dezembro de 2018 - Vitória - ES.

\title{
O USO DO BIG DATA NO ESTUDO DO MERCADO CONSUMIDOR, POTENCIALIDADES PARA APLICAÇÃO NO BRASIL
}

\section{THE USE OF BIG DATA IN THE CONSUMER MARKET STUDY, POTENTIAL FOR THE APPLICATION IN BRAZIL}

\author{
ALEX BRANDÃO ROSSOW \\ INSTITUTO FEDERAL DO ESPÍRITO SANTO \\ alex.rossow@ifes.edu.br
}

\begin{abstract}
Resumo - Este artigo apresenta o potencial do Big Data para o estudo do mercado consumidor. O Big Data pode ser visto como um conjunto de técnicas e ferramentas para obtenção de informações úteis a partir de dados gerados por diferentes fontes, como redes sociais, sistema financeiro e sensores. Neste trabalho é apresentado o conceito do Big Data, um resumo dos aspectos técnicos desse conjunto de ferramentas e como pode ser utilizado para a obtenção de informações sobre os clientes e a dinâmica do mercado de consumo. Por fim são apresentados fatores que indicam o potencial para o uso do Big Data no Brasil. Como indicadores foram adotados os números de usuários da telefonia celular e de internet fixa e a participação dos brasileiros nas redes sociais. Esses parâmetros foram adotados por representarem importantes fontes de dados para análise do mercado consumidor por técnicas de Big Data.

Palavras-chave: Big Data. Projeto de produtos. Mercado consumidor. Projeção de mercados.
\end{abstract}

Abstract - This article presents the potential of Big Data for the study of the consumer market. Big Data can be seen as a set of techniques and tools for obtaining useful information from data generated by different sources, such as social networks, the financial system and sensors. This paper presents the Big Data concept, a list of the technical aspects of this toolkit and how it can be used to obtain information about customers and the dynamics of the consumer market. Finally, factors that indicate the potential for the use of Big Data in Brazil are presented. As indicators were adopted the numbers of users of mobile telephony and fixed Internet and the participation of Brazilians in social midias. These parameters were adopted because they represent important sources of data for analysis of the consumer market by Big Data techniques.

Keywords: Big data. Product design. Consumer market. Market projection.

\section{INTRODUÇÃO}

A ideia de elaborar esta pesquisa surgiu da percepção do crescente nível de integração de novas tecnologias à vida cotidiana. A expansão da internet e a popularização das formas de interação pelas mídias sociais criaram um contexto onde cada indivíduo tem condição de divulgar de forma bastante ampla seus sentimentos, opiniões e informações diversas sobre sua rotina. Observou-se que esse grande volume de dados, produzido diariamente, poderia fornecer informações importantes sobre $\mathrm{o}$ mercado consumidor.
Nesse cenário de novas tecnologias e novas formas de produção de dados surgiu o Big Data, que consiste em um conjunto de ferramentas e técnicas para a extração de informações úteis a partir de grandes conjuntos de dados digitais que se originam de fontes diversas e sem estrutura definida.

Com o Big Data, uma empresa poderia, por exemplo, saber quais as características de seus produtos são mais apreciadas e quais são mais criticadas, através de postagens dos clientes em redes sociais. Avançando um pouco mais nos dados do exemplo, poderia ser avaliada a relação entre o poder aquisitivo dos clientes e as características mais apreciadas dos produtos, como durabilidade, design ou preço. Com essas informações poderiam ser criadas linhas de produtos direcionadas para cada segmento.

O objetivo desta pesquisa é apresentar as principais características e aplicações do Big Data, além de avaliar o potencial para sua utilização no Brasil com base nos requisitos para aplicação dessa tecnologia.

\section{METODOLOGIA}

Esse artigo busca analisar o Big Data com base nos seus aspectos técnicos e suas potencialidades para análise de mercado. Com base na descrição realizada, é feita a avaliação do capacidade dessa tecnologia para aplicação no Brasil.

O estudo do cenário atual do Big Data foi feito por pesquisa bibliográfica, pois é a forma mais eficiente de obter informações atuais e em quantidade significativa sobre o assunto pesquisado. Por se tratar de uma tecnologia desenvolvida recentemente, as principais fontes de consulta foram artigos de empresas e instituições de pesquisa.

Para avaliação das possibilidades de aplicação no Brasil foram utilizadas informações relativas ao uso de tecnologias que promovam a produção de dados com potencial para obtenção de informações úteis para estudo de mercado por técnicas de Big Data. 


\section{APLICAÇÃO DO BIG DATA NO ESTUDO DE MERCADO}

Esta seção apresenta a importância dos estudos de mercado e como o Big Data pode complementar as técnicas já existentes para conhecimento do mercado consumidor.

\section{1 - A importância de conhecer o cliente e o mercado}

Apesar de a pesquisa na área de Big Data ter sido iniciada há pouco tempo, a importância de conhecer os desejos e necessidades dos clientes já é levada em consideração no projeto de produtos há mais tempo. Sobre a importância dos clientes no desenvolvimento de novos produtos Slack et al. afirmam,

"O objetivo de projetar produtos e serviços é satisfazer os consumidores atendendo a suas necessidades e expectativas atuais e futuras. Isto, por sua vez, melhora a competitividade da organização. Pode-se observar, portanto, que o projeto de produto e serviço tem seu início com o consumidor e nele termina (2006 p. 113)."

Segundo Seleme e de Paula (2012 p.102), "as necessidades dos clientes, conhecidas tecnicamente como conceitos, constituem um dos princípios norteadores da elaboração de um projeto de produto".

A falta de conhecimento sobre o cliente e o mercado é importante causa de fracasso no lançamento de novos produtos, Hooley, Piercy e Nicoulaud (2011) listam algumas dessas formas de fracasso, apresentadas aqui em resumo:

- Lançamento de produtos sem demanda, que mesmo apresentando algum nível de inovação não despertam o interesse dos consumidores.

- Produtos que não conseguem se equiparar ao líder de mercado.

- O surgimento de produtos concorrentes que acabam por se sobrepor a algum produto que obteve sucesso no seu lançamento.

- Ignorância sobre o ambiente ou o mercado, onde por algum motivo prático o produto lançado enfrenta resistência. Questões culturais ou ambientais podem ocasionar esse tipo problema.

- Produtos que apresentam elevado número de problemas técnicos.

- Prática de preços elevados que desmotivam o consumo.

Pelo que foi exposto, o Big Data não altera a importância do cliente no projeto de produtos, ele pode ser usado como uma nova ferramenta com capacidade de aumentar a velocidade e a precisão da avaliação dos clientes e do mercado.

A lista de possíveis motivos para o fracasso de novos produtos mostrou que a maioria pode ser evitada conhecendo-se os desejos dos clientes, quais características consideram mais importantes e quanto estão dispostos a pagar.

\section{2 - Formas tradicionais de conhecer os clientes}

Para o posicionamento de uma empresa no mercado é fundamental conhecer os clientes, de forma a atender suas expectativas. É importante que as empresas conheçam seus consumidores atuais para poderem aumentar seu nível de satisfação. Também devem buscar conhecer os clientes futuros, que podem ser os consumidores atuais com novas necessidades ou clientes que ainda não se relacionam com a empresa. Neste segundo caso, é importante que sejam analisadas as tendências de mercado, como o surgimento de novos produtos ou tecnologias que possam exigir a busca da inovação. As principais formas de conhecer os clientes são as pesquisas de marketing, ou pesquisas de mercado, para a coleta de informações sobre os clientes, e a modelagem de mercado, para aproveitar os dados obtidos na pesquisa de marketing (HOOLEY; PIERCY; NICOULAUD, 2011).

Como o enfoque deste estudo está na obtenção de informações sobre os clientes, serão apresentadas as técnicas tradicionais de pesquisa de mercado, para que se possam entender as possibilidades do Big Data para melhorar ou complementar as ferramentas já existentes. Segundo Hooley, Piercy e Nicoulaud (2011), as formas de pesquisa de mercado são: os registros internos, a pesquisa pronta e a pesquisa sob encomenda. A seguir é apresentado um resumo de cada um desses métodos.

Os registros internos são as informações presentes na própria empresa, e mesmo não sendo coletadas com objetivo de análise de mercado, podem fornecer conhecimentos relevantes. Podem ser, por exemplo, os registros das vendas realizadas. Nesses registros é possível saber quem são os clientes, qual a quantidade em que compram e se existem padrões nas compras, como a compra conjunta de certos produtos. Como esses dados não são coletados com finalidade de marketing, é importante buscar um padrão de registro que venha a facilitar a obtenção de informações no futuro.

A pesquisa pronta consiste em serviços de pesquisa que não fazem parte da empresa. Hooley, Piercy e Nicoulaud (2011) dividem esse tipo de pesquisa em três categorias. A primeira é a pesquisa secundária, ou desk research, que consiste no uso de dados já disponibilizados por pesquisas realizadas por órgãos sem relação alguma com a empresa, como as pesquisas realizadas pelos órgãos públicos ou instituições privadas que estudam determinada área. Essas informações podem ser encontradas sem custo, porém podem estar desatualizadas ou serem de difícil interpretação. O segundo tipo de pesquisa pronta é a pesquisa sindicalizada. Nessa modalidade, um grupo de interessados contrata uma empresa de pesquisa, compartilhando os custos e os dados obtidos. Empresas de um mesmo setor, por exemplo, podem contratar esse tipo de pesquisa para avaliar o comportamento de determinado mercado de consumo. $\mathrm{O}$ terceiro tipo de pesquisa pronta é a pesquisa compartilhada ou de "ônibus", que consiste no compartilhamento dos custos de campo para a realização da pesquisa, sem que os dados sejam compartilhados entre os contratantes. $\mathrm{Na}$ pesquisa compartilhada, cada empresa tem o direito de incluir algumas perguntas no questionário. Esse tipo de pesquisa possui o inconveniente de exigir um limite pequeno de perguntas de cada empresa, para o questionário não ficar extenso.

A pesquisa sob encomenda permite que a empresa contratante planeje a pesquisa para atender exatamente às suas necessidades. Esse tipo de pesquisa pode empregar uma técnica qualitativa ou quantitativa. $\mathrm{Na}$ pesquisa qualitativa costuma-se envolver um pequeno número de entrevistados, buscando o aprofundamento nas informações coletadas, como as opiniões dos consumidores, por exemplo. Já na pesquisa quantitativa trabalha-se com um número maior de entrevistados e com instrumentos de 
pesquisa mais estruturados, de forma que os dados sejam facilmente quantificáveis, permitindo a análise estatística dos dados.

\section{3 - O Big Data}

O Big Data é uma ferramenta responsável por extrair informações com valor a partir de uma ampla variedade de fontes de dados, incluindo mídias sociais, dispositivos móveis, como os telefones celulares, informações públicas disponíveis na internet, sensores embarcados em carros e edifícios, entre outros (FUJITSU, 2012).

Para a definição do Big Data é comum o uso do modelo dos três Vs, que representam o volume, a velocidade e a variedade.

$\mathrm{O}$ volume se refere ao fato de o Big Data trabalhar com a análise de grandes volumes de informações (FUJITSU, 2012). Esse conjunto de dados pode variar de terabytes (1000 GB) até petabytes (um milhão de GB) (THE PARLIAMENTARY OFFICE OF SCIENCE AND TECHNOLOGY, 2014).

A velocidade reflete a intensa velocidade com que os dados são gerados e mudam. A característica de velocidade do Big Data é importante para os dados que devam ser coletados e analisados rapidamente para serem úteis. Frequentemente devem ser avaliados na mesma taxa em que são coletados (em tempo real), entre os exemplos estão os dados do mercado de ações e as imagens de vigilância militar (THE PARLIAMENTARY OFFICE OF SCIENCE AND TECHNOLOGY, 2014).

A variedade descreve o fato de os dados processados pelo Big Data serem provenientes de uma grande quantidade de fontes, em vários formatos e estruturas. O fluxo de informação avaliado pode incluir textos, informações geográficas, imagens, vídeos e áudios (FUJITSU, 2012). Entre as fontes que geram essa grande variedade de informações estão, por exemplo, sensores, dispositivos inteligentes e mídias sociais. O fato desses dispositivos fornecerem informações de forma semiestruturada ou não estruturada e em uma grande variedade de formatos é um fator que dificulta o armazenamento e o processamento dos dados (ZICARI et al. 2016).

\section{4 - Informações que o Big Data pode fornecer}

O potencial do Big Data está na capacidade de extrair informações relevantes a partir de uma grande quantidade de dados provenientes de fontes diversas e sem padronização. A busca de relações entre diferentes tipos de informações pode ser útil para o surgimento de ideias ou para a tomada de decisões. Um exemplo foi o estudo, por parte do Walmart, para descobrir os produtos mais comprados antes de uma região ser atingida por um ciclone. $\mathrm{O}$ primeiro item da lista, que foi baterias, não apresentou surpresa. Porém, o segundo item da lista, inesperado, foi uma torta de frutas da Kellogg's, chamada Pop-Tarts. Essas tortas duram longo tempo, não necessitam de refrigeração ou preparação e são fáceis de transportar e armazenar. Com essa informação o Walmart pode dimensionar seus estoques desse produto nas áreas atingidas por tornados nos períodos de maior incidência desse fenômeno (FINGAR, 2011).

Pelo exemplo apresentado fica mais simples o entendimento das potencialidades do Big Data, Kubina, Varmus e Kubinova (2015) listam cinco capacidades do Big Data para gerar valor, apresentadas a seguir:
- Aumentar a transparência, por deixar algumas informações mais amplamente disponíveis para novas possibilidades.

- Permitir que empresas realizem experimentos, avaliando o resultado. Por exemplo, experimentos com mudanças de processos utilizando técnicas de Big Data para coletar e analisar os resultados, buscando identificar possíveis melhorias.

- Realizar uma segmentação detalhada dos clientes, de forma a customizar ações e preparar serviços específicos.

- Ajudar o processo de tomada de decisões, mostrando correlações e riscos ocultos. Pode-se, por exemplo, criar ferramentas responsáveis pela análise do risco de fraudes contra seguradoras.

- Possibilitar o descobrimento de novos modelos de negócios. Os dados sobre as formas de utilização de um produto, por exemplo, podem contribuir para o aprimoramento ou o desenvolvimento de novas versões do produto.

\section{5 - Princípios para aplicação do Big Data}

A implementação de uma estrutura de Big Data para o desenvolvimento de novos produtos depende de quatro princípios básicos, consciência, utilidade, agilidade e disponibilidade (SIGNALS ANALYTICS, [201-]).

Consciência - Pelo fato dos dados analisados pelo Big Data serem provenientes de fontes diversas, é importante que o interessado saiba separar as informações relevantes para seu negócio dos dados que são apenas ruído. Com a correta seleção das informações a empresa pode prever descontinuidades do mercado, evitando o lançamento de produtos com vida curta. Esses dados também podem ajudar na identificação de tendências de mercado, contribuindo para o desenvolvimento de produtos inovadores.

Utilidade - É importante que as informações obtidas através do Big Data tenham valor prático na tomada de decisões. O poder do Big Data está em permitir a análise conjunta de dados provenientes de várias fontes para que seja tomada a decisão mais assertiva em questões como: qual tecnologia escolher, qual estratégia de comercialização adotar ou a busca por novos mercados.

Agilidade - Processando dados de forma eficiente, uma empresa pode antecipar fatores dinâmicos do mercado e remodelar suas decisões sobre produtos. Com a escolha correta da tecnologia é possível processar as informações em tempo real. O Big Data pode antecipar mudanças, como novos produtos fornecidos por concorrentes ou novas demandas de mercado. Sua utilidade está na capacidade das empresas absorverem, de forma ágil, as informações obtidas e tomarem as decisões necessárias.

Disponibilidade constante - Como o cenário competitivo está em constante mudança, é necessário que as empresas estejam constantemente monitorando o ambiente para poderem prever mudanças, podendo tomar decisões e criar produtos que se destaquem nos novos contextos de mercado.

\section{6 - Potencialidades para o Brasil}

Diante das características expostas neste artigo, serão apresentados números relativos às condições que favorecem a produção de dados para o Big Data no Brasil. Os dados apresentados consistem no número de pessoas morando em zonas urbanas, na estimativa de usuários da internet e de 
telefonia celular, no número de usuários das principais mídias sociais e nos valores de pagamentos por cartões de crédito e de débito. Esses tópicos possuem função de indicar a capacidade de geração de dados que podem ser explorados por meio do Big Data no Brasil.

O censo de 2010 revela que a população urbana era de 160.925.792 habitantes, contra 29.830.007 habitantes da zona rural (IBGE - INSTITUTO BRASILEIRO DE GEOGRAFIA E ESTATÍSTICA, 2011). Essa proporção de $84,36 \%$ da população morando em zonas urbanas facilita o acesso aos serviços de conectividade, principalmente rede elétrica, telefonia e internet.

O Brasil registrou 234,25 milhões de linhas móveis em operação em setembro de 2018 (ANATEL - AGENCIA NACIONAL DE TELECOMUNICAÇÕES, 2018). Esse valor indica que o número de linhas registradas é maior que a população brasileira, estimada em 209,08 milhões de habitantes em novembro de 2018 (IBGE - INSTITUTO BRASILEIRO DE GEOGRAFIA E ESTATÍSTICA, 2018), uma média de 1,12 linhas de telefonia celular por habitante.

Com relação ao uso da internet fixa, o serviço de banda larga fixa totalizou 30,73 milhões de contratos ativos em setembro de 2018, o que representa uma densidade de $44,2 \%$ dos domicílios com acesso à internet fixa (AGENCIA NACIONAL DE TELECOMUNICAÇÕES, nov 2018).

Esses números indicam que o Brasil possui uma estrutura de dados, para uso da população, bem desenvolvida e em processo de expansão. Essa capacidade de conexão é importante para que sejam disponibilizados meios de produção de dados em massa para alimentar os sistemas de análise por Big Data.

Para estudo do uso das mídias sociais, são apresentados, na Tabela 1 , os números de usuários das principais redes sociais utilizadas no Brasil, listando os países com maior quantidade de usuários para comparação. Os dados apresentados são uma compilação de informações obtidas no portal de informações estatísticas Statista (STATISTA, 2018). Junto a cada rede social é apresentada a data correspondente à informação. Junto ao nome de cada país é apresentado o número de usuários, em milhões.

Tabela 1 - Número de usuário das principais redes sociais.

\begin{tabular}{cccc}
\hline & $\begin{array}{c}\text { Facebook } \\
\text { (Jul 2018) }\end{array}$ & $\begin{array}{c}\text { Twitter } \\
\text { (Abr 2018) }\end{array}$ & $\begin{array}{c}\text { Instagram } \\
(\text { Jul 2018) }\end{array}$ \\
\hline $1^{\circ}$ & Índia & EUA & EUA \\
& $(270)$ & $(72,3)$ & $(120)$ \\
$2^{\circ}$ & EUA & Japão & Índia \\
& $(210)$ & $(50,9)$ & $(67)$ \\
$3^{\circ}$ & Brasil & Reino Unido & Brasil \\
& $(\mathbf{1 3 0 )}$ & $(18,6)$ & $(\mathbf{6 3 )})$ \\
$4^{\circ}$ & Indonésia & Arábia Saudita & Indonésia \\
& $(130)$ & $(13,8)$ & $(59)$ \\
$5^{\circ}$ & México & Turquia $(10,8)$ & Turquia \\
& $(85)$ & $(36)$ \\
$6^{\circ}$ & Filipinas & Brasil & Rússia \\
& $(70)$ & $(\mathbf{1 0 , 1 )}$ & $(33)$ \\
\hline
\end{tabular}

Como se pode observar, o Brasil possui um elevado número de usuários de redes sociais. Essas mídias sociais podem ser uma importante fonte de informações sobre preferências de um grande número de pessoas e podem indicar tendências de mercado, constituindo uma fonte de dados para o Big Data.
O uso de cartões de crédito e débito pode ser um meio importante de conhecer hábitos de consumo. Os dados inerentes a essas formas de pagamento fornecem muitas informações sobre consumo de modo direto. Além de já possuírem os dados cadastrais dos usuários, os operadores de cartões possuem acesso a informações como a localização e horário das compras, assim como o histórico dos seus clientes. Esses dados podem ser processados, pelo Big Data, juntamente aos provenientes de outras fontes, fornecendo informações relevantes para o desenvolvimento de novos produtos com enfoque no mercado.

O valor movimentado pelos cartões de crédito em 2017 aumentou $12,4 \%$ em relação a 2016 , atingindo $R \$ 842,6$ bilhões. Os cartões de débito tiveram alta de 12,6\%, chagando a R 508 bilhões. Para efeito de comparação, os saques em dinheiro movimentaram R \$ 1,31 trilhão em 2017 (LARGHI, 2018).

Observa-se que os pagamentos por meio eletrônico apresentam valor bastante expressivo em relação ao valor dos saques. Esse fato indica que esse é um mercado bem estabelecido no Brasil, sendo adequado para fornecer informações.

\section{CONCLUSÃO}

Observou-se, neste estudo, que o surgimento do Big Data disponibiliza uma nova forma de as empresas conhecerem seus clientes atuais e potenciais. Através da coleta de dados digitais gerados por ferramentas como redes sociais ou o sistema bancário, por exemplo, pode-se avaliar a dinâmica do mercador consumidor. Esse conhecimento pode orientar a tomada de decisões, com a sinalização antecipada de mudanças no mercado ou a indicação de novas demandas.

Pela análise do nível de recursos tecnológicos em uso pela população brasileira, observa-se que grande parte da população é atendida pelos serviços de telefonia móvel e de internet fixa. A análise do uso de redes sociais revela que o Brasil figura entre os países com maior número de usuários. Essas informações são relevantes para indicar o elevado potencial do Big Data no Brasil, visto que tratam de importantes fontes de dados para análise dos consumidores.

$\mathrm{O}$ crescente uso de cartões de crédito e de débito também indica o potencial do Big Data para o Brasil. O Big Data pode ser usado para relacionar informações como localização e horário das compras com dados provenientes de outras fontes, podendo identificar a presença de padrões nas compras.

Por tudo que foi visto, o Big Data pode ser uma ferramenta promissora para utilização no Brasil, visto que é abundante o número de fontes de dados, os quais constituem a matéria prima para a aplicação dessa nova tecnologia.

\section{REFERÊNCIAS BIBLIOGRÁFICAS}

$\begin{array}{lcrr}\text { ANATEL } & \text { AGENCIA NACIONAL } & \text { DE } \\ \text { TELECOMUNICAÇÕES, Telefonia } & \text { Móvel } & \text { - } & \text { Acessos, } \\ 2018 . & \text { Disponível } & \text { em: }\end{array}$
<http://www.anatel.gov.br/dados/acessos-telefonia-movel>. Acesso em: 08 nov 2018.

Banda larga - Acessos, 2018. Disponível em: <http://www.anatel.gov.br/dados/acessos-banda-larga-fixa>. Acesso em: 08 nov 2018. 
FINGAR, P. Big Data + Predictive Analytics = Actionable Business Insights: Consider Big Data as the Most Important Thing for Business since the Internet. BPTrends, 2011. Disponível em: <https://www.bptrends.com/publicationfiles/12-06-2011COL-Extreme\%20Competition-Big\%20Data-Fingar.pdf $>$. Acesso em: 02agosto 2018.

FUJITSU. Big DataThe definitive guide to the revolution in business analytics. Fujitsu Services Ltd, 2012.

HOOLEY, G., PIERCY, N. F., NICOULAUD, B. Estratégia de marketing e posicionamento competitivo. 4. edição. São Paulo: Pearson Prentice Hall, 2011.

IBGE - INSTITUTO BRASILEIRO DE GEOGRAFIA E ESTATÍSTICA - Censo Demográfico - Principais resultados - Sinopse, 2011. Disponível em: <https://www.ibge.gov.br/estatisticas-

novoportal/sociais/populacao/9662-censo-demografico2010.html?=\&t=destaques $>$. Acesso em: 10 de agosto de 2018.

População - Projeção da população do Brasil e das Unidades da Federação, 2018.Disponível em <https://www.ibge.gov.br/apps/populacao/projecao/>, Acesso em: 08 nov 2018.

KUBINA, M., VARMUS, M., KUBINOVA, I. Use of big data for competitive advantage of company. Procedia Economics and Finance, Elsevier, n. 26, p. 561-565, 2015.

LARGHI, N. Operações com cartão de crédito crescem em 2017 para R\$ 843 bilhões, Valor Econômico, mai 2018. Disponível

$<$ https://www.valor.com.br/financas/5381833/operacoescom-cartao-de-credito-crescem-em-2017-para-r-843bilhoes>. Acesso em: 12 de agosto de 2018.

SElEME, R; DE PAULA, A. Projeto de Produto: Planejamento, Desenvolvimento e Gestão.1. edição. Curitiba: Intersaberes, 2012.

SIGNALS ANALYTICS, Product Development in the Age of Big Data:What You Need To Know, [201-]. Disponível em:

$<$ https://cdn2.hubspot.net/hubfs/548488/docs/White_Papers _and_Articles/WP_Product_Development_in_Age_of_Big_ Data.pdf $>$. Acesso em: 08 de agosto de 2018.

SLACK, N. CHAMBERS, S. HARLAND, C. HARRISON A.; JOHNSTON, R. Administração da produção - Edição Compacta. 1. edição. São Paulo: Atlas, 2006.

STATISTA, The Statistics Portal - Statistics and Studies from more than 22,500 Sources, 2018. Disponível em: <https://www.statista.com/>. Acesso em: 10 de agosto de 2018.

THE PARLIAMENTARY OFFICE OF SCIENCE AND TECHNOLOGY. Big Data: An Overview. POSTnote 468, Londres, jul. 2014.

ZICARI, R. V., ROSSELLI, M., IVANOV, T., Korfiatis, N., TOLLE, K., NIEMANN, R., REICHENBACH, C. Setting Up a Big Data Project: Challenges, Opportunities, Technologiesand Optimization. Big Data Optimization: Recent Developments and Challenges, Springer International Publishing, p. 17-47, 2016.

\section{COPYRIGHT}

Direitos autorais: O autor é o único responsável pelo material incluído no artigo. 


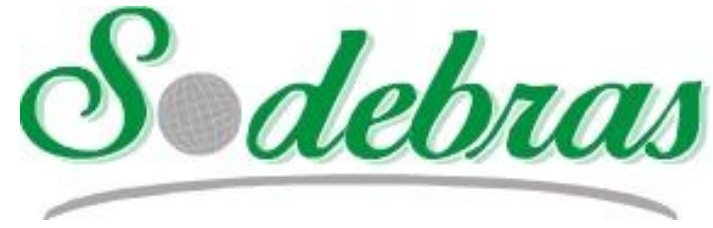

Volume 14 - No 159 - Março/2019.

XL International Sodebras Congress

10 a 12 de dezembro de 2018 - Vitória - ES.

\title{
USO GERENCIAL DAS FERRAMENTAS DA QUALIDADE PARA TOMADA DE DECISÃO: UM ESTUDO DE CASO SOBRE O ELEVADO ÍNDICE DE DEVOLUÇÃO NA DISTRIBUIÇÃO LOGÍSTICA E A CRIAÇÃO DA ÁREA DE CUSTOMER SERVICE
}

\section{MANAGEMENT USE OF QUALITY TOOLS FOR DECISION MAKING: A CASE STUDY ON HIGH RETURN INDEX OF LOGISTICAL DISTRIBUTION AND CREATING THE CUSTOMER SERVICE AREA}

\author{
LUCAS DE SOUZA CAMPOS ${ }^{1}$; JOSÉ ELMO DE MENEZES ${ }^{1}$
}

1 - PONTIFÍCIA UNIVERSIDADE CATÓLICA DE GOIÁS.

lucasszcampos@gmail.com; jelmo.maf@gmail.com;

\begin{abstract}
Resumo - Este artigo evidência as causas dos retornos e devoluções do processo logístico de uma empresa alimentícia, a fim de compreender as causas, foi efetuado um estudo por meio da análise teórica especificando os conceitos e mensuração de eficiência, o método de aplicação e segmentação utilizado para organização dos dados foi o PDCA, determinando as etapas das ferramentas da qualidade. Com isso é possível identificar as causas da não conformidade e tratar cada problema de acordo com sua significância através da extração explícita. Logo o artigo abordará uma metodologia como Estudo de Caso, um trabalho de modo empírico que considera, investiga e pondera um fenômeno. A presente pesquisa apresentará hipóteses para sustentação e ratificação dos resultados propondo a criação da área de Customer Service (Atendimento ao Cliente), com o propósito da minimização de custos e maximização dos lucros. Palavras-chave: Logística; Ferramentas da qualidade; Customer service; Redução de custos
\end{abstract}

\begin{abstract}
This article evidences the causes of returns and returns of the logistic process of a food company, in order to understand the causes, a study was carried out through the theoretical analysis specifying the concepts and measurement of efficiency, the application method and segmentation used for organization of the data was the PDCA, determining the steps of the quality tools. With this it is possible to identify the causes of nonconformity and treat each problem according to its significance through explicit extraction. Soon the article will approach a methodology like Case Study, an empirical work that considers, investigates and ponders a phenomenon. The present research will present hypotheses to support and ratify the results proposing the creation of the Customer Service area, with the purpose of minimizing costs and maximizing profits.

Keywords: Logistics. Quality tools. Customer service. Reduction of costs.
\end{abstract}

\section{INTRODUÇÃO}

Fazer mais com menos, maximizar lucro e reduzir o custo, otimização de processos, maior eficiência, prospecção, automação, todas essas ações e demandas tem apenas um só objetivo, rentabilidade. Todas as empresas, companhias ou órgãos cujo objetivo é de gerar lucro, foca em diversas atividades do seu processo visando enxugar e reduzir. Só que além disso tudo, é necessário investir em relacionamento com o cliente, entender a sua real necessidade, dar foco para o que é de interesse do cliente e assim oferecer o serviço ou o produto que realmente o satisfaz. O TQM (Total Quality Management) Gerenciamento da Qualidade Total tem como o objetivo assegurar, garantir essa satisfação ao cliente, na visão de Oakland (1994, p. 9), pode ser assim definida:

"A redução contínua dos custos, a produtividade e a melhoria da qualidade têm demonstrado que são essenciais para as organizações se manterem em operação. Não podemos deixar de ver como a qualidade transformou-se na mais importante arma competitiva e muitas organizações estão convencidas de que o TQM é o modo de gerência do futuro. O TQM, em suas aplicações, vai muito além do que apenas garantir a qualidade do produto ou do serviço - é uma maneira de gerenciar os processos da empresa para assegurar a completa satisfação do "cliente", em cada etapa, tanto interna como externamente OAKLAND (1994, p. 9).”

É extremamente importante que as empresas estejam focadas e atentas as expectativas dos seus clientes, pois a partir daí a confiabilidade, credibilidade e fidedignidade irão garantir uma prospecção de mais clientes e um aumento significativo para o seu negócio (serviço ou produto). Performance Research Associates (2008, p.11) "Proporcionar um atendimento nota 10 é criar uma experiência positiva e inesquecível para cada cliente. Significa procurar oportunidades de surpreender e cativar o cliente de um modo único e inesperado".

\section{2 - Logística um elemento estratégico}

A logística tem um papel essencial nas companhias, este processo pode proporcionar uma maior rentabilidade, como também pode causar muitos danos a imagem do negócio. Uma logística eficiente dentro de uma organização representa um alto nível de qualidade, deste a entrada de 
matéria prima (input) até a entrega do produto acabado (output). Segundo Martin (2006, p. 326), “a logística é responsável pelo planejamento, operação e controle de todo o fluxo de mercadorias e informação, desde a fonte fornecedora até o consumidor”. Já para Dias (1993, p. 12), "A logística compõe-se de dois subsistemas de atividades: administração de materiais e distribuição física, cada qual envolvendo o controle da movimentação e a coordenação da demanda de suprimento". Ainda sobre o papel da logística, afirma Ballou (1993, p. 40):

“A distribuição física é o ramo da logística empresarial que trata da movimentação, estocagem e processamento de pedidos dos produtos finais da firma. Absorve cerca de dois terços dos custos logísticos. Preocupa-se principalmente com bens acabados ou semi-acabados BALLOU (1993, p. 40)."

Com o desenvolvimento dos negócios, focando no cliente, ouvindo a voz do cliente, e servindo o cliente a logística se tornou um elemento estratégico, o que antes era visto como um meio transacional do negócio agora se tornou um elemento relacional, com novos atributos, valorizando a relação, com processamento e gestão de pedidos, organizando e gerindo fluxo de materiais e toda a cadeia de suprimentos, de acordo com Christopher (2007, p. $3)$ :

"Logística é o processo de gerenciamento estratégico da compra, do transporte e da armazenagem de matérias-primas, partes e produtos acabados (além dos fluxos de informação relacionados) por parte da organização e de seus canais de marketing, de tal modo que a lucratividade atual e futura sejam maximizadas mediante a entrega de encomendas com o menor custo associado CHRISTOPHER (2007, p. 3).”

\section{3 - Customer Service mecanismo de produtividade}

Surge aí a necessidade do (Customer Service) Atendimento ao Cliente, para além de colaborar com o cliente na entrega é preciso proporcionar uma excepcional experiência de compra. Os canais de comunicação entre empresa e cliente precisam ser ampliados, nos dias atuais a tecnologia da informação abre espaço para isso e poucas companhias olham isso como relevante, veja o que Chiavenato (2005, p. 209) destaca:

"No negócio, o atendimento ao cliente é um dos aspectos mais importantes, sendo que o cliente é o principal objetivo do negócio, [...] que todo negócio deve ser voltado ao cliente, sendo que só permanecerá se o cliente estiver disposto a continuar comprando o produto/serviço CHIAVENATO (2005, p. 209)."

O principal escopo do Customer Service é destacado por Salzano (2008, p.7) "oferecer serviços de forma a permitir não somente a manutenção da carteira de clientes atuais, como a conquista de novos clientes".

Com relação às contribuições que poderão ser encontradas no desenvolver deste estudo, destacam-se o foco dado à Logística de Distribuição (Outbound), como fator determinante do Nível de Serviço Logístico e a integração de processos entre o fornecedor e o cliente para a maximização da satisfação dos mesmos. De acordo com Christopher (1997, p. 6):

“(...) o serviço está relacionado ao processo de desenvolvimento de relações com os clientes através da disponibilidade de uma oferta incrementada. Este incremento pode tomar várias formas, incluindo-se o serviço de entrega, serviço pós-venda, pacotes financeiros, apoio técnico e assim por diante CHRISTOPHER (1997, p. 6)."

O Customer Service tem como objetivo interagir e se relacionar com o cliente, através dessa relação pode-se aplicar uma política efetiva ao serviço, gerando a um mecanismo de produtividade no qual permite cumprir com a distribuição no tempo correto, com a totalidade do pedido e ao menor custo possível. Este estudo irá evidenciar uma situação real expondo as causas de retorno e devolução de uma empresa de alimentos, utilizando as ferramentas da qualidade será explanado o quanto a área de Customer Service poderia reduzir esta perda.

\section{4 - Ciclo PDCA}

Conhecido também como ciclo de Deming o ciclo PDCA é umas das representações mais conhecidas da filosofia de melhoria contínua (Kaizen). Método amplamente eficiente no conjunto de atividades de uma operação, atuando em quatro fases, a base da filosofia do Kaizen.

O ciclo é composto porá 4 etapas sendo, Planejamento (Plan) plano de ação desenvolvido após a extração dos problemas e suas causas, este plano irá corrigir as não conformidades com o objetivo de alcançar o resultado e metas definidas. Execução (Do), nesta etapa cumpre-se e executa o que foi planejado, em sequência vem a verificação (Check), onde se acompanha os resultados das ações planejadas e se as mesmas chegaram nos resultados definidos, logo vem a última etapa (Action) onde se elabora planos adicionais e se padroniza as melhores práticas.

\section{5 - Ferramenta da Gestão da Qualidade}

Constantes mudanças, incertezas, vivemos um cenário em que as empresas precisam se manter competitivas e as Ferramentas de Gestão da Qualidade vai de encontro a isso, podendo atuar direto na causa e melhorar o seu produto e seu serviço. Essas ferramentas ajudam na identificação da causa e na atuação do problema raiz, podendo ser usadas para atingir as metas e objetivos.

As ferramentas da qualidade são um meio para chegar ao objetivo da organização, identificando as causas fundamentais e ações a serem tomadas para alcance do propósito, seguindo os passos de cada etapa, identificação do problema e coletar dados históricos (Histogramas; Pareto); Estabelecer meta geral; Desdobrar o problema (Estratificação; Gráfico de Pareto); Analisar o processo e detectar a raiz das causas do problema e determinar oportunidades nas variações do processo (Brainstorming; Diagrama de Ishikawa; 5 Por quês); Priorizar problemas (GUT); Estabelecer as metas especificas (Diagrama de Árvore); Identificar as causas (Ishikawa); Com isso podemos estabelecer ações para cada causa priorizada (Elaborar Plano de Ação). As ações devem ser concretizas, os resultados devem ser checados e as causas tratadas. 


\section{OBJETIVOS E JUSTIFICATIVAS}

Inúmeros trabalhos têm sido publicados a respeito de Qualidade, explanando seu impacto e amplitude, a exemplo de outras obras deste mesmo tema, entende-se que este artigo se reveste de uma etapa crucial do processo como um todo, a logística de distribuição do produto acabado (outbound) e seu impacto com a ausência da área Customer Service. Este artigo pretende contribuir para o entendimento e evidenciar os impactos de uma situação real, onde os elementos que contribuem para um aceitável nível de serviço são impactados, levando a companhia a situações indesejáveis.

\section{OBJETO DE ESTUDO}

A pesquisa foi realizada em um centro de distribuição localizada no município de Aparecida de Goiânia - GO, a fim de preservar sua identidade iremos denominar como empesa "X".

A empresa " $\mathrm{X}$ " tem como atividade principal a comercialização dos seus produtos, usando um centro de distribuição (CD) para atender seus clientes de forma estratégica, pois este $\mathrm{CD}$ encontra-se em um posicionamento geográfico para realizar a distribuição no menor custo possível e no tempo certo.

\section{APLICAÇÃO DA METODOLOGIA}

O objetivo desta seção é de explanar os dados coletados através das ferramentas da qualidade, bem como o ciclo PDCA, método usado para estruturação deste trabalho. Neste artigo foi analisado o MIT para um veículo elétrico, porém o circuito implementado pode ser utilizado para controlar a velocidade de motores de indução para outras finalidades, sejam residenciais ou industriais. A Figura 1 representa a chave seletora ligada ao pedal.

\section{1 - Identificação do problema}

Foi realizado uma visita técnica na empresa " $\mathrm{X}$ " para entendimento do processo de distribuição, conhecendo procedimentos de entrada de pedidos, roteirização, separação, expedição e distribuição, o processo funciona conforme Figura 1:

Figura 1 - Ciclo do processo logístico da empresa "X"

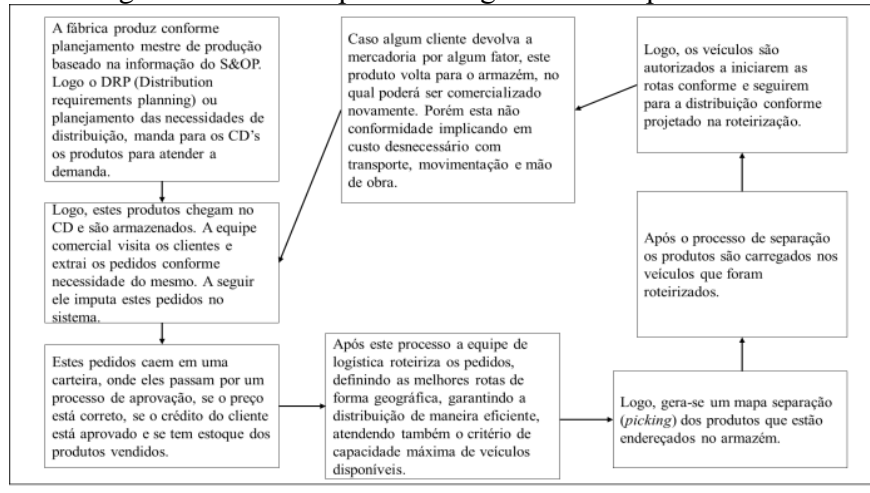

Fonte: Próprio autor, 2018

Como pode ver na Figura 1 o CD é abastecido conforme planejamento feito pelo S\&OP (Sales and Operations Planning), abastecendo o volume necessário para efetivação da meta de vendas da equipe comercial.
Logo os pedidos são tratados para dar início aos embarques e dar sequência a distribuição.

Observou-se um grande índice de devolução dos clientes e um elevado custo de frete e um alto custo de movimentação, pois a operação da empresa " $X$ " é terceirizada e a cada movimentação é paga para um operador logístico.

Foi analisado o índice de devolução do ano de 2017, a companhia estabeleceu como meta um aceite de até $1,5 \%$ de devolução, e conforme Figura 2 abaixo fica evidente que este número não foi alcançado no ano analisado.

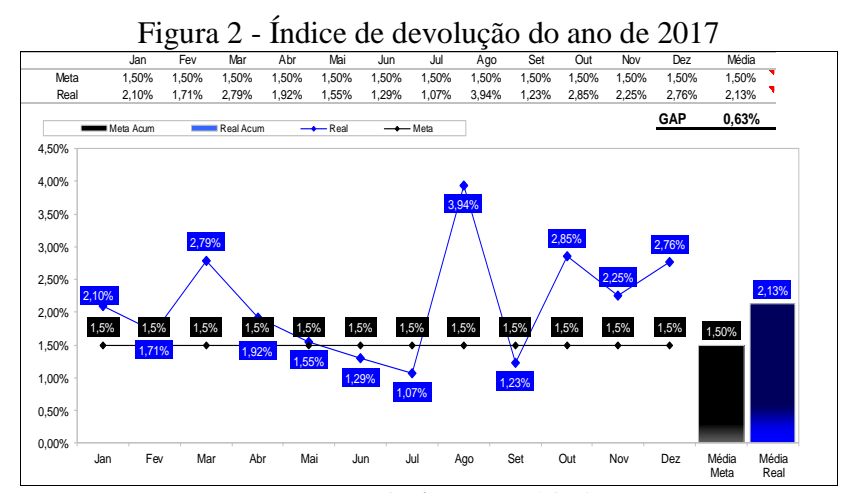

Fonte: Próprio autor, 2018

Para tingir o objetivo da empresa " $\mathrm{X}$ " iremos adotar o PDCA como método e através das ferramentas da qualidade iremos mensurar e medir propondo soluções para o cumprimento da meta esperada.

\subsection{1 - Identificação do problema}

Foi analisado todos os motivos de devolução no ano de 2017 da empresa estudada, conforme Tabela 1 que vem logo a seguir evidencia no detalhe as 122,9 toneladas de devolução.

Como princípio do método adotado, essa estratificação se faz necessária para encontramos os maiores motivos das causas não conformes que acarretam em devoluções, nessa mesma tabela evidencia-se o volume devolvido, sua representatividade e o acumulo dos outros motivos.

Tabela 1 - Índice de devolução do ano de 2017

\begin{tabular}{|c|c|c|c|}
\hline TÓPICOS DA ESTRATIFICAC̣̃̃O & N.'DE OCORRÊNCIAS & $\%$ ACUMULADO & \% UNITÁRIO \\
\hline$\overline{\text { SEM PEDIDO }}$ & 28.658 & $23 \%$ & $23 \%$ \\
\hline PEDIDO CANCELADO & 26.981 & $45 \%$ & $22 \%$ \\
\hline PREÇO INCORRETO & 16.851 & $59 \%$ & $14 \%$ \\
\hline DUPLICIDADE DE PEDIDO & 16.132 & $72 \%$ & $13 \%$ \\
\hline SEM CONDIÇÕES DE RECEBER ESTOQUE ELEVADO & 5.338 & $76 \%$ & $4 \%$ \\
\hline DVG DE DADOS NA NF(R. SOCIAL, CNPJ, ETC) & 4.870 & $80 \%$ & $4 \%$ \\
\hline PEDIDO FAT. P/LOJA/DPTO ERRADO CLIENTE & 4.039 & $84 \%$ & $3 \%$ \\
\hline FALTA ESPACO NO ESTAB.DO CLIENTE & 3.793 & $87 \%$ & $3 \%$ \\
\hline PROBLEMAS TECNICOS EQUIP.CLIENTE & 3.092 & $89 \%$ & $3 \%$ \\
\hline PEDIDO DIGITADO COM OP. FATUR. INCORRETA & 2.670 & $91 \%$ & $2 \%$ \\
\hline ITEM OU VOLUME INCORRETO EM PEDIDO & 2.165 & $93 \%$ & $2 \%$ \\
\hline DIVERGENCIA DE IMPOSTO & 1.842 & $95 \%$ & $1 \%$ \\
\hline SEM CONDIÇÕES DE RECEBER CAMARA QUEBRADA & 1.678 & $96 \%$ & $1 \%$ \\
\hline ESTAB.DO CLIENTE FECHADO & 1.554 & $97 \%$ & $1 \%$ \\
\hline SEM CONDIÇÕES DE RECEBER INVENTARIO & 1.315 & $98 \%$ & $1 \%$ \\
\hline QTDE./PESO MAIOR QUE O SOLIC. P/ CLIENTE & 947 & $99 \%$ & $1 \%$ \\
\hline NAO ENTREGUE VEICULO RETIDO OUTRO CLIENT & 319 & $99 \%$ & $0 \%$ \\
\hline DIVERGENCIA NA CONDICAO DE PAGAMENTO & 239 & $100 \%$ & $0 \%$ \\
\hline PERCENTUAL VIDA UTIL DIVERGE DO NEGOCIAD & 224 & $100 \%$ & $0 \%$ \\
\hline CADASTRO INCORRETO DE VIDA UTIL & 202 & $100 \%$ & $0 \%$ \\
\hline
\end{tabular}

Fonte: Próprio autor, 2018

Quando analisamos seus maiores motivos de devolução identificamos que $72 \%$ se resumem em quatro causas representando 88,6 toneladas. De acordo com a Figura 3 estaremos analisando o Diagrama de Pareto, onde evidencia a curva de porcentagens acumuladas, e a ordem de prioridades a serem atacadas.

O princípio do Diagrama de Pareto afirma que aproximadamente $80 \%$ dos efeitos vêm de $20 \%$ das causas, através desta ferramenta as maiores causas são evidentes e o 
seu tratamento passa a ser imediato. "Um gráfico de barras que organiza os dados do maior para o menor para direcionar atenção nos itens importantes" (HAGEMEYER; GERSHENSON; JOHNSON, 2006, p. 464).

Figura 3 - Gráfico de Pareto

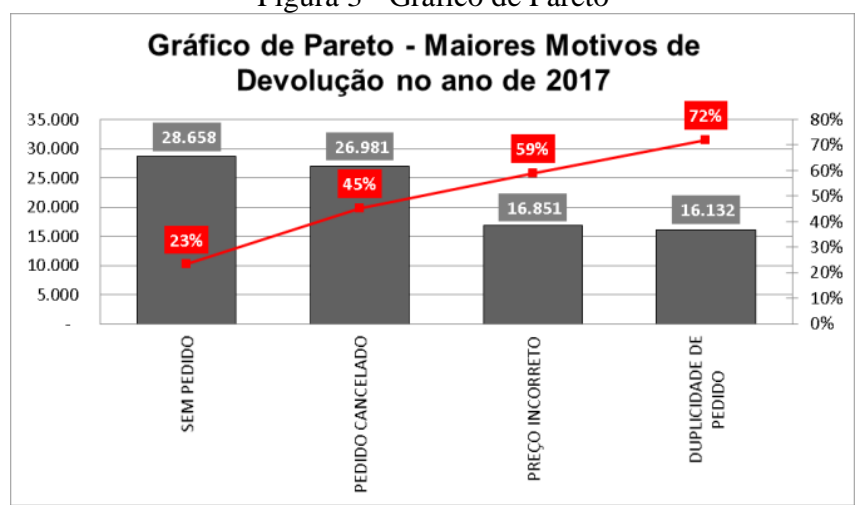

Fonte: Próprio autor, 2018.

Logo análise da causa identificamos as quatro principais, sem pedido, pedido cancelado, preço incorreto e duplicidade de pedido, estes representam $72 \%$ dos problemas.

O Diagrama de Ishikawa irá indicar a relação entre o efeito e as causas de cada ocorrência, essa é uma ferramenta da qualidade criado na década de 60 por Kaoru Ishikawa, onde seu maior e principal objetivo é levantar as causasraízes de um problema, que ao eliminar a sua causa consequentemente elimina-se o problema. Segue abaixo a figura 4, 5, 6 e 7 onde foi realizado o Diagrama de Ishikawa das principais não conformidades, a fim de encontrar a causa-raiz de todas elas. Segue definições por Ivanovic; Majstorovic, 2006; Venkatraman, 2007:

"É uma representação gráfica que permite a organização de informações por semelhança a partir de seis eixos principais (método, material, máquinas, meio ambiente, mão de obra e medição), possibilitando a identificação das possíveis causas de um determinado problema, ou efeito, de forma específica e direcionada."

Diagrama de Causa e Efeito: Também conhecido como "espinha de peixe" ou diagrama de Ishikawa. É uma maneira de descrever e analisar um problema decompondoo em suas diversas prováveis causas. É estruturado de maneira que o problema fica ao longo de uma linha central da qual partem ramificações com as possíveis causas, lembrando uma espinha de peixe (ZARPELON; CARVALHO, 2013);
Figura 4 - Diagrama de Ishikawa - Causa Sem Pedido

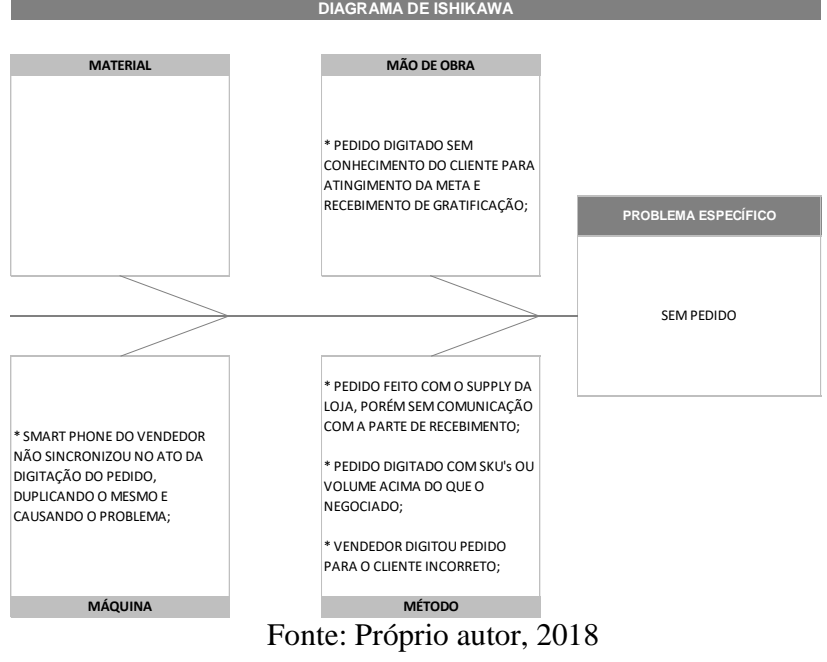

Figura 5 - Diagrama de Ishikawa - Causa Pedido Cancelado

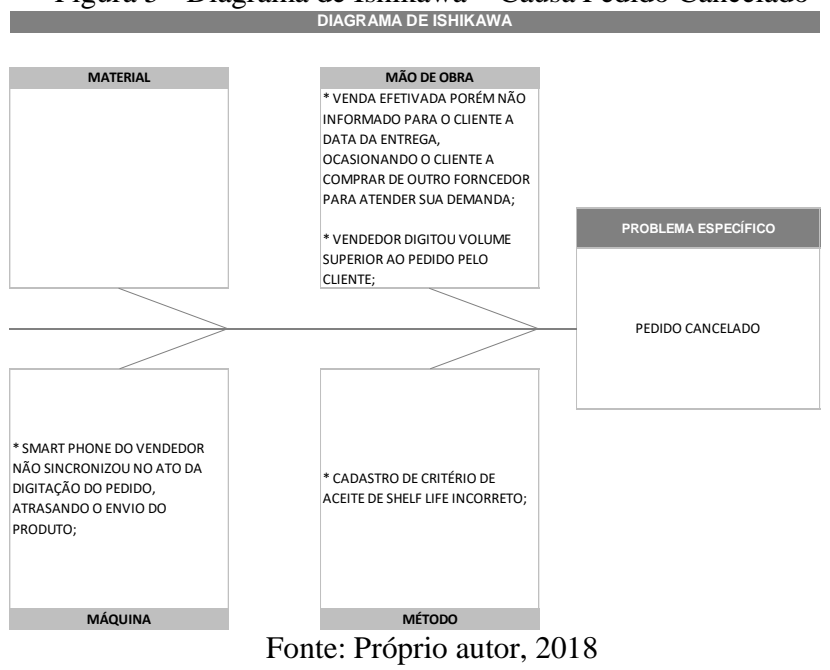

Figura 6 - Diagrama de Ishikawa - Causa Preço Incorreto

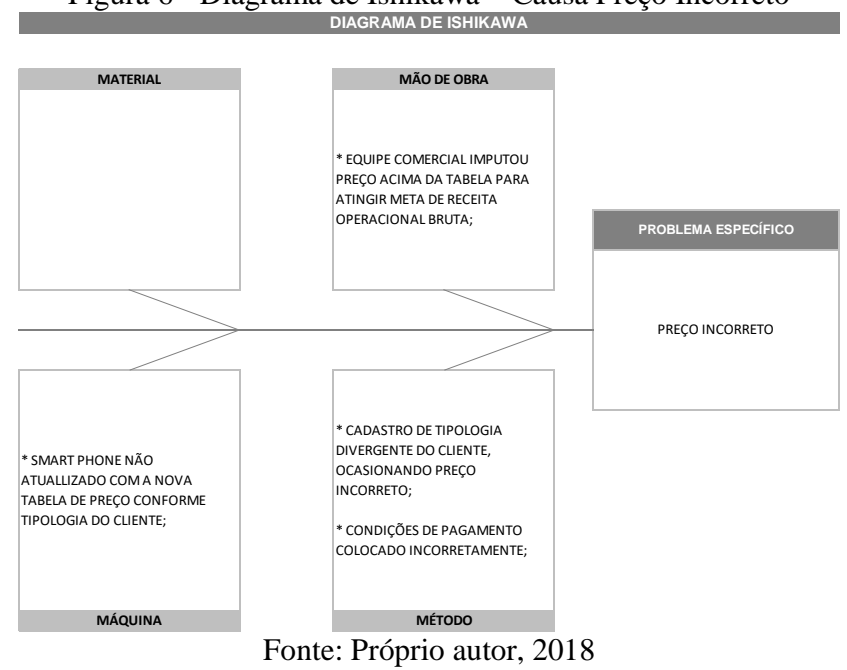


Figura 7 - Diagrama de Ishikawa - Causa Duplicidade de Pedido

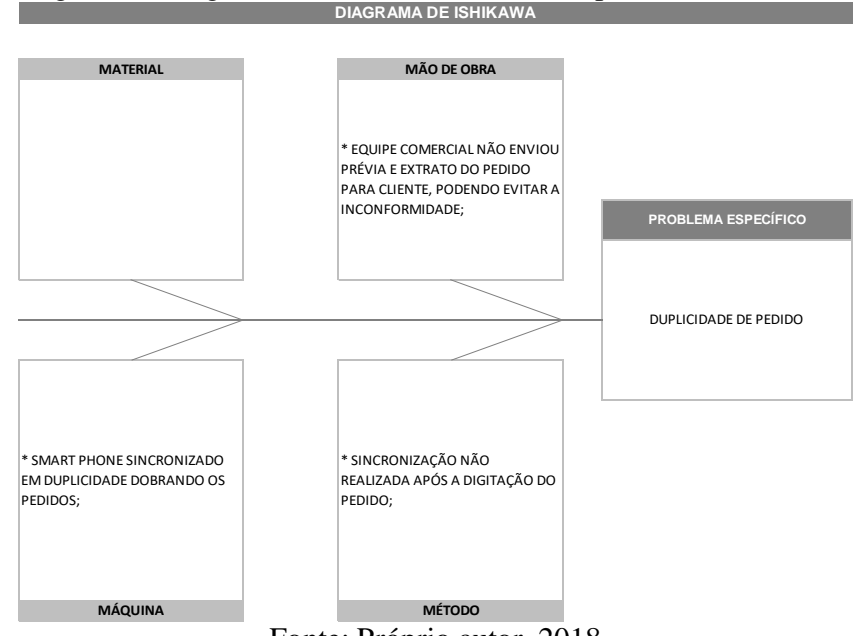

Fonte: Próprio autor, 2018

\section{2 - Identificação do problema}

Após identificação das causas dos problemas foi utilizado uma outra ferramenta da qualidade chamada Matriz GUT (gravidade, urgência e tendência), onde foi categorizado e criado uma métrica racional nas causas que devem ter mais atenção.

Foi criado uma escala de 1 a 5 atribuindo valores para os possíveis maiores impactos, conforme Tabela 2, ou seja, quanto menor impacto menor a escala, isso associado a gravidade, urgência e tendência. Logo multiplicamos os resultados e identificamos os maiores valores, e estes serão a prioridade para as devidas tratativas.

Tabela 2 - Matriz GUT

\begin{tabular}{|c|c|c|c|c|}
\hline CAUSAS PRIORITÁRIAS & GRAVIDADE & URGÊNCIA & TENDÊNCIA & TOTAL \\
\hline $\begin{array}{l}\text { CADASTRO DE TIPOLOGIA DIVERGENTE DO } \\
\text { CLIENTE, OCASIONANDO PREÇO INCORRETO; }\end{array}$ & 5 & 5 & 3 & 75 \\
\hline $\begin{array}{l}\text { CONDIÇÕES DE PAGAMENTO COLOCADO } \\
\text { INCORRETAMENTE; }\end{array}$ & 5 & 5 & 3 & 75 \\
\hline $\begin{array}{l}\text { CADASTRO DE CRITÉRIO DE ACEITE DE SHELF } \\
\text { LIFE INCORRETO; }\end{array}$ & 4 & 5 & 3 & 60 \\
\hline $\begin{array}{l}\text { PEDIDO FEITO COM O SUPPLY DA LOJA, } \\
4 \text { PORÉM SEM COMUNICAÇÃO COM A PARTE DE } \\
\text { RECEBIMENTO; }\end{array}$ & 4 & 4 & 3 & 48 \\
\hline $\begin{array}{l}\text { VENDA EFETIVADA PORÉM NÃO INFORMADO } \\
\text { PARA O CLIENTE A DATA DA ENTREGA, }\end{array}$ & & & & \\
\hline $\begin{array}{l}5 \text { OCASIONANDO O CLIENTE A COMPRAR DE } \\
\text { OUTRO FORNCEDOR PARA ATENDER SUA } \\
\text { DEMANDA; }\end{array}$ & 5 & 3 & 3 & 45 \\
\hline $\begin{array}{l}\text { EQUIPE COMERCIAL IMPUTOU PRECCO ACIMA } \\
6 \text { DA TABELA PARA ATINGIR META DE RECEITA } \\
\text { OPERACIONAL BRUTA: }\end{array}$ & 5 & 3 & 3 & 45 \\
\hline $\begin{array}{l}\text { EQUIPE COMERCIAL NÃO ENVIOU PRÉVIA E } \\
7 \text { EXTRAO DO PEIDO PARA CLIENTE, } \\
\text { PODENDO EVITAR A INCONFORMIDADE: }\end{array}$ & 4 & 3 & 3 & 36 \\
\hline $\begin{array}{l}\mathbf{v} \text { VENDEDOR DIGITOU PEDIDO PARA O CLIENTE } \\
\text { INCORRETO; }\end{array}$ & 4 & 3 & 3 & 36 \\
\hline $\begin{array}{l}\text { PEDIDO DIGITADO SEM CONHECIMENTO DO } \\
\text { 9 CLIENTE PARA ATINGIMENTO DA META E } \\
\text { RECEBIMENTO DE GRATIFICACCÃO; }\end{array}$ & 4 & 4 & 2 & 32 \\
\hline $\begin{array}{l}10 \text { VENDEDOR DIGITOU VOLUME SUPERIOR AO } \\
\text { PEDIDO PELO CLIENTE; }\end{array}$ & 3 & 3 & 3 & 27 \\
\hline $\begin{array}{l}\text { SMART PHONE NÃO ATUALIZADO COM A } \\
\text { 11 NOVA TABELA DE PRECOO CONFORME } \\
\text { TIPOLOGIA DO CLIENTE; }\end{array}$ & 3 & 3 & 3 & 27 \\
\hline $\begin{array}{l}12 \text { SMART PHONE SINCRONIZADO EM } \\
\text { DUPLICIDADE DOBRANDO OS PEDIDOS; }\end{array}$ & 4 & 3 & 2 & 24 \\
\hline $\begin{array}{l}13 \text { PEDIDO DIGITADO COM SKU's OU VOLUME } \\
\text { ACIMA DO QUE O NEGOCIADO; }\end{array}$ & 4 & 2 & 3 & 24 \\
\hline $\begin{array}{l}\text { SMART PHONE DO VENDEDOR NÃO } \\
14 \text { SINCRONIZOU NO ATO DA DIGITACÃ̃O DO } \\
\text { PEDIDO, ATRASANDO O ENVIO DO PRODUTO; }\end{array}$ & 4 & 3 & 2 & 24 \\
\hline $\begin{array}{l}\text { SMART PHONE DO VENDEDOR NÃO } \\
\text { SINCRONIZOU NO ATO DA DIGITAČ̃̃ DO } \\
\text { PEDIDO, DUPLICANDO O MESMO E CAUSANDO } \\
\text { O PROBLEMA; }\end{array}$ & 3 & 3 & 2 & 18 \\
\hline $\begin{array}{l}\text { SINCRONZZAČ̃̃ NÃO REALIZADA APÓS A } \\
16 \text { DIGITAÇÃO DO PEDIDO; }\end{array}$ & 2 & 3 & 2 & 12 \\
\hline
\end{tabular}

Fonte: Próprio autor, 2018

A partir da análise da Matriz GUT alguns questionamentos sucessivos de determinadas situações foram realizadas, até chegarmos a causa raiz, onde se inicia os problemas. De acordo com a Tabela 3 utilizamos a ferramenta da qualidade 5 Por quês, método que indaga as causas até chegar ao ponto inicial do problema. Neste caso até mesmo antes do quinto já encontramos a inconformidade.

Tabela 3 - 5 Por quês
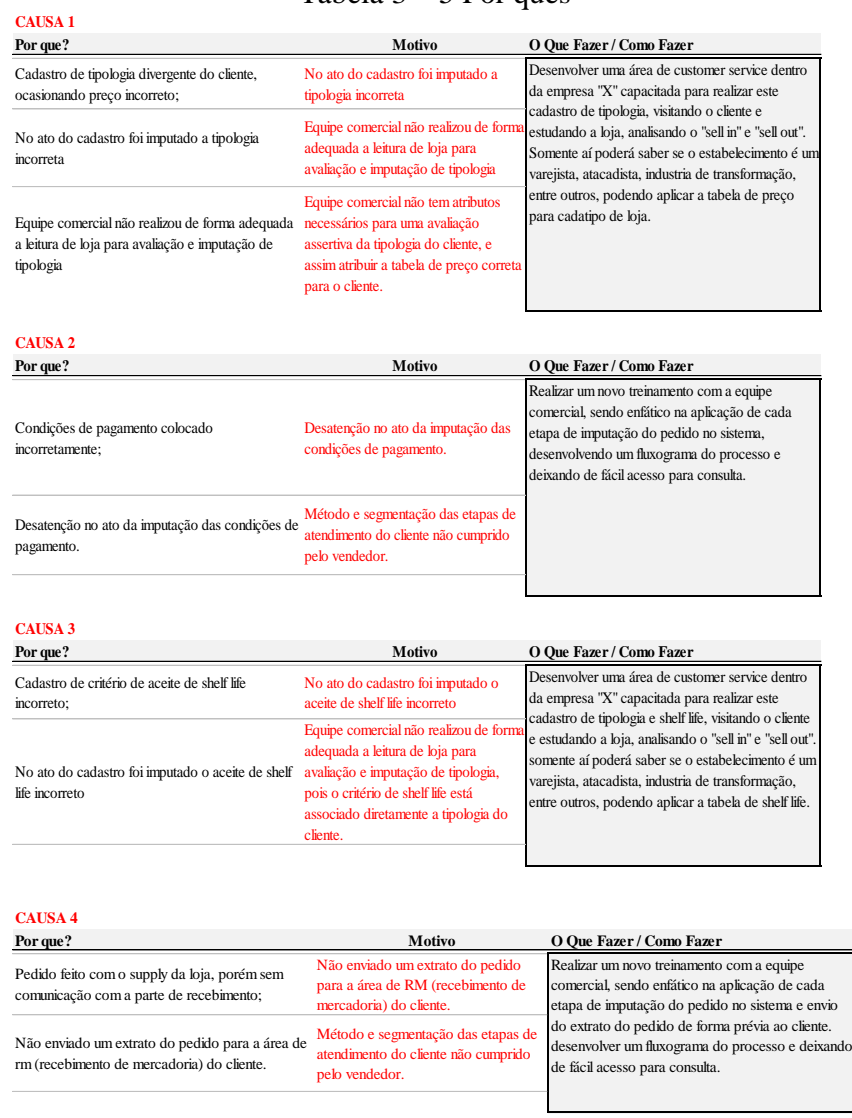

CAUSA

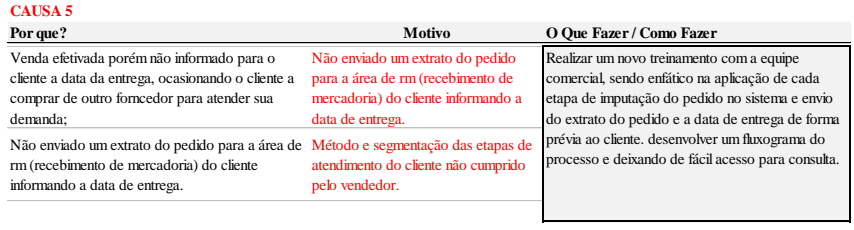

CAUSA 6

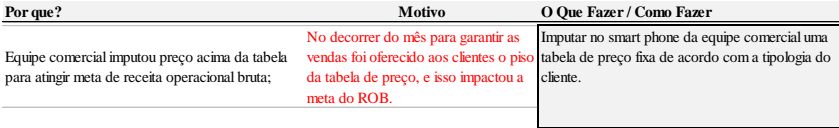

Fonte: Próprio autor, 2018

Encontrando a causa raiz foi estruturado ações para resolução das inconformidades, estabelecendo o que fazer, quem irá fazer, quando fazer, onde fazer, o por que será feito, como e quanto custará. Essa é mais uma ferramenta da qualidade com o objetivo de corrigir as falhas, esta ferramenta denomina-se de $5 \mathrm{~W} 2 \mathrm{H}$.

\section{CONCLUSÃO}

Foi ratificado neste estudo a importância da área de customer service e principalmente o nível de serviço, o principal objetivo da logística é atender os requerimentos e expectativa do cliente. $\mathrm{E}$ os consumidores avaliam a empresa pela qualidade do seu produto, preço e serviço prestado.

Através dos métodos estudados como ferramenta da qualidade e estrutura do PDCA, foi identificado as principais causas das devoluções da empresa " $\mathrm{X}$ ", e com isso foi traçado um plano de ação para tratativas das causas. Observamos que a não existência da área de customer 
service implica em alguns desgastes com o próprio cliente desencadeando um custo desnecessário, como frete e movimentação de produto, já que a operação é terceirizada por um operador logístico, até mesmo porque a receita gerada pelas vendas e os custos da operação logística determinam o lucro da empresa.

Entretanto o estudo mostrou que o fator decisivo está também na falta de treinamento e mudança de comportamento da equipe comercial, com descumprimento de métodos, informações deficitárias e processos errôneos que são fatores diretos para o alto índice de devolução.

Através deste trabalho foi possível implantar as ações de correções planejadas, desenvolvendo um analista de customer service, onde o mesmo visita os clientes com maiores frequências e volume de devoluções, desenvolvendo um plano para melhor atender o cliente, aumentando a produtividade do mesmo, minimizando os custos logísticos e maximizando o lucro da empresa " $\mathrm{X}$ ". No mês de abril do ano de 2018 a empresa " $X$ " fechou o indicador de devolução com $1,32 \%$, número reduzido em comparação ao ano anterior, reflexo da aplicação das ferramentas da qualidade.

\section{REFERÊNCIAS BIBLIOGRÁFICAS}

BENJAMIM MOURA. Logística Conceitos e Tendências. Lisboa, Portugal. Editora Centro Atlântico 2006.

CHIAVENATO, Idalberto. Empreendedorismo: Dando asas ao espírito empreendedor. São Paulo: Saraiva, 2005.

CHILESHE, N. Quality management concepts, principles, tools and philosophies: a valid methodology for deployment within UK construction-related SMEs. Journal of Engineering, Design and Technology, v. 5, n. 1, p. 49-67, 2007.

CHRISTOPHER, M. Logística e Gerenciamento da Cadeia de Suprimentos. $2^{\mathrm{a}}$ ed. São Paulo: Cengage Learning 2009.

CHRISTOPHER, Martin. Logística e gerenciamento da cadeia de suprimentos: estratégias para a redução de custos e melhoria de serviços. São Paulo: Thomson Pioneira, 1997.

DIAS, Marco Aurélio. Administração de Materiais: Uma abordagem a Logística. 4 ed. - São Paulo: atlas, 1993.

HAGEMEYER, C.; GERSHENSON, J. K.; JOHNSON, D. $M$. Classification and application of problem solving quality tools: a manufacturing case study. The TQM Magazine, v. 18, n. 5, p. 455-483, 2006.

Hayrton do Prado/ Usando o PDCA focado em resultados. / Vicente Falconi: o PDCA focado nos resultados, / São Paulo, São Paulo Brasil / Edição 271 / janeiro, 2015/ Disponível

em:http://revistas.banasqualidade.com.br/BQ_271/files/asset s/common/downloads/publication.pdf Acesso em: 19/04/2018).

IVANOVIC, M. D.; MAJSTOROVIC, V. D. Model developed for the assessment of quality management level in manufacturing systems. The TQM Magazine, v. 18, n. 4, p. 410-423, 2006.

MARTINS, Petrônio Garcia e ALT, Paulo Renato Campos. Administração de Materiais e Recurso Patrimoniais. 3 ed.rev. e atualizada. São Paulo: Saraiva 2009.

MIGUEL, P. A. C. Metodologia de pesquisa em engenharia de produção e gestão de operações. Editora Elsevier, 2012. Rio de Janeiro, 2012.
OAKLAND, John. Gerenciamento da Qualidade Total. São Paulo: Nobel, 19941

PERFORMANCE RESEARCH ASSOCIATES. Atendimento nota 10. Rio de Janeiro: Sextante, 2008.

SALZANO, Wagner, Customer Service nas Atividades Logísticas, São Paulo: Iman, 2008.

TRACEY, M., \& Tan, C. L. (2001). Empirical analysis of supplier selection and involvement, customer satisfaction, and firm performance. Supply Chain Management: An International Journal, 6(4), 174-188.

VENKATRAMAN, S. A framework for implementing TQM in higher education programs. Quality Assurance in Education, v. 15, n. 1, p. 92-112, 2007.

ZARPELON M. I.; CARVALHO D. M. W. Informação de Qualidade: a Proposta do Modelo Infoqual. In: Revista SODEBRAS. v. 8, n. 89, mai. 2013.

\section{AGRADECIMENTO}

Este trabalho foi realizado durante uma bolsa de estudos apoiada pela Coordenação de Aperfeiçoamento de Pessoal de Nível Superior (CAPES).

\section{COPYRIGHT}

O autor Lucas de Souza Campos é o único responsável pelo material incluído neste trabalho. 